\title{
IN-PLANT TESTING OF MICROBUBBLE COLUMN FLOTATION
}

FInal Report

\section{By}

R.-H. Yoon

G. H. Luttrell

G. T. Adel

M. J. Mankosa

July 31, 1991

Work Performed Under Contract No. AC22-89PC89909

\section{For}

U.S. Department of Energy Plttsburgh Energy Technology Center Plttsburgh, Pennsylvanla

By Virginia Polytechnic Institute and State University Blacksburg, Virginla 


\section{DISCLAIMER}

This report was prepared as an account of work sponsored by an agency of the United States Goverriment. Neither the United States Government nor any agency thereof, nor any of their employees, makes any warranty, express or implied, or assumes any legal liability or responsibility for the accuracy, completeness, or usefulness of any information, apparatus, product, or process disclosed, or represents that its use would not infringe privately owned rights. Reference herein to any specific commercial product, process, or service by trade name, trademark, manufacturer, or otherwise does not necessarily constitute or imply its endorsement, recommendation, or favoring by the United States Government or any agency thereof. The views and opinions of authors ex. pressed herein do not necessarily state or reflect those of the United States Government or any agency thereof.

This report has been reproduced directly from the best available copy.

Available to DOE and DOE contractors from the Office of Scientific and Technical Information, P.O. Box 62, Oak Ridge, TN 37831; prices available from (615)576-8401, FTS 626-8401.

Available to the public from the National Technical Information Service, U. S. Department of Commerce, 5285 Port Royal Rd., Springfield, VA 22161. 
Final Report:

\title{
IN-PLANT TESTING OF MICROBUBBLE COLUMN FLOTATION
}

\author{
by \\ R.-H. Yoon, G. H. Luttrell, G. T. Adel, and M. J. Mankosa \\ Virginia Center for Coal and Minerals Processing \\ Department of Mining and Minerals Engineering \\ Virginia Polytechnic Institute and State University \\ Blacksburg, Virginia 24061-0258
}

\section{Contract Number:}

DE-AC22-89PC89909

\section{Prepared for:}

Thomas J. Feeley III

United States Department of Energy

Pittsburgh Energy Technology Center

P.O. Box 10940

Pittsburgh, Pennsylvania 15236 


\section{EXECUTIVE SUMMARY}

Microbubble column flotation (MCF) was developed at the Virginia Center for Coal and Minerals Processing (VCCMP) for the selective recovery of fine particles. Bench-scale test work conducted at VCCMP, largely under the sponsorship of the U.S. Department of Energy (DOE), showed that the technology worked well for both coal and mineral applications. For the technology to be commercially successful, however, a full-scale demonstration of the MCF technology was deemed necessary. This report summarizes the results of work performed under the DOE project entitled "In-plant Testing of Microbubble Column Flotation." The objectives of this research and development effort were to duplicate the bench-scale performance of the MCF process in a full-scale unit, to verify the scale-up procedure developed in an earlier project (DE-AC22-86PC91274), and to demonstrate the applicability of the MCF technology to the coal industry.

The project was conducted in three phases. In Phase I - Preliminary In-Plant Testing, a pilot-scale MCF cell with a 30-inch diameter and 25-foot height was constructed and installed at the Tug Valley Processing Plant near Naugatuck, West Virginia. This coal preparation facility is owned and operated by the Marrowbone Development Company, a subsidiary of the Shell Mining Corporation. The test work was conducted using a slip-stream from the classifying cyclone overflow containing mostly -150 mesh material and assaying 50-60\% ash. Past attempts by Shell Mining to upgrade this stream by conventional flotation were unsuccessful. The Phase I effort was financed by VCCMP and Shell Mining Company, although the cost of the pilot-scale column was subsequently reimbursed by the DOE in Phase II.

The MCF test results showed that for this particular coal the maximum volumetric throughput of the 30-inch column was approximately 100-120 gpm, which was equivalent to about 1.4 tph of dry feed at $4-6 \%$ solids. Typical operating conditions were: $25 \mathrm{gpm}$ of wash water, $16 \mathrm{scfm}$ of air, $0.7 \mathrm{lb} /$ ton of diesel fuel collector, and $1.0 \mathrm{lb} /$ ton of Betz M-150 frother. Under these conditions, a clean coal product assaying less than $10 \%$ ash was readily obtainable at a $60 \%$ combustible recovery. The corresponding reject stream typically assayed $76 \%$ ash. The heating value of the product was in the range of $12,900-13,700 \mathrm{Btu}$ on a dry-basis. The grade vs. recovery curve obtained using the 30 -inch diameter column was similar to that obtained with a 2-inch diameter laboratory column.

The scale-up procedures developed in the earlier project were used to estimate the number and size of columns required to process the entire classifying cyclone overflow stream at the Marrowbone plant. From the performance data obtained in the laboratory and pilot-scale columns, it was estimated that eight 8-foot or five 10-foot diameter columns would be necessary. Approxinnate operating costs for these full-size columns were also estimated from the test data. The cost of reagents required to obtain the desired results were projected to be about $\$ 1.15 /$ ton of feed. The power consumption associated with the bubble generation system was estimated to be $3.6 \mathrm{kwhr} /$ ton of feed, which is approximately one-third of that required by conventional flotation cells.

Based on the scale-up projections and the initial cost estimates, it was estimated that approximately 35 tph of additional saleable clean coal (excluding the loss of fine coal in the 
screen-bowl centrifuge) could be produced at the Marrowbone preparation plant by the MCF technology. Even if the penalty associated with the higher moisture content of the flotation product is considered, the effective production gain would be approximately 20 twh. At a market price of $\$ 30 /$ ton for the clean coal product, the plant could have an additional revenue of over $\$ 3$ million per annum, which gives rise to a payback period of less than 8 months for this new investment.

Following the successful completion of the Phase I effort, a close-out report was submitted to DOE in November 1989. Based on the results of the technical and economic feasibility studies presented in the Phase I report, authorization was given to proceed with Phase II and Phase III efforts.

The Phase II - Continued In-Plant Testing effort involved detailed testing of the 30-inch column to provide additional information on column operation, optimization, scale-up and control. The objectives of this work were to establish the viability of the MCF technology and to further verify the scale-up procedure developed in the previous project.

Control systems were installed to provide stabilizing control of the column operation and data acquisition capabilities. These capabilities were integrated into a single programmable logic controller that was capable of controlling and monitoring the operation of the 30-inch diameter column. The control system included instrumentation for the following measurements:

1) the volumetric flow rates of the feed, reject, wash water and air, and the mass flow rate of the feed;

2) the differential pressure at two points along the height of the column to control the pulp level and to estimate the air holdup and bubble size; and

3) the pressure drop across the static mixer bubble generators and the power draw on the purnp mcior as a means of monitoring the performance of the bubble generation system.

In addition, a sequencing routine was developed for the 8-foot column which allowed for automated start-up and shut-down of the prototype unit. The performance of both control systems was exemplary; the columns were operated without supervision for extended periods of time. The system allowed both columns to respond well to large fluctuations in the volumetric flow rate and solids content of the feed stream.

After completing the column installation and initial shakedown tests, an extensive, 54 test Box \& Behnken experimental design technique was employed to evaluate the performance of the 30 -inch diameter column. In each test, column performance was quantified in terms of the separation efficiency, which was defined as recovery of combustibles minus the recovery of ash in the froth product. The significant trends resulting from this analysis are:

1) The height of the stabilized froth zone has a minimal impact on the separation efficiency, except under high feed rates where separation efficiency drops rapidly due to a sharp decrease in overall recovery. 
2) High gas flow rates improve the separation efficiency; however, high gas rates require high frother dosages to maintain small bubble sizes.

3) Higher gas flow rates generally require higher wash water flow rates in order to maintain desired ash rejection levels. As the gas rate increases, the amount of feed water reporting to the froth product (clean coal) also increases, causing a higher degree of entrainment. In order to maintain a desired ash level in the product, the entrainmeint must be reduced by increasing the wash water rate.

4) Higher frother dosages increase the separation efficiency. Too low a frother dosage produces large unstable bubbles and, hence, results in a loss of recovery (which reduces the separation efficiency). However, an excessive frother dosage rate creates a froth that is too stable. This type of froth carries a large amount of feed water and, hence, entrained ash into the froth product, resulting in a decrease in the separation efficiency.

Also of interest during the Phase II effort was the performance of the bubble generation circuit in terms of wear. Visual examination of the static mixer bubble generators showed that there was no significant wear in this particular application, indicating that maintenance requirements for the MCF system would be minimal.

The Phase III - Testing of a Prototype Column effort, which was conducted concurrently with the Phase II effort, involved the scale-up, design, engineering, installation, and testing of a full-size prototype MCF cell. The preliminary scale-up projections made in Phase I were revalidated using a detailed computational procedure incorporating the effects of bubble diameter, air hold-up, carrying capacity, axial mixing, and various superficial velocities. The results of these calculations suggested that a prototype column should be built having a diameter of 8-feet and a height of 25 -feet in order to process approximately 15 tph of the -150 mesh cyclone overflow. This full-scale column would be capable of producing 5-5.5 tph of clean coal assaying $8-10 \%$ ash. The column design specifications called for a set of four 4-inch static mixer bubble generators, through which approximately $1,700 \mathrm{gpm}$ of flotation pulp would be recirculated by means of a $32 \mathrm{HP}$ centrifugal pump. At an aeration rate of $160 \mathrm{cfm}$, this system would produce an average bubble diameter of $0.26 \mathrm{~mm}$ and an air hold-up of approximately $41 \%$ at the exit of the bubble generators.

The structural components of the full-size MCF cell were designed by ICF Kaiser Engineers. The column was installed by Shell Mining Corporation in April, 1990, and has been in operation since that time. Long term test runs demonstrated that the column was capable of achieving all of the projected performance goals in terms of product recovery, quality, and throughput capacity. Dewatering of the clean coal product was achieved using a screen-bowl centrifuge, which had already been in operation at the plant. The loss of fine clean coal product in the plant dewatering circuit was estimated to be approximately $10 \%$. However, detailed economic calculations conducted after the installation of the full-scale column indicated that fines losses as large as $30 \%$ would still yield a highly attractive rate of return.

The performance of the 8-foot diameter prototype column was optimized using the factorial design technique. The results of the statistical analysis of the column performance are 
summarized as follows:

1) Product Ash Content - An increase in the aeration rate has a more significant impact on the product ash content than does the frother addition rate. This suggests that the aeration rate has a larger influence on entrainment than does the frother addition rate. The entrainment problem can be partially offset by increasing the wash water addition rate. An increase in the collector addition rate also tends to increase the product ash content. This increase is probably due to the increased flotation rate of middlings and the increased entrapment of mineral matter in coal agglomerates.

2) Product Yield - An increase in either the frother addition or aeration rate increases the product yield. At very high collector addition rates, however, neither the frother nor the aeration rate has significant impact on yield. At a given throughput, an increase in the wash water flow rate results in a decrease in yield. The loss in yield can be attributed to a decrease in the slurry retention time and a decrease in the stability of the froth at the higher wash water addition rates.

3) Separation Efficiency - An increase in either the aeration rate or frother addition rate gives rise to a higher separation efficiency, i.e., an increase in either parameter produces a large increase in yield with only a small increase in product ash. An increase in collector addition rate also increases the separation efficiency for the same reason. In general, the maximum separation efficiency can be achieved by selecting the appropriate combination of operating conditions which allow the column to operate at the "elbow" in the grade vs. recovery curve.

Based on the information obtained in the present work, a number of general observations have been made. These include:

1) For a given sample, column performance closely approximates, but never exceeds, the results obtained from a release analysis test. This finding is in agreement with previous studies which demonstrate that release analysis provides information regarding the maximum flotation recovery obtainable at a desired product ash content.

2) The results obtained using a 2-inch laboratory flotation column can be used to predict the performance of a full-size industrial column in terms of throughput, retention time, reagent consumption, grade, and recovery. The availability of a reliable scale-up procedure makes it possible to design full-size columns which can duplicate the grade and recovery results obtained using laboratory columns.

3) A properly designed coal flotation column should operate at its maximum froth carrying capacity limit. This limit is largely determined by the particle size distribution and density of particles to be recovered in the froth product. Sufficient particle retention time should be allowed so that the mass rate of solids from the pulp to the froth phase matches or slightly exceeds the maximum carrying capacity. This procedure maximizes column capacity and minimizes column volume. 
The information summarized in Table 1 represents the average of test results obtained during the course of a 3-day period using the 8-foot diameter MCF cell. The column was operating at the optimum conditions established using the statistical techniques emplnyed in the present work. Also shown in Table 1 are the scale-up projections made for the 30-inch and 8foot diameter columns based on the 2-inch diameter column test results. In this particular series of tests, the actual volumetric feed flow rate and, hence, the superficial feed rate to the 8-foot diameter column were significantly lower than predicted. This discrepancy was due to the fact that the solids content of the feed stream to the 8-foot diameter column was considerably higher than that used in the 2- and 30-inch diameter column tests. Nevertheless, the actual solids throughput (feed mass flow rate) of the 8-foot column was the same as that predicted, because the column was operating under carrying capacity limited conditions.

Based on the test results obtained with the 30-inch and the 8-foot diameter MCF cells, two possible fine coal flotation circuits have been suggested for the Marrowbone preparation plant. The first corresponds to the original plan, in which the -150 mesh cyclone overflow stream is fed to a bank of eight 8 -foot or five 10 -foot diameter columns. This arrangement would produce 30-35 tph of additional saleable clean coal of approximately 8-10\% ash. The second possibility is to by-pass the classifying cyclones and to feed the -28 mesh screen underflow directly to the flotation circuit. At present, the cyclone underflow $(-28+150$ mesh) is processed by the fine dense-medium cyclone circuit, which is presently the most costly cleaning circuit in the plant. If the MCF circuit can effectively process the 28 mesh $\times 0$ coal with an acceptable recovery, significant savings in operating cost can potentially be realized. Although this alternative appears promising, further work is needed to verify this concept.

Table 1. Scale-up predictions for the 8-foot diameter microbuble column flotation cell.

\begin{tabular}{|l|c|c|c|c|c||}
\hline Porameter & $\begin{array}{c}\text { 2-inch } \\
\text { Measured }\end{array}$ & $\begin{array}{c}30 \text {-inch } \\
\text { Predicted }\end{array}$ & $\begin{array}{c}\text { 30-inch } \\
\text { Measured }\end{array}$ & $\begin{array}{c}\text { 8-foot } \\
\text { Predicted }\end{array}$ & $\begin{array}{c}\text { 8-foot } \\
\text { Measured }\end{array}$ \\
\hline \hline $\begin{array}{l}\text { Superficial } \\
\text { Feed Rate }\end{array}$ & $0.82 \mathrm{~cm} / \mathrm{s}$ & $1.59 \mathrm{~cm} / \mathrm{s}$ & $1.69 \mathrm{~cm} / \mathrm{s}$ & $1.55 \mathrm{~cm} / \mathrm{s}$ & $1.24 \mathrm{~cm} / \mathrm{s}$ \\
\hline $\begin{array}{l}\text { Volumetric } \\
\text { Flow Rate }\end{array}$ & $0.26 \mathrm{gpm}$ & $113 \mathrm{gpm}$ & $120 \mathrm{gpm}$ & $1147 \mathrm{gpm}$ & $921 \mathrm{gpm}$ \\
\hline $\begin{array}{l}\text { Feed Mass } \\
\text { Flow Rate }\end{array}$ & $6.7 \mathrm{lb} / \mathrm{hr}$ & $1.44 \mathrm{tph}$ & $1.40 \mathrm{tph}$ & $14.6 \mathrm{tph}$ & $14.6 \mathrm{tph}$ \\
\hline Product Ash & $10.3 \%$ & $10.1 \%$ & $9.46 \%$ & $10.1 \%$ & $7.33 \%$ \\
\hline Recovery & $61.8 \%$ & $61.8 \%$ & $61.2 \%$ & $61.8 \%$ & $59.6 \%$ \\
\hline \hline
\end{tabular}


In conclusion, the project has demonstrated that the MCF technology is useful for processing difficult-to-clean fine coal streams that are typically rejected in many coal preparation plants. Also, the testing of the technology using a full-size column in an operating plant validates the scale-up procedure developed at VCCMP. Furthermore, the economic analysis conducted in the present work indicates that the adoption of the MCF technology offers a very favorable return on investment. 


\section{TABLE OF CONTENTS}

EXECUTIVE SUMMARY $\ldots \ldots \ldots \ldots \ldots \ldots \ldots \ldots \ldots$ i

TABLE OF CONTENTS $\ldots \ldots \ldots \ldots \ldots \ldots \ldots \ldots \ldots$ vii

LIST OF FIGURES $\ldots \ldots \ldots \ldots \ldots \ldots \ldots \ldots \ldots \ldots \ldots \ldots \ldots$ ix

LIST OF TABLES $\ldots \ldots \ldots \ldots \ldots \ldots \ldots \ldots \ldots \ldots \ldots \ldots \ldots \ldots \ldots \ldots$

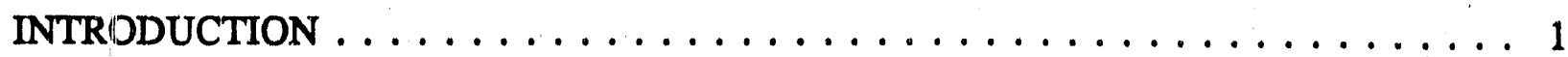

PHASE I - PRELIMINARY IN-PLANT TESTING $\ldots \ldots \ldots \ldots \ldots \ldots$

Task 1.1 Site Evaluation $\ldots \ldots \ldots \ldots \ldots \ldots \ldots \ldots \ldots \ldots$

Task 1.2 Laboratory Testing . . . . . . . . . . . . . . . . 4

Task 1.3 Column Design, Fabrication, and Installation $\ldots \ldots \ldots \ldots \ldots$

Task 1.4 Shakedown Testing $\ldots \ldots \ldots \ldots \ldots \ldots \ldots \ldots \ldots \ldots$

Task 1.5 Data Analysis . . . . . . . . . . . . . . . . . . . 13

Task 1.6 Scale-Up Projections $\ldots \ldots \ldots \ldots \ldots \ldots \ldots \ldots \ldots$

Task 1.7 Feasibility Analysis $\ldots \ldots \ldots \ldots \ldots \ldots \ldots \ldots \ldots$

PHASE II - CONTINUED IN-PLANT TESTING $\ldots \ldots \ldots \ldots \ldots \ldots \ldots \ldots$

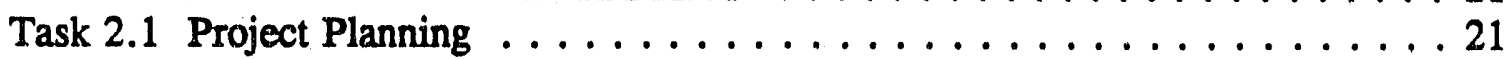

Task 2.2 Advanced Instrumentation $\ldots \ldots \ldots \ldots \ldots \ldots \ldots \ldots \ldots \ldots$

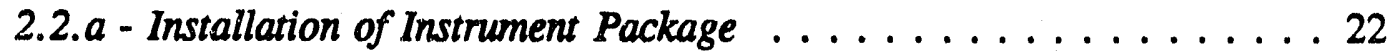

2.2.b - Installation of Control Loops . . . . . . . . . . . . . . 26

2.2.c - Installation of Data Acquisition System . . . . . . . . . 27

Task 2.3 Detailed Testing . . . . . . . . . . . . . . . 28

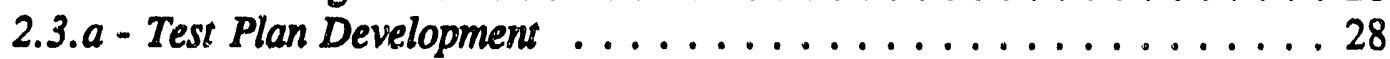

2.3.b - Perform Exploratory Tests . . . . . . . . . . . . . 28

2.3.c - Perform Parametric Tests . . . . . . . . . . . . . 39

Task 2.4 Design Evaluation/Modification . . . . . . . . . . . . 57

2.4.a - Evaluate Column Design Features . . . . . . . . . . 57

2.4.b - Measure Wear of Key Components . . . . . . . . . . 72

Task 2.5 Control Systems $\ldots \ldots \ldots \ldots \ldots \ldots \ldots \ldots \ldots \ldots \ldots$

2.5.a - Pulp Level . . . . . . . . . . . . . . . . . . 76

2.5.b - Air Hold-Up and Bubble Size Control . . . . . . . . . . 77

PHASE III - PROTOTYPE TESTING $\ldots \ldots \ldots \ldots \ldots \ldots \ldots$

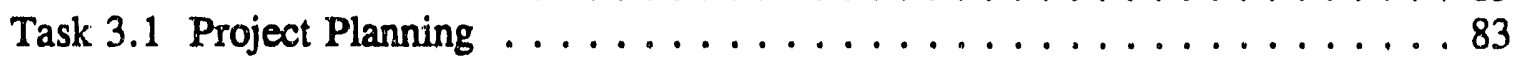

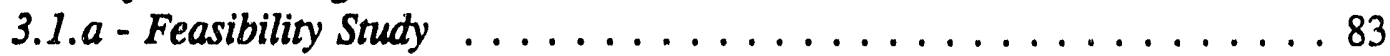

3.1.b - Economic/Cost Analysis . . . . . . . . . . . . . . 97

Task 3.2 Column Installation . . . . . . . . . . . . . . . 99

3.2.a - Column Fabrication . . . . . . . . . . . . . . . 99 99

3.2.b - Site Preparation and Column Installation . . . . . . . . . 99 
3.2.c - Develop Test Plan . . . . . . . . . . . . . . . 100

Task 3.3 Column Testing . . . . . . . . . . . . . . . . 105

3.3.a - Shakedown Tests . . . . . . . . . . . . . . . 105

3.3.b,c,d-Initiate Task 3.2 Tesi Plan . . . . . . . . . . . . . . . 109

3.3.e - Scale-Up Validation . . . . . . . . . . . . . . . 120

Task 3.4 Cost Analysis . . . . . . . . . . . . . . . . . . . . . 121

Task 3.4.a - Data Analysis . . . . . . . . . . . . . . . . 121

Task 3.4.b - Economic/Cost Analysis . . . . . . . . . . . . . 122

Task 3.4.c - Assess Future Applications . . . . . . . . . . . . 126

Task 3.5 Final Recommendations $\ldots \ldots \ldots \ldots \ldots$. . . . . . . . 127

ACKNOWLEDGEMENTS . . . . . . . . . . . . . . . . . . . . 129

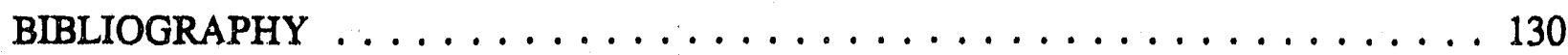

Appendix 1: Material balances for the 30 -inch column exploratory tests $\ldots \ldots \ldots 132$

Appendix 2: Material balances for the 30-inch column long-term test $\ldots \ldots \ldots \ldots 145$

Appendix 3: Material balances for the 2-inch column particle size tests $\ldots \ldots \ldots 161$

Appendix 4: Material balances for the 30 -inch column cyclone feed tests $\ldots \ldots \ldots 179$

Appendix 5: Summary of the statistical data analysis computations for the 30-inch column parametric test program . . . . . . . . . . . . 193

Appendix 6: Response surface plots for the 30-inch column parametric test program . 215

Appendix 7: Ladder logic program for column control . . . . . . . . . . . 237

Appendix 8: Material balances for the 8-foot column long-term test . . . . . . . 275

Appendix 9: Summary of the statistical data analysis computations for the 8-foot column parametric test program . . . . . . . . . . . 285

Appendix 10: Predicted response surfaces for product ash percent (Figs. A), product yield (Figs. B), and separation efficiency (Figs. C) . . . . . . . . . . 299

Appendix 11: Cash flow analyses $\ldots \ldots \ldots \ldots \ldots \ldots \ldots \ldots \ldots \ldots \ldots$ 


\section{LIST OF FIGURES}

Figure 1. Schematic representation of the laboratory microbubble column flotation cell. ........................... 6

Figure 2. Schematic representation of the in-line microbubble generator. . . . . . 7

Figure 3. Recovery versus product ash obtained using Betz 1012 and Oreprep 303 frothers for various feed slurry conditions. . . . . . . . . . . 8

Figure 4. CAD drawing of the 30-inch diameter microbubble column flotation cell. . . . . . . . . . . . . . . . . . . . . . 10

Figure 5. Cut-away view of the bottom section of the microbubble column flotation cell. . . . . . . . . . . . . . . . . . . . . . 11

Figure 6. Recovery versus product ash as a function of feed slumy rate for two levels of wash water addition. . . . . . . . . . . . . . . . . . 14

Figure 7. Recovery versus product ash obtained with 2- and 30-inch diameter columns over a wide range of operating conditions. . . . . . . . . . . 15

Figure 8. Recovery versus product ash obtained with 2 -inch and 30-inch diameter columns over a wide range of operating conditions. . . . . . . . 16

Figure 9. Projected capacity (gpm) as a function of column diameter required to obtain a $10 \%$ ash product and $60 \%$ combustible recr ery. . . . . . . . 19

Figure 10. Simplified schematic of the proposed instrumentatiou package for the 30inch microbubble flotation column. . . . . . . . . . . . . . 23

Figure 11. Effect of feed rate on combustible recovery and product ash content. . . . 29

Figure 12. Effect of feed rate on the solids content of the product, reject, and feed streams. . . . . . . . . . . . . . . . . . . . . . . 30

Figure 13. Effect of air flow rate on combustible recovery and product ash

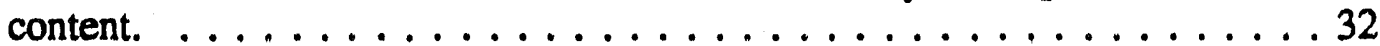

Figure 14. Effect of air flow rate on the solids content of the product, reject and feed streams. . . . . . . . . . . . . . . . . . . . . . 33

Figure 15. Effect of froth depth rate on combustible recovery and product ash

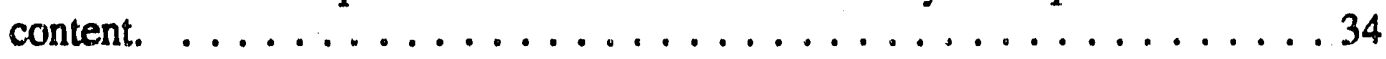

Figure 16. Effect of froth depth on the solids content of the product, reject and feed streams. . . . . . . . . . . . . . . . . . . . . . 35

Figure 17. Variations in combustible recovery and product ash content as a function of time for the 30 -inch column. . . . . . . . . . . . . . 36

Figure 18. Combustible recovery and product ash values obtained with various size: fractions using a laboratory microbubble flotation column. . . . . . . . 37

Figure 19. Combustible recovery and product ash values obtained during the processing of classifying cyclone feed. . . . . . . . . . 38

Figure 20. Yield and energy recovery obtained for each of the replicate tests conducted throughout the parametric testing program. . . . . . . . . . 44

Figure 21. Btu recovery and combustible recovery as a function of ash rejection for all the test conditions examined in the parametric study. . . . . . . . . 46

Figure 22. Btu recovery and combustible recovery as a function of total sulfur rejection for all the test conditions examined in the parametric study. . . . 4 47 
Figure 23. Combustible separation efficiency and overall separation efficiency as a function of ash rejection for all the test conditions examined in the parametric study. ....................48

Figure 24. Combustible separation efficiency and overall separation efficiency as a function of total sulfur rejection for all the test conditions examined in the parametric study. . . . . . . . . . . . . . . . . . . 49

Figure 25. Relationship between ash rejection and total sulfur rejection for tests results obtained during the parametric study. . . . . . . . . . 51

Figure 26. Comparison of experimental results with predictions made by the empirical model developed to describe energy recovery as a function of the various operating parameters. . . . . . . . . . . . . . 54

Figure 27. Comparison of experimental results with predictions made by the empirical model developed to describe product ash content as a function of the various operating parameters. . . . . . . . . . . . 55

Figure 28. Comparison of experimental results with predictions made by the empirical model developed to describe product sulfur rejection as a function of the various operating parameters. . . . . . . . . . 56

Figure 29. Comparison of experimental results with predictions made by the empirical model devcloped to describe separation efficiency as a function of the various operating parameters. . . . . . . . . . . . 57

Figure 30. Schematic showing the different wash water distributor designs evaluated during the testing of the 30 -inch microbubble flotation column. . . . . 61 61

Figure 31. Schematic diagram of experimental set-up for RTD studies. . . . . . . . 64

Figure 32. Typical normalized RTD for the 30 -inch column. . . . . . . . . 65

Figure 33. Measured versus predicted values of Peclet number. . . . . . . . 67

Figure 34. Fractional air content as a function of gas flow rate for $2, y$ and 4 bubble generators in the absence of frother. . . . . . . . . . . . 68

Figure 35. Total volumetric flow rate and flow per generator as a function of the total nurnber of bubble generators. . . . . . . . . . . . . 70

Figure 36. Fractional air content as a function of gas flow rate for 2, 3 and 4 bubble generators with $3 \times 10^{-5} \mathrm{M}$ Betz $1012 . \ldots \ldots \ldots \ldots \ldots \ldots$

Figure 37. Calculated bubble size as a function of gas flow rate for 2, 3 and 4 bubble generators in the absence of frother. . . . . . . . . . . . 73

Figure 38. Calculated bubble size as a function of gas flow rate for 2,3 and 4 bubble generators with $3 \times 10^{-5}$ Betz 1012. . . . . . . . . . 74

Figure 39. Schematic diagram of column level control system. . . . . . . . . 76

Figure 40. Schematic diagram of the laboratory frother control system. . . . . . . 79

Figure 41. Results of 2-inch laboratory frother control studies. . . . . . . . 80

Figure 42. Results of 30-inch in-plant frother control studies. . . . . . . . . .81

Figure 43. Summary of test results obtained using microbubble flotation columns of various diameters. . . . . . . . . . . . . . . . . 84

Figure 44. Proposed microbubble flotation column flowsheet for the Marrowbone Preparation Plant. . . . . . . . . . . . . . . . . 85

Figure 45. Pressure versus flow curve for the microbubble generation pump . . . . . 94

Figure 46. Schematic representation of the full-scale (8-foot diameter) microbubble

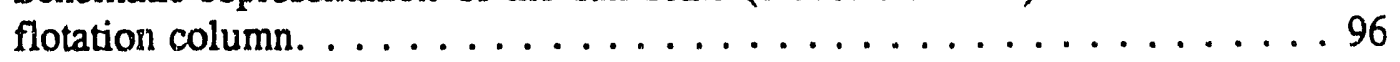


Figure 47. Combustible recovery as a function of product ash percent using the 30inch column. . . . . . . . . . . . . . . . . . . . . . . 103

Figure 48. Combustible recovery as a function of feed ash rejection using the 30-inch column. . . . . . . . . . . . . . . . . . . . . . . . . . . 104

Figure 49. Combustible recovery as a function of separation efficiency using the 30inch column. . . . . . . . . . . . . . . . . . . . . . 105

Figure 50. Expected performance of the microbubble flotation column at low and optimum wash water addition rates. . . . . . . . . . . . . . . . 107

Figure 51. Feed ash, product ash and combustible recovery as a function of time for the 8 -foot microbubble column. . . . . . . . . . . . . . . . 108

Figure 52. Product grade versus recovery curve for column flotation using 2-inch, 6inch, 30-inch and 8-foot diameter cells. . . . . . . . . . . . . . . . . 109

Figure 53. Yield and product ash obtained for each of the replicate tests conducted throughout the factorial testing program. . . . . . . . . . . 112

Figure 54. Combustible recovery as a function of product ash percent for the 8-foot column factorial test program. . . . . . . . . . . . . . 113

Figure 55. Yield as a function of product ash percent for the 8-foot column factorial test program. . . . . . . . . . . . . . . . . . . 114

Figure 56. Combustible recovery and separation efficiency as a function of ash rejection for the 8-foot column factorial test program . . . . . . 115

Figure 57. Combustible recovery as a function of product ash percent for all column flotation tests conducted on the Coalburg seam coal. . . . . . . . . 116

Figure 58. Comparison of experimental results with predictions made by the empirical model developed to describe separwion efficiency as a function of the various operating conditions. . . . . . . . . . . . . 117

Figure 59. Comparison of experimental results with predictions made by the empirical model developed to describe product ash percent as a function of the various operating conditions. . . . . . . . . . . . . 118

Figure 60. Comparison of experimental results with predictions made by the empirical model developed to describe product yield as a function of the various operating conditions. . . . . . . . . . . . . . . . . . 119

Figure 61. Net cash flow predicted over ten year basis for 10, 20, 30 percent loss of 'anes during the dewatering stage. . . . . . . . . . 124

Figure 62. Internal rate of return for various cash flow scenaric, for different percentages of lost fines. . . . . . . . . . . . . . . . . 125

Figure 63. Proposed flowsheet for column flotation of 150 mesh $\times 0$ cyclone overflow material. . . . . . . . . . . . . . . . . . . . . . . . 127

Figure 64. Proposed flowsheet for column flotation of -28 mesh cyclone feed. . . . 128 


\section{LIST OF TABLES}

Table 1. Recommended levels for the detailed parametric testing. . . . . . . . . 39

Table 2. Standard conditions used for parametric test plan. . . . . . . . . . 40

Table 3. Parametric test plan utilized in the in-plant optimization studies. . . . . 41

Table 4. Test results obtained during the parametric testing. . . . . . . . . 43

Table 5. Estimated values of standard deviation for various assays used in the parametric test work. . . . . . . . . . . . . . . . . . 45

Table 6. Results of frother addition point tests. . . . . . . . . . . . . . 59

Table $7 . \quad$ Results of wash water addition point tests. $\ldots \ldots \ldots \ldots$

Table 8. Results of RTD testing. . . . . . . . . . . . . . . . 65

Table 9. Scale-up predictions for the 30 -inch and 8-foot diameter microbubble column flotation cells. . . . . . . . . . . . . . . . . . . . 89

Table 10. Design dimensions for the full-scale microbubble flotation column. . . . . 90

Table 11. Summary of bubble generation calculations. . . . . . . . . . . 91

Table 12. Summary of head loss values for each component in the bubble generation circuit. . . . . . . . . . . . . . . . . . . . . . . . 93

Table 13. Cost-benefit anaiysis for a full-scale microbubble flotation column (all values approximate) $\ldots \ldots \ldots \ldots \ldots$. . . . . . . . . . . . 98

Table 14. Standard conditions used for parametric test plan. . . . . . . . . . . 101

Table 15. Levels utilized in the factorial test program. . . . . . . . . . . . . . 101

Table 16. Factorial test program. . . . . . . . . . . . . . . . . . . . 102

Table 17. Preliminary test results obtained from the full-scale microbubble flotation column. . . . . . . . . . . . . . . . . . . . . . . 106

Table 18. Results of factorial design for 8 -foot column. . . . . . . . . . . . 110

Table 19. Scale-up predictions for the 8-foot diameter microbubble column flotation cell. . . . . . . . . . . . . . . . . . . . . . 120

Table 20. Predicted expenditures for one 10-foot diameter Microcel. . . . . . . . . 123 


\section{INTRODUCTION}

Froth flotation has long been recognized as a practical and low-cost technique for upgrading fine coal. Unfortunately, the effectiveness of conventional coal flotation equipment is limited to a relatively narrow particle size range, between 100-500 microns. Because of this limitation, a significant quantity of the fine coal produced by today's mechanized mining equipment is often lost in conventional flotation circuits. In addition, fine coal streams may contain disproportionate amounts of ultrafine minerals, such as clay, that are easily carried into the froth product by hydraulic entrainment. As a result, conventional coal flotation circuits are often characterized by a high-product-ash content.

In order to overcome some of the deficiencies common to conventional coal flotation circuits, a novel process known as microbubble column flotation (MCF) was developed at Virginia Tech in the early 1980's. The development of this process originated from hydrodynamic studies that suggested that smaller air bubbles could be used to improve the capture rate and, hence, the recovery of fine particles. It was also discovered that these bubbles could best be utilized in a flotation column where countercurrent wash water could be used to prevent the nonselective entrainment of mineral fines.

Although column flotation has emerged as an attractive method for upgrading ores in the minerals industries, many uncertainties still exist in regard to the development of criteria for the design, operation, and scale-up of columns. This is particularly true for the microbubble column flotation of coal, where the operational characteristics may be quite different from those of mineral columns. In addition, g!idelines need to be developed for 
the design and operation of large-scale columns in the coal industry, where few commercial applications have been attempted.

This study, which addresses these concerns, was broken down into three phases:

Phase I - Preliminary In-Plant Testing involved the testing of a 30-inch diameter microbubble flotation column. The work was carried out as a joint effort between the Shell Mining Corporation and the Virginia Center for Coal and Minerals Processing (VCCMP). The test work was performed on-site at the Marrowbone Preparation Plant, located near Naugatuck, West Virginia. The Phase I work was carried out without funding from the Department of Energy (DOE).

Phase II - Continued In-Plant Testwork involved the testing of the 30-inch column to obtain detailed information about the operation, optimization, scale-up, and control of the microbubble flotation column. This phase of the test work was carried out as a joint venture between the VCCMP, DOE and the Shell Mining Corporation.

Phase III - Testing of a Prototype Column involved a preliminary study of the technical and economic feasibility of installing a full-scale prototype column in the Marrowbone plant; the design, construction, installation, and testing of an 8-foot unit; and a final analysis of column performance, cost, and potential applicability of the microbubble column flotation technolcgy. 


\section{PHASE I - PRELIMINARY IN-PLANT TESTING}

\section{Task 1.1 Site Evaluation}

The Marrowbone Preparation Plant, which is located near Naugatuck, West Virginia, was selected for the preliminary in-plant test program. Raw coal is supplied to the plant from three underground mines and one surface mine that work the Coalburg, Clarion, and No. 5 Block coal seams in southern West Virginia. The plant has a capacity of 1500 tph of raw feed and operates at an overall recovery of approximately $55 \%$. The clean coal product assays about $10-12 \%$ ash, $0.66 \%$ sulfur and $12,000 \mathrm{Btu} / \mathrm{lb}$.

Approximately $7 \%$ of the raw coal feed is present in the -150 mesh classifying cyclone overflow. The material contained in this stream is difficult to upgrade by conventional processes because of its fine size (-150 mesh), high-ash content $(58 \%)$ and low-solids content ( $0 .-6 \%)$. The low solids content of this stream requires the processing of a large volumetric flow of slurry in order to obtain an acceptable throughput of solids. It is estimated that approximately $9,000-10,000 \mathrm{gpm}$ of slurry must be handled by the fines cleaning circuit. The separation is further complicated by the presence of large quantities of ultrafine clay minerals, or slimes, which are contained in the feed coal.

Early attempts to recover the fine coal contained in the -150 mesh classifying cyclone overflow were unsuccessful. The original plant flowsheet developed by Dravo Engineers included four 4-cell banks of $300 \mathrm{t}^{3}$ conventional flotation cells. However, the conventional flotation cells were unable to produce an acceptable product grade or recovery because of the aforementioned difficulties. These cells have since been removed from the plant. For lack of a better processing scheme, the fine coal fraction is presently being discarded. 
During 1989, personnel from the Shell Mining Group contacted VCCMP at Virginia Tech seeking new and effective methods for recovering the fine coal being lost in the classifying cyclone overflow. As a result of these discussions, a preliminary test program was outlined in which a 1-2 tph MCF cell would be installed and tested in the Marrowbone Preparation Plant. The objective of the test program was to determine the applicability of the MCF technology for producing a product assaying less than $10 \%$ ash at an acceptable level of recovery. The on-site test work was performed by personnel from the VCCMP in conjunction with a senior preparation engineer from Shell Mining Corporation. Preliminary inspection of the plant site indicated that the 1-2 tph column could be installed along the interior wall of the plant filter-press room, which was not then being utilized. This area was ideally suited for installation of columns because it was in close proximity to the transfer line for the classifying cyclone overflow, sufficient head room was available, and it did not interfere with normal day-to-day operation of the plant. In addition, the vacated filter-press control room served as an ideal area for installing the electronic instrumentation required to monitor and control the operation of the MCF cell.

\section{Task 1.2 Laboratory Testing}

Prior to installing the 1-2 tph column, a series of small-scale laboratory tests were performed to establish the general applicability of the MCF technology for upgrading this coal. The material used in these tests was obtained directly from a sampling port installed in the mid-section of the cyclone overflow transfer line. The samples were collected in 55 gallon drums and transported to the laboratories at Virginia Tech for testing. 
A 2-inch diameter MCF cell with a height-to-diameter ratio of 20 was used for the laboratory test work. A schematic representation of the laboratory column is shown in Figure 1. Feed slurry is introduced to the column at a point just below the froth-pulp interface. As the slurry flows down the column, hydrophobic particles contained in the feed slurry are collected by the rising air bubbles. This section of the column behaves like a rougher cell in a conventional flotation circuit. The particle-laden bubbles enter the froth layer where they rise against a countercurrent flow of wash water. Acting as a cleaner stage, this section of the column prevents entrained particles of mineral matter from entering the froth product. Particles that are not sufficiently hydrophobic to be collected in the main section of the column eventually become part of the slurry that is recycled through the bubble generators for producing microbubbles. The co-current flow of particles and bubbles through the turbulent region inside the bubble generator enhances the contact between bubbles and particles and allows for the additional recovery of fine coal. This section of the column behaves much like a scavenger cell in a conventional flotation circuit. Hydrophilic particles eventually pass to the bottom of the column where they are rejected via an overflow weir. A schematic representation of the microbubble generator used in the laboratory test work is shown in Figure 2. In order to generate microbubbles, air is mixed with a portion of the flotation pulp and pumped under pressure through a single in-line motionless mixer. Inside the generator, multiple small blades are arranged to cause a rapid change in the direction of fluid flow along the length of the generator. The shear induced into the liquid by this action breaks larger bubbles into smaller ones in a very uniform manner. The generator is capable of producing a relatively narrow distribution of bubble sizes in the range of $0.1-0.4 \mathrm{~mm}$ in diameter. 


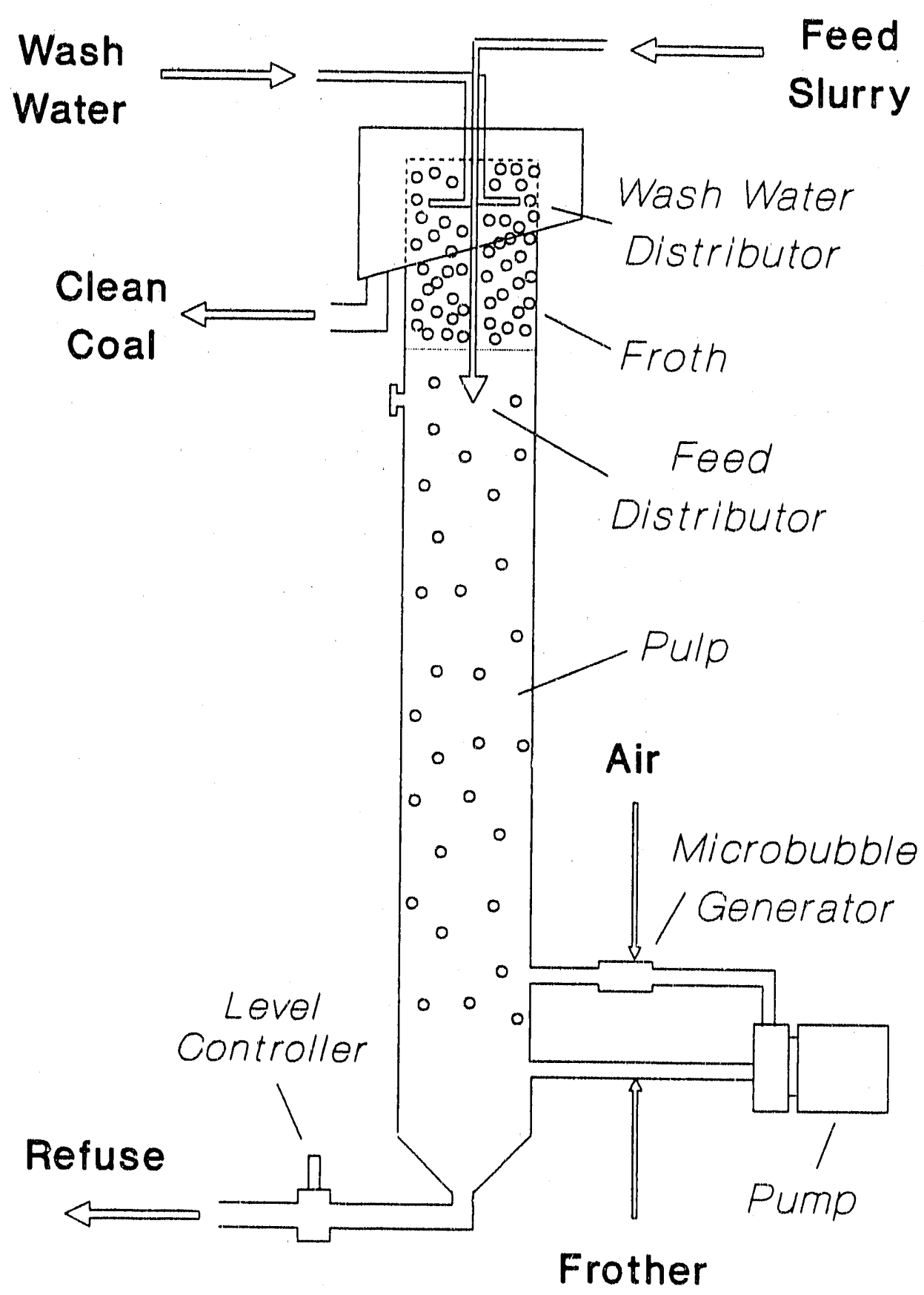

Figure 1. Schematic representation of the laboratory microbubble column flotation cell. 


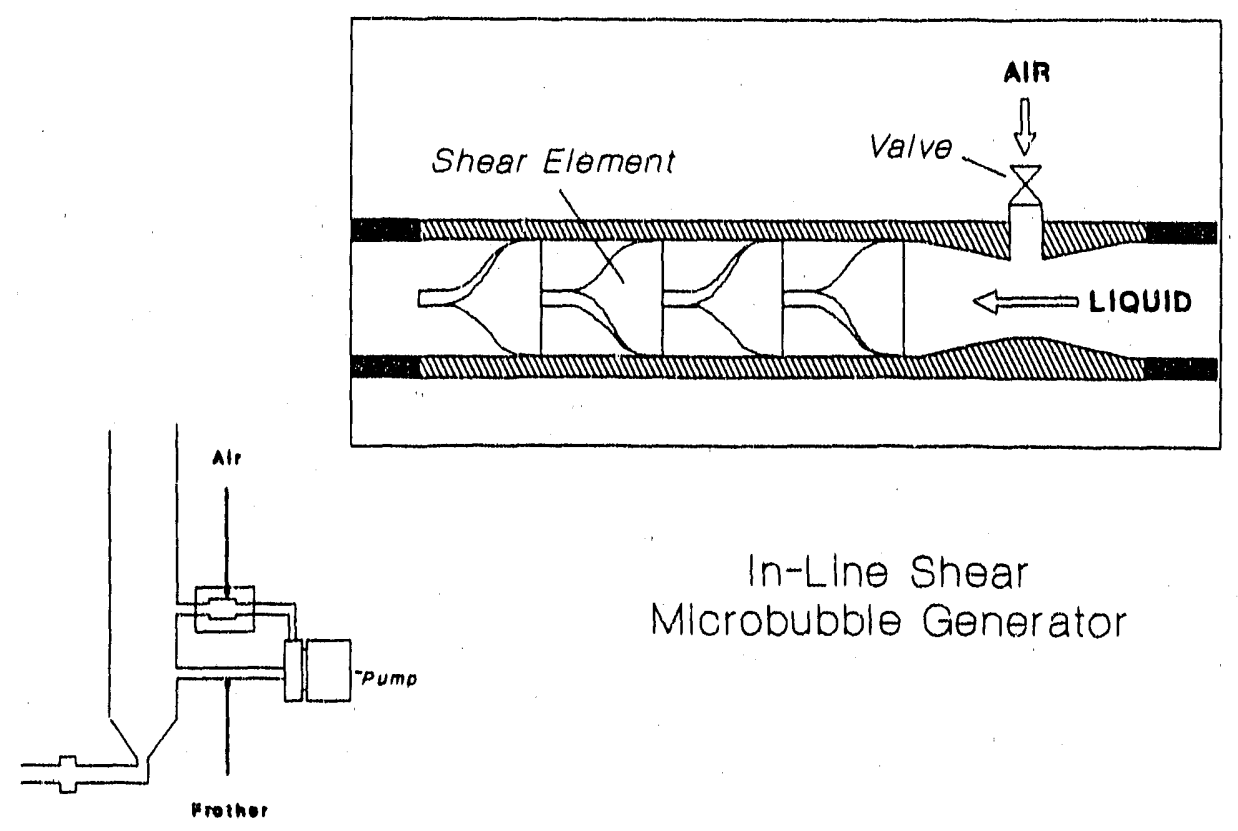

Figure 2. Schematic representation of the in-line microbubble generator.

Flotation samples were prepared by adding approximately $0.5 \mathrm{lb} /$ ton of fuel to the well-mixed slurry. Because of problems associated with conditioning large volumes of slurry in the plant, the conditioning time was kept very short in the laboratory tests. For most tests, conditioning time was less than 30 seconds. Two different frothers, Betz 1012 and Oreprep 303, were utilized in the test work. Typical frother dosages varied between 0.5 and $1.0 \mathrm{lb} /$ ton for Betz 1012 and between 2.0 and $3.0 \mathrm{lb} /$ ton for Oreprep 303. Unless otherwise specified, the aeration rate was held constant at $1.2 \mathrm{liter} / \mathrm{min}$. It should be noted that these values do not necessarily represent the best conditions for treating this coal. Unfortunately, neither the reagent package nor the operating parameters could be optimized because of the short amount of time allotted for this particular subtask. 
Since the classifying cyclones in the plant were subject to frequent plugging, the laboratory tests were conducted using both fine (i.e., normal cyclone operation) and coarse (i.e., plugged cyclone) coal feeas. In order to remove extremely coarse material that had no chance of being recovered during flotation, each sample was screened at 28 mesh, and the oversize was discarded prior to testing.

The results of the laboratory flotation tests are shown in Figure 3. The results shown in this figure clearly demonstrate the ability of the MCF process to produce a $10 \%$ ash product while maintaining a combustible recovery of at least $60 \%$. These results are encouraging in light of the difficult nature of this coal and the fact that none of the operating parameters had been optimized. The preliminary data also indicated that both the Betz 1012

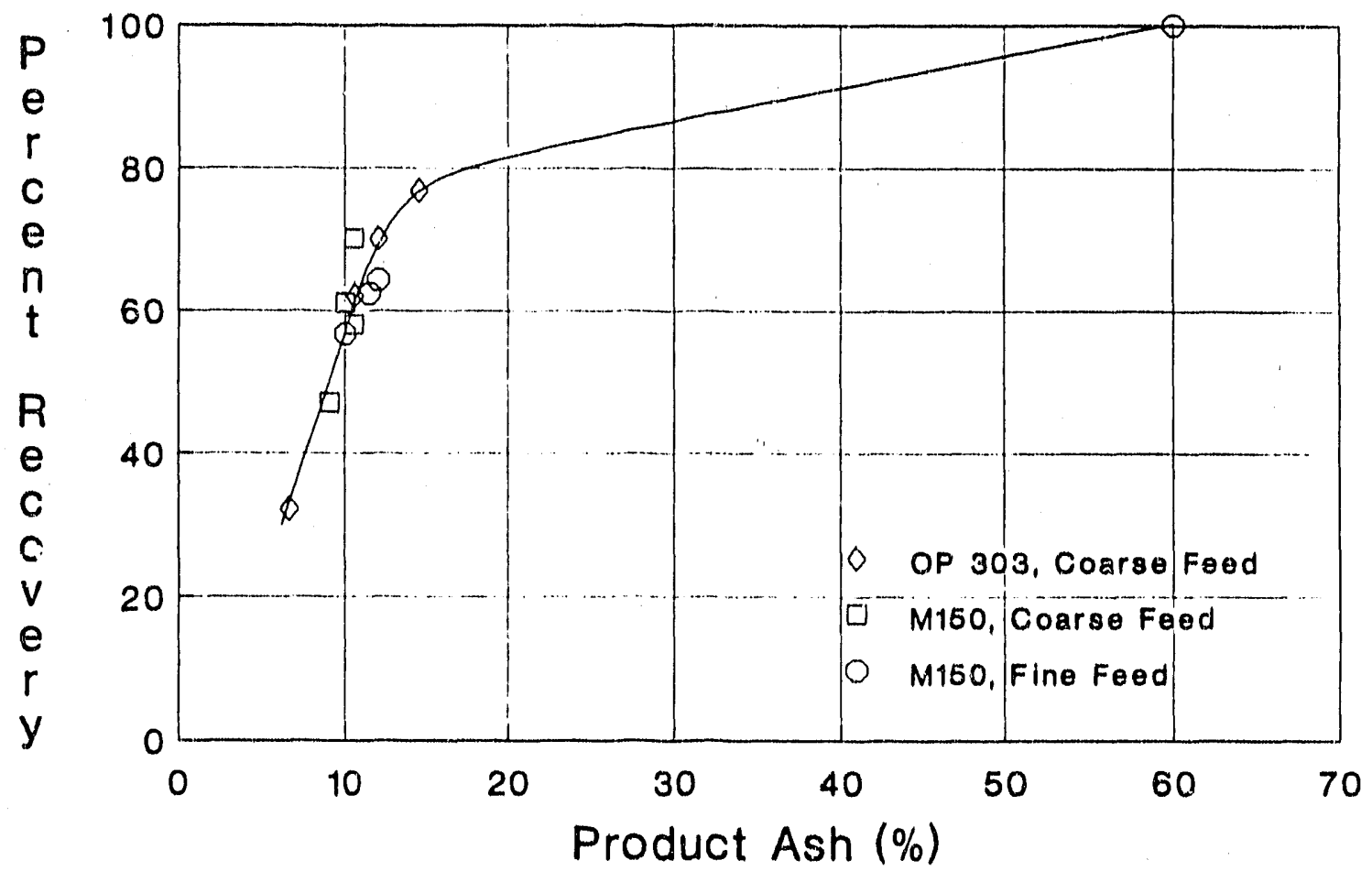

Figure 3. Recovery versus product ash obtained using Betz 1012 and Oreprep 303 frothers for various feed slurry conditions. 
and Oreprep 303 reagents produce essentially the same recovery-ash curve, although the Oreprep frother required more than twice the reagent dosage in order to achieve the same results. Since the commercial prices of Oreprep and Betz are $\$ 0.86 / 1 \mathrm{~b}$ and $\$ 1.09 / 1 \mathrm{~b}$, respectively, the Betz appears to be the more attractive alternative.

\section{Task 1.3 Column Design, Fabrication, and Installation}

In light of the promising laboratory test results, steps were taken to begin the construction of the 1-2 tph MCF cell. Preliminary scale-up projections indicated that a 30-inch diameter column would be required to achieve the desired throughput capacity. Conceived by the staff of the VCCMP, the basic cell design was passed to ICF-Kaiser Engineers in Pittsburgh, Pennsylvania, for further development. This group was responsible for the development of the engineering/fabrication prints, evaluation of structural integrity, and specification/acquisition of the various column components.

A computer-generated schematic of the selected column design is shown in Figure 4. The column consists of three basic sections. The top section of the column serves as the froth collection launder as well as a support brace for the feed and wash water distribution piping. The intermediate portion of the column consists of modular subsections, each measuring 5 feet in length, that can be added or removed to accommodate changes in column height. The bottom section of the column, which is shown in greater detail in Figure 5, houses the microbubble generation system and provides a means for collecting and removing refuse from the column. In addition, this section provides the structural footing that supports the column weight. When three intermediate subsections are utilized the total height of the column is 26 feet. 


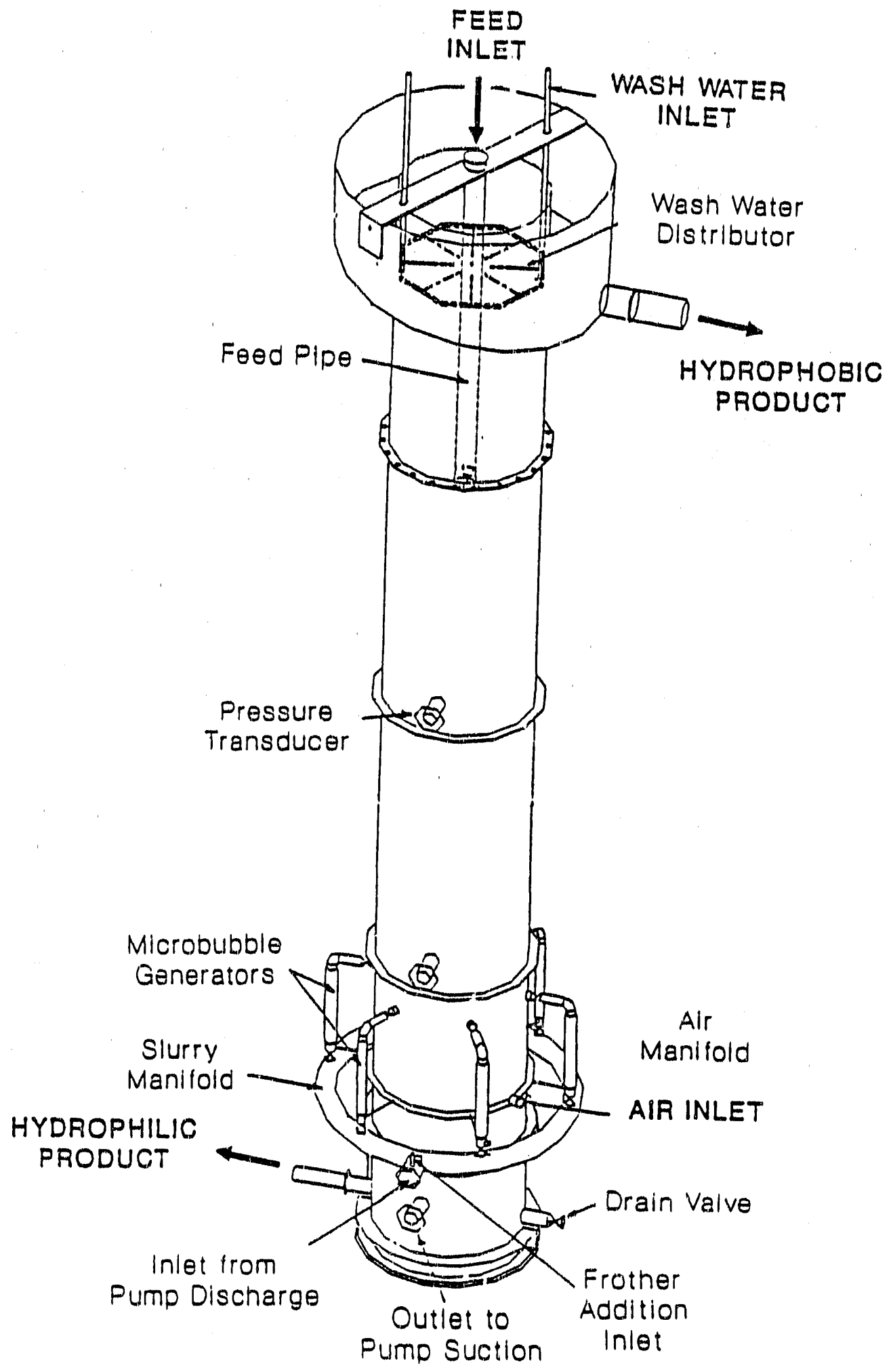

Figure 4. CAD drawing of the 30-inch diameter microbubble column flotation cell. 


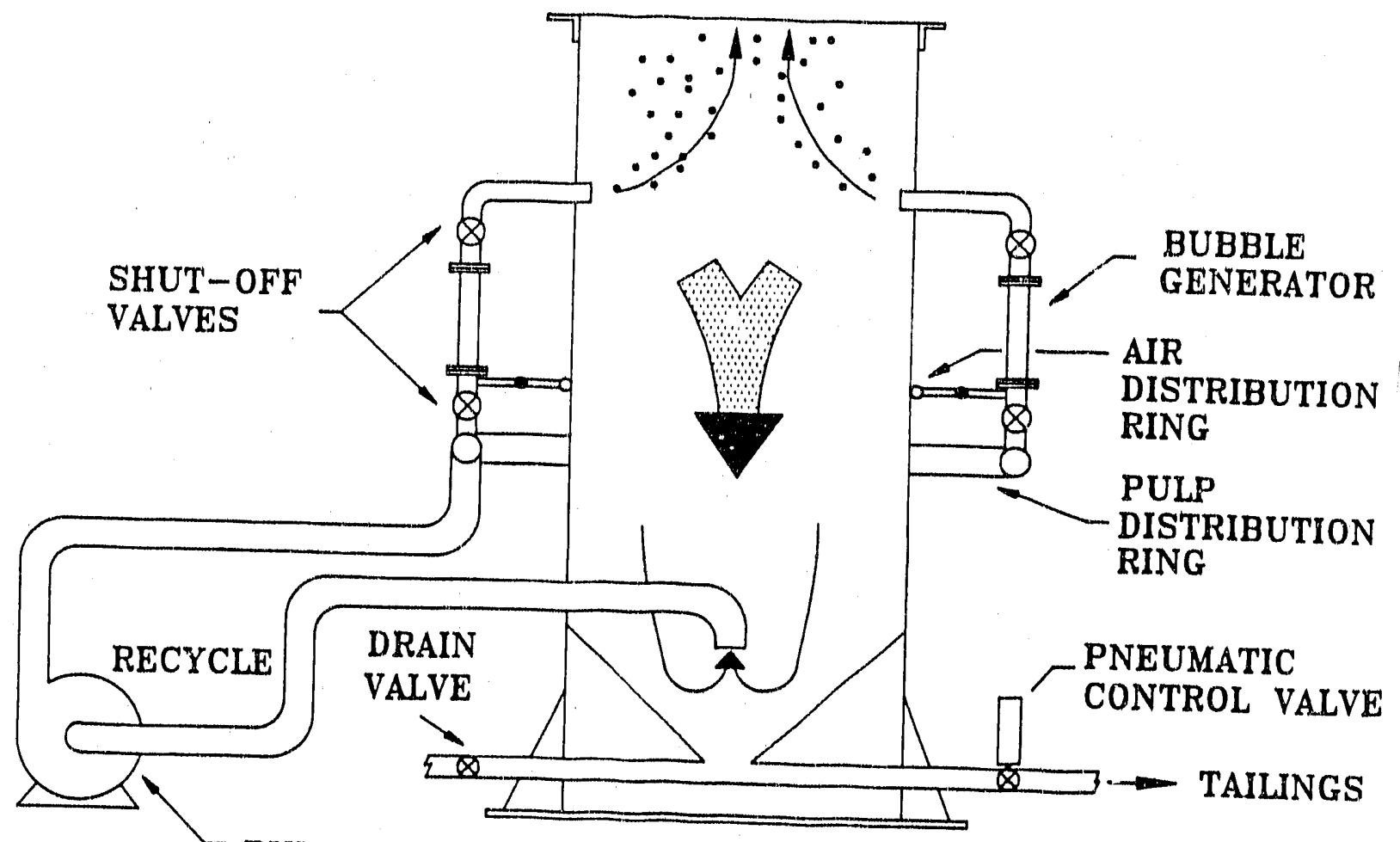

BUBBLE GENERATION PUMP

Figure 5. Cut-away view of the bottom section of the microbubble column flotation cell.

Feed is introduced into the column by means of an interchangeable central feed pipe. The use of feed pipes of different lengths allows one to easily vary the location of the feed injection point. The top section of the column is also equipped with a 2-inch wide plexiglas window that runs vertically along the length of the column. This window allows easy monitoring of the location of the froth-pulp interface and provides the operator with a rough visual estimate of the size of bubbles present in the column. The wash water distribution manifold is suspended from the support brace and can be easily raised or lowered as required. A final notable feature of the column design is the inclusion of bolt mounted flanges in each section so that various types of instrumentation, e.g., pressure sensors, can be installed when deemed necessary. 
The design for the microbubble generation circuit consists of a 10-HP centrifugal pump that passes flotation pulp through several parallel in-line microbubble generators. Although the column is equipped with six 2-inch diameter generators, scale-up projections indicated that only three would be required for normal operating conditions. Equal distribution of air and slurry to each generator was facilitated by cylindrical distribution rings that are concentric with the lower section of the column. Gate valves were placed on both sides of each generator in order to allow servicing and/or replacement of the generators without shutting down the column. The inlet port for frother solution was placed in the suction line of the centrifugal pump to improve mixing prior to passage through the bubble generators.

The only instrumentation included as part of the original column design was that deemed essential to the operation of the column. Rotameters were used to monitor the flow rates of air and wash water to the column. The feed rate of slurry to the column was monitored by a magnetic flow meter installed ahead of the column in the discharge line from the conditioning sump. An automatic control circuit maintained the pulp level in the column by monitoring the pressure in the column adjusting an automatic control value in the reject line. The addition rates of frother and diesel fuel were controlled using chemical metering pumps.

After approval of the final engineering prints, construction of the column was initiated by Ceramic Technologies Incorporated of Wardell, Virginia. This group was responsible for ordering raw materials, fabricating the column sections, and transporting the column to the plant site. Contractors hired locally by Shell Mining were responsible for installation of the major column components. Personnel from the VCCMP were responsible for installing minor column components (i.e., valves, hoses, fittings, etc.) as well as the various instruments required to monitor the operation of the process unit. 


\section{Task 1.4 Shakedown Testing}

Several different sets of operating conditions were examined during the preliminary testing of the 30-inch diameter MCF cell. These included aeration rate, reagent dosage, wash water flow rate, and feed slurry flow rate. In each of these tests, column feed was prepared by conditioning the slurry in an agitated 200-gallon tank into which diesel fuel was added at a controlled rate. The longest conditioning time was approximately 1 minute, although most of the tests were performed with considerably shorter conditioning times. The conditioned slurry flowed by gravity into the column at a point about 4 feet below the overflow lip. Clarified plant water was introduced to the column through a distributor located just below the overflow lip of the product discharge. The frother dosages used during the testing varied from approximately 0.7 to $1.1 \mathrm{lbs} /$ ton of feed. Betz 1012 was used as the frother for the majority of the test work. Although slight variations were noted, the dosage of diesel fuel was generally held at approximately $0.7 \mathrm{lbs} / \mathrm{ton}$, while the aeration rate was maintained in the range of 12 to $20 \mathrm{scfm}$.

\section{Task 1.5 Data Analysis}

Figure 6 shows the first series of test results obtained with the 30 -inch diameter column. A feed slurry flow rate of 100-120 gpm was used for the majority of the tests. Because of line-pressure restrictions on the fresh water feed, the first tests were conducted using a sub-optimal wash water flow rate of only 15 gpm (i.e., a superficial velocity of 12.5 $\mathrm{cm} / \mathrm{min}$ ). These results show that a combustible recovery of $60 \%$ can be obtained only at a product ash content of approximately $12 \%$. After the line-pressure problems on the wash water supply were corrected, a second series of tests was performed at the proper wash water 


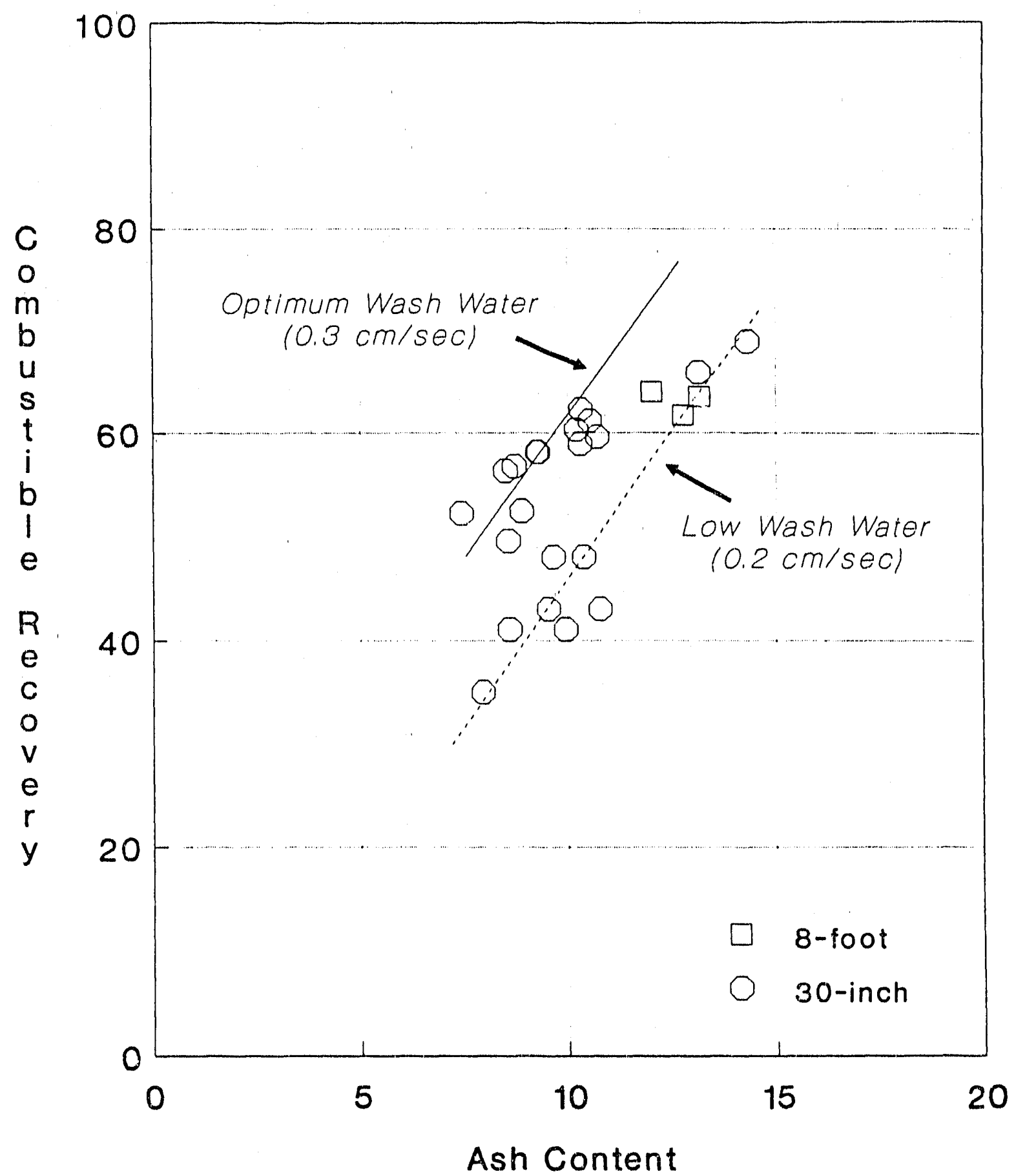

Figure 6. Recovery versus product ash as a function of feed slurry rate for two levels of wash water addition. 
flow rate of $25 \mathrm{gpm}$ (i.e., $19 \mathrm{~cm} / \mathrm{min}$ ). As shown in Figure 6, this adjustment reduced the product ash content by an additional $2 \%-3 \%$, thus shifting the recovery-ash curve. These results support the findings of the laboratory test work, which indicated that a $60 \%$ combustible recovery is possible at a product ash content of $10 \%$. The heating values of the products obtained from the 30 -inch diameter column tests ranged from 12,900 to $13,700 \mathrm{Btu} / \mathrm{lb}$ (dry).

Figure 7 summarizes the test results obtained using the 30 -inch diameter MCF cell under a wide variety of operating conditions. The 2-inch diameter test results are also included on this figure as a source of reference. The same results are also shown in Figure 8 , but the scale representing product ash has been expanded so that the degree of data scatter can be better observed. The resultant data scatter was primarily due to changing feed characteristics brought about by intermittent plugging of the classifying cyclones.

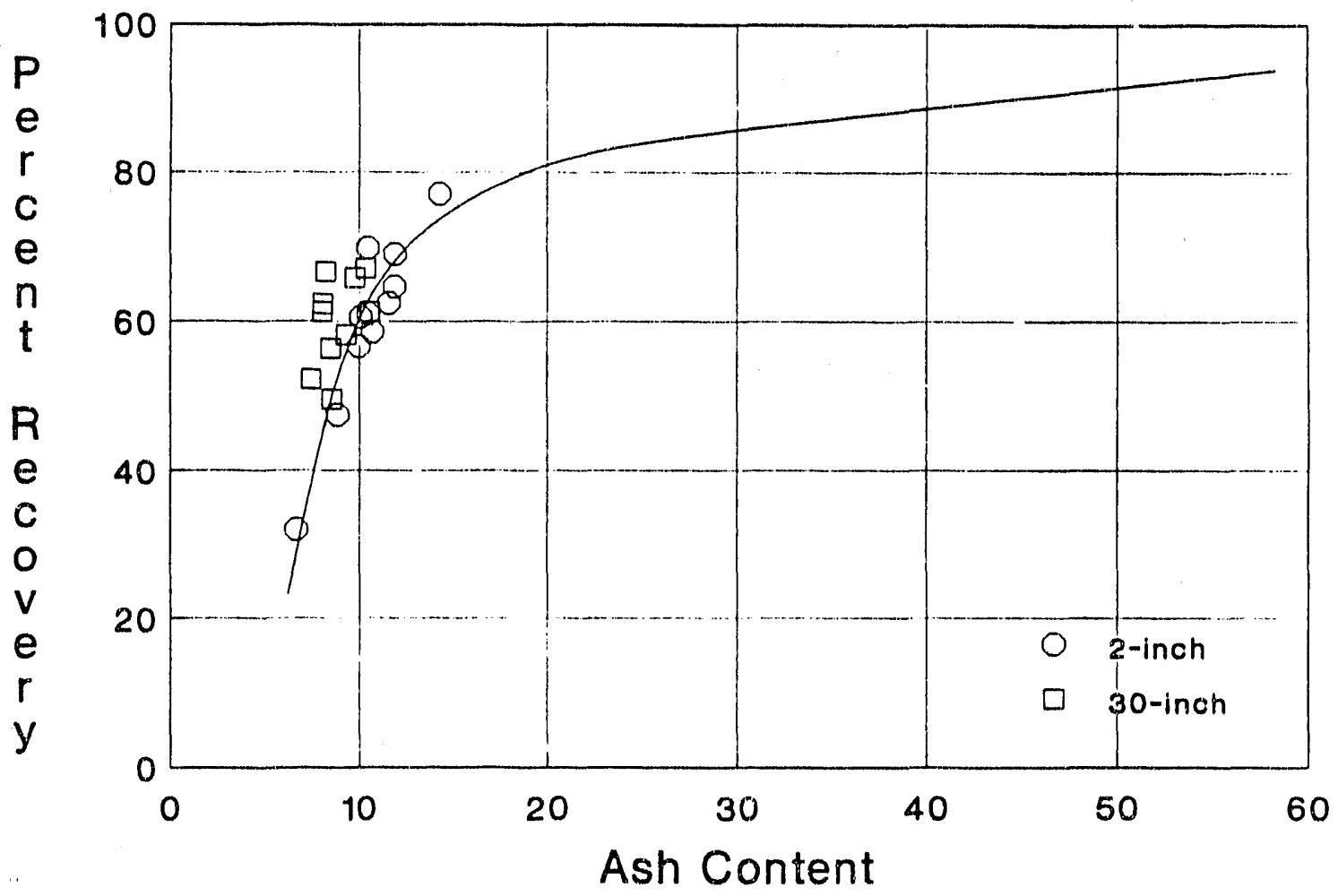

Figure 7. Recovery versus product ash obtained with 2- and 30-inch diameter columns over a wide range of operating conditions. 


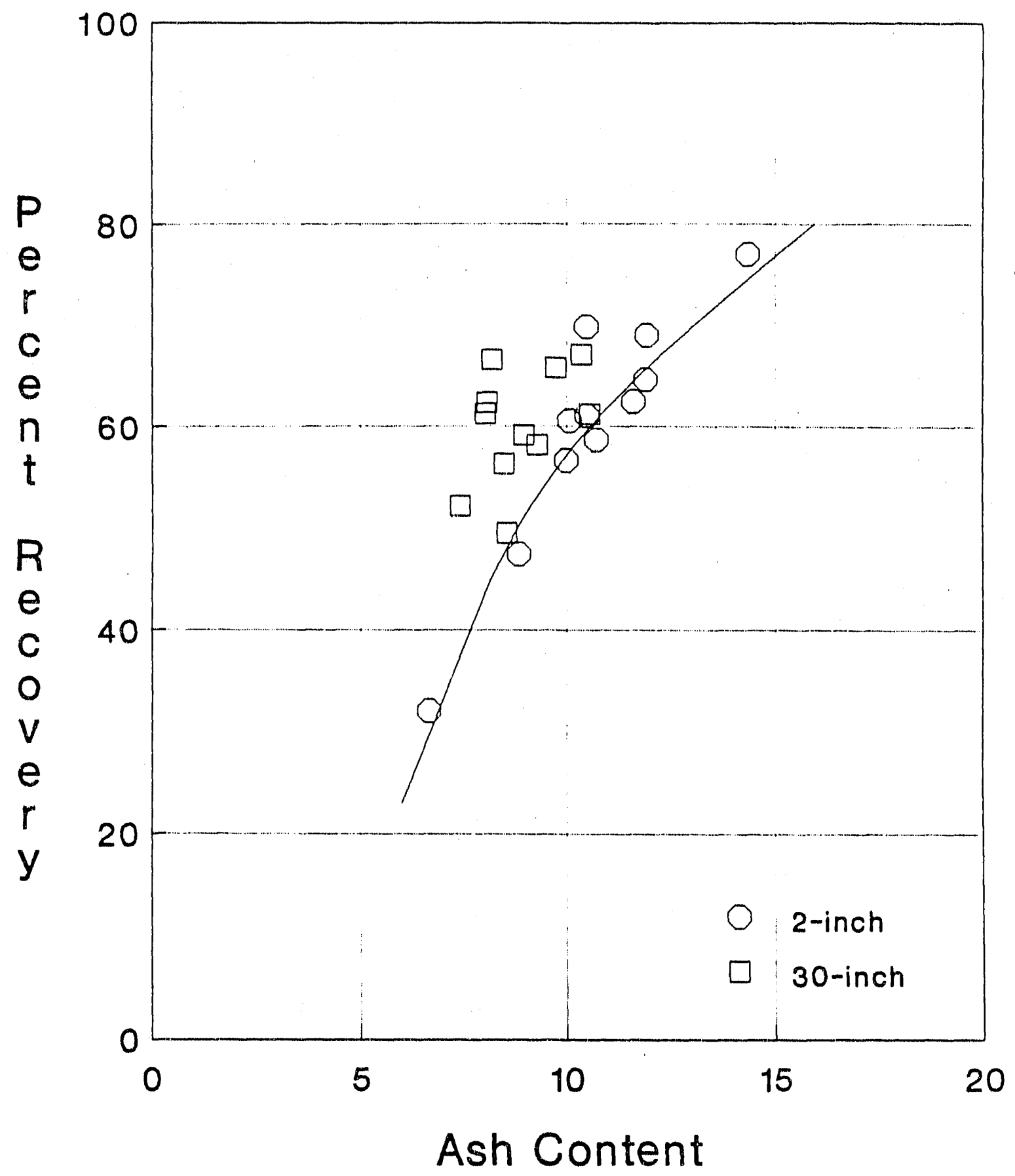

Figure 8. Recovery versus product ash obtained with 2-inch and 30-inch diameters columns over a wide range of operating conditions. 
Nevertheless, these results show that the recovery-ash curve is essentially the same for both columns despite the wide range of operating conditions. In fact, the test data indicate that the 30-inch column produced slightly better results than those obtained using the laboratory column.

Based on the aforementioned results, a reasonable operating capacity for the 30 -inch column appears to be approximately $100-120 \mathrm{gpm}$. This corresponds to a feed solids throughput of $1.6 \mathrm{tph}$. These results can be sustained at reagent dosages of approximately $0.7 \mathrm{lb} /$ ton for diesel fuel and $1.0 \mathrm{lb} /$ ton for Betz 1012. Under these conditions, it is expected that a full-scale column can produce a $10 \%$ product ash while maintaining a combustible recovery of at least $60 \%$. The reject stream would have a corresponding ash content in the range of approximately $76 \%$.

\section{Task 1.6 Scale-Up Projections}

During the past several years, considerable attention has been given to the development of an effective and reliable scale-up procedure for column flotation. The most recent version of the scale-up procedure allows the required column diameter and length to be determined for any desired throughput capacity. The scale-up methodology is based on maintaining a constant recovery and grade during scale-up. The procedure is also based on the assumption that the bubble size and the characteristics of the feed material do not change for the larger scale unit.

In order to validate the scale-up procedure, the test data obtained from the 2 -inch diameter column tests were used to project the column geometry required to achieve the throughput obtained in the 1-2 tph column. The scale-1up procedure indicated that the 
maximum allowable superficial velocity of feed slurry through the large-scale column could not exceed $1.56 \mathrm{~cm} / \mathrm{s}$. At this superficial rate, the column diameter required to maintain a volumetric flow rate of $100 \mathrm{gpm}$ is 29.8 inches. This value agrees quite well with the actual column diameter of 30 inches used in the test work. A preliminary estimate of the column length was found to be only about 20 feet for this particular application.

The preliminary scale-up projections for larger column cells are shown in Figure 9. As shown, the scale-up data indicate that approximately eight 8-foot diameter columns would be needed in order to handle the total flow of the classifying cyclone overflow. Little or no increase in the column length is expected over that used for the 30-inch diameter column. These values are derived from the assumption that the columns are being designed to obtain a product quality of about $10 \%$ ash at a combustible recovery of $60 \%$.

\section{Task 1.7 Feasibility Analysis}

The test work outlined in this report demonstrates that the microbubble column flotation process can be used to successfully upgrade the classifying cyclone overflow from the Marrowbone Preparation Plant. At a feed throughput of 100-120 gpm, the 30-inch diameter column was able to produce a combustible recovery of approximately $60 \%$ with product and reject ash contents of $10 \%$ and $76 \%$, respectively.

Rough estimates of the operational costs for a full-scale MCF cell can be figured from the data collected from the preliminary test work. The cost of reagents required to obtain the desired results is estimated to be about $\$ 1.15$ per ton of feed. Energy consumption associated with the operation of the microbubble generation pump has been shown to be approximately $1 / 3$ that of the power consumed by conventional flotation circuits of the same 


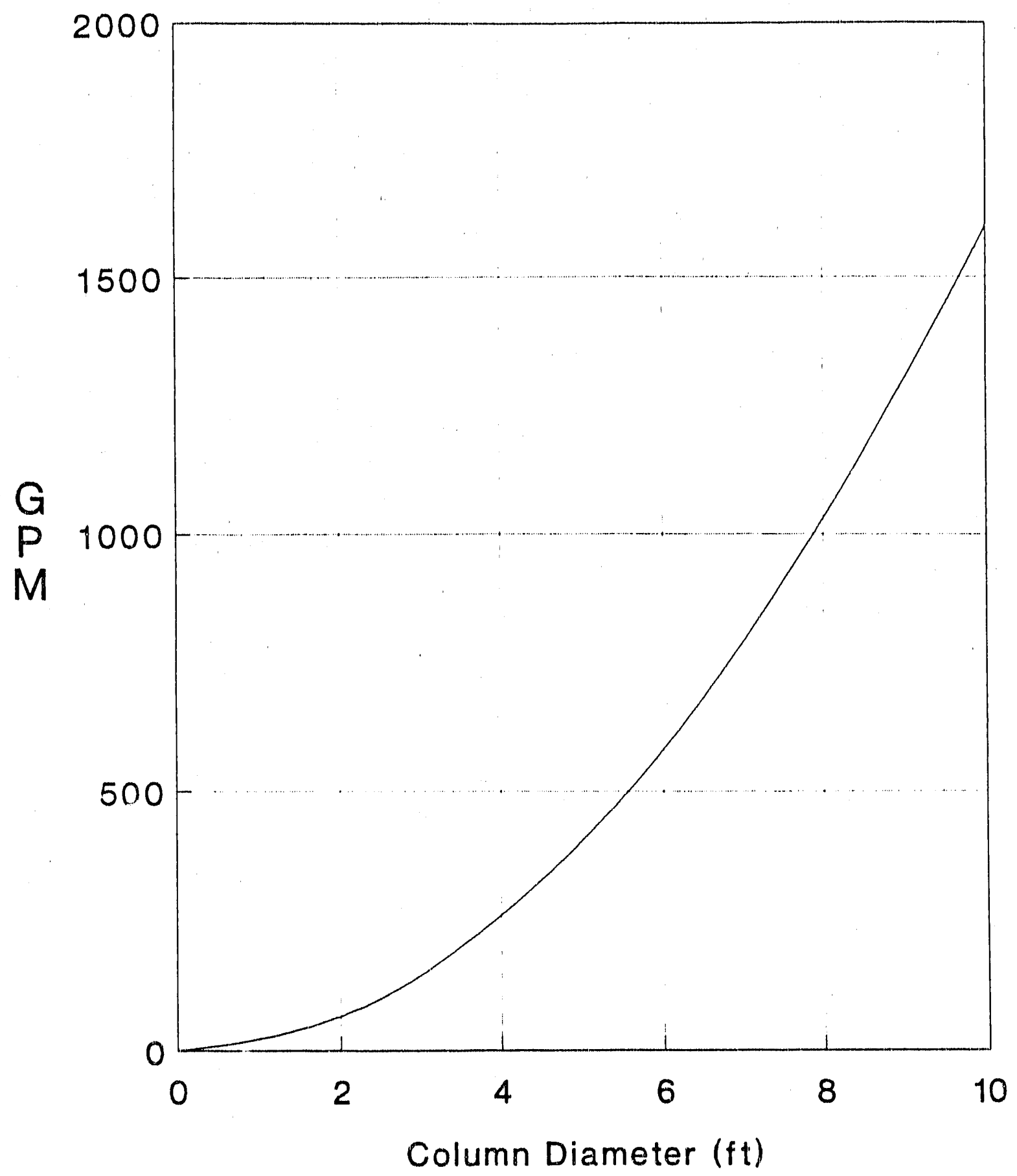

Figure 9. Projected capacity (gpm) as a function of column diameter required to obtain a $10 \%$ ash product and $60 \%$ combustible recovery. 
capacity. The power consumption of the 30 -inch diameter column was found to be only 3.6 $\mathrm{kW}-\mathrm{hr}$ per ton of feed. The capital cost of the equipment and expenses associated with column installation will be presented in Task 3.4 .

Based on the test data collected in the present work, approximately 35 tph of salable clean coal can be produced at the Marrowbone Preparation Plant by the MCF technology. Unfortunately, the higher moisture content of the fine coal from the flotation circuit indicates that the gravity of the coarse-coal heavy media circuit may need to be decreased slightly to compensate for the higher moisture content. As a result, the net recovery of clean coal from the plant has been estimated to be in the range of approximately $20 \mathrm{tph}$. Nevertheless, at this level of production an additional revenue of over $\$ 3$ million annually should be realized. The payback period for the MCF cells has been estimated to be considerably less than one year. 


\section{PHASE II - CONTINUED IN.PLANT TESTING}

\section{Task 2.1 Project Planning}

This project was originally divided into three phases. Phase I - Preliminary In-Plant Testing, was a joint effort between the VCCMP and Shell Mining Corporation to test the feasibility of using the MCF process to treat fine coal on a commercial scale. This task utilized a 30-inch diameter column and was carried out at the Marrowbone Preparation Plant near Naugatuck, West Virginia. Following the successful completion of the Phase I work, a close-out report was issued to the DOE on November 13,1989, detailing the results of this test work and providing preliminary information on the technical and economic feasibility of the MCF process. The DOE then gave authorization to proceed with Phase II - Continued In-Plant Testing and Phase III - Testing of a Prototype Column.

The Phase II work involved the continued testing of the 30 -inch column to obtain detailed information on the operation, optimization, scale-up, and control of the microbubble flotation column. The Phase III effort involved the scale-up, engineering, design, and testing of the full-scale prototype column. Both phases of the test work were carried out as a joint venture between the VCCMP, the DOE, and the Shell Mining Corporation.

\section{Task 2.2 Advanced Instrumentation}

In order to properly instrument the column according to the requirements of Task 2.2 , the following three areas were addressed:
i) measurement of pressure, density, and volumetric flow rates,
ii) loop control for bubble size and pulp level, and
iii) microprocessor-based data acquisition. 
Although each of these tasks could be handled independently, it was determined that a single, integrated system would be more efficient and would interface most readily with existing plant control systems. In addition, the system should accommodate sequencing operations so as to provide the operator with push-button start-up, shut-down, and control of the column. Based on discussions with Shell Mining's control and instrumentation experts, a programmable logic controller (PLC) based system was selected and installed for control of the 30-inch and 8-foot columns. An Allen-Bradley 5/25 programmable controller was selected for this application. The $5 / 25$ system is a rack-mounted unit containing the required I/O cards, the process controller and the power supply in one self-contained unit. This system should be capable of handling all control requirements for both columns.

All process instrument signals were supplied to the PLC via 4-20 mA current signals. Loop control for level, bubble size, and flow was also maintained by means of the PID capabilities of the PLC. All of the associated motor starters, solenoid valves (i.e., feed, wash water and air) and limit switches were also terminated at the PLC to provide sequencing capabilities. This arrangement provided one centralized system for column control. Local access to the system was provided through an Allen-Bradley Panel View control monitor located in the immediate vicinity of the column. Panel View is a CRT display equipped with limited operator access for control of column operation.

\section{2.a - Installation of Instrument Package}

A simplified schematic of the proposed instrumentation package for the 30-inch column is shown in Figure 10. As shown, the package consists of volumetric flow measurements on the feed, reject, and wash water streams to aid in determining the material 
(P) Pressure

(F) Flow Rate

(D) Density

(A) Power Draw

(C) Conduotivity

(S) Speclallty
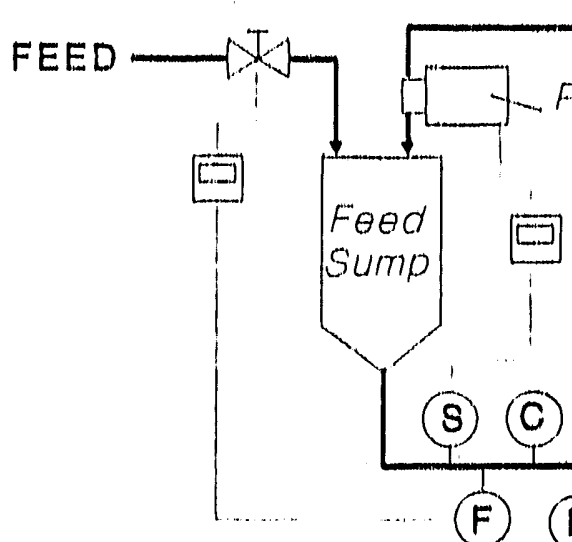

COLLECTOR

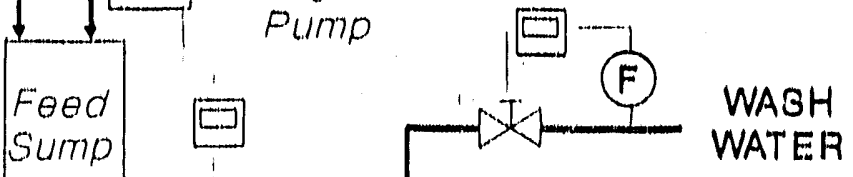

Sump
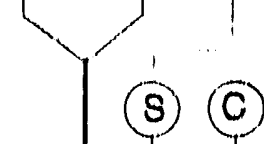

(C)

WATER

$\square$ Controller
¿ Control Valve

Nole: Slgnals from all sensors and controllers must lead to main comiputer

Nole: All slgnals 4-20 mA

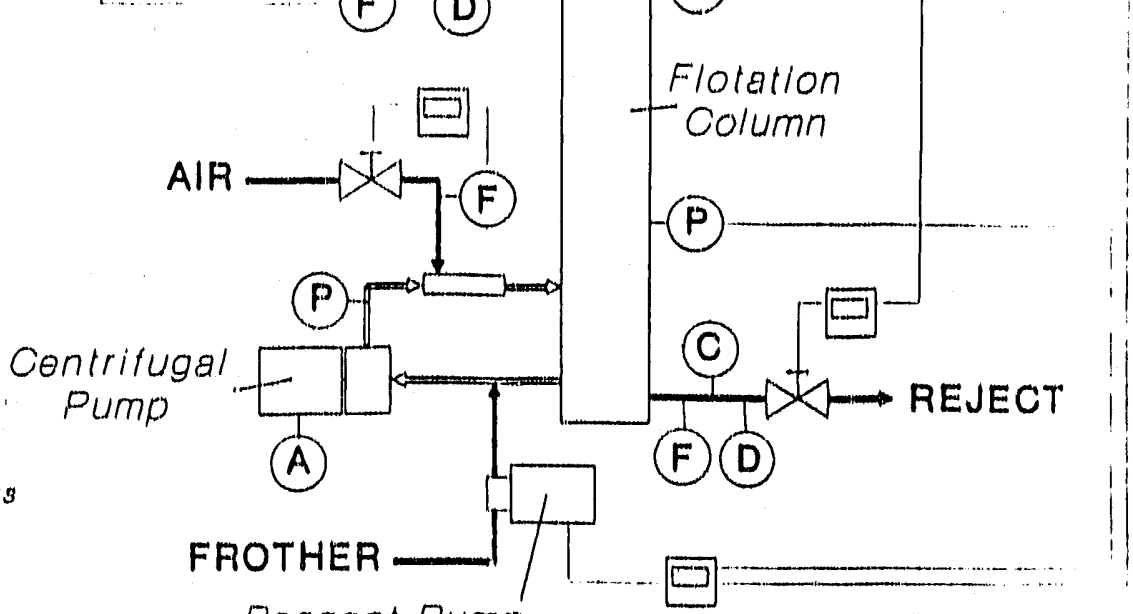

Reagent Pump

Figure 10. Simplified schematic of the proposed instrumentation package for the 30-inch microbubble flotation column.

balance around the column. Feed mass flow rate was also determined through a combination of volumetric flow rate and density, the latter determined by means of a Coriolis density/mass flow meter. The Coriolis-type mass flow meter was selected over a nuclearbased instrument due to government restrictions regarding interstate transportation of radioactive materials. Pressure sensors mounted on the side of the column were used to control pulp level and to determine air hold-up for estimating and controlling bubble size. Several sensors were also located around the bubble generation system in order to monitor air flow rate, pressure on the static mixers, and power draw on the pump motor. The 
information obtained from these instruments was used to characterize the performance of the bubble generation system. These results are presented under Task 2.4. Controllable reagent pumps were used to maintain constant addition rates for frother and diesel fuel. Finally, a conductivity probe was located in the column reject line to determine the residence time distribution in the column by means of salt tracer tests. Accommodations were also made to incorporate this same sensor into the 8-foot column for additional RTD testing.

Initially, the flow rates of air and wash water were measured using mechanical rotometers. Prior to the installation of these meters, however, it was found necessary to install pressure regulators on both the air and fresh water feed lines to prevent fluctuations in flow rate due to changes in the plant pressure supply. In general, the mechanical rotameters performed quite well except for one problem. The presence of condensed water in the air line frequently made the flow rate difficult to measure accurately. Remounting the air flow meter ahead of the pressure regulator on the high pressure side of the supply line helped reduce this problem. A Poro-Stone air filter/moisture trap has since been installed on the air feed line and has eliminated the moisture problems. Electronic sensors were also installed on these lines in order to provide an output signal for the PLC system; however, the rotameters were left operational for purposes of instrument calibration.

Volumetric air flow rate was measured using an RCM Industries differential pressure, direct reading flow meter. This instrument provides a local display of the air flow rate for a specified instrument pressure as well as a 4-20 mA output signal for remote sensing. The display reading must be corrected for the actual input pressure according to the following equation: 


$$
Q_{a}=Q_{m} \sqrt{\left(\frac{P_{a}+14.7}{P_{c}+14.7}\right)}
$$

where,

$$
\begin{aligned}
& Q_{\mathrm{a}}=\text { actual flow rate }[\mathrm{SCFM}] \\
& Q_{\mathrm{at}}=\text { measured flow rate }[\mathrm{CFM}] \\
& P_{\mathrm{a}}=\text { actual gas pressure }[\mathrm{psig}] \text {, and } \\
& P_{\mathrm{c}}=\text { calibrated gas pressure [psig]. }
\end{aligned}
$$

Wash water and feed slurry flow rates were measured using Brooks Series 7400 electromagnetic flow meters. These meters were calibrated to provide a $\pm 1.0 \%$ flow accuracy over a range from 20-200 gpm. In addition, frother and collector were added using Metronics chemical metering pumps. Both the feed flow meters and the reagent pumps were equipped with 4-20 mA output signals, which were connected to the PLC. Each of these flows was controlled using pneumatic valves, actuated remotely by means of the PLC system.

In order to control column level and monitor air hold-up, twin differential pressure transducers (Honeywell ST 3000) were installed in the upper and lower sections of the 30inch and 8-foot diameter columns. The upper transducer was mounted approximately 6 feet from the top of the column for use in sensing the pulp level, while the lower transducer was installed just above the inlets for the microbubble generators. The lower sensor was used in conjunction with the upper to determine air hold-up in the column. The air hold-up and flow rate measurements provide an on-line method for determining the average size of bubbles within the column. 
Feed density was determined by means of a Coriolis mass flow meter. This instrument determines the bulk density of a fluid as it passes through a pair of S-shaped sensor elements. In the current project, these elements are continuously oscillated by means of an electro-mechanical driver system. As the fluid passes through the elements, a shift occurs in their natural vibrational frequency. Detected by magnetic pick-ups, this phase shift was proportional to the mass of the fluid passing through the sensor and can be converted to fluid density.

Finally, allowances were made to install a conductivity sensor in the tailings discharge line for boin the 30-inch and 8-foot diameter columns. This sensor was located just prior to the level control valve. The probe was used to detect changes in conductivity of the column tailings stream as a function of time. When a salt tracer was added with the column feed, it provided a means for on-line measurement of the residence time distribution for each column. The output signal from this device was also connected to the PLC system for data logging purposes.

\section{2.b - Installation of Control Loops}

Two main loops were installed for control of the 30-inch column, as shown in Figure 10. The first control loop was designed to rnaintain a constant level in the column and was successfully installed and tested. A $420 \mathrm{~mA}$ signal from the pressure transducer was fed to a Honeywell UDC 2000 Mini-Pro digital controller. Using PID control logic, the controller determines the required adjustments to the reject control valve. The valve selected for tailings control was a 2-inch diameter pneumatic "pinch" valve manufactured by the Red 
Valve Corporation. This system is capable of holding level to within \pm 1 inch during normal operation.

The second control loop installed on the column was designed to maintain a constant bubble size in the pulp. This system consists of a controller that determines differential pressure from the two DP cells mounted on the column and converts readings to fractional air hold-up. Air hold-up values are used in conjunction with the air, wash water and reject flow rates to provide on-line estimates of bubble size. The procedure for estimating bubble size from column operating conditions has been described previously (M.J. Mankosa et al., 1990). They found that if the bubble size is too large, the air hold-up will fall below a setpoint value and the addition rate of frother will be increased. If the bubble size becomes too small, the air hold-up will overshoot the desired set point and the frother flow rate will be decreased.

In the case of the 30 -inch cell, bubble size control is conducted by the PLC system. The differential pressure measurements are recorded by the PLC and directly converted to fractional air hold-up by the ladder logic routine used for data collection. The ladder logic program construction is explained in greater detail under Task 2.5 . The bubble diameter within the column is determined based on the measured air fraction and flow conditions. This value is used as the measured process variable for purposes of control. The controlled output is the column frother addition pump.

\section{2.c - Installation of Data Acquisition System}

Data was also acquired through the Allen-Bradley PLC system. This system is capable of handling 1024 input/output instrument signals. These signals can be either analog 
(i.e., 4-20 mA, 0-10 volts, 0-5 volts) or discrete (48 VDC, $120 \mathrm{VAC}$ ). All instrument signals used in this project were 4-20 mA current proportional signals. Data logging, trending, manipulation, and display were achieved through the Control View software package obtained from Allen-Bradley. This software contains built-in subroutines that are specifically designed for data acquisition using a PLC-based system. The software can accommodate a wide variety of data acquisition functions by simply specifying $\mathrm{I} / \mathrm{O}$ port addresses for specific instrument signals.

\section{Task 2.3 Detailed Testing}

\section{3.a - Test Plan Development}

A detailed test plan describing the parametric study to be carried out on the 30 -inch column was submitted to the DOE on January 22,1990 . This test plan consisted of two parts: an exploratory test plan and a parametric test plan. The exploratory test program was designed to establish the appropriate levels at which the various operating parameters would be set for the detailed parametric study. The detailed parametric study was designed to establish mathematical relationships between column operating parameters and column performance.

\section{3.b - Perform Exploratory Tests}

Several preliminary tests were performed to determine the overall response of the 30 inch column to changes in key operating variables. The tests were performed by varying one test parameter at a time while holding all others constant. The standard test conditions were: 

1) feed rate
$100 \mathrm{gpm}$
2) wash water rate
$23 \mathrm{gpm}$
3) aeration rate
$16.4 \mathrm{cfm}$
4) froth depth 40 inches
5) frother dosage
$1.25 \mathrm{lb} / \mathrm{ton}$
6) collector dosage
$1.25 \mathrm{lb} / \mathrm{ton}$

The metallurgical balance sheets for these tests are provided in Appendix 1 .

The effect of feed rate on the performance of the column is shown in Figure 11. As shown, combustible recovery decreased slightly from $65.7 \%$ to $59.8 \%$ when the feed rate was increased from 78 to $120 \mathrm{gpm}$. A corresponding decrease in product ash content was observed over the same range of feed rates. The slight dip in the ash curve at $100 \mathrm{gpm}$ was due primarily to a momentary decrease in the feed ash to the column, which resulted in a

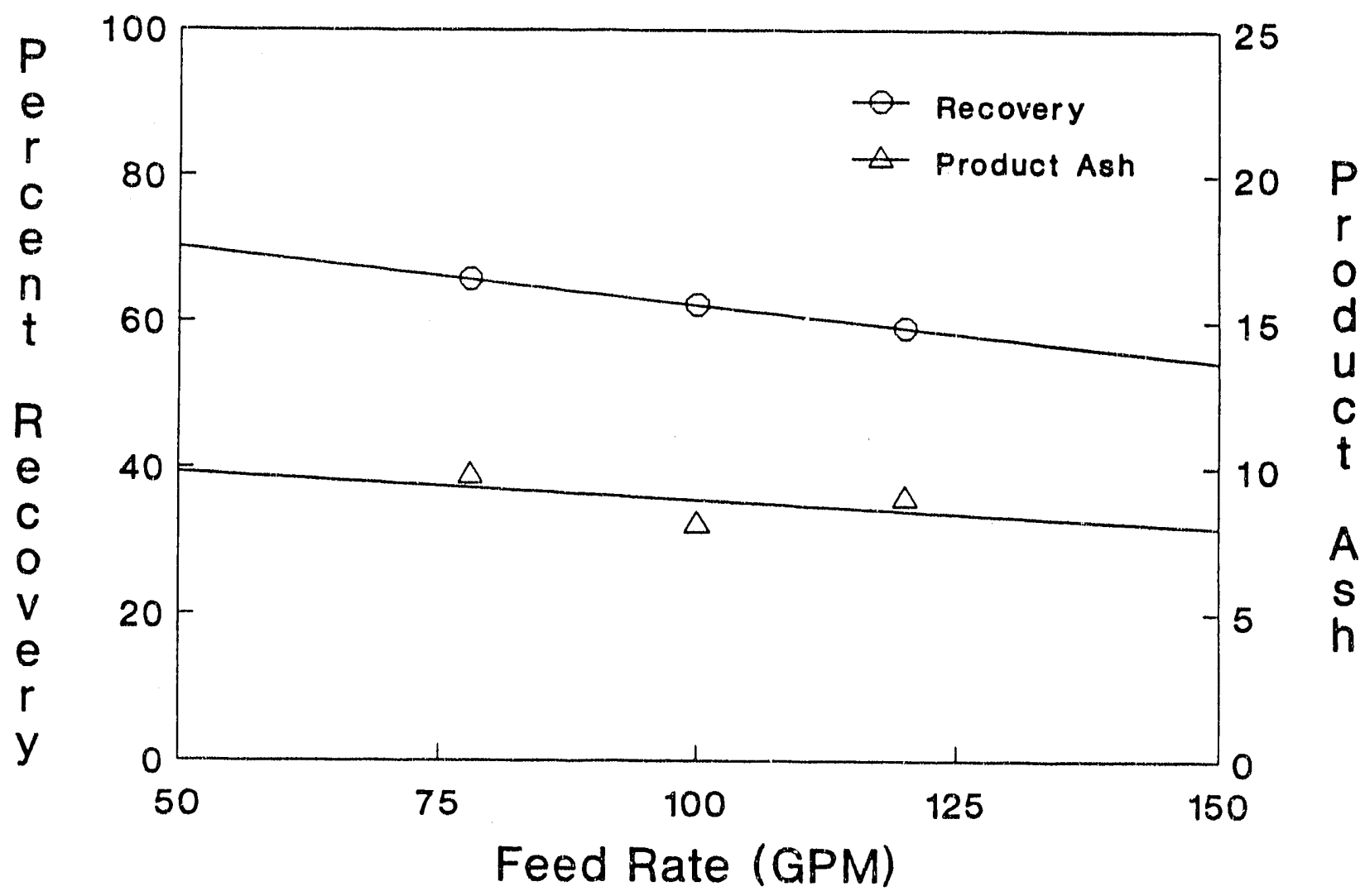

Figure 11. Effect of feed rate on combustible recovery and product ash content. 
slightly improved clean coal quality. That feed rate had only a limited impact on column performance tends to indicate that the column is operating under rate limited conditions. Under such conditions, changes in retention time slightly affect overall column recovery.

The solids content of the feed, product, and reject streams for the various feed flow rates is shown in Figure 12. In general, the solids content of the feed and reject streams remained relatively constant. The product stream, on the other hand, appeared to decrease as the feed rate increased. The decrease in the product solids content may be a result of several interactions. The first is an increase in the frother concentration in the column. Since the $\mathrm{lb} /$ ton dosage of frother was held constant, a higher feed rate resulted in a larger volumetric flow rate of frother to the cell. However, the wash water flow rate remained constant as feed rate was increased. Therefore, the ratio of frother flow to total volumetric

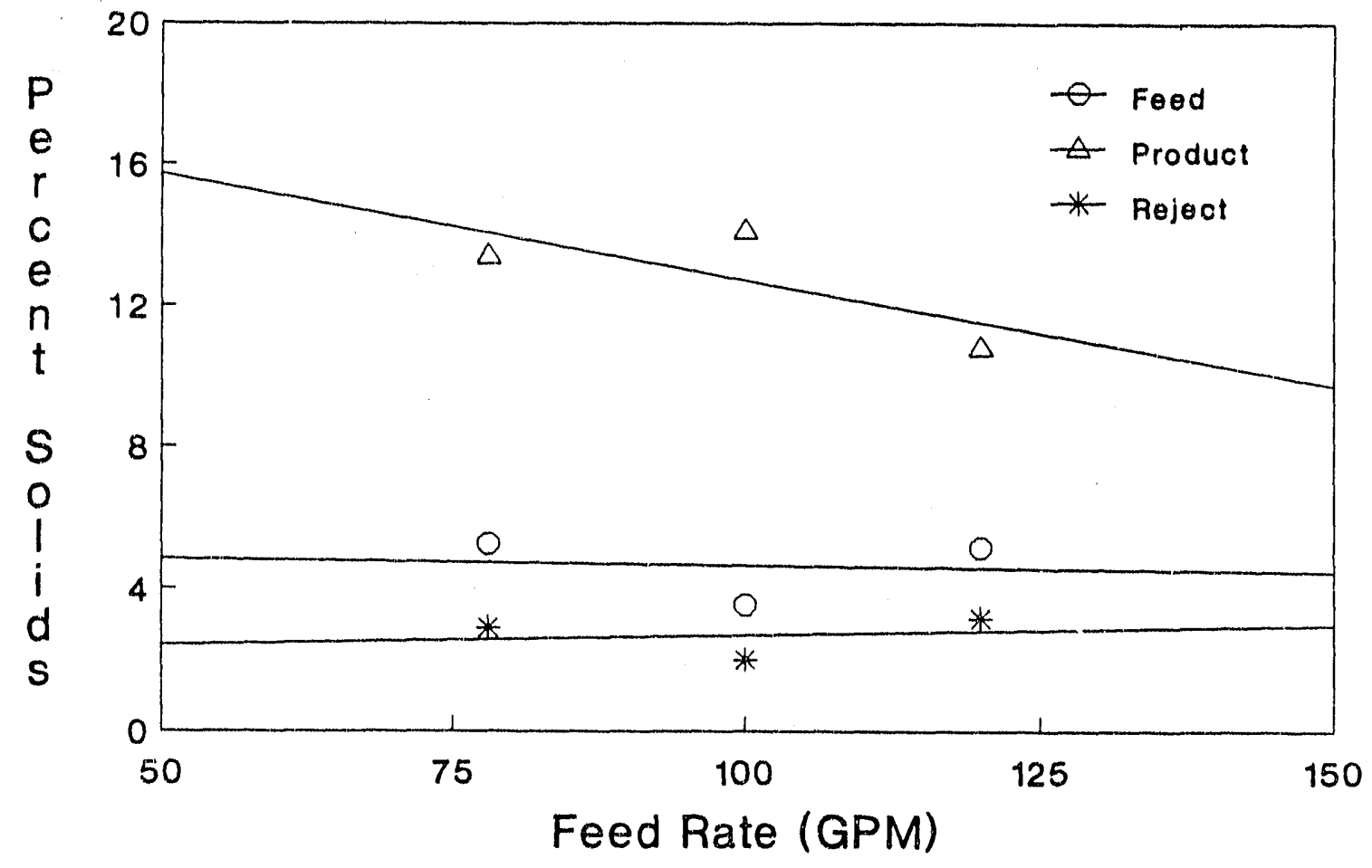

Figure 12. Effect of feed rate on the solids content of the product, reject, and feed streams. 
flow increased with an increase in feed rate. This resulted in a higher concentration of frother in the cell. The increased frother concentration, in turn, reduced the bubble size in the froth, producing a wetter froth and a lower solids content in the product.

In addition to the frother concentration effect, the increase in feed rate brought the column closer to the carrying capacity limitation of the cell. The concept of froth carrying capacity will be discussed in greater detail in the following sections of this report.

Laboratory results indicate that as the carrying capacity limitation is approached coarse particles are preferentially rejected from the froth. This, in turn, results in a decrease in the product mass flow rate and, hence, the froth percent solids.

The response of the column to changes in aeration rate is shown in Figure 13. As shown, the combustible recovery was relatively insensitive to changes in aeration rate over a range of 12.3 to $19.9 \mathrm{scfm}$. This is most likely a result of an increase in bubble size with increasing gas rate. In contrast, the product ash content increased significantly from $8.0 \%$ to over $10.5 \%$ by increasing the air flow rate. The increased product ash was probably due to an increase in nonselective entrainment of fine particles of mineral matter as air rate was increased. In general, higher air rates produce an increase in the water recovery rate, which in turn decreases the effectiveness of the wash water. This conclusion is supported by examination of the solids content plot shown in Figure 14. As the air rate increased, the solids content of the product dropped from $14.1 \%$ to $10.9 \%$, despite the fact that the solids content of the feed stream was increasing during this period. This result indicates that the effectiveness of the wash water is impacted by a very strong relationship between product grade and factors such as frother addition, aeration rate, wash water rate and wash water injection point. This may be an area that will require further study. 


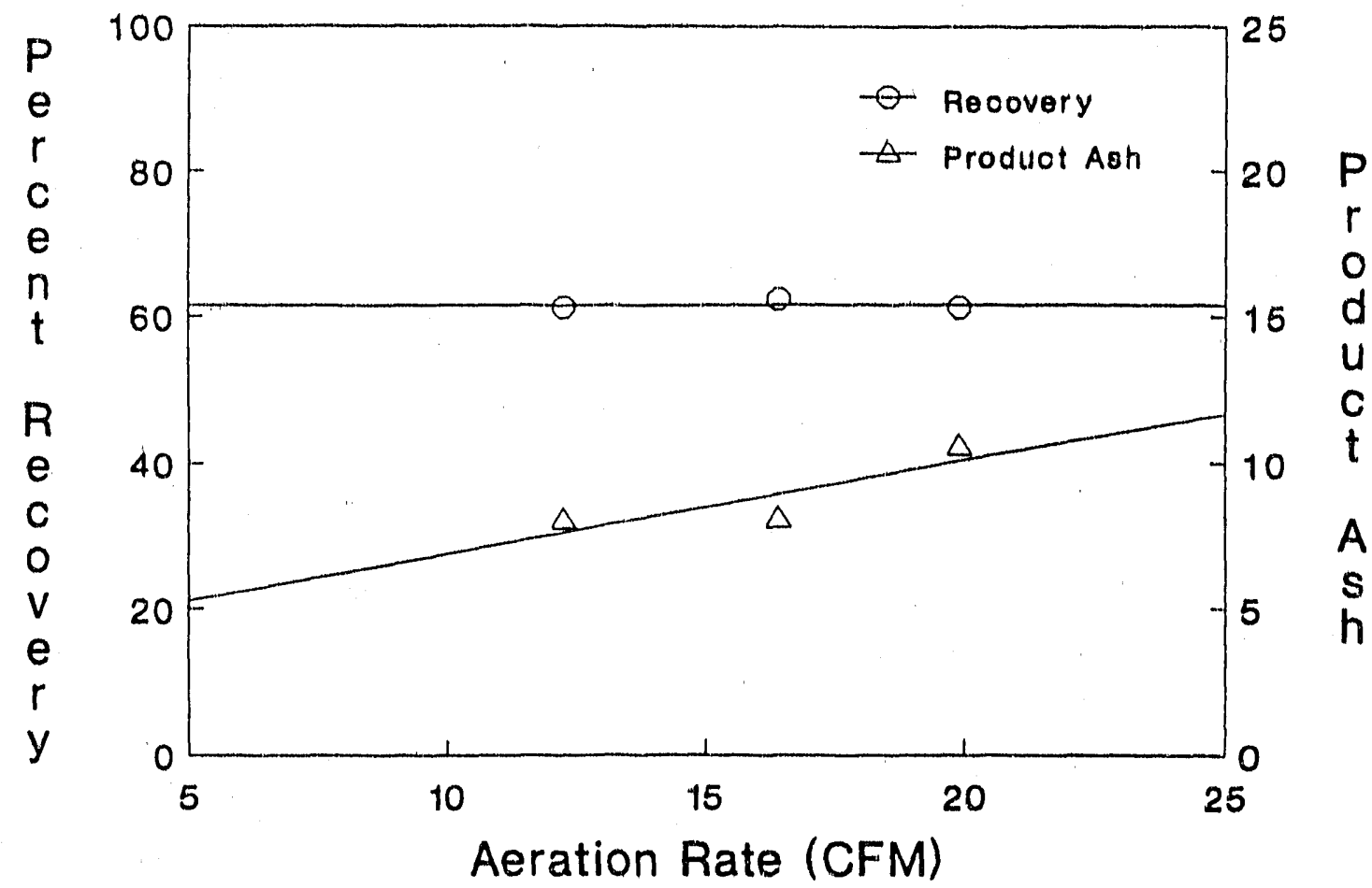

Figure 13. Effect of air flow rate on combustible recovery and product ash content.

The effect of froth depth on combustible recovery is shown in Figure 15. As shown, a froth depth of 31 inches produced a combustible recovery of $52.2 \%$, while an increase in froth depth by 16 inches increased the combustible recovery to $66.5 \%$. The product ash content, on the other hand, remained relatively unchanged over the same range of froth depths. The exact cause of the improved recovery with a deep froth bed is not yet fully understood. However, preliminary indications suggest that this response may be due to a shift in the split of wash water that enters the column. As shown in Figure 16, the froth appears to become wetter as the froth depth is increased. This implies that a larger percentage of the wash water is reporting to the product stream and that a smaller portion is diluting the pulp. This behavior may have many implications on column performance. First, since less wash water reports to the pulp when using a deep froth, less dilution of the 


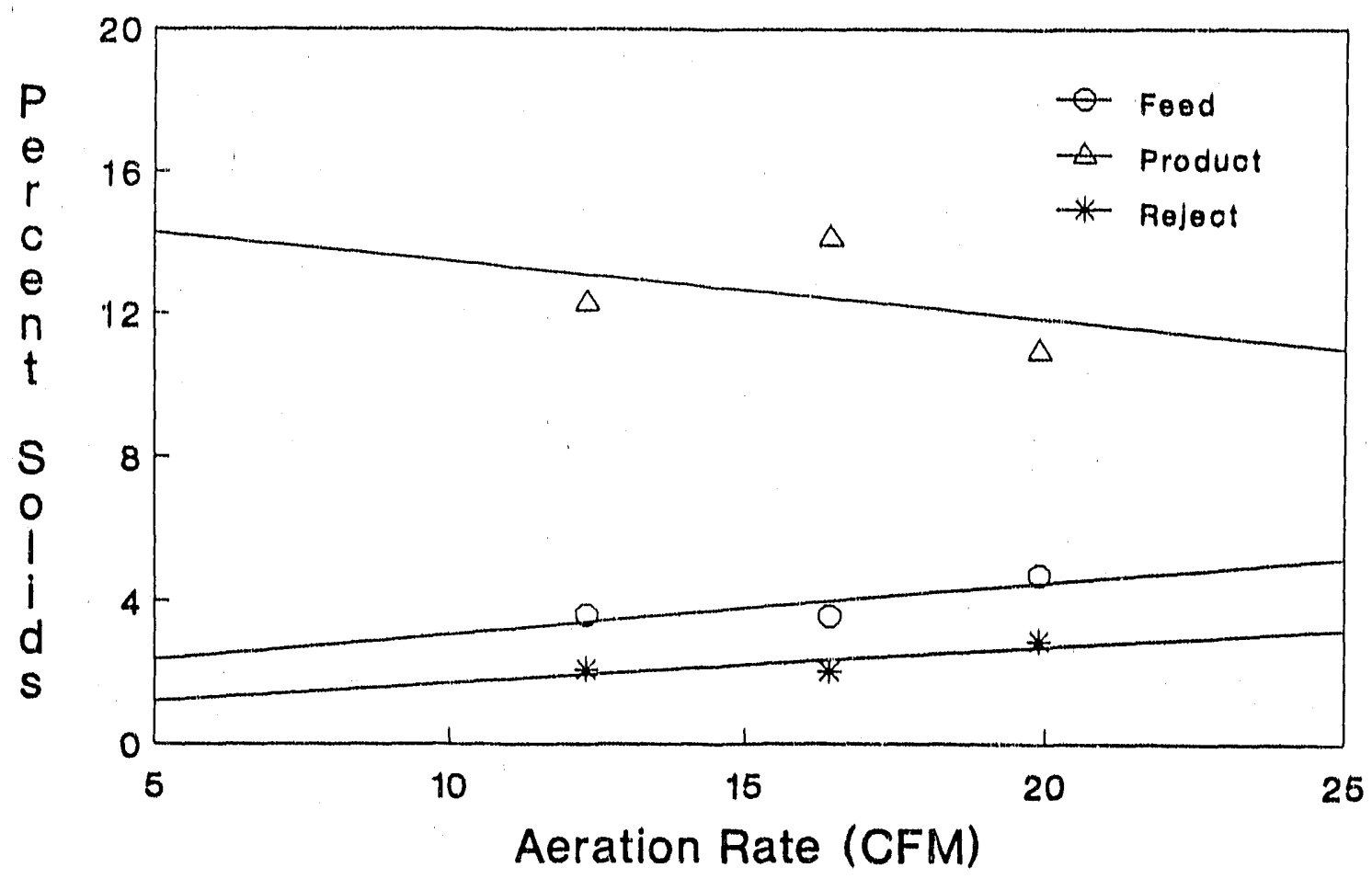

Figure 14. Effect of air flow rate on the solids content of the product, reject and feed streams.

frother occurs. This produces a higher residual concentration of frother in the cell, which allows smaller bubbles to be produced. The smaller bubbles may account for the higher recovery rates. It may also be possible that the increased water content of a deep froth may reduce bubble coalescence. This would result in larger bubble surface area available for carrying particles, thus, increasing the carrying capacity of the froth. Nevertheless, the results shown in Figures 15 and 16 do demonstrate the importance of maintaining a deep and stable froth in order to achieve good recoveries while keeping a low product ash content.

In addition to the exploratory tests conducted for the purpose of establishing parameter levels for the detailed parametric study, a long-term test was conducted to determine whether column performance would remain stable during normal feed fluctuations occurring over the period of several plant shifts. This long-term test was carried out over a 


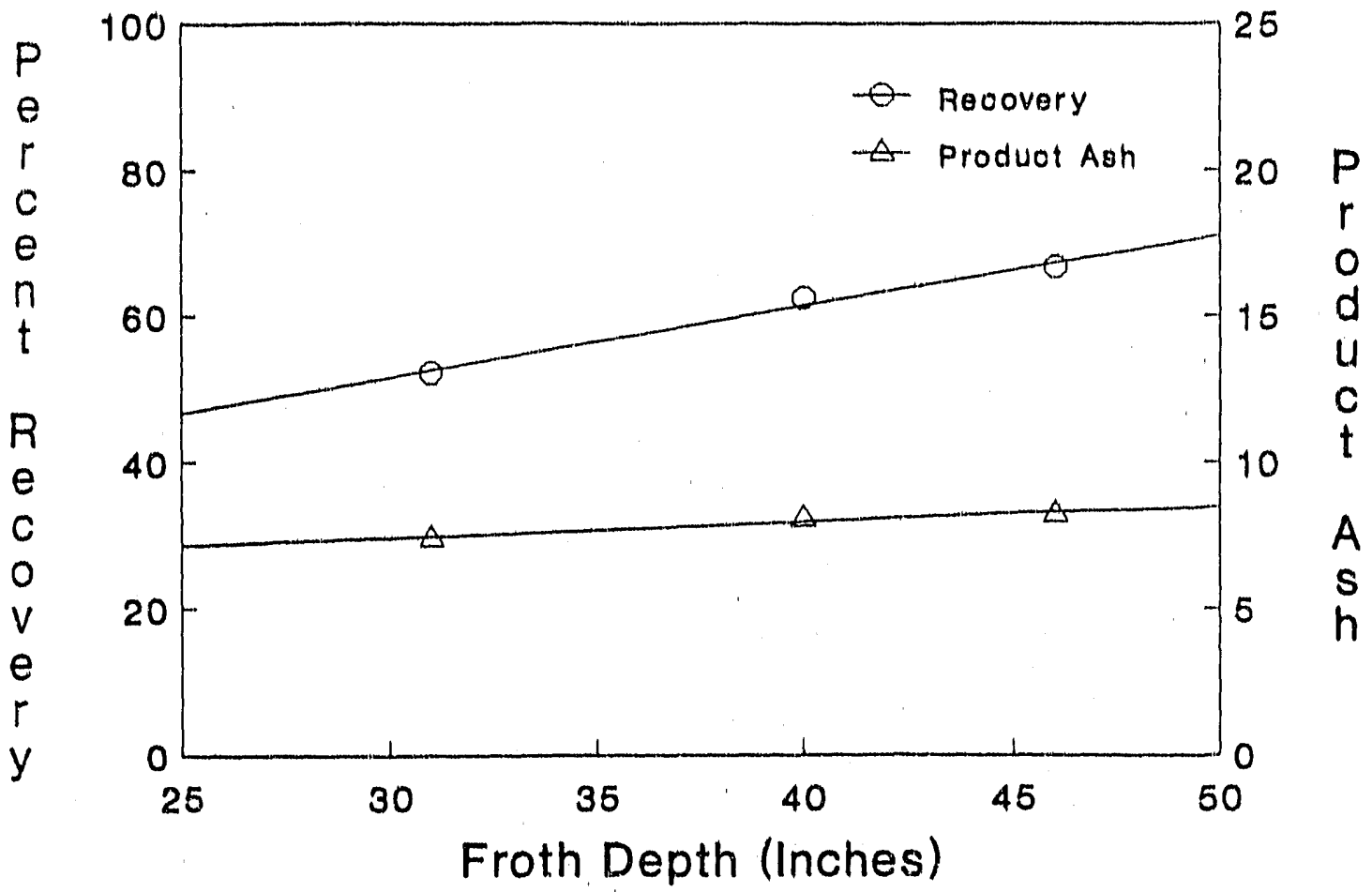

Figure 15. Effect of froth depth rate on combustible recovery and product ash content.

period of 48 hours, during which samples were taken approximately every three hours. The feed rate was fixed at $100 \mathrm{gpm}$ during the entire run. The aeration rate and wash water rates were held constant at $16.4 \mathrm{scfm}$ and $23 \mathrm{gpm}$, respectively. Both collector and frother addition rates were set at $1.25 \mathrm{lb} /$ ton.

Figure 17 shows the combustible recovery and product ash values obtained during the extended test run. The metallurgical balance sheets for these tests are shown in Appendix 2. For reference, the feed ash content is also provided to show the large variations in the feed stream quality during testing. As can be seen, the product ash content remained relatively constant and well within the target value of $10 \%$ during the entire duration of the test. The 


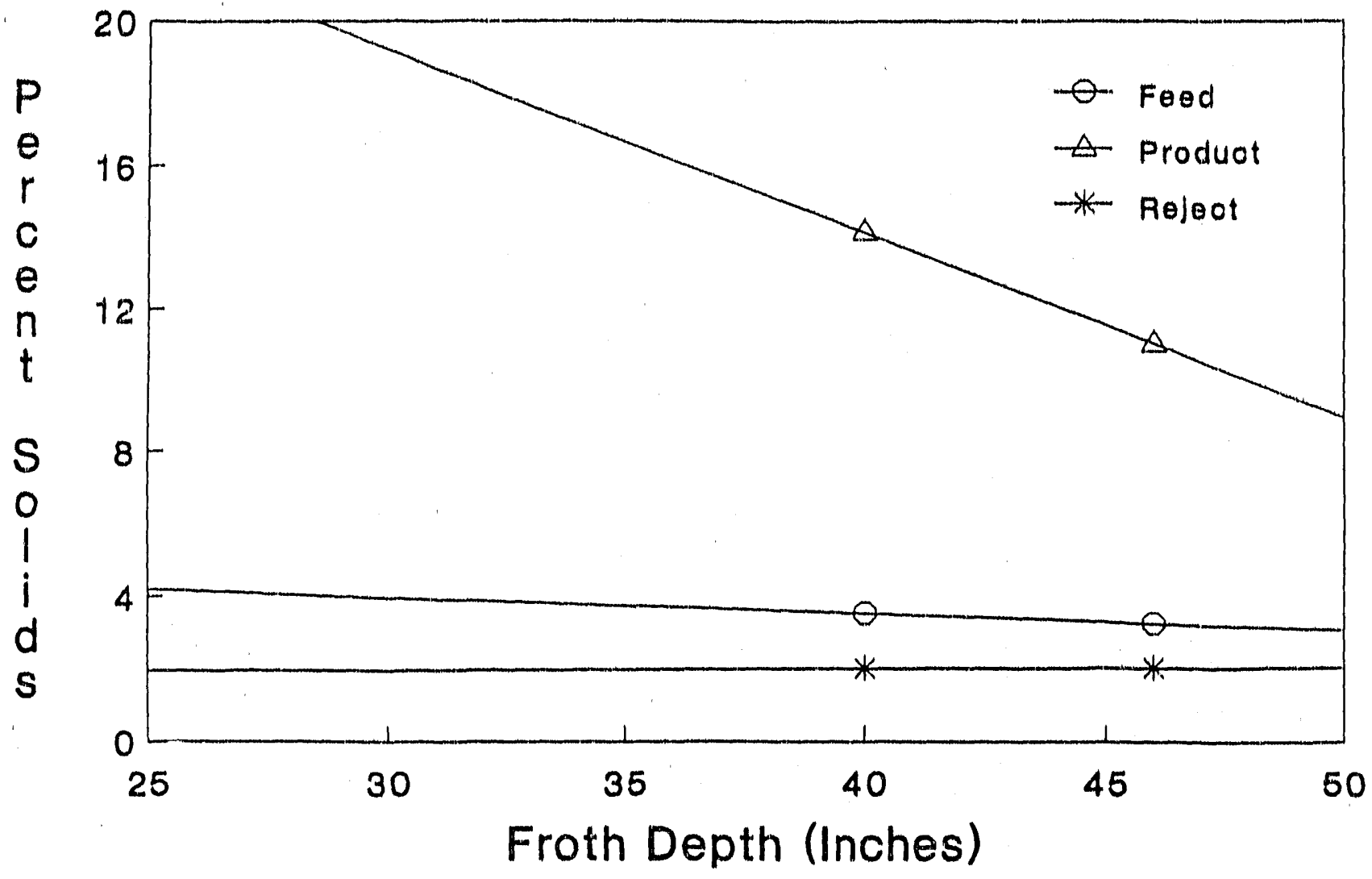

Figure 16. Effect of froth depth on the solids content of the product, reject and feed streams.

average values of the combustible recovery and product ash for the entire test run were $61.2 \%$ and $9.46 \%$, respectively. The major impact of fluctuations in the ash content of the feed stream appeared to be reflected only in the combustible recovery. From a plant operation point-of-view, this is a very significant finding since it indicates that product quality is always maintained.

The results shown in Figure 17 also demonstrate the importance of adding a proper amount of diesel collector. At one point in the test run, the supply tank for the diesel fuel ran empty. Recovery immediately fell in response to the loss of collector. However, product grade still remained stable. These results are very encouraging and suggest that the 


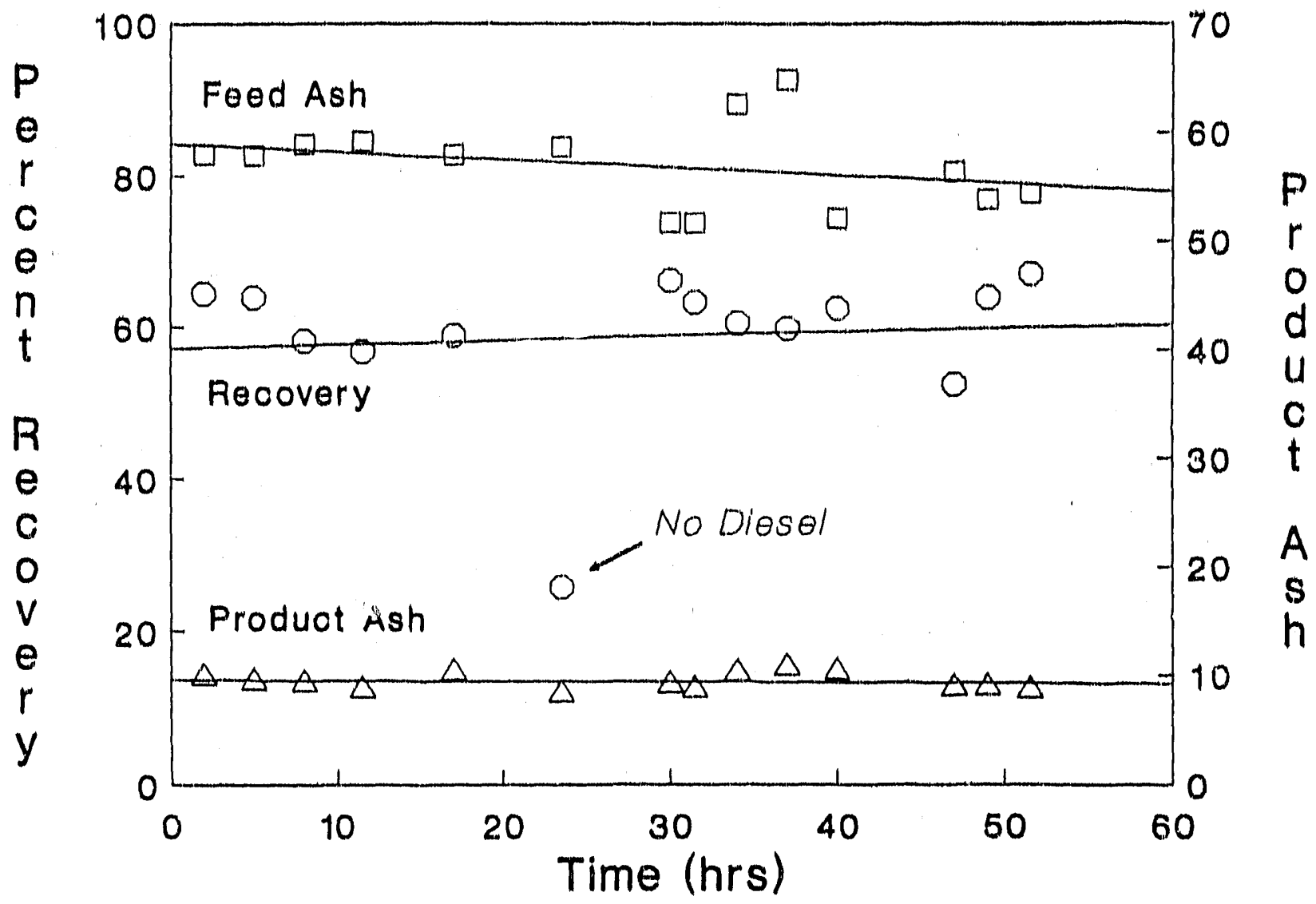

Figure 17. Variations in combustible recovery and product ash content as a function of time for the 30-inch column.

column should be able to maintain product grade within a close tolerance specification despite the presence of system disturbances.

Another objective of the preliminary test work was to determine whether coarse particles could be effectively treated by microbubble column flotation without sacrificing either recovery or grade. This may have several advantages in the existing operation including improved dewatering, improved classification performance, and simplification of the plant flowsheet. Initial test work was conducted using a 2-inch laboratory column and a sample collected at the plant site from the classifying cyclone feed stream. The sample, as received, was split into four representative lots and then screened to produce four different 
size distributions. The sizes selected for the preliminary work included -28 mesh, -48 mesh, -65 mesh and -150 mesh.

Figure 18 shows the results of this test work, while the metallurgical balance sheets for these tests are provided in Appendix 3. As shown, the coarser material generally appeared to produce a higher overall grade-recovery curve. Contrary to preliminary estimates, these results imply that the coarse size fractions contain substantial quantities of low ash coal that can be recovered by flotation.

The potential benefits to plant operation resulting from processing coarser material by flotation made it worthwhile to conduct additional follow-up test work with the 30-inch column at the plant site. In order to get a coarser size distribution at the plant site, a portion

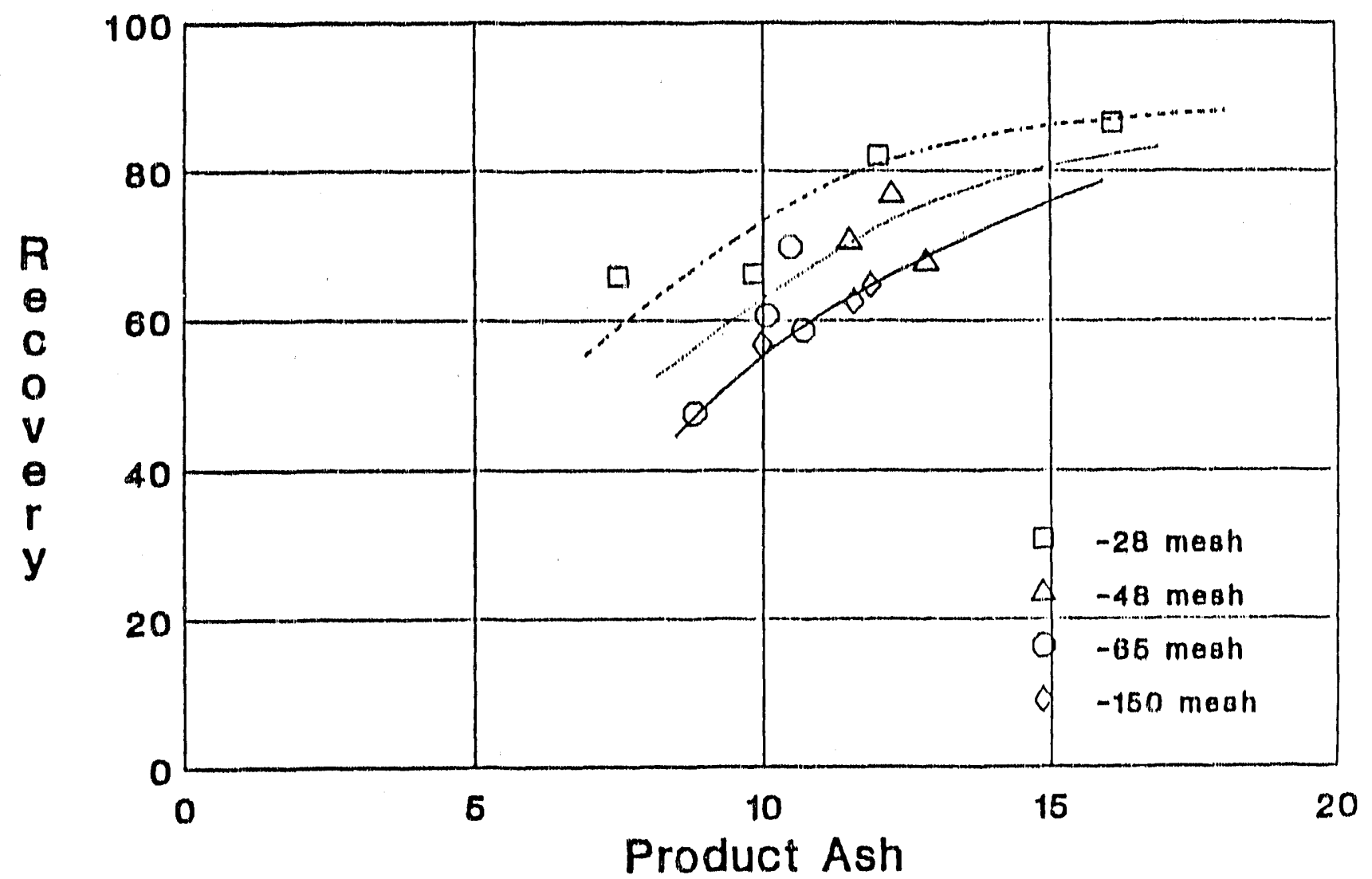

Figure 18. Combustible recovery and product ash values obtained with various size fractions using a laboratory microbubble flotation column. 
of the cyclone feed stream was used as feed to the column. Several different sets of operating conditions were oxamined in an attempt to duplicate the laboratory data. The results of this work are shown in Figure 19, and the metallurgical balance sheets are provided in Appendix 4. As shown, a combustible recovery greater than $45 \%$ was never achieved in any of the test work. Several possible explanations may be given for the discrepancy between the laboratory and in-plant test results. The most likely reason, however, was the inability to maintain a reliable feed size distribution. Because of upstream problems with classification, a substantial portion of $+1 / 8$-inch material was generally present in the feed stream to the cyclones. At times, this accounted for nearly $60-70 \%$ of the feed stream by weight. Additional testing would be required in order to resolve this discrepancy. However, that was considered to be beyond the scope of this project.

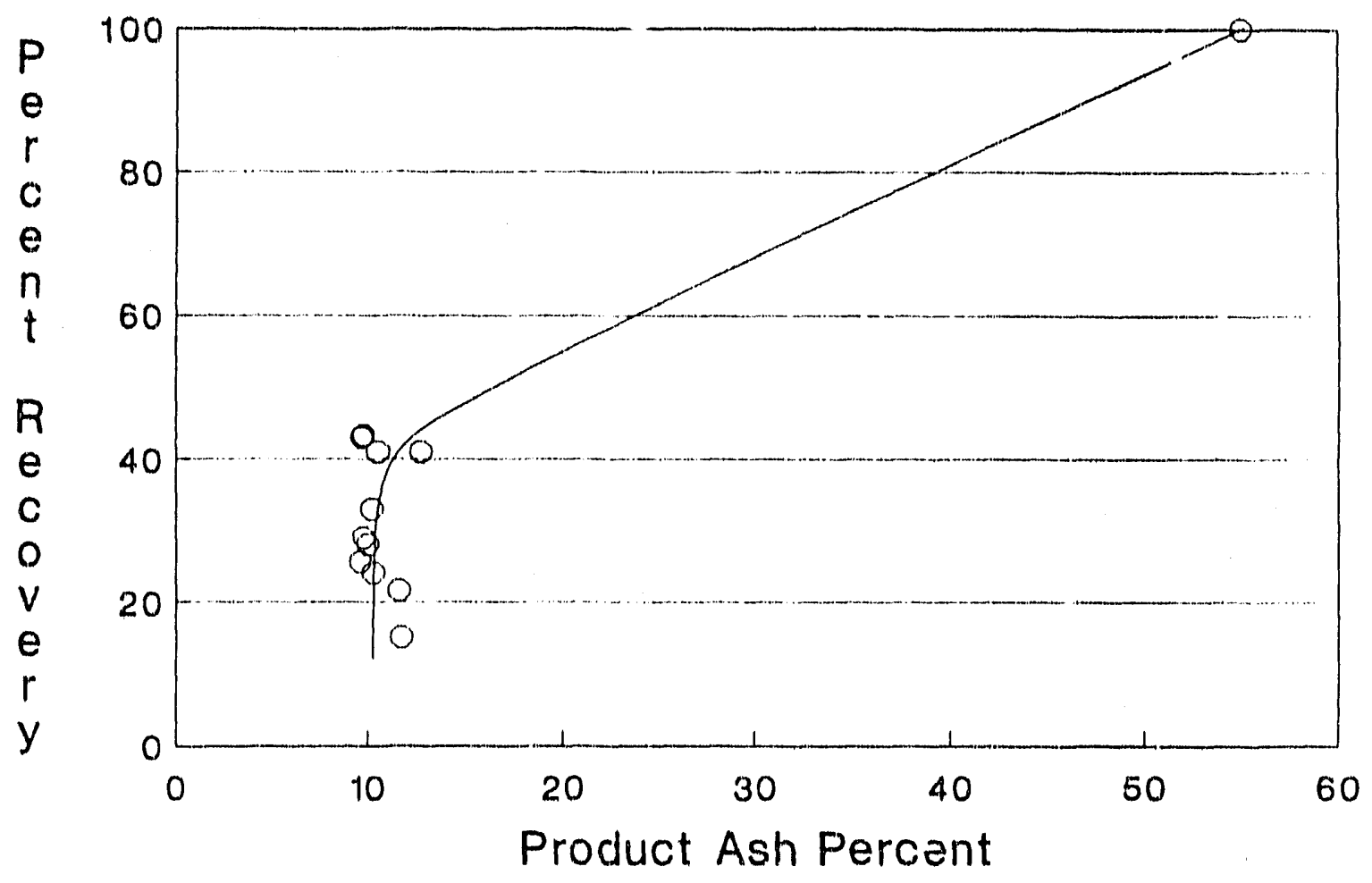

Figure 19. Combustible recovery and product ast values obtained during the processing of classifying cyclone feed. 


\section{3.c - Perform Parametric Tests}

General: As a result of the data collected in the exploratory test program, the appropriate levels were determined for the parametrio test work. The recommended settings for each parameter are summarized in Table 1. It should be noted that the measured parameter settings are very close to those initially suggested in the original work outline. The only major change is in the frother and collector addition rates, which have been changed from a weight ratio (i.e., lb/ton) to a flow rate $(\mathrm{ml} / \mathrm{min})$. This change is necessitated by difficulties in maintaining a fixed soilds content in the feed stream. Since the feed solids content is variable, a lb/ton dosage cannot be determined until after the samples are obtained. However, the levels recommended in Table 1 for the flow rates of frother and collector should provide $\mathrm{lb} /$ ton dosages very close to those which were originally proposed. The standard operating conditions for the remaining variables are listed in Table 2. A statistical design and data analysis program (DESIGN-EXPERT, developed by Stat-Ease of Minneapolis, Minnesota) was used to set-up the experimental design and to perform all

Table 1. Recommended levels for the detailed parametric testing.

\begin{tabular}{||l|c|c|c|c|}
\hline \multicolumn{1}{|c|}{ Parameter } & Unit & Low & Normal & High \\
\hline \hline pulp height & inches & 20 & 40 & 60 \\
\hline frother rate & $\mathrm{ml} / \mathrm{min}$ & 6 & 11 & 16 \\
\hline collector rate & $\mathrm{ml} / \mathrm{min}$ & 6 & 11 & 16 \\
\hline feed rate & $\mathrm{gpm}$ & 60 & 100 & 140 \\
\hline wash water rate & $\mathrm{gpm}$ & 20 & 25 & 30 \\
\hline aeration rate & $\mathrm{cfm}$ & 10 & 16 & 22 \\
\hline
\end{tabular}


Table 2. Standard conditions used for parametric test plan.

\begin{tabular}{|l|c|}
\hline Parameter & Setting \\
\hline \hline Column Diameter & 30 inches \\
\hline Column Length & 26 feet \\
\hline Wash Water Addition Point & \\
Upper Ring & 3 inches above lip \\
Lower Ring & 16.5 inches below lip \\
\hline Generator Length & 17 inches \\
\hline Generator Diameter & 2 inches \\
\hline Number of Generators & 3 \\
\hline Frother Type & Betz 1012 \\
\hline Collector Type & $\# 2$ Diesel \\
\hline Baffles & None \\
\hline
\end{tabular}

required statistical computations and regressions. A Box-and-Behnken experimental design was selected for use in the present work. This type of design is well suited for the study of fiotation systems since it:

1) provides a means of measuring the contribution of each parameter to the given response,

2) allows the influence of joint interactions between the various test parameters to be estimated, and

3) minimizes the number of test runs necessary to complete the test program.

The specific tests required by the Box-and-Behnken design are summarized in Table 3 . The statistical design requires that 54 individual flotation tests be conducted in order to quantify 


\begin{tabular}{|c|c|c|c|c|c|c|c|c|c|c|c|c|c|c|c|c|c|c|c|c|c|c|c|c|c|}
\hline 总总总总 & 0 & 0 & -1 & 0 & - & 0 & 0 & - & 0 & -7. & -0 & T & i & 10 & T & 0 & - & 0 & $T$ & 70 & $p$ & $\Rightarrow 0$ & - & - & 0 \\
\hline 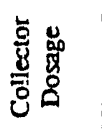 & - & - & 0 & - & 0 & 0 & $T$ & $\rightarrow$ & 0 & 7 & 07 & 10 & T & ד & 0 & 0 & 0 & - & 0 & 70 & 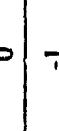 & $1-$ & 10 & - & 0 \\
\hline 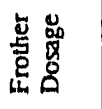 & 0 & 0 & 0 & $T$ & $T$ & -1 & -1 & 0 & 0 & 0 & $\circ$ & T & 10 & T & - & - & 0 & 0 & 0 & 0 & T & 7 & $1-$ & 0 & $T$ \\
\hline 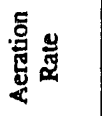 & $T$ & 7 & 0 & 0 & - & 0 & 0 & 0 & 0 & 0. & $-1-$ & $-1-$ & 4 & 10 & T & 0 & 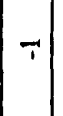 & - & $T$ & 0 & 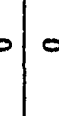 & D & ד ד & 0 & 0 \\
\hline 㢦 & -1 & 7 & ד & 0 & 0 & -1 & 0 & ד' & 0 & - & 0 & -0 & $0-$ & 0 & 0 & - & 0 & $T$ & 0 & - & 1 & o & 0 & - & $T$ \\
\hline 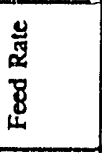 & 0 & 0 & 0 & -1 & 0 & $T$ & $T$ & 0 & 0 & 0.7 & 10 & 0 & 0 & ד & 0 & -1 & - & 0 & $T$ & 0 & -1 & - & 0 & 0 & $T$ \\
\hline 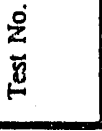 & \pm & $m$ & है & 임 & $\approx$ & 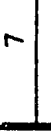 & $\hat{N}$ & m & $\approx$ & $\infty$ & $\because 1=$ & $\theta$ & 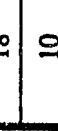 & 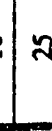 & 9 & $\infty$ & $\mathscr{T}$ & $\simeq$ & $F$ & $\bar{m}=0$ & -1 & N) $\approx$ & $\hat{n}$ & 8 & -1 \\
\hline 营惹 & $ד$ & $T$ & - & 0 & 0 & $T$ & $T$ & 0 & 0 & - & T- & -10 & 0 & 10 & 0 & 0 & -1 & 0 & 0 & ד & c & 0 & ד ד & 0 & 0 \\
\hline 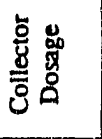 & 0 & $T$ & 0 & -1 & 0 & -1 & 0 & 0 & 0 & 0 & 0 & $01-$ & -0 & 0 & T & 7 & 0 & 0 & 0 & 0 & & - & - & 0 & $T$ \\
\hline $\begin{array}{l}\text { 总品 } \\
\text { 总 }\end{array}$ & 0 & 0 & - & 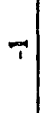 & 7 & 0 & - & 0 & $T$ & 7 & 1) & 0 & - & $4-$ & 0 & - & 0 & 0 & 0 & 00 & $\Rightarrow$ & - & 0 & 0 & 0 \\
\hline 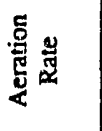 & T & 0 & - & 0 & 0 & 0 & - & 0 & 0 & ד & 7 & -1 & -10 & e & ד & 0 & $T$ & 0 & 0 & -1 & 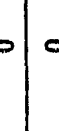 & 0 & 0 & 0 & - \\
\hline 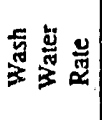 & 0 & $T$ & 0 & 0 & - & $T$ & 0 & 0 & - & 0 & 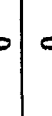 & $0-$ & -7 & 4 & ד: & 0 & 0 & 0 & 0 & 0 & 0 & 0 & - & 0 & $\rightarrow$ \\
\hline $\begin{array}{l}\frac{2}{5} \\
\frac{5}{5} \\
8 \\
5\end{array}$ & -1 & 0 & 0 & $T$ & - & 0 & 0 & 0 & $T$ & 0 & 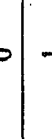 & $T$ & 07 & 1 & $\begin{array}{lll}-1 & 0\end{array}$ & - & $T$ & 0 & 0 & 7 & 0 & $T$ & -1 & 0 & 0 \\
\hline $\begin{array}{l}\dot{0} \\
\dot{z} \\
\dot{g}\end{array}$ & $F$ & $m$ & $\ddot{N}$ & D) & + & $\tilde{\sim}$ & 요 & 8 & $m$ & $\bar{\sim}$ & $=0$ & $F=$ & 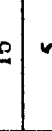 & . & 0 & $\underset{\sim}{\infty}$ & $q$ & $\ddot{n}$ & $\bar{n}$ & 80 & $\tilde{E}$ & $\bar{m}$ & 7 & in & $=$ \\
\hline
\end{tabular}


the effects of the 6 specified test parameters. The specific test levels utilized in the design were selected using the exploratory test results as a guideline. All tests were conducted in random order to minimize experimental bias, and the results were analyzed and adjusted using a single-node material balance program to produce a consistent set of results prior to proceeding to the next step. In most cases, only minor adjustments to the experimental data were required, indicating that the measured assay values were reliable.

Parametric Test Overview: The results obtained from the parametric test work are summarized in Table 4. In order to obtain a consistent set of experimental data, all test values were analyzed and adjusted using a single-node material balance program.

Baseline Tests: As indicated in Tables 3 and 4, six replicate "baseline" tests were performed at various times throughout the test program. These replicate tests were required so that the amount of pure experimental error could be assessed. In the present work, the experimental errors consisted of random errors associated with the testing procedure, data collection, and sample analysis. The yield and energy recovery data obtained from these replicate tests are plotted in Figure 20. As shown, the variation within the data set for the first four replicate tests is within the range that can be expected for in-plant studies. These differences can be accounted for by the natural variations in the system (e.g., slight changes in the feed material, surges in the reagents pumps or feed rate, inaccuracies in reading metering gauges, etc.). Figure 20 also indicates that there is a slight difference in the data from replicate tests 5 and 6 as compared to the first four replicate tests. Two possibilities can be given for this 
Table 4. Test results obtained during the parametric testing.

\begin{tabular}{|c|c|c|c|c|c|c|c|c|c|c|c|c|c|c|c|c|c|}
\hline ID & $\begin{array}{l}\text { Food } \\
\text { Aeb }\end{array}$ & $\begin{array}{l}\text { Prod } \\
\text { Ael }\end{array}$ & $\begin{array}{l}\text { Tail } \\
\text { Aats }\end{array}$ & $\begin{array}{l}\text { Food } \\
\text { Sulfur }\end{array}$ & $\begin{array}{l}\text { Prod } \\
\text { Sulf }\end{array}$ & $\begin{array}{l}\text { Rejoct } \\
\text { Sulfur }\end{array}$ & $\begin{array}{l}\text { Food } \\
\text { Datu }\end{array}$ & $\begin{array}{l}\text { Prod } \\
\text { Bau }\end{array}$ & $\begin{array}{l}\text { Toil } \\
\text { Beul }\end{array}$ & $\begin{array}{l}\text { Prod } \\
\text { Yield }\end{array}$ & $\begin{array}{l}\text { Combb } \\
\text { Rocury }\end{array}$ & $\begin{array}{c}\text { Red } \\
\text { Revry }\end{array}$ & $\begin{array}{c}\text { Bou } \\
\text { Rocory }\end{array}$ & $\begin{array}{c}\text { Aeb } \\
\text { Rejoet }\end{array}$ & $\begin{array}{l}\text { Sulfur } \\
\text { Rejoct }\end{array}$ & $\begin{array}{c}\text { Comb } \\
\text { SE }\end{array}$ & $\begin{array}{c}\text { Toul } \\
\text { SE } \\
\end{array}$ \\
\hline 42 & 61.03 & 9.46 & 74.04 & 0.21 & 0.50 & 0.14 & 4836 & 13522 & 2.646 & 20.15 & 46.80 & 3.12 & 56.32 & 96.88 & 53.24 & 43.68 & 9.56 \\
\hline 33 & $59.9 ?$ & 13.23 & 79.92 & 0.21 & 0.45 & 0.11 & 4939 & 12953 & 1546 & 29.91 & 64.84 & 6.60 & 78.14 & 93.40 & 36.71 & $58.2 \mathrm{~A}$ & 14.85 \\
\hline 24 & 60.41 & 8.70 & 72.78 & 0.21 & 0.47 & 0.15 & 4962 & 13564 & 2904 & 19.30 & 44.52 & 2.78 & 52.76 & 97.22 & 57.04 & 41.74 & 10.40 \\
\hline 29 & 61.50 & 7.85 & 76.66 & 0.25 & 0.50 & 0.18 & 4734 & 13831 & 2165 & 22.03 & 52.73 & 2.81 & 64.36 & 97.19 & 56.14 & 49.92 & 20.50 \\
\hline 4 & 61.74 & 6.93 & 70.28 & 0.25 & 0.47 & 0.21 & 4708 & 13994 & 3262 & 13.48 & 32.79 & 1.51 & 40.07 & 98.49 & 72.68 & 31.28 & 12.74 \\
\hline 35 & 63.29 & 13.22 & 78.15 & 0.25 & 0.50 & 0.18 & 4383 & 12930 & 1847 & 22.89 & 54.10 & 4.78 & 67.51 & 95.22 & 35.52 & 49.32 & 20.03 \\
\hline 20 & 62.34 & 15.97 & 73.38 & 0.21 & 0.49 & 0.14 & 4482 & 12400 & 2504 & 19.23 & 42.91 & 4,93 & 53.46 & 95.07 & 53.85 & 37.98 & 7.30 \\
\hline 49 & 60.61 & 8.99 & 71.79 & 0.24 & 0.45 & 0.20 & 4918 & 13668 & 3023 & 17.80 & 41.13 & 2.64 & 49.47 & 97.36 & 68.50 & 38.49 & 17.97 \\
\hline 3 & 59.37 & 6.97 & 67.18 & 0.26 & 0.50 & 0.22 & 5090 & 13934 & 3771 & 12.97 & 29.70 & 1.52 & 35.51 & 98.48 & 73.64 & 28.18 & 9.15 \\
\hline 21 & 58.92 & 6.89 & 62.53 & 0.23 & 0.42 & 0.22 & 5148 & 14000 & 4533 & 6.49 & 14.71 & 0.76 & 17.65 & 99.24 & 39.45 & 13.95 & 7.09 \\
\hline 17 & 58.82 & 8.19 & 68.15 & 0.25 & 0.46 & 0.21 & 5177 & 13777 & 3592 & 15.56 & 34,69 & 2.17 & 41.41 & 97.83 & 70.93 & 32.52 & 12.33 \\
\hline 47 & 58.87 & 10.81 & 83.51 & 0.25 & 0.48 & 0.13 & 5211 & 13348 & 1040 & 33.19 & 73.50 & 6.22 & 26.82 & 93.78 & 34.38 & 67.27 & 21.20 \\
\hline 16 & 57.79 & 11.12 & 79.86 & 0.28 & 0.50 & 0.18 & 589 & 13237 & 1832 & 32.11 & 67.61 & 6.18 & 77.35 & 93.82 & 43.65 & 61.43 & 21.00 \\
\hline 5 & 59.32 & 13.74 & 82.55 & 0.23 & 0.46 & 0.12 & 5011 & 12813 & 1035 & 33.76 & 71.59 & 7.82 & 86.31 & 92.18 & 34.56 & 63.77 & 20.87 \\
\hline 6 & 58.46 & 9.07 & 75.44 & 0.26 & 0.48 & 0.18 & 5246 & 13566 & 2385 & 25.58 & 56.00 & 3.97 & 66.16 & 96.03 & 51.52 & 52.03 & 17,68 \\
\hline 9 & 59.26 & 7.60 & 74.53 & 0.24 & 0.46 & 0.17 & 5125 & 13858 & 2543 & 22.81 & 51.75 & 2.93 & 61.69 & 97.07 & 34.67 & 48.82 & 16.36 \\
\hline 28 & 56.32 & 8.95 & 66.78 & 0.33 & 0.48 & 0.29 & 5724 & 13528 & 4001 & 16.09 & 37.70 & 2.87 & 42.74 & 97.13 & 71.98 & 34.83 & 14.73 \\
\hline 45 & 63.65 & 1.00 & 72.31 & 0.20 & 0.47 & 0.16 & 4298 & 13758 & 2125 & 13.47 & 34.08 & 1.69 & 43.10 & 98.31 & 69.23 & 32.39 & 12.33 \\
\hline 54 & 65.68 & 11.45 & 72.94 & 0.19 & 0.46 & 0.16 & 3867 & 13221 & 2613 & 11.11 & 30.46 & 2.06 & 40.37 & 97.94 & 74.27 & 28.40 & 14.64 \\
\hline 51 & 62.76 & 10.78 & 72.60 & 0.22 & 0.47 & 0.17 & 4381 & 13350 & 2683 & 15.92 & 38.13 & 2.73 & 48.51 & 97.27 & 64.97 & 35.40 & 13.48 \\
\hline 43 & 62.04 & 27.80 & 77.35 & 0.22 & 0.40 & 0.14 & $46 \mathrm{M}$ & 10540 & 2007 & 30.90 & 38.77 & 13.25 & 70.13 & 86.15 & 43.97 & 41.92 & 14.10 \\
\hline 52 & 04.17 & 11.02 & 70.65 & 0.20 & 0.42 & 0.17 & 4134 & 13257 & 3023 & 80.87 & 26.99 & 1.87 & 34.85 & 98.13 & 75.76 & 25.12 & 10.61 \\
\hline 31 & 63.62 & 17.68 & 74.80 & 0.21 & 0.43 & 0.16 & 4253 & 12234 & 2311 & 19.57 & 44.29 & 5.44 & 56.30 & 91.56 & 61.28 & 38.25 & 17.58 \\
\hline$\mu$ & 63.24 & 23.05 & 76.53 & 0.21 & 0.39 & 0.16 & 4372 & 11306 & 20079 & 24.15 & 52.02 & 9.06 & 44.26 & 90.94 & 57.26 & 42.9 & 21.52 \\
\hline 36 & 62.45 & 23.08 & 79.45 & 0.23 & 0.41 & 0.16 & 4615 & 11287 & 1735 & 30.16 & 61.78 & 21.15 & 73.75 & 81.05 & 48.59 & 50.63 & 22.34 \\
\hline so & 64.4 & 1.46 & 76.30 & 0.22 & 0.54 & 0.16 & 4179 & 13660 & 2031 & 16.69 & 13.90 & 220 & 55.22 & 97.80 & 60.44 & 41.78 & 15.66 \\
\hline 11 & 65.33 & 12.90 & 79.14 & 0.23 & 0.57 & 0.14 & 4132 & 13000 & 1796 & 20.25 & 52.38 & 4.12 & 65.58 & 95.118 & 48.18 & 48.26 & 13.76 \\
\hline 14 & 64.00 & 7.4 & 75.53 & 0.25 & 0.60 & 0.18 & 4356 & 1347 & 2408 & 17.00 & 43.61 & 200 & 54.15 & 97.91 & 39.74 & 41.52 & 23.88 \\
\hline 13 & 4.17 & 7.89 & 73.11 & 0.24 & 0.61 & 0.18 & 4300 & 13750 & 2601 & 14.62 & 37.59 & 1.50 & 46.78 & 91.20 & 0.03 & 35.20 & 10.79 \\
\hline 39 & 63.25 & 11.45 & 71.11 & 0.24 & 0.57 & 0.19 & 4205 & 13211 & 2831 & 13.17 & 31.74 & 2.38 & 41.39 & 97.52 & 68.74 & 29.36 & 10.12 \\
\hline 30 & 69.37 & 1.90 & 78.26 & 0.20 & 0.60 & 0.14 & 347 & 13647 & 1811 & 13.58 & 40.36 & 1.76 & 53.26 & 80.24 & 60.49 & 38.60 & 13.75 \\
\hline 22 & 65.68 & 11.34 & 67.16 & 0.23 & 0.55 & 0.22 & 4046 & 13238 & 3795 & 2.65 & 6.13 & 0.46 & 8.60 & 99.54 & 93.12 & 6.39 & 1.79 \\
\hline 7 & 66.91 & 9.60 & 87.30 & 0.21 & 0.56 & 0.00 & 381 & 13012 & 618 & 26.11 & 71.61 & 3.79 & 28.25 & 96.21 & 31.61 & 67.82 & 19.18 \\
\hline 27 & 65.76 & 13.29 & 83.50 & 0.26 & 0.65 & 0.00 & 4216 & 12935 & 470 & 30.05 & 76.10 & 6.07 & 92.19 & 93.93 & 21.21 & 70.02 & 16.40 \\
\hline 37 & 65.95 & 9.53 & 76.65 & 0.23 & 0.57 & 0.16 & 3975 & 23573 & 2155 & 15.94 & 42.36 & 230 & 54.43 & 97.70 & 58.48 & 40.05 & 12.91 \\
\hline 53 & 4.46 & 8.36 & 20.42 & 0.21 & 0.60 & 0.14 & 411 & 18191 & 1631 & 22.15 & 57.11 & 2.87 & 71.13 & 97.13 & 45.41 & 54.24 & 16.54 \\
\hline 31 & 63.94 & 12.60 & 729 & 0.22 & 0.57 & 0.16 & 4981 & 1300 & 2075 & 14.90 & 36.30 & 297 & 43.66 & 97.03 & 61.12 & 33.33 & 3.48 \\
\hline 4 & 0.20 & 9.53 & 74.41 & 0.26 & 0.57 & 0.19 & 4755 & 19539 & 2725 & 18.77 & 43.00 & 287 & 53.44 & 97.13 & 59.36 & 42.16 & 12.80 \\
\hline 12 & 72.63 & 17.13 & 25.00 & 0.18 & 0.57 & 0.10 & 20032 & 12238 & 721 & 18.33 & 55.51 & 4.32 & 70.22 & 95.68 & 45.37 & 51.19 & 24.59 \\
\hline 11 & 72.76 & 12.66 & 1287 & 0.17 & 0.60 & 0.10 & 249 & 13019 & 1190 & 4.40 & 46.17 & 251 & 4.7 & 97.49 & 50.35 & 43.66 & 15.12 \\
\hline 10 & R.99 & 10.61 & 81.52 & 0.17 & 0.61 & 0.10 & $2 \pi 9$ & 13372 & 1304 & 12.40 & 41.04 & 1.20 & 59.22 & 98.20 & 51.53 & 39.24 & 10.75 \\
\hline 25 & 72.82 & 9.29 & 79.23 & 0.17 & 0.60 & 0.12 & 2074 & 13536 & 1796 & 9.17 & 30.59 & 1.17 & 43.22 & 91.83 & 4.12 & 20.42 & 7,34 \\
\hline 19 & 73.24 & 13.43 & 4.17 & 0.17 & 0.60 & 0.00 & 2753 & 12484 & 901 & 15.45 & 49.96 & 283 & 72.31 & 97.17 & 44.76 & 47.15 & 17.07 \\
\hline 8 & 73.12 & 11.25 & 30.55 & 0.17 & 0.59 & 0.12 & 264 & 13245 & 1417 & 10.72 & 35.40 & 1.65 & 52.90 & 98.35 & 63.02 & 33.75 & 15.92 \\
\hline 46 & 70.99 & 8.57 & 75.17 & 0.11 & 0.58 & 0.15 & 3100 & 13720 & 2389 & 6.21 & $19 . n$ & 0.76 & 27.77 & 99.24 & $\pi .10$ & 19.02 & 5.87 \\
\hline 15 & 60.79 & 14.56 & 79.39 & 0.25 & 0.52 & 0.14 & 4870 & 12741 & 1701 & 28.60 & 62.52 & 6.87 & 73.06 & 93.13 & 39.91 & 55.65 & 15.00 \\
\hline 41 & 58.74 & 15.45 & 79.10 & 0.26 & 0.53 & 0.13 & 4078 & 12625 & 1258 & 32.73 & 67.06 & 8.61 & 83.00 & 91.39 & 33.54 & 51.46 & 16.64 \\
\hline 34 & 60.47 & 11.25 & 79.28 & 0.25 & 0.54 & 0.13 & 4736 & 13188 & 1455 & 27.50 & 62.21 & 5.47 & 77.68 & 94.53 & 37.49 & 56.74 & 15.17 \\
\hline 2 & 59.99 & 8.28 & 72.96 & 0.25 & 0.54 & 0.17 & 4747 & 13527 & 254 & 20.05 & 45.97 & $2 \pi$ & 57.14 & 97.23 & 54.36 & 43.20 & 11.51 \\
\hline 26 & 63.36 & 7.71 & 74.28 & 0.25 & 0.57 & 0.11 & 434 & 13651 & 2526 & 17.15 & 13.20 & 200 & 52.80 & 97.91 & 59.65 & 41.11 & 12.46 \\
\hline 32 & 64.20 & 9.96 & 80.31 & 0.23 & 0.55 & 0.14 & 4281 & 23521 & 1587 & 22.90 & 57.59 & 9.55 & 72.19 & 96.45 & 46.93 & 34.04 & 19.12 \\
\hline 23 & 63.93 & 8.75 & 80.61 & 0.23 & 0.54 & 0.13 & 4334 & 13418 & 1589 & 23.21 & 38.72 & 3.18 & 71.05 & 96.82 & 43.40 & 55.54 & 15.26 \\
\hline 40 & 63.53 & 9.73 & 80.46 & 0.24 & 0.56 & 0.14 & 4454 & 13493 & 1623 & 23.94 & 59.25 & 3.67 & 72.34 & 96.33 & 44.37 & 55.58 & 16.71 \\
\hline 1 & 63.71 & 10.20 & 81.93 & 0.24 & 0.57 & 0.13 & 4314 & 13411 & 1217 & 25.40 & 62.85 & 4.07 & 78.96 & 95.93 & 40.41 & 38.79 & 19,37 \\
\hline
\end{tabular}




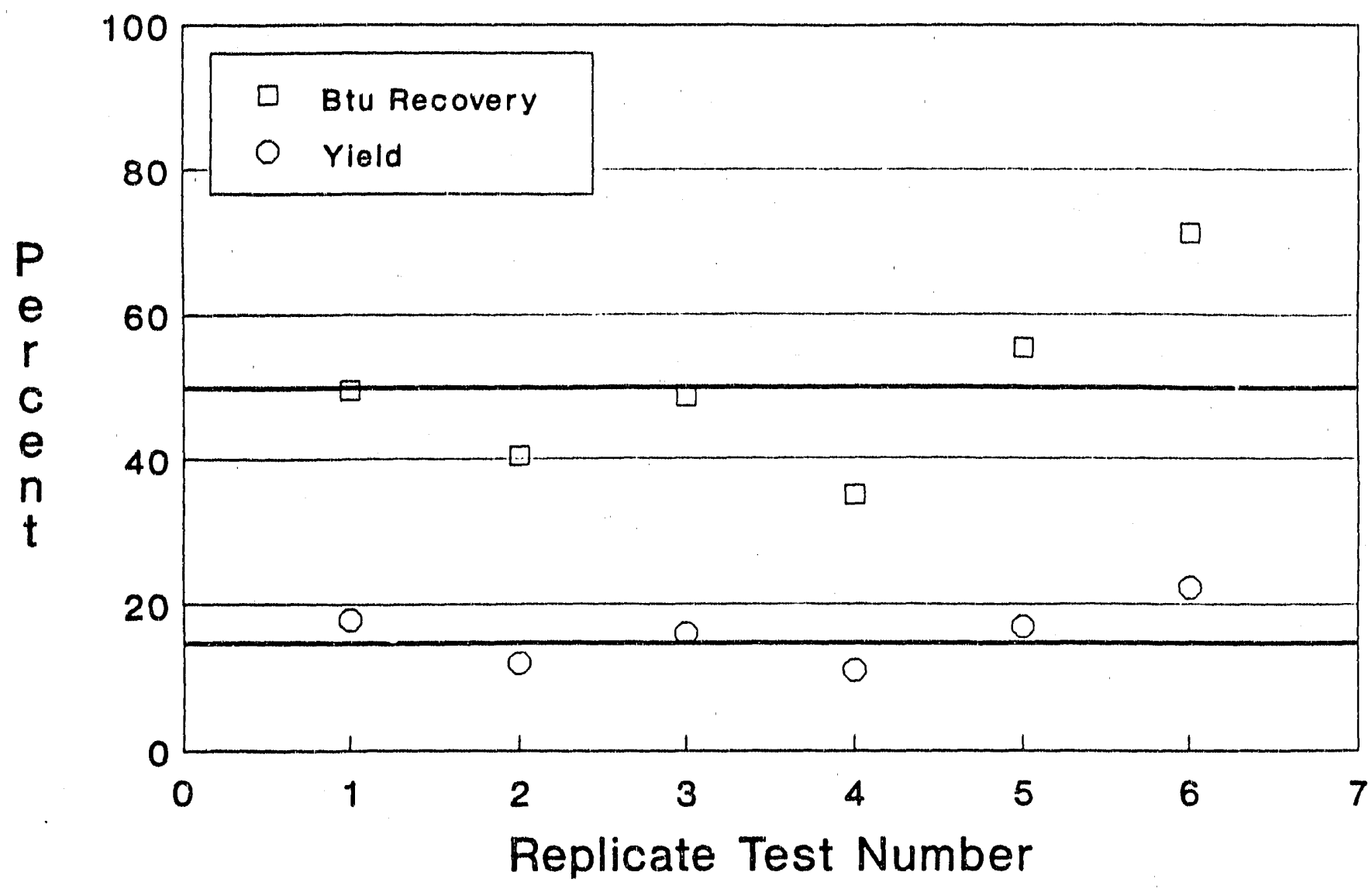

Figure 20. Yield and energy recovery obtained for each of the replicate tests conducted throughout the parametric testing program.

inconsistency. First, during "miners vacation," detailed maintenance was performed on the plant. The maintenance included rebuilding and replacing several of the classifying cyclones in the circuit ahead of the test column. Since the feed material to the column comes from the cyclone overflow, the modifications performed may have changed the characteristics of the feed material. Second, the feed to the column for the first four replicate tests came from a single cyclone. This was done to reduce the variations in the feed material. However, this cyclone was removed during the maintenance program. Therefore, the feed to the fifth and sixth replicate tests came from a bank of cyclones. 
Even though changes to the plant introduced additional variation, the estimated standard deviations were reasonable. The estimated standard deviations for each of the assays determined in the present work are tabulated in Table 5. The relatively low values indicate that the test data acquired from the parametric testing program are reliable and reproducible. It should be noted that the product assays appear to be the most reliable, while the reject assays are the least dependable. This result was not unexpected since the reject stream contains a low concentration of solids and a disproportionate amount of very fine clay particles.

Performance Overview: The effects of the various operating conditions on the recovery and ash rejection relationship are plotted in Figure 21 for each of the tests conducted in the

Table 5. Estimated values of standard deviation for various assays used in the parametric test work.

\begin{tabular}{||l|c|}
\hline \multicolumn{1}{|c|}{ Component } & Estimated Standard Deviation \\
\hline \hline Yield & 4.32 \\
\hline Product Ash (\%) & 1.39 \\
\hline Reject Ash (\%) & 3.82 \\
\hline Feed Ash (\%) & 1.70 \\
\hline Product Sulfur (\%) & 0.15 \\
\hline Reject Sulfur (\%) & 0.12 \\
\hline Feed Sulfur (\%) & 0.07 \\
\hline Product Btu & 365 \\
\hline Reject Btu & 513 \\
\hline Feed Btu & 362 \\
\hline
\end{tabular}




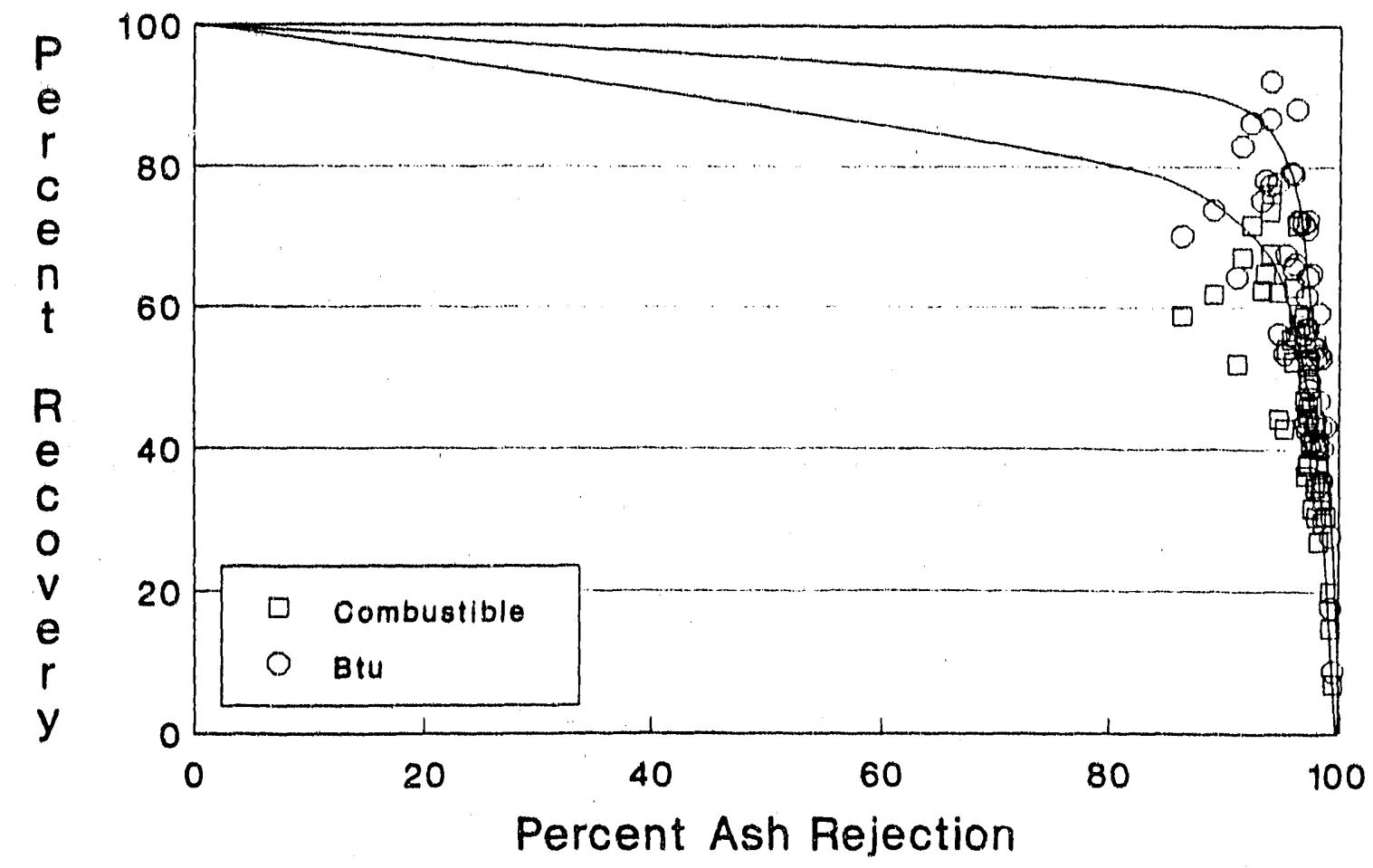

Figure 21. Btu recovery and combustible recovery as a function of ash rejection for all the test conditions examined in the parametric study.

parametric study. For comparison, both the values of energy (i.e., Btu) recovery and combustible recovery have been plotted in the figure. Although there is a considerable degree of scatter among the various test points, most of the points tend to group along a single grade-recovery curve. The separation curve indicates that very high rejections of ash can be obtained with this coal. At the desired market ash content of $10 \%$, a combustible recovery of over $60 \%$ and an ash rejection of more than $93 \%$ were attainable using the microbubble flotation column. The high ash rejections can be attributed to the high concentration of fine clays in the feed stream, which are readily rejected by the microbubble flotation column process. It should also be noted that, as with most coals, the energy 
recoveries tend to fall slightly above the combustible recoveries for the same level of ash rejection for this coal.

Figure 22 shows the effects of the various operating conditions on recovery and sulfur rejection. In contrast to the ash rejection, an increase in the rejection of sulfur was only possible by sharply decreasing the recovery. This result was expected since the majority of the sulfur in the feed material is associated with the organic fraction of the coal. The slight upward bend in the recovery-sulfur rejection curve does, however, indicate that flotation produced a slight improvement in coal quality.

The effects of the operating parameters on separation efficiency are demonstrated in Figures 23 and 24. Two different separation efficiencies have been calculated, one based on

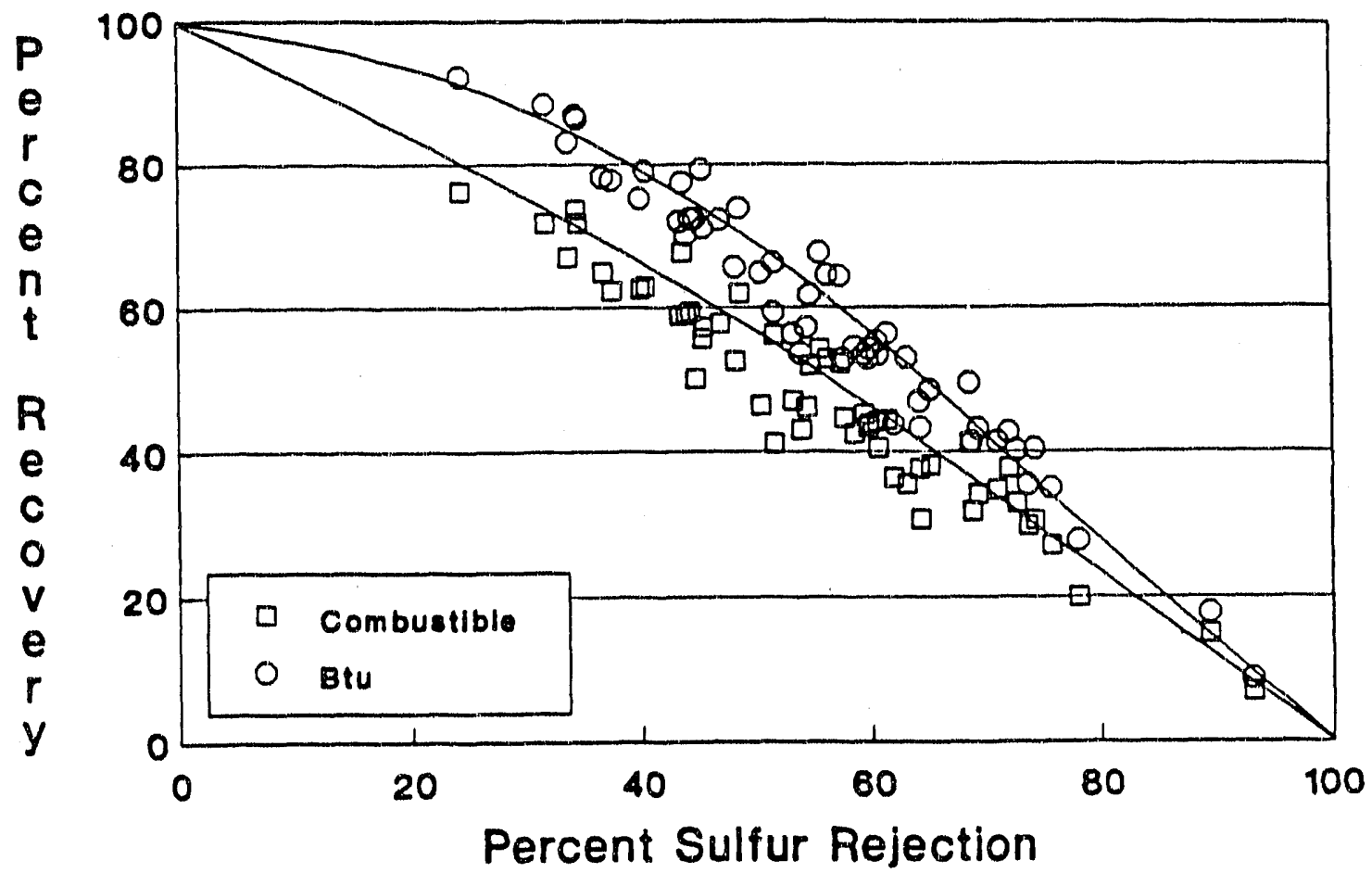

Figure 22. Btu recovery and combustible recovery as a function of total sulfur rejection for all the test conditions examined in the parametric study. 


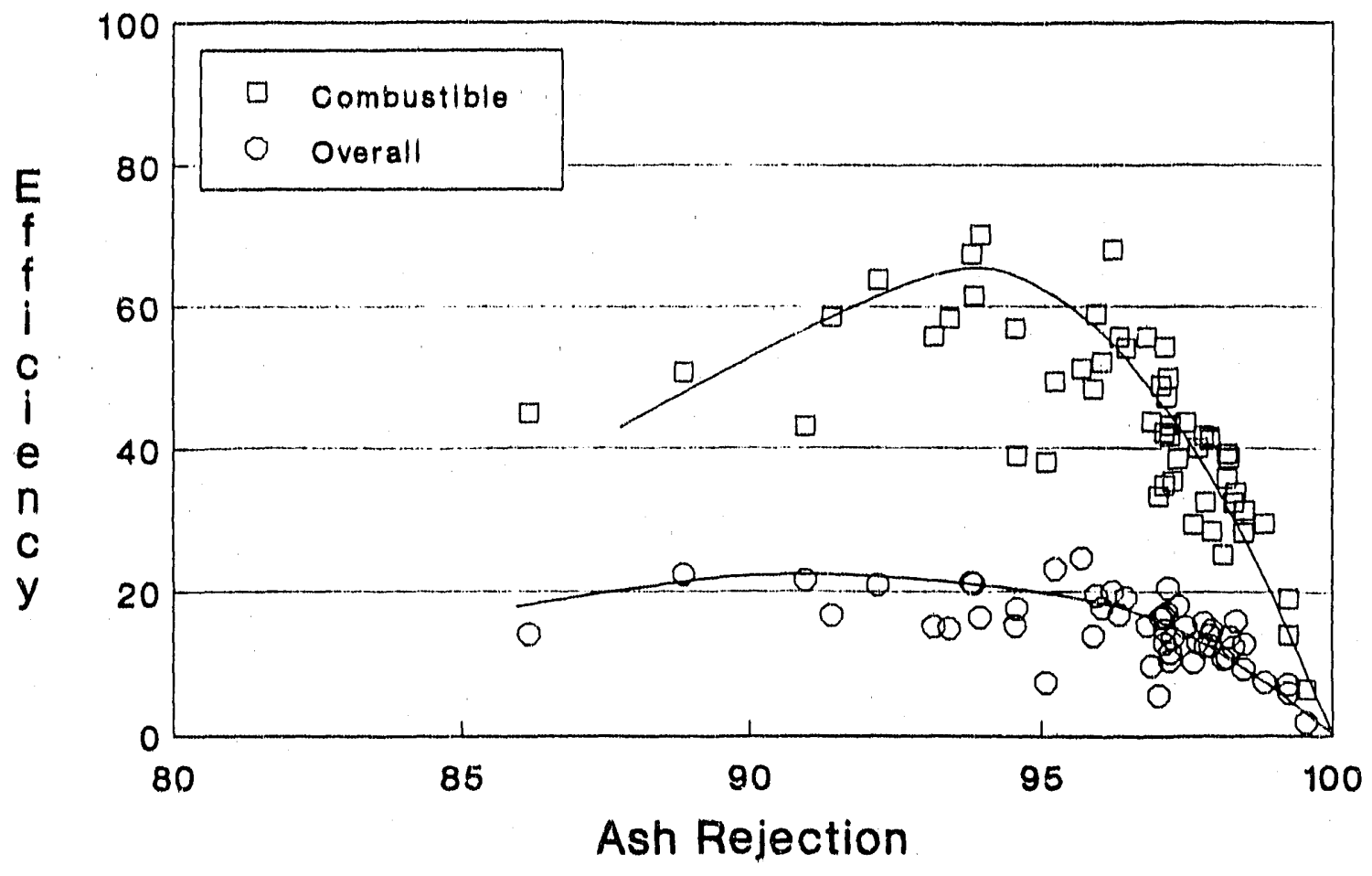

Figure 23. Combustible separation efficiency and overall separation efficiency as a function of ash rejection for all the test conditions examined in the parametric study.

the separation of combustibles from ash and the other based on the overall separation of energy and sulfur. Combustible efficiency ( $\left.S E_{\text {comb }}\right)$ has been calculated using the expression:

$$
S E_{\text {comb }}=100 Y\left(\frac{100-A_{p}}{100-A_{f}}-\frac{A_{r}}{A_{f}}\right)
$$

in which $Y$ is the product yield, and $A_{p}, A_{r}$ and $A_{f}$ are the ash contents of the product, reject and feed streams, respectively. The energy-sulfur separation efficiency $\left(S E_{\text {overaul }}\right)$ was calculated from: 


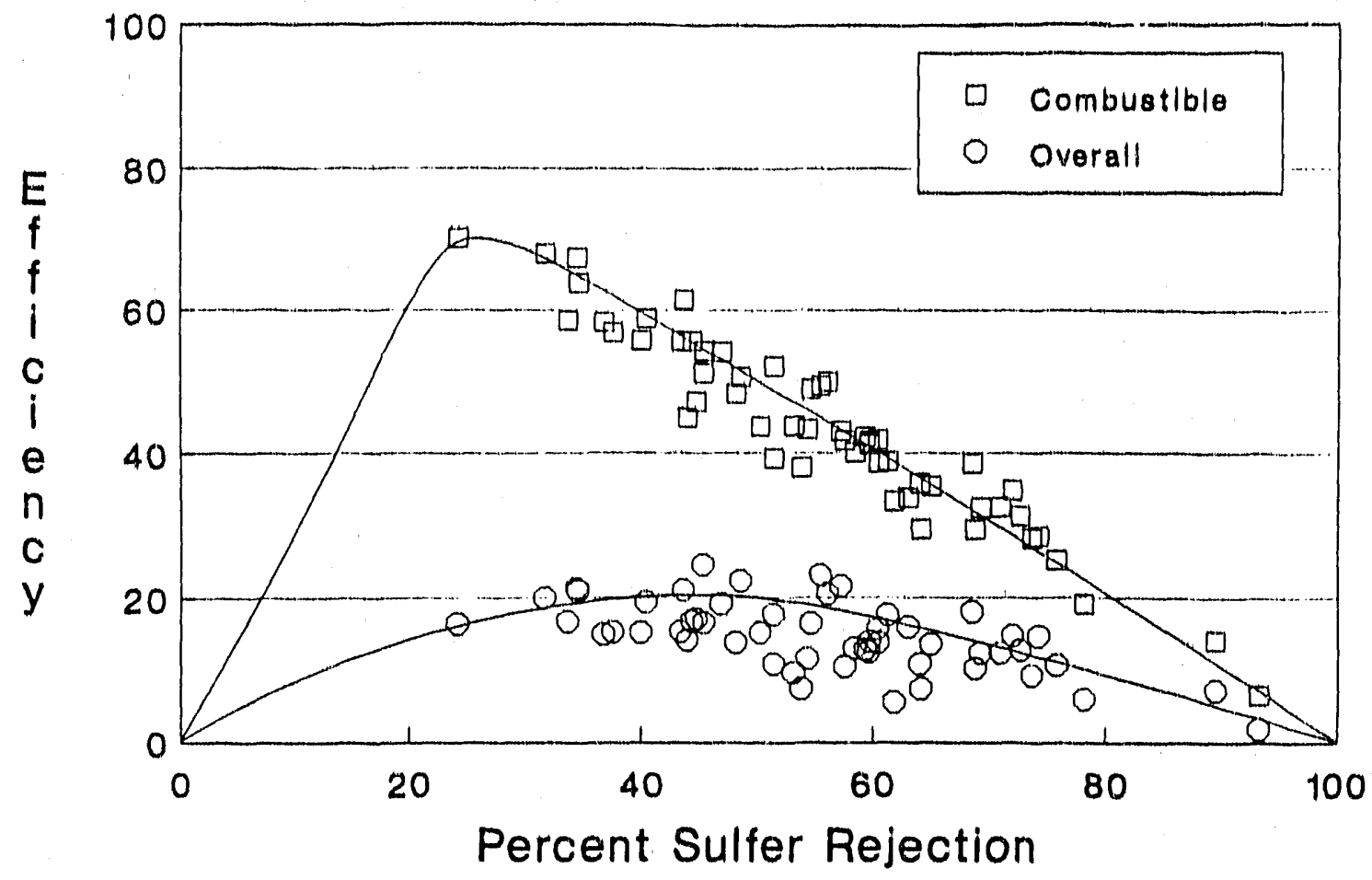

Figure 24. Combustible separation efficiency and overall separation efficiency as a function of total sulfur rejection for all the test conditions examined in the parametric study.

$$
S E_{\text {owrall }}=Y \frac{B T U_{p}}{B T U_{f}}+(100-Y) \frac{S_{r}}{S_{f}}-100
$$

in which $B T U_{p}$ and $B T U_{f}$ are the respective calorific (BTU) values for the product and reject streams, and $S_{r}$ and $S_{f}$ are the respective sulfur contents of the reject and feed streams. A more appropriate form of this equation would utilize pyritic sulfur in place of total sulfur, but those assays were not determined for this study.

Figure 23 shows that most of the separation efficiency values fall along two distinct curves. In both cases, however, a maximum separation efficiency could be obtained at an ash rejection of approximately $95 \%$. This value appears to be independent of whether the separation efficiency was calculated on a combustible or overall basis. This level of ash 
rejection corresponds to the linear portion (above $95 \%$ ash rejection) in the recovery-ash rejection curve shown in Figure 21. Therefore, it can be concluded that the maximum separation efficiency occurs at the point just before the large deterioration in yield. In the present work, the maximum separation efficiency-ash rejection relationship appears to be a function of the coal characteristics. As a result, various combinations of operating conditions can be utilized to obtain the same maximum separation efficiency.

Figure 24 shows the separation efficiency values calculated for the various tests as a function of sulfur rejection. As before, most of the points fall along two distinct curves. However, Figure 24 shows that as sulfur rejection increases, both $S E_{\text {comb }}$ and $S E_{\text {overall }}$ decrease. This finding indicates that the sulfur is intimately associated with the coal and that the only way to reject more sulfur is to simultaneously recover less coal. This phenomenon is demonstrated more clearly in Figure 25, in which sulfur rejection has been plotted as a function of ash rejection. As shown, there is a distinct relationship between ash rejection and sulfur rejection. If both sulfur and ash were rejected equally, the points should fall along the dashed line shown in the figure. Since this is clearly not the case, this plot once again demonstrates that the ash-bearing components in this coal are more readily rejected than the sulfur-bearing components (i.e., the sulfur is more closely associated with the organic fractions in the coal). The data plotted in Figure 25 suggest that the best separation point for this particular coal would be at an ash rejection of $92 \%$ and a sulfur rejection of $30 \%$.

Although the experimental test program was carried out over a wide range of operating conditions, the performance curves shown in Figures 21-24 indicate that most of the data points fall roughly along a single grade-recovery curve. In fact, a close inspection 


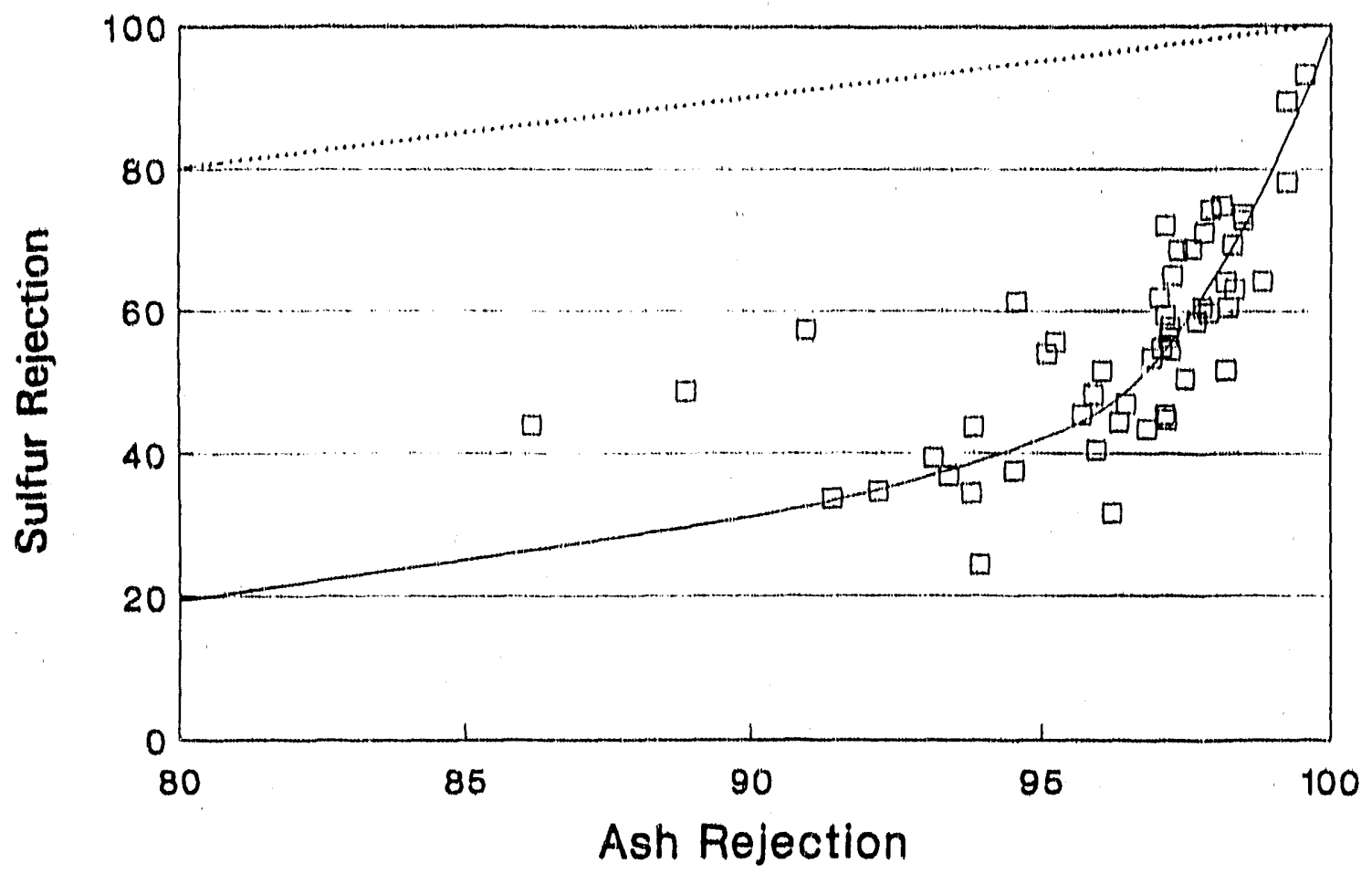

Figure 25. Relationship between ash rejection and total sulfur rejection for tests results obtained during the parametric study.

of the test data indicates that a great deal of the experimental scatter can be attributed to the tests in which the bias flow rate (1.e., flow rate of wash water downward through the stabilized froth phase) was affected by the test variables. It is now believed that when a flotation separation is made over a range of operating conditions, only those parameters that can alter entrainment (i.e., the hydraulic carry-over of feed water into the product launder) are capable of substantially impacting the grade-recovery curve for a given sample. Therefore, the grade-recovery relationship obtained from a properly operated flotation column should be primarily determined by the characteristic nature of the coal sample, i.e., the degree of liberation and hydrophobicity of the various components in the feed stream. It must be stressed, however, that this general conclusion holds true only if the wash water that 
is added to the column is effective in preventing entrainment. Changes in any of the operational parameters that would produce a change in the blas flow rate could produce a sharp change in the performance of the column.

Statistical Data Analysis and Response Surface Development: The assay values were also analyzed using the DESIGN-EXPERT statistical data analysis program. The overall objective of this effort was to develop an empirical relationship between the various operating parameters (i.e., feed rate, wash water, etc.) and a variety of response, or dependent, variables (e.g., recovery). This goal was accomplished via the following steps:

1) Data Analysis - After the specified experimental data were collected, the response data were entered into the DESIGN-EXPERT software package. The data analysis was an iterative process since, in most cases, several analyses were required to obtain a suitable response surface. When deemed necessary, data transformations were conducted in orcier to obtain the response surface that best described the experimental data. In the present work, either no transformation or a log transformation was found to provide the best fits for the experimental data. After an appropriate transformation and response surface were selected, the initial model fitting was performed by the DESIGN-EXPERT software. The available models included standard linear, quadratic and cubic models. After selecting an appropriate model, a variety of statistical routines were executed to identity the goodness-offit. For all runs, the values of regression coefficients, standard errors, variances, t-tests, etc., wore determined as means of quantifying the statistical significance of each of the coefficients in the model. 
2) Response Surface Plotting - After a reasonable mathematical model of the desired response was analyzed in light of the various operational parameters, the resultant response surface was plotted using a surface contour program. When combined with the modeling expressions, these plots provide the final product from the parametric test work. The influence of key operating parameters and the joint interaction of various parameters on the process performance can be visualized from the response surface plots.

The following performance indicators have been analyzed using the aforementioned procedures:

1) energy recovery,

2) product ash,

3) total sulfur rejection, and

4) combustible separation efficiency. A summary of the statistical data analysis computations is provided in Appendix 5 for each of the performance indicators. Comparisons between the results predicted by the modeling exercise and results obtained from the experimental measurements are shown in Figures 26-

- 29. In general, very good correlations were obtained between the predictions gained from the empirical model predictions and the experimental test results.

Appendix 6 provides the response surface plots for each of the four performance indicators. Because of the relatively large amount of response data contained in Appendices 5 and 6 , it is not practical within this report to discuss the wealth of information that can be obtained from the parametric test program. However, because separation efficiency is important in establishing the trade-off between grade and recovery, a detailed examination of 


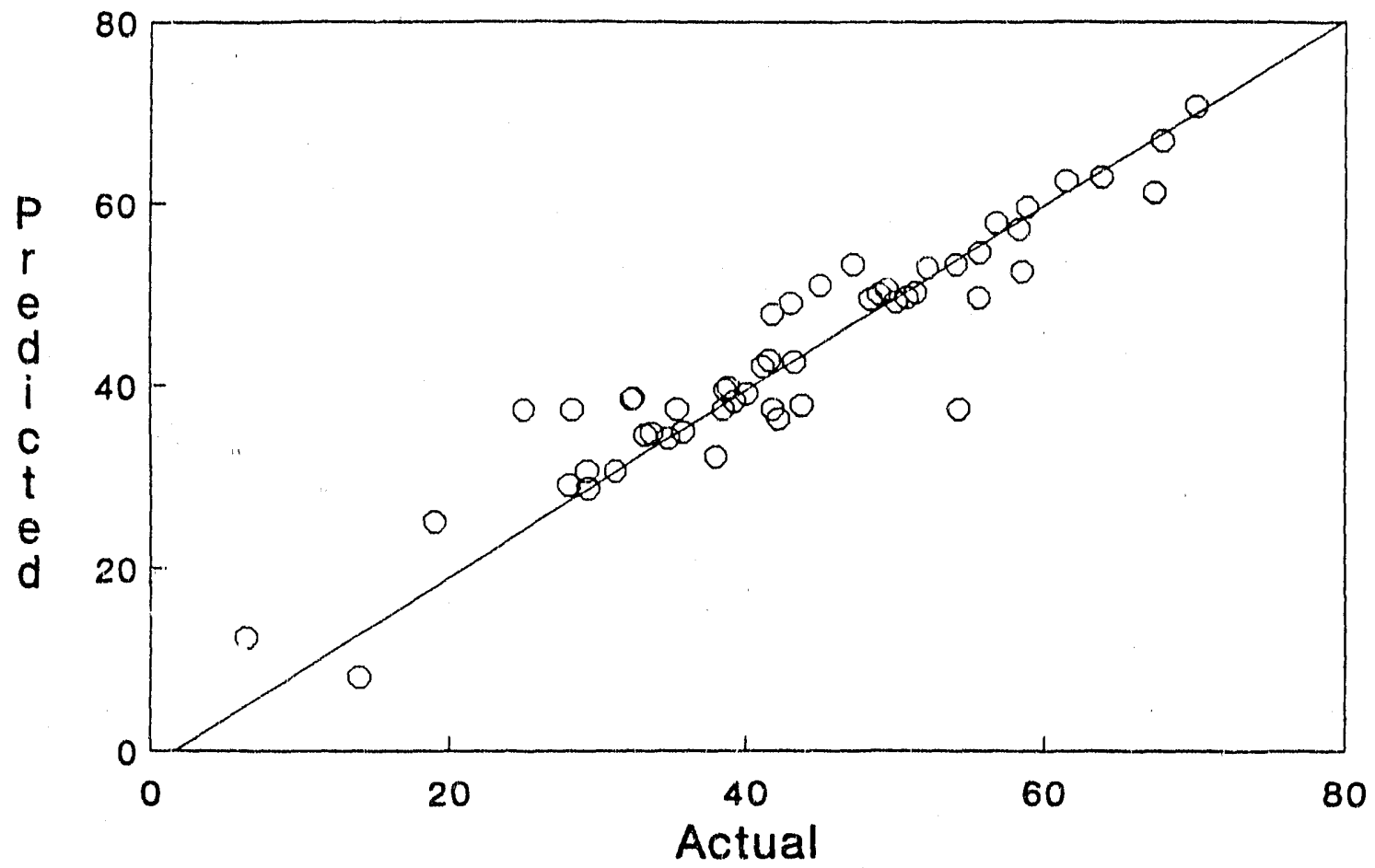

Figure 26. Comparison of experimental results with predictions made by the empirical model developed to describe energy recovery as a function of the various operating parameters.

these response surfaces should provide information about the appropriate level for each of the operating parameters (gas rate, frother dosage, collector dosage, etc.).

A number of significant trends can be observed from an analysis of the separation efficiency response curves. These include:

1) The height of the stabilized froth zone appears to have only a limited impact on the separation efficiency, except under conditions of high feed rates.

Under this condition, the separation efficiency drops rapidly due to a sharp decrease in overall recovery.

2) Higher gas flow rates appear to have a beneficial effect on separation efficiency for all cases. However, the response surface plots appear to suggest 


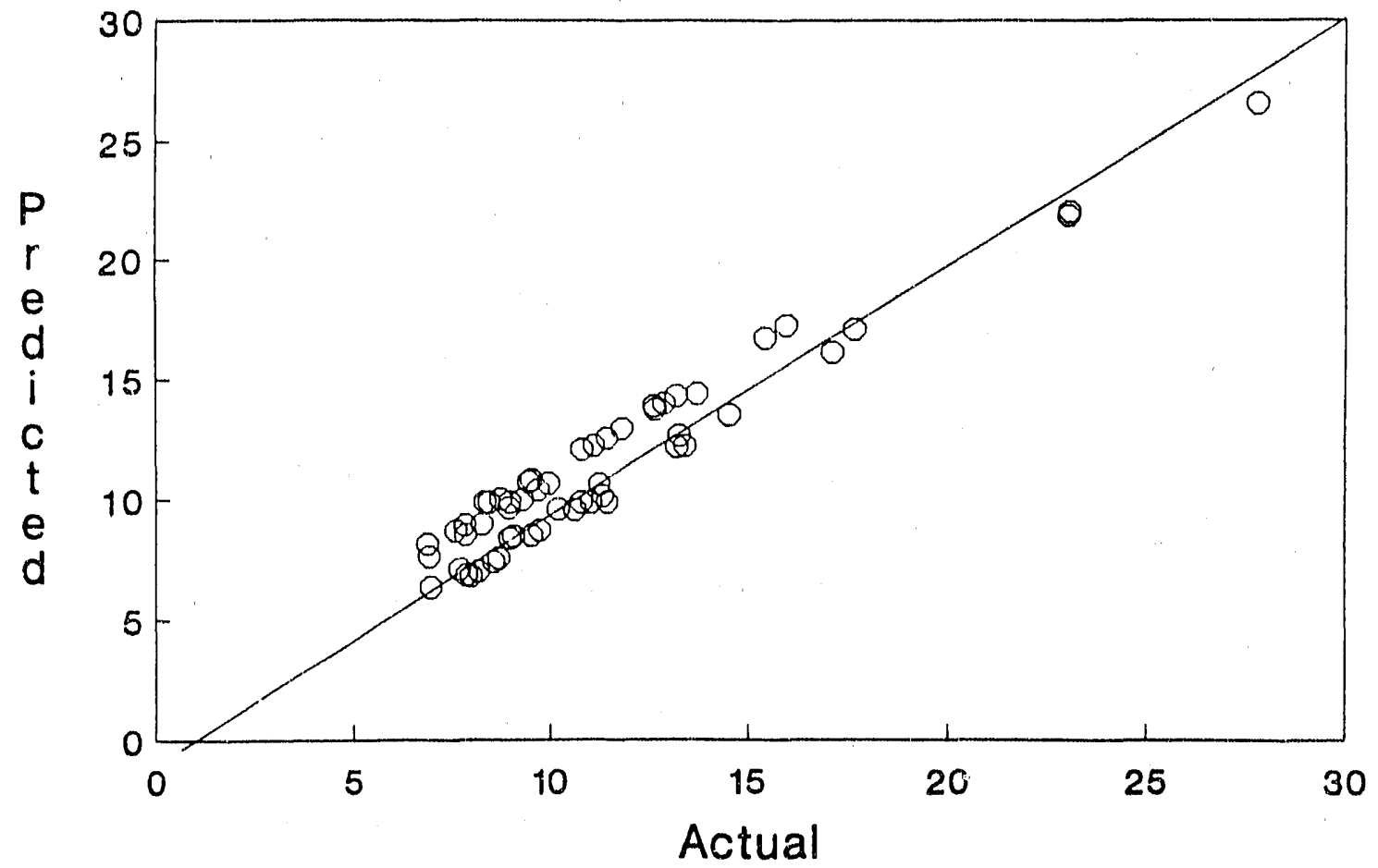

Figure 27. Comparison of experimental results with predictions made by the empirical model developed to describe product ash content as a function of the various operating parameters.

that higher frother dosages may be required when using the high gas rates, in order to obtain the highest possible separation efficiencies. This result can probably be attributed to the fact that large amounts of bubble surface area are generated at the higher gas rates. Higher frother dosages could then be required to maintain a small bubble size.

3) Higher gas rates generally dictate the use of larger wash water flow rates. At the higher gas rates, more water is carried into the froth launder by the increased flow of air bubbles. In order to maintain the desired bias flow rate for removing entrained particles, additional wash water must be added to compensate for water lost at higher gas rates. 


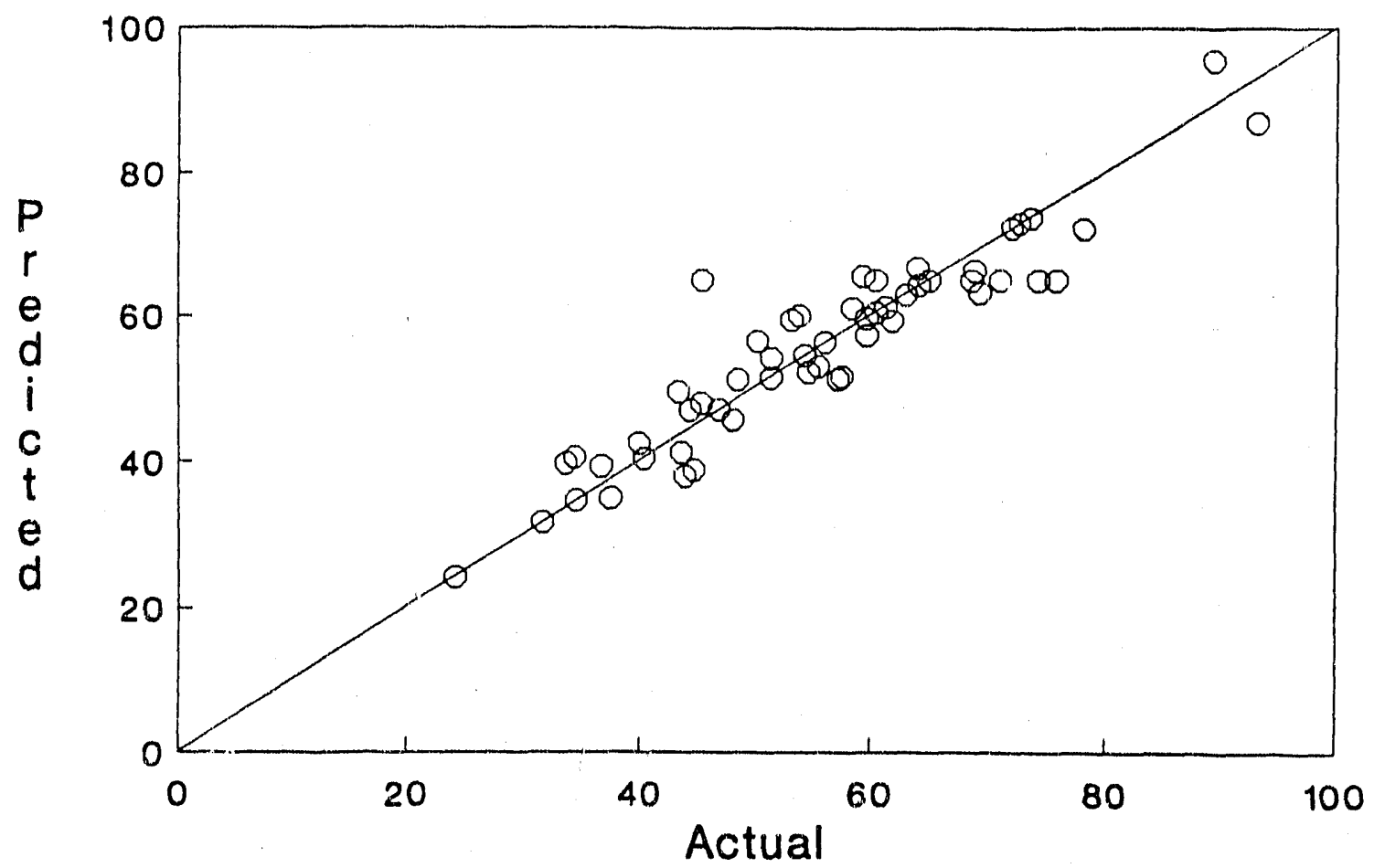

Figure 28. Comparison of experimental results with predictions made by the empirical model developed to describe product sulfur rejection as a function of the various operating parameters.

4) Separation efficiency was found to increase at the higher frother dosages In general, too low a frother dosage resulted in the production of large bubbles and a loss of recovery (which reduced the separation efficiency). Low frother dosages also contributed to a decrease in froth stability, which also adversely affected the flotation recovery. On the other hand, the increased production of small bubbles at higher frother dosages enhanced the stability of the froth. It should be noted, however, that if the frother dosage exceeds a critical amount, too stable a froth can be produced. As indicated previously, this condition results in an excessive flow of water into the product stream and, in many cases, a decrease in the separation efficiency. 


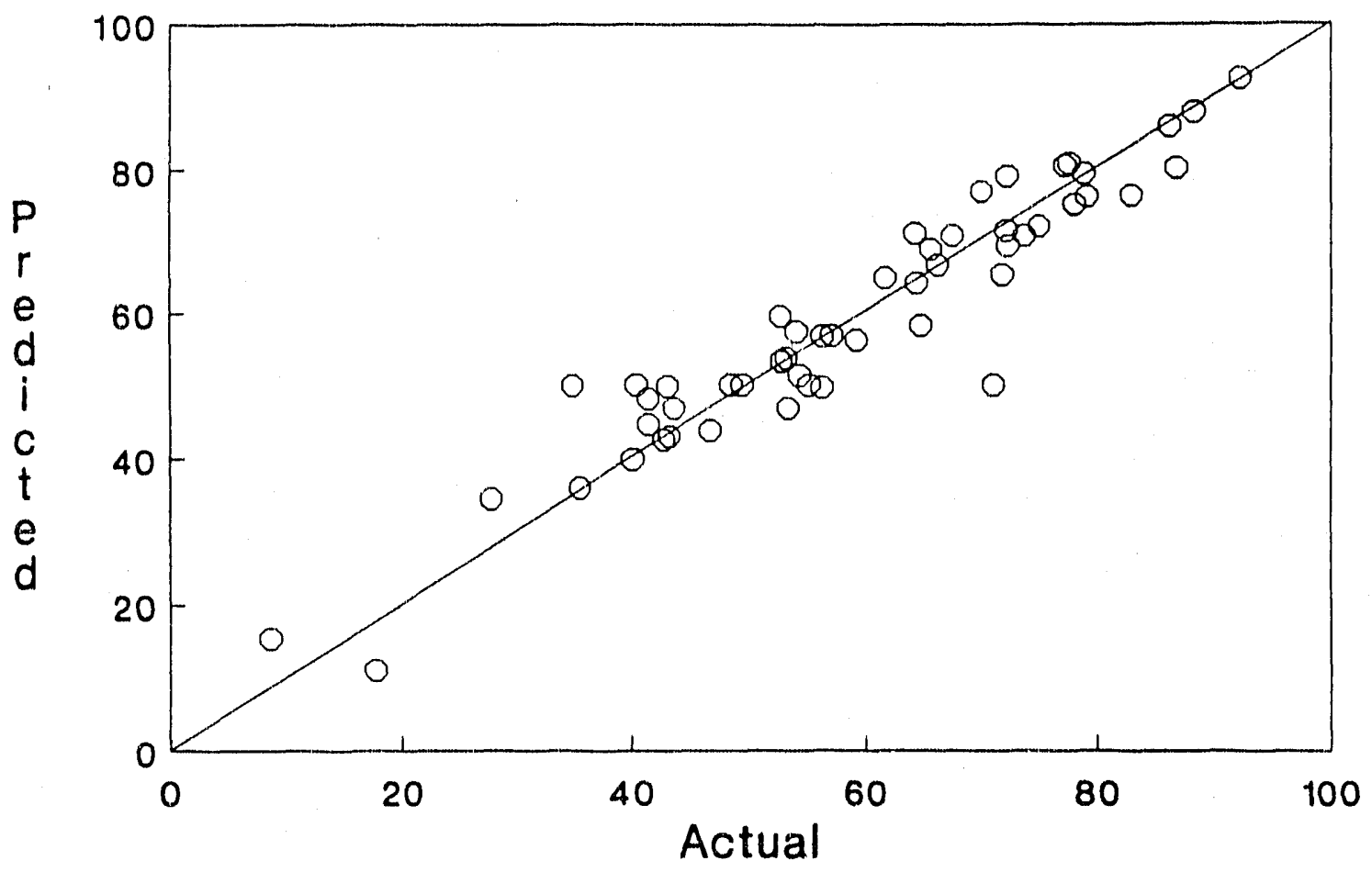

Figure 29. Comparison of experimental results with predictions made by the empirical model developed to describe separation efficiency as a function of the various operating parameters.

\section{Task 2.4 Design Evaluation/Modification}

\section{4.a - Evaluate Column Design Features}

A number of key design features of the microbubble flotation column were evaluated in order to determine whether the design was appropriate for full-scale industrial operation. These included launder design, frother inje stion point, wash-water addition point and mixing conditions within both the 30 -inch and 8 -foot diameter columns. Additionally, the scale-up and performance relationships that describe the operating characteristics of the bubble generation circuit were also verified. 
Launder Design: One concern regarding the original column design was whether the froth product would flow unrestricted from the launder through the product collection line. High-pressure, low-flow water sprays were mounted just above the launder to break the froth should problems arise. In addition, a very smooth ceramic coating was used in the launder construction to help in product removal. After conducting a wide range of tests, it was found that the ceramic coating was sufficiently slick to prevent hold-up of the froth and that little or no additional water was required in the launder to break the froth.

However, froth handling problems were encountered with the 8-foot cell. Although the froth flowed freely through the launder, build-up tended to occur at the point of discharge. This was probably a result of either the product line being too small in diameter to handle the large flow of froth, or the vertical drop being very short relative to the total span of the pipe. The latter problem is a physical restriction of the plant due to the location of the column with respect to the feed distribution box for the screen bowl centrifuges.

Frother Addition Systems: As discussed in the original project work plan, frother was to be added in several different locations in order to determine the optimum addition point. The results of these tests are shown in Table 6 . It can be seen that the best result has been obtained when the frother is added directly into the bubble generation circuit. The worst result occurred when the frother was added with the wash water. In this instance, the deci case in recovery was probably a result of a portion of the frother being lost with the wash water that reports to the column product. Because the column wash water splits after it is introduced to the column, the portion of the frother associated with the water reporting to the column product will be not be available for bubble generation. 
Table 6. Results of frother addition point tests.

\begin{tabular}{|c|c|c|c||}
\hline $\begin{array}{c}\text { Test } \\
\text { No. }\end{array}$ & $\begin{array}{c}\text { Addition } \\
\text { Point }\end{array}$ & $\begin{array}{c}\text { Product } \\
\text { Ash (\%) }\end{array}$ & $\begin{array}{c}\text { Combustible } \\
\text { Recovery (\%) }\end{array}$ \\
\hline \hline 1 & Pump (10) & 8.38 & 67.49 \\
\hline 2 & Feed (10) & 7.89 & 64.53 \\
\hline 3 & Pump/Feed (5/5) & 9.65 & 63.22 \\
\hline 4 & Pump/Wash Water (5/5) & 9.42 & 61.47 \\
\hline 5 & Wash Water (10) & 7.72 & 49.99 \\
\hline
\end{tabular}

Note: (\#) represents the flow of frother in $\mathrm{ml} / \mathrm{min}$.

Wash Water Addition System: A similar series of tests was conducted for the wash water addition point. As mentioned above, the wash water will split in the column with a certain portion reporting to the column product and the remainder to the tailings. The percentage of the total flow reporting to the column tailings, known as the bias factor, is controlled, in part, by the linear position along the column axis of the wash water distributor. For example, if the water distributor is located close to the cell lip, the majority of the wash water will report to the column product. As the distributor is lowered deeper into the cell, more of the water will report to the column tailings. As a result, the froth percent solids will increase and froth will tend to become unstable. Under extreme conditions (i.e., coarse or weakly hydrophobic coal) the froth structure may begin to collapse. As such conditions are encountered the column recovery will begin to decline. This point is illustrated in Table 7. It can be seen that as the water distributor is lowered from 6.5 to 26.5 inches, the combustible recovery drops nearly 10 percent. 
Table 7. Results of wash water addition point tests.

\begin{tabular}{||c|c|c|c||}
\hline $\begin{array}{c}\text { Test } \\
\text { No. }\end{array}$ & $\begin{array}{c}\text { Addition } \\
\text { Point }\end{array}$ & $\begin{array}{c}\text { Product } \\
\text { Ash (\%) }\end{array}$ & $\begin{array}{c}\text { Combustible } \\
\text { Recovery (\%) }\end{array}$ \\
\hline \hline 1 & $6.5^{\prime \prime}$ & 9.79 & 61.93 \\
\hline 2 & $16.5^{\prime \prime}$ & 10.93 & 53.08 \\
\hline 3 & $26.5^{\prime \prime}$ & 9.64 & 52.33 \\
\hline
\end{tabular}

Three different wash water distributors were constructed and tested in the 30 -inch column. These three designs are shown in Figure 30. As a result of this test work, it was found that the original design (Figure 30a) did not provide sufficient distribution of wash water across the top of the froth. A second distributor with more wash water "legs" (Figure 30b) was constructed and installed to provide better wash water distribution; however, this distributor presented a new problem. In a normal laboratory test, the wash water injection point is usually 1-3 inches below the froth surface. This allows the portion of froth above the wash water injection point to dewater slightly before it leaves the column, and it tends to allow more water to pass down through the froth for improved cleaning action. However, on larger diameter columns, the center of the froth tends to drain too much and collapse when the wash water distributor is positioned below the top of the froth. When the wash water distributor is raised high enough to prevent the collapse of the center of the froth, the wash water becomes less effective in removing entrained mineral matter.

One industrial column manufacturer has tried to solve this problem by introducing a patented froth crowder into the center of the column. This device is simply an inverted cone which directs material to the cell overflow lip. Unfortunately, the presence of the froth 

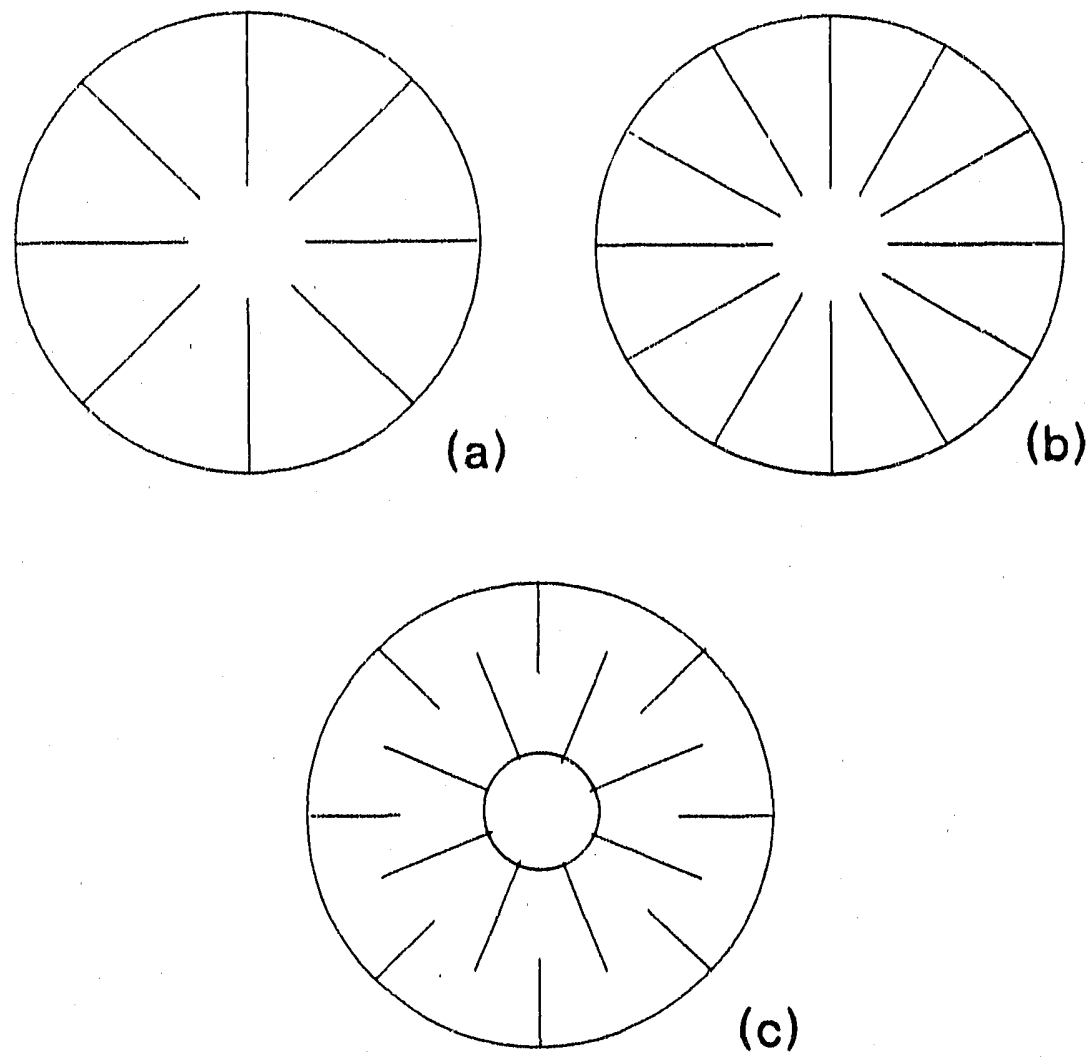

Figure 30. Schematic showing the different wash water distributor designs evaluated during the testing of the 30-inch microbubble flotation column.

crowder tends to reduce the column carrying capacity, since carrying capacity is directly proportional to the available cross-sectional area. As a result, a twin ring design (Figure 30c) was developed to maximize the washing action while improving the stability of the center of the froth. In this design, the center ring was positioned just above the froth to maintain a very wet and stable froth in this region, while the outer ring was positioned just below the cell lip. This arrangement allowed the froth to drain slightly just before it spilled over the cell lip. Also, the wash water split could be easily altered by adjusting the depth of the outer ring. For example, if the outer ring were positioned too deep, less wash water reported to the product, the product solids content increased and better washing action was 
achieved. However, the resultant bubble coalescence in the froth reduced the amount of available bubble surface area for particle attachment and decreased the overall product yield. If the outer ring was positioned too high, more wash water reported to the product and improved froth stability was observed. However, this decreased the effectiveness of the wash water in removing entrained particles. Thus, by properly adjusting the depth of the outer ring, an optimum balance between yield and grade could be achieved. Because of the excellent results and flexibility provided by this system, a similar type of wash water distribution system was designed and installed on the full-scale column.

Other Distribution Systems: The other distribution systems in the column were found to operate quite well. The feed slurry seemed to distribute within just a few feet of depth within the column. The turbulence caused by the bubble generators near the bottom of the column also provided an excellent method for properly distributing the air across the column cross-section.

Mixing Conditions: The three most influential factors in column scale-up are the rate of flotation, particle retention time and axial dispersion (mixing) conditions within the column. Although the flotation rate constant and retention time have been quantified for a wide range of conditions, mixing conditions in large diameter columns have not been thoroughly examined.

Typically, mixing in a vessel is quantified by the axial dispersion coefficient. The axial dispersion coefficient is related to the non-dimensional Peclet number as follows: 


$$
P_{.}=\frac{\mu_{L} L}{D}
$$

In this form, a Peclet number of zero represents perfectly mixed conditions, while a Peclet number approaching infinity represents an ideal plug flow reactor. The Peclet number is determined from a residence time distribution (RTD) test conducted in an operating cell. The RTD curve represents the measured response of a slug of tracer as makes it way through the vessel. The tracer material is usually an aliquot of salt solution ( $\mathrm{KCl}$ in water) which is injected with the vessel feed. The corresponding change in conductivity of the column tailings is indicative of the mixing conditions within the cell.

In this case, conductivity changes were determined with an in-line conductivity probe located in the column tailings discharge line. This provided quantitative information on the mixing conditions within the column collection zone. It was also necessary to determine the fractional air hold-up during the test period. This was accomplished by means of the differential pressure measurements described previously. A schematic diagram of the column arrangement is shown in Figure 31.

RTD studies were conducted for both the 30 -inch and 8 -foot diameter units. A typical normalized RTD is shown in Figure 32. The data have been corrected for background noise and normalized with respect to the total area under the initial response curve. The mean residence time, $\tau_{m}$, can be calculated from the normalized RTD using the following equation:

$$
\tau_{m}=\frac{\sum C_{i} \Delta t}{\sum C_{i} \Delta t}
$$




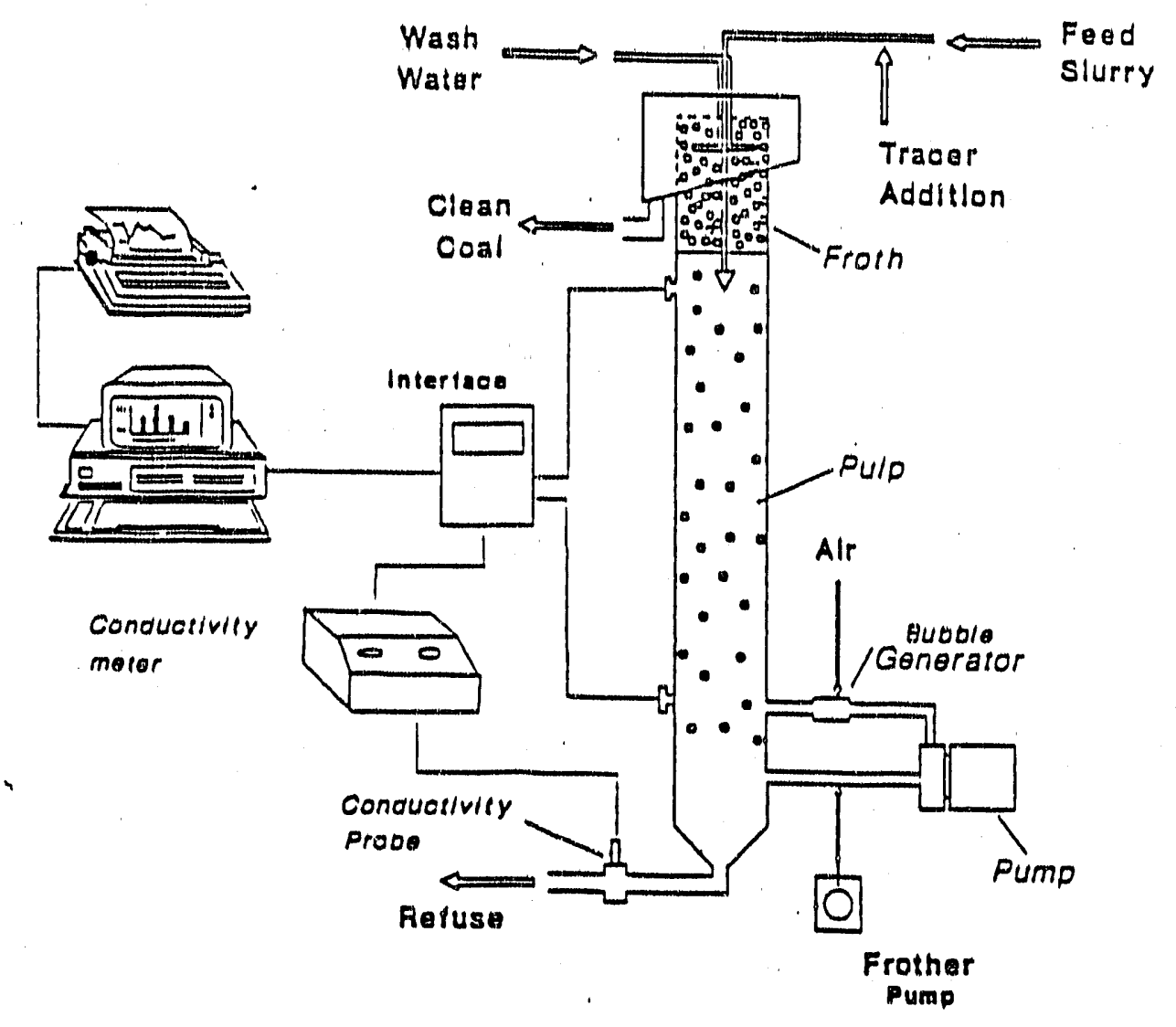

Figure 31. Schematic diagram of experimental set-up for RTD studies.

where $C_{i}$ represents the concentration (or conductivity) at time $t_{i}$. The Peclet number can then be determined by a sum-of-squares fit to the cumulative version of the normalized response curve according to the following equation:

$$
\frac{C}{C_{0}}=\frac{1}{2}\left(1-e f\left[\frac{1}{2} \sqrt{P_{0}} \frac{1-t / \tau_{m}}{t / \tau_{m}}\right]\right)
$$

The Peclet number and retention time determined for both the 30-inch and 8-foot diameter columns are shown in Table 8. Also shown in Table 8 are the predicted Peclet numbers. These values were determined based on the following relationship: 
30-minute RTD Test

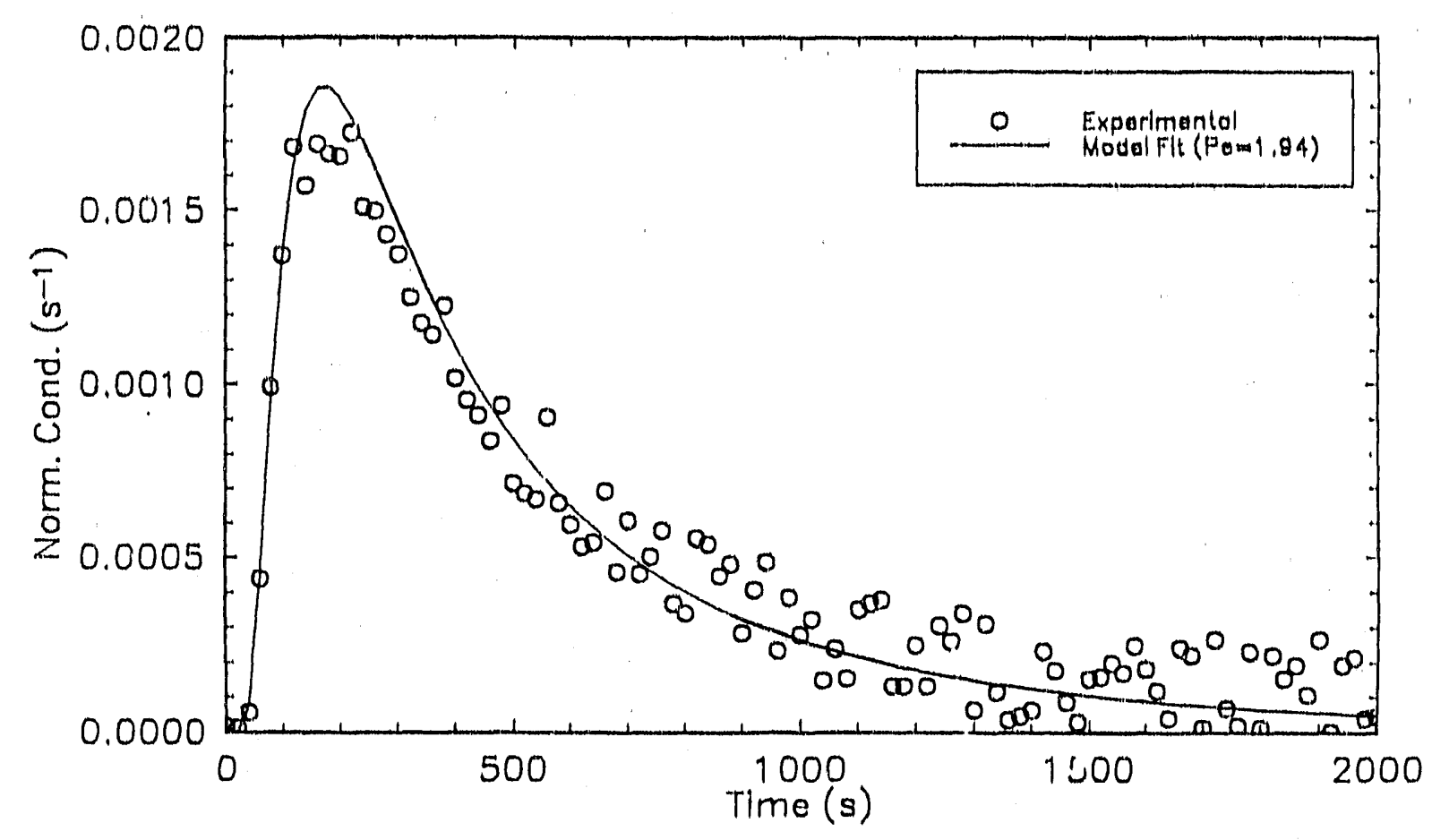

Figure 32. Typical normalized RTD for the 30-inch column.

$$
P_{a}=0.7\left[\left(\frac{L}{D}\right)^{0.63}\left(\frac{\mu_{i}}{V_{g}}\right)^{0.50}\right]
$$

Table 8. Results of RTD testing.

\begin{tabular}{|c|c|c|c|c|}
\hline & $\begin{array}{c}\text { Measured } \\
\text { Retention Time }\end{array}$ & $\begin{array}{c}\text { Calculated } \\
\text { Retention Time }\end{array}$ & $\begin{array}{c}\text { Measured } \\
\mathrm{Pe}\end{array}$ & $\begin{array}{c}\text { Predicted } \\
\mathrm{Pe}\end{array}$ \\
\hline 30-inch & 10.2 & 9.72 & 1.94 & 2.52 \\
\hline 8-foot & 4.02 & 4.31 & 2.21 & 1.39 \\
\hline
\end{tabular}


where $L$ and $D$ are column length and diameter, respectively, $\mu_{i}$ is interstitial liquid velocity and $V_{s}$ is superficial gas rate. The derivation of equation 7 is based on a dimensional analysis procedure and has been described elsewhere (Mankosa et al. 1991).

It can be seen from Table 8 that the measured and calculated retention times correspond quite closely. This provides a good indication of the relative accuracy of the RTD test. In other words, if the measure retention time does not closely correspond to the calculated value, the RTD is probably not accurate. It should also be noted that the measured and predicted values of $\mathrm{Pe}$ are also quite similar. This is particularly encouraging since only a limited amount of data is available for large-scale industrial columns. This result is shown in Figure 33 along with previously determined laboratory results. It can be seen that the data collected for both the 30-inch and 8-foot diameter columns correlates well with the laboratory results. This implies that the mixing conditions in large-scale columns can be predicted based on column geometry and flow conditions.

Bubble Generation Circuit: Performance of the bubble generation circuit was evaluated by measuring the fractional air content within the column recovery zone for various gas flow rates, number of mixers and frother concentrations. Tests were conducted using 2 , 3 , and 4 generators over a range of gas flow rates from 0 to 50 SCFM. Tests were attempted using 5 and 6 generators; however, under these conditions the bubble generation pump would overload and trip its circuit breaker. This is a result of the low back pressure on the pump when 5 or more generators are used. Therefore, it was not possible to collect data for more than 4 bubble generators. 


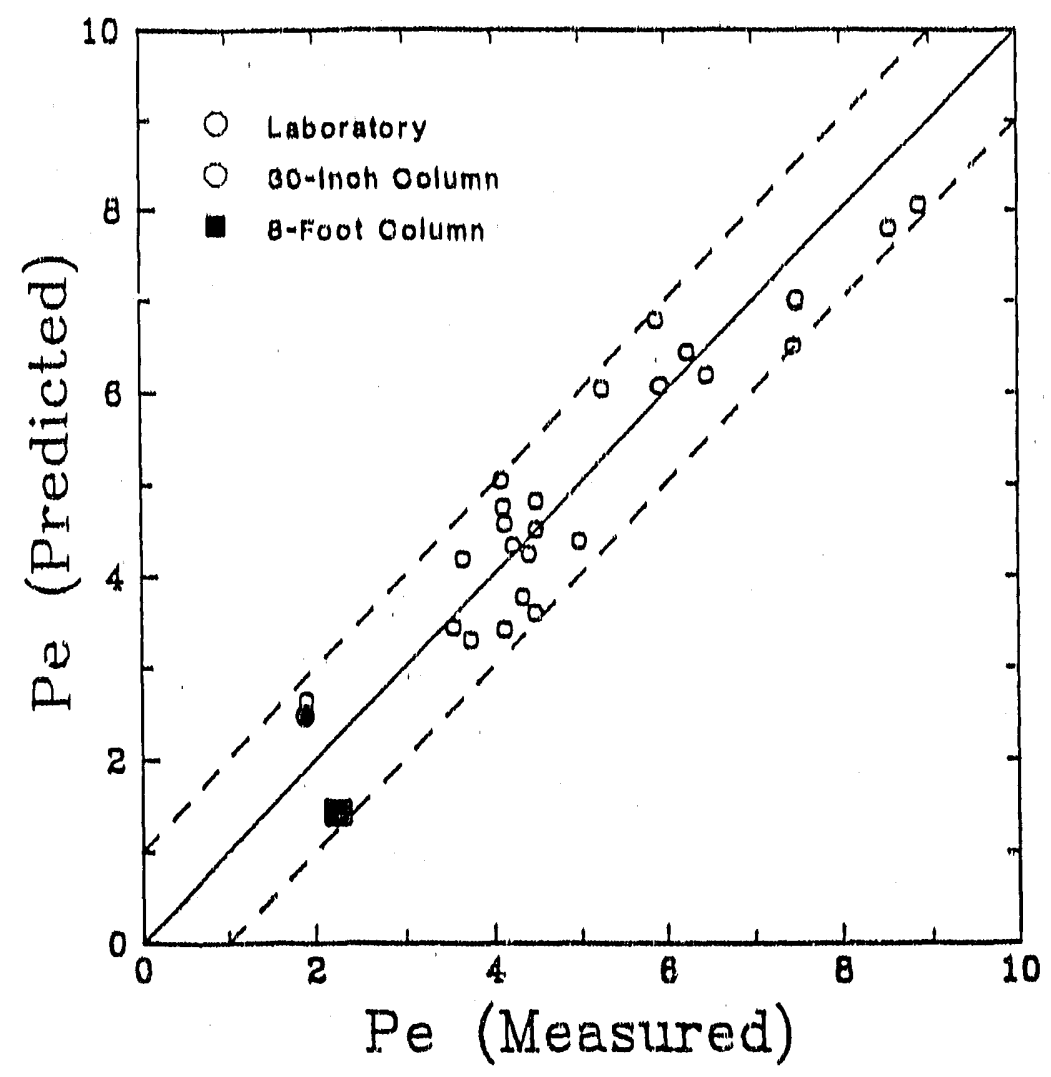

Figure 33. Measured versus predicted values of Peclet number.

The air fraction within the column was determined by means of differential pressure. The pressure measurements were collected using Honeywell pressure transducers. By determining the differential pressure the fractional air hold-up can be determined as follows:

$$
\varepsilon=1-\frac{\Delta P}{\Delta H}
$$

where $\Delta \mathrm{P}$ is the measured differential pressure in inches of water and $\Delta \mathrm{H}$ is the separation distance of the tranducers in inches.

The results of air fraction studies for 2,3 and 4 in-line mixers in the absence of frother are shown in Figure 34. It can be seen that the fractional air hold-up in the cell 


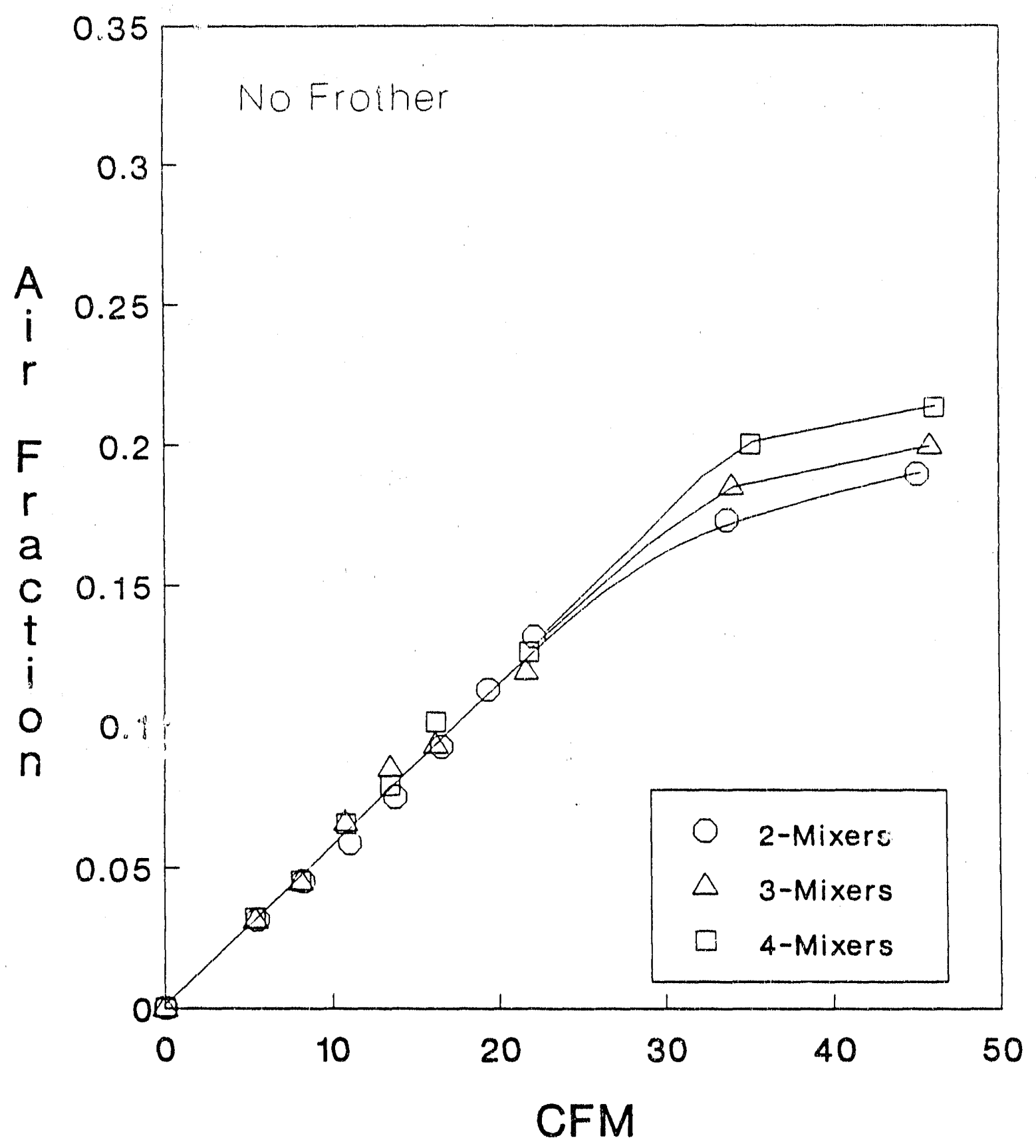

Figure 34. Fractional air content as a function of gas flow rate for 2,3 and 4 bubble generators in the absence of frother. 
increases from 0 to 20 percent over a range of 0 to $45 \mathrm{CFM}$. It is interesting to note that there is little difference in performance in regards to the number of bubble generators until a gas flow rate of approximately $25 \mathrm{CFM}$ is exceeded. At higher gas flow rates, the fractional air hold-up increases with the number of generators. The increase in air fraction is due to the larger total volume flow of liquid through the system as a result of the reduced backpressure on the bubble generation pump. This provides a larger volume of liquid for dispersing the same quantity of air. Therefore, the bubbles are not as densely packed and the amount of coalescence is reduced. This results in an overall higher air fraction within the column.

The change in volume flow is further illustrated by Figure 35, which shows the total system flow and the flow per generator as a function of the number of mixers. It can be see that by increasing the number of generators from 2 to 4 the total flow through the system increases from 200 to nearly $400 \mathrm{GPM}$. The flow through each generator, however, remains nearly constant. This indicates that bubble size does not change significantly as the number of generators is increased.

The effect of surfactant addition on air fraction is illustrated in Figure 36. In this instance, the fractional air hold-up within the column was increased by more than $75 \%$ by adjusting the frother concentration within the cell to $3 \times 10^{-5} \mathrm{M}$ Betz 1012 . It is also interesting to note that an upper limit of approximately $30 \mathrm{CFM}$ was encountered. Beyond this limit, flooding conditions were observed. Such conditions are a result of the higher air fractions and smaller bubble sizes created by the addition of frother. Under these conditions, bubbles enter the column more quickly than they are capable of rising out of the cell. This enhances the degree of coalescence, resulting in the formation of large slugs of air. At this 


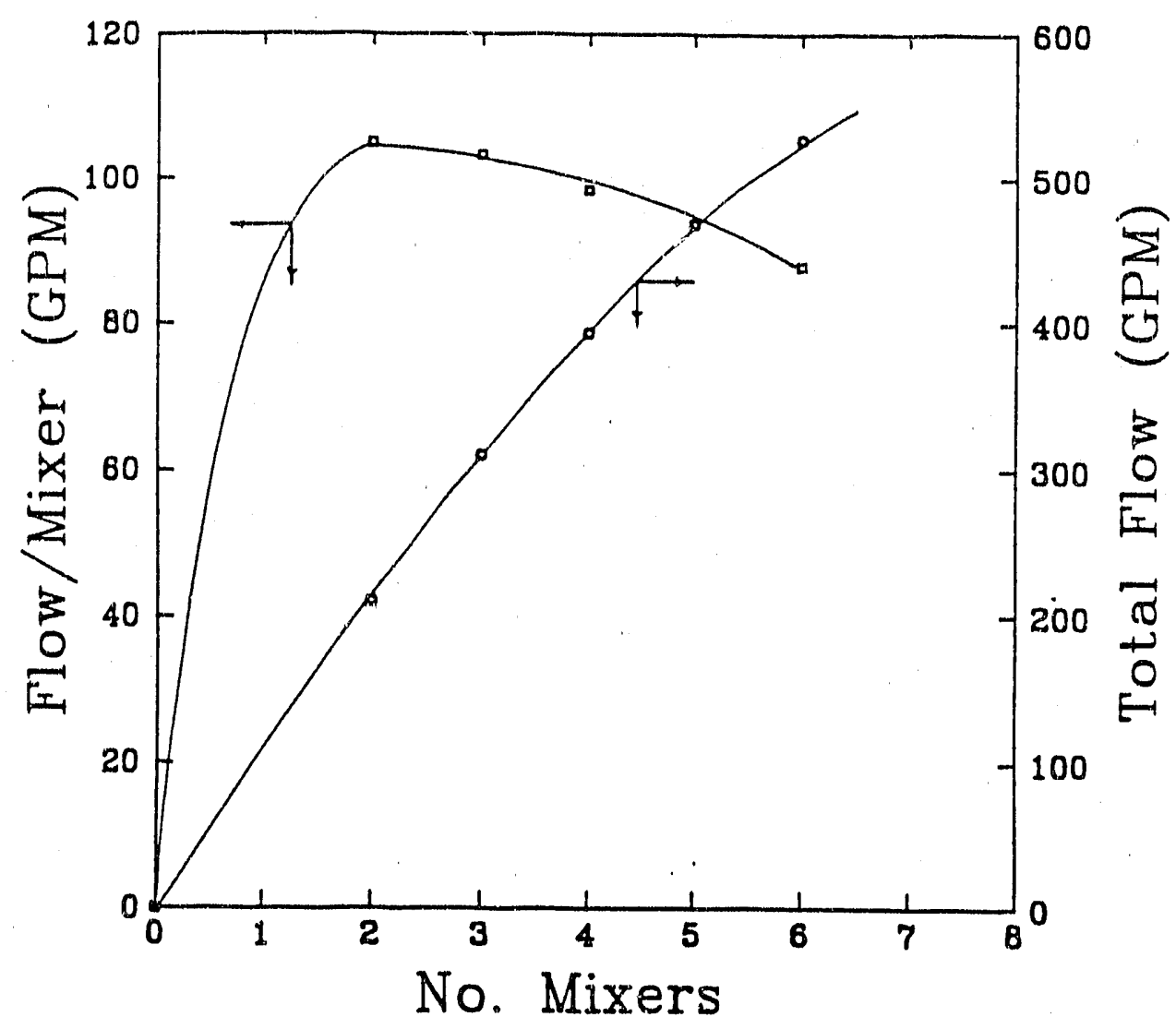

Figurc 35. Total volumetric flow rate and flow per generator as a function of the total number of bubble generators.

point, the column is no longer operating in the bubbly-flow regime, and cell performance drastically deteriorates.

It is also interesting to note that the highest air fraction within the cell was obtained with three in-line mixers, as opposed to four in the case of no frother addition. This is a result of the decrease in bubble size provided by the addition of surfactant. In this case, as the total fow through the system increases, the amount of air which is recirculated also increases due to the low bubble rise velocity. This results in deterioration of the pump performance and the total system flow decreases. Therefore, an optimum number of bubble generators exists for a given set of operating conditions. 


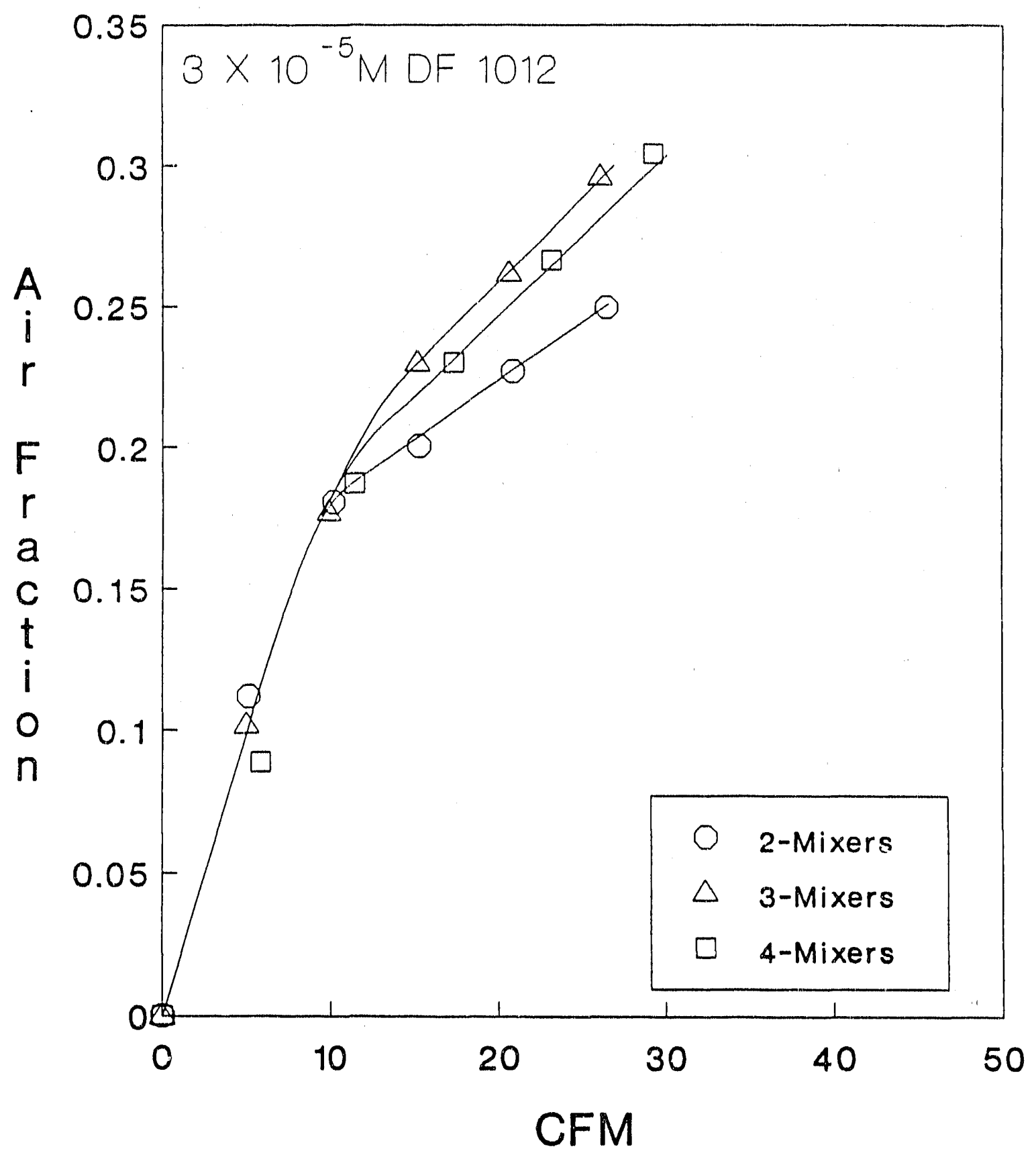

Figure 36. Fractional air content as a function of gas flow rate for 2,3 and 4 bubble generators with $3 \times 10^{-5} \mathrm{M}$ Betz 1012 . 
Using a population balance model of the air phase within the column, the average bubble size within the cell was back-calculated from the measured air fraction and the gas flow rate. These results are shown in Figures 37 and 38 as a function of the gas flow rate through the cell. It can be seen that the average bubble diameter produced in the absence of frother is approximately 1700 microns. This value increases to nearly 2400 microns at gas flow rates in excess of $30 \mathrm{CFM}$. In the presence of frother, however, the average bubble diameter increases from 500 to 1200 microns over a range of gas flow rates of 0,30 CFM. These latter results are representative of the range of bubble sizes which are typically encountered in normal operation.

\section{4.b - Measure Wear of Key Components}

The major components for which wear is a concern include bubble generators, the centrifugal bubble generation pump, tailing discharge valve, and associated piping. The wear rates of the centrifugal pump, discharge control valve, and associated piping are expected to be in line with that of other similar systems within the plant. As a result, the life expectancy of these components has been well documented by plant personnel and is now believed to be of no great concern. However, because of the tortuous path and relatively high slurry velocity through the bubble generators, it was believed that wear might be of particular concern in these devices. In fact, the original column design called for quick-release couplings so that the generators could be removed, inspected, and replaced if necessary on a routine basis. However, throughout the course of this investigation, examinations of both the 30-inch and 8-foot diameter columns qualitatively indicate that the wear of the generators is 


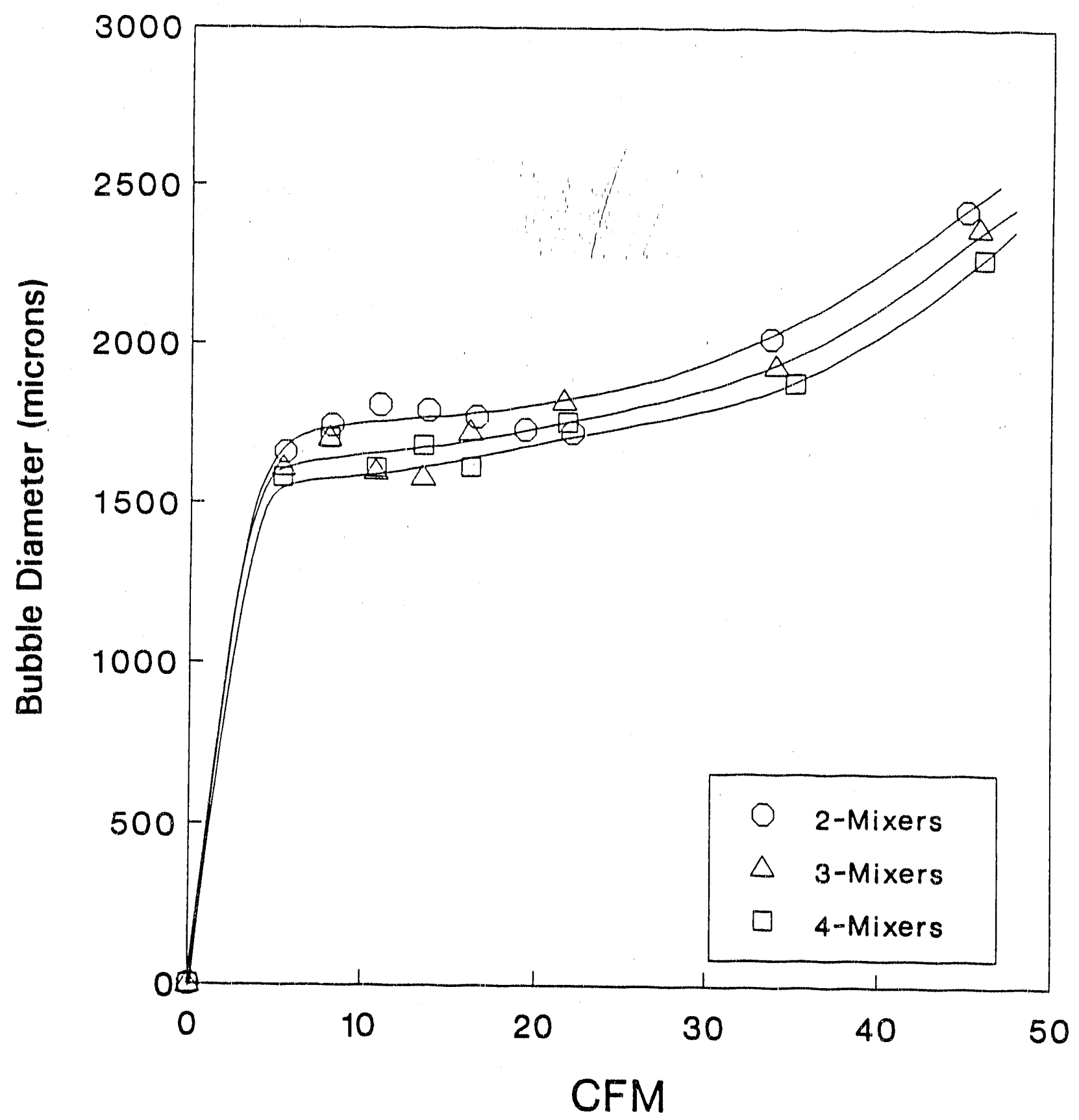

Figure 37. Calculated bubble size as a function of gas flow rate for 2, 3 and 4 bubble generators in the absence of frother. 


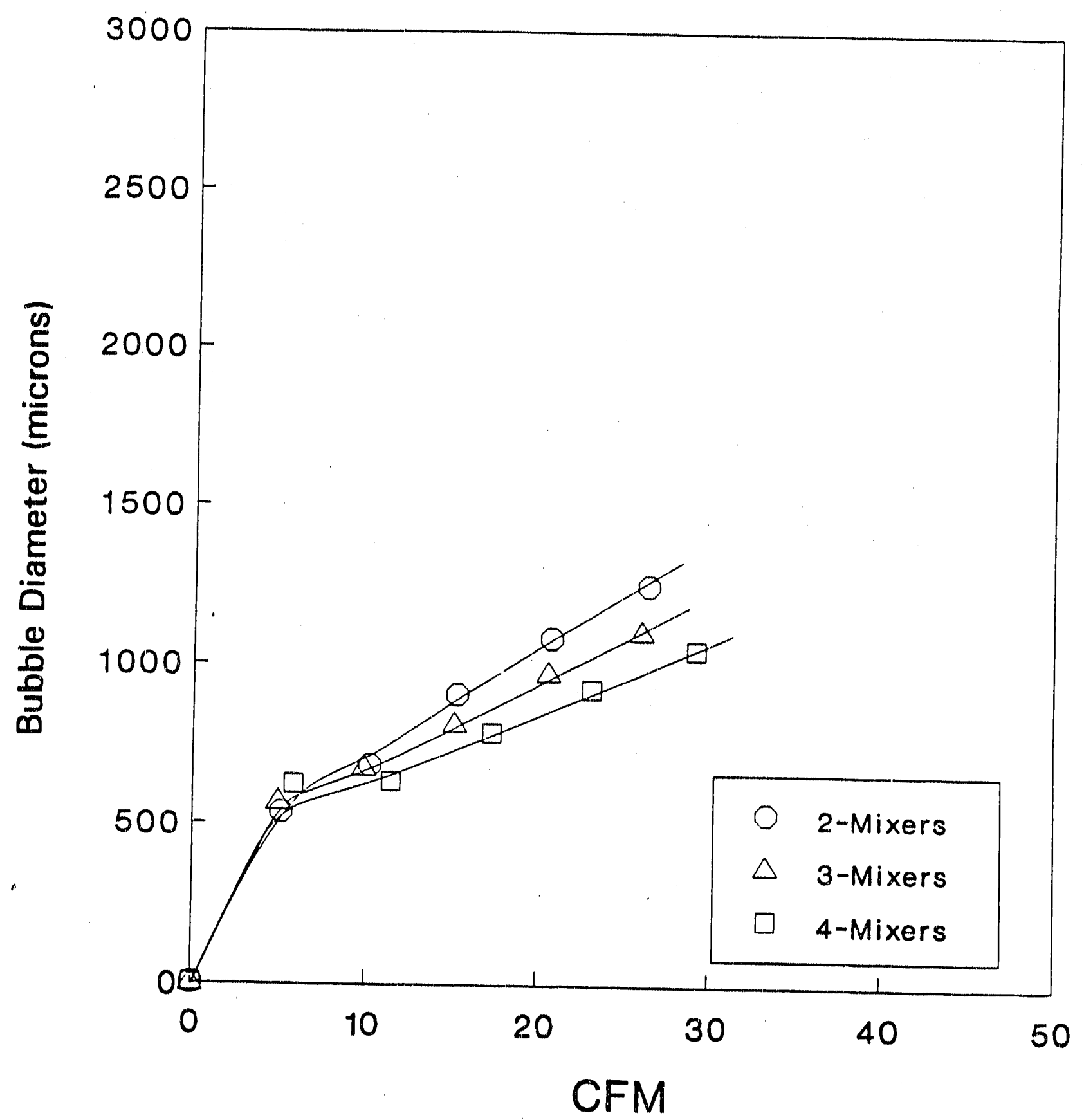

Figure 38. Calculated bubble size as a function of gas flow rate for 2, 3 and 4 bubble generators with $3 \times 10^{-5}$ Betz 1012. 
not a major concern. Estimates now suggest that the hardened-steel generators will have a life of at least 6-12 months. It should also be noted, however, that microbubble generators can also be cast from wear-resistant urethane. Tests carried out in a separate project have demonstrated that these new wear-resistant generators last at least 4 times longer than the original hardened-steel mixers. In addition, the urethane mixers are nearly $1 / 3-1 / 2$ the cost of their hardened-steel counterparts.

\section{Task 2.5 Control Systems}

As previously described in Section 2.3 , both the 30 -inch and 8 -foot diameter columns were controlled through an Allen-Bradley programmable logic controller. This system provided an automated start-up, shut-down and interlock sequence for all equipment associated with the 8-foot column. The interlock sequence provides a means of selectively removing a single piece of equipment from the automated start/stop sequence. This system provided operators and maintenance personnel with a means of servicing equipment without disrupting column operation. The system also controlled all PID loops and data acquisition for both columns. The listing for the ladder logic program is provided in Appendix 7.

A Panelview plant floor terminal was installed as an operator interface. This station allows the operator limited access to the column for manipulation of reagent dosages and column pulp level. The operator terminal has been programmed to provide a graphic display of the column and all ancillary equipment. The equipment graphic symbols are displayed in either green or red to provide the operator with information about the current state of each unit. 


\section{5.a-Pulp Level}

The pulp level control system was installed and integrated with the PLC control

system. A schematic diagram of the current level control system is shown in Figure 39.

This system uses a pressure measurement determined from a Honeywell DP cell as the input

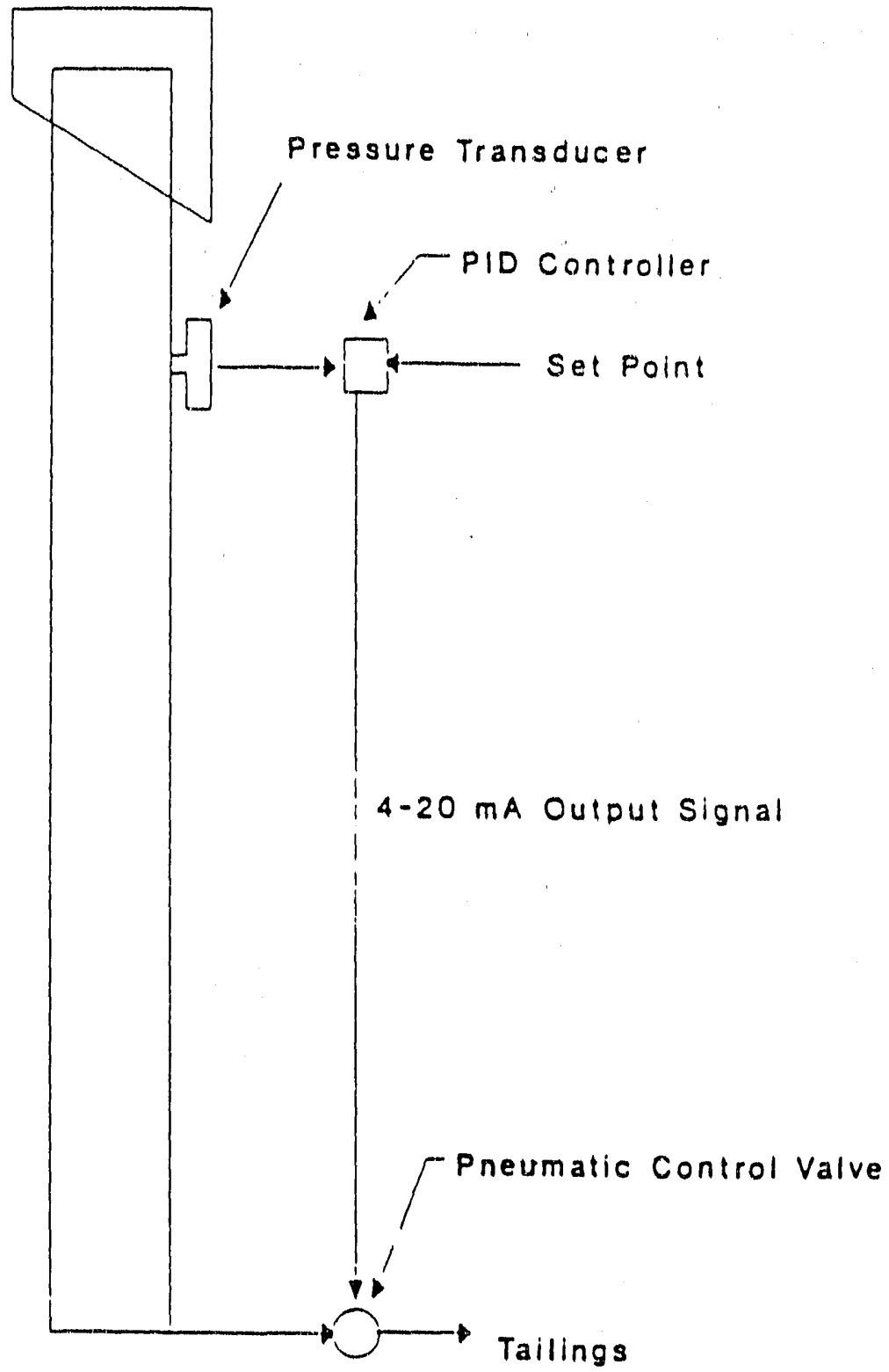

Figure 39. Schematic diagram of column level control system. 
to the PID controller. Based on a given set-point, the controller automatically actuates a pneumatic pinch valve in order to maintain a constant level within the cell. This system is capable of maintaining level within \pm 1 inch.

\section{5.b - Air Hold-Up and Bubble Size Control}

In addition to the DP cell used for level control, a second DP cell has been added for the purpose of determining differential pressure within the column recovery zone. Utilizing the two-point measurement, the fractional air hold-up, $\epsilon_{\mathrm{m}}$, can be determined according to equation 8. The fractional air hold-up is used in conjunction with the measured gas and liquid flow rates to calculate the average bubble diameter in the column collection zone. The bubble diameter can be determined from the following differential equations derived from a volumetric air balance around the recovery zone:

$$
\begin{gathered}
\frac{d e_{1}}{d t}=\left[Q_{t} e_{2}-\left(Q_{1} e_{1}+U_{1} e_{1}\right)\right] / V_{z^{\prime}} \\
\frac{d e_{2}}{d t}=\left[\left(Q_{8}+Q_{d e_{2}}+U_{1} A e_{1}\right)-\left(Q_{1} e_{2}+U_{2} A e_{2}\right)\right] / V_{z^{\prime}}
\end{gathered}
$$

where $Q_{8}$ and $Q_{1}$ represent the gas and tailings flow rates, respectively; $Q_{\mathrm{d}}$ is the difference between the gas and tailings flow rates; $U_{1}$ is the bubble hindered rise velocity, and $V_{2}$ is the theoretical zone volume. 
By utilizing a numerical resubstitution technique, the fractional air hold-up that should exist for a predetermined bubble diameter and column flow conditions can be determined. Direct comparison of the calculated air fraction and the measured air fraction provides an error signal from which the new frother addition rate can be determined. This signal is used in conjunction with the standard proportional/integral control algorithm, which is described as follows:

$$
m(t)=K_{c}\left[e+\frac{1}{T} \int e d t\right]
$$

where $m(t)$ is the controller output, $K_{c}$ is the proportional gain, $T_{i}$ is the integral time constant and $e$ is the error signal expressed as:

$$
e=C_{R}-c(t)
$$

where $C_{R}$ is controller set-point $\approx u c(t)$ is the measured process variable.

In order to refine the frother control system prior to implementation in the 30 -inch cell, preliminary tests, utilizing the above relationships, were conducted in a 2-inch laboratory column. A schematic diagram of the system used for the laboratory tests is shown in Figure 40. The system hardware for the 2-inch cell paraliels that installed on the 30-inch cell.

Preliminary results for the case of simple, untuned proportional control are shown in Figure 41. In this case, the objective of the control strategy was to maintain a constant bubble size when a step change in aeration rate was encountered. As expected, a decrease in the column aeration rate resulted in a decrease in the fractional air content. The simulated 


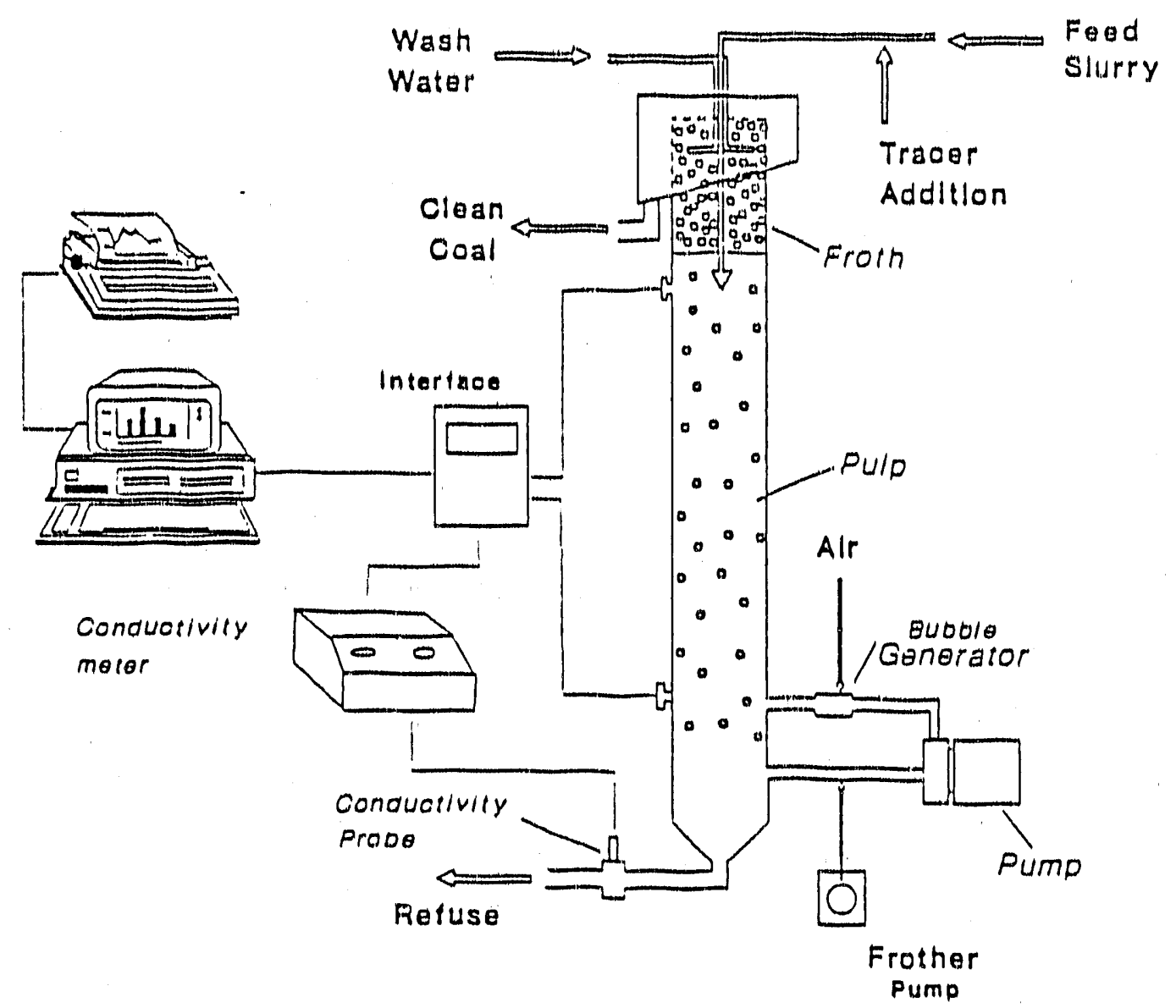

Figure 40. Schematic diagram of the laboratory frother control system.

air rate in the process controller was also decreased simultaneously with the column aeration rate, while the bubble diameter was held constant. The new value of fractional air hold-up determined by the simulator was then used as the set-point value, $C_{R}$, for the laboratory column control loop. This action resulted in a decrease in the controller output (i.e., reduction in frother addition rate), which reduced the fractional air hold-up in the 2-inch cell. It can also be seen from Figure 41 that an increase in aeration rate resulted in a similar response by the controller. The offset between the measured and calculated values of air fraction are attributed to the fact that only proportional control was used for the laboratory 


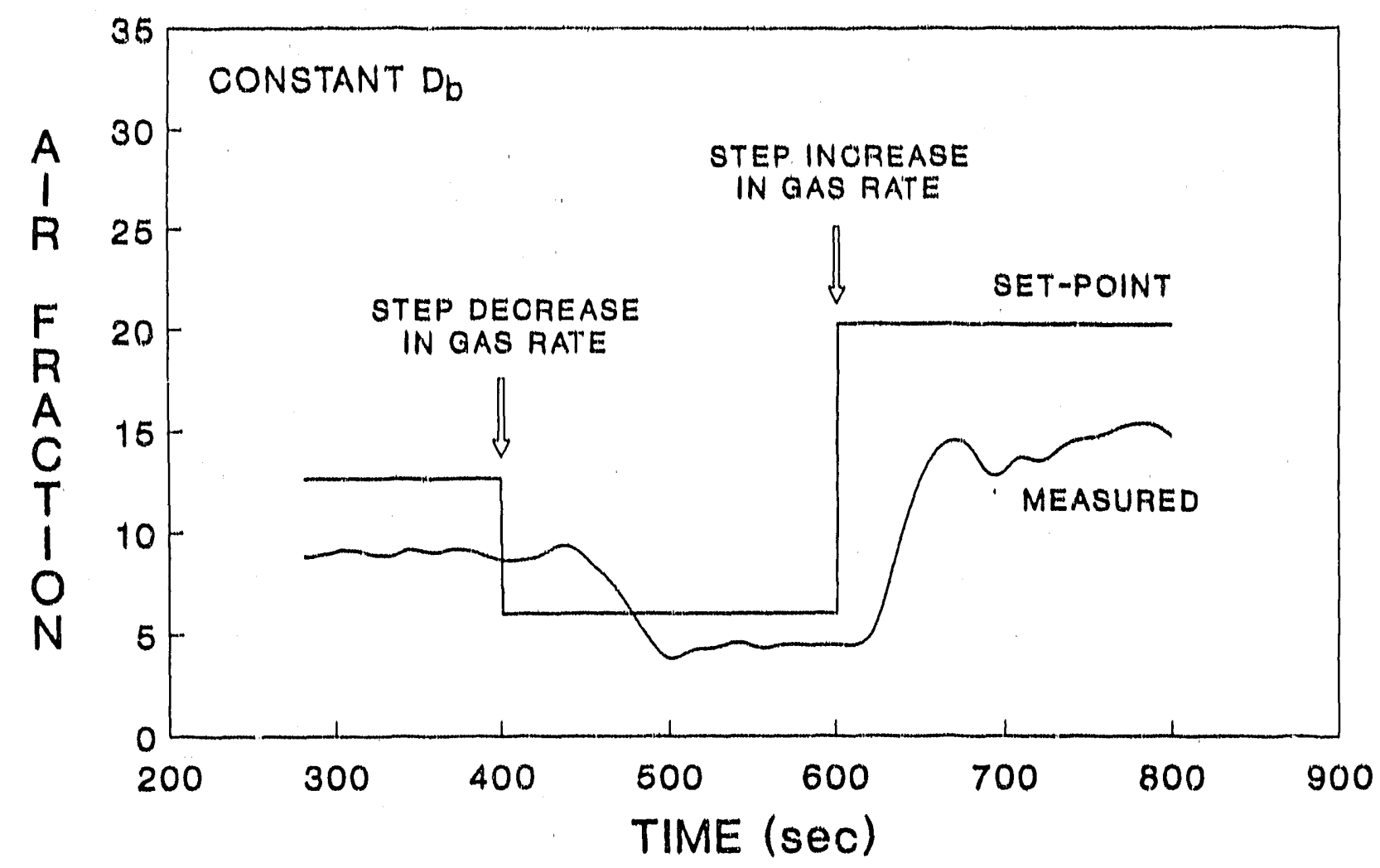

Figure 41. Results of 2-inch laboratory frother control studies.

cell. This type of offset is characteristic of a controller that utilizes only proportional control.

Based on the encouraging results of this initial lab work, a similar control system was installed and tested on the 30 -inch column. In this case, full PI (proportional/integral) control was used in conjunction with the PLC system in order to initiate bubble size control in thrs 30-inch column. The model equations were loaded directly into the PLC's C language processor. The $\mathrm{C}$ language processor operates under a multi-tasking environment, thus allowing for data collection and other process control loops to continue to operate.

Results of the in-plant bubble size control studies are shown in Figure 42. As shown, the 30 -inch column responded in a similar fashion to the laboratory study. The step increase 


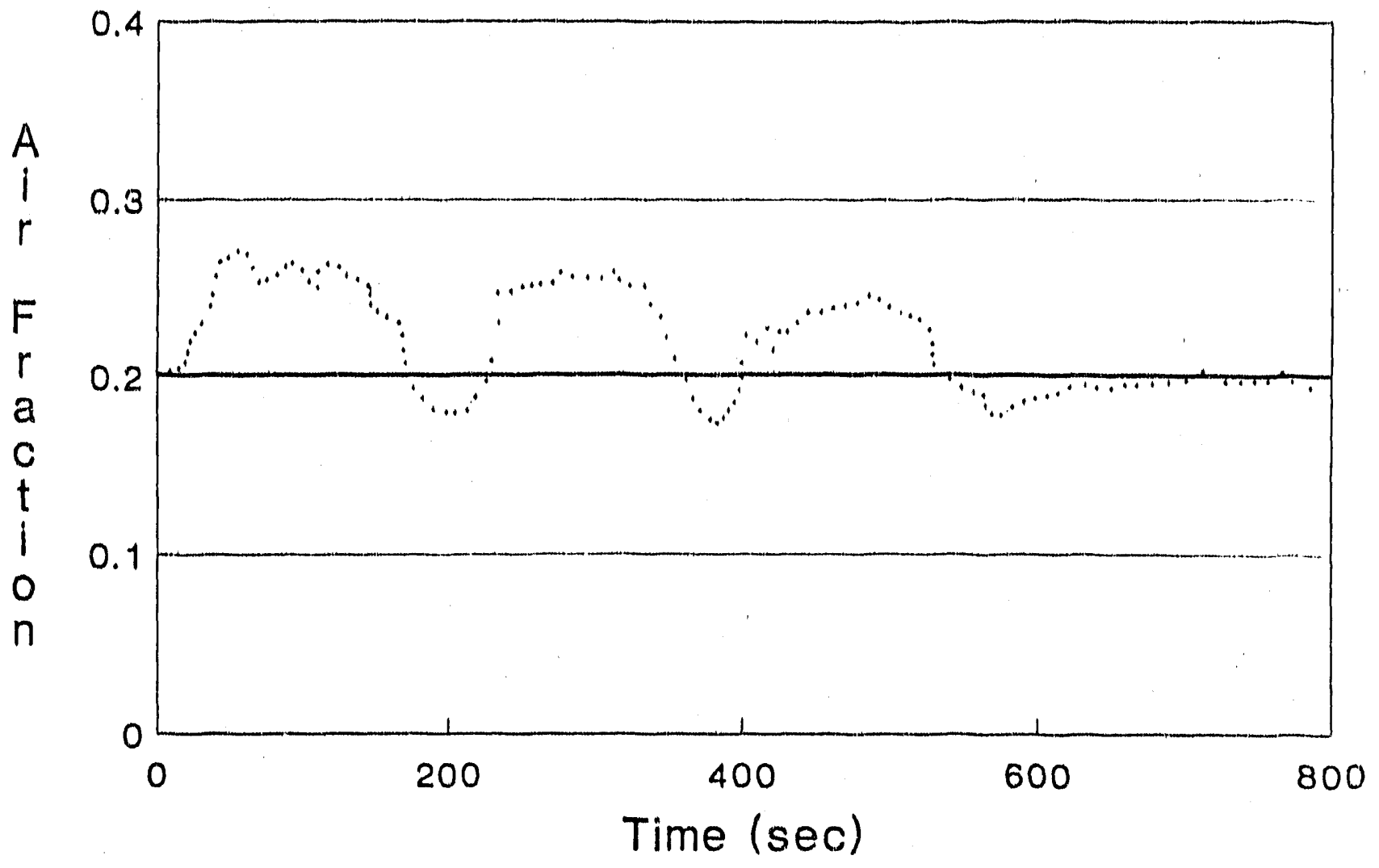

Figure 42. Results of 30-inch in-plant frother control studies.

in colurnn aeration rate resulted in an increased air fraction within the column. In this instance, the air hoid-up increased from 20 to nearly 30 percent. The controller responded by decreasing the frother addition rate in order to compensate for this increase. It can be seen that within approximately 20 minutes the column air fraction had returned to normal operating conditions.

This system provides an important degree of stabilizing control to the column. This is particularly imiportant in light of the wide fluctuations in feed volumetric flow rate and percent solids that are encountered in a plant environment. For instance, during the course of one day, the feed percent solids from the classifying cyclone overflow (i.e., column feed) decreased from nearly 7 percent to 3.7 percent. This reduction in percent solids represents a 
decrease in solids mass flow rate from 180 tph to 94 tph. The lower solids feed rate results in the net frother addition rate increasing from 0.7 to $1.4 \mathrm{lb} /$ ton in the column flotation circuit. As discussed before, these circumstances result in a dramatic increase in the rate of water recovery to the column froth product. In this instance, if a correction is not made (i.e., increase wash water, decrease aeration rate or decrease frother addition) the product ash can increase significantly beyond the contract specification of 10 percent. Therefore, the frother/bubble size control system adds a degree of stability to the column operation that helps maintain a constant product ash content. 


\section{PHASE III - PROTOTYPE TESTING}

\section{Task 3.1 Project Planning}

\section{1.a - Feasibility Study}

Prior to initiating this phase of the work, a detailed feasibility study was conducted to determine whether a full-scale prototype of the microbubble flotation column should be installed in the Marrowbone Preparation Plant for recovery of fine coal. The study was conducted jointly by the engineering staff of the Shell Mining Group and by peisonnel from the Virginia Center for Coal and Minerals Processing. In addition, ICF-Kaiser Engineers provided data related to the structural design of the column and fabrication specifications.

Several meetings were required in order to resolve many of the uncertainties related to the further development, testing and commercialization of this technology. In these meetings, several topics were discussed in regard to the expected performance of the largescale unit (i.e., recovery, grade and throughput) and specific details concerning the engineering design. This section provides a summary of the test results and engineering calculations that were considered in the detailed analysis of the microbubble column flotation process.

Coal Quality: The first step of the feasibility study was to closely examine the preliminary test data obtained from the 30 -inch diameter column tests to determine whether the desired product quality could be obtained at acceptable recoveries. The test data obtained from 2-inch laboratory columns and 6-inch and from 30-inch pilot-scale columns are summarized in Figure 43. Also shown on this figure are the results of a release analysis test which was conducted using a composite sample taken over an extended period of time from 


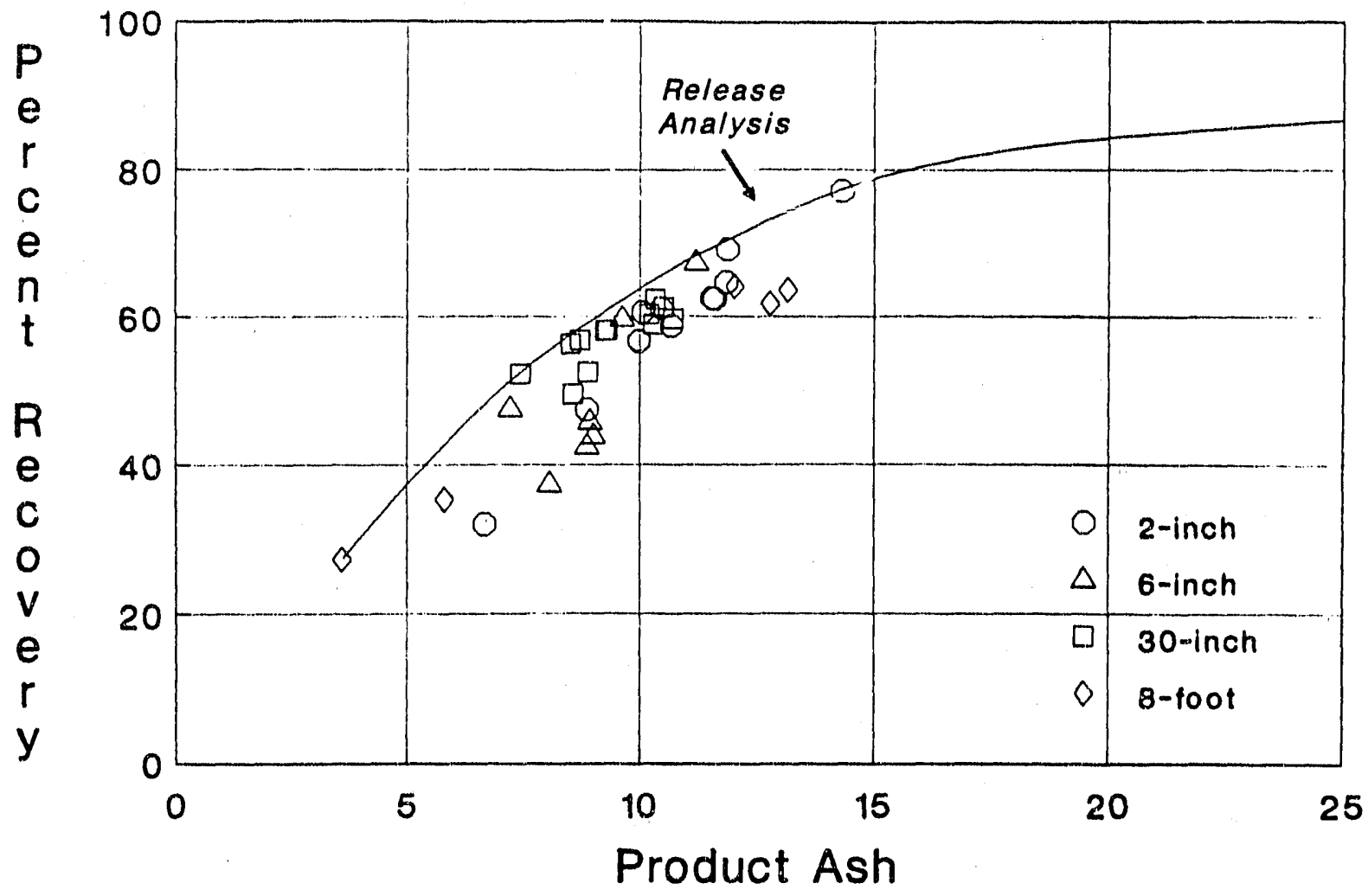

Figure 43. Summary of test results obtained using microbubble flotation columns of various diameters.

the plant classifying cyclone overflow. The release analysis data provide an estimate of the best possible flotation results attainable with this particular sample (Dell, 1953; Dell et al., 1972; Pratten et al., 1989), and the curve is often described as being the flotation equivalent of the washability curve of gravity separations. As shown, nearly the same metallurgical performance, i.e., grade-recovery curve, was achieved in each series of tests. It should also be noted that the various column results are very close to the maximum cleanability predicted by release analysis. In general, it was estimated that when the column was operated properly a combustible recovery of approximately $60 \%$ could be achieved while still meeting the target grade of $10 \%$ ash or less. 
Proposed Flowsheet: Figure 44 shows the flowsheet proposed for the retrofit of the microbubble flotation column into the Marrowbone Preparation Plant. Prior to installation of the column, the -28 mesh material from the preparation plant was fed to multiple banks of classifying cyclones, the $28 \times 150$ mesh underflow fraction from these cyclones was processed using a fine coal heavy media cyclone circuit, and the overflow was discarded without treatment. At present, it is estimated that the cyclone underflow stream contains 100 tph of fine solids at approximately 4 percent solids (i.e., total flow of 9000 GPM). For the proposed flowsheet, part of the -150 mesh fraction would be passed directly to the microbubble flotation column. The reject from this column would flow by gravity to the

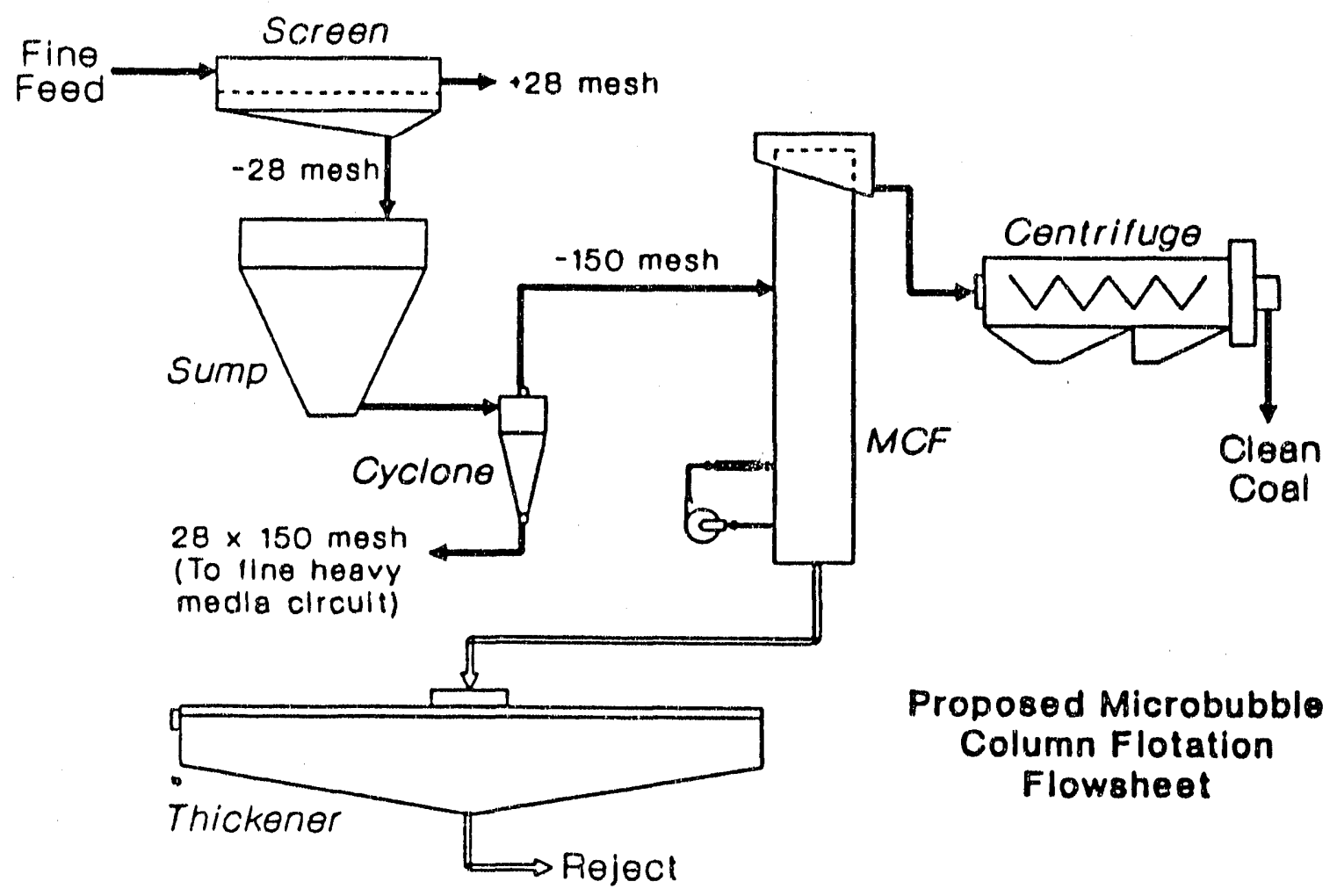

Figure 44. Proposed microbubble flotation column flowsheet for the Marrowbone Preparation Plant. 
thickener for water clarification. The clean coal flotation product would be mixed into one of the coarser streams and then dewatered using a screen bowl centrifuge already in operation at the plant.

Column Capacity: One of the major focuses of the feasibility study was to determine whether the microbubble column was capable of producing the desired product quality and recovery at acceptable throughputs. This was an area of particular concern because of the very fine size ( -150 mesh) and low solids content (3-5\% solids) of the flotation feed from the classifying cyclones. In addition, since this was a high-volume stream (over $9000 \mathrm{gpm}$ of slurry), some questions were raised as to whether an excessive number of columns would be required to handle the large volumetric flow. Therefore, the main goal of this analysis was to provide a preliminary estimate of the capacity of a full-scale column and to estimate the number of full-scale units required to process this entire cyclone overflow stream.

Based on the test results obtained in the 2- and 30-inch pilot-scale columns, the capacity of the full-scale column was calculated using scale-up procedures developed at Virginia Tech. Although the full details of this procedure are too extensive for inclusion in this report, portions of the scale-up calculations are presented below for sake of completeness. Specific details related to the scale-up strategy have been described in the final report submitted to DCE in August, 1990 for a related project entitled "Pilot-Scale Testing of Microbubble Flotation" (DE-AC22-86PC91274).

The first step of the scale-up procedure required that a series of small-scale laboratory tests be conducted until the desired level of performance, i.e., grade and recovery, was obtained. The laboratory tests were conducted in a relatively short column so that carrying 
capacity restrictions did not limit throughput, i.e., the column throughput was determined only by the flotation rate. The data collected in these tests became the basis for the scale-up calculations.

After completing the laboratory scale-up tests, two expressions were used to determine the capacity of the full-scale columns. The first of these describes the operation of the column when the capacity is limited by the flotation rate and is given by:

$$
V_{f}=L(1-\varepsilon) / \tau_{p}-V_{b}
$$

where $V_{f}$ is the superficial feed rate of slurry; $L$ is the column length, $\varepsilon$ is the fractional air hold-up; $\tau_{p}$ is the mean particle retention time and $V_{b}$ is the superficial bias flow of wash water. This expression assumes that the flotation rate constant remains unchanged during scale-up, which implies that the superficial gas rate $\left(V_{g}\right)$ and bubble diameter $\left(D_{b}\right)$ should be the same for both the laboratory and full-scale units. This dictated an air flow rate of approximately $160 \mathrm{cfm}$ for the full-scale unit.

The second expression used for determining scale-up capacity is given by:

$$
V_{f}=\frac{4 V_{g} D_{p} S_{p} \beta}{Y D_{b f}}\left[\frac{1}{S_{f}}+\frac{1}{P}-1\right]
$$

in which $V_{g}$ is the superficial aeration rate; $D_{p}$ and $S_{p}$ are the respective diameter and specific gravity of particles in the froth product; $\beta$ is the particle packing factor; $Y$ is the product yield by weight; $D_{b f}$ is the bubble size in the froth; $S_{f}$ is the specific gravity of particles in the feed slurry, and $P$ is the fractional solids content of the feed. This expression represents the restriction on column throughput due to carrying capacity limitations. The carrying capacity 
constraint is related to the fact that a larger portion of the bubble surface area becomes covered with particles when more material is fed to the column. At some point, more particles are fed to the column than can be removed by the available bubble surface area. This condition defines the upper limit on the feed rate to the column.

Equations [13] and [14] were used to determine the maximum superficial feed rate that could be processed under the specified conditions. These values were checked using an air fraction model developed at Virginia Tech to ensure that the flooding limit of the column would not be exceeded. Flooding orcurs when the superficial velocity of slurry passing down the column exceeds the average rise velocity of the bubbles. If flooding occurs, air enters the column faster than it can rise out, the air fraction in the: column rapidly approaches unity, and bubbles are either washed out of the column with the reject or the column begins to "burp" or "slug." In order to verify that the predicted scale-up values would not cause column flooding, the fractional air hold-up was calculated as a function of bubble diameter and gas and liquid flow rates in the column. A system of simultaneous differential equations must be solved to determine the change in fractional air hold-up during scale-up. Using these equations, it was possible to verify that the predicted scale-up flow rates would not violate the flooding limit.

The superficial feed rates calculated from the scale-up procedure were used to predict the expected capacity of the 30-inch and 8-foot diameter columns, as shown in Table 9. Also shown in this table are the average test values obtained using the 30 -inch column. As shown, the scale-up predictions are very close to the actual test results. The slight offset between the predicted and measured values can be attributed to a minor decrease in the plant feed percent solids relative to the value used for scale-up, the latter being determinied from the 2-inch laboratory column testing. 
Table 9. Scale-up predictions for the 30-inch and 8-foot diameter microbubble column flotation cells.

\begin{tabular}{||l|c|c|c|c||}
\hline Parameter & $\begin{array}{c}\text { 2-inch } \\
\text { Measured }\end{array}$ & $\begin{array}{c}30 \text {-inch } \\
\text { Predicted }\end{array}$ & $\begin{array}{c}\text { 30-inch } \\
\text { measured }\end{array}$ & $\begin{array}{c}\text { 8-foot } \\
\text { Predicted }\end{array}$ \\
\hline \hline Superficial Feed Rate & $0.82 \mathrm{~cm} / \mathrm{s}$ & $1.59 \mathrm{~cm} / \mathrm{s}$ & $1.69 \mathrm{~cm} / \mathrm{s}$ & $1.55 \mathrm{~cm} / \mathrm{s}$ \\
\hline Volumetric Flow Rate & $0.26 \mathrm{gpm}$ & $113 \mathrm{gpm}$ & $120 \mathrm{gpm}$ & $1147 \mathrm{gpm}$ \\
\hline Feed Mass Flow Rate & $6.7 \mathrm{lb} / \mathrm{hr}$ & $1.44 \mathrm{tph}$ & $1.40 \mathrm{tph}$ & $14.6 \mathrm{tph}$ \\
\hline Product Ash & $10.3 \%$ & $10.1 \%$ & $9.46 \%$ & $10.1 \%$ \\
\hline Recovery & $61.8 \%$ & $61.8 \%$ & $61.2 \%$ & $61.8 \%$ \\
\hline
\end{tabular}

Column Geometry: Equations [13] and [14] were also used to determine the column height necessary to achieve the desired recovery in the full-scale columns. The calculations indicated that a collection zone (i.e., the zone between the feed inlet and bubble injection point) 87 inches long would be needed to provide a sufficiently long retention time to collect the particles. However, extra length had to be added to this value to accommodate the froth zone (i.e., the zone above the wash water inlet) and the stabilized froth or cleaning zone (i.e., the zone between the wash water inlet and the pulp/froth interface of the collection zone). In addition, an allowance was also necessary for the distribution of the bubbles and feed into the column and for the collection of rejert material in the bottom of the column. A distance of half the column diameter was estimated for the distribution of each of these streams. A total column height of 24.3 feet was required to satisfy the above criteria. The final design selected for the full-scale column is summarized in Table 10.

Bubble Generation: The most important feature of the microbubble column flotation cell is its novel air sparging system. At Virginia Tech, a great deal of effort has gone 
Table 10. Design dimensions for the full-scale microbubble flotation column.

\begin{tabular}{|l|c|}
\hline Zone & Height \\
\hline \hline Froth & 12 inches \\
\hline Stabilized Froth & 36 inches \\
\hline Feed Distribution & 48 inches \\
\hline Collection & 87 inches \\
\hline Air Distribution & 48 inches \\
\hline Reject Collection & 61 inches \\
\hline Total & 292 inches $(24.3 \mathrm{ft})$ \\
\hline
\end{tabular}

towards the development of expressions that can be used to scale-up the microbubble generation circuit. In general, the performance of the generators can be described by:

$$
D_{b}=\frac{2190 D_{8}}{K W e^{0.71}}
$$

in which $D_{b}$ is the bubble diameter at the generator exit; $D_{g}$ is the generator diameter; We is the dimensionless Weber number and $K$ is the generator pressure-drop constant. The $K$ value for a given mixer can be experimentally determined from plots of pressure drop versus volumetric liquid flow rate. A second factor to be considered is whether the generator can handle the required air fraction. This phenomenon can be quantified by the expression:

$$
\epsilon_{8}=V_{8} /\left(V_{r}+V_{8}\right)
$$


in which $V_{g}$ is the superficial gas rate to the generator and $V_{r}$ is the recycle flow of liquid ihrough the bubble generator. Studies conducted using large-scale generators indicate that $\varepsilon_{\mathrm{g}}$ should not exceed approximately $40 \%$ for effective air sparging.

Using Equation [16], a recycle flow of approximately $2000 \mathrm{gpm}$ was selected for the initial test flow for the full-scale column. After examining standard charts developed for various generator geometries, it was determined that four 4-inch diameter microbubble generators would be required to pass the desired flow while maintaining a Weber number likrge enough to produce small bubbles. The results of the bubble generation calculations are summarized in Table 11.

Table 11. Summary of bubble generation calculations.

\begin{tabular}{|l|c|}
\hline Required Number of Generators & 4 \\
\hline Generator Diameter & $4 \mathrm{inch}$ \\
\hline Total Recycle Flow & $1700 \mathrm{gpm}$ \\
\hline Recycle Flow/Generator & $425 \mathrm{gpm}$ \\
\hline Total Aeration Rate & $160 \mathrm{cfm}$ \\
\hline Aeration Rate/Generator & $40 \mathrm{cfm}$ \\
\hline Exit Air Fraction & 0.41 \\
\hline Exit Bubble Diameter & $0.26 \mathrm{~mm}$ \\
\hline Operating Pressure & $44 \mathrm{ft}(19 \mathrm{psi})$ \\
\hline Operating Efficiency & 0.70 \\
\hline Required Brake Horsepower & $27 \mathrm{HP}$ \\
\hline Estimated Motor Efficiency & 0.85 \\
\hline Estimated Motor Horsepower & $32 \mathrm{HP}$ \\
\hline
\end{tabular}


The next step in the design of the bubble generation circuit was the selection of a centrifugal pump. The primary head loss to be overcome in the pumping circuit is that across the microbubble generators. Studies conducted at Virginia Tech have shown that the pressure drop $(P)$ across a generator is given by:

$$
P=K \frac{0.316}{R e^{25}}\left[\frac{L_{8}}{D_{8}}\right]\left[\frac{S V^{2}}{2}\right]
$$

where $K$ is the mixer constant; $R e$ is the Reynolds number; $S$ is the slurry specific gravity; $V$ is the superficial slurry velocity through the generator and $L_{g}$ and $D_{g}$ are the generator length and diameter, respectively. This expression provides a means of determining pressure loss through the mixer as a function of volumetric flow raie.

In addition to the pressure drop across the generator, head losses in the piping network of the bubble generation circuit must also be taken into account in order to select an appropriate pump. In the present work, standard values available in Cameron Hydraulic Data, published by the Ingersol-Rand Company, have been used to quantify the head losses in the piping network. These calculations are relatively straightforward once the geometric arrangement of the piping system has been identified. Head loss values for each component in the piping network are summarized in Table 12 for the required flow rate of $1700 \mathrm{gpm}$. The total system head was determined to be 44 feet (19 psi). Using these values, various pump curves were examined and a Warman International 10x8 centrifugal pump was selected. The pressure-flow curve for this pump is shown in Figure 45. As shown, a pump speed of approximately $520 \mathrm{rpm}$ was required to obtain the desired flow and pressure. A pumping efficiency of approximately $70 \%$ was possible at this operating point. 

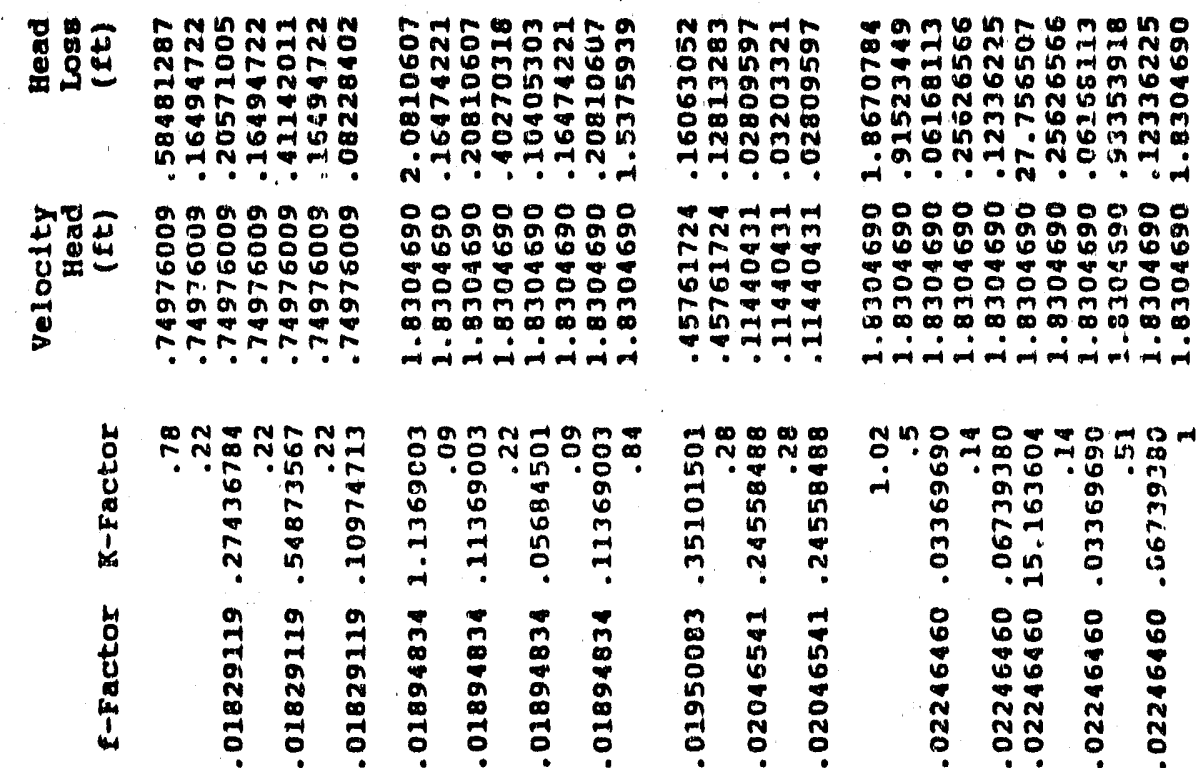

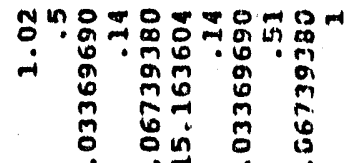

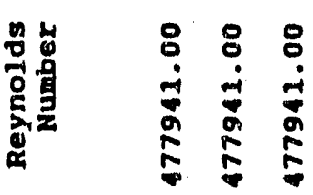

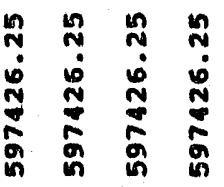

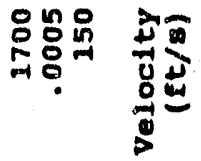

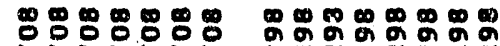

oิ̃

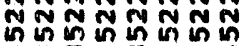

๑.

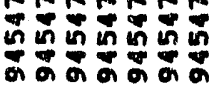

ல் ம்

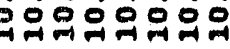

望
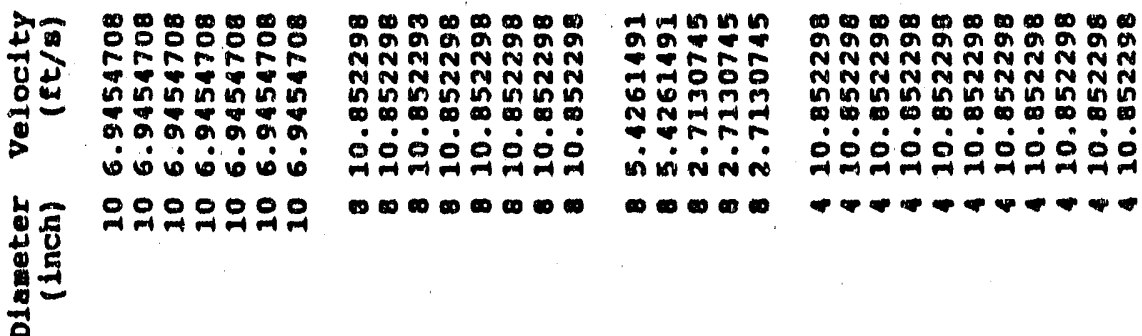

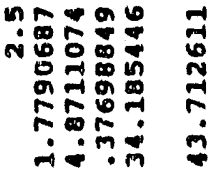

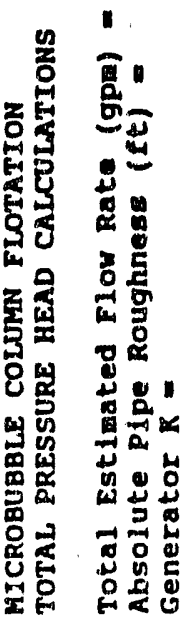

䓪

n

N

$\infty N$

$\infty$

!

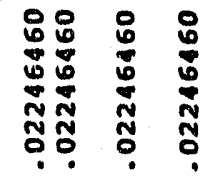

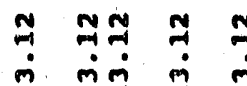

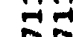

D.

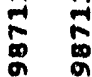

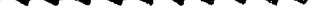

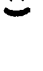$$
\text { tat }
$$

HANNMOE MUOONND

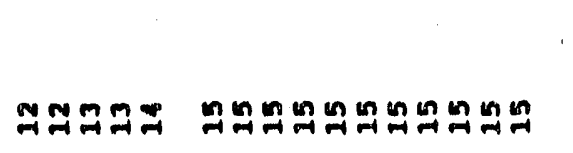

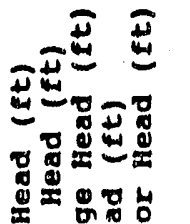

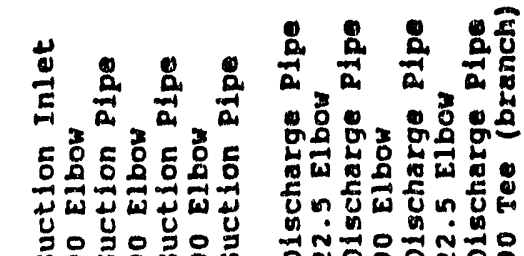

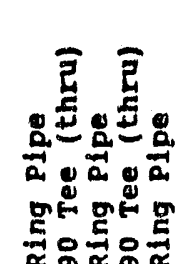

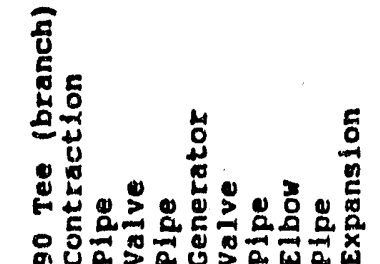

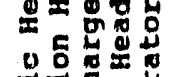

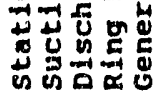

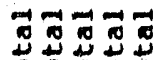




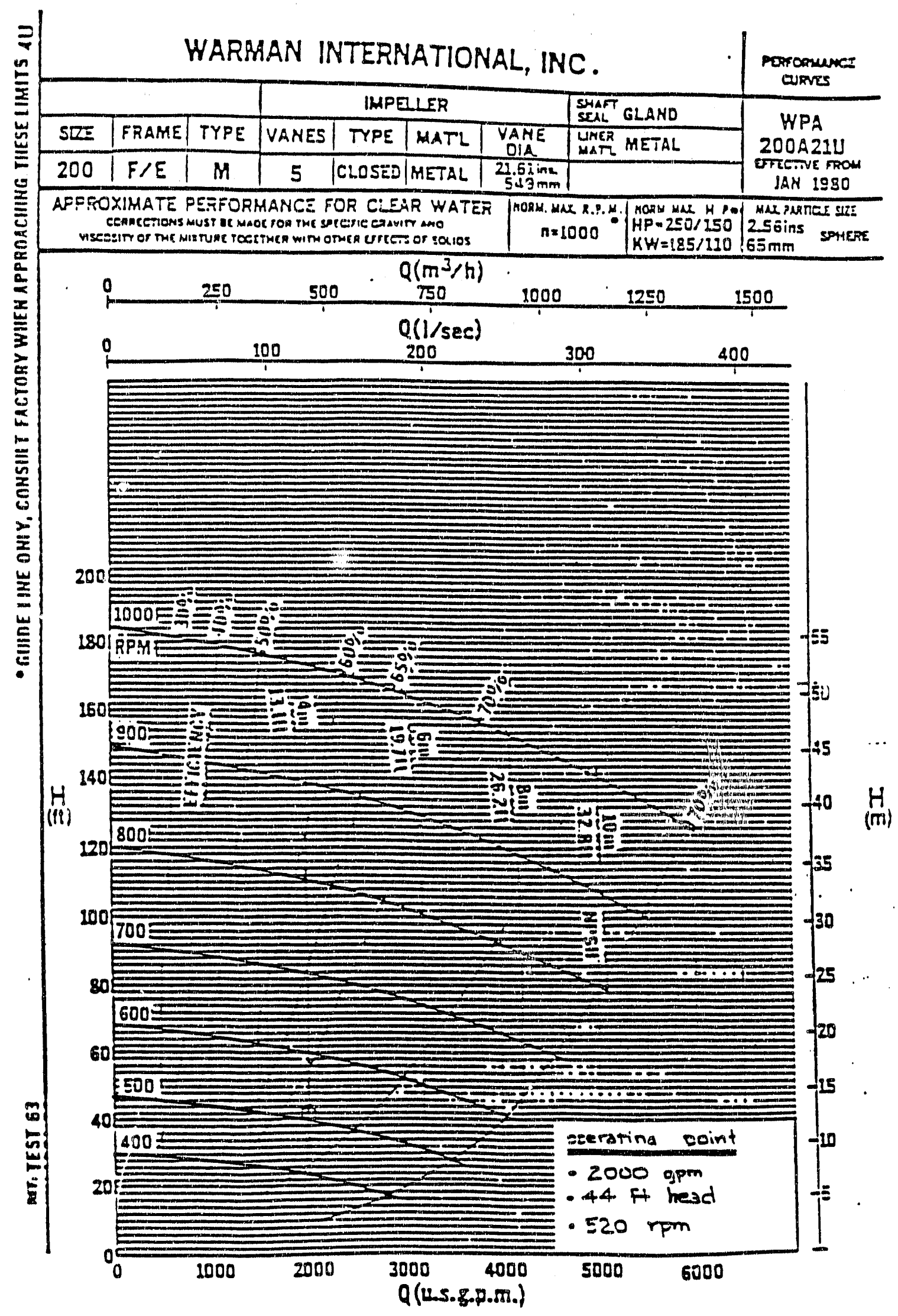

Figure 45. Pressure versus flow curve for the microbubble generation pump 
The brake horsepower for the pump motor was calculated from the expression:

$$
\text { Brake HP }=\frac{Q H S}{3960 E} \text {, }
$$

in which $Q$ is the volumetric flow; $H$ is the required head; $S$ is the slurry specific gravity and $E$ is the pump efficiency. For the given conditions, a brake (shaft) horsepower of 27 was estimated. The required motor horsepower was determined to be approximately 32 by assuming a motor efficiency of $85 \%$. However, in order to allow for flexibility in testing the bubble generators, an oversized motor with a $50 \mathrm{HP}$ rating was selected for testing the first full-scale unit.

Engineering and Fabrication: Based on the column geometry conceived from the scale-up projections, ICF-Kaiser Engineers developed a detailed set of specifications for the bidding and construction of the full-scale microbubble flotation column. A schematic representation of the full-scale column design is shown in Figure 46. (The specifications prepared by ICF-Kaiser Engineers covered the requirements for furnishing labor, piping, hoses, valves, structural steel, platework, materials, and transportation and to shop-detail, furnish, fabricate, shop prime, finish coat and deliver the full-scale column.) The fabrication prints included all parts, supplies, and miscellaneous supports required for the assembly/installation of the column. A detailed set of standards were also specified by ICFKaiser Engineers regarding guidelines for fabrication workmanship. All specifications conformed to material codes and standards specified by the American Society for Testing and Materials (ASTM). 


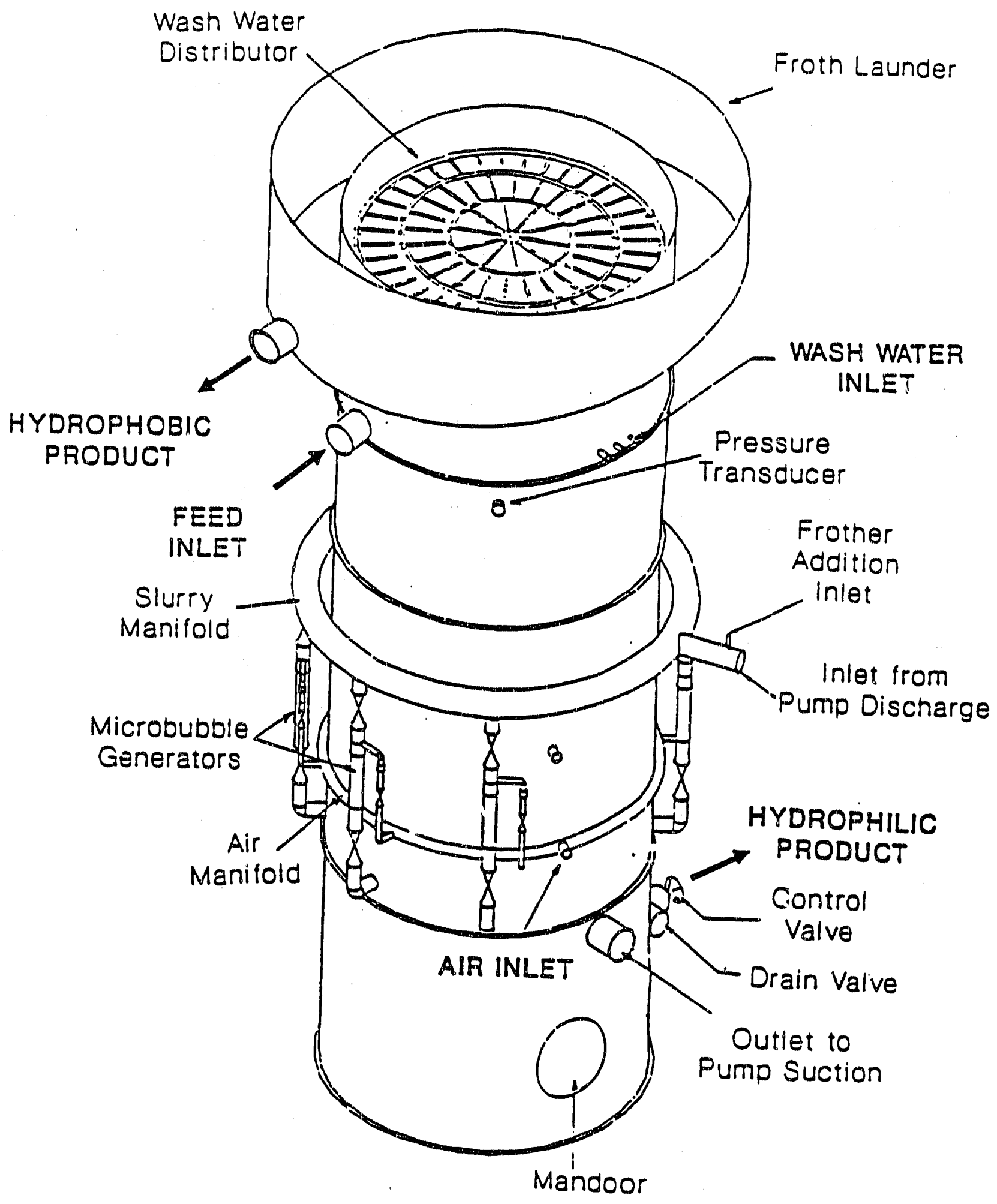

Figure 46. Schematic representation of the full-scale (8-foot diameter) microbubble flotation column. 


\section{1.b - Economic/Cost Analysis}

After the above engineering feasibility study was completed, a simple cost analysis was conducted to estimate the benefits of installing a full-scale microbubble flotation column. In these values, summarized in Table 13 , a fixed market price is assumed for the clean coal product of $\$ 30 /$ ton. A penalty of 1.4 tph has also been applied in the cost estimates to account for losses of clean coal in the heavy media circuit when the gravities are adjusted to maintain a fixed overall product moisture. All costs are presented on a per column basis.

These preliminary calculations indicate that a typical payback period on the capital investment for a microbubble flotation circuit is on the order of 8-9 months. As such, continued development of this technology appears to be very attractive. However, this analysis did not consider such items as the cost of capital, depreciation, and manpower requirements. These items will be included in the final analysis presented in section 3.4.b. The analysis also did not consider additional costs that might be associated with dewatering the fine coal product, which could be significant, since the dewatering circuit presently in service at the Marrowbone plant was believed to have sufficient surplus capacity to handle the additional fine coal product.

The Shell Mining Group also generated a detailed cost analysis for the microbubble flotation circuit. In their analysis, additional factors were considered that were specific to the characteristics of the Marrowbone plant production and sales contracts. As a result, their analysis was far more detailed and considered several factors not accounted for in the analysis presented above. Unfortunately, these data cannot be included for public disclosure due to the proprietary nature of the cost figures used in the analysis. However, in light of the commitment by Shell Mining to continue the testing and development of a full-scale unit, it was apparent that this analysis was also favorable. 
Table 13. Cost-benefit analysis for a full-scale microbubble flotation column (all values approximate)

\begin{tabular}{||l|c|}
\hline Yield & $30 \%$ \\
\hline Column Capacity & $14.6 \mathrm{tph}$ \\
\hline Recoverable Fines & 4.4 \\
\hline Moisture Penalty & $1.4 \mathrm{tph}$ \\
\hline Net Recoverable Tons & $3.0 \mathrm{tph}$ \\
\hline Plant Availability & $85 \%$ \\
\hline Hours/Shift & 8 hours \\
\hline Shifts/Day & 3 shift \\
\hline Operating Days/Year & 230 days \\
\hline Operating Hours/Year & 4692 hours \\
\hline Net Tonnage/Year & 14,076 tons \\
\hline Reagent Costs & $\$ 1 /$ ton \\
\hline Pump/Compressor Power Costs & $\$ 0.20 /$ ton \\
\hline Coal Worth & $\$ 30 /$ ton \\
\hline Net Worth/Year & $\$ 422,300$ \\
\hline Reagent Cost/Year & $\$ 68,500$ \\
\hline Power Cost/Year & $\$ 13,700$ \\
\hline Maintenance Cost/Year ${ }^{1}$ & $\$ 7,500$ \\
\hline Net Return/Year & $\$ 332,600$ \\
\hline Column Equipment Cost & $\$ 60,000$ \\
\hline Compressor Equipment Cost ${ }^{2}$ & $\$ 15,000$ \\
\hline Installed Cost & $\$ 225,000$ \\
\hline Expected Payback & 0.7 years \\
\hline
\end{tabular}

1 - Estimated as $10 \%$ of the total equipment costs annually.

2 - Estimated compressor costs per column for a full-scale plant installation. 3 - Total estimated capital cost is based on Hoffman-Munter Report No. EPA600/7-78-124, "An Engineering/Economic Analysis of Coal Preparation Plant Operation and Cost." This report estimates that the in stalled capital cost can be obtained by multiplying the total equipment cost by a factor of 3 . 


\section{Task 3.2 Column Installation}

\section{2.a - Column Fabrication}

The fabricition specifications were issued by ICF-Kaiser Engineers on March 19, 1990. After obtaining bids from several firms, Ironton Steel of Charleston, West Virginia was chosen as the fabricator on the basis of their submission of the lowest bid. Column fabrication began shortly after the award notification was provided to the fabricator, and the column was delivered to the Marrowbone Preparation Plant on April 6, 1990.

In order to reduce costs, several standard components were also procured separately by personnel at the Marrowbone Preparation Plant. These items included the bubble generation pump, reject control valve, and associated instruments to monitor and control the column performance.

\section{2.b - Site Preparation and Column Insta"lation}

The retrofit of the microbubble flotation column into the existing flowsheet of the Marrowbone Preparation Plant required extensive modification. A private engineering firm was contracted to examine possible locations for the installation of the column. Two primary sites were identified as possible locations for the installation. The first recommendation was to install the columns outside the northern wall of the plant. The second was to locate the column inside the plant within filter press bays which are now idle. After considering several factors related to pipe routing, demolition costs, effects of weather, available head pressures, etc., the interior plant location was selected.

In order to make room for the full-scale column, one of the filter press bays had to be cleared. The disassembly and removal of the filter press was carried out concurrently with the fabrication of the microbubble flotation column. After removing the filter press, the bay 
was widened slightly and a subfloor was built to support the base of the column. Additional steel beams were added to support the weight of the column and slurry. Once the column arrived, panels were removed from the side of the preparation plant, and the column was hoisted into place one section at a time. Sections were assembled and the necessary runs of piping were installed for the feed, product, and reject streams. Electrical connections were made by a separate contractor hired by Shell Mining. Control switches were located in the filter press control room.

Installation of the key components of the microbubble flotation columin was completed on May 16, 1990.

\section{2.c - Develop Test Plan}

The parametric test results from the 30-inch column (Task 2.4) were analyzed in detail by personnel from VCCMP and Shell Mining. Based on these discussions, it was determined that gas flow rate, wash water flow rate, frother addition, and collector dosage were the major parameters that influence column separation efficiency, and it was decided that these factors would be used in the parametric study for the prototype 8-foot column. The standard operating conditions for this study are given in Table 14. The test levels for the prototype 8-foot column and the corresponding parametric test program are presented in Tables 15 and 16, respectively.

The feed size distribution that was to be used for the 8-foot column testwork was also discussed in great detail. As noted earlier, significant savings could be realized in the operating expenses associated with the fine heavy medium circuit if the column were to be fed with cyclone feed material (28 mesh x 0), rather than with the cyclone overflow stream (150 mesh $\times 0$ 0). Preliminary results, shown in Figure 47, indicate that the coarser feed, i.e., 
Table 14. Standard conditions used for parametric test plan.

\begin{tabular}{||l|c|}
\hline Parameter & Setting \\
\hline Column Diameter & 8 feet \\
\hline Column Length & 24 feet \\
\hline Wash Water Addition Point & \\
\hline Upper Ring & 3 inches above lip \\
\hline Middle Ring & 3 inches above lip \\
\hline Lower Ring & 10 inches below lip \\
\hline Generator Length & 30 inches \\
\hline Generator Diameter & 4 inches \\
\hline Number of Generators & 4 \\
\hline Frother Type & Betz 1012 \\
\hline Collector Type & $\# 2$ Diesel \\
\hline Baffles & None \\
\hline
\end{tabular}

Table 15. Levels utilized in the factorial test program.

\begin{tabular}{||c|c|c|c|}
\hline Parameter & Low & Normal & High \\
\hline $\begin{array}{c}\text { Frother Dosage } \\
\text { (ml/min) }\end{array}$ & 50 & 75 & 100 \\
\hline $\begin{array}{c}\text { Collector Dosage } \\
\text { (ml/min) }\end{array}$ & 50 & 100 & 150 \\
\hline $\begin{array}{c}\text { Aeration Rate } \\
\text { (SCFM) }\end{array}$ & 120 & 160 & 200 \\
\hline $\begin{array}{c}\text { Wash Water Rate } \\
\text { (GPM) }\end{array}$ & 150 & 200 & 250 \\
\hline
\end{tabular}


Table 16. Factorial test program.

\begin{tabular}{||c|c|c|c|c||}
\hline $\begin{array}{c}\text { Test } \\
\text { No. }\end{array}$ & $\begin{array}{c}\text { Frother } \\
(\mathrm{cc} / \mathrm{min})\end{array}$ & $\begin{array}{c}\text { Collector } \\
\text { (cc/min) }\end{array}$ & $\begin{array}{c}\text { Aeration } \\
\text { (SCFM) }\end{array}$ & $\begin{array}{c}\text { Wash Water } \\
\text { (GPM) }\end{array}$ \\
\hline \hline 1 & 50 & 50 & 120 & 250 \\
\hline 2 & 75 & 100 & 160 & 200 \\
\hline 3 & 100 & 150 & 200 & 250 \\
\hline 4 & 75 & 100 & 160 & 200 \\
\hline 5 & 100 & 50 & 120 & 150 \\
\hline 6 & 50 & 150 & 200 & 150 \\
\hline 7 & 100 & 150 & 200 & 150 \\
\hline 8 & 50 & 50 & 200 & 250 \\
\hline 9 & 50 & 50 & 200 & 150 \\
\hline 10 & 100 & 150 & 120 & 250 \\
\hline 11 & 75 & 100 & 160 & 200 \\
\hline 12 & 50 & 150 & 200 & 250 \\
\hline 13 & 75 & 100 & 160 & 200 \\
\hline 14 & 50 & 150 & 120 & 250 \\
\hline 15 & 100 & 50 & 200 & 250 \\
\hline 16 & 100 & 50 & 200 & 150 \\
\hline 17 & 100 & 50 & 120 & 250 \\
\hline 18 & 50 & 150 & 120 & 150 \\
\hline 19 & 100 & 150 & 120 & 150 \\
\hline 20 & 50 & 50 & 120 & 150 \\
\hline & & & & \\
\hline
\end{tabular}




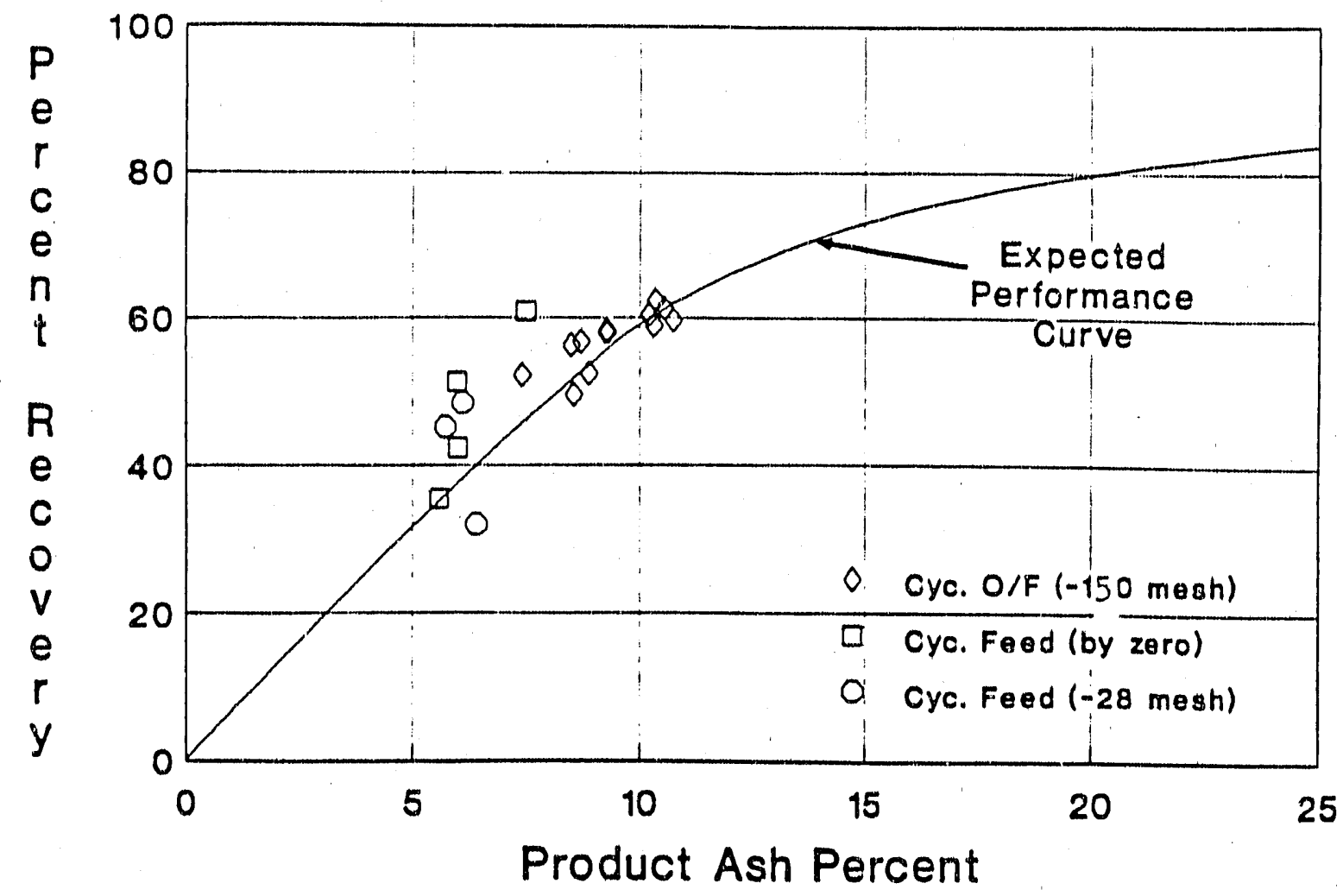

Figure 47. Combustible recovery as a function of product ash percent using the 30-inch column.

cyclone feed (by zero) or scalped cyclone feed (-28 mesh) actually provided a lower product ash than the cyclone overflow. This indicates that the +150 mesh fractions in the cyclone feed contain significant quantities of low ash coal. Also, there appeared to be no reduction in product recovery or separation efficiency for the coarser particle sizes.

The separation efficiency of the 30-inch column also appears to be maintained for the coarser sizes, as indicated by Figures 48 and 49 . These diagrams show combustible recovery as a function of ash rejection and separation efficiency, respectively. It can be seen that the cyclone feed and the true -28 mesh fraction both fall on the same curve as the cyclone overflow results. This indicates that the efficiency of separation has not been affected by the addition of coarse material. Unfortunately, an extensive data base for the coarse feed was not established, primarily because of the extreme variability in the size 


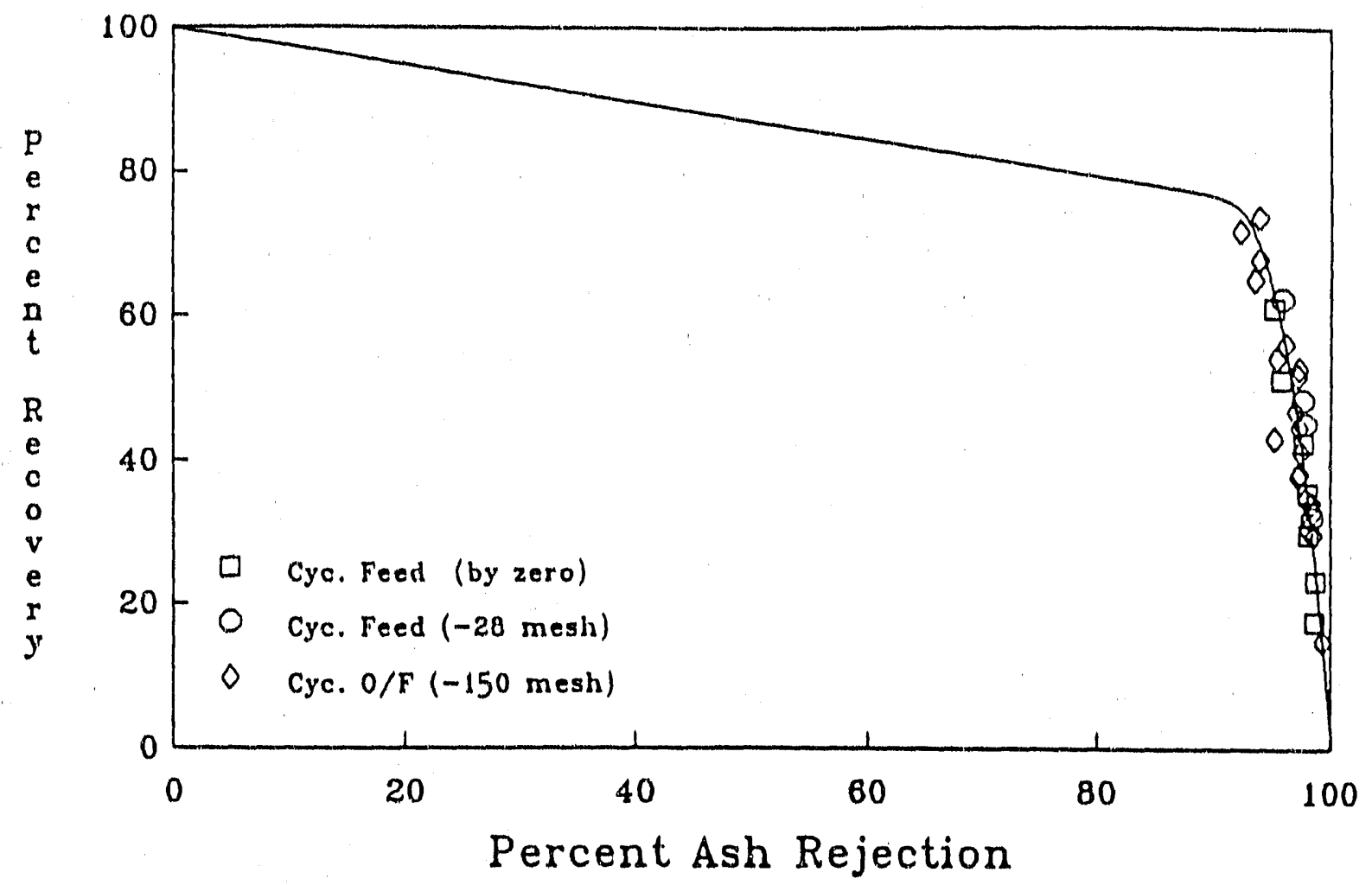

Figure 48. Combustible recovery as a function of feed ash rejection using the 30 -inch column.

distribution of the cyclone feed stream. For example, the cyclene feed top size varied on an hourly basis from 28 mesh up to $3 / 8$ inch. To accurately test this stream would require the installation of an additional sieve bend that would be dedicated to the 8-foot column. Since this was not practical, it was decided to conduct the prototype parametric testing on the minus 150 mesh cyclone overflow stream. This alternative had the added advantage of permitting direct comparison of the performances of the 30-inch and 8-foot test columns. It also provided the opportunity to further validate the established column scale-up procedure. 


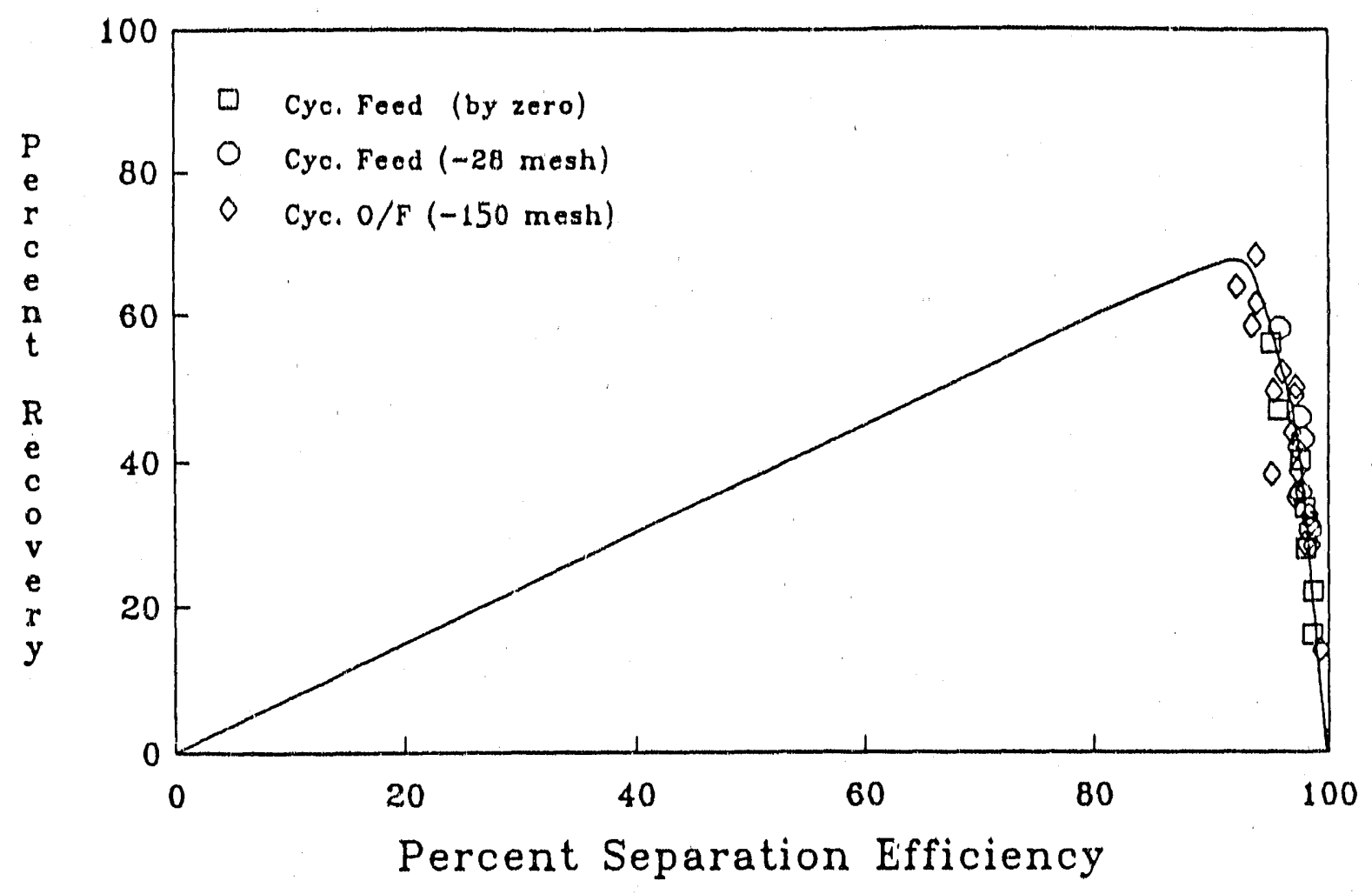

Figure 49. Combustible recovery as a function of separation efficiency using the 30 -inch column.

\section{Task 3.3 Column Testing}

\section{3.a - Shakedown Tests}

Shakedown tests by personnel from the VCCMP and ICF-Kaiser Engineers began shortly after installation of the column was completed. These tests were conducted primarily to identify possible shortcomings in the design of the column. Several problems were encountered during this phase of the work, including mechanical problems with the plant air compressors, instabilities in column level because of an oversized reject control valve, plugging of the feed line by coarse particles, an inability to obtain reliable feed flow rate readings, and poor distribution of the wash water due to an insufficient number of holes in the wash water ring. With the help of personnel from the Marrowbone Preparation Plant, most of these problems were resolved within a two-week period. 
Preliminary data collected from the 8-foot diameter column are provided in Table 17. In general, the column performed well. All three samples collected during the second and third full days of testing gave recovery values greater than the target value of $60 \%$.

Although the target value for the product ash content of $10 \%$ was not achieved during the preliminary testing, it should be pointed out that this was due to piping problems that dictated lower than desired wash water flow rates. As shown in Figure 50, a similar result was obtained for the 30-inch test work when a low wash water addition rate was utilized. After the piping problem was corrected, there were no further problems with achieving target grade and recovery.

Additional tests were conducted over a three-day period to assess column stability. Results from these tests are presented in Figure 51. It can be seen that the 8-foot column consistently produced a clean coal product containing less than 10 percent ash at an average combustible recovery of 60 percent. The product consistency is particularly impressive when considering that the feed ash percent varied from 45 to 60 during the test program.

These same results are presented in the product grade versus recovery curve shown in Figure 52. It is interesting to note that the product grade from these tests was somewhat

Table 17. Preliminary test results obtained from the full-scale microbubble flotation column.

\begin{tabular}{|c|c|c|c|c|c||}
\hline \multirow{2}{*}{ Test \# } & \multicolumn{3}{|c|}{ Ash Percent } & & Combustible \\
\cline { 2 - 5 } & Feed & Product & Reject & Yield (\%) & Recovery \\
\hline \hline 1 & 62.74 & 12.79 & 80.63 & 26.37 & 61.72 \\
\hline 2 & 62.11 & 13.17 & 80.90 & 27.74 & 63.58 \\
\hline 3 & 62.38 & 12.03 & 81.38 & 27.40 & 64.07 \\
\hline
\end{tabular}




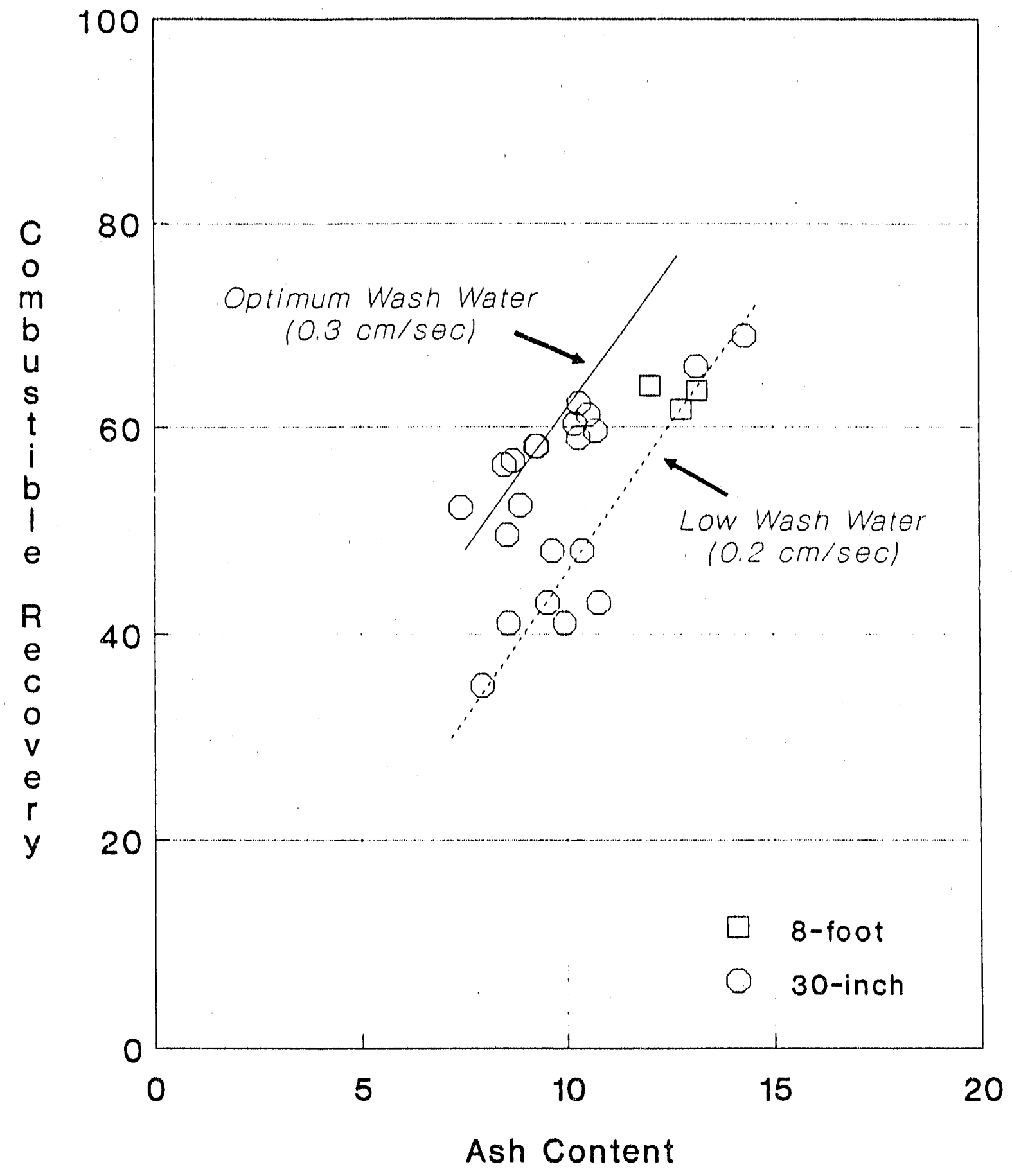

Figure 50. Expected performance of the microbubble flotation column at low and optimum wash water addition rates. 


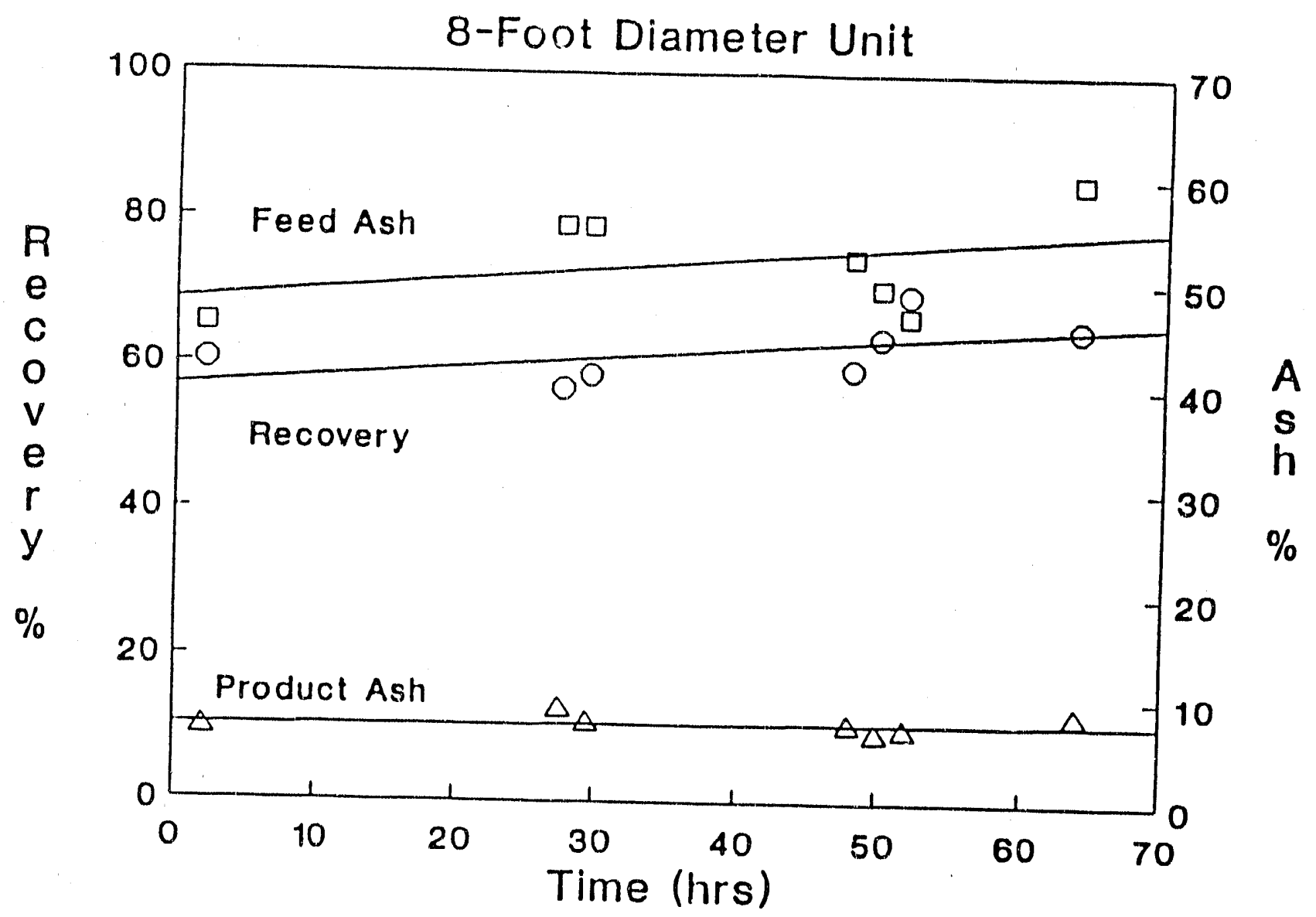

Figure 51. Feed ash, product ash and combustible recovery as a function of time for the 8foot microbubble column.

improved over those previously reported for the 2-, 6- and 30-inch columns. It is believed that the plant was processing a different blend of coals during the time when this data was collected. This is not unlikely, since the Tug Valley plant processes coal from three mines and three different coal seams. The possibility that a different brand of coal was processed is further supporter by the fact that the ash content of the product from the 8-foot column averaged 2 to 3 percentage points lower than expected from the release analysis work. The complete material balance information for each test is given in Appendix 8. 


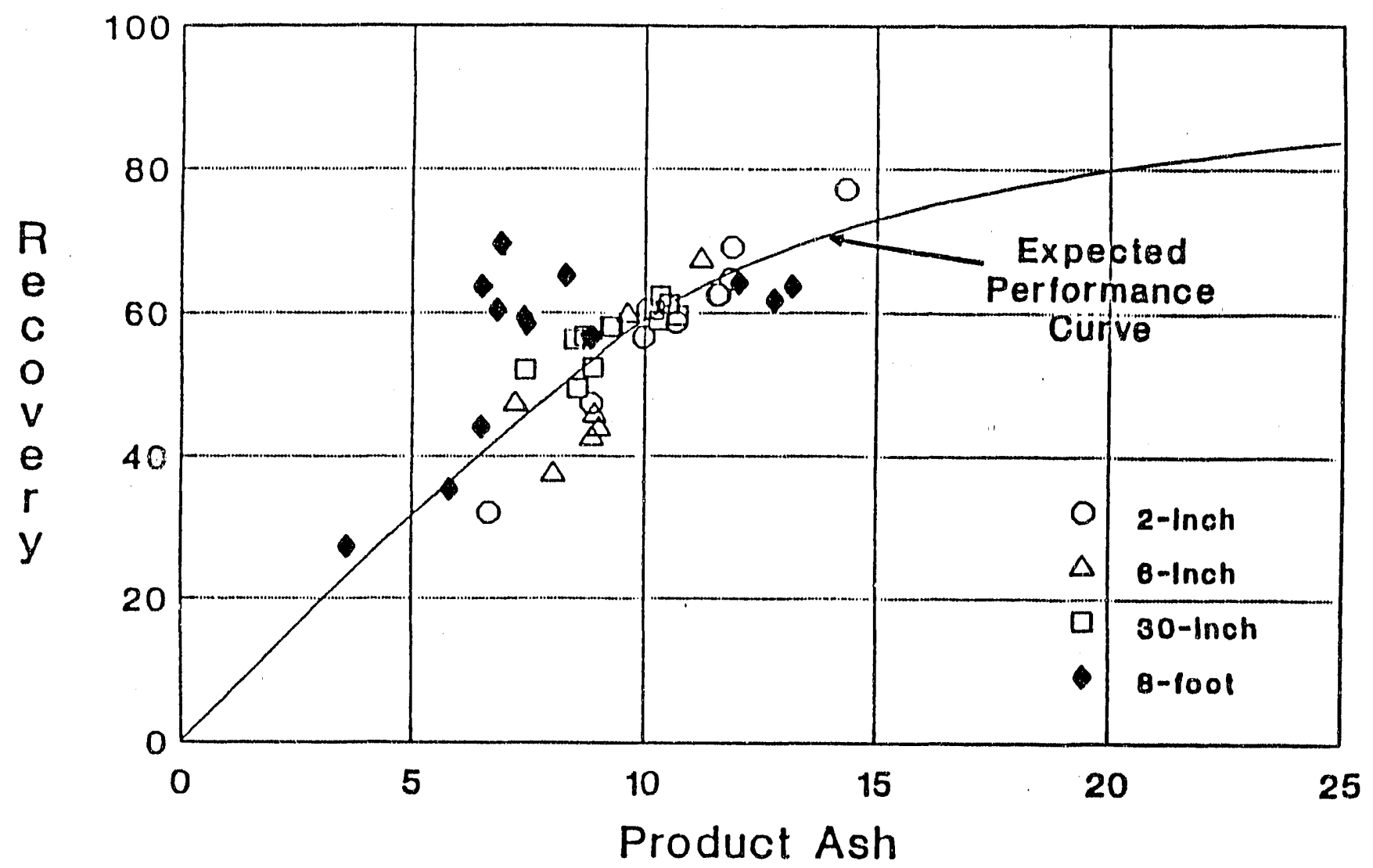

Figure 52. Product grade versus recovery curve for column flotation using 2-inch, 6-inch, 30-inch and 8-foot diameter cells.

\section{3.b,c,d - Initiate Task 3.2 Test Plan}

Once commissioning and shakedown testing had been completed, VCCMP staff initiated the factorial design testwork outlined in Task 3.2.c. This test program required that 20 individual flotation tests be conducted in order to quantify the effects of the four specified test parameters. The specific test levels utilized in the design were selected based on the exploratory test results that were obtained in the earlier stages of this project. The tests were conducted in random order to minimize experimental bias.

A complete proximate analysis was performed on each sample collected in the factorial test program. These results are summarized in Table 18. The feed, product and 


\begin{tabular}{|c|c|c|c|c|c|c|c|c|c|c|c|c|c|c|c|c|c|c|c|c|c|}
\hline & $\begin{array}{l}\text { 焉 } \\
\text { 怘 }\end{array}$ & $\frac{n}{n}$ & 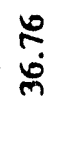 & $\stackrel{2}{\stackrel{q}{q}}$ & 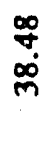 & 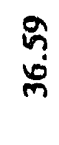 & $\begin{array}{l}\stackrel{p}{p} \\
\stackrel{F}{F}\end{array}$ & $\begin{array}{l}n \\
\tilde{n} \\
\tilde{n}\end{array}$ & $\begin{array}{l}\bar{\delta} \\
\dot{n}\end{array}$ & $\begin{array}{l}\infty \\
\dot{0} \\
\forall\end{array}$ & $\stackrel{\sim}{\tilde{n}}$ & $\begin{array}{l}\varnothing \\
\stackrel{0}{\dot{H}}\end{array}$ & $\begin{array}{l}\frac{0}{n} \\
\text { 气n }\end{array}$ & $\begin{array}{l}\infty \\
0 \\
g\end{array}$ & $\begin{array}{l}\alpha \\
\text { ஸे }\end{array}$ & $\begin{array}{l}8 \\
0 \\
0\end{array}$ & $\begin{array}{l}\text { क } \\
0 \\
8\end{array}$ & 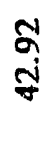 & $\frac{\bar{b}}{\sigma}$ & $\begin{array}{l}8 \\
\infty \\
\dot{\theta}\end{array}$ & 号 \\
\hline & 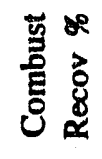 & $\stackrel{\infty}{\stackrel{\sim}{*}}$ & $\begin{array}{l}\widetilde{N} \\
\infty \\
\infty \\
m\end{array}$ & ָี & $\begin{array}{l}\frac{1}{9} \\
\dot{q}\end{array}$ & $\begin{array}{l}\infty \\
\infty \\
\infty \\
\infty \\
m\end{array}$ & के & $\frac{8}{0}$ & $\begin{array}{l}\exists \\
\vec{n}\end{array}$ & $\frac{\sigma}{\sigma}$ & 站 & $\underset{\sim}{\stackrel{N}{\infty}}$ & $\frac{0}{0}$ & $\begin{array}{l}\text { ָे } \\
\text { ஸ் }\end{array}$ & ָั & $=$ & 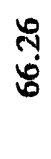 & $\begin{array}{l}\text { gे } \\
\dot{v}\end{array}$ & $\stackrel{g}{j}$ & $\begin{array}{l}\tilde{\infty} \\
\dot{\sigma} \\
\dot{\sigma}\end{array}$ & $\stackrel{5}{n}$ \\
\hline & $\underset{\nabla}{2}$ & ¿ & $\begin{array}{l}\infty \\
0 \\
\underline{\omega}\end{array}$ & $\begin{array}{l}\bar{J} \\
\text { సี }\end{array}$ & $\stackrel{m}{=}$ & 气ू & $\frac{0}{\text { జై }}$ & $\begin{array}{l}\delta \\
\text { ని }\end{array}$ & 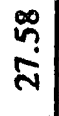 & $\begin{array}{l}2 \\
\ddot{n} \\
\ddot{n}\end{array}$ & ఫั & 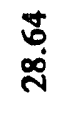 & จั & $\begin{array}{l}8 \\
\text { yे } \\
\text { aे }\end{array}$ & ñ. & $\underset{\sim}{\stackrel{\infty}{n ̃ n}}$ & $\stackrel{\mathscr{n}}{m}$ & $\frac{8}{4}$ & $\frac{n}{\pi}$ & $\stackrel{\infty}{\underset{\lambda}{\lambda}}$ & 吕 \\
\hline \multirow{4}{*}{$\overline{\tilde{\omega}}$} & $\begin{array}{l}8 \\
8 \\
0\end{array}$ & $\begin{array}{l}0 \\
0 \\
0\end{array}$ & $\frac{\nabla}{0}$ & 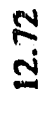 & ָึ & $\begin{array}{l}\mathbb{J} \\
\text { Q }\end{array}$ & $\begin{array}{l}\bar{y} \\
\Xi\end{array}$ & ڤั. & $\begin{array}{l}n \\
0 \\
\dot{Z} \\
\end{array}$ & $\begin{array}{l}50 \\
0 \\
0\end{array}$ & ڤ̆ & $\stackrel{\nabla}{\tilde{\Xi}}$ & $\begin{array}{l}\bar{a} \\
\dot{m}\end{array}$ & $\begin{array}{l}8 \\
0 \\
0\end{array}$ & $\stackrel{5}{\sigma}$ & $\begin{array}{l}\infty \\
\stackrel{\Xi}{\Xi}\end{array}$ & $\frac{m}{\simeq}$ & $\begin{array}{l}\tilde{y} \\
\infty \\
\infty\end{array}$ & $\begin{array}{l}\infty \\
0 \\
0 \\
0\end{array}$ & $\begin{array}{l}\bar{a} \\
\dot{0}\end{array}$ & 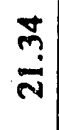 \\
\hline & x 步 & $\begin{array}{l}\text { के } \\
80\end{array}$ & : & $\begin{array}{l}5 \\
0\end{array}$ & $\stackrel{m}{n}$ & 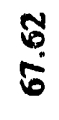 & $\begin{array}{l}5 \\
0 \\
0\end{array}$ & $\frac{n}{0}$ & $\underset{F}{F}$ & $\begin{array}{l}\text { तू } \\
\stackrel{0}{\circ}\end{array}$ & $\stackrel{m}{*}$ & $\begin{array}{l}\infty \\
\infty \\
\stackrel{n}{\infty}\end{array}$ & 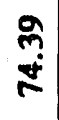 & $\stackrel{0}{5}$ & $\begin{array}{l}5 \\
8 \\
8\end{array}$ & $\begin{array}{l}5 \\
0 \\
0\end{array}$ & $\begin{array}{l}\infty \\
0 \\
0\end{array}$ & $\begin{array}{c}\infty \\
\stackrel{m}{0} \\
\infty \\
0\end{array}$ & $\begin{array}{l}\bar{\sigma} \\
\frac{1}{6}\end{array}$ & $\ddot{0}$ & $\begin{array}{l}\infty \\
\dot{\sigma}\end{array}$ \\
\hline & 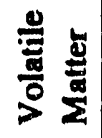 & $\stackrel{\text { fu}}{\mathscr{m}}$ & $\stackrel{n}{\beth}$ & $\equiv$ & $\stackrel{J}{\mathcal{Z}}$ & $\stackrel{\vec{m}}{m}$ & ֵૂ & $\stackrel{\text { స్ }}{\Xi}$ & $\stackrel{0}{ }$ & $\underset{\sim}{\mathbb{I}}$ & $\stackrel{m}{\rightleftarrows}$ & $\stackrel{\infty}{n}$ & $\Xi$ & 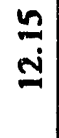 & $\begin{array}{l}\mathscr{D} \\
\stackrel{m}{2}\end{array}$ & $\stackrel{\infty}{\stackrel{\infty}{\Xi}}$ & $\stackrel{5}{=}$ & $\frac{n}{m}$ & $\bar{m}$ & $\begin{array}{l}\stackrel{2}{\mathbf{j}} \\
\stackrel{y}{*}\end{array}$ & $\begin{array}{l}q \\
\stackrel{9}{2}\end{array}$ \\
\hline & 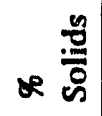 & $\stackrel{m}{m}$ & స్ & $\stackrel{\bar{m}}{\dot{m}}$ & $\vec{m}$ & ํㅗํ & $m$ & $\begin{array}{l} \pm \\
N\end{array}$ & $\stackrel{\text { N̦ }}{\text { N }}$ & $\hat{a}$ & $\stackrel{\widetilde{\sigma}}{6}$ & 9 & $\bar{\sigma}$ & $\underset{\sim}{\tilde{N}}$ & $\begin{array}{l}n \\
\tilde{v} \\
\text {. }\end{array}$ & 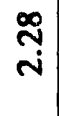 & $\bar{m}$ & in & $\tilde{n}$ & $\underset{j}{J}$ & $\stackrel{2}{i}$ \\
\hline \multirow{4}{*}{ 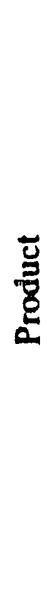 } & 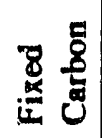 & $\begin{array}{l}\text { ถั } \\
\text { ดे }\end{array}$ & ڤั & ָ̊. & $\begin{array}{l}\qquad \\
0 \\
0 \\
0\end{array}$ & $\begin{array}{l}\mathbb{Z} \\
\infty \\
0\end{array}$ & $\begin{array}{l} \pm \\
0 \\
: 0\end{array}$ & ن: & $\frac{0}{6}$ & 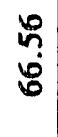 & $\begin{array}{l}\mathbf{0} \\
80\end{array}$ & $\frac{n}{6}$ & 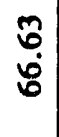 & $\frac{7}{5}$ & $\begin{array}{l}\bar{n} \\
\infty \\
0\end{array}$ & $\frac{0}{\dot{1}}$ & $\begin{array}{l}2 \\
\dot{0}\end{array}$ & $\begin{array}{l}q \\
\dot{\infty} \\
0\end{array}$ & $\frac{5}{5}$ & 触 & $\stackrel{n}{\infty}$ \\
\hline & $\mathscr{2}$ & ڤ̊ & $\because$ & $\begin{array}{l}0 \\
\infty\end{array}$ & o. & $\begin{array}{l}\bar{\sigma} \\
\dot{0}\end{array}$ & $\stackrel{\infty}{\sim}$ & $\underset{\infty}{6}$ & $\underset{\sim}{\infty}$ & $\underset{\infty}{\stackrel{N}{*}}$ & $\frac{6}{2}$ & $\stackrel{9}{n}$ & 9 & $\stackrel{n}{n}$ & $\underset{i 0}{\stackrel{\nabla}{0}}$ & $\underset{\infty}{+}$ & $\begin{array}{l}\infty \\
\infty \\
\infty\end{array}$ & चु & $\begin{array}{l}0 \\
\text { ดे }\end{array}$ & $\begin{array}{l}8 \\
8 \\
i \\
-1\end{array}$ & $\underset{6}{\stackrel{N}{0}}$ \\
\hline & 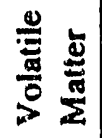 & $\begin{array}{l}\overline{0} \\
\dot{N}\end{array}$ & $\begin{array}{l}\stackrel{N}{*} \\
\ddot{N}\end{array}$ & $\stackrel{\stackrel{R}{d}}{\vec{d}}$ & $\begin{array}{l}\text { के } \\
\text { yे }\end{array}$ & $\frac{\pi}{2}$ & 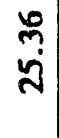 & $\begin{array}{l}\text { mon } \\
\dot{d} \\
\text { in }\end{array}$ & $\begin{array}{l}\mathbb{N} \\
\stackrel{+}{N}\end{array}$ & $\begin{array}{l}\mathbb{N} \\
\dot{U} \\
\mathbb{N}\end{array}$ & 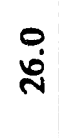 & $\begin{array}{l}q \\
\dot{7}\end{array}$ & సั. & $\begin{array}{l}\bar{a} \\
\vec{d}\end{array}$ & ฟุ & $\begin{array}{l}J \\
\dot{N}\end{array}$ & $\begin{array}{l}\stackrel{N}{*} \\
\stackrel{N}{*}\end{array}$ & $\bar{y}$ & $\begin{array}{l}5 \\
\text { ฟे }\end{array}$ & $\begin{array}{l}\bar{\sigma} \\
\text { ஸे }\end{array}$ & $\frac{m}{\dot{y}}$ \\
\hline & $x \stackrel{\frac{n}{0}}{\bar{c}}$ & $\stackrel{\sim}{\dot{I}}$ & $\frac{\Xi}{\dot{m}}$ & $\stackrel{\swarrow}{=}$ & $\begin{array}{l}\infty \\
\stackrel{0}{g} \\
\end{array}$ & $\begin{array}{l}q \\
\dot{\Xi}\end{array}$ & ํㅗ․ & $\begin{array}{l}: \\
\stackrel{8}{ } \\
\end{array}$ & $\begin{array}{l}\tilde{n} \\
\stackrel{n}{n}\end{array}$ & $\begin{array}{l}\text { जิ } \\
\text { บิ }\end{array}$ & $\begin{array}{l}\stackrel{Q}{0} \\
\dot{m}\end{array}$ & $\begin{array}{l}\bar{a} \\
\underline{\Xi}\end{array}$ & 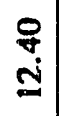 & $\stackrel{a}{a}$ & $\stackrel{\vec{n}}{\underline{\nu}}$ & 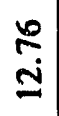 & 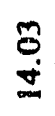 & $\begin{array}{l}\stackrel{0}{:} \\
\dot{m}\end{array}$ & $\stackrel{\infty}{\stackrel{\infty}{2}}$ & 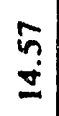 & $\begin{array}{l}\qquad 0 \\
\dot{z}\end{array}$ \\
\hline \multirow{4}{*}{$\begin{array}{c}\text { \$\$ } \\
\$ \\
\end{array}$} & 敢 & $\begin{array}{l}\stackrel{n}{\dot{n}} \\
\dot{\vec{d}}\end{array}$ & ติ & ํ. & \begin{tabular}{l}
$\frac{\infty}{4}$ \\
\multirow{2}{*}{}
\end{tabular} & 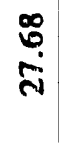 & $\begin{array}{l}\tilde{y} \\
\stackrel{\sim}{+}\end{array}$ & స్ల & $\begin{array}{l}\infty \\
\stackrel{0}{0} \\
9\end{array}$ & 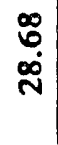 & $\stackrel{\infty}{\stackrel{\infty}{\sim}}$ & $\begin{array}{l}q \\
\text { aें }\end{array}$ & गั. & $\begin{array}{l}\text { वे. } \\
\text { จें }\end{array}$ & $\begin{array}{l}\text { ते } \\
\text { ลे }\end{array}$ & $\begin{array}{l}\stackrel{a}{1} \\
\dot{0}\end{array}$ & 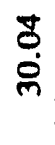 & $\begin{array}{l}\infty \\
0 \\
\text { సి }\end{array}$ & शे. & $\begin{array}{l}\overline{0} \\
\infty \\
\infty \\
\omega\end{array}$ & $\begin{array}{l}\tilde{\sigma} \\
\text { ลे }\end{array}$ \\
\hline & 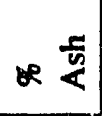 & $\begin{array}{l}\text { مْ } \\
8 \\
8\end{array}$ & $\begin{array}{l}8 \\
8 \\
8\end{array}$ & 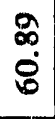 & $\stackrel{\infty}{8}$ & $\begin{array}{l}\hat{b} \\
\dot{0} \\
\omega^{2}\end{array}$ & \begin{tabular}{l}
$\stackrel{0}{~}$ \\
\multirow{2}{*}{}
\end{tabular} & $\begin{array}{l}\tilde{n} \\
\text { iे }\end{array}$ & $\vec{n}$ & $\begin{array}{l}\bar{\infty} \\
n \\
n\end{array}$ & 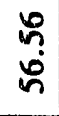 & $\begin{array}{l}\overrightarrow{0} \\
\dot{\nabla} \\
\dot{n}\end{array}$ & $\begin{array}{l}N \\
\infty \\
\dot{\forall} \\
\dot{v}\end{array}$ & $\frac{\nabla}{n}$ & \begin{tabular}{l}
$\tilde{n}$ \\
\multirow{n}{*}{}
\end{tabular} & $\begin{array}{l}\text { ळे } \\
\hat{n}\end{array}$ & $\frac{n}{\dot{v}}$ & $\frac{n}{\dot{n}}$ & $\begin{array}{l}\text { F } \\
\text { in }\end{array}$ & $\begin{array}{l}\text { na } \\
\text { in }\end{array}$ & 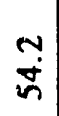 \\
\hline & 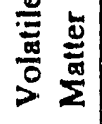 & $\begin{array}{l}\bar{n} \\
\dot{\Xi}\end{array}$ & $\begin{array}{l}\dot{v} \\
\dot{\Xi}\end{array}$ & $\Xi$ & $\begin{array}{l}\vec{m} \\
\dot{\Xi}\end{array}$ & 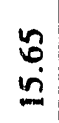 & $\begin{array}{l}F \\
\stackrel{\dot{v}}{2}\end{array}$ & $\begin{array}{l}\beth \\
\ddot{n}\end{array}$ & $\begin{array}{l}\bar{N} \\
\underline{u}\end{array}$ & $\begin{array}{l}\bar{n} \\
\underline{v}\end{array}$ & 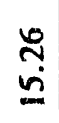 & $\begin{array}{l}6 \\
\dot{0} \\
\underline{0}\end{array}$ & 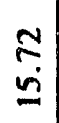 & $\begin{array}{l}\hat{m} \\
\underline{n}\end{array}$ & $\begin{array}{l}\vec{\nabla} \\
\stackrel{\sim}{2}\end{array}$ & $\begin{array}{c}\tilde{n} \\
\underline{n}\end{array}$ & $\begin{array}{l}\tilde{\infty} \\
\stackrel{\omega}{ }\end{array}$ & $\begin{array}{l}n \\
n\end{array}$ & $\begin{array}{l}q \\
i\end{array}$ & 홈 & 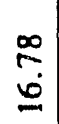 \\
\hline & * & $\stackrel{\infty}{\stackrel{\infty}{\sigma}}$ & $\begin{array}{l}n \\
0 \\
0\end{array}$ & ôn & $\begin{array}{l}\infty \\
\infty \\
\infty \\
i\end{array}$ & 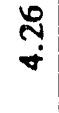 & $\bar{n}$ & $\stackrel{0}{\dot{\sigma}}$ & $\begin{array}{l}\infty \\
\infty \\
+\end{array}$ & $\underset{+}{\forall}$ & $\begin{array}{l}\infty \\
\forall \\
\dot{m}\end{array}$ & ণ্ & $\frac{0}{\dot{m}}$ & $\begin{array}{l}m \\
\dot{q}\end{array}$ & $\begin{array}{l}\mathscr{n} \\
\dot{\nabla}\end{array}$ & $\begin{array}{l}\forall \\
\dot{\nabla}\end{array}$ & $\begin{array}{l}\stackrel{0}{0} \\
\dot{\forall}\end{array}$ & $\frac{N}{v}$ & $\begin{array}{l}\infty \\
0 \\
\dot{m} \\
\dot{m}\end{array}$ & $\bar{n}$ & $\underset{0}{\tilde{O}}$ \\
\hline & 总 & - & $N$ & $m$ & $\nabla$ & $n$ & 0 & $r$ & $\infty$ & $a$ & $\stackrel{0}{2}$ & $=$ & $\cong$ & $\underline{m}$ & \pm & $\simeq$ & 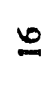 & \pm & $\infty$ & $\underline{a}$ & 유 \\
\hline
\end{tabular}


reject percent solids are also given. Product yield and combustible recovery were calculated from the product assays and are also given in Table 18.

As indicated in Table 16, four replicate tests (Tests 2, 4, 11, and 13) were performed at various times throughout the program. The replicate tests were required in order to determine the amount of pure error. The product yield and ash percent for the replicate tests are given in Figure 53. It can be seen that the amount of variation between tests is insignificant relative to product ash, but a slight bias is indicated by the product yield. This is a result of a drift in the feed ash percent during the time frame in which the tests were conducted. It can be seen from Table 18 that the column feed ash slowly declined from 60 percent to nearly 54 percent throughout the course of the test program. The decrease in feed ash resulted in a higher fractional yield for the latter tests. The drift in column feed ash has been observed on more than one occasion and appears to be within normal fluctuations of plant performance. Unfortunately, this does detract somewhat from the reliability of the model.

The grade versus product recovery curve for all of the data collected in the factorial test program is shown in Figure 54. It can be seen that even with the sharp changes in operating conditions, the column continued to operate on the grade versus recovery curve. This result is particularly encouraging due to the wide fluctuations in pressure and flow that are encountered $n$ day-to-day operation of the plant. These results are also shown in Figure 55 in terms of clean coal yield as a function of product ash percent. It can be seen that a maximum of nearly 35 percent yield can be obtained while maintaining a product ash of slightly under 10 percent. 


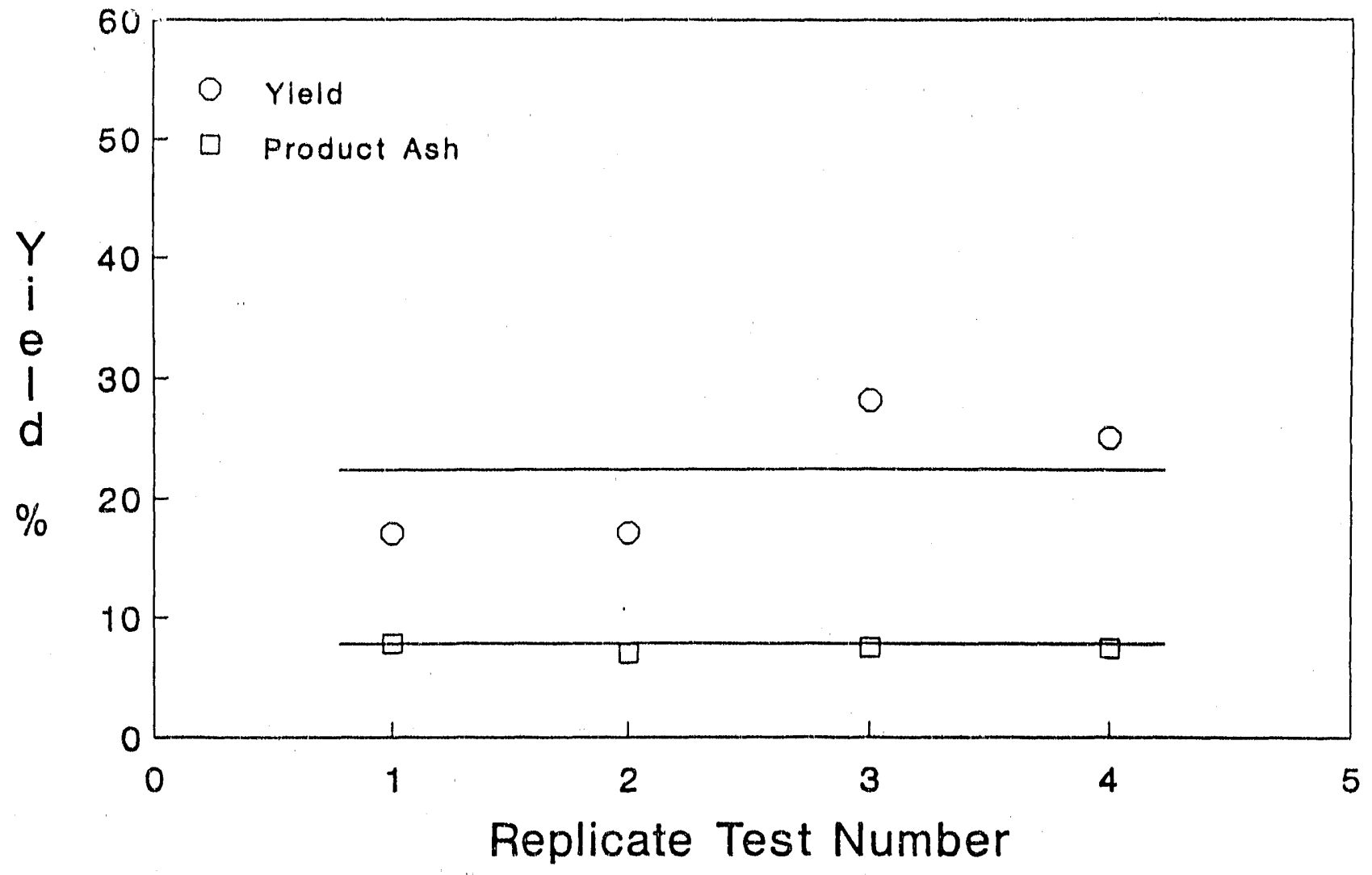

Figure 53. Yield and product ash obtained for each of the replicate tests conducted throughout the factorial testing program.

Figure 56 shows the product combustible recovery as a function of feed ash rejection. Ash rejection is defined as the percent of the feed ash which reports to the column tails. Mathematically it is represented as follows:

$$
\text { Ash Rejection }=(1-Y) \frac{A_{t}}{A_{f}}
$$

where $Y_{f}$ is the fractional yield and $A_{t}$ and $A_{f}$ are the tailings and feed ash, respectively. In this approach, the results are normalized for a change in feed ash percent. It can be seen in Figure 56 that an ash rejection of over 90 percent was achieved at a combustible recovery of approximately 65 percent. 


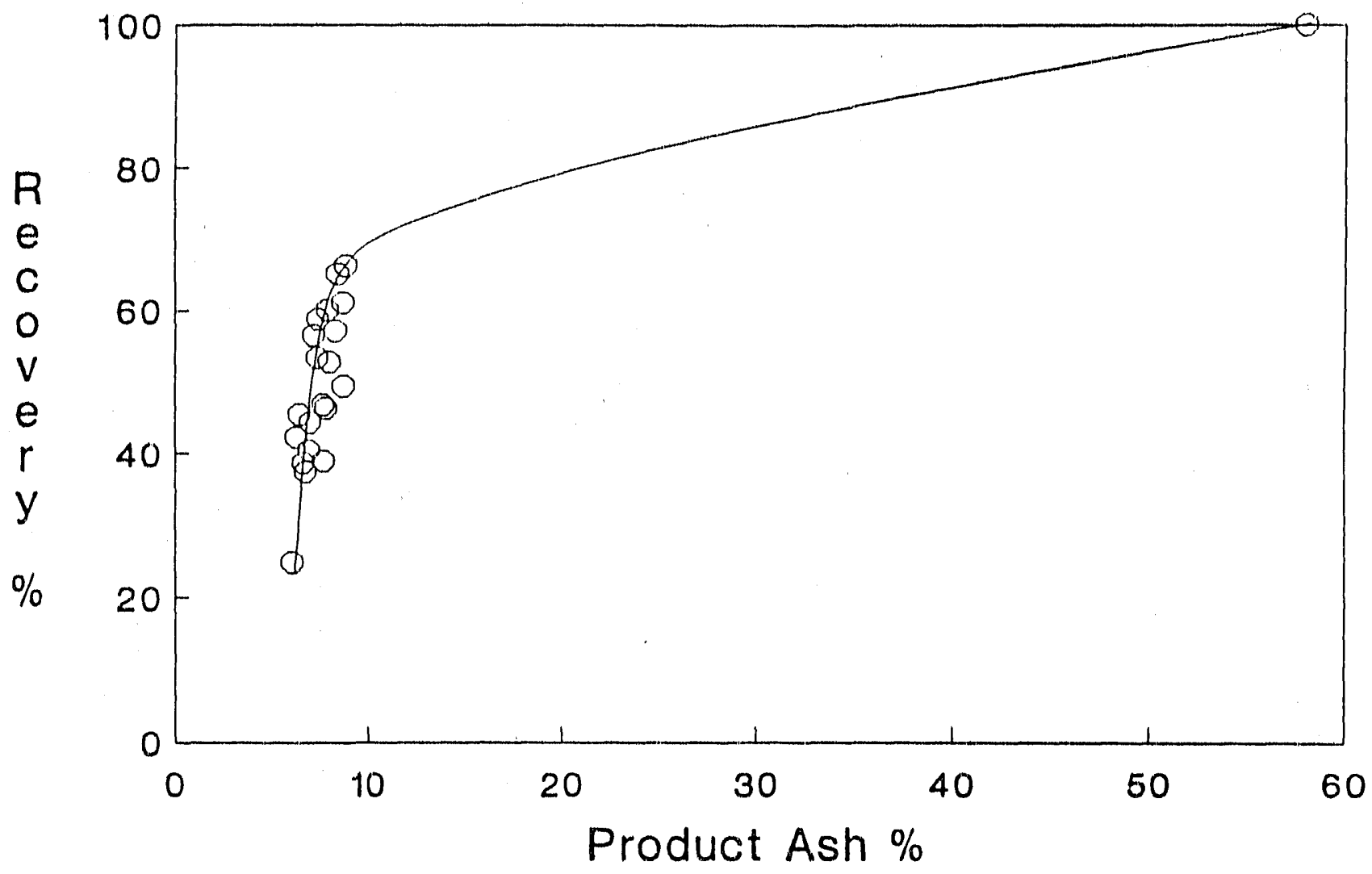

Figure 54. Combustible recovery as a function of product ash percent for the 8-foot column factorial test program.

The column separation efficiency is also shown in Figure 56 as a function of ash rejection. Separation efficiency is defined as the combustible recovery minus the ash recovery to the product. Mathematically, separation efficiency is defined as follows:

$$
\text { Separation Efficiency }=Y_{f}\left(\frac{\left(100-A_{p}\right)}{\left(100-A_{f}\right)}-\frac{A_{p}}{A_{f}}\right)
$$

where $A_{p}$ is the product ash percent. It can be seen from Figure 56 that the optimum separation efficiency occurs at the elbow of the recovery versus ash rejection curve. In this case, the maximum separation efficiency was 60 percent. 


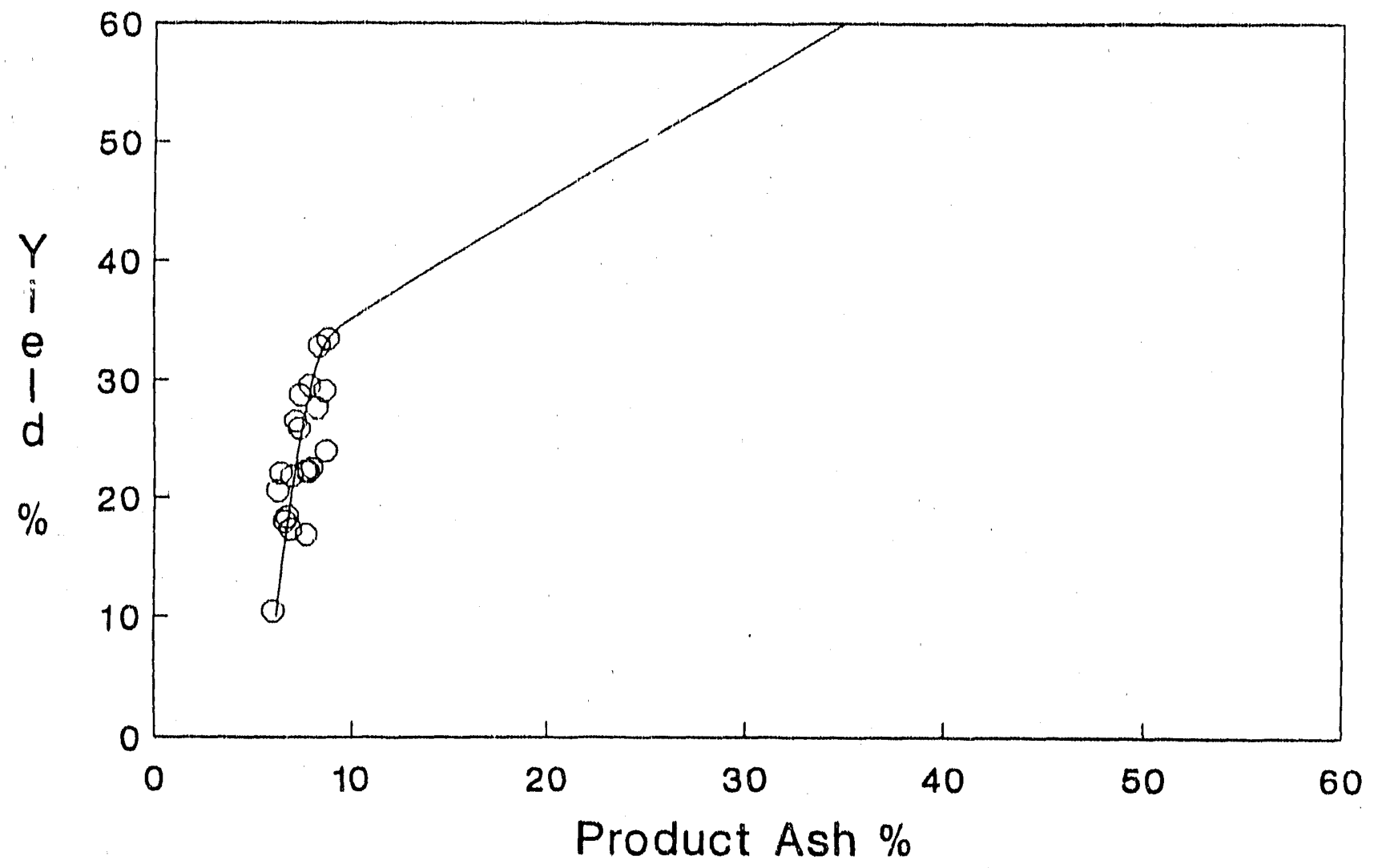

Figure 55. Yield as a function of product ash percent for the 8-foot column factorial test program.

The above results agree quite closely with those obtained from previous tests conducted on the 8-foot column. This is supported by the grade versus recovery data shown in Figure 57. In this figure, the data from the 2-, 6- and 30-inch, as well as the 8-foot column are shown. It can be seen that all of the data lie on the same grade versus recovery curve, indicating that the different columns provide the same level of metallurgical performance.

Statistical Data Analysis and Model Development: After conducting all of the flotation tests, the results were also analyzed using the DESIGN-EXPERT statistical data analysis program. This software was used to set up the experimental design and to perform all 


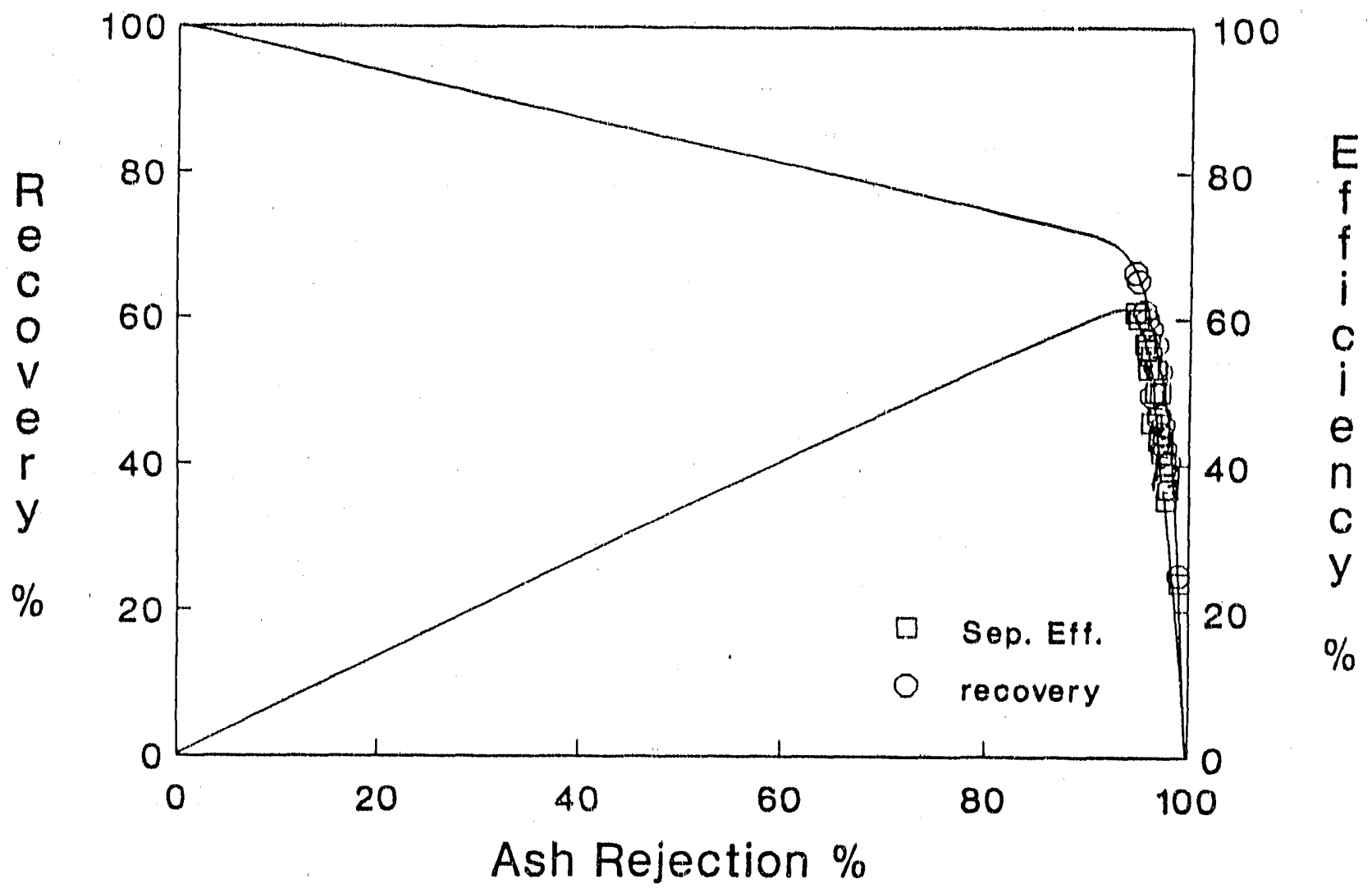

Figure 56. Combustible recovery and separation efficiency as a function of ash rejection for the 8-foot column factorial test program

required statistical computations and regression analyses. The overall objective of this effort was to develop empirical relationships between the various operating parameters and response variables: product yield, ash percent, and separation efficiency. It was felt that these parameters would provide the best indication of column performance relative to the change in operating conditions. A data analysis was then conducted to determine the best approach for representing the results in terms of the appropriate model and data transformation. Data transformations are often required to improve the model fit. In this instance, none was required. 


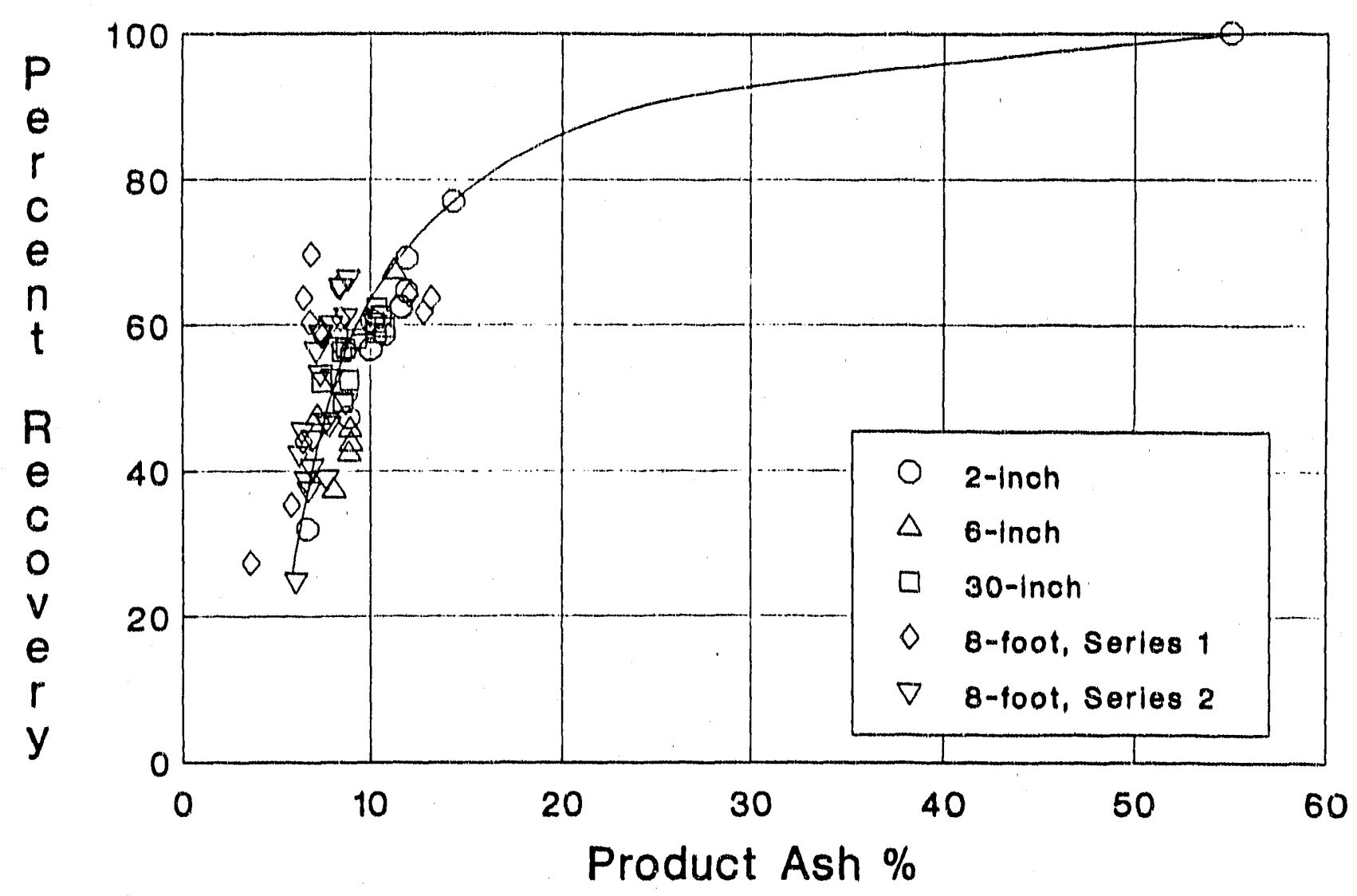

Figure 57. Combustible recovery as a function of product ash percent for all column flotation tests conducted on the Coalburg seam coal.

The DESIGN-EXPERT package offers three different models for data representation:

linear, quadratic and cubic models. After selecting the appropriate model, a variety of statistical routines were executed to identify the goodness-of-fit. For all runs, the values of regression coefficients, standard errors, t-tests, etc. were determined as means of quantifying the statistical significance of the model. After a reasonable mathematical model of the desired response was selected, the resultant response surface was plotted using a surface contour routine. The influence of key operating parameters and the joint interaction of various parameters on the process performance were determined from this information. 
A summary of the statistical data analysis computations is provided in Appendix 9 for each of the different responses. Comparisons between the results predicted by the modeling exercise and results obtained from the experimental measurements are shown in Figures 58 through 60 . In general, good correlations were obtained in each case.

The response surface plots for each of the three performance indicators are shown in Appendix 10, in Figures A - C. A number of significant trends can be observed from an analysis of the different response surfaces.

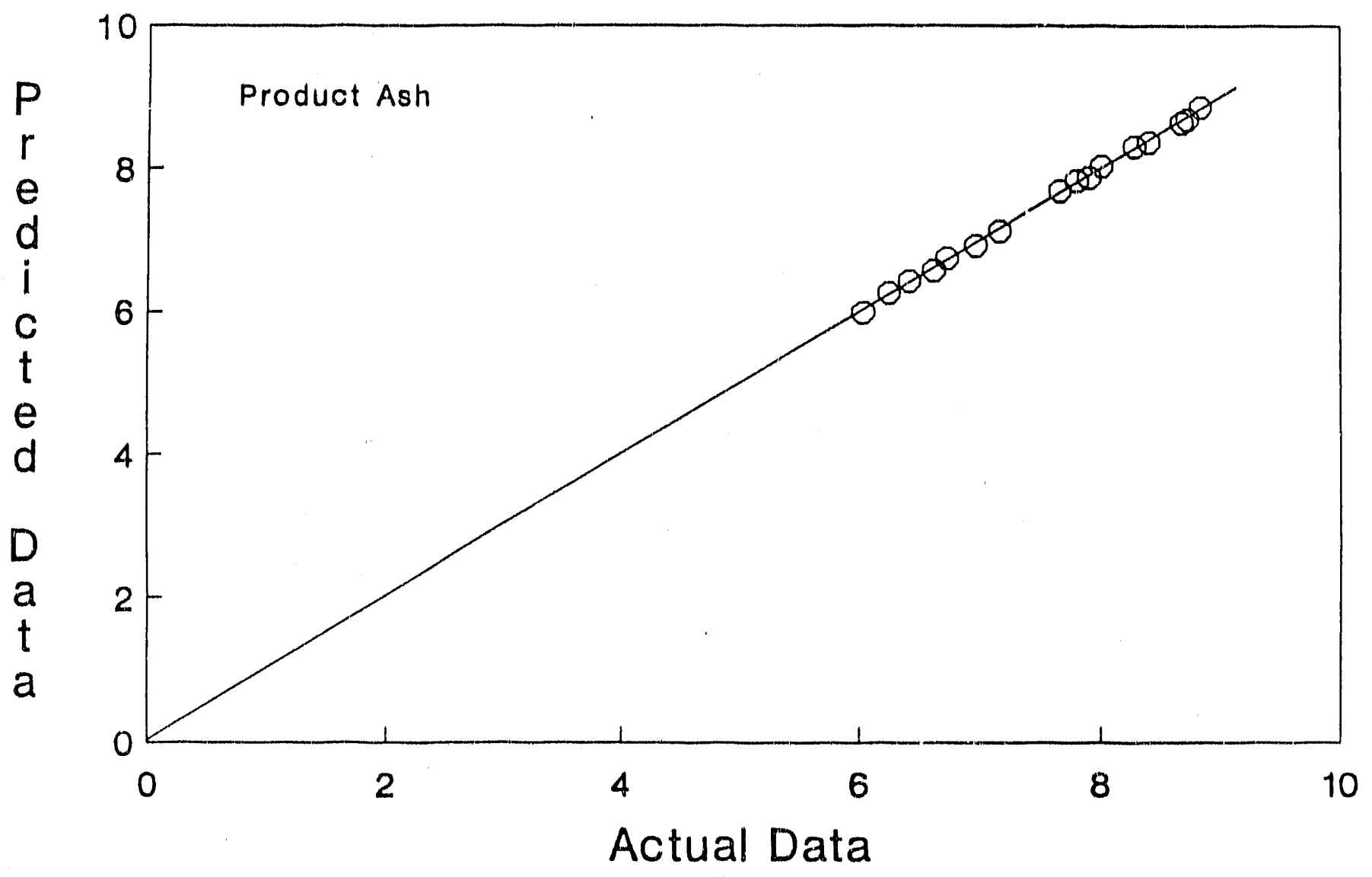

Figure 58. Comparison of experimental results with predictions made by the empirical model developed to describe separation efficiency as a function of the various operating conditions. 


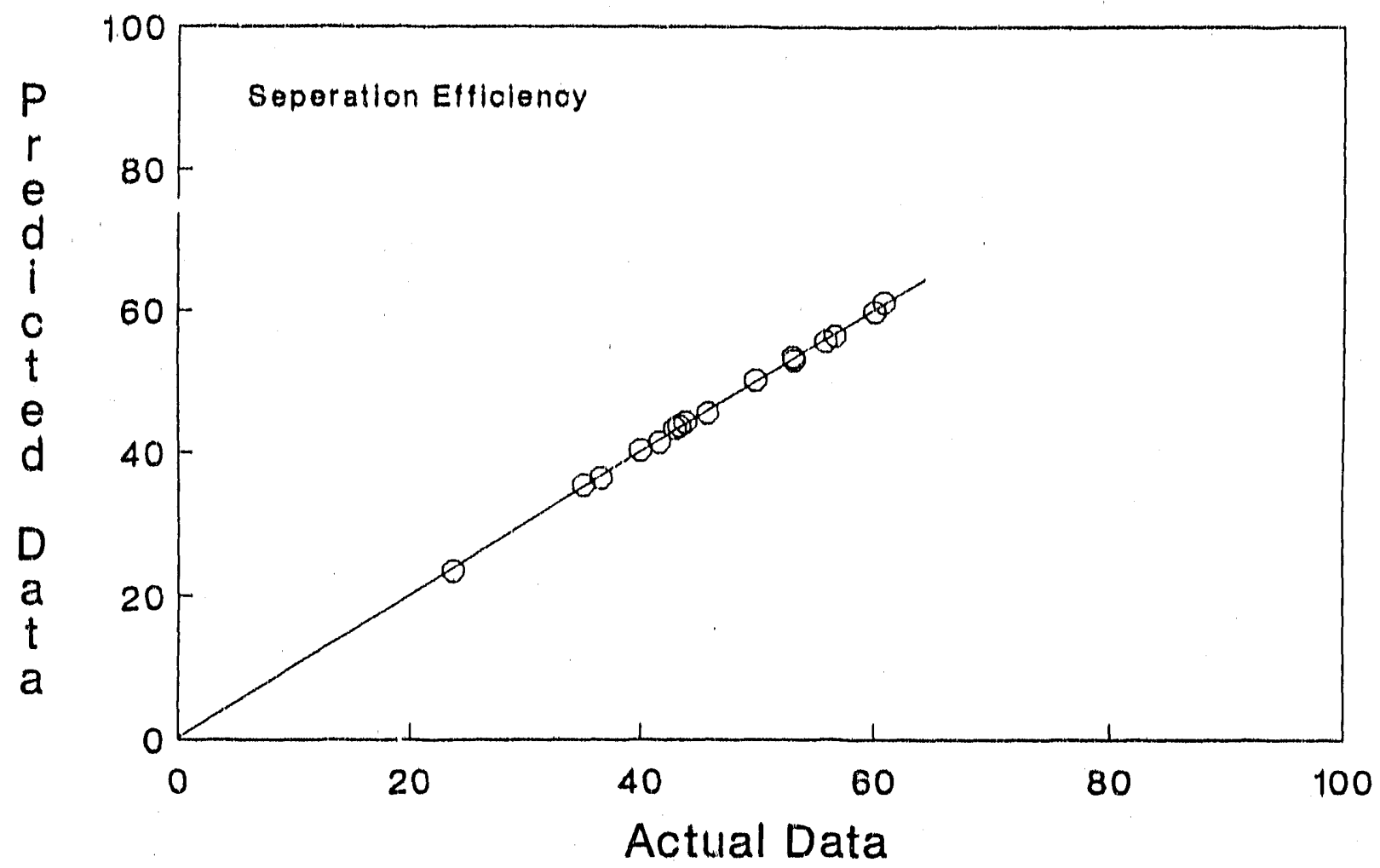

Figure 59. Comparison of experimental results with predictions made by the empirical model developed to describe product ash percent as a function of the various operating conditions.

\section{Response: Product Ash Percent (Figure A)}

An increase in the column aeration rate has a more significant impact on the product ash percent than does frother addition rate. This is probably a result of an increase in water recovery rates as the gas flow rate is increased. As shown in Figure A, however, an increase in wash water addition rate tends to counteract this effect. Figure $\mathrm{A}$ also shows that an increase in collector addition tends to provide a slight increase in product ash percent. This is probably a result of floating an increased quantity of middlings.

\section{Response: Product Yield (Figure B)}

In this instance, both frother addition rate and aeration rate have similar effects on product yield. However, at higher collector additions the yield appears to reach a maximum, 


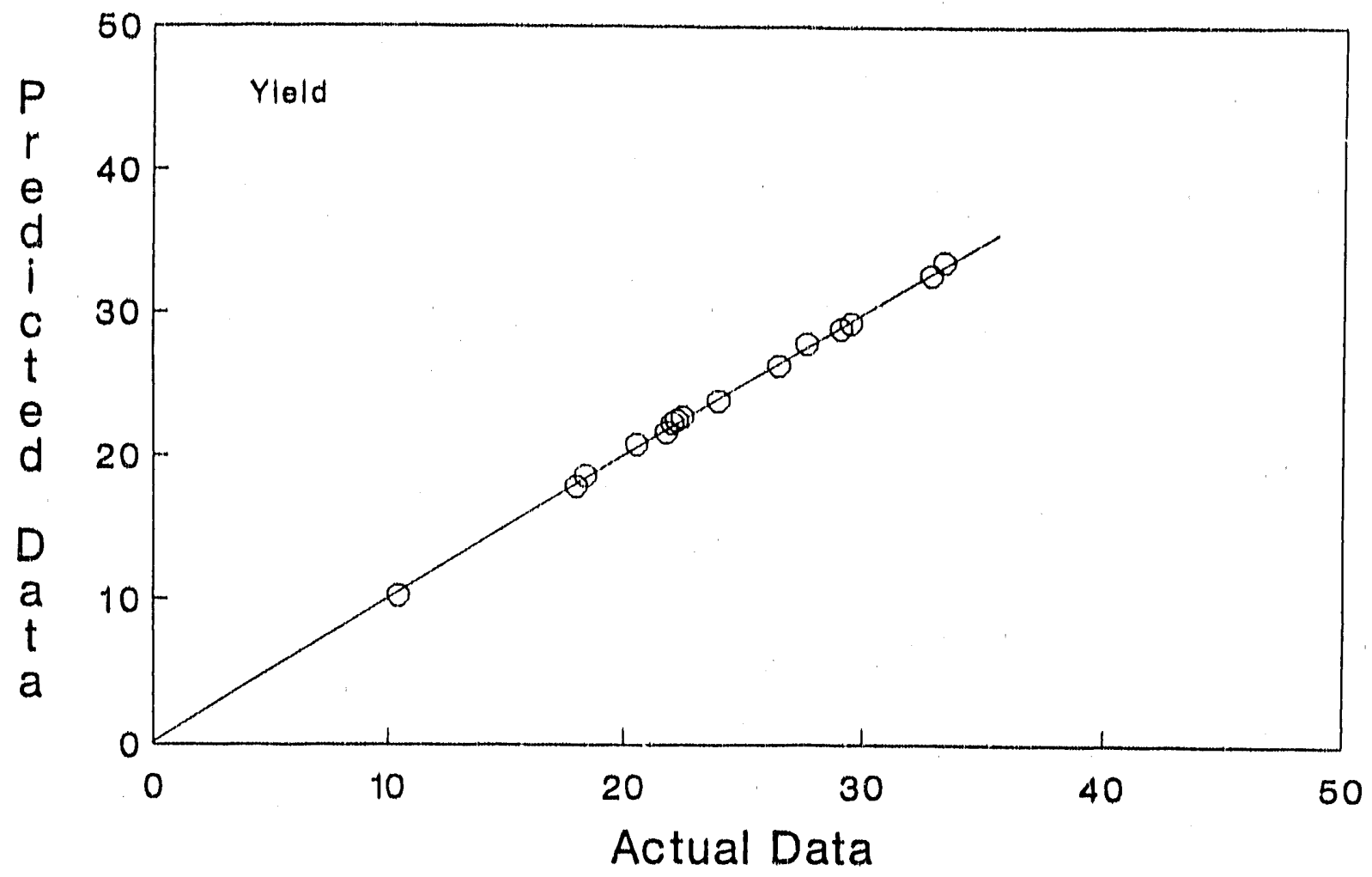

Figure 60. Comparison of experimental results with predictions made by the empirical model developed to describe product yield as a function of the various operating conditions.

at which point an increase in either frother addition or aeration appears to have little effect. An increase in the wash water flow rate tends to slightly reduce product yield. This is probably a result of a decrease in the cell retention time due to the additional water.

\section{Respense: Separation Efficiency (Figure C)}

These response surfaces tend to indicate that an increase in either aeration rate or frother addition rate results in a higher separation efficiency. This is due to the fact that an increase in either parameter results in an increase in recovery. Likewise, as shown in Figure A, only a small increase in product ash is observed over the same range. An increase in collector addition also contributes to an increase in separation efficiency. As described above, this is a result of the increased yield. 


\section{3.e - Scale-Up Validation}

The data collected during the course of the 8-foot test program analyzed in light of the previously described scale-up procedure. In order to validate the previously described scale-up procedure, results for tests conducted on the 8-foot column under similar operating conditions were averaged and compared to the projected scale-up calculations. These values are shown together with the projected values in Table 19.

It should be noted that the measured volumetric feed flow rate and, hence, the superficial rate, are somewhat lower than predicted. This is a result of the increase in feed percent solids during the course of the test program, as indicated in Table 19. This caused a significant increase in the mass of solids in the measured feed to the 8-foot column. Therefore, the feed volumetric flow rate to the 8-foot column was adjusted in order to match the feed solids flow rate on which the scale-up calculations were based.

Table 19. Scale-up predictions for the 8-foot diameter microbubble column flotation cell.

\begin{tabular}{|l|c|c|c|c|c||}
\hline Parameter & $\begin{array}{c}\text { 2-inch } \\
\text { Measured }\end{array}$ & $\begin{array}{c}30 \text {-inch } \\
\text { Predicted }\end{array}$ & $\begin{array}{c}30 \text {-inch } \\
\text { Measured }\end{array}$ & $\begin{array}{c}\text { 8-foot } \\
\text { Predicted }\end{array}$ & $\begin{array}{c}\text { 8-foot } \\
\text { Measured }\end{array}$ \\
\hline $\begin{array}{l}\text { Superficial Feed } \\
\text { Rate }\end{array}$ & $0.82 \mathrm{~cm} / \mathrm{s}$ & $1.59 \mathrm{~cm} / \mathrm{s}$ & $1.69 \mathrm{~cm} / \mathrm{s}$ & $1.55 \mathrm{~cm} / \mathrm{s}$ & $1.24 \mathrm{~cm} / \mathrm{s}$ \\
\hline $\begin{array}{l}\text { Volumetric Flow } \\
\text { Rate }\end{array}$ & $0.26 \mathrm{gpm}$ & $113 \mathrm{gpm}$ & $120 \mathrm{gpm}$ & $1147 \mathrm{gpm}$ & $921 \mathrm{gprn}$ \\
\hline $\begin{array}{l}\text { Feed Mass Flow } \\
\text { Rate }\end{array}$ & $6.7 \mathrm{lb} / \mathrm{hr}$ & $1.44 \mathrm{tph}$ & $1.40 \mathrm{tph}$ & $14.6 \mathrm{tph}$ & $14.6 \mathrm{tph}$ \\
\hline Product Ash & $10.3 \%$ & $10.1 \%$ & $9.46 \%$ & $10.1 \%$ & $7.33 \%$ \\
\hline Recovery & $61.8 \%$ & $61.8 \%$ & $61.2 \%$ & $61.8 \%$ & $59.6 \%$ \\
\hline
\end{tabular}


Although this difference changed the column retention time, it did not affect performance since the 8-foot column was operating under carrying capacity limited conditions. This is supported by the fact that combustible recovery was held constant even though the slurry retention tirne was increased by 25 percent. Normally, under rate limited conditions, the increase in slurry retention time should result in an increased recovery.

Additionally, it is interesting to note that although the combustible recovery dropped slightly, the product yield was constant. This is due to the fact that the increase in percent solids was a result of additional coal and not mineral matter. This can be verified by examining the feed ash percent. During the course of the test period the feed ash averaged 51.9 percent, as compared to 63.7 percent for the 30 -inch parametric test. The increase in percent solids coupled with a decrease in feed ash percent indicates the presence of more coal in the column feed. Accordingly, this will result in a decrease in both combustible recovery and product ash content.

\section{Task 3.4 Cost Analysis}

\section{Task 3.4.a - Data Analysis}

All of the data collected during this investigation have been made available to Shell Mining's engineering staff. This included information on overall column and control system performance, column throughput, product grades and yields, reagent consumption, and scaleup validation. Based on a review of this data with Shell personnel, it was concluded that:

1) Both the 30-inch and 8-foot diameter units had performed as specified by the scale-up procedure.

2) There had been no significant wear to the bubble generators and ancillary mechanical systems on either system. 
3) The PLC-based control system developed for the 8-foot column provided a simple operator interface that was readily accepted by plant personnel.

In addition, the PLC-based control system developed for the 8-foot column provided a simple operator interface that was readily accepted into the plant environment. The design of this system allows for additional flotation columns to be easily incorporated into the existing system.

\section{Task 3.4 - Economic/Cost Analysis}

A detailed economic analysis has been conducted in order to assess the impact of column flotation on total plant economics. This analysis was based on total expenditures and expected revenues for a 10 -foot diameter Microcel column flotation unit, retrofitted into an existing facility. This size of column was selected simply because of the economy of scale (i.e., increased throughput for a minimal cost increase), and was based on cost estimates for different size units provided by Kaiser Engineers. The estimated capital and operating costs for this unit are presented in Table 20. The equipment list includes only those items of equipment and instrumentation that are essential for column operation, and costs were based on actual expenditures incurred during the project. The installation costs also reflect those experienced on this project, i.e. on a retrofit application. Operating costs were based on the predicted performance for one 10-foot diameter column.

Complete cash flow analyses were conducted for several different coal prices. The results of these calculations are presented in Figure 61. This diagram shows the total net cash flow for a ten year period, assuming 10, 20 and 30 percent loss of fine coal during subsequent dewatering of the product. It can be seen that even the worst case $(30 \%$ 
Table 20. Predicted expenditures for one 10-foot diameter Microcel.

\begin{tabular}{||l|c|}
\hline FIXED COST & \\
\hline Column & 85,000 \\
\hline Compressor & 15,000 \\
\hline Ancillary & \\
\hline - Reagent Pumps (2) & 3,000 \\
\hline - Instrumentation & \\
\hline * Control Valve & 1,000 \\
\hline * DP Cell & 1,500 \\
\hline * PID Controller & 500 \\
\hline * Air Flow Meter & 500 \\
\hline * Water Flow Meter & 750 \\
\hline * Actuator Valves (2) & 2000 \\
\hline Total Equipment & 109,250 \\
\hline Installation Costs (@50\%) & 54,625 \\
\hline OPERATING COST (yearly basis) & 19,233 \\
\hline Reagents & 10,925 \\
\hline - Collector & 85,560 \\
\hline - Frother & 190,601 \\
\hline Power & \\
\hline Maintenance (10\% of installed cost) & 19,907 \\
\hline Labor & \\
\hline Total Operating Cost & \\
\hline
\end{tabular}

Note: Collector based on 106,865 tons per year and $0.7 \mathrm{lb} /$ ton \#2 diesel @ \$0.20/1b.

Frother based on 106,865 tons per year and $0.7 \mathrm{lb} /$ ton ShurCoal $214 @ \$ 0.80 / \mathrm{lb}$.

Power expenditures based on $\$ 0.06 / \mathrm{kwh}, 4692 \mathrm{hrs} / \mathrm{year}, 80 \%$ diversity and a total connected power draw of $85.4 \mathrm{HP}$.

Manpower expenditures based on one (1/2 time) class A equipment operator with salary and benefits@55\%. 

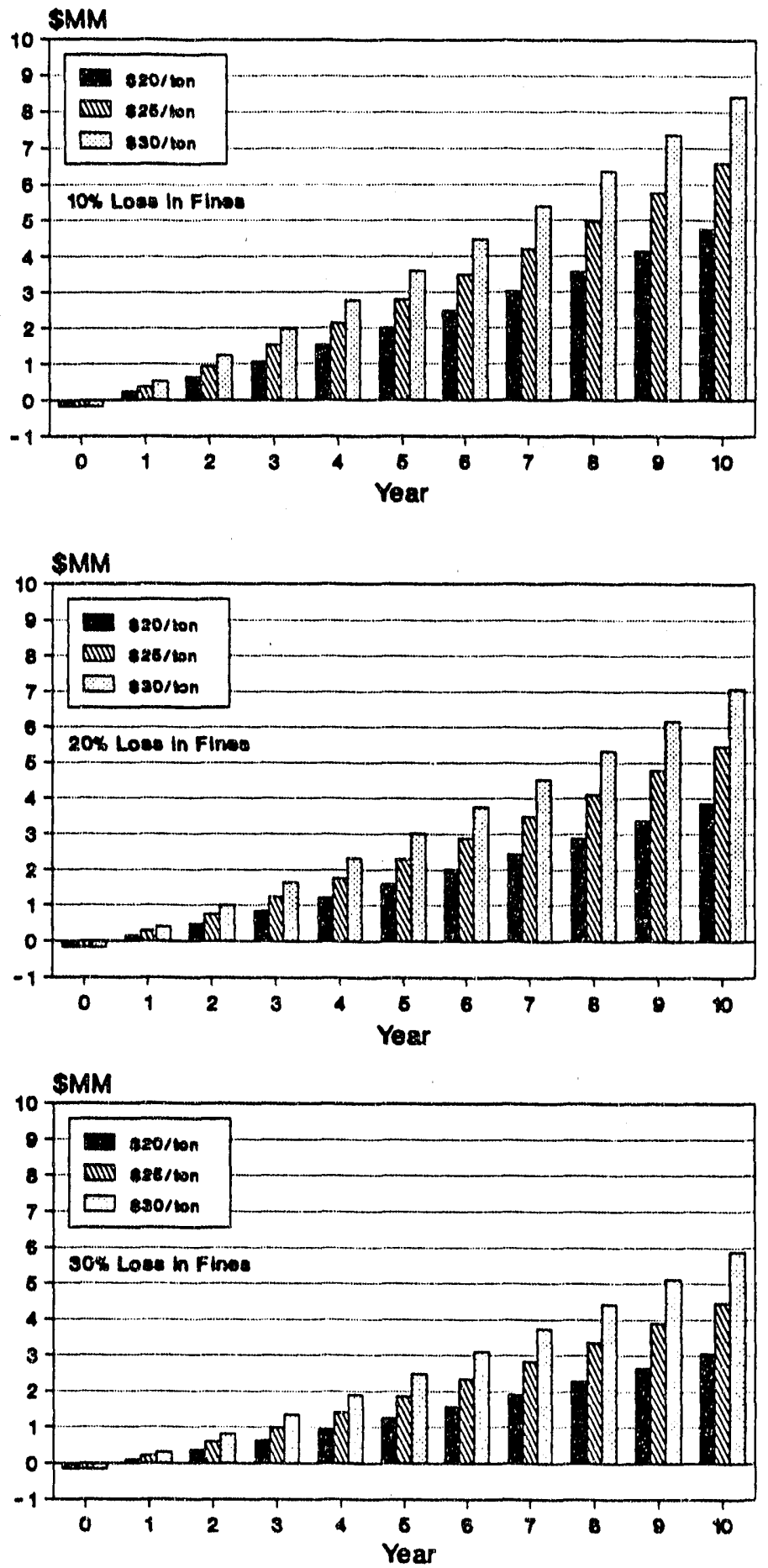

Figure 61. Net cash flow predicted over ten year basis for $: 0,20,30$ percent loss of fines during the dewatering sta',e. 
dewatering losses and $\$ 20 /$ ton) gives an anticipated break-even point of less than one year. To further illustrate this point, the internal rate of return for each cash flow scenario was also determined. These results are illustrated in Figure 62 for different percentages of lost fines. It can be seen from Figure 62 that the internal rate of return is dramatic, ranging from 150 to over 400 percent. The detailed cash flows for each case are presented in Appendix 11.

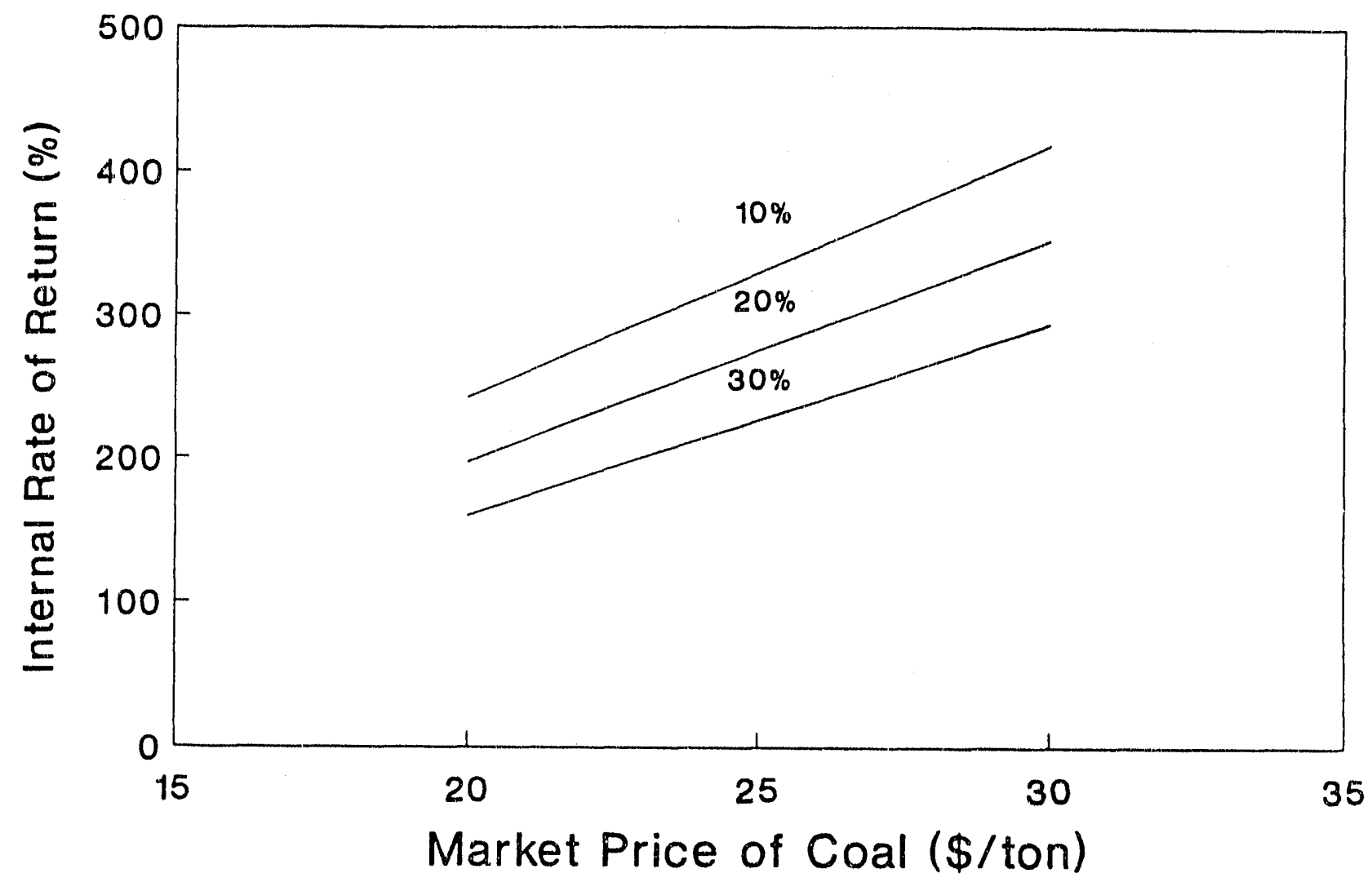

Figure 62. Internal rate of return for various cash flow scenarios, for different percentages of lost fines. 


\section{Task 3.4.c - Assess Future Applications}

The work conducted in the Marrowbone Development Corporation's preparation plant has shown that the Microcel flotation column can be successfully used to treat difficult-toclean, fine coal streams, i.e., streams that are typically rejected by present day preparation plants. The following guidelines can be used when applying the microbubble column flotation process in these situations:

1) Column performance on a given sample closely approaches that predicted by a standard release analysis test on that sample. The release analysis test determines the maximum product yield for a specified product ash content in a flotation separation process, and parallels the washability analysis used to evaluate and specify heavy media separations.

2) The potential performance of a large-scale industrial flotation column can be determined from testwork conducted in a 2-inch laboratory column. Information on factors such as column throughput, reagent addition rates, combustible recovery, product yield and product ash content, can be obtained from these tests and used to design large-scale columns.

3) A flotation column should be designed to operate at its maximum froth carrying capacity. Because froth carrying capacity (or the maximum tons per hour of product per square foot of column area) is strongly influenced by product particle size and density, each column installation will be unique. In general, however, a column processing a -150 mesh cyclone overflow stream will have a much lower throughput than one processing -28 mesh feed.

4) Dewatering of the clean coal product from the column must be given careful consideration. Extremely fine flotation products can be lost during dewatering in the 
typical screen bowl centrifuge and the installation of additional dewatering equipment may markedly increase overall treatment costs. However, even at losses as high as $30 \%$, the payback period on the capital investment remains relatively short.

\section{Task 3.5 Final Recommendations}

Based on the results of this test program, two separate flow sheets were suggested for the Marrowbone column flotation circuit. The first is shown in Figure 63. In this case, the entire -150 mesh cyclone overflow stream is fed directly to a bank of five 10 -foot diameter flotation columns. This scheme will provide an additional 30 to 35 tons per hour of clean coal having an ash content of approximately 8 percent.

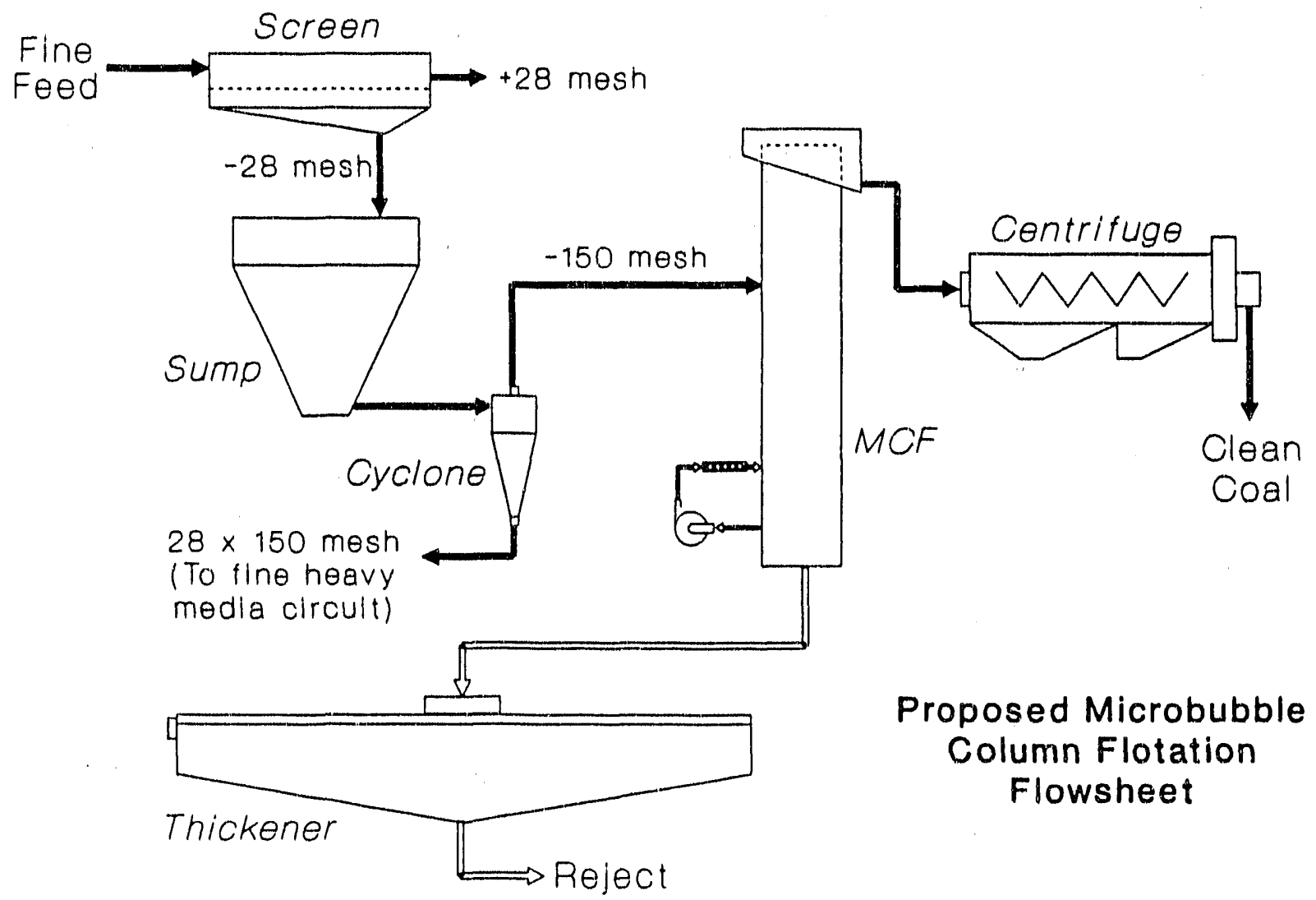

Figure 63. Proposed flowsheet for column flotation of 150 mesh $\times 0$ cyclone overflow material. 
The second conceptual design involves feeding the entire -28 mesh cyclone feed stream directly to column flotation. Currently, the $28 \times 150$ mesh fraction is discharged to a bank of 150 mesh Derrick screens for additional desliming and the screen overflow sent to a fine heavy-media circuit. However, this circuit tends to be expensive to operate due to media losses and excessive screen wear. Therefore, consideration has been given to eliminating the fine heavy media circuit in favor of column flotation. This concept needs to be further validated with additional coarse coal flotation studies. The flowsheet for this arrangement is shown in Figure 64.

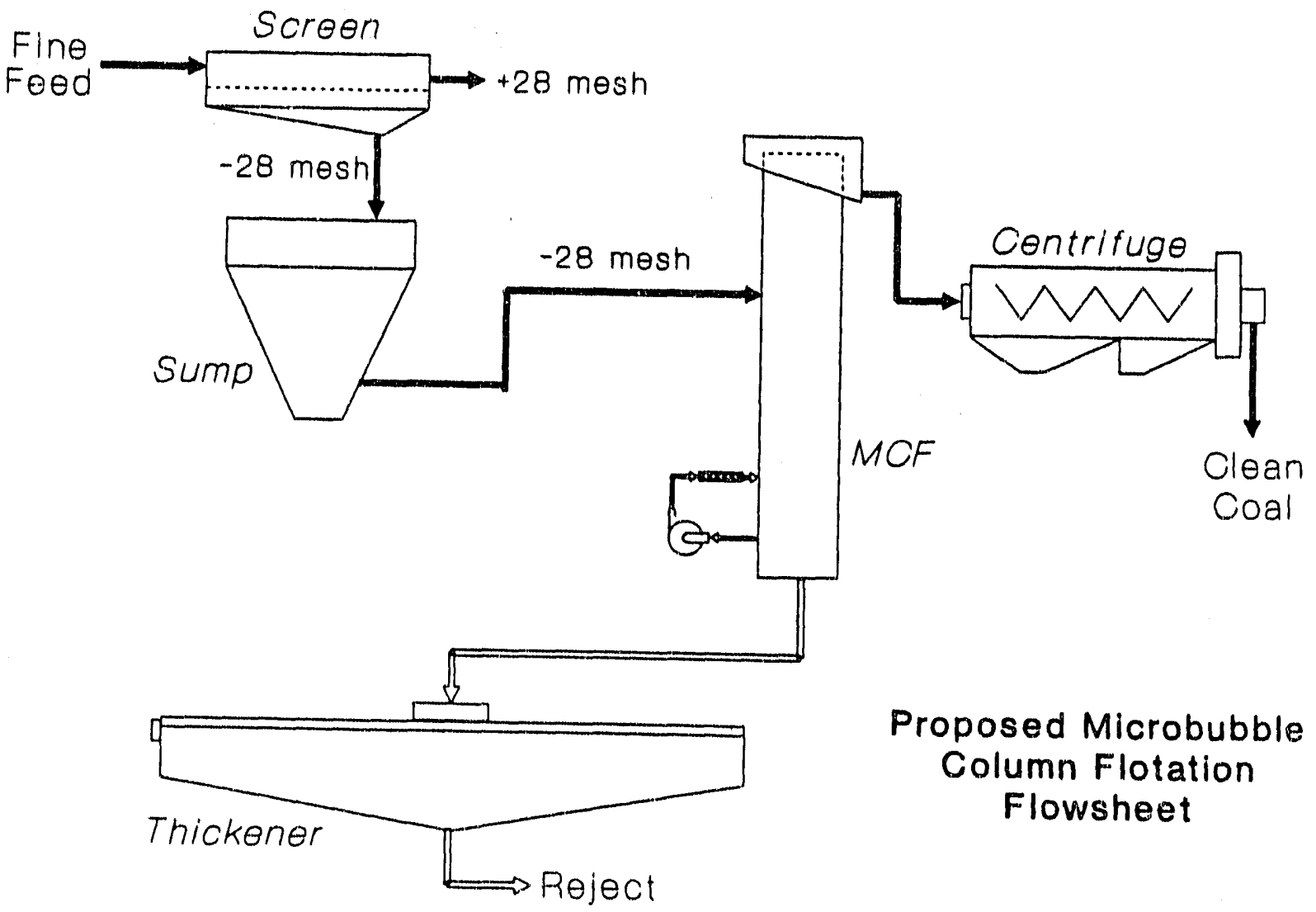

Figure 64. Proposed flowsheet for column flotation of -28 mesh cyclone feed. 


\section{ACKNOWLEDGEMENTS}

The Principal Investigators would like to express their thanks to the Shell Mining Corporation, its Marrowbone Development subsidiary and Dennis Phillips, Senior Mining Engineer, for their support and encouragement of this project. Gratitude is also expressed to Ed Jackson, Elbert "Big E" Hunt, Julie Glavin, Oscar Triplett, and Sam Diamond for their technical assistance throughout the investigation. The investigators wish to thank Richard E. Hucko and Thomas J. Feeley, III, of the DOE's Coal Preparation and Solids Transportation Division, for their advice during the course of this investigation. 


\section{BIBLIOGRAPHY}

C.C. Dell, 1953, "Release Analysis, A New Tool for Ore Dressing Research," Recent Developments in Mineral Dressing, Institution of Mining and Metallurgy, London, pp. 109-118.

C.C. Dell, M.J. Bunyard, W.A. Rickelton and P.A. Young, 1972, "Release Analysis: A Comparison of Techniques," Trans. IMM (Sect. C: Min. Proc. \& Extr. Met.), 81, pp. C89-C96.

M.J. Mankosa, G.A. Adel, G.H. Luttrell and R-H. Yoon, 1990, "Modeling of Column Flotation with a View Toward Scale-Up and Control," Control ' 90 - Mineral and Metallurgical Processing (R.K. Rajamani and J.A. Herbst, Eds.), SME, Inc., Littleton, CO, pp. 35-41.

M.J. Mankosa, G.H. Luttrell, G.T. Adel and R-H. Yoon, 1991, "A Study of Axial Mixing in Column Flotation," accepted for publication: International Journal of Minerals Processing.

S.J. Pratten, C.N. Bensley and S.K. Nicol, 1989, "An Evaluation of the Flotation Response of Coals," International Journal of Mineral Processing, 27, pp. 243-262.

R-H. Yoon, G.T. Adel, G.H. Luttrell and M.J. Mankosa, 1990, "Pilot Scale Testing of Microbubble Flotation," Final Report of Work Performed Under DOE Contract No. DE-AC22-86PC91274, 325 pp. 
Appendix 1: Material balances for the 30-inch column exploratory tests 


\begin{tabular}{|c|l|}
\hline MICROBUBBLE COLUMN FLOTATION TESTWOAK & Date: \\
\hline Sample: Marrowbone Prop. PInt. (Feed Rate) In-Plant & Test No: 1 \\
\hline
\end{tabular}

\begin{tabular}{|l|l|}
\hline Sample Characteristics: & 5.6 \\
\hline Percent Sollds (As Received) & -150 mesh \\
\hline Particle Size & \\
\hline
\end{tabular}

\begin{tabular}{|l|l|}
\hline Column Geometry: & \\
\hline Overall Height (bubble generators to cell lip) & 21.5 foet \\
\hline Diameter & 29.25 inches \\
\hline Feed Entry Point & 4.5 feet \\
\hline Froth Height & 40 inches \\
\hline
\end{tabular}

\begin{tabular}{|l|l|l|}
\hline Reagent Additions: & \multicolumn{1}{|c|}{ Dosage (lbs/ton) } & \multicolumn{1}{|c|}{ Type } \\
\hline Collector & 0.77 & Diesel \\
\hline Frother & 1.09 & DF1012 \\
\hline pH Modifier & & \\
\hline Dispersant & & \\
\hline
\end{tabular}

\begin{tabular}{|l|l|l|l|}
\hline Column Flows: & \multicolumn{1}{|c|}{$\mathrm{gpm}$} & $\mathrm{gms} / \mathrm{min}$ & $\%$ solids \\
\hline Gas Flowrate & 16.4 (sofml & & \\
\hline Wash Water Flowrate & 21 & & \\
\hline Foed Flowrate & 78 & & \\
\hline Product Flowrate & & & \\
\hline Reject (Tailings) Flowrate & & & \\
\hline
\end{tabular}

\begin{tabular}{|c|c|c|c|c|c|}
\hline Assays: & $A \sin (\%)$ & Comb. $(\%)$ & Tot. $5(\%)$ & Pyr. S $(\%)$ & Btu/h \\
\hline Product & 9.72 & 90.28 & & & \\
\hline Reject & 81.18 & 18.82 & & & \\
\hline Foed & 60.76 & 39.24 & & & \\
\hline
\end{tabular}

\begin{tabular}{|c|c|c|c|c|c|c|}
\hline Recoveries $(\%)$ : & Yiold & Ash & Comb. & Tot. $\mathrm{S}$ & Pyr, S & Btu \\
\hline Product & 28.58 & 4.57 & 65.74 & & & \\
\hline Neject & 71.42 & 95.43 & 34.26 & & & \\
\hline Foed & 100 & 100 & 100 & 900 & 100 & 100 \\
\hline
\end{tabular}




\begin{tabular}{|c|l|}
\hline MICROBUBBLE COLUMN FLOTATION TESTWOFK & Date: \\
\hline Sample: Marrowbone Prop. Plant (Feed Rate) In Plant & Tost No: 2 \\
\hline
\end{tabular}

\begin{tabular}{|l|l||}
\hline Sample Characteristics: & \\
\hline Percent Solids (As Rocelved) & 5.6 \\
\hline Particle Slze & -150 mesh \\
\hline
\end{tabular}

\begin{tabular}{|l|l|}
\hline Column Geometry: & 21.5 feet \\
\hline Overall Height (bubble generators to cell lip) & 29.25 inches \\
\hline Diameter & 4.5 feet \\
\hline Feed Entry Point & 40 inches \\
\hline Froth Height & \\
\hline
\end{tabular}

\begin{tabular}{|l|l|l|}
\hline Reogent Additions: & \multicolumn{1}{|c|}{ Dosage (lbs/ton) } & \multicolumn{1}{|c|}{ Type } \\
\hline Collector & 1.13 & Diesel \\
\hline Frother & 1.59 & DF1012 \\
\hline pH Modifier & & \\
\hline Dispersant & & \\
\hline
\end{tabular}

\begin{tabular}{|l|c|c|c|}
\hline Column Flows: & opm & oms/min & \%olids \\
\hline Gas Flowrate & 16.4 (scfm) & & \\
\hline Wash Water Flowrate & 21 & & \\
\hline Feed Flowrate & 100 & & \\
\hline Product Flowrate & & & \\
\hline Bejoct (Tallings) Flowrate & & & \\
\hline
\end{tabular}

\begin{tabular}{|l|r|r|r|r|r|}
\hline Assays: & Ash $(\%)$ & Comb. $(\%)$ & Tot. S $(\%)$ & Pyr. S $(\%)$ & Btu/b \\
\hline Product & 8.06 & 91.94 & & & \\
\hline Roject & 72.74 & 27.26 & & & \\
\hline Foed & 51.49 & 48.51 & & & \\
\hline
\end{tabular}

\begin{tabular}{|l|c|c|c|c|c|c|}
\hline Recoveries (\%): & Yield & Ash & Comb. & Tot. S & Pyr. S & Btu \\
\hline Product & 32.85 & 5.14 & 62.27 & & & \\
\hline Reject & 61.15 & 94.86 & 37.73 & & & \\
\hline Foed & 100 & 100 & 100 & 100 & 100 \\
\hline
\end{tabular}




\begin{tabular}{|l|l|}
\hline MICROBUBBLE COLUMN FLOTATION TESTWOHK & Date: \\
\hline Sample: Marrowbone Prep. Plant (Feed Rate) In-Plant & Test No: 3 \\
\hline
\end{tabular}

\begin{tabular}{|l|l|}
\hline Sample Characteristius: & \\
\hline Porcont Solids (As Rocelved) & 5.6 \\
\hline Partiole Size & -150 mesh \\
\hline
\end{tabular}

\begin{tabular}{|c|c|c|}
\hline \multicolumn{3}{|l|}{ Column Geometry: } \\
\hline \multicolumn{2}{|c|}{ Overall Helght (bubble generators to cell ||p) } & 21.5 feet \\
\hline \multicolumn{2}{|l|}{ Diameter } & 29.25 inches \\
\hline \multicolumn{2}{|l|}{ Foed Entry Point } & 4.5 feet \\
\hline \multicolumn{2}{|l|}{ Froth Helght } & 40 inches \\
\hline Reagent Additions: & Dosage (lbs/ton) & Type \\
\hline Collector & 0.77 & Diesel \\
\hline Frother & 1.09 & DF1012 \\
\hline \multicolumn{3}{|l|}{ pH Modifier } \\
\hline Dispersarit & & \\
\hline
\end{tabular}

\begin{tabular}{||l|l|c|c|}
\hline Column Flows: & opm & oms/min & \% solids \\
\hline Gas Flowrate & 16.1 (scfm) & & \\
\hline Wash Water Flowrate & 21 & & \\
\hline Feed Flowrate & 120 & & \\
\hline Product Flowrate & & & \\
\hline Reject (Tailings) Flowrate & & & \\
\hline
\end{tabular}

\begin{tabular}{|l|r|r|r|r|r|}
\hline Assays: & Ash $(\%)$ & Comb. (\%) & Tot. S $(\%)$ & Pyr. S $(\%)$ & Btu/lb \\
\hline Product & 8.96 & 91.04 & & & \\
\hline Reject & 76.05 & 23.95 & & & \\
\hline Feed & 57.58 & 42.42 & & & \\
\hline
\end{tabular}

\begin{tabular}{|l|c|c|c|c|c|c|}
\hline Recoveries $(\%):$ & Yieid & Ash & Comb. & Tot. S & Pyr. S & Btu \\
\hline Product & 27.53 & 4.28 & 59.08 & & \\
\hline Reject & 72.47 & 95.72 & 40.92 & & & \\
\hline Feed & 100 & 100 & 100 & 100 & 100 & 100 \\
\hline
\end{tabular}




\begin{tabular}{|l|l|}
\hline MICROBUBBLE COLUMN FLOTATION TESTWORK & Dato: \\
\hline Sample: Marrowbone Prop. Plant (Aeration Rate) In-Plant & Test No: 1 \\
\hline
\end{tabular}

\begin{tabular}{|l|l|}
\hline Sample Characteristios: \\
\hline Porcent Solids (As Received) & 5.6 \\
\hline Particle Size & -150 mesh \\
\hline
\end{tabular}

\begin{tabular}{|l|l|}
\hline Column Geometry: & 21.5 feet \\
\hline Overall Heigti (bubble generators to cell lip) & 29.25 inches \\
\hline Diameter & 4.5 foet \\
\hline Foed Entry Point & 30 inches \\
\hline Froth Height & \\
\hline
\end{tabular}

\begin{tabular}{|l|l|l|}
\hline Reagent Additions: & \multicolumn{1}{|c|}{ Dosage llbs/ton) } & \multicolumn{1}{c|}{ Type } \\
\hline Collector & 1.11 & Diesel \\
\hline Frother & 1.58 & DF1012 \\
\hline pH Modifier & & \\
\hline Dispersant & & \\
\hline
\end{tabular}

\begin{tabular}{|l|l|l|l|}
\hline Column Flows: & \multicolumn{1}{|c|}{$\mathrm{gpm}$} & gms/min & $\%$ solids \\
\hline Gas Flowrate & 12.3 (scfm) & & \\
\hline Wash Water Flowrate & 21 & & \\
\hline Foed Flowrate & 100 & & \\
\hline Product Flowrate & & & \\
\hline Roject (Tailings) Flowrate & & & \\
\hline
\end{tabular}

\begin{tabular}{|l|r|r|r|r|r|}
\hline Assays: & Ash (\%) & Comb. (\%) & Tot. S (\%) & Pyr. S (\%) & Btu/lb \\
\hline Product & 8.02 & 91.98 & & & \\
\hline Reject & 75.39 & 24.81 & & & \\
\hline Feed & 55.29 & 44.71 & & & \\
\hline
\end{tabular}

\begin{tabular}{|l|c|c|c|c|c|c|}
\hline Recoveries (\%): & Yiald & Ash & Comb. & Tot. S & Pyr. S & Btu \\
\hline Product & 29.74 & 4.31 & 61.19 & & & \\
\hline Roject & 70.26 & 95.69 & 38.81 & & & \\
\hline Foed & 100 & 100 & 100 & 100 & 100 & 100 \\
\hline
\end{tabular}




\begin{tabular}{|c|c|c|}
\hline MICROBUBBLE COLUMN FLOTATION TESTWORK & Date: \\
\hline Sample: Marrowbone Prep. Plant (Aeration Rate) In-Plant & Test No: 2 \\
\hline
\end{tabular}

\begin{tabular}{||l|l|}
\hline Sample Characteristics: \\
\hline Percent Solids (As Received) & 5.6 \\
\hline Particle Size & $-150 \mathrm{mesh}$ \\
\hline
\end{tabular}

\begin{tabular}{|l|l|}
\hline Column Geometry: & \\
\hline Overall Height (bubble generators to cell lip) & 21.5 feet \\
\hline Diameter & 29.25 inches \\
\hline Feed Entry Point & 4.5 feet \\
\hline Froth Height & 40 inches \\
\hline
\end{tabular}

\begin{tabular}{||l|l|l||}
\hline Reagent Additions: $\because$ & \multicolumn{1}{|c|}{ Dosage (lbs/ton) } & \multicolumn{1}{c|}{ Type } \\
\hline Collector & 1.13 & Diesel \\
\hline Frother & 1.59 & DF1012 \\
\hline pH Modifier & & \\
\hline Dispersant & & \\
\hline
\end{tabular}

\begin{tabular}{|l|l|l|l|}
\hline Column Flows: & \multicolumn{1}{|c|}{ opm } & oms/min & $\%$ solids \\
\hline Gas Flowrate & 16.4 (scfm) & & \\
\hline Wash Water Flowrate & 21 & & \\
\hline Feed Flowrate & 100 & & \\
\hline Product Flowrate & & & \\
\hline Rejact (Tailings) Flowrate & & & \\
\hline
\end{tabular}

\begin{tabular}{|c|c|c|c|c|c|}
\hline Assays: & Ash (ㄸ? & $\begin{array}{c}\text { Comb. } \\
\left|\psi_{0}\right|\end{array}$ & Tot. $S(\%)$ & Pyr. S $(\%)$ & Btu/lb \\
\hline Product & 8.06 & 91.94 & & & \\
\hline Reject & 72.74 & 27.26 & & & \\
\hline Feed & 55.29 & 44.71 & & & \\
\hline
\end{tabular}

\begin{tabular}{|l|c|c|c|c|c|c|}
\hline Recoveries (\%): & Yield & Ash & Comb. & Tot. S & Pyr. S & Btu \\
\hline Product & 32.85 & 4.79 & 62.27 & & & \\
\hline Reject & 61.15 & 95.21 & 37.73 & & & \\
\hline Feed & 100 & 100 & 100 & 100 & 100 & 100 \\
\hline
\end{tabular}




\begin{tabular}{|l|l|}
\hline \multicolumn{1}{|c|}{ MICROBUBBLE COLUMN FLOTATION TESTWORK } & Date: \\
\hline Sample: Marrowbone Prep. Plant (Aeration Rate) In-Plant & Test No: 3 \\
\hline
\end{tabular}

\begin{tabular}{||l|l|}
\hline Sample Characteristics: & \\
\hline Parcent Solids (As Received) & 5.6 \\
\hline Particle Size & -150 mesh \\
\hline
\end{tabular}

\begin{tabular}{|l|l|}
\hline Column Geometry: & 21.5 feet \\
\hline Overall Height (bubble generators to cell lip) & 29.25 inches \\
\hline Diameter & 4.5 feet \\
\hline Feed Entry Point & 40 inches \\
\hline Froth Height & \\
\hline
\end{tabular}

\begin{tabular}{||l|l|l|}
\hline Reagent Additions: & \multicolumn{1}{|c|}{ Dosage (lbs/ton) } & \multicolumn{1}{|c|}{ Type } \\
\hline Collector & 0.85 & Diesel \\
\hline Frother & 1.20 & DF1012 \\
\hline pH Modifier & & \\
\hline Dispersant & & \\
\hline
\end{tabular}

\begin{tabular}{|l|l|l|l|}
\hline Column Flows: & \multicolumn{1}{|c|}{ gpm } & gms/min & $\%$ solids \\
\hline Gas Flowrate & 19.9 (scfm) & & \\
\hline Wash Water Flowrate & 21 & & \\
\hline Foed Flowrate & 100 & & \\
\hline Product Flowrate & & & \\
\hline Reject (Tailings) Flowrate & & & \\
\hline
\end{tabular}

\begin{tabular}{|l|r|r|r|r|}
\hline Assays: & Ash $(\%)$ & Comb. (\%) & Tot. S (\%) & Pyr. S (\%) \\
\hline Product & 10.52 & 89.48 & & \\
\hline Reject & 78.94 & 21.06 & & \\
\hline Foed & 60.43 & 39.57 & & \\
\hline
\end{tabular}

\begin{tabular}{|c|c|c|c|c|c|c|}
\hline Recoveries (\%): & Yieild & Ash & Comb. & Tot. $\mathbf{S}$ & Pyr. S & Btu \\
\hline Product & 27.05 & 3.60 & 61.18 & & & \\
\hline Reject & 72.95 & 96.4 & 38.82 & & & \\
\hline Foed & 100 & 100 & 100 & 100 & 100 & 100 \\
\hline
\end{tabular}




\begin{tabular}{|l|l|l|}
\hline \multicolumn{1}{|c|}{ MICROBUBBLE COLUMN FLOTATION TESTWORK } & Date: \\
\hline Sample: Marrowbone Prep. Plant (Froth Height) In-Plant & Test No: 1 \\
\hline Sample Characteristics: & 5.6 \\
\hline Percent Solids (As Received) & $-150 \mathrm{mesh}$ \\
\hline Particle Size
\end{tabular}

\begin{tabular}{|l|l|}
\hline Column Geometry: & 21.5 feet \\
\hline Overall Height (bubble generators to cell lip) & 29.25 inches \\
\hline Diemeter & 4.5 feet \\
\hline Feed Entry Point & 31 inches \\
\hline Froth Height & \\
\hline
\end{tabular}

\begin{tabular}{||l|l|l||}
\hline Reagent Additions: & \multicolumn{1}{|c|}{ Dosage (lbs/ton) } & \multicolumn{1}{c|}{ Type } \\
\hline Collector & 0.99 & Diesel \\
\hline Frother & 1.40 & DF1012 \\
\hline pH Modifier & & \\
\hline Dispersant & & \\
\hline
\end{tabular}

\begin{tabular}{||l|l|l|l|}
\hline Column Flows: & \multicolumn{1}{|c|}{ opm } & \multicolumn{1}{c|}{ oms/min } & \% solids \\
\hline Gas Flowrate & 16.4 (scfm) & & \\
\hline Wash Water Flowrate & 21 & & \\
\hline Feed Flowrate & 100 & & \\
\hline Product Flowrate & & & \\
\hline Reject (Tailings) Flowrate & & & \\
\hline
\end{tabular}

\begin{tabular}{|l|r|r|r|r|r|}
\hline Assays: & Ash (\%) & Comb. (\%) & Tot. S (\%) & Pyr. S (\%) & Btu/lb \\
\hline Product & 7.41 & 92.59 & & & \\
\hline Reject & 69.65 & 30.35 & & & \\
\hline Feed & 53.27 & 46.73 & & & \\
\hline
\end{tabular}

\begin{tabular}{|l|c|c|c|c|c|c||}
\hline Recoveries (\%): & Yield & Ash & Comb. & Tot. S & Pyr. S & Btu \\
\hline Product & 26.32 & 3.66 & 52.15 & & & \\
\hline Reject & 73.68 & 96.34 & 47.85 & & & \\
\hline Feed & 100 & 100 & 100 & 100 & 100 & 100 \\
\hline
\end{tabular}




\begin{tabular}{|l|l|}
\hline \multicolumn{1}{|c|}{ MICROBUBBLE COLUMN FLOTATION TESTWORK } & Date: \\
\hline Sample: Marrowbone Prop. Plant (Froth Height) In-Plant & Test No: 2 \\
\hline
\end{tabular}

\begin{tabular}{|l|l|}
\hline Sample Characteristics: \\
\hline Porcant Solids (As Received) & 5.6 \\
\hline Particle Size & -150 mesh \\
\hline
\end{tabular}

\begin{tabular}{|l|l|}
\hline Column Geometry: & 21.5 feet \\
\hline Overall Height (bubble generators to cell lip) & 29.25 inches \\
\hline Dismeter & 4.5 foet \\
\hline Foed Entry Point & 40 inches \\
\hline Froth Hoight & \\
\hline
\end{tabular}

\begin{tabular}{||l|l|l||}
\hline Reagent Additions: & \multicolumn{1}{|c|}{ Dosage (lbs/ton) } & \multicolumn{1}{c|}{ Type } \\
\hline Collector & 1.13 & Diesel \\
\hline Frother & 1.59 & DF1012 \\
\hline pH Modifier & & \\
\hline Dispersant & & \\
\hline
\end{tabular}

\begin{tabular}{|l|l|l|l|}
\hline Column Flows: & \multicolumn{1}{|c|}{ opm } & gms/min & $\%$ solids \\
\hline Gas Flowrate & 16.4 (scfm) & & \\
\hline Wash Water Flowrate & 21 & & \\
\hline Foed Flowrate & 100 & & \\
\hline Product Flowrate & & & \\
\hline Reject Tailings) Flowrate & & & \\
\hline
\end{tabular}

\begin{tabular}{|l|r|r|r|r|r|}
\hline Assays: & Ash (\%) & Comb. (\%) & Tot. S (\%) & Pyr. S (\%) & Btunb \\
\hline Product & 8.06 & 91.94 & & & \\
\hline Reject & 72.74 & 27.26 & & & \\
\hline Foed & 51.49 & 48.51 & & & \\
\hline
\end{tabular}

\begin{tabular}{|c|c|c|c|c|c|c|}
\hline Recoveries (\%): & Yield & Ash & Comb. & Tot. $\mathbf{S}$ & Pyr. S & Btu \\
\hline Product & 32.85 & 5.14 & 62.27 & & & \\
\hline Reject & 61.15 & 94.86 & 37.73 & & & \\
\hline Feed & 100 & 100 & 100 & 100 & 100 & 100 \\
\hline
\end{tabular}




\begin{tabular}{|l|l|}
\hline MICROBUBBLE COLUMN FLOTATION TESTWORK & Date: \\
\hline Sample: Marrowbone Prep. Plant (Froth Height) In-Plant & Test No: 3 \\
\hline
\end{tabular}

\begin{tabular}{|l|l|}
\hline Sample Characteristics: \\
\hline Percent Solids (As Received) & 5.6 \\
\hline Particle Size & $-150 \mathrm{mesh}$ \\
\hline
\end{tabular}

\begin{tabular}{||l|l|}
\hline Column Geometry: & 21.5 feet \\
\hline Overall Height (bubble generators to cell lip) & 29.25 inches \\
\hline Diameter & 4.5 feet \\
\hline Feed Entry Point & 46 inches \\
\hline Froth Height & \\
\hline
\end{tabular}

\begin{tabular}{|l|l|l|}
\hline Reagent Additions: & \multicolumn{1}{|c|}{ Dosage (lbs/ton) } & \multicolumn{1}{|c|}{ Type } \\
\hline Collector & 1.22 & Diesel \\
\hline Frother & 1.72 & DF1012 \\
\hline pH Modifier & & \\
\hline Dispersant & & \\
\hline
\end{tabular}

\begin{tabular}{|l|l|l|l||}
\hline Column Flows: & \multicolumn{1}{|c|}{$\mathrm{gpm}$} & gms/min & $\%$ solids \\
\hline Gas Flowrate & $16.4(\mathrm{scfm})$ & & \\
\hline Wash Water Flowrate & 21 & & \\
\hline Feed Flowrate & 100 & & \\
\hline Product Flowrate & & & \\
\hline Reject (Tailings) Flowrate & & & \\
\hline
\end{tabular}

\begin{tabular}{|l|r|r|r|r|r|}
\hline Assays: & Ash (\%) & Comb. (\%) & Tot. S (\%) & Pyr. S (\%) & Btu/b \\
\hline Product & 8.19 & 91.81 & & & \\
\hline Reject & 77.92 & 22.08 & & & \\
\hline Feed & 55.37 & 44.63 & & & \\
\hline
\end{tabular}

\begin{tabular}{|l|c|c|c|c|c|c|}
\hline Recoveries (\%): & Yield & Ash & Comb. & Tot. S & Pyr. S & Btu \\
\hline Product & 32.34 & 4.78 & 66.53 & & & \\
\hline Reject & 67.66 & 95.22 & 33.47 & & & \\
\hline Feed & 100 & 100 & 100 & 100 & 100 & 100 \\
\hline
\end{tabular}


Appendix 2: Material balances for the 30-inch column long-term test 


\begin{tabular}{|l|l||}
\hline MICROBUBBLE COLUMN FLOTATION TESTWOAK & Date: \\
\hline Sample: Marrowbone Prep. Plt. (Long-Term) In-Plant & Tost No: 1 \\
\hline
\end{tabular}

\begin{tabular}{|l|l||}
\hline Sample Characteristics: \\
\hline Percent Solids (As Received) & 3.56 \\
\hline Particle Size & -150 mesh \\
\hline
\end{tabular}

\section{Column Geometry:}

Overall Height (bubble generators to cell lip)

21.5 feet

Diameter

29.25 inches

Foed Entry Point

4.5 feet

Froth Height

40 inches

\begin{tabular}{|l|l|l|}
\hline Reagent Additions: & \multicolumn{1}{|c|}{ Dosage (lbs/ton) } & \multicolumn{1}{|c|}{ Type } \\
\hline Collector & 1.26 & Diesel \\
\hline Frother & 2.50 & DF1012 \\
\hline pH Modifier & & \\
\hline Dispersant & & \\
\hline
\end{tabular}

\begin{tabular}{||l|l|l|l||}
\hline Column Flows: & \multicolumn{1}{|c|}{ opm } & \multicolumn{1}{c|}{ gms/min } & \% solids \\
\hline Gas Flowrate & 17.2 (sctm) & & \\
\hline Wash Water Flowrate & 20 & & \\
\hline Feed Flowrate & 98 & & \\
\hline Product Flowrate & & & \\
\hline Reject (Tailings) Flowrate & & & \\
\hline
\end{tabular}

\begin{tabular}{|l|r|r|r|r|r||}
\hline Assays: & Ash $(\%)$ & Comb. $(\%)$ & Tot. S (\%) & Pyr. S (\%) & Btu/b \\
\hline Product & 9.85 & 90.15 & & & \\
\hline Reject & 78.50 & 21.50 & & & \\
\hline Feed & 57.91 & 42.09 & & & \\
\hline
\end{tabular}

\begin{tabular}{||l|c|c|c|c|c|c|}
\hline Recoveries (\%): & Yield & Ash & Comb. & Tot. S & Pyr. S & Btu \\
\hline Product & 29.99 & 5.10 & 64.24 & & & \\
\hline Reject & 70.01 & 94.90 & 35.76 & & & \\
\hline Feed & 100 & 100 & 100 & 100 & 100 & 100 \\
\hline
\end{tabular}




\begin{tabular}{|l|l|}
\hline MICROBUBBLE COLUMN FLOTATION TESTWORK & Date: \\
\hline Sample: Marrowbone Prep. Plt. (Long-Term) In-Plant & Test No: 2 \\
\hline
\end{tabular}

\begin{tabular}{|l|l|}
\hline Sample Characteristics: & 4.13 \\
\hline Percent Solids (Ao Received) & -150 mesh \\
\hline Particle Size & \\
\hline Column Geometry: & 21.5 feet \\
\hline Overall Height (bubble generators to cell lip) & 29.25 inches \\
\hline Diameter & 4.5 feet \\
\hline Foed Entry Point & 40 inches \\
\hline Froth Height &
\end{tabular}

\begin{tabular}{||l|l|l|}
\hline Reagent Additions: & \multicolumn{1}{|c|}{ Dosage (lbs/ton) } & \multicolumn{1}{c|}{ Type } \\
\hline Collector & 1.08 & Diesel \\
\hline Frother & 1.52 & DF1012 \\
\hline pH Modifier & & \\
\hline Dispersant & & \\
\hline
\end{tabular}

\begin{tabular}{|l|l|l|l|}
\hline Column Flows: & \multicolumn{1}{|c|}{ gpm } & oms/min & $\%$ solids \\
\hline Gas Flowrate & $16.8(\mathrm{scfm})$ & \\
\hline Wash Water Flowrate & 21 & & \\
\hline Food Flowrate & 98 & & \\
\hline Product Flowrate & & & \\
\hline Reject (Tailings) Flowrate & & & \\
\hline
\end{tabular}

\begin{tabular}{|l|r|r|r|r|r|}
\hline Assays: & Ash $(\%)$ & Comb. (\%) & Tot. S (\%) & Pyr. S $(\%)$ & Btu/lb \\
\hline Product & 9.44 & 90.56 & & & \\
\hline Reject & 78.21 & 21.79 & & & \\
\hline Foed & 57.79 & 42.21 & & & \\
\hline
\end{tabular}

\begin{tabular}{|c|c|c|c|c|c|c|}
\hline Recoveries $(\%)$ : & Yiold & Ash & Comb. & Tot. $\mathrm{S}$ & Pyr. S & Btu \\
\hline Product & 29.69 & 4.87 & 63.71 & & & \\
\hline Roject & 70.31 & 95.13 & 36.29 & & & \\
\hline Foed & 100 & 100 & 100 & 100 & 100 & 100 \\
\hline
\end{tabular}




\begin{tabular}{|c|l|}
\hline MICROBUBBLE COLUMN FLOTATION TESTWORK & Date: \\
\hline Sample: Marrowbone Prep. PIt. (Long-Torm) In-Plant & Tost No: 3 \\
\hline
\end{tabular}

\begin{tabular}{|l|l||}
\hline Sample Characteristics: & 4.80 \\
\hline Percent Solids (As Recelved) & -150 mesh \\
\hline Particle Size & \\
\hline
\end{tabular}

\begin{tabular}{|l|l|}
\hline Column Geometry: & \\
\hline Overall Height (bubble generators to cell lip) & 21.5 foet \\
\hline Diameter & 29.25 inches \\
\hline Feed Entry Point & 4.5 feet \\
\hline Froth Height & 40 inches \\
\hline
\end{tabular}

\begin{tabular}{||l|l|l||}
\hline Reagent Additions: & \multicolumn{1}{|c|}{ Dosage (lbs/ton) } & \multicolumn{1}{c|}{ Type } \\
\hline Collector & 0.93 & Diesel \\
\hline Frothor & 1.09 & DF1012 \\
\hline pH Modifier & & \\
\hline Dispersant & & \\
\hline
\end{tabular}

\begin{tabular}{|l|l|l|l||}
\hline Column Flows: & \multicolumn{1}{|c|}{$\mathrm{gpm}$} & \multicolumn{1}{c|}{ gms/min } & \%olids \\
\hline Gas Flowrate & 16.4 (scfm) & & \\
\hline Wash Water Flowrate & 21 & & \\
\hline Feed Flowrate & 98 & & \\
\hline Product Flowrate & & & \\
\hline Reject (Tailings) Flowrate & & & \\
\hline
\end{tabular}

\begin{tabular}{|l|r|r|r|r|r|}
\hline Assays: & Ash (\%) & Comb. (\%) & Tot. S (\%) & Pyr. S (\%) & Btu/lb \\
\hline Product & 9.24 & 90.76 & & & \\
\hline Reject & 76.58 & 23.42 & & & \\
\hline Feed & 58.86 & 41.14 & & & \\
\hline
\end{tabular}

\begin{tabular}{|l|c|c|c|c|c|c|}
\hline Recoveries (\%): & Yield & Ash & Comb. & Tot. S & Pyr. S & Btu \\
\hline Product & 26.31 & 4.13 & 58.05 & & & \\
\hline Rejtct & 73.69 & 95.87 & 41.95 & & & \\
\hline Foed & 100 & 100 & 100 & 100 & 100 & 100 \\
\hline
\end{tabular}




\begin{tabular}{|c|l|}
\hline MICROBUBBLE COLUMN FLOTATION TESTWORK & Dato: \\
\hline Sample: Marrowbone Prop. PIt. (Long-Torm) In.Plant & Tost No: 4 \\
\hline
\end{tabular}

\begin{tabular}{|l|l|}
\hline Sample Charactoristics: \\
\hline Porcent Solids (As Recoived) & 4.62 \\
\hline Particle Size & -150 mesh \\
\hline
\end{tabular}

Column Goomotry:

Overall Height (bubble generators to cell lip)

Diamoter

21.5 foet

Foed Entry Point

29.25 inchos

Froth Hoight

4.5 feet

40 inches

\begin{tabular}{||l|l|l|}
\hline Reagent Additions: & \multicolumn{1}{|c|}{ Dosage (lbs/ton) } & \multicolumn{1}{|c|}{ Typo } \\
\hline Colloctor & 1.02 & Diesel \\
\hline Frothor & 1.24 & DF1012 \\
\hline pH Modifior & & \\
\hline Dispersant & & \\
\hline
\end{tabular}

\begin{tabular}{|l|l|l|l|}
\hline Column Flows: & \multicolumn{1}{|c|}{ gpm } & gms/min & $\%$ solids \\
\hline Gas Flowrate & $16.8(\mathrm{scfm})$ & & \\
\hline Wash Water Flowrate & 21 & & \\
\hline Foed Flowrate & 98 & & \\
\hline Product Flowrate & & & \\
\hline Reject (Tailings) Flowrate & & & \\
\hline
\end{tabular}

\begin{tabular}{|c|c|c|c|c|c|}
\hline Assays: & $\operatorname{Ash}\left(\%_{0}\right)$ & Comb. (\%) & Tot. $S(\%)$ & Pyr. S $(\%)$ & Btu/lb \\
\hline Product & 8.69 & 91.31 & & & \\
\hline Reject & 76.32 & 23.68 & & & \\
\hline Feed & 59.16 & 40.84 & & & \\
\hline
\end{tabular}

\begin{tabular}{|c|c|c|c|c|c|c|}
\hline Pecoverios $(\%)$ : & Yiold & Ash & Comb. & Tot. $\mathbf{S}$ & Pyr. $\mathrm{s}$ & Btu \\
\hline Product & 25.37 & 3.72 & 56.73 & & & \\
\hline Roject & 74.63 & 96.28 & 43.27 & & & \\
\hline Foed & 100 & 100 & 100 & 100 & 100 & 100 \\
\hline
\end{tabular}




\begin{tabular}{|c|c|}
\hline MICROBUBBLE COLUMN FLOTATION TESTWOAK & Datol \\
\hline Sample: Marrowbone Prap. Plt. (Long-Term) In.Plant & Test No: $\mathbf{5}$ \\
\hline \multicolumn{2}{|l|}{ Sample Characteriatios! } \\
\hline Porcont Solids (As Recoived) & 9.89 \\
\hline \multicolumn{2}{|l|}{ Particle Size } \\
\hline \multicolumn{2}{|l|}{ Column Geometry! } \\
\hline Overall Height (bubble generators to cell lip) & 21.5 feet \\
\hline Diameter & 29.25 inches \\
\hline Foed Entry Point & 4.5 feet \\
\hline Froth Hoight & 40 inches \\
\hline
\end{tabular}

\begin{tabular}{||l|l|l|}
\hline Reagent Additions: & \multicolumn{1}{|c|}{ Dosage (lbs/ton) } & \multicolumn{1}{|c|}{ TYpe } \\
\hline Collector & 1.02 & Diesel \\
\hline Frother & 1.32 & DF1012 \\
\hline pH Modifier & & \\
\hline Dispersant & & \\
\hline
\end{tabular}

\begin{tabular}{||l|l|l|l|}
\hline Column Flows: & \multicolumn{1}{|c|}{ opm } & oms/min & \% solids \\
\hline Gas Flowrate & 17.2 (sctm) & & \\
\hline Wash Water Flowrate & 21 & & \\
\hline Foed Flowrate & 100 & & \\
\hline Product Flowrate & & & \\
\hline Reject (Tailings) Flowrate & & & \\
\hline
\end{tabular}

\begin{tabular}{|c|c|c|c|c|c|}
\hline Assays: & $\operatorname{Ash}(\%)$ & Comb. $(\%)$ & Tot. S $(\%)$ & Pyr. S $(\%)$ & Btu/lb \\
\hline Product & 10.29 & 89.71 & & & \\
\hline Reject & 76.07 & 23.93 & & & \\
\hline Feed & 57.89 & 42.11 & & & \\
\hline
\end{tabular}

\begin{tabular}{|c|c|c|c|c|c|c|}
\hline Recoveries $(\%)$ : & Yiold & Ash & Comh. & Tot. $S$ & Pyr. S & Btu \\
\hline Product & 27.64 & 4.91 & 58.88 & & & \\
\hline Reject & 72.36 & 95.09 & 41.12 & & & \\
\hline Foed & 100 & 100 & 100 & 100 & 100 & 100 \\
\hline
\end{tabular}




\begin{tabular}{|l|l|}
\hline MICROBUBBLE COLUMN FLOTATION TESTWORK & Date: \\
\hline Sampla: Marrowbone Prop. PIt. (Long-Tolm) In-PIant & Tast No: 6 \\
\hline
\end{tabular}

\begin{tabular}{||l|l||}
\hline Sample Choracteriotiosi & \\
\hline Parcorit Solids (As Reoolved) & 4.73 \\
\hline Partiole Size & -150 mosh \\
\hline
\end{tabular}

\begin{tabular}{|l|l|}
\hline Column Geomatry: & 21.5 foat \\
\hline Overall Haight (bubble gonerators to call llp) & 29.25 inches \\
\hline Diameter & 4.5 foet \\
\hline Foed Entry Point & 40 inches \\
\hline Froth Height & \\
\hline
\end{tabular}

\begin{tabular}{|l|l|l|}
\hline Resgent Additions: & \multicolumn{1}{|c|}{ Dosage flbs/ton) } & \multicolumn{1}{c|}{ Typo } \\
\hline Collector & 0.48 & Diesel \\
\hline Frother & 1.14 & DF1012 \\
\hline $\mathrm{pH}$ Modifier & & \\
\hline Dispersant & & \\
\hline
\end{tabular}

\begin{tabular}{|l|l|c|c|}
\hline Column Flows: & gpm & gms/min & $\%$ solids \\
\hline Gas Flowrato & 10.0 (sc fm) & & \\
\hline Wash Wator Flowrate & 20 & & \\
\hline Foed Flowrate & 104 & & \\
\hline Product Flowrate & & & \\
\hline Reject (Tailings) Flowrate & & & \\
\hline
\end{tabular}

\begin{tabular}{|l|r|r|r|r|r|}
\hline Assays: & Ash $(\%)$ & Comb. $(\%)$ & Tot. S (\%) & Pyr. S (\%) & Btu/lb \\
\hline Product & 8.29 & 91.71 & & & \\
\hline Roject & 65.18 & 34.82 & & & \\
\hline Foed & 58.57 & 41.43 & & & \\
\hline
\end{tabular}

\begin{tabular}{|c|c|c|c|c|c|c|}
\hline Recoveries (\%): & Yield & Ash & Comb. & Tot. $\mathrm{s}$ & Pyr. 5 & Btu \\
\hline Product & 11.62 & 1.48 & 25.72 & & & \\
\hline Rejuct & 88.38 & 98.52 & 74.28 & & & \\
\hline Food & 100 & 100 & 100 & 100 & 100 & 100 \\
\hline
\end{tabular}




\begin{tabular}{|c|l|}
\hline MICROBUBBLE COLUMN FLOTATION TESTWORK & Date: \\
\hline Sample: Marrowbone Prep. PIt. (Long-Torm) In-Plant & Test No: 7 \\
\hline
\end{tabular}

\begin{tabular}{|l|l|}
\hline Sample Charooteristios: & \\
\hline Peroent Solids (As Roovived) & 4.44 \\
\hline Particle Slxe & $.150 \mathrm{mesh}$ \\
\hline
\end{tabular}

\begin{tabular}{|l|l|}
\hline Column Geometry: & 21.5 foet \\
\hline Overall Height (bubble generators to cell llp) & 29.25 inches \\
\hline Diameter & 4.5 feet \\
\hline Feed Entry Point & 40 inches \\
\hline Froth Helght & \\
\hline
\end{tabular}

\begin{tabular}{|l|l|l||}
\hline Reagent Additionis: & \multicolumn{1}{|c|}{ Dosage (lbs/ton) } & \multicolumn{1}{|c|}{ TYps } \\
\hline Collector & 0.94 & Diesel \\
\hline Frother & 1.22 & DF1012 \\
\hline pH Modifier & & \\
\hline Dispersant & & \\
\hline
\end{tabular}

\begin{tabular}{|l|c|c|c|}
\hline Column Flows: & opm & oms/min & $\%$ solids \\
\hline Gas Flowrate & 16.4 (sofm) & & \\
\hline Wash Water Flowrate & 17 & & \\
\hline Food Flowrate & 104 & & \\
\hline Product Flowrate & & & \\
\hline Reject (Tailings) Flowrate & & & \\
\hline
\end{tabular}

\begin{tabular}{|l|r|r|r|r|r|}
\hline Assays: & Ash (\%) & Comb. (\%) & Tot. S (\%) & Pyr. S (\%) & Btu/lb \\
\hline Product & 9.13 & 90.87 & & & \\
\hline Reject & 74.57 & 25.43 & & & \\
\hline Feed & 51.57 & 48.43 & & & \\
\hline
\end{tabular}

\begin{tabular}{|c|c|c|c|c|c|c|}
\hline Heooveries (\%): & Yiein & Ash & Comb. & Tot. $\mathrm{S}$ & Pyr. S & Btu \\
\hline Product & 35.15 & 6.22 & 65.95 & & & \\
\hline Reject & 64.85 & 93.78 & 34.05 & & & \\
\hline Food & 100 & 100 & 100 & 100 & 100 & 100 \\
\hline
\end{tabular}




\begin{tabular}{|l|l|}
\hline MICROBUBBLE COLUMN FLOTATION TESTWOAK & Dato: \\
\hline Sample: Marrowbont Prop. Plt. (Long-Torm) In-Plant & Test No: 8 \\
\hline
\end{tabular}

\begin{tabular}{|l|l|}
\hline Sample Charaoterlatics: & 4.47 \\
\hline Porcent Sollds (As Recoived) & -150 mosh \\
\hline Particlo Size & \\
\hline
\end{tabular}

\begin{tabular}{|l|l|}
\hline Column Goometry: & 21.5 feet \\
\hline Ovorall Holght (bubble generators to ooll lip) & 29.25 inches \\
\hline Diamoter & \\
\hline Feed Entry Point & 40 inches \\
\hline Froth Height & \\
\hline
\end{tabular}

\begin{tabular}{|l|l|l|}
\hline Reagent Additions: & \multicolumn{1}{|c|}{ Dosage (lbs/ton) } & \multicolumn{1}{|c|}{ Typo } \\
\hline Collector & 0.98 & Diesel \\
\hline Frother & 1.26 & DF1012 \\
\hline pH Modifier & & \\
\hline Dispersant & & \\
\hline
\end{tabular}

\begin{tabular}{|l|l|l|l|}
\hline Column Flows: & \multicolumn{1}{|c|}{ opm } & oms/min & $\%$ solids \\
\hline Gas Flowrate & 16.8 (sctm) & & \\
\hline Wash Water Flowrate & 21 & & \\
\hline Feod Flowrate & 100 & & \\
\hline Product Flowrate & & & \\
\hline Rejoct (Tailings) Flowrate & & & \\
\hline
\end{tabular}

\begin{tabular}{|c|c|c|c|c|c|}
\hline Assays: & $\operatorname{Ash}(\%)$ & Comb. $(\%)$ & Tot. S $(\%)$ & Pyr. S $(\%)$ & Btu/lb \\
\hline Product & 8.67 & 91.33 & & & \\
\hline Reject & 73.06 & 26.94 & & & \\
\hline Food & 51.53 & 48.47 & & & \\
\hline
\end{tabular}

\begin{tabular}{|c|c|c|c|c|c|c|}
\hline Prooveries $(\%)$ : & Yiold & Ash & Comb. & Tot. S & Pyr. S & Btu \\
\hline Product & 33.44 & 3.97 & 63.00 & & & \\
\hline Reject & 66.56 & 96.03 & 37.00 & & & \\
\hline Feed & 100 & 100 & 100 & 100 & 100 & 100 \\
\hline
\end{tabular}




\begin{tabular}{||l|l|}
\hline MICROBUBBLE COLUMN FLOTATION TESTWORK & Date: \\
\hline Sample: Marrowbone Prep. PH. (Long-Term) In-Plant & Test No: 9 \\
\hline
\end{tabular}

\begin{tabular}{||l|l||}
\hline Sample Characteristics: \\
\hline Percent Solids (As Received) & 4.07 \\
\hline Particle Size & -150 mesh \\
\hline
\end{tabular}

\begin{tabular}{|l|l||}
\hline Columin Geometry: & \\
\hline Overall Height (bubble generators to cell lip) & 21.5 feet \\
\hline Diameter & 29.25 inches \\
\hline Feed Entry Point & 4.5 feet \\
\hline Froth Height & 40 inches \\
\hline
\end{tabular}

\begin{tabular}{|l|l|l||}
\hline Reagent Additions: & \multicolumn{1}{|c|}{ Dosage (lbs/ton) } & \multicolumn{1}{|c|}{ Type } \\
\hline Collector & 1.15 & Diesel \\
\hline Frother & 1.35 & DF1012 \\
\hline pH Modifier & & \\
\hline Dispersant & & \\
\hline
\end{tabular}

\begin{tabular}{|l|c|c|c|}
\hline Column Flows: & \multicolumn{1}{|c|}{$\mathrm{gpm}$} & \multicolumn{1}{c|}{$\mathrm{gms} / \mathrm{min}$} & $\%$ solids \\
\hline Gas Flowrate & 16.4 (scfm) & & \\
\hline Wash Water Flowrate & 18 & & \\
\hline Feed Flowrate & 102 & & \\
\hline Product Flowrace & & & \\
\hline R ject (Tailings) Flowrate & & & \\
\hline
\end{tabular}

\begin{tabular}{|c|c|c|c|c|c|}
\hline Assays: & $\operatorname{Ash}(\%)$ & Comb. $(\%)$ & Tot. $S(\%)$ & Pyr. S $(\%)$ & Btu/lb \\
\hline Product & 10.20 & 89.80 & & & \\
\hline Reject & 80.14 & 19.86 & & & \\
\hline Feed & 62.56 & 37.44 & & & \\
\hline
\end{tabular}

\begin{tabular}{|c|c|c|c|c|c|c|}
\hline Recoveries $(\%)$ : & Yield & Ash & Comb. & Tot. $\mathrm{S}$ & Pyr, s & Btu \\
\hline Product & 25.14 & 4.10 & 60.29 & & & \\
\hline Reject & 74.86 & 95.90 & 39.71 & & & \\
\hline Foró & 100 & 10 & 100 & 100 & 100 & 100 \\
\hline
\end{tabular}




\begin{tabular}{|l|l|}
\hline \multicolumn{1}{|c|}{ MICROBUBBLE COLUMN FLOTATION TESTWORK } & Date: \\
\hline Sample: Marrowbone Prep. PIt. (Long-Term) In-Plant & Test No: 10 \\
\hline
\end{tabular}

\begin{tabular}{|l|l|}
\hline Sample Characteristics: & 3.93 \\
\hline Percent Solids (As Received) & -150 mesh \\
\hline Particle Size & \\
\hline
\end{tabular}

\begin{tabular}{|l|l|}
\hline Column Geometry: & 21.5 feet \\
\hline Overall Height (bubble generators to cell lip) & 29.25 inches \\
\hline Diameter & 4.5 feet \\
\hline Feed Entry Point & 40 inches \\
\hline Froth Height & \\
\hline
\end{tabular}

\begin{tabular}{|l|l|l|}
\hline Reagent Additions: & \multicolumn{1}{|c|}{ Dosage (lbs/ton) } & \multicolumn{1}{c|}{ Type } \\
\hline Collector & 1.01 & Diesel \\
\hline Frother & 1.43 & DF 1012 \\
\hline pH Modifier & & \\
\hline Dispersant & & \\
\hline
\end{tabular}

\begin{tabular}{|l|l|l|l|}
\hline Column Flows: & \multicolumn{1}{|c|}{ opm } & gms/min & $\%$ solids \\
\hline Gas Flowrate & 16.0 (scfm) & \\
\hline Wash Water Flowrate & 21 & & \\
\hline Feed Flowrate & 100 & & \\
\hline Product Flowrate & & & \\
\hline Reject (Tailings) Flowrate & & & \\
\hline
\end{tabular}

\begin{tabular}{|c|c|c|c|c|c|}
\hline Assays: & Ash (\%) & Comb. $(\%)$ & Tot. S $(\%)$ & Pyr. $\mathbf{s}(\%)$ & Btu/lb \\
\hline Product & 10.72 & 89.28 & & & \\
\hline Reject & 81.39 & 18.61 & & & \\
\hline Foed & 64.75 & 35.25 & & & \\
\hline
\end{tabular}

\begin{tabular}{|c|c|c|c|c|c|c|}
\hline Recoveries $(\%)$ : & Yiold & Ash & Comb. & Tot, $\mathbf{S}$ & Pyr. S & Btu \\
\hline Product & 23.55 & 3.90 & 59.64 & & & \\
\hline Reject & 76.45 & 96.10 & 40.36 & & & \\
\hline$F= \pm d$ & 100 & 100 & 100 & 100 & 100 & 100 \\
\hline
\end{tabular}




\begin{tabular}{|l|l|}
\hline MICROBUBBLE COLUMN FLOTATION TESTWORK & Date: \\
\hline Sample: Marrowbone Prop. PIt. (Long-Term) In-Plant & Test No: 11 \\
\hline
\end{tabular}

\begin{tabular}{|l|l|}
\hline Sample Characteristics: & \\
\hline Percent Solids (As Received) & 3.73 \\
\hline Particle Size & -150 mesh \\
\hline
\end{tabular}

\begin{tabular}{|l|l||}
\hline Column Geometry: & 21.5 feet \\
\hline Overall Height (bubble generators to cell lip) & 29.25 inches \\
\hline Diameter & 4.5 feet \\
\hline Feed Entry Point & 40 inches \\
\hline Froth Height & \\
\hline
\end{tabular}

\begin{tabular}{||l|l|l|}
\hline Reagent Additions: & \multicolumn{1}{|c|}{ Dosage (lbs/ton) } & \multicolumn{1}{|c|}{ Type } \\
\hline Collector & 1.07 & Diesel \\
\hline Frother & 1.51 & DF1012 \\
\hline pH Modifier & & \\
\hline Dispersant & & \\
\hline
\end{tabular}

\begin{tabular}{|l|l|l|l||}
\hline Column Flows: & \multicolumn{1}{|c|}{ gpm } & gms/min & solids \\
\hline Gas Flowrate & 16.8 (scfm) & & \\
\hline Wash Water Flowrate & 20 & & \\
\hline Foed Flowrate & 100 & & \\
\hline Product Flowrate & & & \\
\hline Reject (Tailings) Flowrate & & & \\
\hline
\end{tabular}

\begin{tabular}{||l|r|r|r|r|r|}
\hline Assays: & Ash (\%) & Comb. (\%) & Tot. S (\%) & Pyr. S (\%) & Btu/lb \\
\hline Product & 10.33 & 89.67 & & & \\
\hline Reject & 72.83 & 27.17 & & & \\
\hline Feed & 51.97 & 48.03 & & & \\
\hline
\end{tabular}

\begin{tabular}{|l|c|c|c|c|c|c|}
\hline Recoveries (\%): & Yiold & Ash & Comb. & Tot. S & Pyr. S & Btu \\
\hline Product & 33.38 & 6.63 & 62.31 & & & \\
\hline Reject & 66.62 & 93.37 & 37.69 & & & \\
\hline Foed & 100 & 100 & 100 & 100 & 100 & 100 \\
\hline
\end{tabular}




\begin{tabular}{|l|l|}
\hline MICROBUBBLE COLUMN FLOTATION TESTWORK & Date: \\
\hline Sample: Marrowbone Prop. Pit. (Long-Term) In-Plant & Test No: 12 \\
\hline
\end{tabular}

\begin{tabular}{||l|l|}
\hline Sample Characteristics: \\
\hline Percent Solids (As Received) & 4.31 \\
\hline Particle Size & -150 mesh \\
\hline
\end{tabular}

Column Goomotry:

Overall Height (bubble generators to cell lip)

Diamoter

Foed Entry Point

Froth Hoight

21.5 feet

29.25 inches

4.5 feet

40 inches

\begin{tabular}{|l|l|l|}
\hline Reagent Additions: & \multicolumn{1}{|c|}{ Dosage (lbs/ton) } & \multicolumn{1}{|c|}{ Type } \\
\hline Collector & 1.01 & Diesel \\
\hline Frother & 1.31 & DF1012 \\
\hline pH Modifier & & \\
\hline Dispersant & & \\
\hline
\end{tabular}

\begin{tabular}{|l|l|l|l|}
\hline Column Flows: & \multicolumn{1}{|c|}{ gpm } & gms/min & \% solids \\
\hline Gas Flowrate & 16.4 (scim) & & \\
\hline Wash Water Flowrate & 20 & & \\
\hline Foed Flowrate & 100 & & \\
\hline Product Flowrate & & & \\
\hline Reject (Tailings) Flowrate & & & \\
\hline
\end{tabular}

\begin{tabular}{|c|c|c|c|c|c|}
\hline Assays: & Ash (\%) & Comb. $(\%)$ & Tot. S $(\%)$ & Pyr. S $(\%)$ & Btu/b \\
\hline Product & 8.86 & 91.14 & & & \\
\hline Reject & 72.15 & 27.85 & & & \\
\hline Foed & 56.22 & 51.92 & & & \\
\hline
\end{tabular}

\begin{tabular}{|c|c|c|c|c|c|c|}
\hline Recoveries (\%): & Yiold & Ash & Comb. & Tot. $\mathbf{S}$ & Prr. S & Btu \\
\hline Product & 25.17 & 3.97 & 52.40 & & & \\
\hline Reject & 74.83 & 96.03 & 47.60 & & & \\
\hline Fead & 100 & 100 & 100 & 100 & 100 & 100 \\
\hline
\end{tabular}




\begin{tabular}{|l|l|}
\hline MICROBUBBLE COLUMN FLOTATION TESTWORK & Date: \\
\hline Sample: Marrowbone Prep. Plt. (Long-Term) In-Plant & Test No: 13 \\
\hline
\end{tabular}

\begin{tabular}{||l|l||}
\hline Sample Characteristics: \\
\hline Percent Solids (As Received) & 3.59 \\
\hline Particle Size & $-150 \mathrm{mesh}$ \\
\hline
\end{tabular}

\begin{tabular}{|l|l|}
\hline Column Geometry: & 21.5 feet \\
\hline Overall Height (bubble generators to cell lip) & 29.25 inches \\
\hline Diameter & 4.5 feet \\
\hline Feed Entry Point & 40 inches \\
\hline Froth Height & \\
\hline
\end{tabular}

\begin{tabular}{|l|l|l|}
\hline Resgent Additions: & \multicolumn{1}{|c|}{ Dosage (lbs/ton) } & \multicolumn{1}{c|}{ Type } \\
\hline Collector & 1.17 & Diesel \\
\hline Frother & 1.51 & DF1012 \\
\hline pH Modifier & & \\
\hline Dispersent & & \\
\hline
\end{tabular}

\begin{tabular}{|l|l|l|l|}
\hline Column Flows: & \multicolumn{1}{|c|}{ gpm } & gms/min & solids \\
\hline Gas Flowrate & 16.4 (scfm) & & \\
\hline Wash Water Flowrate & 21 & & \\
\hline Feed Flowrate & 104 & & \\
\hline Product Flowrate & & & \\
\hline Reject (Tailings) Flowrate & & & \\
\hline
\end{tabular}

\begin{tabular}{|l|r|r|r|r|r|}
\hline Assays: & Ash $(\%)$ & Comb. (\%) & Tot. S (\%) & Pyr. S $(\%)$ & Btu/nb \\
\hline roduct & 8.92 & 91.08 & & & \\
\hline Rejest & 75.16 & 24.84 & & & \\
\hline Foed & 53.71 & 48.08 & & & \\
\hline
\end{tabular}

\begin{tabular}{|l|c|c|c|c|c|c|}
\hline Recoveries (\%): & Vield & Ash & Comb. & Tot. S & Pyr. S & Btu \\
\hline Product & 32.38 & 5.38 & 63.72 & & & \\
\hline Reject & 67.62 & 94.62 & 36.28 & & & \\
\hline Feod & 100 & 100 & 100 & 100 & 100 & 100 \\
\hline
\end{tabular}




\begin{tabular}{|l|l|}
\hline \multicolumn{1}{|c|}{ MICROBUBBLE COLUMN FLOTATION TESTWORK } & Date: \\
\hline Sample: Marrowbone Prop. Plt. (Long-Term) In-PIant & Test No: 14 \\
\hline
\end{tabular}

\begin{tabular}{|l|l|}
\hline Sample Characteristics: \\
\hline Percent Solids (As Received) & 3.24 \\
\hline Particle Size & -150 mesh \\
\hline
\end{tabular}

\begin{tabular}{|l|l|}
\hline Column Goometry: & \\
\hline Overall Hoight (bubble generators to coll lip) & 21.5 feet \\
\hline Diameter & 29.25 inches \\
\hline Foed Entry Point & 4.5 feet \\
\hline Froth Hoight & 40 inches \\
\hline
\end{tabular}

\begin{tabular}{|l|l|l|}
\hline Reagent Additions: & \multicolumn{1}{|c|}{ Dosage (lbs/ton) } & \multicolumn{1}{c|}{ TYpo } \\
\hline Collector & 1.54 & Diesel \\
\hline Frother & 1.68 & DF 1012 \\
\hline pH Modifier & & \\
\hline Dispersant & & \\
\hline
\end{tabular}

\begin{tabular}{|l|l|l|l|}
\hline Column Flows: & \multicolumn{1}{|c|}{ opm } & oms/min & solids \\
\hline Gas Flowrate & 16.0 (scfm) & & \\
\hline Wash Water Flowrate & 21 & & \\
\hline Foed Flowrate & 104 & & \\
\hline Product Flowrate & & & \\
\hline Roject (Tailings) Flowrate & & & \\
\hline
\end{tabular}

\begin{tabular}{|l|r|r|r|r|r|}
\hline Assays: & Ast $(\%)$ & Comb. (\%) & Tot. S (\%) & Pyr. S (\%) & Btu/lb \\
\hline Product & 8.64 & 91.36 & & & \\
\hline Reject & 77.22 & 22.78 & & & \\
\hline Feed & 54.31 & 45.69 & & & \\
\hline
\end{tabular}

\begin{tabular}{|c|c|c|c|c|c|c|}
\hline Recoveries (\%): & Yiold & Ash & Comb. & Tot. $\mathrm{S}$ & Pyr. S & Etu \\
\hline Product & 33.41 & 5.32 & 66.80 & & & \\
\hline Reject & 66.59 & 94.68 & 33.20 & & & \\
\hline Food & 100 & 100 & 100 & 100 & 100 & 100 \\
\hline
\end{tabular}


Appendix 3: Material balances for the 2-inch column particle size tests 


\begin{tabular}{||c|l|}
\hline MICROBUBBLE COLUMN FLOTATION TESTWORK & Date: \\
\hline Sample: Marrowbone Prep. Plt. (Feed Sz. Distr.) Lab Test & Test No: 1 \\
\hline
\end{tabular}

\begin{tabular}{|l|l||}
\hline Sample Characteristics: & \\
\hline Percent Solids (As Received) & 5.2 \\
\hline Particle Size & -28 mesh \\
\hline
\end{tabular}

\section{Column Geometry:}

Overall Height (bubble generators to cell lip)

Diameter

Foed Entry Point

Froth Height

\begin{tabular}{||l|l|l||}
\hline Reagent Additions: & \multicolumn{1}{|c|}{ Dosage (lbs/ton) } & \multicolumn{1}{|c|}{ Type } \\
\hline Collector & 1.25 & Diesel \\
\hline Frother & 1.39 & DF1012 \\
\hline pH Modifier & & \\
\hline Dispersant & & \\
\hline
\end{tabular}

\begin{tabular}{|l|l|l|l||}
\hline Column Flows: & \multicolumn{1}{|c|}{$\mathrm{ml} / \mathrm{min}$} & oms/min & $\%$ solids \\
\hline Gas Flowrate & $1000(\mathrm{cc} / \mathrm{min})$ & & \\
\hline Wash Water Flowrate & 400 & & \\
\hline Foed Flowrate & 1000 & & \\
\hline Product Flowrate & & & \\
\hline Reject (Tailings) Flowrate & & & \\
\hline
\end{tabular}

\begin{tabular}{|l|r|r|r|r|r|}
\hline Assays: & Ash $(\%)$ & Comb. $(\%)$ & Tot. S (\%) & Pyr. S $(\%)$ & Btu/fb \\
\hline Product & 16.09 & 83.91 & & & \\
\hline Reject & 84.17 & 15.83 & & & \\
\hline Foed & 46.94 & 53.06 & & & \\
\hline
\end{tabular}

\begin{tabular}{|l|c|c|c|c|c|c|}
\hline Recoveries (\%): & Yiold & Ash & Comb. & Tot. S & Pyr, S & Btu \\
\hline Product & 54.74 & 18.76 & 86.51 & & & \\
\hline Reject & 42.26 & 81.24 & 13.49 & & & \\
\hline Foed & 100 & 100 & 100 & 100 & 100 & 100 \\
\hline
\end{tabular}




\begin{tabular}{|c|l|}
\hline MICROBUBBLE COLUMN FLOTATION TESTWORK & Date: \\
\hline Sample: Marrowbone Prep. PIt. (Foed Sz. Distr.) Lab Test & Test No: 2 \\
\hline
\end{tabular}

\begin{tabular}{|l|l|}
\hline Sample Charactoristics: & 5.2 \\
\hline Percent Solids (As Recoived) & -28 mesh \\
\hline Particlo Size & \\
\hline
\end{tabular}

\begin{tabular}{|l|l|}
\hline Column Geometry: & 72 inches \\
\hline Overall Hoight (bubble generators to cell lip) & 2.0 inches \\
\hline Diamoter & 18.5 inches \\
\hline Foed Entry Point & \\
\hline Froth Height & \\
\hline
\end{tabular}

\begin{tabular}{|l|l|l|}
\hline Reagent Additions: & \multicolumn{1}{|c|}{ Dosege (Ibs/ton) } & \multicolumn{1}{|c|}{ Type } \\
\hline Collector & 1.25 & Diesel \\
\hline Frother & 1.68 & DF1012 \\
\hline pH Modifier & & \\
\hline Dispersant & & \\
\hline
\end{tabular}

\begin{tabular}{|l|c|c|c|}
\hline Column Flows: & ml/min & gms/min & \%olids \\
\hline Gas Flowrate & $1300(\mathrm{cc} / \mathrm{min})$ & & \\
\hline Wash Water Flowrate & 400 & & \\
\hline Foed Flowrate & 1500 & & \\
\hline Product Flowrate & & & \\
\hline Poject (Tailings) Flowrate & & & \\
\hline
\end{tabular}

\begin{tabular}{|c|c|c|c|c|c|}
\hline Assays: & Ash $(\%)$ & Comb. $(\%)$ & Tot. S $(\%)$ & Pyr. $5(\%)$ & Btu/hb \\
\hline Product & 11.98 & 88.02 & & & \\
\hline Reject & 81.05 & 18.95 & & & \\
\hline Foed & 46.77 & 53.23 & & & \\
\hline
\end{tabular}

\begin{tabular}{|c|c|c|c|c|c|c|}
\hline Recoveries (\%): & Yiold & Ash & Comb. & Tot. $\mathbf{s}$ & Pyr. S & Btw \\
\hline Product & 49.63 & 12.71 & 82.07 & & & \\
\hline Paject & 50.37 & 87.29 & 17.93 & & & \\
\hline Foed & 100 & 100 & 100 & 100 & 100 & 100 \\
\hline
\end{tabular}




\begin{tabular}{|l|l|}
\hline MICROBUBBLE COLUMN FLOTATION TESTWORK & Date: \\
\hline Sample: Marrowbone Prep. PIt. (Foed Sz, Distr.) Lab Tost & Test No: 3 \\
\hline
\end{tabular}

\begin{tabular}{|l|l|}
\hline Sample Characteristics: \\
\hline Percent Solids (As Received) & 5.2 \\
\hline Particle Size & -28 mesh \\
\hline
\end{tabular}

\begin{tabular}{|l|l|}
\hline Column Geomotry: & 72 inches \\
\hline Overall Hoight (bubble generators to cell lip) & 2.0 inches \\
\hline Diameter & 18.5 inches \\
\hline Foed Entry Point & \\
\hline Froth Height & \\
\hline
\end{tabular}

\begin{tabular}{|l|l|l||}
\hline Reagent Additions: & \multicolumn{1}{|c|}{ Dosage (lbs/ton) } & \multicolumn{1}{c|}{ Type } \\
\hline Collector & 1.25 & Diesel \\
\hline Frother & 2.12 & DF1012 \\
\hline pH Modifier & & \\
\hline Dispersant & & \\
\hline
\end{tabular}

\begin{tabular}{|l|l|l|l|}
\hline Column Flows: & \multicolumn{1}{|c|}{$\mathrm{ml} / \mathrm{min}$} & gms/min & \% solids \\
\hline Gas Flowrate & $1200(\mathrm{cc} / \mathrm{min})$ & & \\
\hline Wash Water Flowrate & 400 & & \\
\hline Foed Flowrate & 2000 & & \\
\hline Product Flowrate & & & \\
\hline Reject (Tailings) Flowrate & & & \\
\hline
\end{tabular}

\begin{tabular}{|l|r|r|r|r|r|}
\hline Assays: & Ash $(\%)$ & Comb. (\%) & Tot. S (\%) & Pyr. S (\%) & Btu/lb \\
\hline Product & 9.81 & 90.19 & & & \\
\hline Reject & 72.12 & 27.88 & & & \\
\hline Foed & 48.55 & 51.45 & & & \\
\hline
\end{tabular}

\begin{tabular}{|l|c|r|r|r|r|l|}
\hline Recoveries $(\%):$ & Yiold & Ash & Comb. & Tot. S & Pyr. S & Btu \\
\hline Product & 37.83 & 7.64 & 66.31 & & & \\
\hline Reject & 62.17 & 92.36 & 33.69 & & & \\
\hline Foed & 100 & 100 & 100 & 100 & 100 & 100 \\
\hline
\end{tabular}




\begin{tabular}{|l|l|}
\hline MICROBUBBLE COLUMN FLOTATION TESTWORK & Date: \\
\hline Sample: Marrowbone Prop. Plt. (Foed Sz. Distr.) Lab Tost & Test No: 4 \\
\hline
\end{tabular}

\begin{tabular}{|l|l|}
\hline Sample Characteristics! \\
\hline Porcent Solids (As Recoived) & 5.9 \\
\hline Particle Size & -28 mesh \\
\hline
\end{tabular}

\section{Column Goomotry:}

Overall Hoight (bubtole gonerators to oall lip)

Diameter

Fogd Entry Point

72 inches

2.0 inches

Froth Helght

\begin{tabular}{|l|l|l|}
\hline Reagent Additions: & \multicolumn{1}{|c|}{ Dosage (lbs/ton) } & \multicolumn{1}{|c|}{ Type } \\
\hline Collector & 1.25 & Diesel \\
\hline Frother & 1.25 & DF1012 \\
\hline pH Modifier & & \\
\hline Dispersant & & \\
\hline
\end{tabular}

\begin{tabular}{|l|l|l|l|}
\hline Column Flows: & \multicolumn{1}{|c|}{$\mathrm{ml} / \mathrm{min}$} & $\mathrm{gms} / \mathrm{min}$ & $\%$ solids \\
\hline Gas Flowrate & $1000(\mathrm{cc} / \mathrm{min})$ & & \\
\hline Wash Water Flowrate & 400 & & \\
\hline Foed Flowrate & 2000 & & \\
\hline Product Flowrate & & & \\
\hline Reject (Tallings) Flowrate & & & \\
\hline
\end{tabular}

\begin{tabular}{|l|r|r|r|r|r|}
\hline Assays: & Ash (\%) & Comb. (\%) & Tot. S (\%) & Pyr. S (\%) & Btu/lb \\
\hline Product & 7.47 & 92.53 & & & \\
\hline Reject & 73.81 & 26.19 & & & \\
\hline Foed & 50.33 & 49.67 & & & \\
\hline
\end{tabular}

\begin{tabular}{|c|c|c|c|c|c|c|}
\hline Aecoveries (\%): & Yiold & Ash & Comb. & Tot. $\mathrm{S}$ & Pyr. S & Btu \\
\hline Product & 35.39 & 3.58 & 65.93 & & & \\
\hline Reject & 64.61 & 96.42 & 34.07 & & & \\
\hline Foed & 100 & 100 & 100 & 100 & 100 & 100 \\
\hline
\end{tabular}




\begin{tabular}{||l|l|}
\hline Sample Characteristics! \\
\hline Parcent Solids (As Recoived) & 4.3 \\
\hline Particle Size & -48 megh \\
\hline
\end{tabular}

\section{Column Geomatry:}

Overall Height (bubble generators to cell lip)

72 inches

Dlameter

2.0 inches

Foed Entry Point

18.5 inches

Froth Height

\begin{tabular}{|l|l|l|}
\hline Reagent Additions: & \multicolumn{1}{|c|}{ Dosage (lbs/ton) } & \multicolumn{1}{|c|}{ Type } \\
\hline Collector & 1.25 & Diesel \\
\hline Frother & 1.25 & DF1012 \\
\hline pH Modifier & & \\
\hline Dispersant & & \\
\hline
\end{tabular}

\begin{tabular}{|l|l|l|l||}
\hline Column Flows: & \multicolumn{1}{|c|}{$\mathrm{ml} / \mathrm{min}$} & $\mathrm{gms} / \mathrm{min}$ & \% solids \\
\hline Gas Flowrate & $2140(\mathrm{cc} / \mathrm{min})$ & & \\
\hline Wash Water Flowrate & 400 & & \\
\hline Foed Flowrate & 1000 & & \\
\hline Product Flowrate & & & \\
\hline Reject (Tailings) Flowrate & & & \\
\hline
\end{tabular}

\begin{tabular}{|l|r|r|r|r|r|}
\hline Assays: & Ash $(\%)$ & Comb. $(\%)$ & Tot. S (\%) & Pyr. S (\%) & Btu/lb \\
\hline Product & 11.48 & 88.52 & & & \\
\hline Reject & 82.06 & 17.94 & & & \\
\hline Feed & 58.82 & 41.18 & & & \\
\hline
\end{tabular}

\begin{tabular}{|l|c|c|c|c|c|c|}
\hline Recoveries $(\%):$ & Yield & Ash & Comb. & Tot. S & Pyr. S & Btu \\
\hline Product & 32.96 & 6.43 & 70.78 & & & \\
\hline Reject & 67.04 & 93.57 & 29.22 & & & \\
\hline Foed & 100 & 100 & 100 & 100 & 100 & 100 \\
\hline
\end{tabular}




\begin{tabular}{|l|l|}
\hline MICAOBUBELE COLUMN FLOTATION TESTWOAK & Datei \\
\hline Samplo: Marrowbone Prop. Ple. (Foad Sz. Distr.) Lab Tost & Test No: 2 \\
\hline
\end{tabular}

\begin{tabular}{|l|l|}
\hline Sumple Characteristicst & 4.3 \\
\hline Percent Solids (As Rocelved) & -48 mosh \\
\hline Particle Size & \\
\hline
\end{tabular}

\begin{tabular}{l|l|}
\hline Column Goomotry: & \\
\hline Ovarall Holght & 72 inches \\
\hline Diamotor & 2.0 inches \\
\hline Foed Entry Point (bubble genorators to foed point) & 18.5 inches \\
\hline Froth Hoight & \\
\hline
\end{tabular}

\begin{tabular}{|l|l|l|}
\hline Reagent Additions: & \multicolumn{1}{|c|}{ Dosage (lbs/tonl } & \multicolumn{1}{|c|}{ Typo } \\
\hline Collector & 1.25 & Diesel \\
\hline Frother & $1.25:$ & DF1012 \\
\hline pH Modifier & & \\
\hline Dispersant & & \\
\hline
\end{tabular}

\begin{tabular}{|l|c|c|c|}
\hline Column Flows: & \multicolumn{1}{|c|}{$\mathrm{mi} / \mathrm{min}$} & oms/min & solids \\
\hline Gas Flowrate & $2140(\mathrm{co} / \mathrm{min})$ & & \\
\hline Wash Water Flowrate & 400 & & \\
\hline Foed Flowrate & 1500 & & \\
\hline Product Flowrate & & & \\
\hline Roject (Tailings) Flowrate & & & \\
\hline
\end{tabular}

\begin{tabular}{|l|r|r|r|r|r|}
\hline Assays: & Ash (\%) & Comb. (\%) & Tot. S (\%) & Pyr. S (\%) & Btu/ib \\
\hline Product & 12.21 & 87.79 & & & \\
\hline Roject & 85.10 & 14.90 & & & \\
\hline Foed & 58.82 & 41.18 & & & \\
\hline
\end{tabular}

\begin{tabular}{|l|c|c|c|c|c|c|}
\hline Rocoveries (\%): & Yiold & Ash & Comb. & Tot. S & Pyr. S & Btu \\
\hline Product & 36.05 & 7.48 & 76.86 & & & \\
\hline Poject & 63.95 & 92.52 & 23.14 & & & \\
\hline Foed & 100 & 100 & 100 & 100 & 100 & 100 \\
\hline
\end{tabular}




\begin{tabular}{|l|l||}
\hline MICROBUEBLE COLUMN FLOTATION TESTWORK & Date: \\
\hline Sample: Marrowbone Prop. Plt, (Foed Sz. Diatr.) Lab Tost & Test No: 3 \\
\hline
\end{tabular}

\begin{tabular}{|c|c|}
\hline Porcent Sollds (As Recelved) & 4.3 \\
\hline Particlo Size & .48 mesh \\
\hline
\end{tabular}

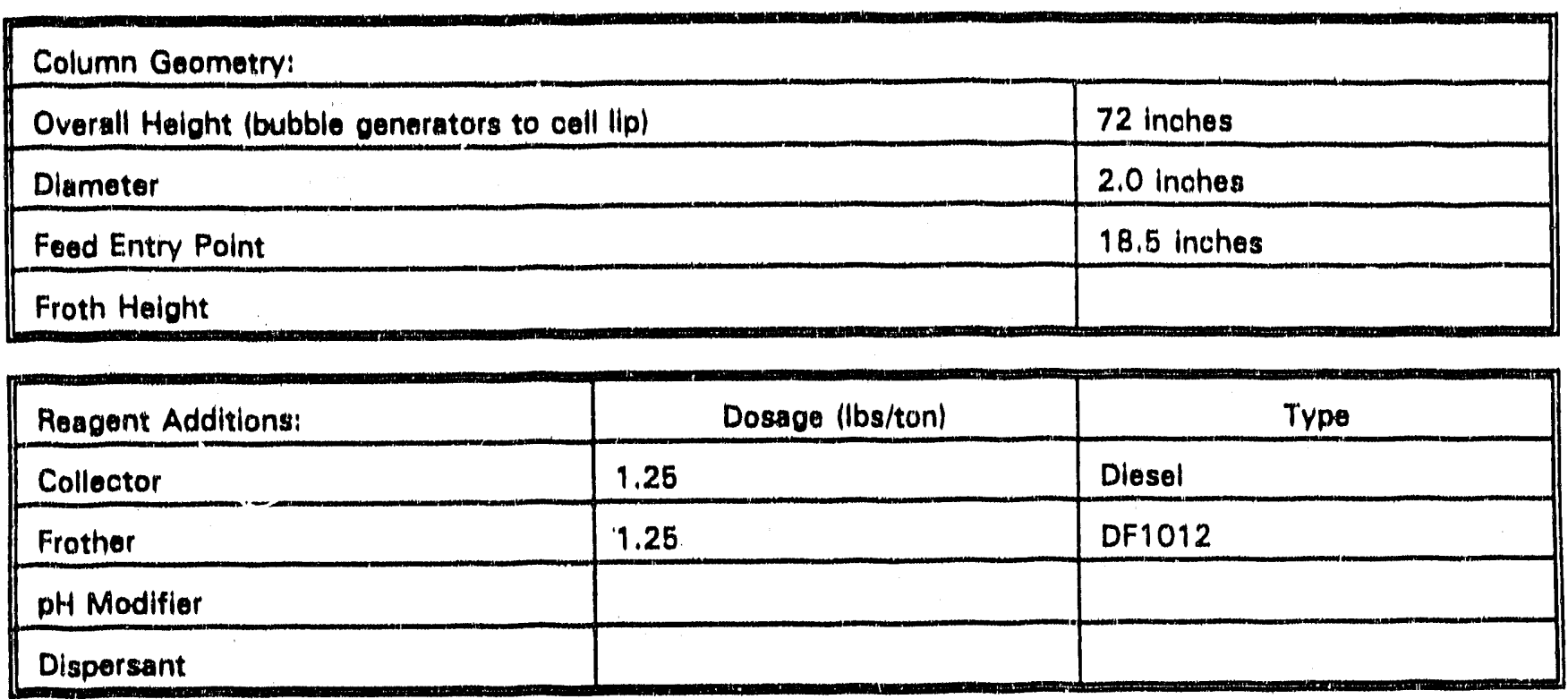

\begin{tabular}{|l|l|l|l|}
\hline Column Flows: & \multicolumn{1}{|c|}{$\mathrm{mi} / \mathrm{min}$} & gms/min & $\%$ solids \\
\hline Gas Flowrate & $2140(\mathrm{coc} / \mathrm{min})$ & & \\
\hline Wash Water Flowrate & 400 & & \\
\hline Foed Flowrate & 2000 & & \\
\hline Product Flowrate & & & \\
\hline Reject (Tailings) Flowrate & & & \\
\hline
\end{tabular}

\begin{tabular}{|c|c|c|c|c|c|}
\hline Assays: & $A \operatorname{sh}(\%)$ & Comb. $(\%)$ & Tot, $\mathbf{s}(\%)$ & Prr. S $(\%)$ & Btu/lb \\
\hline Product & 12.81 & 87.19 & & & \\
\hline Foject & 80.51 & 19.49 & & & \\
\hline Feed & 58.82 & 41.18 & & & \\
\hline
\end{tabular}

\begin{tabular}{|c|c|c|c|c|c|c|}
\hline Recoveries $(\%)$ : & Yiold & Ash & Comb. & Tot, $\mathrm{S}$ & Pyr. S & Btu \\
\hline Product & 32.04 & 6.98 & 67.83 & & & \\
\hline Rejoct & 67.96 & 93.02 & 32.17 & & & \\
\hline Foed & 100 & 100 & 100 & 100 & 100 & 100 \\
\hline
\end{tabular}




\begin{tabular}{|l|l|}
\hline \multicolumn{1}{|c|}{ MICROBUBBLE COLUMN FLOTATION TESTWORK } & Date: \\
\hline Sample: Marrowbone Prop. PIt. (Feod Sz. Distr.) Lab Tost & Tost No: 1 \\
\hline
\end{tabular}

\begin{tabular}{|l|l|}
\hline Sample Characteris: Cs: & \\
\hline Percent Solids (As Recoived) & 5.5 \\
\hline Particle Size & -65 mesh \\
\hline
\end{tabular}

\begin{tabular}{|l|l|}
\hline Column Geometry: & 72 inches \\
\hline Overall Height (bubble generators to cell lip) & 2.0 inches \\
\hline Diameter & 18.5 inches \\
\hline Feed Entry Point & \\
\hline Froth Height & \\
\hline
\end{tabular}

\begin{tabular}{|l|l|l|}
\hline Reagent Additions: & \multicolumn{1}{|c|}{ Dosage (lbs/ton) } & \multicolumn{1}{|c|}{ Type } \\
\hline Collector & 1.00 & Diesel \\
\hline Frother & 0.63 & DF 1012 \\
\hline pH Modifier & & \\
\hline Dispersant & & \\
\hline
\end{tabular}

\begin{tabular}{|l|l|l|l|}
\hline Column Flows: & \multicolumn{1}{|c|}{$\mathrm{ml} / \mathrm{min}$} & gms/min & $\%$ solids \\
\hline Gas Flowrate & $1500(\mathrm{cc} / \mathrm{min})$ & & \\
\hline Wash Water Flowrate & 400 & & \\
\hline Feed Flowrate & 500 & & \\
\hline Product Flowrate & & & \\
\hline Reject (Tailings) Flowrate & & & \\
\hline
\end{tabular}

\begin{tabular}{|l|r|r|r|r|r|}
\hline Assays: & Ash $(\%)$ & Comb. (\%) & Tot. S (\%) & Pyr. S (\%) & Eru/fb \\
\hline Product & 10.45 & 89.55 & & & \\
\hline Reject & 80.44 & 19.56 & & & \\
\hline Feed & 56.94 & 43.06 & & & \\
\hline
\end{tabular}

\begin{tabular}{|l|r|r|r|r|r|r|}
\hline Recoveries (\%): & Yield & Ash & Comb. & Tot. S & Pyr. S & Btu \\
\hline Product & 33.58 & 6.16 & 69.83 & & & \\
\hline Reginet & 66.42 & 93.84 & 30.17 & & & \\
\hline Feed & 100 & 100 & 100 & 100 & 100 & 100 \\
\hline
\end{tabular}




\begin{tabular}{|l|l|}
\hline MICROBUBBLE COLUMN FLOTATION TESTWOAK & Date: \\
\hline Sample: Marrowbone Prop. PIt. (Foed Sz. Distr.) Lab Tost & Test No: 2 \\
\hline
\end{tabular}

\begin{tabular}{|l|l|}
\hline Sample Characteristics: \\
\hline Percent Solids (As Received) & 5.5 \\
\hline Porticle Size & -65 mesh \\
\hline
\end{tabular}

\begin{tabular}{|l|l|}
\hline Column Geometry: & 72 inches \\
\hline Overall Haight (bubble generators to cell lipl & 2.0 inches \\
\hline Diameter & 18.5 inches \\
\hline Feed Entry Point (bubble generators to foed point) & \\
\hline Froth Height & \\
\hline
\end{tabular}

\begin{tabular}{|l|l|l|}
\hline Reageni Additions: & \multicolumn{1}{|c|}{ Dosege (lbs/ton) } & \multicolumn{1}{|c|}{ Type } \\
\hline Collector & 1.00 & Diesel \\
\hline Frosher & 0.90 & DF1012 \\
\hline pH Modifier & & \\
\hline Dispersant & & \\
\hline
\end{tabular}

\begin{tabular}{|l|l|l|l|}
\hline Column Flows: & \multicolumn{1}{|c|}{$\mathrm{ml} / \mathrm{min}$} & gms/min & \%olids \\
\hline Gas Flowrate & $1500 \mathrm{lcc} / \mathrm{min})$ & & \\
\hline Wash Water Flowrate & 400 & & \\
\hline Feed Flowrate & 1000 & & \\
\hline Product Flowrate & & & \\
\hline Reject (Tailings) Flowrate & & & \\
\hline
\end{tabular}

\begin{tabular}{|l|r|r|r|r|r||}
\hline Assays: & Ash (\%) & Comb. (\%) & Tot. S (\%) & Pyr. S (\%) & Btu/lb \\
\hline Product & 10.05 & 89.95 & & & \\
\hline Reject & 78.27 & 21.73 & & & \\
\hline Feed & 57.19 & 42.81 & & & \\
\hline
\end{tabular}

\begin{tabular}{|l|c|c|c|c|c|c|}
\hline Recoveries (\%): & Yield & Ash & Comb. & Tot. S & Pyr. S & Btu \\
\hline Pruduct & 30.90 & 5.43 & 64.93 & & & \\
\hline Reject & 69.10 & 94.57 & 35.07 & & & \\
\hline Feed & 100 & 100 & 100 & 100 & 100 & 100 \\
\hline
\end{tabular}




\begin{tabular}{|c|l|}
\hline MICROBUBBLE COLUMN FLOTATION TESTWORK & Date: \\
\hline Sample: Marrowbone Prep. PIt. (Feed Sz. Distr.) Lab Test & Test No: 3 \\
\hline
\end{tabular}

\begin{tabular}{|l|l|}
\hline Sample Characteristics: \\
\hline Percent Solids (As Received) & 5.5 \\
\hline Particle Size & -65 mesh \\
\hline
\end{tabular}

\begin{tabular}{|l|l|}
\hline Colurin Geometry: & 72 inches \\
\hline Overall Height (bubble generators to cell lip) & 2.0 inches \\
\hline Diameter & 18.5 inches \\
\hline Foed Entry Point & \\
\hline Froth Height & \\
\hline
\end{tabular}

\begin{tabular}{|l|l|l|}
\hline Roagent Additions: & \multicolumn{1}{|c|}{ Dosage (lbs/ton) } & \multicolumn{1}{c|}{ Type } \\
\hline Collector & 1.00 & Diesel \\
\hline Frother & 1.02 & DF1012 \\
\hline pH Modifier & & \\
\hline Dispersan: & & \\
\hline
\end{tabular}

\begin{tabular}{|l|c|c|c|}
\hline Column Flows: & ml/min & oms/min & $\%$ solids \\
\hline Gas Flowrate & $1500 \mathrm{lcc} / \mathrm{min} /$ & & \\
\hline Wash Water Flowrate & 400 & & \\
\hline Feed Flowrate & 1500 & & \\
\hline Product Flowrate & & & \\
\hline Rejoct (Tailings) Flowrate & & & \\
\hline
\end{tabular}

\begin{tabular}{|l|r|r|r|r|r|}
\hline Assays: & Ash $(\%)$ & Comb. $(\%)$ & Tot. S (\%) & Pyr. S (\%) & Rtu/lb \\
\hline Product & 10.68 & 89.32 & & & \\
\hline Peject & 75.40 & 24.60 & & & \\
\hline Food & 57.26 & 42.74 & & & \\
\hline
\end{tabular}

\begin{tabular}{|c|c|c|c|c|c|c|}
\hline Recoveries (\%): & Yiold & Ash & Comb. & Tot. $\mathbf{S}$ & Pyr. $\mathbf{S}$ & Btu \\
\hline Product & 28.03 & 5.23 & 58.58 & & & \\
\hline Rejact & 71.97 & 94.77 & 41.42 & & & \\
\hline Foed & 100 & 100 & 100 & ivo & 100 & 100 \\
\hline
\end{tabular}




\begin{tabular}{||l|l|}
\hline MICROBUBBLE COLUMN FLOTATION TESTWORK & Date: \\
\hline Sample: Marrowbone Prep. PIt. (Feed Sz. Distr.) Lab Test & Test No: 4 \\
\hline
\end{tabular}

\begin{tabular}{|l|l|}
\hline Sample Characteristics: & \\
\hline Percent Solids (As Received) & 5.5 \\
\hline Particle Size & -65 mesh \\
\hline
\end{tabular}

\begin{tabular}{|l|l|}
\hline Column Geometry: & 72 inches \\
\hline Overall Height (bubble generators to cell lip) & 2.0 inches \\
\hline Diameter & 18.5 inches \\
\hline Feed Entry Point & \\
\hline Froth Height & \\
\hline
\end{tabular}

\begin{tabular}{||l|l|l|}
\hline Reagent Additions: & \multicolumn{1}{|c|}{ Dosage (lbs/ton) } & \multicolumn{1}{|c|}{ Type } \\
\hline Collector & 1.00 & Diesel \\
\hline Frother & 0.87 & DF1012 \\
\hline pH Modifier & & \\
\hline Dispersant & & \\
\hline
\end{tabular}

\begin{tabular}{|l|l|l|l|}
\hline Column Flows: & \multicolumn{1}{|c|}{$\mathrm{ml} / \mathrm{min}$} & gms/min & $\%$ solids \\
\hline Gas Flowrate & $1500 \mathrm{ccc} / \mathrm{min})$ & & \\
\hline Wash Water Flowrate & 400 & & \\
\hline Foed Flowrate & 2000 & & \\
\hline Product Flowrate & & & \\
\hline Reject (Tailingsi Flowrate & & & \\
\hline
\end{tabular}

\begin{tabular}{|c|c|c|c|c|c|}
\hline Assays: & $A \operatorname{sh}(\%)$ & Comb. $(\%)$ & Tot. S $(\%)$ & Pyr. S $(\%)$ & Btu/lb \\
\hline Product & 8.80 & 91.20 & & & \\
\hline Reject & 71.40 & 28.60 & & & \\
\hline Feed & 56.94 & 43.06 & & & \\
\hline
\end{tabular}

\begin{tabular}{|l|c|c|c|c|c|c|}
\hline Recoveries (\%): & Yield & Ash & Comb. & Tot. S & Pyr. S & Btu \\
\hline Product & 22.52 & 3.48 & 48.11 & & & \\
\hline Reject & 77.48 & 96.52 & 51.89 & & & \\
\hline Feed & 100 & 100 & 100 & 100 & 100 & 100 \\
\hline
\end{tabular}




\begin{tabular}{|c|l|}
\hline MICROBUBBLE COLUMN FLOTATION TESTWORK & Date: \\
\hline Sample: Marrowbone Prep. PIt. (Feed Sz. Distr.) Lab Tost & Test No: 1 \\
\hline
\end{tabular}

\begin{tabular}{|l|l|}
\hline Sample Characteristics: & \\
\hline Percent Solids (As Received) & 4.9 \\
\hline Particle Size & -150 mesh \\
\hline Column Geometry: & \\
\hline Overall Height (bubble generators to cell lip) & 72 inches \\
\hline Diameter & 2.0 inches \\
\hline Feed Entry Point & 18.5 inches \\
\hline Froth Height & \\
\hline
\end{tabular}

\begin{tabular}{|l|l|l|}
\hline Reagent Additions: & \multicolumn{1}{|c|}{ Dosage (lbs/ton) } & \multicolumn{1}{|c|}{ Typo } \\
\hline Collector & 1.00 & Diesel \\
\hline Frother & 0.85 & PSM \\
\hline pH Modifier & & \\
\hline Dispersant & & \\
\hline
\end{tabular}

\begin{tabular}{|l|c|c|c|}
\hline Column Flows: & \multicolumn{1}{|c|}{$\mathrm{mi} / \mathrm{min}$} & grns/min & \% solids \\
\hline Gas Flowrate & 1500 (cc/min) & & \\
\hline Wash Water Flowrate & 400 & & \\
\hline Feed Flowrate & 500 & & \\
\hline Product Flowrate & & & \\
\hline Reject (Tailings) Flowrate & & & \\
\hline
\end{tabular}

\begin{tabular}{|l|r|r|r|r|r|}
\hline Assays: & Ash (\%) & Comb. (\%) & Tot. S (\%) & Pyr. S (\%) & Btu/fb \\
\hline Product & 11.85 & 88.15 & & & \\
\hline Reject & 78.13 & 29.87 & & & \\
\hline Foed & 57.50 & 42.50 & & & \\
\hline
\end{tabular}

\begin{tabular}{|l|c|c|c|c|c|c|}
\hline Recoveries (\%): & Yiold & Ash & Comb. & Tot. S & Pyr. S & Btu \\
\hline Product & 31.13 & 6.42 & 64.56 & & & \\
\hline Reject & 68.87 & 93.58 & 35.44 & & & \\
\hline Feed & 100 & 100 & 100 & 100 & 100 & 100 \\
\hline
\end{tabular}




\begin{tabular}{||l|l|}
\hline Sample Characteristics: & \\
\hline Percent Solids (As Received) & 4.9 \\
\hline Particle Size & -150 mesh \\
\hline
\end{tabular}

\begin{tabular}{|l|l|}
\hline Column Geometry: & 72 inches \\
\hline Overall Height (bubble generators to cell lip) & 2.0 inches \\
\hline Diameter & 18.5 inches \\
\hline Feed Entry Point & \\
\hline Froth Height & \\
\hline
\end{tabular}

\begin{tabular}{|l|l|l|}
\hline Resgent Additions: & \multicolumn{1}{|c|}{ Dosage (lbs/ton) } & \multicolumn{1}{|c|}{ Type } \\
\hline Collector & 1.00 & Diesel \\
\hline Frother & 1.12 & PSM \\
\hline pH Modifier & & \\
\hline Dispersant & & \\
\hline
\end{tabular}

\begin{tabular}{|l|l|l|l|}
\hline Column Flows: & \multicolumn{1}{|c|}{$\mathrm{ml} / \mathrm{min}$} & oms/min & $\%$ solids \\
\hline Gas Flowrate & 1500 (cc/min) & & \\
\hline Wash Water Flowrate & 400 & & \\
\hline Feed Flowrate & 1000 & & \\
\hline Product Flowrate & & & \\
\hline Reject (Tailings) Flowrate & & & \\
\hline
\end{tabular}

\begin{tabular}{|c|c|c|c|c|c|}
\hline Assays: & $A \operatorname{sh}(\%)$ & Comb. $(\%)$ & Tot. S $\{\% \mid$ & Pyr. S $(\%)$ & Btu/b \\
\hline Product & 11.61 & 88.39 & & & \\
\hline Reject & 76.47 & 23.53 & & & \\
\hline Fead & 56.61 & 43.39 & & & \\
\hline
\end{tabular}

\begin{tabular}{|l|c|c|c|c|c|c|}
\hline Recoveries (\%): & Yiold & Ash & Comb. & Tot. S & Pyr. S & Btu \\
\hline Product & 30.62 & 6.28 & 62.38 & & & \\
\hline Reject & 69.38 & 93.72 & 37.62 & & & \\
\hline Feed & 100 & 100 & 100 & 100 & 100 & 100 \\
\hline
\end{tabular}




\begin{tabular}{|l|l|}
\hline \multicolumn{1}{|c|}{ MICROBUBBLE COLUMN FLOTATION TESTWORK } & Date: \\
\hline Sample: Marrowbone Prep. PIt. (Feed Sz. Distr.) Lab Tost & Test No: 3 \\
\hline
\end{tabular}

\begin{tabular}{|l|l|}
\hline Sample Characteristics: & \\
\hline Percent Solids (As Received) & 4.9 \\
\hline Particle Size & -150 mesh \\
\hline
\end{tabular}

\section{Column Geometry:}

\begin{tabular}{|l|l|}
\hline Overall Hoight (bubble generators to coll lip) & 72 inches \\
\hline Diamoter & 2.0 inches \\
\hline Fead Entry Point & 18.5 inches \\
\hline Froth Height & \\
\hline
\end{tabular}

\begin{tabular}{|l|l|l|}
\hline Reagent Additions: & \multicolumn{1}{|c|}{ Dosage (lbston) } & \multicolumn{1}{|c|}{ Type } \\
\hline Collector & 1.00 & Diesel \\
\hline Frother & 1.31 & PSM \\
\hline pH Modifier & & \\
\hline Dispersent & & \\
\hline
\end{tabular}

\begin{tabular}{|l|l|l|l|}
\hline Column Flows: & \multicolumn{1}{|c|}{$\mathrm{ml} / \mathrm{min}$} & gms/min & $\%$ solids \\
\hline Gas Flowrate & $1500 \mathrm{lcc} / \mathrm{min})$ & & \\
\hline Wash Water Flowrate & 400 & & \\
\hline Feed Flowrate & 1500 & & \\
\hline Product Flowrate & & & \\
\hline Reject (Tailings) Flowrate & & & \\
\hline
\end{tabular}

\begin{tabular}{|l|r|r|r|r|r|}
\hline Assays: & Ash (\%) & Comb. (\%) & Tot. S (\%) & Pyr. S (\%) & Btu/lb \\
\hline Produet & 11.34 & & & \\
\hline Rojuct & 74.26 & & & \\
\hline Foed & 57.06 & & & & \\
\hline
\end{tabular}

\begin{tabular}{|l|c|c|c|c|c|c|}
\hline Recoveries (\%): & Vield & Ash & Comb. & Tot. S & Pyr. S & Btu \\
\hline Product & 27.33 & 5.43 & 56.44 & & & \\
\hline Reject & 72.67 & 94.57 & 43.56 & & & \\
\hline Foed & 100 & 100 & 100 & 100 & 100 & 100 \\
\hline
\end{tabular}




\begin{tabular}{|l|l|}
\hline MICROBUBBLE COLUMN FLOTATION TESTWORK & Date: \\
\hline Sample: Marrowbone Prep. Plt. (Foed Sz. Distr.) Lab Test & Test No: 1 \\
\hline
\end{tabular}

\begin{tabular}{|l|l||}
\hline Sample Characteristics: & \\
\hline Parcent Solids (As Received) & 3.54 \\
\hline Particle Size & $28 \times 150$ mesh \\
\hline
\end{tabular}

\begin{tabular}{|l|l|}
\hline Column Geometry: & 72 inches \\
\hline Overail Height (bubble generators to cell lip) & 2.0 inches \\
\hline Diameter & 18.5 inches \\
\hline Feed Entry Point & 15 inches \\
\hline Froth Haight & \\
\hline
\end{tabular}

\begin{tabular}{|l|l|l||}
\hline Reagent Additions: & \multicolumn{1}{|c|}{ Dosage (lbs/ton) } & \multicolumn{1}{c|}{ Type } \\
\hline Collector & 1.25 & Diesel \\
\hline Frother & 0.12 & DF1012 \\
\hline pH Modifier & & \\
\hline Dispersant & & \\
\hline
\end{tabular}

\begin{tabular}{|l|l|l|l|}
\hline Column Flows: & \multicolumn{1}{|c|}{$\mathrm{ml} / \mathrm{min}$} & oms/min & \% solids \\
\hline Gas Flowrate & $760(\mathrm{cc} / \mathrm{min})$ & & \\
\hline Wash Water Flowrate & 560 & & \\
\hline Feed Flowrate & 1500 & & \\
\hline Product Flowrate & & & \\
\hline Reject (Tailings) Flowrate & & & \\
\hline
\end{tabular}

\begin{tabular}{|l|r|r|r|r|r|}
\hline Assays: & Ash $(\%)$ & Comb. (\%) & Tot. S (\%) & Pyr. S (\%) & Btu/lb \\
\hline Product & 21.39 & 78.61 & & & \\
\hline Reject & 83.77 & 16.23 & & & \\
\hline Feed & 31.38 & 68.62 & & & \\
\hline
\end{tabular}

\begin{tabular}{|c|c|c|c|c|c|c|}
\hline Recoveries (\%): & Yiold & Ash & Comb. & Tot, $\mathbf{S}$ & Prr. S & Btu \\
\hline Product & 83.99 & 57.25 & 96.21 & & & \\
\hline Roject & 16.01 & 42.75 & 3.79 & & & \\
\hline Feed & 100 & 100 & 100 & 100 & 100 & 100 \\
\hline
\end{tabular}


Appendix 4: Material balances for the 30 -inch column cyclone feed tests 


\begin{tabular}{|c|l|}
\hline MICROBUBBLE COLUMN FLOTATION TESTWORK & Date: Cyolone Feed \\
\hline Sample: Marrowbone (Feed Size Distribution) In-Plant, Cyolone Feed & Test No: 1 \\
\hline
\end{tabular}

\begin{tabular}{|l|l|}
\hline Sample Characteristics: & \\
\hline Percent Solids (As Received) & 6.17 \\
\hline Particle Size & coarse (-28 mesh) \\
\hline
\end{tabular}

\begin{tabular}{|l|l|}
\hline Column Geometry: & 21.5 feot \\
\hline Overall Height (bubble generators to cell lip) & 29.25 inches \\
\hline Diameter & 4.5 foet \\
\hline Feod Entry Point & 42 inches \\
\hline Froth Hoight & \\
\hline
\end{tabular}

\begin{tabular}{|l|l|l|}
\hline Reagent Additions: & \multicolumn{1}{|c|}{ Dosage (lbs/ton) } & \multicolumn{1}{c|}{ Type } \\
\hline Collector & 0.76 & Diesel \\
\hline Frother & 1.14 & DF1012 \\
\hline pH Modifier & & \\
\hline Dispersant & & \\
\hline
\end{tabular}

\begin{tabular}{|l|l|l|l|}
\hline Column Flows: & \multicolumn{1}{|c|}{$\mathrm{gpm}$} & oms/min & \%olids \\
\hline Gas Flowrate & $18.5(\mathrm{scfm})$ & & \\
\hline Wash Water Flowrate & 23 & & \\
\hline Foed Flowrate & $95(+1-10 \mathrm{gall}$ & & \\
\hline Product Flowrate & & & \\
\hline Reject (Tailings) Flowrate & & & \\
\hline
\end{tabular}

\begin{tabular}{|c|c|c|c|c|c|}
\hline Assays: & $A \sin (\%)$ & Comb. $(\%)$ & Tot. $\mathbf{s}(\%)$ & Pyr. $5(\%)$ & Btu/lb \\
\hline Product & 10.88 & 89.12 & & & \\
\hline Reject & 58.64 & 41,36 & & & \\
\hline Foed & 42.39 & 42.97 & & & \\
\hline
\end{tabular}

\begin{tabular}{|c|c|c|c|c|c|c|}
\hline Recoveries $(\%)$ : & Yiold & Ash & Comb. & Tot. $\mathbf{S}$ & Pyr. S & Btu \\
\hline Product & 34.02 & 8.73 & 52.63 & & & \\
\hline Reject & 65.98 & 91.27 & 47.37 & & & \\
\hline Food & 100 & 100 & 100 & 100 & 100 & 100 \\
\hline
\end{tabular}




\begin{tabular}{|c|l|}
\hline MICROBUBBLE COLUMN FLOTATION TESTWORK & Date: Cyclone Fned \\
\hline Sample: Marrowbone (Feod Size Distribution) In-Plant, Cyclone Foed & Tost No: 2 \\
\hline
\end{tabular}

\begin{tabular}{|c|c|}
\hline Porcent Solids (As Rocoived) & 8.68 \\
\hline Particle Size & conarge $(-28$ mesh $)$ \\
\hline \multicolumn{2}{|l|}{ Column Goometry: } \\
\hline Overall Hoight (bubble generators to cell ||$p)$ & 21.5 feet \\
\hline Diameter & 29.25 inches \\
\hline Food Entry Point & 4.5 foet \\
\hline Froth Hoight & 42. inches \\
\hline
\end{tabular}

\begin{tabular}{|l|l|l|}
\hline Reagent Additions: & \multicolumn{1}{|c|}{ Dosage (lbs/ton) } & \multicolumn{1}{|c|}{ Type } \\
\hline Collector & 0.73 & Diesol \\
\hline Frother & 0.99 & DF1012 \\
\hline pH Modifior & & \\
\hline Dispersant & & \\
\hline
\end{tabular}

\begin{tabular}{|l|l|l|l|}
\hline Colurnn Flows: & \multicolumn{1}{|c|}{ opm } & gms/min & \%olids \\
\hline Gas Flowrate & 18.5 (sctm) & & \\
\hline Wash Water Flowrate & 23 & & \\
\hline Foed Flowrate & $95(+1.10$ oal) & & \\
\hline Product Flowrate & & & \\
\hline Roject (Tailings) Flowrate & & & \\
\hline
\end{tabular}

\begin{tabular}{|c|c|c|c|c|c|}
\hline Assays: & Ash (x) & Comb. $(\%)$ & Tot. $\mathbf{S}(\%)$ & Pyr. S $(\%)$ & Btu/b \\
\hline Product & 10.44 & 89.56 & & & \\
\hline Roject & 58.14 & 41.86 & & & \\
\hline Foed & 46.14 & 53.86 & & & \\
\hline
\end{tabular}

\begin{tabular}{|c|c|c|c|c|c|c|}
\hline Recoveries $(\%)$ : & Yield & Ash & Comb. & iot. $\mathrm{s}$ & Pyr. S & Btu \\
\hline Product & 24.78 & 5.61 & 41.34 & & & \\
\hline Reject & 75.22 & 94.39 & 58.66 & & & \\
\hline Food & 100 & 100 & 100 & 100 & 100 & 100 \\
\hline
\end{tabular}




\begin{tabular}{||c|l||}
\hline MICROBUBBLE COLUMN FLOTATION TESTWORK & Date: Cyolone Feed \\
\hline Sample: Marrowbone (Foed Size Dlstribution) In-PIant, Cyolone Feed & Test No: 3 \\
\hline
\end{tabular}

\begin{tabular}{|l|l|}
\hline Sample Characteristios: \\
\hline Percent Solids (As Recoived) & 8.16 \\
\hline Partiole Size & coarse (-28 mesh) \\
\hline
\end{tabular}

\begin{tabular}{|l|l|}
\hline Column Geometry: & 21.5 feet \\
\hline Overall Helght (bubble generators to cell lip) & 29.25 inches \\
\hline Diameter & 4.5 feet \\
\hline Feed Entry Point (bubble generators to feed point) & 42 inohes \\
\hline Froth Height & \\
\hline
\end{tabular}

\begin{tabular}{||l|l|l||}
\hline Reagent Additions: & \multicolumn{1}{|c|}{ Dosage (lbs/ton) } & \multicolumn{1}{c|}{ Type } \\
\hline Collector & 0.78 & Diesel \\
\hline Frather & 0.72 & DF1012 \\
\hline ply Modifier & & \\
\hline Dispersant & & \\
\hline
\end{tabular}

\begin{tabular}{|l|l|l|l|}
\hline Column Flows: & \multicolumn{1}{|c|}{$\mathrm{gpm}$} & oms/min & $\%$ solids \\
\hline Gas Flowrate & 18.5 (scfm) & & \\
\hline Wash Water Flowrate & 23 & & \\
\hline Foed Flowrate & $95(+1.10$ gall) & & \\
\hline Product Flowrate & & & \\
\hline Rejoct (Tailings) Flowrate & & & \\
\hline
\end{tabular}

\begin{tabular}{|l|r|r|r|r|r|}
\hline Assays: & Ash $(\%)$ & Comb. (\%) & Tot. S (\%) & Pyr. S (\%) & Btu/lb \\
\hline Product & 9.97 & 90.03 & & & \\
\hline Reject & 57.18 & 42.82 & & & \\
\hline Foed & 44.66 & 55.34 & & & \\
\hline
\end{tabular}

\begin{tabular}{|l|c|c|c|c|c|c|}
\hline Recoveries $(\%):$ & Yield & Ash & Comb. & Tot. S & Pyr. S & Btu \\
\hline Product & 26.52 & 5.92 & 43.14 & & & \\
\hline Roject & 73.48 & 94.08 & 56.86 & & & \\
\hline Foed & 100 & 100 & 100 & 110 & 100 & 100 \\
\hline
\end{tabular}




\begin{tabular}{|c|l|}
\hline MICROBUBBLE COLUMN FLOTATION TESTWOAK & Date: Cyolono Foed \\
\hline Sample: Marrowbono (Operating Par./Froth Add.) In.Plant, Cyolone Feed & Tost No: 1 \\
\hline
\end{tabular}

\begin{tabular}{|l|l|}
\hline Sample Characteristios: & \\
\hline Parcent Solids (As Received) & 6.52 \\
\hline Particle Size & -28 mesh \\
\hline
\end{tabular}

\begin{tabular}{|l|l|}
\hline Column Geometry: & 21.5 feet \\
\hline Overall Hoight (bubble generators to oell lip) & 29.25 Inches \\
\hline Dlameter & 4.5 foet \\
\hline Foed Entry Point & 40 inches \\
\hline Froth Hoight & \\
\hline
\end{tabular}

\begin{tabular}{|l|l|l||}
\hline Reagent Additions: & \multicolumn{1}{|c|}{ Dosage (lbs/ton) } & \multicolumn{1}{c|}{ TYpo } \\
\hline Collector & 1.30 & Diesel \\
\hline Frother & 0.79 & DF1012 \\
\hline pH Modifier & & \\
\hline Dispergant & & \\
\hline
\end{tabular}

\begin{tabular}{|l|l|l|l||}
\hline Column Flows: & \multicolumn{1}{|c|}{$\mathrm{gpm}$} & gms/min & $\%$ solids \\
\hline Gas Flowrate & $16.4(\mathrm{scfm})$ & \\
\hline Wash Wuter Flowrate & 23 & & \\
\hline Foed Flowrate & 100 & & \\
\hline Product Flowrate & & & \\
\hline Reject (Tallings) Flowrato & & & \\
\hline
\end{tabular}

\begin{tabular}{|c|c|c|c|c|c|}
\hline Assays: & Ash (\%) & Comb. $(\%)$ & Tot. $\mathbf{S}(\%)$ & Pyr. S $(\%)$ & Btu/lb \\
\hline Product & 12.68 & 87.32 & & & \\
\hline Reject & 61.33 & 38.67 & & & \\
\hline Foed & 49.69 & 50.31 & & & \\
\hline
\end{tabular}

\begin{tabular}{|c|c|c|c|c|c|c|}
\hline Recoveries $(\%)$ : & Yiold & Ash & Comb. & Tot. $\mathbf{S}$ & Pyr. S & Btw \\
\hline Product & 23.93 & 6.11 & 41.53 & & & \\
\hline Roject & 76.07 & 93.89 & 58.47 & & & \\
\hline Foed & 100 & 100 & 100 & 100 & 100 & 100 \\
\hline
\end{tabular}




\begin{tabular}{|l|l|}
\hline MICROBUBBLE COLUMN FLOTATION TESTWORK & Date: Cyolone Foed \\
\hline Sarnple: Marrowbone (Operating Par./Froth Add.) In-Plant, Cyolone Feed & Test No: 2 \\
\hline
\end{tabular}

\begin{tabular}{|l|l||}
\hline Sample Characteristics: & \\
\hline Percent Sollds (As Received) & 7.41 \\
\hline Particle Size & -28 mesh \\
\hline
\end{tabular}

\begin{tabular}{|l|l|}
\hline Column Geometry: & 21.5 feet \\
\hline Overall Helght (bubble generators to cell lip) & 29.25 inches \\
\hline Diameter & 4.5 feet \\
\hline Feed Entry Point & 40 inches \\
\hline Froth Helght & \\
\hline
\end{tabular}

\begin{tabular}{|l|l|l|}
\hline Reagent Additions: & \multicolumn{1}{|c|}{ Dosage (lbs/ton) } & Typo \\
\hline Collector & 1.14 & Diesel \\
\hline Frother & 1.04 & DF1012 \\
\hline pH Modifier & & \\
\hline Dispersant & & \\
\hline
\end{tabular}

\begin{tabular}{|l|l|c|c|}
\hline Column Flows: & \multicolumn{1}{|c|}{ gpm } & gms/min & $\%$ solids \\
\hline Gas Flowrate & 16.4 (scfm) & & \\
\hline Wash Water Flowrate & 23 & & \\
\hline Foed Flowrate & 100 & & \\
\hline Product Flowrate & & & \\
\hline Reject (Tallings) Flowrate & & & \\
\hline
\end{tabular}

\begin{tabular}{|l|r|r|r|r|r|}
\hline Assays: & Ash (\%) & Comb. (\%) & Tot. S (\%) & Pyr. S (\%) & Btu/lb \\
\hline Product & 10.21 & 89.79 & & & \\
\hline Reject & 56.94 & 43.06 & & & \\
\hline Foed & 49.37 & 50.63 & & & \\
\hline
\end{tabular}

\begin{tabular}{|l|c|c|c|c|c|c|}
\hline Rocoveries (\%): & Yield & Ash & Comb. & Tot. S & Pyr. S & Btu \\
\hline Product & 16.20 & 3.35 & 28.73 & & & \\
\hline Reject & 83.80 & 96.64 & 71.27 & & & \\
\hline Foed & 100 & 100 & 100 & 100 & 100 & 100 \\
\hline
\end{tabular}


Sample: Marrowbone (Operating Par./Froth Add.) In-Plant, Cyclone Feed

Test No: 3

Sample: Marrowbone (Oparating Par Froth Add) In-Plant, Cvclong Foed

\begin{tabular}{|l|l|}
\hline Sample Characteristics: & \\
\hline Porcent Solids (As Received) & 8.00 \\
\hline Particle Size & -28 mesh \\
\hline
\end{tabular}

\section{Column Geometry:}

Overall Height (bubble generators to cell lip)

21.5 feet

Diameter

29.25 inches

Food Entry Point

4.5 feet

Froth Height

40 inches

\begin{tabular}{|l|l|l|}
\hline Reagent Additions: & \multicolumn{1}{|c|}{ Dosage (lbs/ton) } & \multicolumn{1}{|c|}{ Type } \\
\hline Collector & 1.05 & Diesel \\
\hline Frother & 1.60 & DF1012 \\
\hline pH Modifior & & \\
\hline Dispersant & & \\
\hline
\end{tabular}

\begin{tabular}{|l|l|l|l|}
\hline Column Flows: & \multicolumn{1}{|c|}{$\mathrm{gpm}$} & gms/min & \%olids \\
\hline Gas Flowrate & $16.4(\mathrm{scfm})$ & & \\
\hline Wash Water Flowrate & 23 & & \\
\hline Foed Flowrate & 120 & & \\
\hline Product Flowrato & & & \\
\hline Raject (Tailingsi Flowrate & & & \\
\hline
\end{tabular}

\begin{tabular}{|c|c|c|c|c|c|}
\hline Assays: & $\operatorname{Ash}(\%)$ & Comb. $(\%)$ & Tot. $\mathbf{S}(\%)$ & Pyr. S $(\%)$ & Btu/b \\
\hline Product & 9.92 & 90.08 & & & \\
\hline Reject & 57.54 & 42.46 & & & \\
\hline Food & 50.12 & 49.88 & & & \\
\hline
\end{tabular}

\begin{tabular}{|c|c|c|c|c|c|c|}
\hline Pecoveries (\%): & Yield & Ash & Comb. & Tot. $\mathrm{s}$ & Pyr. $\mathbf{S}$ & Btu \\
\hline Product & 15.58 & 3.08 & 28.14 & & & \\
\hline Reject & 84.42 & 96.92 & 71.86 & & & \\
\hline Foed & 100 & 100 & 100 & 100 & 100 & 100 \\
\hline
\end{tabular}


Sample: Marrowbone (Operating Par./Froth Add.) In-Plant, Cyclone Foed

Date: Cyclone Feed

Test No: 4

\begin{tabular}{|l|l|}
\hline Sample Characteristics: \\
\hline Percent Solids (As Received) & 7.79 \\
\hline Particle Size & -28 mosh \\
\hline
\end{tabular}

\begin{tabular}{|l|l|}
\hline Column Geometry: & 21.5 feet \\
\hline Overall Height (bubble generators to cell lip) & 29.25 inches \\
\hline Diameter & 4.5 feet \\
\hline Feed Entry Point & 40 inches \\
\hline Froth Height & \\
\hline
\end{tabular}

\begin{tabular}{|l|l|l|}
\hline Reagent Additions: & \multicolumn{1}{|c|}{ Dosage (lbs/ton) } & \multicolumn{1}{c|}{ Type } \\
\hline Collector & 1.08 & Diesel \\
\hline Frother & 1.64 & DF1012 \\
\hline pH Modifier & & \\
\hline Dispersant & & \\
\hline
\end{tabular}

\begin{tabular}{|l|l|l|l|}
\hline Column Flows: & \multicolumn{1}{|c|}{$\mathrm{gpm}$} & gms/min & \% \\
\hline Gas Flowrate & 18.5 (scfm) & & \\
\hline Wash Water Flowrate & 23 & & \\
\hline Foed Flowrate & 100 & & \\
\hline Product Flowrate & & & \\
\hline Reject (Tailings) Flowrate & & & \\
\hline
\end{tabular}

\begin{tabular}{|l|r|r|r|r|r|}
\hline Assays: & Ash (\%) & Comb. (\%) & Tot. S (\%) & Pyr. S (\%) & Btu/b \\
\hline Product & 10.35 & 89.65 & & & \\
\hline Rejøct & 54.27 & 45.73 & & & \\
\hline Feod & 46.25 & 53.75 & & & \\
\hline
\end{tabular}

\begin{tabular}{|l|c|c|c|c|c|c|}
\hline Recoveries (\%): & Yield & Ash & Comb. & Tot. S & Pyr. S & Btu \\
\hline Product & 18.26 & 4.09 & 30.46 & & & \\
\hline Rejact & 81.74 & 95.91 & 69.54 & & & \\
\hline Foed & 100 & 100 & 100 & 100 & 100 & 100 \\
\hline
\end{tabular}




\section{MICROBUBBLE COLUMN FLOTATION TESTWORK}

Date: Cyclone Feed

Sample: Marrowbone (Operating Par./Froth Add.) In-Plant, Cyclone Feod

Test No: 5

Tost No: 5

Sample Characteristics:

Percent Solids (As Received)

8.53

Particle Size

-28 mesh

Column Geometry:

Overall Height (bubble generators to cell lip)

Diameter

21.5 feet

Food Entry Point

29.25 inches

Froth Height

4.5 feet

40 inches

\begin{tabular}{|l|l|l|}
\hline Reagent Additions: & \multicolumn{1}{|c|}{ Dosage (lbstton) } & \multicolumn{1}{|c|}{ Typo } \\
\hline Collector & 0.99 & Diesel \\
\hline Frother & 0.90 & DF1012 \\
\hline pH Modifier & & \\
\hline Dispersant & & \\
\hline
\end{tabular}

\begin{tabular}{|l|l|l|l|}
\hline Column Flows: & \multicolumn{1}{|c|}{$\mathrm{opm}$} & oms/min & \% solids \\
\hline Gas Flowrote & 18.5 (scfm) & & \\
\hline Wash Water Flowrate & 23 & & \\
\hline Foed Flowrate & 100 & & \\
\hline Product Flowrate & & & \\
\hline Reject (Tailings) Flowrate & & & \\
\hline
\end{tabular}

\begin{tabular}{|c|c|c|c|c|c|}
\hline Assays: & Ast $(\%)$ & Comb. $(\%)$ & Tot. $S(\%)$ & Pyr. S $(\%)$ & Btu/b \\
\hline Product & 10.66 & 89.34 & & & \\
\hline Roject & 61.07 & 38.93 & & & \\
\hline Food & 52.25 & 47.75 & & & \\
\hline
\end{tabular}

\begin{tabular}{|c|c|c|c|c|c|c|}
\hline Recoveries (\%): & Yield & Ash & Comb. & Tot. $\mathbf{S}$ & Pyr. S & Btu \\
\hline Product & 17.50 & 3.57 & 32.74 & & & \\
\hline Reject & 82.50 & 96.43 & 67.26 & & & \\
\hline Foed & 100 & 100 & 100 & 100 & 100 & 100 \\
\hline
\end{tabular}




\begin{tabular}{|c|l|}
\hline MICROBUBBLE COLUMN FLOTATION TESTWORK & Dete: Cyclone Feed \\
\hline Sample: Marrowbone (Oporating Par./Froth Add.) In-Plant, Cyclone Feed & Test No: 6 \\
\hline
\end{tabular}

\begin{tabular}{|l|l|}
\hline Sample Characteristics: & \\
\hline Percent Solids (As Received) & 9.87 \\
\hline Particle Size & -28 mesh \\
\hline
\end{tabular}

\begin{tabular}{|l|l|}
\hline Column Geometry: & \\
\hline Overall Height lbubble venerators to cell lipl & 21.5 feet \\
\hline Diameter & 29.25 inches \\
\hline Feed Entry Point & 4.5 feet \\
\hline Froth Height & 40 inches \\
\hline
\end{tabular}

\begin{tabular}{|l|l|l|}
\hline Reagent Additions: & \multicolumn{1}{|c|}{ Dosage (lbs/ton) } & \multicolumn{1}{|c|}{ Type } \\
\hline Collector & 0.85 & Diesel \\
\hline Frother & 0.51 & DF 1012 \\
\hline pH Modifier & & \\
\hline Dispersant & & \\
\hline
\end{tabular}

\begin{tabular}{|l|l|l|l|}
\hline Column Flows: & \multicolumn{1}{|c|}{$\mathrm{gpm}$} & gms/min & \%olids \\
\hline Gas Flowrate & 18.5 (scfm) & & \\
\hline Wash Water Flowrate & 23 & & \\
\hline Foed Flowrate & 100 & & \\
\hline Product Flowrate & & & \\
\hline Reject (Tailings) Flowrate & & & \\
\hline
\end{tabular}

\begin{tabular}{|l|r|r|r|r|r|}
\hline Assays: & Ash $(\%)$ & Comb. $(\%)$ & Tot. S (\%) & Pyr. S (\%) & Btu/b \\
\hline Product & 9.63 & 90.37 & & & \\
\hline Reject & 57.69 & 42.31 & & & \\
\hline Feed & 51.14 & 48.86 & & & \\
\hline
\end{tabular}

\begin{tabular}{|c|c|c|c|c|c|c|}
\hline Recoveries $(\%)$ : & Yiold & Ash & Comb. & Tot. $\mathbf{S}$ & Pyr. S & Btu \\
\hline Produet & 13.63 & 2.57 & 25.21 & & & \\
\hline Rejoct & 86.37 & 97.43 & 74.79 & & & \\
\hline Food & 100 & 100 & 100 & 100 & 100 & 100 \\
\hline
\end{tabular}




\begin{tabular}{|l|l|}
\hline MICROBUBBLE COLUMN FLOTATION TESTWORK & Date: Cyclone Feed \\
\hline Sample: Marrowbone 1Operating Par./Froth Add.) In-Plant, Cyclone Feed & Test No: 7 \\
\hline
\end{tabular}

\begin{tabular}{|l|l|}
\hline Sample Characteristics: \\
\hline Porcent Solids (As Received) & 9.20 \\
\hline Particle Sizo & -28 mesh \\
\hline
\end{tabular}

\begin{tabular}{|l|l|}
\hline Column Goomotry: & 21.5 foet \\
\hline Overall Height (bubble generators to cell lip) & 29.25 inches \\
\hline Diameter & 4.5 feet \\
\hline Foed Entry Point & 40 inches \\
\hline Froth Height & \\
\hline
\end{tabular}

\begin{tabular}{|l|l|l|}
\hline Reagent Additions: & \multicolumn{1}{|c|}{ Dosage (lbs/ton) } & \multicolumn{1}{|c|}{ Type } \\
\hline Collector & 0.69 & Diesel \\
\hline Frother & 0.55 & DF1012 \\
\hline pH Modifier & & \\
\hline Disporsant & & \\
\hline
\end{tabular}

\begin{tabular}{|l|l|l|l|}
\hline Column Flows: & \multicolumn{1}{|c|}{ gpm } & gms/min & \% solids \\
\hline Gas Flowrate & 18.5 (sctm) & & \\
\hline Wash Water Flowrate & 23 & & \\
\hline Foed Flowrate & 100 & & \\
\hline Product Flowrate & & & \\
\hline Reject (Tailings) Flowrate & & & \\
\hline
\end{tabular}

\begin{tabular}{|c|c|c|c|c|c|}
\hline Assays: & Ash (\%) & Coinb. $(\%)$ & Tot. S $(\%)$ & Pyr. $5(\%)$ & Btu/Ab \\
\hline Product & 10.33 & 89.67 & & & \\
\hline Reject & 57.72 & 42.28 & & & \\
\hline Foed & 51.65 & 48.35 & & & \\
\hline
\end{tabular}

\begin{tabular}{|c|c|c|c|c|c|c|}
\hline Recoveries (\%): & Yiold & Ash & Comb. & Tot. $\mathbf{S}$ & Pyr. S & Btu \\
\hline Product & 12.81 & 2.56 & 23.75 & & & \\
\hline Reject & 87.19 & 97.44 & 76.25 & & & \\
\hline Food & 100 & 100 & 100 & 100 & 100 & 100 \\
\hline
\end{tabular}




\begin{tabular}{|l|l|}
\hline Sample Characteristics: \\
\hline Percent Solids (As Received) & 9.20 \\
\hline Particle Size & +28 mesh \\
\hline
\end{tabular}

\begin{tabular}{|l|l|}
\hline Column Geometry: & \\
\hline Overall Heipt,c (bubble generators to cell lip) & 21.5 feet \\
\hline Diameter & 29.25 inches \\
\hline Feed Entry Point & 4.5 feet \\
\hline Froth Height & 40 inches \\
\hline
\end{tabular}

\begin{tabular}{|l|l|l|}
\hline Reagent Additions: & \multicolumn{1}{|c|}{ Dosage (lbs/ton) } & \multicolumn{1}{|c|}{ Type } \\
\hline Collector & 0.69 & Diesel \\
\hline Frother & 0.83 & DF1012 \\
\hline pH Modifier & & \\
\hline Dispersant & & \\
\hline
\end{tabular}

\begin{tabular}{|l|l|l|l|}
\hline Column Flows: & \multicolumn{1}{|c|}{ gpm } & gms/min & \%olids \\
\hline Gns Flowrate & 18.4 (scfm) & & \\
\hline Wash Water Flowrate & 23 & & \\
\hline Foed Flowrate & 100 & & \\
\hline Product Flowrato & & & \\
\hline Reject (Tailings) Flowrate & & & \\
\hline
\end{tabular}

\begin{tabular}{|c|c|c|c|c|c|}
\hline Assays: & $A \sin (\%)$ & Comb. $(\%)$ & Tot. $\mathbf{S}(\%)$ & Pyr. S $(\%)$ & Btu/lb \\
\hline Product & 11.69 & 88.31 & & & \\
\hline Reject & 55.69 & 44.31 & & & \\
\hline Foed & 52.08 & 47.92 & & & \\
\hline
\end{tabular}

\begin{tabular}{|c|c|c|c|c|c|c|}
\hline Recoveries (\%): & Yield & Ash & Comb. & Tot. $\mathrm{S}$ & Pyr. S & Btu \\
\hline Product & 8.20 & 1.84 & 15.12 & & & \\
\hline Reject & 91.80 & 98.16 & 84.88 & & & \\
\hline Foed & 100 & 100 & 100 & 100 & 100 & 100 \\
\hline
\end{tabular}




\begin{tabular}{|c|l|}
\hline MICROBUBBLE COLUMN FLOTATION TESTWORK & Date: Cyclone Foed \\
\hline Sample: Marrowbono (Operating Par./Froth Add.) In-PIant, Cyclone Foed & Tost No: 9 \\
\hline
\end{tabular}

\begin{tabular}{|l|l|}
\hline Sample Characteristics: & \\
\hline Porcent Solids (As Received) & 9.20 \\
\hline Particle Size & -28 mesh \\
\hline
\end{tabular}

\section{Column Geomotry:}

Overall Height (bubble generators to cell lip)

21.5 foot

Diameter

29.25 inches

Food Entry Point

4.5 feet

Froth Height

40 inches

\begin{tabular}{|l|l|l|}
\hline Reagent Additions: & \multicolumn{1}{|c|}{ Dosage (lbs/ton) } & \multicolumn{1}{|c|}{ Type } \\
\hline Collector & 1.38 & Diesel \\
\hline Frother & 0.69 & DF1012 \\
\hline pH Modifier & & \\
\hline Dispersant & & \\
\hline
\end{tabular}

\begin{tabular}{|l|l|l|l|}
\hline Column Flows: & \multicolumn{1}{|c|}{ gpm } & \multicolumn{1}{c|}{ oms $/ \mathrm{min}$} & \% solids \\
\hline Gas Flowrate & $18.4(\mathrm{scfm})$ & & \\
\hline Wash Water Flowrate & 23 & & \\
\hline Foed Flowrate & 100 & & \\
\hline Product Flowrate & & & \\
\hline Reject (Tailings) Flowrate & & & \\
\hline
\end{tabular}

\begin{tabular}{|l|r|r|r|r|l|}
\hline Assays: & Ash (\%) & Comb. (\%) & Tot. S (\%) & Pyr. S (\%) & Btu/lb \\
\hline Product & 11.60 & 88.40 & & & \\
\hline Roject & 56.81 & 43.19 & & & \\
\hline Foed & 51.53 & 48.47 & & & \\
\hline
\end{tabular}

\begin{tabular}{|l|c|c|c|c|c|c|}
\hline Recoveries (\%): & Yiold & Ash & Comb. & Tot. S & Pyr. S & Btu \\
\hline Product & 11.68 & 2.63 & 21.30 & & & \\
\hline Reject & 88.32 & 97.37 & 78.70 & & & \\
\hline Foed & 100 & 100 & 100 & 100 & 100 & 100 \\
\hline
\end{tabular}


Appendix 5: Summary of the statistical data analysis computations for the 30-inch column parametric test program 


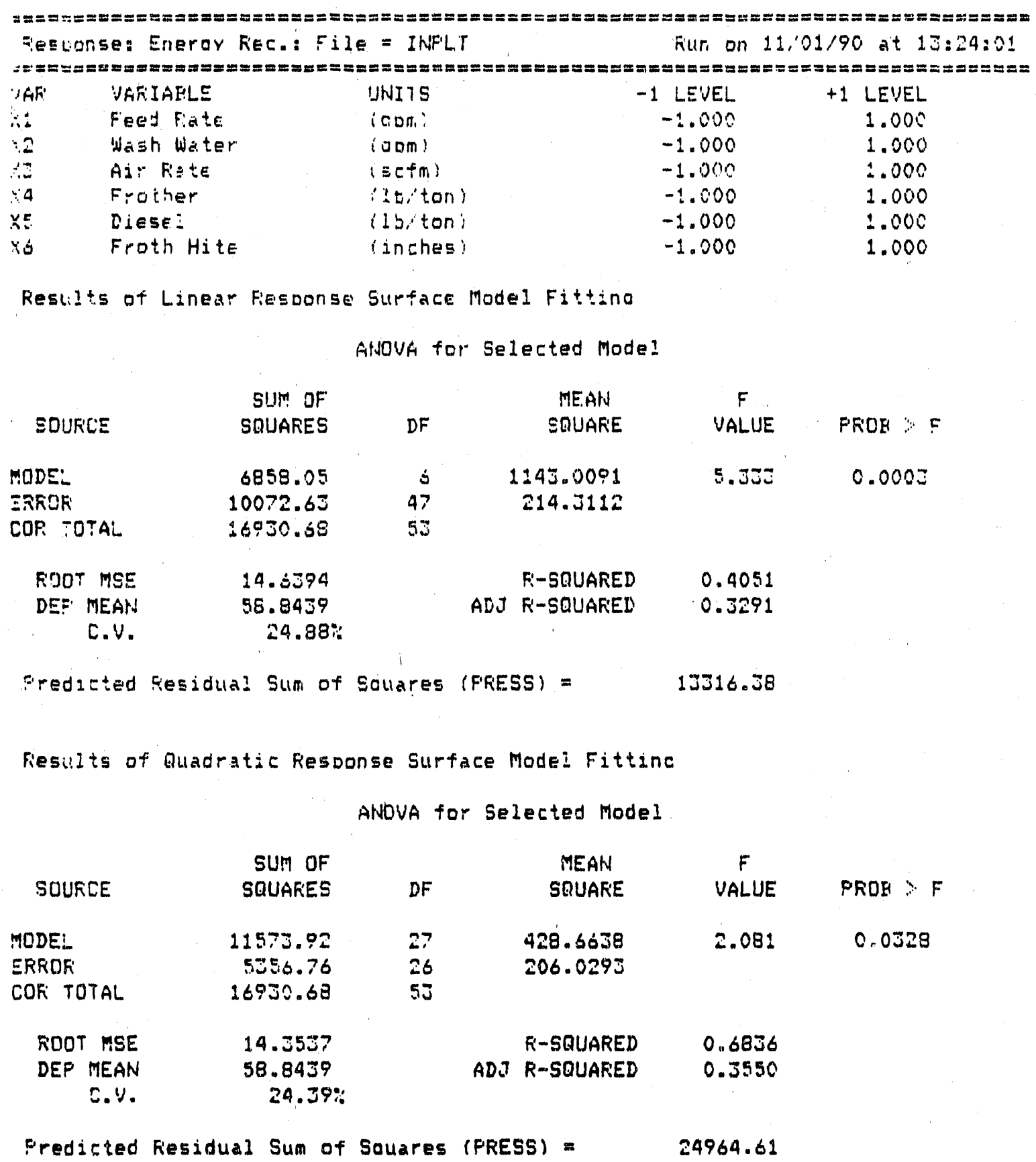

\section{Results of Cubic Resoonse Surface Model Fittino}

ANOUA for Selected Model

\begin{tabular}{|c|c|c|c|c|c|}
\hline & SUM of & & MEAN & $F$ & \\
\hline SOUFEE & SQUAFEES & DF & SQUARE & VALUE & FROE $\supset F$ \\
\hline $\begin{array}{l}\text { TODE: } \\
\text { EFROF: } \\
\text { SOF TCTAL }\end{array}$ & $\begin{array}{r}15200.05 \\
15.0 .55 \\
10050.68\end{array}$ & $\begin{array}{r}45 \\
8 \\
5\end{array}$ & $\begin{array}{l}359.1: 22 \\
\text { 208.8295 }\end{array}$ & 1.024 & 0.2401 \\
\hline FUOT MSE & 12.1500 & & R-SQUAKED & 0.0013 & \\
\hline
\end{tabular}




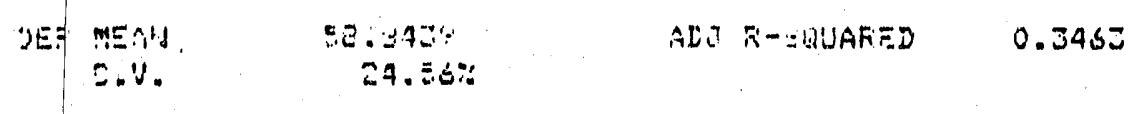

Freglizted Fesidual Sun of Squares (FRESS) = 224428.49

ANour S:Immary of models fit

\begin{tabular}{|c|c|c|c|c|c|}
\hline & SUM LF & & TEAN & 5 & \\
\hline SOUJCE & SQUAFIES & $D F$ & SUIJAR:E & VALUEE & FF:OE \\
\hline LINEAF & $68: 8.05$ & í & $1: 93.01$ & 5.353 & 0.0003 \\
\hline JADHATIC & 4715.57 & 21 & $22 Q_{0} 5$ & 1.090 & 0.9127 \\
\hline CUgIC & 3686.15 & 10 & 224.78 & 0.9806 & 0.5437 \\
\hline EF:FEOR & \pm 670.63 & 8 & 208.83 & & \\
\hline OR TOTAL & 16930.68 & 5 & & & \\
\hline
\end{tabular}

Latil or Fit tests

\begin{tabular}{|c|c|c|c|c|c|}
\hline MODEL & $\begin{array}{l}\text { SUM OF } \\
\text { SQUARES }\end{array}$ & DF & $\begin{array}{c}\text { MEAN } \\
\text { SQUARE }\end{array}$ & $\begin{array}{c}\text { F } \\
\text { VALUE }\end{array}$ & PFOE \& F \\
\hline $\begin{array}{r}\text { INEAF } \\
\text { QUAINFATIC } \\
\text { CUEIC } \\
\text { PUIRE EFF }\end{array}$ & $\begin{array}{r}9274.18 \\
4558.31 \\
872.18 \\
708.45\end{array}$ & $\begin{array}{r}42 \\
21 \\
3 \\
5\end{array}$ & $\begin{array}{l}220.81 \\
217.06 \\
200.73 \\
159.69\end{array}$ & $\begin{array}{l}1.383 \\
1.359 \\
1.821\end{array}$ & $\begin{array}{l}0.3902 \\
0.3950 \\
0.2603\end{array}$ \\
\hline
\end{tabular}

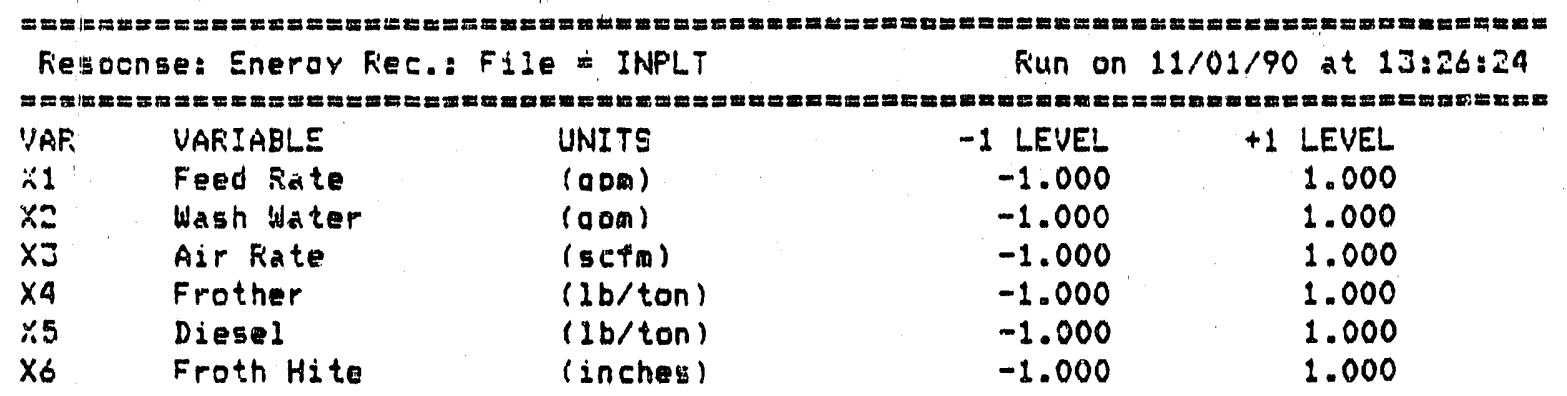

Results of Cubic Resoonse Surface Model Fittino

ANOUA for Selected Model

\begin{tabular}{|c|c|c|c|c|c|}
\hline SOURCE & $\begin{array}{r}\text { SUM OF } \\
\text { SQUARES }\end{array}$ & DF & $\begin{array}{l}\text { MEAN } \\
\text { SQUARE }\end{array}$ & $\begin{array}{c}\text { F } \\
\text { VALUEE }\end{array}$ & PFOB $>F$ \\
\hline $\begin{array}{l}\text { MODEL } \\
\text { ERROK } \\
\text { COR TOTAL }\end{array}$ & $\begin{array}{r}15260.05 \\
1670.65 \\
16930.68\end{array}$ & $\begin{array}{r}45 \\
0 \\
53\end{array}$ & $\begin{array}{l}339.1122 \\
208.8293\end{array}$ & 1.624 & 0.2401 \\
\hline $\begin{array}{c}\text { ROOT MSE } \\
\text { DEP MEAN } \\
\text { C.V. }\end{array}$ & $\begin{array}{r}14.4509 \\
58.8439 \\
24.56 \%\end{array}$ & & $\begin{aligned} & R-\text { SQUARED } \\
\text { ADJ } & R \text {-SQUARED }\end{aligned}$ & $\begin{array}{l}0.9013 \\
0.346 j\end{array}$ & \\
\hline Predicted & Residual sum of & Souares & (PRESS) $=$ & 224428.49 & \\
\hline VAKIALLE & $\begin{array}{l}\text { PARAMETER } \\
\text { ESTIMATE }\end{array}$ & $D F$ & $\begin{array}{l}\text { STANIDARDD } \\
\text { ERRROR }\end{array}$ & $\begin{array}{c}\text { \& FOK HO } \\
\text { CAF'AMETEF'=0 }\end{array}$ & FFDE $\vartheta: t:$ \\
\hline Interceot. & $4 \% .9250$ & 1 & 5.5996 & 8. 465 & \\
\hline
\end{tabular}




\begin{tabular}{|c|c|c|c|c|c|}
\hline$\because 1$ & $-4.385 C$ & 1 & 5.1092 & $-0.358 \mathrm{~J}$ & 0.7157 \\
\hline Y.2 & 3.2450 & 1 & 5.1092 & 0.6351 & 0.5431 \\
\hline$\times 3$ & -2.7437 & 1 & 5.1092 & -0.5762 & 0.5803 \\
\hline$\times 4$ & 14.7338 & 1 & $5.10 \% 2$ & 2.884 & 0.0204 \\
\hline$\times 5$ & 0.1350 & 1 & 5.1092 & $2.54 E-02$ & 0.9796 \\
\hline$\ddot{x i s}$ & $-10.12 \leqslant 2$ & 1 & 5.1092 & $-1.98 I$ & 0.0825 \\
\hline $12 * 2 \times 1$ & 9.76.71 & $:$ & $4.505 \%$ & 1.746 & 0.0876 \\
\hline$\times 2 x \times 2$ & $8.447:$ & 1 & 4.5059 & 1.075 & 0.0977 \\
\hline vitus & 1.5993 & $\dot{1}$ & 9.5059 & 0.3528 & 0.7334 \\
\hline 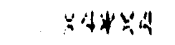 & -3.9767 & $i$ & 4.5050 & -0.8826 & 0.4032 \\
\hline$\therefore \Delta x x^{5}$ & $4 ., 1,1$ & 1 & 4.5059 & 1.091 & 0.3069 \\
\hline$\because 6 * \times 5$ & 0.3233 & 1 & 4.5059 & $7.19 E-02$ & 0.9446 \\
\hline$\times 1 \times \times 2$ & 1.3975 & 1 & 5.1092 & 0.2735 & 0.7914 \\
\hline 足1 $1 \times 3$ & 0.3450 & 1 & 5.1092 & $6.755-02$ & 0.9478 \\
\hline$\div 1 * 4 \times$ & -4.3925 & 1 & 3.6127 & -1.210 & 0.2587 \\
\hline 政彞 & 5.5895 & 1 & 5.1092 & 1.093 & 0.3064 \\
\hline$\because: * \times 6$ & -2.0200 & 1 & 5.1092 & -0.3954 & 0.7029 \\
\hline$\times 2 \times 3$ & 1.3762 & 1 & 5.1092 & 0.2594 & 0.7945 \\
\hline$Y \pm * \times 4$ & 5.1500 & 1 & 5.1092 & \pm .204 & 0.2531 \\
\hline$\times 2 * \times 5$ & 2.9331 & 1 & $3.612 ?$ & 0.8119 & 0.4403 \\
\hline$\because 2 \times 6$ & $\therefore .9000$ & 1 & 5.1092 & $0.352 \pi$ & 0.7337 \\
\hline Xวะ $\times 4$ & -6.5413 & 1 & $5.10 \% 2$ & -1.280 & $0.236 J$ \\
\hline$x=\times \times 5$ & 3.4512 & 1 & 5.1092 & 0.6755 & 0.5184 \\
\hline $13 * \times 0$ & 2.6094 & 1 & 3.6127 & 0.7223 & 0.4907 \\
\hline$\times 4+255$ & -5.5050 & 1 & 5.1092 & -0.6860 & 0.5121 \\
\hline$\times 4 * \times 6$ & 9.8362 & 1 & 5.1092 & 1.925 & 0.0904 \\
\hline$\therefore 5 \times \times 6$ & 3.7750 & 1 & 5.1092 & 0.7389 & 0.4811 \\
\hline$x 1 * \times 1 * x=1$ & ALIASED & 0 & & & \\
\hline 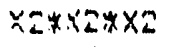 & ALIASED & 0 & & ' & \\
\hline 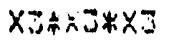 & ALIASED & 0 & & & \\
\hline$x 4 x \times 4 \times \times 4$ & ALIASED & 0 & & & \\
\hline 石5 & AL I ASED & 0 & & & \\
\hline$x \leqslant x \times \leq x \times 6$ & ALIASED & 0 & & & \\
\hline$\{1 \times \times 1 * \times 2$ & -12.2250 & 1 & 7.2255 & -1.692 & 0.1291 \\
\hline$\times 1 * \times 1 * x=$ & 11.0012 & 1 & 7.2255 & $1.52 j$ & 0.1564 \\
\hline 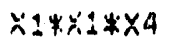 & -8.5113 & 1 & 7.2255 & -1.178 & 0.2727 \\
\hline$x 1 * \times 1 * \times 5$ & 1.7600 & 1 & 7.2255 & 0.2456 & 0.8137 \\
\hline$<1 \times \times 1 * \times 6$ & 2.3037 & 1 & 7.2255 & 0.3188 & 0.7580 \\
\hline 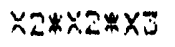 & 12.3675 & 1 & 7.2255 & 1.712 & 0.1253 \\
\hline$x 心 \times=\times \times 4$ & 4.0200 & 1 & 7.2255 & 0.5564 & 0.5932 \\
\hline ำ. $\times 2 * \times 5$ & ALI ISED & 0 & & & \\
\hline$\times 2 \times 52 * 2 \times 6$ & -0.5312 & 1 & 7.2255 & $-7.35 E-02$ & 0.9432 \\
\hline$x 3 * \times 3 * \times 4$ & ALIASED & 0 & & & \\
\hline$\times 3 \times \times 3 * \times 5$ & -1.6837 & 1 & 7.2255 & -0.2350 & 0.8216 \\
\hline$\times 3 * \times 3 * \times 6$ & ALIASED & 0 & & & \\
\hline$x 4 * \times 4 * \times 5$ & ALIASED & 0 & & & \\
\hline$\times 4 \times \times 4 * \times 6$ & ALIASED & 0 & & & \\
\hline$\times 5 * \times 5 * \times 6$ & ALIASED & 0 & & & \\
\hline$\times 1 * x 2 * x 2$ & -4.7100 & 1 & 7.2255 & -0.0519 & 0.5328 \\
\hline$x: * x=* x J$ & -5.7725 & 1 & 7.2255 & -0.7989 & 0.4474 \\
\hline$x .1 * \times 4 * x 4$ & ALIASED & 0 & & & \\
\hline$x 1 * 05 \times x 5$ & ALIASED & 0 & & & \\
\hline$x 1 * \times 6 * x 6$ & ALIASED & 0 & & & \\
\hline 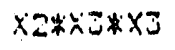 & -0.6388 & 1 & 7.2255 & $-8.84 E-02$ & 0.7317 \\
\hline$\times 24 \times 4 x \times 4$ & ALIASED & 0 & & & \\
\hline 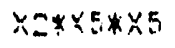 & ALIASED & 0 & & & \\
\hline 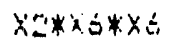 & ALIASED & 0 & & & \\
\hline 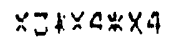 & ALIASED & 0 & & & \\
\hline 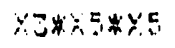 & ALIASEI & 0 & & & \\
\hline$\because: 7 x \leq x: 26$ & ALIASES & 0 & & & \\
\hline
\end{tabular}




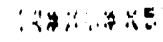

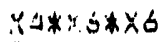 \\ $\therefore 5 * 50 x \div 6$ \\ $\because 1 \times \times 2 * x 3$ \\ 1. $1 \times 5 * 244$ \\ $x: 4 x 2 * x 5$

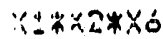 \\ $\times 1 * \times 3 * \times 4$ \\ $x: * x 3 * \times 5$ \\ $x: 4 x=x \times s$ \\ $x: \pm x a \neq x:$ \\ $\therefore 1 * 34 \times x^{\prime}$ \\ $\because 1 * x=5 * 6$ \\ 12* \\ :27ะ3*ะ5

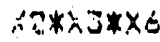 \\ $x=2 \times 4 \times \times 5$ \\ $\because \pi \times 4 * \times 6$ \\ $\because 24 \times 5 * 5 \times$ \\ $x J * \times 4 \times \times 5$ \\ $\because 3 * \times 4 * X 6$ \\ X3*X5*XE

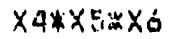

Std ERROF:

Obs
ord

1
A.Z + YE:

ALIASED

AI. I ASED

Ai. IASED

- .1 .1975

ALIASED

ALIASED

A'IASED

ALIASED

$-4.8575$

16.7935

ALIASED

FLIASED

ALIASED

- 2.0513

ALIASED

ALIASED

ALIASED

4.3775

ALIASED

4.0112

ALI ASED

ALIASED

1.9665

ACTLAL VALUE

\section{FREDICTED VALUE}

78.7600
57.1400
35.5100
40.0700
96.3100
66.1000
88.2500
52.9000
61.6900
59.2200
65.5800
79.2200
46.7600
54.1500
75.0600
77.3500
41.4100
64.7700
72.3100
53.4600
17.6500
8.6800
71.8500
52.7600
43.2200
52.8000
72.1900
45.7400
64.5000
55.2000
55.3000

79.3475

56.7525

35.8975

39.6825

85.9225

66.5475

87.9625

53.2875

64.8094

56.1006

68.6994

76.1006

43.6406

57.2694

71.9406

80.4694

$98.0906^{\circ}$

58.0894

78.9906

46.7794

10.9694

15.3606

65.1694

59.4406

42.8325

53.1875

92.5775

42.3525

00.9725

5. . 0475

56.6895
5.1092

$-1.017$

0.5588

5.10 .2

$-0.9507$

‥ 105

0.3696

5.1092

2.105

0.0685

$\$ .1092 \quad-0.5199 \quad 0.5179$

$\begin{array}{lll}5.1092 & 0.8568 & 0.4165\end{array}$

$5.1092 \quad 0.7851 \quad 0.4550$
REEIDUAL LEVEF RESID DIST VALUE Ord

-0.3875
0.3875
-0.3875
0.3875
0.3875
-0.3875
0.3875
-0.3875
-3.1194
3.1194
-3.1194
3.1194
3.1194
-3.1194
3.1194
-3.1194
-6.6806
6.6806
-0.6806
6.6806
6.6806
-6.6806
6.6806
-6.6806
0.3875
-0.3875
-0.3875
0.3875
0.3875
-0.3875
-0.3375

$\begin{array}{rrr}0.004 & -0.303 & 54 \\ 0.004 & 0.303 & 49 \\ 0.004 & -0.303 & 9 \\ 0.004 & 0.303 & 5 \\ 0.004 & 0.303 & 14 \\ 0.004 & -0.303 & 15 \\ 0.004 & 0.303 & 33 \\ 0.004 & -0.303 & 44 \\ 0.243 & -2.326 & 16 \\ 0.243 & 2.326 & 41 \\ 0.243 & -2.326 & 27 \\ 0.243 & 2.326 & 39 \\ 0.243 & 2.326 & 29 \\ 0.243 & -2.326 & 28 \\ 0.243 & 2.326 & 46 \\ 0.243 & -2.326 & 13 \\ 1.115 & -3.958 & 11 \\ 1.115 & 3.958 & 40 \\ 1.115 & -3.958 & 43 \\ 1.115 & 3.958 & 7 \\ 1.115 & 3.958 & 10 \\ 1.115 & -3.958 & 32 \\ 1.115 & 3.958 & 52 \\ 1.115 & -3.958 & 3 \\ 0.004 & 0.303 & 42 \\ 0.004 & -0.303 & 50 \\ 0.004 & -0.303 & 34 \\ 0.004 & 0.303 & 27 \\ 0.004 & 0.303 & 4 \\ 0.004 & -0.303 & 3: \\ 0.004 & -0.303 & 23\end{array}$




\begin{tabular}{|c|c|c|c|c|c|c|c|}
\hline$\because:$ & $\because .1700$ & 71.3025 & $2.25-5$ & 0.957 & $0.10 \%$ & 0.004 & 0.303 \\
\hline 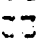 & -8.1400 & 75.0200 & 3.1194 & 0.937 & 0.863 & 0.243 & 2.326 \\
\hline$\therefore 7$ & 77.6800 & 30.7094 & -3.1194 & 0.937 & -0.803 & 0.243 & -2.326 \\
\hline 35 & 57.5100 & 70.0294 & -5.1174 & 0.037 & $-0.86 j$ & 0.243 & -2.326 \\
\hline$\because \dot{0}$ & 75.7500 & 70.5300 & 3.1194 & 0.937 & $0.86 \mathrm{~J}$ & 0.243 & 2. 325 \\
\hline$j$ & 54.4300 & $5 . .3100$ & 3.1194 & 0.937 & 0.863 & 0.243 & E. . $2 E$ \\
\hline 25 & 43.5600 & $46.7,794$ & $-j .1194$ & 0.937 & $-0.50 J$ & 0.243 & -2.326 \\
\hline$?$ & 41.3900 & 44.5094 & -3.1194 & 0.937 & -0.363 & 0.243 & $-2.32 \varepsilon$ \\
\hline 28 & 72.3400 & .59 .2205 & $=.1194$ & 0.937 & $0.8 \leq Z$ & 0.243 & 2.320 \\
\hline 4: & 8.0000 & 75.3194 & 6.6800 & 0.938 & 1.849 & $\dot{10115}$ & 3.355 \\
\hline $4 \%$ & 50.3200 & 49.0374 & $3.6800^{\circ}$ & 0.938 & 1.349 & 1.115 & 3.958 \\
\hline$\because$ & 70.1300 & 76.8106 & -6.6800 & 0.738 & $-1.34 ?$ & $1 . \pm 15$ & -3.958 \\
\hline 74 & 64.2600 & 70.0400 & -6.6606 & 0.938 & -1.349 & 1.115 & -3.958 \\
\hline 45 & 45.1000 & 49.7006 & -6.6806 & 0.936 & -1.849 & 1.115 & -3.958 \\
\hline 70 & $=7.700$ & 34.7506 & $-6.5800^{\circ}$ & 0.938 & -1.549 & 1.115 & -3.958 \\
\hline 97 & 80.8200 & 80.1394 & 6.6806 & 0.938 & 1.849 & 1.115 & 3.058 \\
\hline 48 & 53.4400 & 45.7594 & 5.5806 & 0.938 & $1.84 \%$ & 1.115 & 3.958 \\
\hline 20 & $4 \div .4700$ & $4: .9250$ & -0.4550 & 0.157 & -0.054 & 0.000 & -0.098 \\
\hline 50 & 55.2200 & 49.9250 & 5.2950 & 0.167 & 0.401 & 0.001 & 1.124 \\
\hline$\therefore:$ & 48.5100 & 49.9250 & -1.4150 & 0.167 & -0.107 & 0.000 & כ0.30 \\
\hline$E 2$ & 34.8500 & 49.0250 & -15.0750 & 0.167 & -1.143 & 0.005 & -2.957 \\
\hline-5 & $\because .1300$ & 49.7250 & 21.2050 & 0.167 & 1.607 & 0.011 & 3.741 \\
\hline 54 & 40.5700 & 40.9250 & -9.5550 & 0.167 & -0.724 & 0.002 & -1.980 \\
\hline
\end{tabular}




\begin{tabular}{|c|c|c|c|c|c|}
\hline \multicolumn{6}{|c|}{ 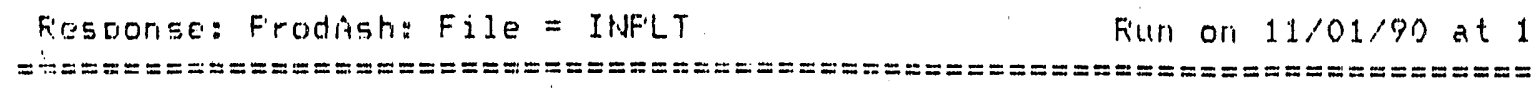 } \\
\hline \multirow{2}{*}{\multicolumn{6}{|c|}{ 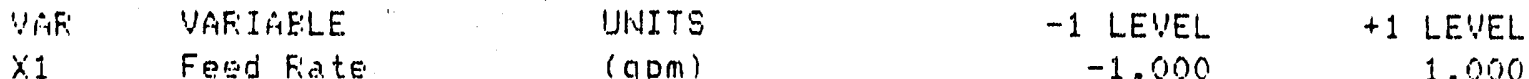 }} \\
\hline & & & & & \\
\hline \multirow{2}{*}{$\begin{array}{l}\times 2 \\
x 3\end{array}$} & Wash Water & (andll) & -1.000 & & 1.000 \\
\hline & Air fiate & $(\operatorname{scfm})$ & -1.000 & & 1.000 \\
\hline \multirow{2}{*}{$\times 9$} & Frather & (1bitori) & -1.000 & & 1.000 \\
\hline & LiEsel & (Ibtton) & -1.000 & & 1.000 \\
\hline$\times 0$ & Froth Hite & (incties) & -1.000 & & 1.000 \\
\hline
\end{tabular}

Fiesults of Linear Fesoorise Surface Model Fittina

AlNOUA for Selected Podel

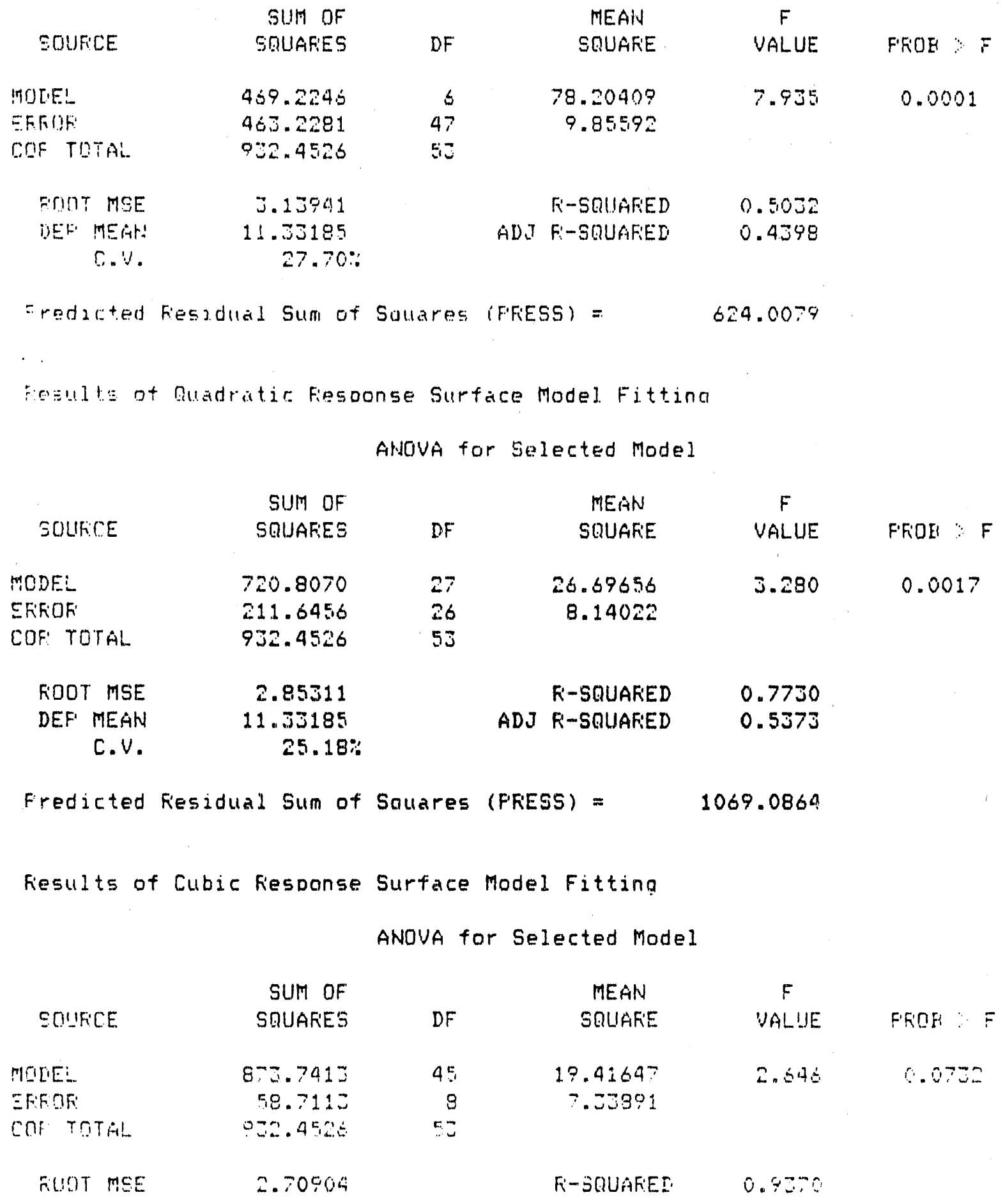




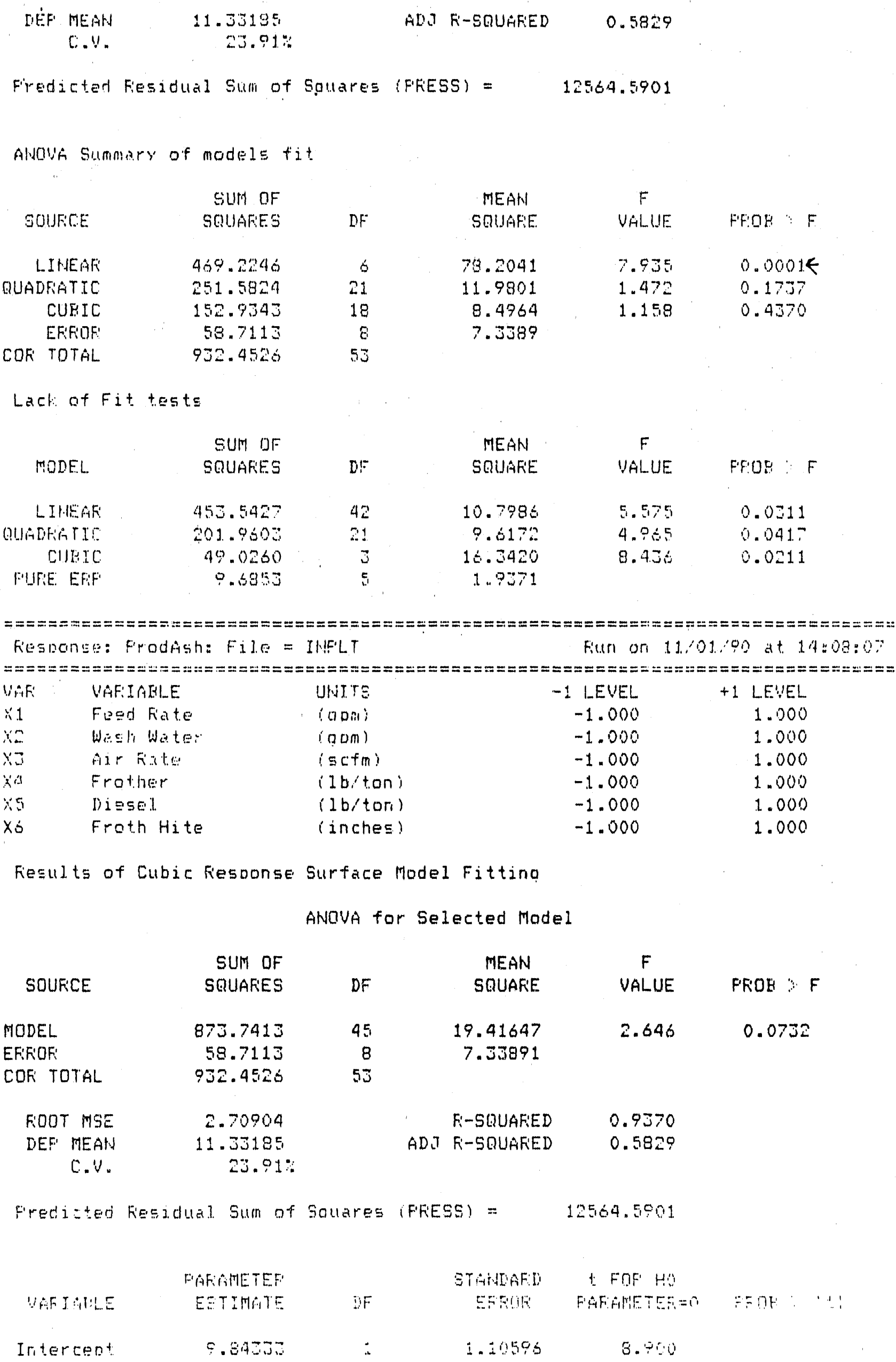




\begin{tabular}{|c|c|c|c|c|c|}
\hline$\because 1$ & -1.56375 & 1 & 0.95779 & -1.633 & 0.1412 \\
\hline$\because z$ & 1.23075 & 1 & 0.95779 & 1.293 & 0.2320 \\
\hline$x$ & 1.42625 & 1 & 0.95779 & 1.489 & 0.1748 \\
\hline$\because 4$ & 0.97125 & 1 & 0.95779 & 1.014 & 0.3402 \\
\hline$\times 5$ & 1.27375 & 1 & 0.95779 & 1.330 & 0.2202 \\
\hline$x \leq$ & -1.821 .25 & 1 & 0.95779 & -1.902 & 0.0937 \\
\hline$x .1 \times 1$ & $1.50,03$ & 1 & 0.34460 & 1.786 & 0.1118 \\
\hline$x=2 \times=$ & -0.00267 & 1 & 0.34469 & $-3.12 E-03$ & 0.9976 \\
\hline$x 34 \times 3$ & 0.42009 & 1 & $0.3446 ?$ & 0.9780 & 0.6519 \\
\hline$x 4 \div 44$ & -1.33347 & 1 & 0.34469 & -2.171 & 0.0518 \\
\hline$\times 5 * x^{\prime} 5$ & 0.74436 & 1 & $0.844 \leq 0$ & 1.119 & 0.2958 \\
\hline$x, * x<$ & $2.3105 \%$ & 1 & 0.84469 & 2.736 & 0.0256 \\
\hline$x 1 * 2=$ & 1.01375 & 1 & 0.95779 & 1.058 & 0.3208 \\
\hline 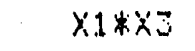 & -0.07625 & 1 & 0.95779 & -7.9 SE-02 & 0.9385 \\
\hline$x 1 * \times 4$ & -0.79750 & 1 & 0.67728 & -1.178 & 0.2728 \\
\hline$x 1 \times \times 5$ & -0.03375 & .1 & 0.95779 & $-8.74 E-02$ & 0.9325 \\
\hline$\times 1 * \times 6$ & 1.25375 & 1 & 0.95779 & 1.309 & 0.2269 \\
\hline$x 2 * x .3$ & -0.27125 & 1 & 0.95770 & -0.2932 & 0.7842 \\
\hline$x 27 \times 4$ & 0.33875 & 1 & 0.95779 & 0.3537 & 0.7327 \\
\hline$\times 2 \times \times 5$ & -0.27250 & 1. & $0.6-720$ & -0.4024 & 0.5990 \\
\hline$x \div 2 x \div 6$ & -0.38125 & 1 & 0.95779 & -0.7201 & 0.3344 \\
\hline$x 3 \times 1 \times 4$ & -0.80375 & 1 & 0.95770 & -0.8392 & 0.7257 \\
\hline 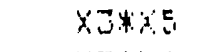 & -0.25375 & 1 & 0.05799 & -0.2441 & 0.8133 \\
\hline$x=18=$ & -1.54878 & 1 & 0.67725 & -2.237 & 0.0515 \\
\hline$y n \neq x=$ & 0.59525 & $:$ & 0.95799 & 0.7259 & 0.4380 \\
\hline$\times 4 *:=$ & $-1.16 \leq 5$ & 1. & 0.75779 & -1.213 & 0.7531 \\
\hline$\ddot{x} 5=5$ & $-1,50125$ & : & 0.95779 & $-1.5,99$ & 0.1485 \\
\hline$\because 2+1: \div$ & AYIASE & 0 & & & \\
\hline$\therefore 21 \times 2+2$ & AL IAEED & 0 & & & \\
\hline 咑品二 & FLLIASER & 0 & & & \\
\hline$x 4 * \times 4 * 019$ & ALIASED & 0 & & & \\
\hline$\because 5 k 95+25$ & ALIASED & 0 & & & \\
\hline 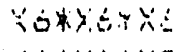 & ALIASED & 0 & & & \\
\hline$\because 1 * x+14 \times$ & $-=.04500$ & \pm & 1.35452 & -1.510 & 0.1695 \\
\hline$\because 1 \times 1 \times 10=$ & 2.28750 & 1 & $1.25,452$ & $1.68 ?$ & 0.1297 \\
\hline$x 1 * x 1 * 2=$ & 1.03500 & 1 & $\therefore .35452$ & 0.7541 & 0.4067 \\
\hline$\times 1+\times 1+2=$ & -0.62000 & 1 & 1.35452 & -0.4577 & 0.5593 \\
\hline$\times 1 * \times 1 k \times$ & $-J_{n} 03500$ & 1 & 1.35452 & -2.241 & 0.0554 \\
\hline$\because 20 \times 2,2=0$ & 1.25500 & 1 & 1.35452 & 0.9561 & 0.3670 \\
\hline$x=* x: 2 \times \times: 1$ & -0.58500 & 1 & 1.35452 & -0.4319 & 0.6772 \\
\hline$x 2 * \times 2 * 2 \times 0$ & ALIASED & 0 & & & \\
\hline$x 2 * x=x *$ & -0.42750 & 1 & 1.35452 & -0.3156 & 0.7604 \\
\hline$X \Xi * X \Xi * X \%$ & ALIASED & 0 & & & \\
\hline$X \Xi * X \Xi * X \Sigma_{1}$ & -2.12750 & 1 & $1.354: 2$ & -1.571 & 0.1549 \\
\hline$X \Xi * X j * x \leq$ & ALIASED & 0 & & & \\
\hline$\times 4 * \times 4 * \times 5$ & ALIASED & 0 & & & \\
\hline$\times 4 * \times 4 * x=$ & ALIASED & 0 & & & \\
\hline$\times 5 * \times 5 * \times 6$ & ALIASED & 0 & & & \\
\hline$x 1 * \times 2 * \div 2$ & 0.95000 & 1 & 1.35452 & 0.6866 & 0.5117 \\
\hline$x \geq * \times 3 * x=$ & 0.13250 & 1 & 1.35452 & $9.78 E-02$ & 0.9245 \\
\hline$x 1 * x 4 * x=$ & ALIASED & 0 & & : & \\
\hline$x 14 \times 5 \times x=$ & ALIASES & 0 & & & \\
\hline$x 1 * x \in * x=$ & ALIASED & 0 & & & \\
\hline$x=* x=4 x=$ & -0.77000 & 1 & 1.35452 & -0.5685 & 0.5850 \\
\hline$x=2 \times 4+x=$ & HLIASED & 0 & & & \\
\hline$x 2+x+5=5$ & ALI I $A E D$ & 0 & & & \\
\hline$\because 2 \neq x \leq x:=$ & MLIASEI & 0 & & & \\
\hline$\because+x+1=1$ & AL T HOE & $n$ & & & \\
\hline 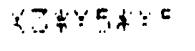 & $\therefore L S A S E Z$ & 9 & & & \\
\hline 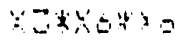 & ALニAEI & i) & & & \\
\hline
\end{tabular}


ratuses

$x+10 \leq 420$

$x=x+x_{0}$

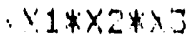

- $1 * \times 2 * 44$

$\times 1+x 2 \times 5$

$\because 1 k \times 2 \times x^{2}$

$\because 1+3 \times 11$

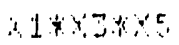

i14.

$x 1+x+1 \times 5$

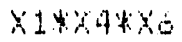

$x 1+250$

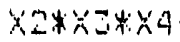

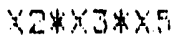

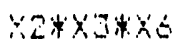

$\times 24 \times 4 \times 5$

$x 2 \times 4 \times 4 \times$

$x 2+55 x<6$

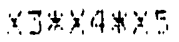

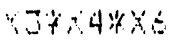

$x$ ond

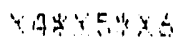

31 EFFOF:
HLIASE:

ALIASED

HL IASEI

AL. IASED

0.54375

AL.TASED

ALI.IASED

ALIASED

AL I ASED

$-0.38625$

$-0.76125$

ALIASED

AL. IASEE

ALIASED

$-0.57625$

ALIASED

ALL TASED

ALIASED

$-2.01375$

ALIAGEI

$-0.32125$

ALIASED

TLLIASED

0.3636

ar

$$
\begin{aligned}
& \text { ACTUAOI } \\
& \text { UGIIUE }
\end{aligned}
$$

10.20000

3.29000

4.97000

6.95000

12.74000

307000

0.60000

11.25000

7.50000

10.51000

12.70000

17.13000

7.89000

$7.8400 \mathrm{~W}$

14.56000

11.12000

8.19000

12.55000

13.43000

15.97000

6.89000

11.34000

9.75000

3.70000

0.20000

$-. .1000$

12.20000

E. 5000

$-.05000$

3.0900

$\because .60000$
FFEOICTED

WALUE

9.54225

0.93275

Q. 31625

7.58375

14.39575

6. 41625

10.34375

10.59625

8.66875

9.54125

13.96875

16.06125

6.82125

8.90875

13.49125

12.18875

6.96750

13.88250

12.20750

17.19250

8.11250

10.11750

0.97250

7.47750

9.94375

700525

12.62625

0.6005

3.00375

e. $2 \pi \leq 25$

$17.0=225$
0.95770

0.5877

0.5858

$\begin{array}{lll}0.95779 & -0.4033 & 0.6973 \\ 0.95779 & -0.7949 & 0.4997\end{array}$

$0.95779 \quad-0.0016 \quad 0.5541$

$0.95779 \quad-2.102 \quad 0.0587$

$\begin{array}{lll}0.95779 & -0.3554 & 0.7459\end{array}$ $\begin{array}{llcc} & \text { STUDENT COOK's } & t & \text { Fiun } \\ \text { FESIDUAL LEVEF FESID DIST VALUE } & \text { Ord }\end{array}$

0.65375
-0.65375
0.65575
-0.65375
-0.65575
0.65375

0.938

0.065

0.938

0.938

0.938

0.938

0.938

0.938

$-0.65375$

0.55375

$-1.06875$

1.06875

$-1.06875$

1.06875

1.06875

$-1.06875$

1.06875

$-1.06875$

1.22250

$-1.22250$

1. 22250

$-1.22250$

$-1.22250$

1.22250

$-1.22250$

1.22250

$-0.65375$

0.65375

0.65375

$-0.65775$

$-0.65075$

$0.650-5$

0.05075
0.938

0.938

0.938

0.938

0.937

0.937

0.938

0.937

0.937

0.937

0.937

0.937

0.937

0.937

0.937

0.937

0.937

0.937

0.937

0.957

0.93 ?

0.07

$0.0 \mathrm{I}$

0.07
$-0.965$

$-0.965$

0.965

$-0.965$

0.965

$-1.578$

1.578

$-1.578$

1.578

1.578

$-1.578$

1.578

$-1.578$

1.805

$-1.805$

1.805

$-1.805$

$-1.805$

1.805

$-1.805$

1.805

$-0.965$

0.905

0.755

-0.76 :

$-0.755$

0.55

$0.9 \leq 5$
$-0.965$

0.965
0.504

$0.304 \quad-2.566 \quad 40$

0.304

0.304

0.304

0.304

0.304

0.304

0.812

0.812

0.812

0.812

0.812

0.812

0.812

0.812

1.062

1.062

1.062

1.052

1.062

1.052

1.052

1.062

0.304

0.304

0.304

0.30 .7

0.204

0.3017

0.004
2.. 5569

$-2.5655$

-2.566 14

$2.566 \quad 15$

$-2.566 \quad 33$

$2.566 \quad 44$

$-3.70416$

3.70441

$-3.70427$

3.70439

3.70429

$-3.70428$

$3.704 \quad 46$

$-3.704 \quad 13$

$3.931 \quad 11$

$-3.93140$

3.93143

$-3.9317$

$-3.931 \cdot 10$

$3.931 \quad 32$

$-3.9315$

3.931 J

-2.56 42

$2.500 \quad 50$

2450034

-2.58s 1?

-2055 a

2.56 -

2. 


\begin{tabular}{|c|c|c|c|c|c|c|c|}
\hline 22 & 9.75000 & 10.81375 & -0.65375 & 0.937 & -0.965 & 0.304 & -2.566 \\
\hline J & $1 \mathrm{~J} .23000$ & 12.16125 & 1.06875 & 0.937 & 1.578 & 0.812 & 3.704 \\
\hline 34 & 11.85000 & 12.91875 & -1.06875 & 0.937 & -1.578 & 0.812 & -3.704 \\
\hline is & 13.22000 & 14.28875 & -1.06875 & 0.937 & -1.578 & 0.812 & -3.704 \\
\hline 50 & 23.08000 & 22.01125 & 1.06875 & 0.937 & 1.578 & 0.812 & 3.704 \\
\hline J." & .53000 & 8.45125 & 1.06875 & 0.937 & 1.578 & 0.812 & 3.704 \\
\hline 18 & 12.68000 & 13.74875 & -1.06875 & 0.937 & -1.578 & 0.812 & -3.704 \\
\hline , & 11.45000 & 12.51375 & -1.06975 & 0.937 & -1.578 & 0.912 & -3.704 \\
\hline 91 & 9.73000 & 0.66125 & 1.06875 & 0.937 & 1.578 & 0.812 & 3.704 \\
\hline & 15.45000 & 16.67250 & -1.22250 & 0.938 & -1.805 & 1.062 & -3.931 \\
\hline & 9.46000 & 10.62250 & -1.22250 & 0.938 & -1.805 & 1.062 & -3.931 \\
\hline & 27.80000 & 26.57750 & 1.22250 & 0.938 & 1.805 & 1.052 & 3.931 \\
\hline+ & 23.05000 & 21.82750 & 1.22250 & 0.938 & 1.805 & 1.062 & 3.931 \\
\hline 75 & 8.00000 & 5.77750 & 1.22250 & 0.938 & 1.805 & 1.062 & 3.931 \\
\hline 46 & 8.57000 & 7.34750 & 1.22250 & 0.938 & 1.805 & 1.062 & 3.931 \\
\hline 97 & 10.81000 & 1.2 .03250 & -1.22250 & 0.938 & -1.805 & 1.052 & -3.931 \\
\hline 48 & 9.53000 & 10.75250 & -1.22250 & 0.938 & -1.805 & 1.062 & -3.931 \\
\hline 49 & 8.99000 & 9.94333 & -0.85333 & 0.167 & -0.345 & 0.001 & -0.969 \\
\hline 50 & 8.45000 & 9.84333 & -1.38333 & 0.167 & -0.559 & 0.001 & -1.551 \\
\hline 51 & 10.79000 & 9.84333 & 0.93667 & 0.167 & 0.379 & 0.001 & 1.082 \\
\hline 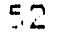 & 11.02000 & 9.84333 & 1.17667 & 0.167 & 0.476 & 0.001 & 1.327 \\
\hline ; & 8.30000 & 9.84533 & -1.48333 & 0.167 & -0.600 & 0.002 & -1.558 \\
\hline & 11.95000 & 9.84333 & 1.60557 & 0.167 & 0.650 & 0.002 & 1.788 \\
\hline
\end{tabular}




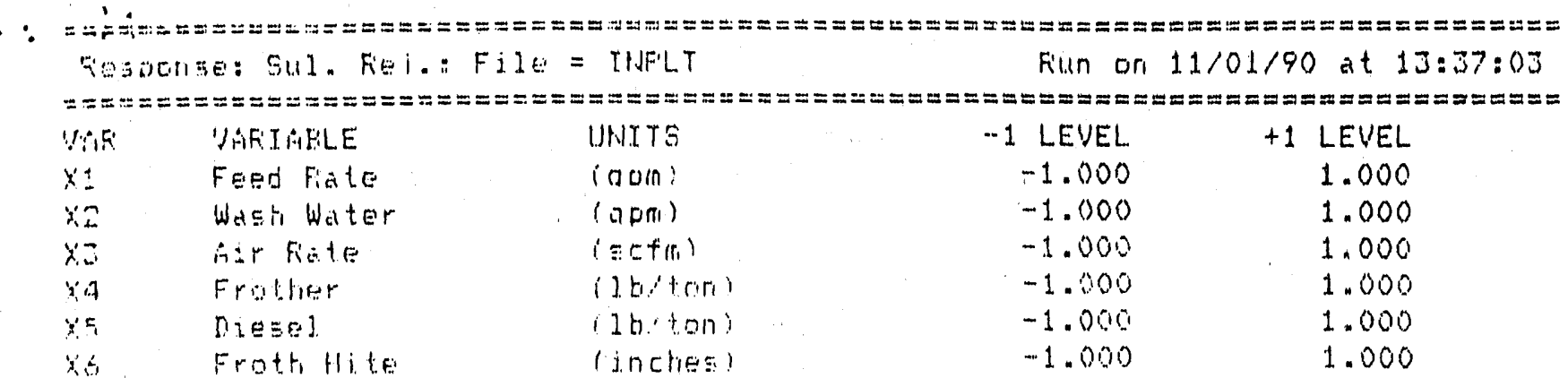

Fesults of lonear fiesoonse Surtace Model Fittina

Aldovit for selected Model

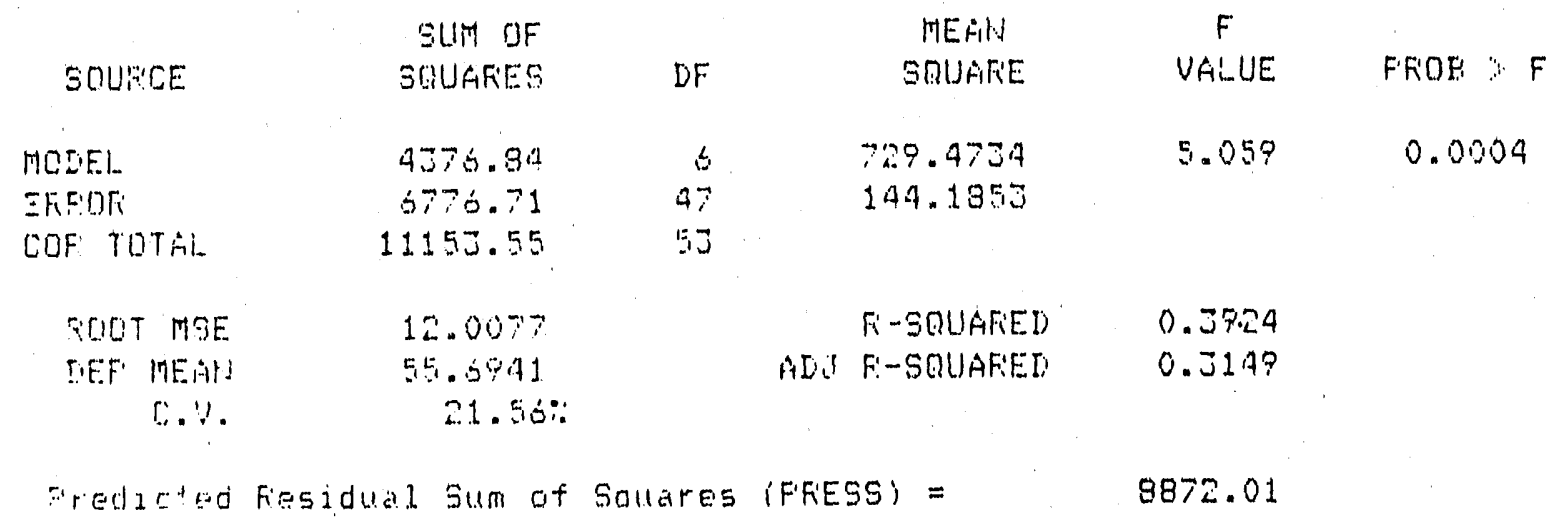

fresults or Budratic Fesoonse Surface Model Fittina

ardove for Salected Model

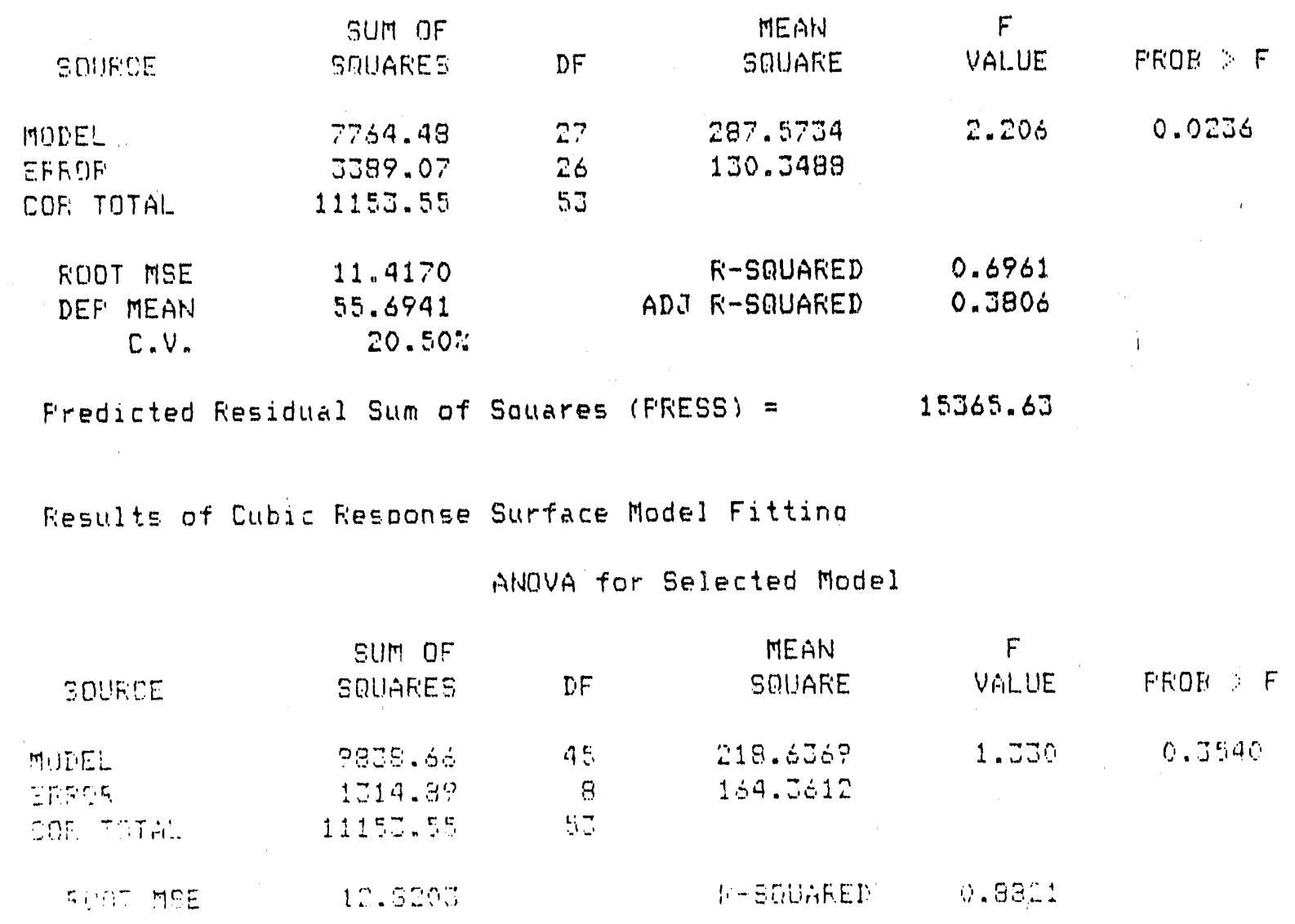




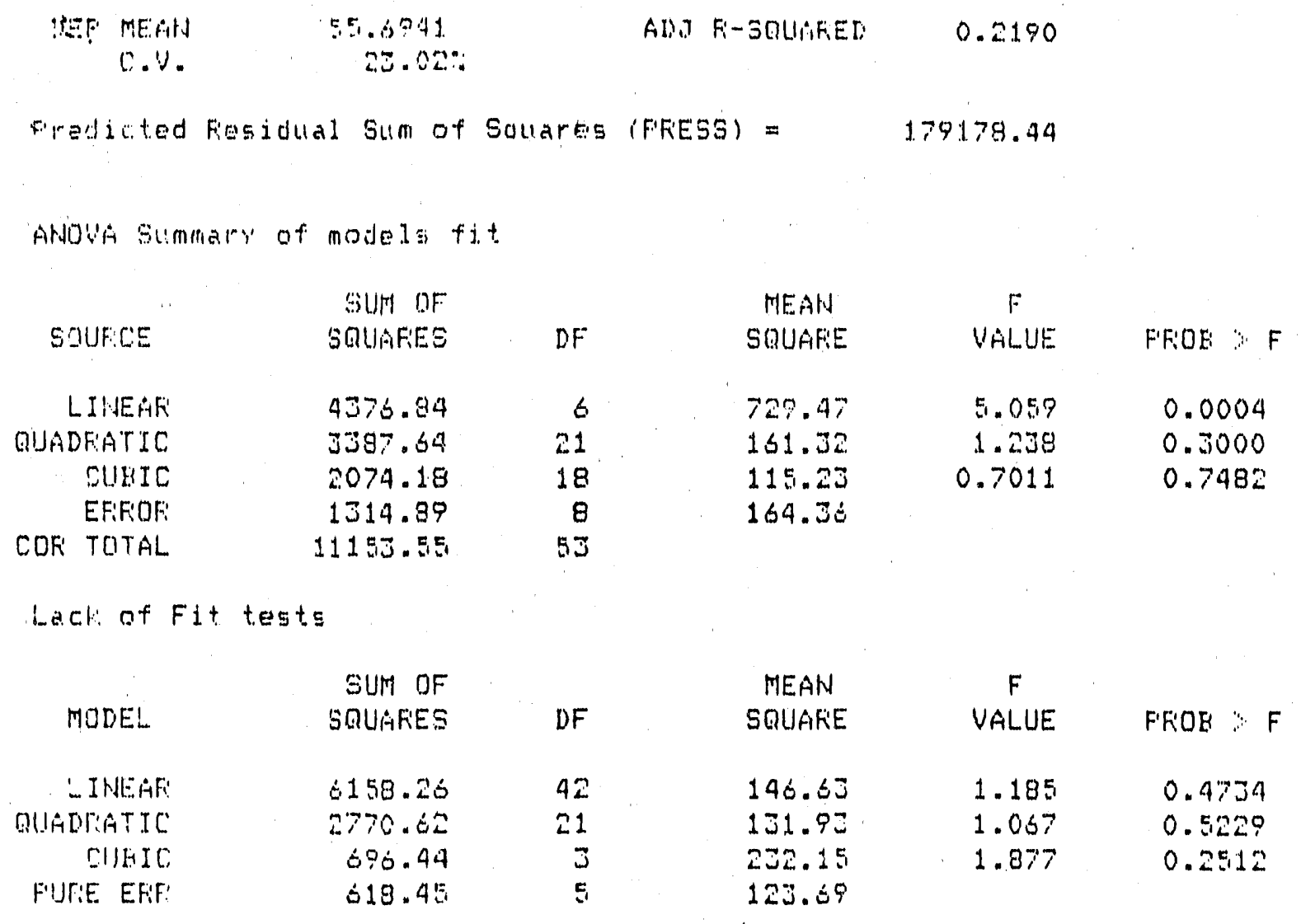




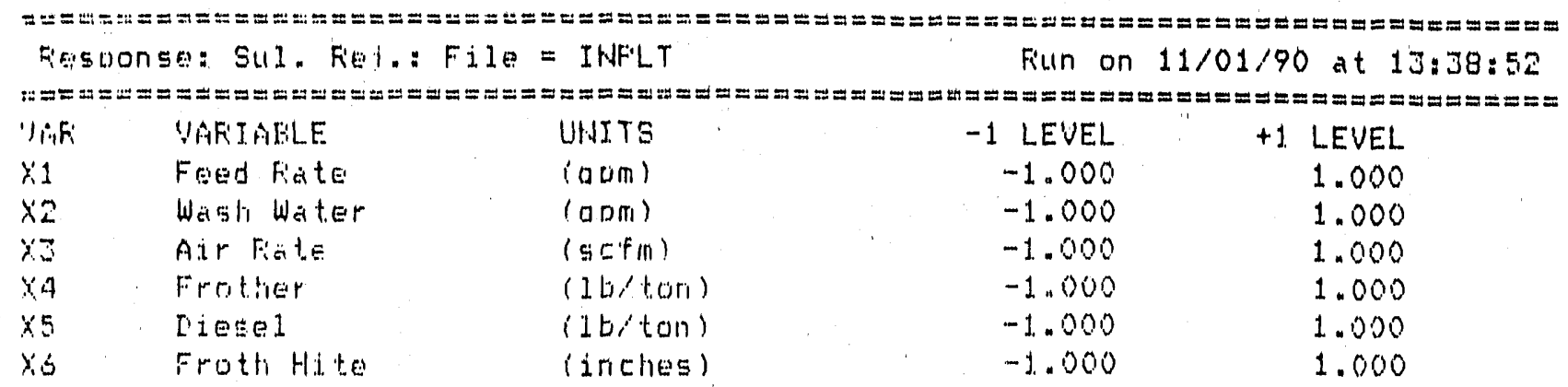

Fiesulte of Cubic Fesoonse Surface Model Fittina

anOUA for Selected model

\begin{tabular}{|c|c|c|c|c|c|c|}
\hline & SUN OF & & & MEANS & $F$ & \\
\hline SOUFICE & SUUAFES & $D F$ & & SQUAFEE & VALUE & FFOH F $F$ \\
\hline MUDE!- & 9839.66 & 45 & & 219.5369 & 1.330 & 0.35140 \\
\hline EFFOR & 1314.39 & 8 & & 104.3612 & & \\
\hline COE TOTAL: & 11153.55 & 53 & & & & \\
\hline FIllOT MGE & 12.8203 & & & FI-SQUAFEED & 0.8821 & \\
\hline $\begin{array}{c}\text { DEF MEAW } \\
\text { C.V. }\end{array}$ & $\begin{array}{c}56.6941 \\
23.02 \%\end{array}$ & & AW $\mathrm{B}$ & B-SQUARED & 0.2190 & \\
\hline Firedicted & Fiesidual Sum of & Souares & (F'FESS & $51=$ & 179178.49 & \\
\hline & F'AF'AMETEF: & & & STANIDAFID & t FOF $\mathrm{HO}$ & \\
\hline WAFIAHLE & ESTIMATE & DF & & EF'F'OFi & $F^{\prime} A F^{\prime} A M E T E F^{\prime}=0$ & FFIOK : it: \\
\hline Interceot & 34.8917 & 1 & & 5.2339 & 12.40 & \\
\hline$x 1$ & 4.1625 & 1 & & 4.5327 & 0.9183 & 0.3853 \\
\hline$x^{\prime \prime 2}$ & -3.3975 & 1 & & 4.5327 & -0.7496 & 0.4750 \\
\hline$\times 3$ & 0.8025 & 1 & & 4.5327 & 0.1770 & 0.8039 \\
\hline$x, 4$ & -13.0250 & 1 & & 4.5327 & -2.874 & 0.0207 \\
\hline$\times 5$ & 2.8400 & 1 & & 4.5327 & 0.6206 & 0.5484 \\
\hline$x_{0}$ & 7.9650 & 1 & & 4.5327 & 1.757 & 0.1169 \\
\hline$x 1 * x 1$ & -7.0981 & 1 & & 3.9974 & -1.776 & 0.1137 \\
\hline$\times 2 * \times 2$ & -7.2508 & 1 & & 3.9974 & -1.815 & 0.1070 \\
\hline$x 3 * \times 3$ & -2.3618 & 1 & & 3.9974 & -0.5908 & 0.5709 \\
\hline$\times 4 * \times 4$ & 2.1919 & 1 & & 3.9974 & 0.5483 & 0.5984 \\
\hline$\times 5 * \times 5$ & -4.3850 & 1 & & 3.9974 & -1.097 & 0.3045 \\
\hline$x=2 \times 6$ & $-1.784 j$ & 1 & & 3.9974 & -0.4464 & 0.6672 \\
\hline$\times 1 * 2$ & -0.0612 & 1 & & 4.5327 & $-1.35 E-02$ & 0.9895 \\
\hline$X^{1} 1 * \times 3$ & 1.2250 & 1 & & 4.5327 & 0.2703 & 0.7938 \\
\hline$\times 1 * \times 4$ & 4.3050 & 1 & & 3.2051 & 1.343 & 0.2160 \\
\hline$x 11 \times x_{5}$ & -6.6025 & 1 & & 4.5327 & $-1.4 \% 0$ & 0.1798 \\
\hline$x 1 * x \cdot 6$ & 0.1200 & 1 & & 4.5327 & $2.65 E-02$ & 0.9795 \\
\hline$x 2 * x J$ & 1.0425 & 1 & & 4.5327 & 0.2300 & 0.8239 \\
\hline$\times 2 \times 49$ & -5.3712 & 1 & & 4.5327 & -1.185 & 0.2700 \\
\hline$x_{2} x^{2} x_{1}$ & -1.8775 & 1 & & 3.2051 & -0.5858 & 0.5742 \\
\hline 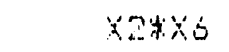 & -1.3600 & 1 & & 4.5327 & -0.7104 & 0.6923 \\
\hline 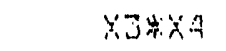 & 5.0500 & 1 & & 4.5327 & 1.110 & 0.2004 \\
\hline$x= \pm x=5$ & $-3.44=5$ & 1 & & $4.532 ?$ & -0.7505 & 0.4653 \\
\hline 20120 & -2.4005 & 1. & & Z.25 1 & -6.7515 & 0.4739 \\
\hline$\because 44 \div 5$ & $=.9050$ & 1 & & A $5-2 \%$ & 9564 & $0.611 \dot{ }$ \\
\hline 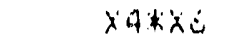 & $-7, \cdots 5$ & $i$ & & $4.55: 2$ & $-1,=2 \pi$ & 0.1452 \\
\hline
\end{tabular}




\begin{tabular}{|c|c|c|c|c|c|}
\hline • "xsass & -4.5575 & 1 & 4.5327 & -1.023 & 0.3362 \\
\hline$\times 1 * \times 1 \times 1$ & HL IASED & 0 & & & \\
\hline$\therefore 0 \times \times 24 \times 2$ & AL I ASED & 0 & & & \\
\hline$\times 3 \times \times 3 \times 3$ & ALI IASED & 0 & & & \\
\hline$Y A * X \times 1 \times A$ & AL IASED & ) & & & \\
\hline$\times 5 * \times 15 * \times 5$ & AL JASED & 0 & & & \\
\hline$x 6 x<\leq x \leq 6$ & ALIASED & 0 & & & \\
\hline$\because 11 \times 1 * \cdots=$ & 10.9137 & 1 & 5.7102 & 1.60 & 0.1271 \\
\hline$x 1+2 \times 1+2=$ & -5.7075 & 1 & 0.4102 & $-(.99904$ & 0.3902 \\
\hline$\therefore 1 * \times 1 * \times 4$ & 8.5250 & 1 & 6.4102 & 1.330 & 0.2202 \\
\hline$x 12 x+12 \times 5$ & -2.2300 & 1 & 6.9102 & -0.3479 & 0.7369 \\
\hline$x 1-3 \times 1.2 \times 6$ & -1.3450 & 1 & 0.4102 & -0.2098 & 0.8391 \\
\hline 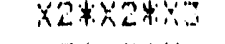 & $-7 \times 4075$ & 1 & 6.4102 & -1.156 & 0.2812 \\
\hline$\times 2 * x=2 \times 4$ & -3.0438 & 1 & 0.9102 & -0.4748 & 0.6476 \\
\hline$Y 2 * x \times 24 \times 5$ & ÁLIASED & 0 & & & \\
\hline$\times 2 * \times 2 * \times 6$ & -1.0775 & 1 & 0.41 .02 & -0.1681 & 0.8707 \\
\hline$\times 3 \times \times 3 \times 4$ & ALIASED & 0 & & & \\
\hline 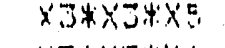 & -1.8900 & 1 & 6.4102 & -0.2948 & 0.7756 \\
\hline$\therefore 3 * \times 3 \times 1 \times 6$ & ALIASED & 2 & & & \\
\hline$x 4 * x 4 * x \div 5$ & ALLIASED & 0 & & & \\
\hline 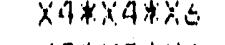 & ALLIASED & 0 & & & \\
\hline 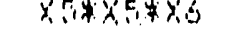 & ALI I ASEI & 0 & & & \\
\hline$\therefore 1 \% \times 27 \times=$ & $=.5038$ & 1 & 3.4102 & 0.5466 & 0.5990 \\
\hline X1 & 4.1800 & 1 & 6.4102 & 0.6521 & 0.5326 \\
\hline$\because 1 * 244 \times 24$ & ÂL. IAEED & 0 & & & \\
\hline$\therefore 1 * x \leq 1, x E$ & Al.. I A EEE & 0 & & & \\
\hline 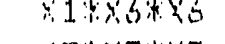 & HL I ASED & 0 & & & \\
\hline 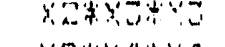 & 2.5825 & 1 & 5.4102 & 0.4029 & 0.6970 \\
\hline$\because 2+x 4 y \times 1$ & ALIASEI & 0 & & & \\
\hline $90 \times \times 5 \times 5$ & HLIASED & 0 & & & \\
\hline 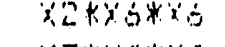 & All.IASED & 0 & & & \\
\hline$\times \Xi: k \times 47 \times 13$ & ALIASED & 0 & & & \\
\hline $23 * 5 \times 45$ & ALL I ASED & 0 & & & \\
\hline$\Leftrightarrow * x \leqslant * x=$ & ALI I ASED & 0 & & & \\
\hline$\because 4 * x \leqslant 5 \%, 5$ & HLIASED & 0 & & & \\
\hline$\therefore 4 * \times \leq * \times 6$ & ALIASED & 0 & & & \\
\hline$x 5 * \times 6 \% \times 4$ & AL I ASED & 0 & & & \\
\hline 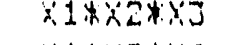 & ALLIASED & 0 & & 09090 & 0.4470 \\
\hline$\times 1 * \times 2 * x 4$ & 3.0662 & 1 & 4.3328 & 0.8008 & 0.44 .0 \\
\hline$\times 1 * x 2 * \times 5$ & AL IASED & 0 & & & \\
\hline$\times 1 * \times 2 \times \times 5$ & ALIASED & 0 & & & \\
\hline$\times 1 \times \times 3 * \times 4$ & ALIASED & 0 & & & \\
\hline$\times 1 * \times 3 * \times 5$ & ALI ASED & ? & 4.5327 & & \\
\hline $11 * \times 3 * \times 6$ & 2.8025 & 1 & 4.5327 & $\begin{array}{r}.0100 \\
-1.956\end{array}$ & 0.0861 \\
\hline$\times 1 * \times 4 * \times 5$ & -8.8675 & 1 & & & \\
\hline$\times 1 * \times 4 * \times 6$ & AL IASED & 0 & & & \\
\hline$\times 1 * \times 5 * x 6$ & ALIASED & 0 & & & \\
\hline$\times 2 * \times 3 * \times 4$ & ALIASED & 0 & & & \\
\hline$\times 2 \times \times 3 * \times 5$ & 0.9600 & 1 & 4.5327 & 0,2118 & 0.8576 \\
\hline 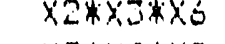 & ALIASED & 0 & & & \\
\hline$\times 2 * \times 4 \times 4 \times 5$ & ALL I ASED & 0 & & & \\
\hline$x=\times 4 \times \times=$ & ALIASED & 0 & & & \\
\hline$x=7 \times 5,2 x=$ & -2.5000 & 1 & 4.5327 & -0.5516 & 0.5963 \\
\hline $3 \% \times 4 * 2$ & ALLIHSET & 0 & & & \\
\hline$\forall 0 \times 4 \times 4 \%$ & -2. 3875 & 1 & 9.5327 & -0.5267 & 0.6127 \\
\hline 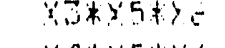 & HLIASED & 0 & & & \\
\hline 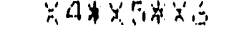 & FLL I HSED & 0 & & & \\
\hline Std EFFECIF & $\therefore-44 i$ & & & & \\
\hline
\end{tabular}


The

3

4

5

0
ACTUAG. VAILIJE

\subsection{0}

54.3600

73.6400

72.4800

34.5600

51.5200

31.6400

60.0200

54.6700

51.5300

48.1800

45.3700

64.0300

5.7400

39.9300

4 . 5500

70.9300

50.3500

44.7500

53.8500

39.4500

9. 1200

4.4000

57.6400

64.1200

59.5500

24.2100

$-1.9800$

50.1400

50.4900

01.2900

40.9300

36.7100

37.4900

55.5200

48.5900

58.4800

61.8200

68.7400

44.3700

33.6400

53.2400

43.9700

57.2000

69.2300

78.1000

34.3800

59.3500

53.5000

00.4400

64.9700

$-5.7000$

4:.410\%

-4.
FFEDICTED

VALUE

40.2969

54.4731

73.5259

72.7531

34.6731

51.9069

31.7501

62.9059

52.1200

54.0800

45.6300

47.9200

60.5800

57.1900

42.4800

41.1000

54.8463

50.4337

38.6732

59.9338

75.5339

67.0352

49.4838

51.5502

64. 2331

59.5369

24.0969

72.0931

56.2531

60.3769

01.1609

47.0431

39.2600

$34.940 i$

52.9700

51.1400

61.0300

59.2700

60.1900

46.9200

39.7238

59.3238

37.8962

51.1762

63.1462

72.0162

40.4638

65.4438

64.8917

64.8917

64.8917

64.3717

64.8717

$54.3 \% 1 ?$
F'ESIIUAL

0.1131

$-0.1131$

$0.11 j 1$

$-0.1131$

$-0.1131$

0.1131

$-0.1 .131$

0.1131

2. 4500

$-2.5500$

2. 5500

$-2.5500$

$-2.5500$

2. 5500

$-2.5500$

2. 5500

6.0938

$-6.0839$

0.0838

$-0.0838$

$-6.0838$

6.0838

$-6.0938$

6.0838

$-0.1131$

0.1131

0.1131

$-0.1131$

$-0.1131$

0.1131

0.1131

$-0.1131$

$-2.5500$

2. 5500

2. 5500

$-2.5500$

$-2.5500$

2. 5.500

2. 5500

$-2.5500$

$-6.0838$

$-6.0838$

6.0838

6.0838

6.0838

6.0838

$-6.0838$

$-6.0038$

j. 0083

$-4.4517$

0.0783

10.8683

$-19.4817$

0.3783

STUIDENT COOK'S FESID

$0.938 \quad 0.035$

0.938

$-0.035$

0.938

0.938

0.939

0.035

$-0.035$

$-0.035$

0.933

0.938

0.953

0.035

$-0.035$

0.035

0.938

0.938

0.938

0.937

0.937

0.938

0.937

0.937

0.937

0.937

0.937

0.937

0.937

0.937

0.937

0.937

0.937

0.937

0.937

0.937

0.937

0.937

0.937

0.937

0.937

0.937

0.937

0.937

0.9 .37

0.937

0.790

$-0.796$

0.795

$-0.796$

$-0.796$

0.796

$-0.796$

0.796

1. 898

$-1.898$

1. 998

$-1.898$

$-1.898$

1.898

$-1.898$

1.898

$-0.035$

0.035

0.035

$-0.035$

$-0.035$ 


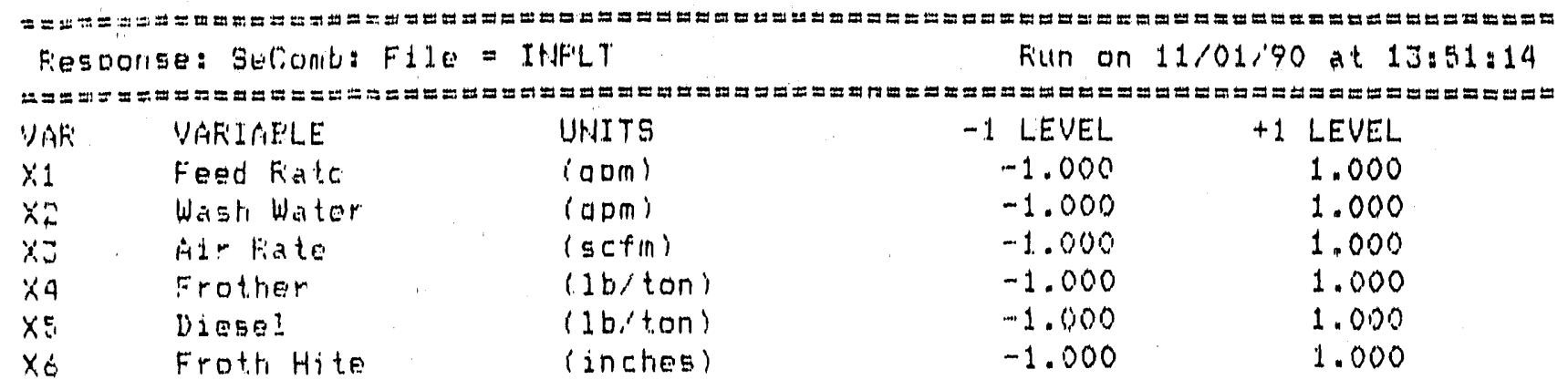

Fiesults of Lingar fiesoonse Surface Model Fittino

ANova for Selected Madel

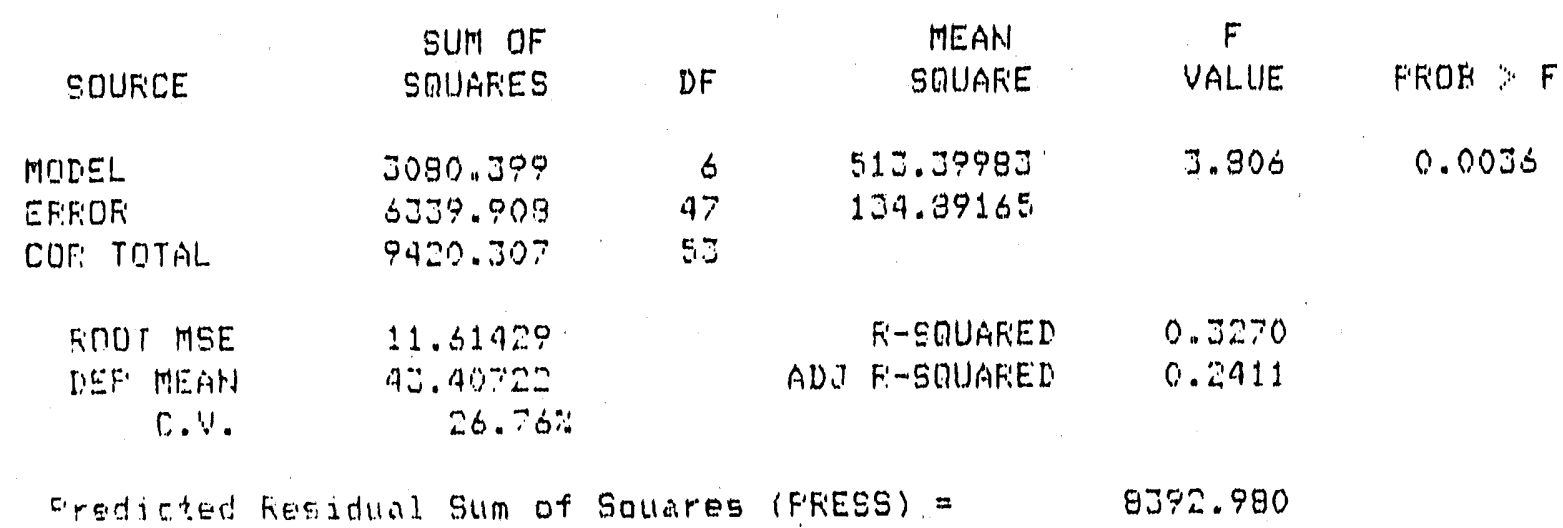

Fiesulte of luadratic Fiesoonse Surface Model Fittano

Alloug for selected Model

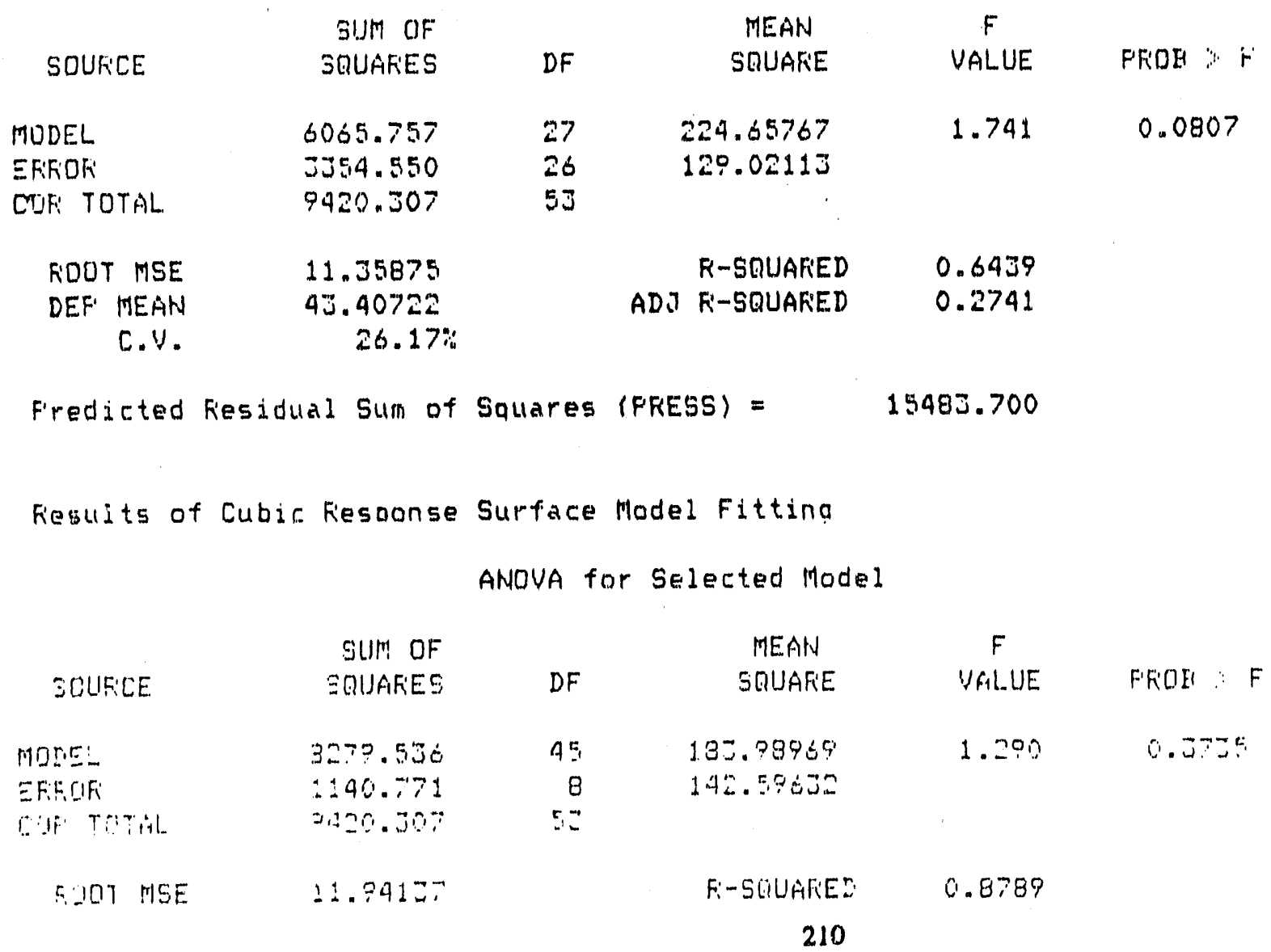




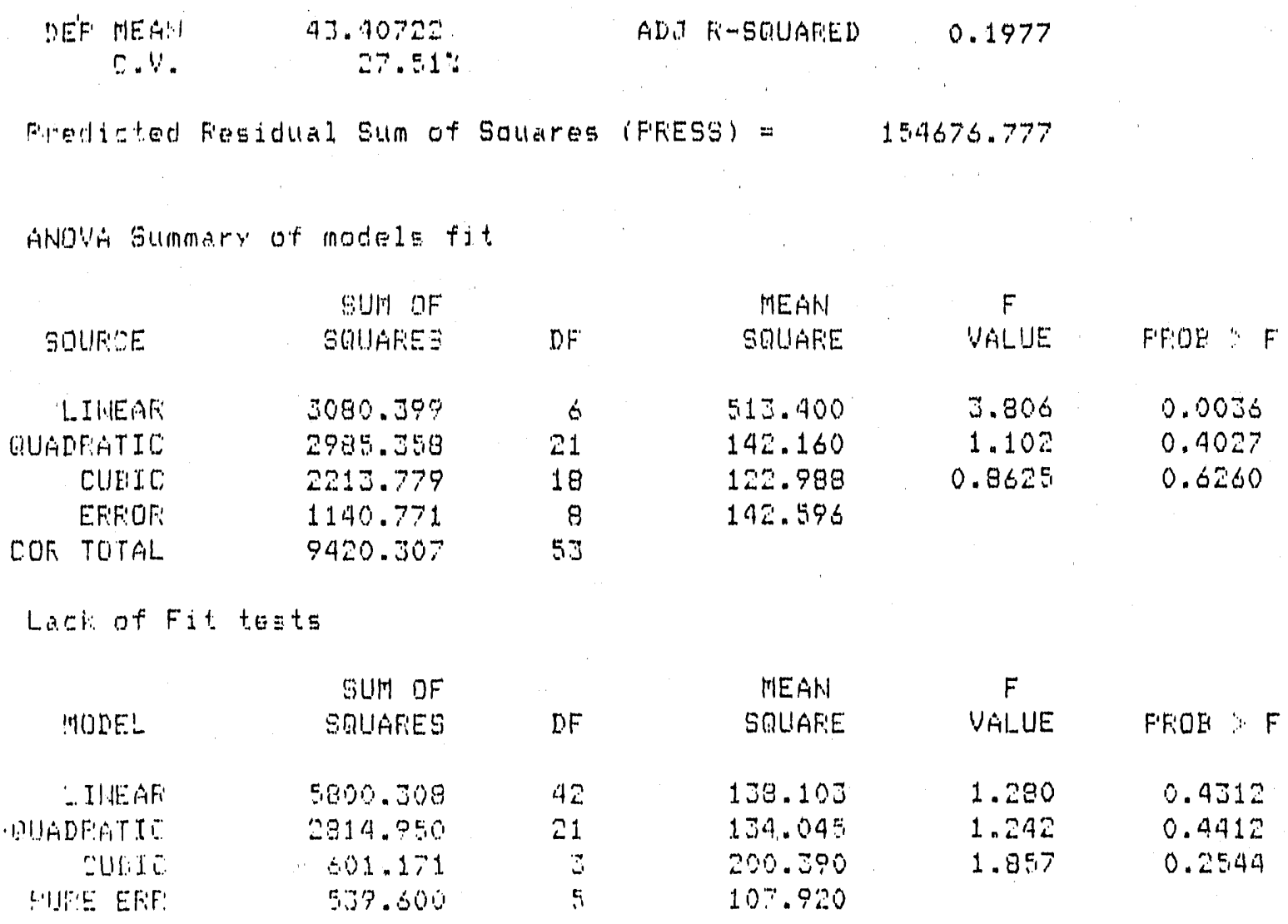




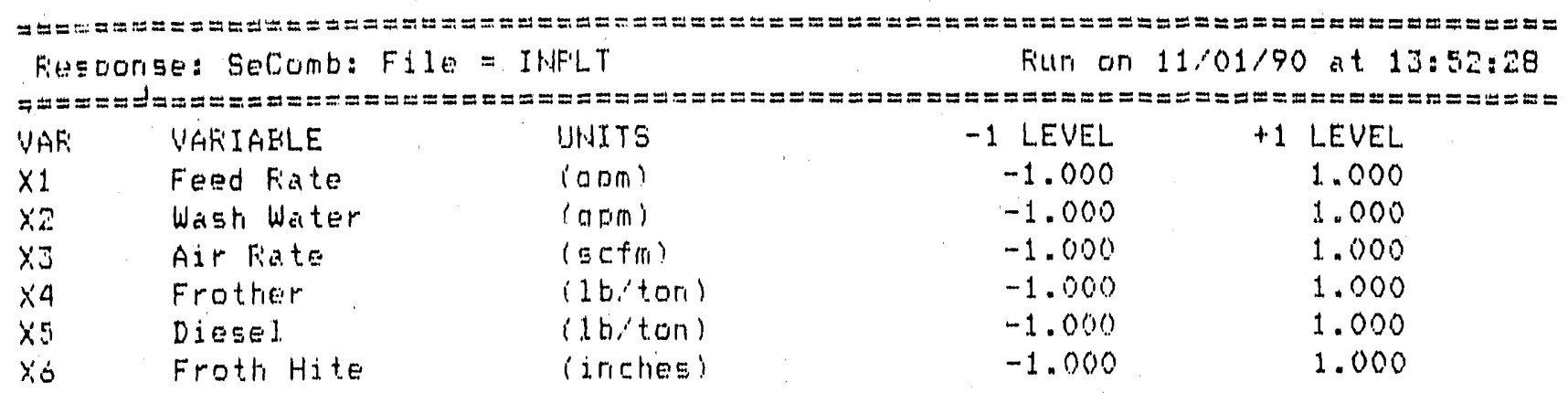

Fesulte of Cubic Fiesponse Surface Model Fitting

ANOWA for Selected Model

\begin{tabular}{|c|c|c|c|c|c|}
\hline \multirow{2}{*}{ SOURICE } & \multicolumn{2}{|l|}{ SUM OF } & MEAN & $F$ & \multirow[b]{2}{*}{ FFOE F } \\
\hline & SQUAFES & $D F$ & SRUAFE & VALUEE & \\
\hline MODELL & 3279.536 & 45 & 133.99969 & 1.290 & 0.3735 \\
\hline EFFIOF & 1140.771 & 8 & 142.59632 & & \\
\hline COF: TOTAL & $=420.307$ & 5.3 & & & \\
\hline FOOT MSE & 11.94137 & & FI-SQUAFED & 0.8789 & \\
\hline $\begin{aligned} & \text { DEF } \text { MEHH } \\
& \text { C.V. }\end{aligned}$ & $\begin{array}{r}43.40722 \\
27.51 \%\end{array}$ & & ADI FI-SQUAFED & 0.1977 & \\
\hline Fredicted & F'esidual Sum of & Saluares & $\left(F^{\prime} F E \Xi S\right)=$ & 154670.777 & \\
\hline UAF IAELE & $\begin{array}{l}\text { F'AFAMETEF: } \\
\text { ESTIMATE }\end{array}$ & DF & $\begin{array}{c}\text { STAFADAF:D } \\
\text { EFIF'DF }\end{array}$ & $\begin{array}{l}t \text { FOF: } H O \\
\text { F'AF'AMETER }=0\end{array}$ & FFOE $: t$ \\
\hline Interceot & 37.23032 & 1 & 4.87504 & 7.639 & \\
\hline$x_{1}$ & -2.45375 & 1 & 4.221 .91 & -0.5812 & 0.5771 \\
\hline$x=$ & 2.41375 & 1 & 4.22191 & 0.5717 & 0.5832 \\
\hline$x \overrightarrow{3}$ & -2.42375 & 1 & 4.22191 & -0.5741 & 0.5817 \\
\hline$\times 4$ & 10.73525 & 1 & 4.22191 & $2.54 j$ & 0.0345 \\
\hline$\times 5$ & -0.43375 & 1 & 4.22191 & -0.1027 & 0.9207 \\
\hline$x_{0}$ & -5.46125 & 1 & 4.22191 & -1.294 & 0.2319 \\
\hline$x 1 * \times 1$ & 6.40167 & 1 & 3.72338 & 1.719 & 0.1239 \\
\hline$\times 2 * \times 2$ & 6.30208 & 1 & 3.72338 & 1.693 & 0.1290 \\
\hline$x 3 * \times 3$ & 0.65000 & 1 & 3.72338 & 0.1746 & 0.8658 \\
\hline$\times 4 * \times 4$ & -2.58958 & 1 & 3.72338 & -0.6955 & 0.5064 \\
\hline$\times 5 * \times 5$ & 3.548jJ & 1 & 3.72338 & 0.9530 & 0.3685 \\
\hline$x_{0} * x_{0}$ & -0.43250 & 1 & 3.72338 & -0.1162 & 0.9104 \\
\hline$\times 1 * 2 \times 2$ & -0.45500 & 1 & 4.22191 & -0.1078 & 0.9168 \\
\hline$\times 1 * x_{3}$ & 0.13500 & 1 & 4.22191 & $3.20 E-02$ & 0.9753 \\
\hline$x 12 \times 4$ & -3.35562 & 1 & 2.98534 & -1.124 & 0.2956 \\
\hline$x 1 * x=$ & 3.42125 & 1 & 4.22191 & 0.8104 & 0.4412 \\
\hline$x 1 * x_{0}$ & -2.71750 & 1 & 4.22191 & -0.6437 & 0.5378 \\
\hline$x 2 * x=3$ & 1.57125 & 1 & 4.22191 & 0.3722 & 0.7194 \\
\hline$x=* x \times 4$ & 3.53750 & 1 & 4.22191 & 0.8379 & 0.4264 \\
\hline 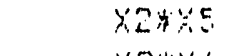 & Ј. & 1 & 2.99534 & 1.128 & 0.2918 \\
\hline$x=4 x 6$ & 2.46125 & 1 & 4. $=2 \pm 1$ & 0.5830 & 0.5700 \\
\hline 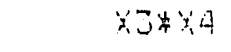 & - 2.01675 & 1 & 4.52191 & $-0 .-951$ & 0.7545 \\
\hline$x=5$ & 2.54525 & 1 & 4. $2=1 ? 1$ & 2.0400 & $0.426 \tilde{J}$ \\
\hline $\begin{array}{lll} \\
0\end{array}$ & $=0.05030$ & 1 & $2.9950=$ & 1.025 & G.3.5. \\
\hline$\checkmark 4 * 5$ & -3.4375 & $i$ & a. $: 21 \div 1$ & -0.896 & $\therefore 7 \ddot{1} 1$ \\
\hline 4435 & $\Xi .490-5$ & 1 & 4.22191 & 2.013 & 0.0789 \\
\hline
\end{tabular}




\begin{tabular}{|c|c|c|c|c|c|}
\hline " $\quad \therefore 5 * 2$ & 3.32375 & 1 & 4.22191 & 0.7873 & 0.4538 \\
\hline$\times 1 * x^{\prime} 1 * \times 1$ & ALIASED & 0 & & & \\
\hline$\times 2 * \times 2 \times 1 \times 2$ & ALIAEED & 0 & & & \\
\hline$\times 3 * \times 3 * \times 3$ & ALIASED & 0 & & & \\
\hline$\times 4 * \times 4 * \times 4$ & ALIASED & 0 & & & \\
\hline$\times 5 \times 1 \times 5 * \times 5$ & ALIAGEL & 0 & & & \\
\hline$x \dot{x} \times x \in x \times 6$ & GILIASED & 0 & & & \\
\hline$\times 1 * 1 \times 1 * 2$ & -9.50875 & 1 & 5.97009 & -1.595 & 0.1499 \\
\hline$\because 11 \times 1 \times 3=$ & 7.89375 & 1 & 5.97069 & 1.32 & 0.2227 \\
\hline$\times 1 * \times 1 \neq \times 4$ & -5.90000 & 1. & 5.07060 & -0.9832 & 0.3520 \\
\hline$\times 1 * \times 1 \times \times 5$ & 1.19750 & 1 & 5.97069 & 0.1099 & 0.8473 \\
\hline$\times 1 \times 1 \times 1 \times 6$ & 1.81375 & 1 & 5.97009 & 0.3038 & 0.7690 \\
\hline$\times 2 k \times 2 \times 3$ & 8.91750 & 1 & 5.97069 & 1.477 & 0.1790 \\
\hline$\times 2 \times \times 2 \times \times 4$ & 2.15375 & 1 & 5.97069 & 0.3507 & 0.7276 \\
\hline$x 2 * x \geq 2 \times 5$ & ALIASED & 0 & & & \\
\hline$\times 2 * \times 2 * \times 6$ & -1.61500 & 1 & 5.97069 & -0.2705 & 0.7936 \\
\hline$\times 3 * \times 3 * \times 4$ & ALIASED & 0 & & & \\
\hline$\times 3$ 米 $\times 3 * 1 \times 5$ & 1.29500 & 1 & 5.97060 & 0.2169 & 0.8337 \\
\hline$\therefore 3 * \times 3 * \times 6$ & ALIASED & 0 & & & \\
\hline$\because 4 \times \times 4 * \times 5$ & ALIASED & 0 & & & \\
\hline$\times 4 * \times 4 * \times 6$ & ALIASED & 0 & & & \\
\hline$\because 5 \% X \leq * X_{0}^{\prime}$ & ALIASED & 0 & & & \\
\hline$\times 1 x_{2}=2 * 2$ & -4.33375 & 1. & 5.97069 & -0.8098 & 0.4416 \\
\hline$x \pm * 3 \times 3 \times 3$ & -4.144875 & 1 & 5.97069 & -0.7451 & 0.4775 \\
\hline$\because 1 *: 4 * \times 4$ & ALLIASED & 0 & & & \\
\hline$\times 1 \times \times \leq \times \times 5$ & ALIASED & 0 & & & \\
\hline$\times 1+x 5 * 60$ & ALIASES & 0 & & & \\
\hline $824 \times 3 * \times=$ & -1.90750 & 1 & 5.97069 & -0.3027 & 0.7698 \\
\hline$\therefore a \times 4 \times Y A$ & AQLIASED & 0 & & & \\
\hline$\because 2 \times \times 5 \times 5 \times 5$ & ALIASED & 0 & & & \\
\hline$x 2+8 \leq 6 \times 0$ & ALIASED & 0 & & & \\
\hline$\therefore 35 \times 4$ 和 $\times 4$ & ALIASED & 0 & & & \\
\hline$\times 30 \times 5 \times 5$ & ALIABSED & 0 & & & \\
\hline$x=* x \leq x \times x_{0}$ & ALIASED & 0 & & & \\
\hline$Y 4 \times X 5 \% Y 5$ & ALJASED & 0 & & & \\
\hline$\because 4 * \times 50 * 60$ & ALIASED & 0 & & & \\
\hline 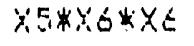 & ALIAGED & 0 & & & \\
\hline$\times 14 \times 2 * \times 3$ & ALIASED & 0 & 4.22191 & & \\
\hline$x 1 * \times 2 * \times 4$ & -5.12750 & 1 & 4.02571 & -1.214 & 0.2592 \\
\hline$\times 1 * \times 2 * \times 5$ & ALIASED & 0 & & & \\
\hline$\therefore 1 * \times 2 * \times 6$ & ALIASED & 0 & & & \\
\hline$\times 1 * \times 3 * \times 4$ & ALIASED & 0 & & & \\
\hline$\times 1 * \times 3 * \times 5$ & ALIASED & 0 & 4.22191 & & \\
\hline$\times 1 * \times 3 * \times 0$ & -3.07000 & 1 & 4.22191 & $\begin{array}{r}-0.7272 \\
2.173\end{array}$ & 0.4879 \\
\hline$\times 1 * \times 4 * \times 5$ & 9.17375 & 1 & & & 0.0615 \\
\hline$\times 1 * \times 4 * \times 6$ & ALIASED & 0 & & & \\
\hline$\times 1 * \times 5 * \times 66$ & ALIASED & 0 & & & \\
\hline$\times 2 * x 3 * \times 4$ & AL.IASED & 0 & & & \\
\hline$\therefore 2 * \times 3 * \times 5$ & -1.55025 & 1 & 4.22191 & -0.3686 & 0.7220 \\
\hline$\times 2 * \times 3 * \times 5$ & ALIASED & 0 & & & \\
\hline$\times 2 * \times 4 * \times 5$ & ALIASED & 0 & & & \\
\hline$\times 2 * \times 4 * \times 6$ & ALIASED & 0 & & & \\
\hline$x 2 \times x=2 \%$ & J.70625 & 1 & 4.22191 & 0.8921 & 0.3984 \\
\hline$\times 3 \times 4 \times 4 \times 5$ & ALIASED & 0 & & & \\
\hline XXYax & 1.75875 & 1 & 4.22191 & 0.4165 & 0.5870 \\
\hline X3X548 & HLIASEL & 0 & & & \\
\hline$\because A 4 \times 5 \times 6$ & HLIHOEL & 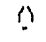 & & & \\
\hline
\end{tabular}


58.79000

43.20000

28.19000

31.29000

65.77000

5.03000

67.80000

23.75000

48.82000

39.24000

48.26000

51.19000

35.90000

41.52000

55.65000

61. 43000

32.55000

75.60000

47.15000

5.98000

13.95000

6. 37000

5. 54000

d 1.74000

29.42000

4.11000

70.02000

39.35000

$4 ? .92000$

3.50000

23.85000

5.04000

50.24000

56.74000

49.32000

50.53000

40.05000

33.33000

$2 \% .36000$

55.58000

58.46000

43.68000

44.92000

42.96000

32.39000

19.02000

6. . .27000

42. 16000

38.49000

41.78000

Es.40000

도. 12000

54.29000

20.90000
$50.5993 \%$

42.39062

28.93037

30.47062

62.76062

52.82928

67.01062

34.55937

49.92000

38.14000

49.36000

50.09000

34.70000

42.62000

54.55000

S2. 5.5000

23.47563

37.68437

53.12565

20.00437

?. 9437

12. 35563

49.54537

47.71503

28.61062

41.91937

70.82936

34.02053

49.1105:

$3 \% .70937$

39.55937

53.23002

57.14000

57.84000

50.42000

49.55000

38.95000

34.45000

30.46000

54.48000

52.48437

37.70437

50.89562

48.93563

38.36563

24.99563

61.29437

30. 18437

37.23353

37.23833

37.2383

7.

2. .2535

37.25823

\section{STUDENT COOK'S}

FESIDUAL

$-0.80937$

0.80938

$-0.80537$

0.80938

0.30938

$-0.30937$

0.80938

$-0.80937$

$-1.10000$

1.10000

$-1.10000$

1.10000

1.10000

$-1.10000$

1.10000

$-1.10000$

$-5.97563$

5.97560

$-5.97563$

5.97563

5.97563

- 5.97505

5.97563

$-5.97563$

0.80938

$-0.80937$

$-0.80937$

0.80938

0.80938

$-0.80937$

$-0.80937$

0.80938

1.10000

$-1.10000$

$-1.10000$

1.10000

1.10000

$-1.10000$

$-1.10000$

1.10000

5.97563

5.97563

$-5.97563$

$-5.97563$

$-5.97563$

$-5.97563$

5.97563

5.97563

1.25167

4.54167

$-1.83833$

$-12.11835$

$17.0016 ?$

$-9.30053$

\subsection{038}

0.038

0.938

0.938

0.938

0.938

0.938

0.938

0.938

0.938

0.937

0.937

0.938

0.937

0.737

0.937

0.937

0.937

0.937

0.937

0.937

0.937

0.0 .57

0.937

0.937

0.937

0.937

0.937

0.937

0.937

0.937

0.937

0.937

0.937

0.937

0.937

0.937

0.937

0.937

0.938

0.938

0.938

0.938

0.938

0.938

0.938

0.938

0.167

0.107

0.167

0.167

0.157

0.167

FIESID DIST

0.271

0.024

0.024

0.024

0.271

0.271

t

Fiun

$-0.763$

$0.024 \quad 0.763$

$-0.76 .5$ 
Appendix 6: Response surface plots for the 30-inch column parametric test program 


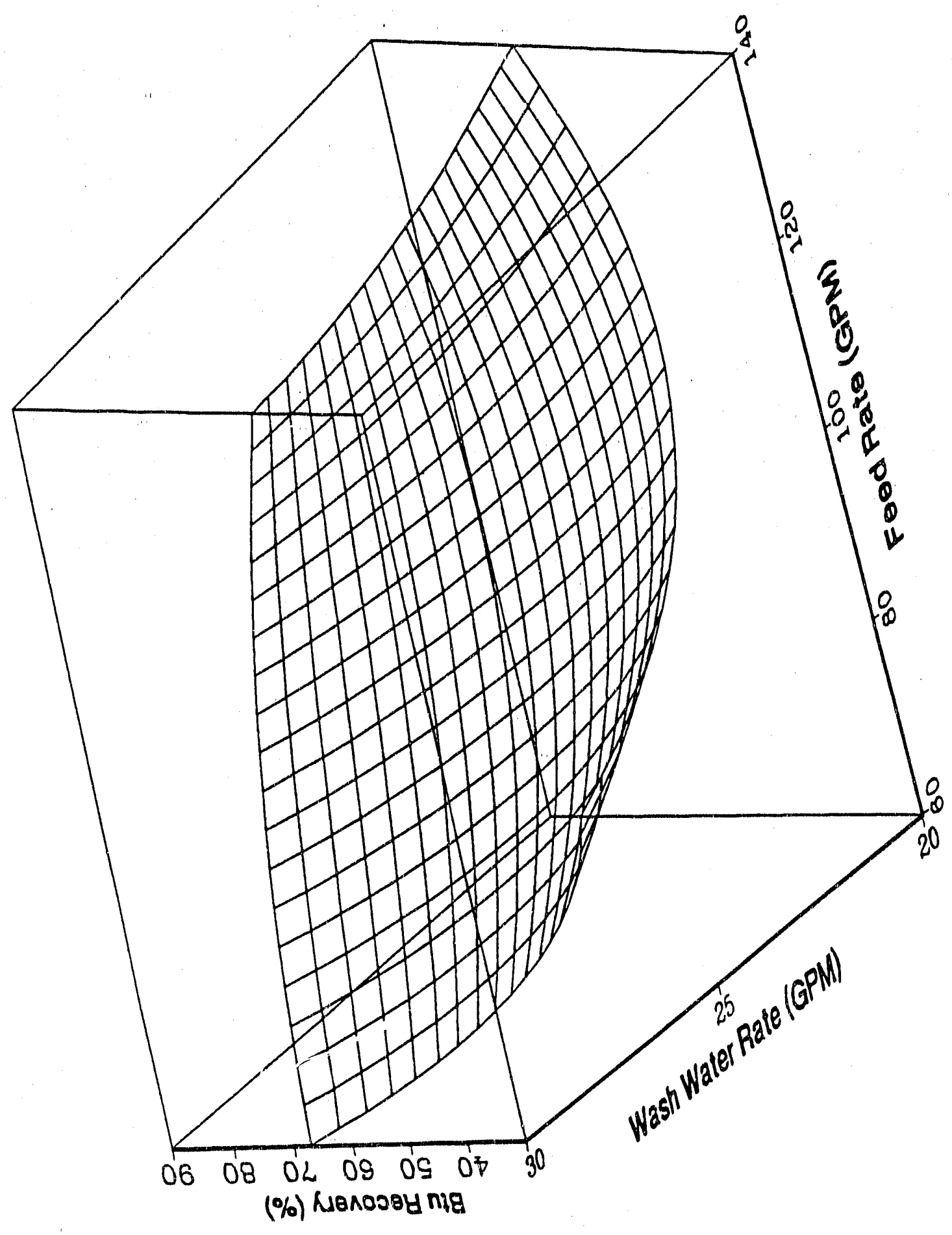




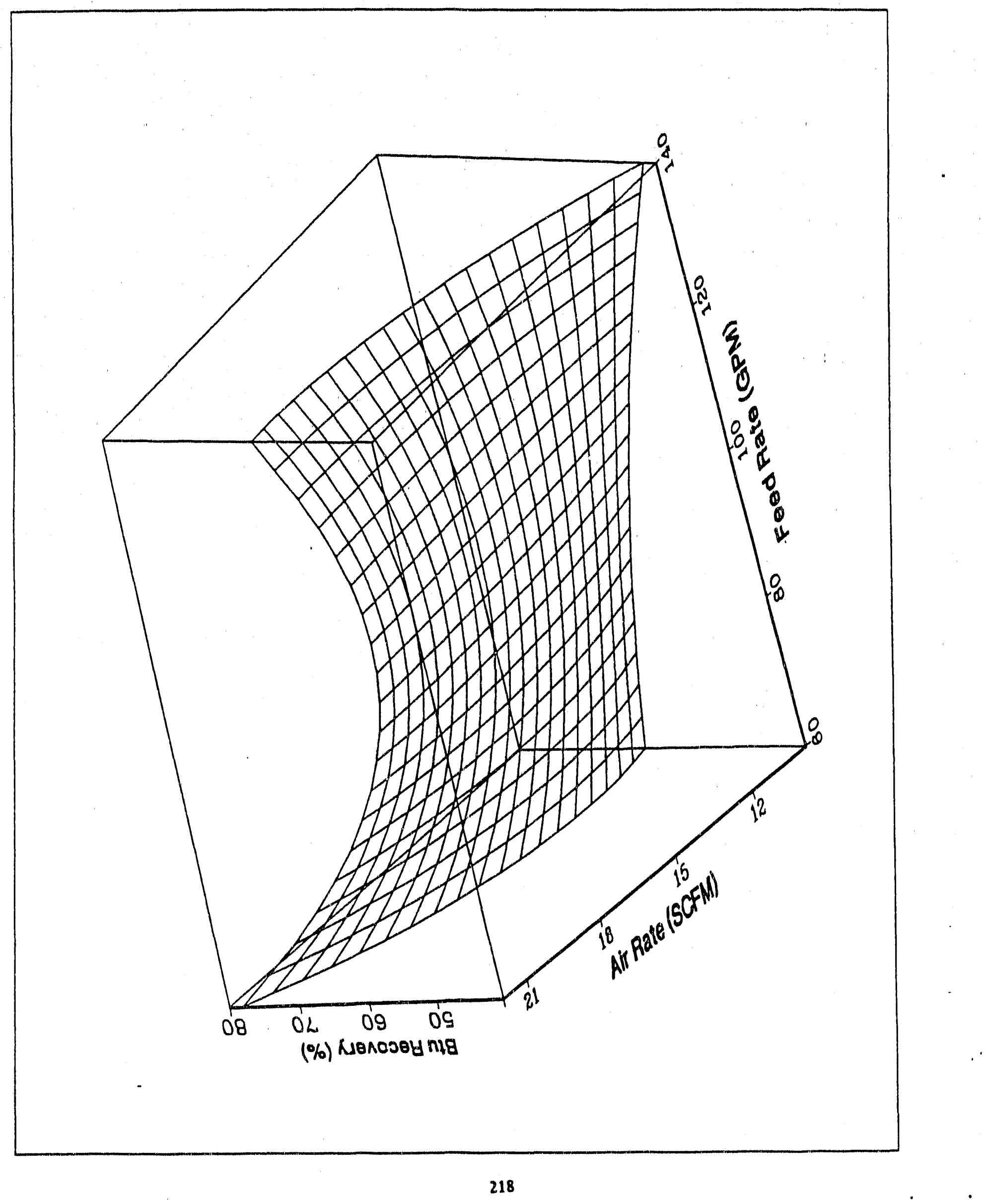




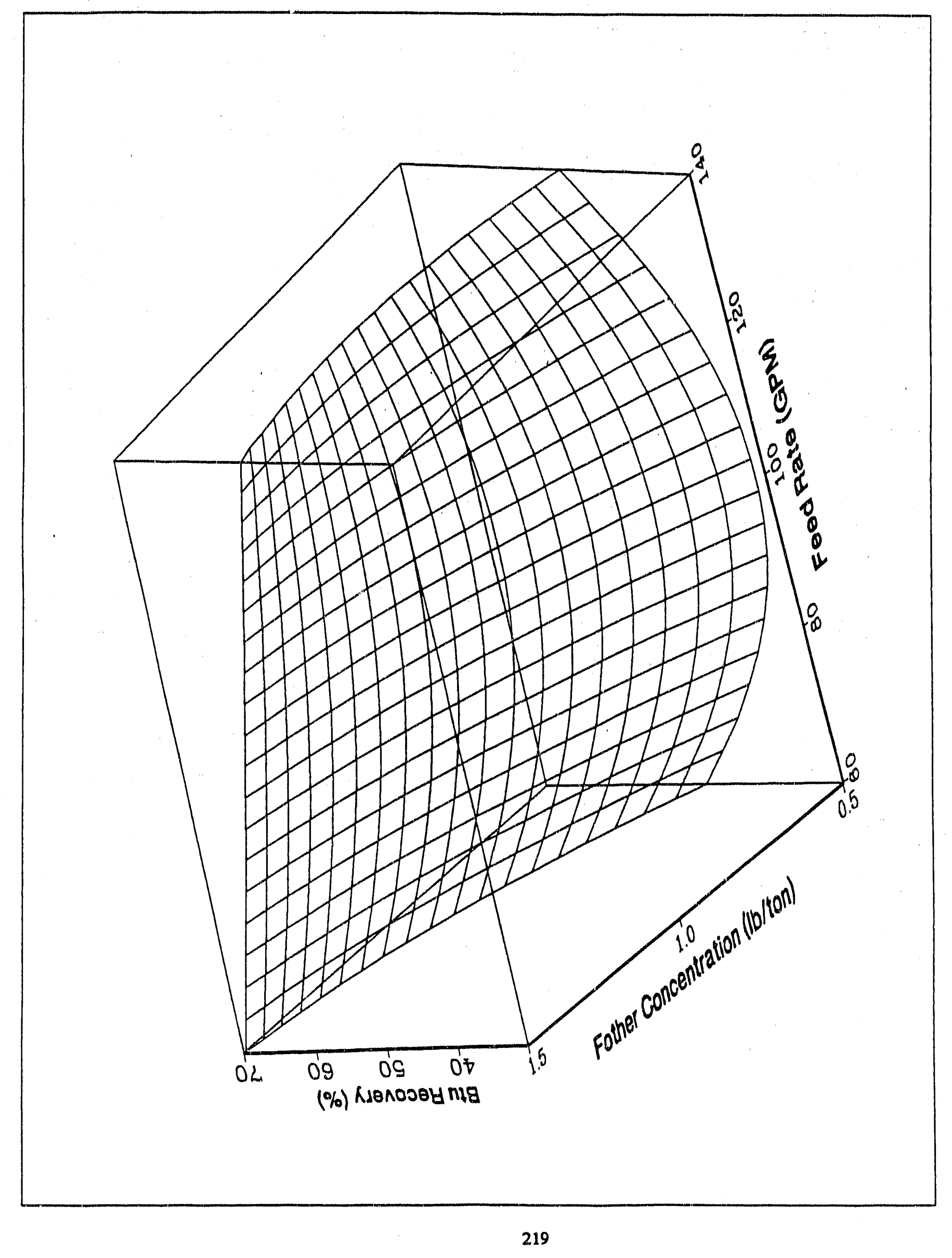




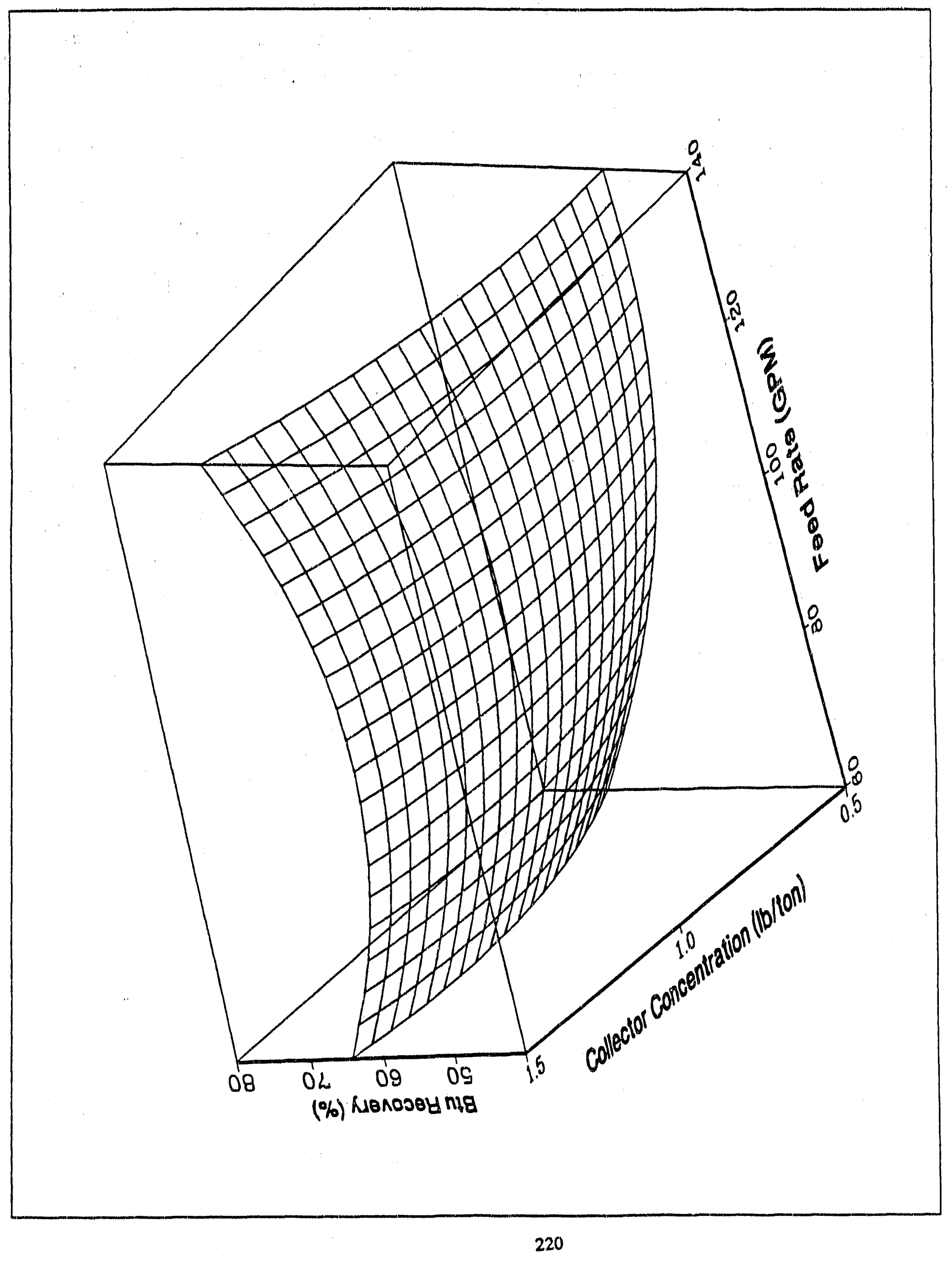




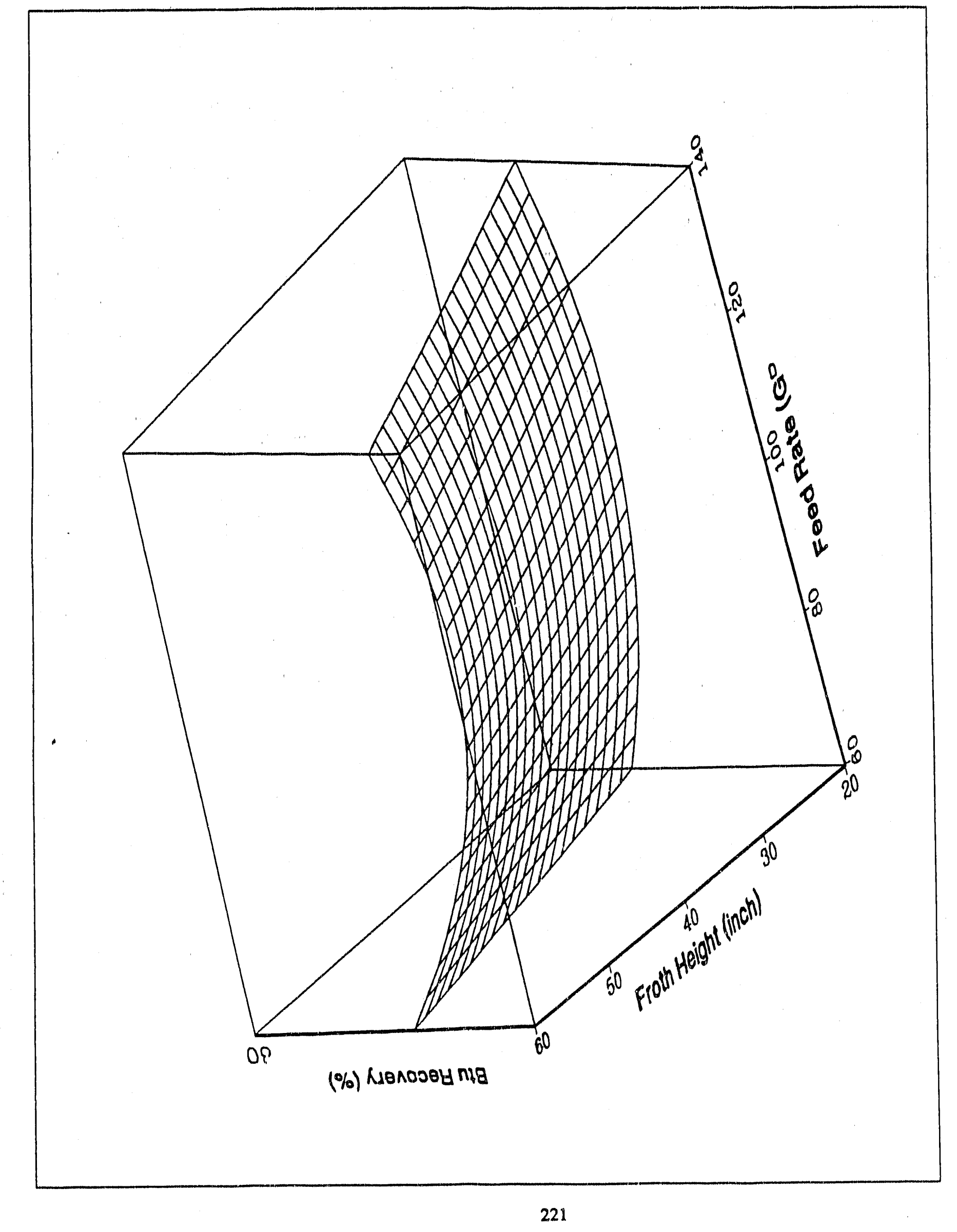




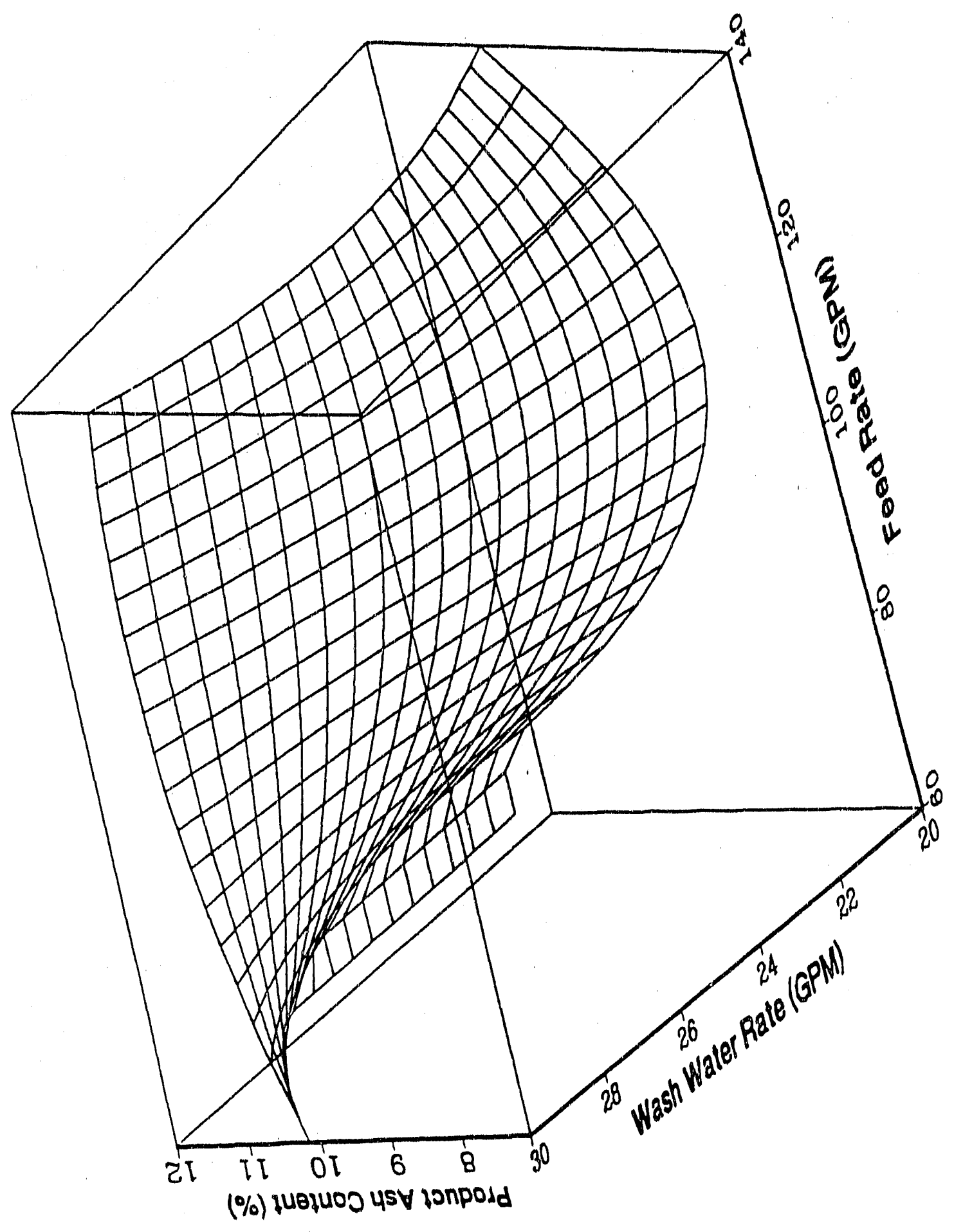




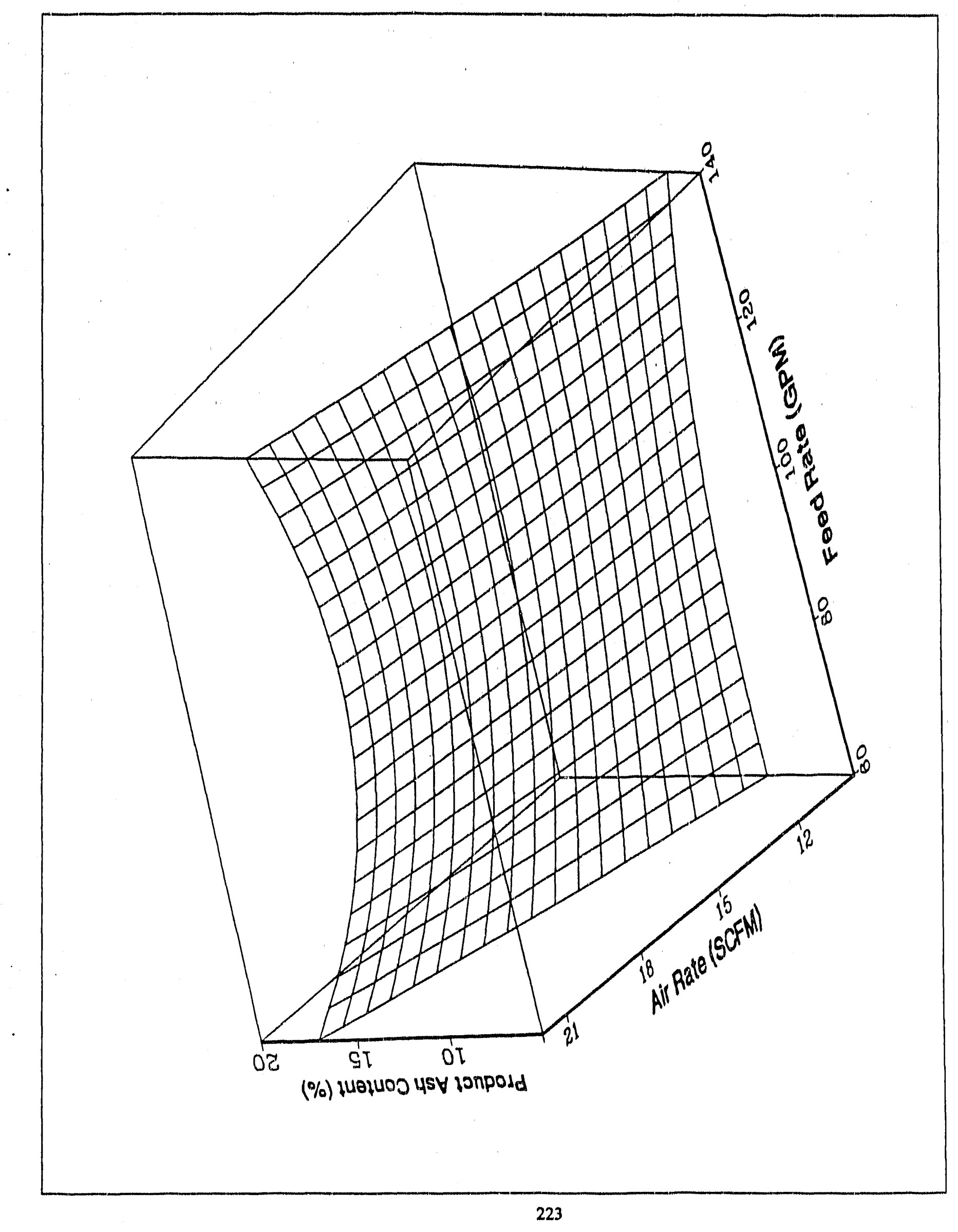




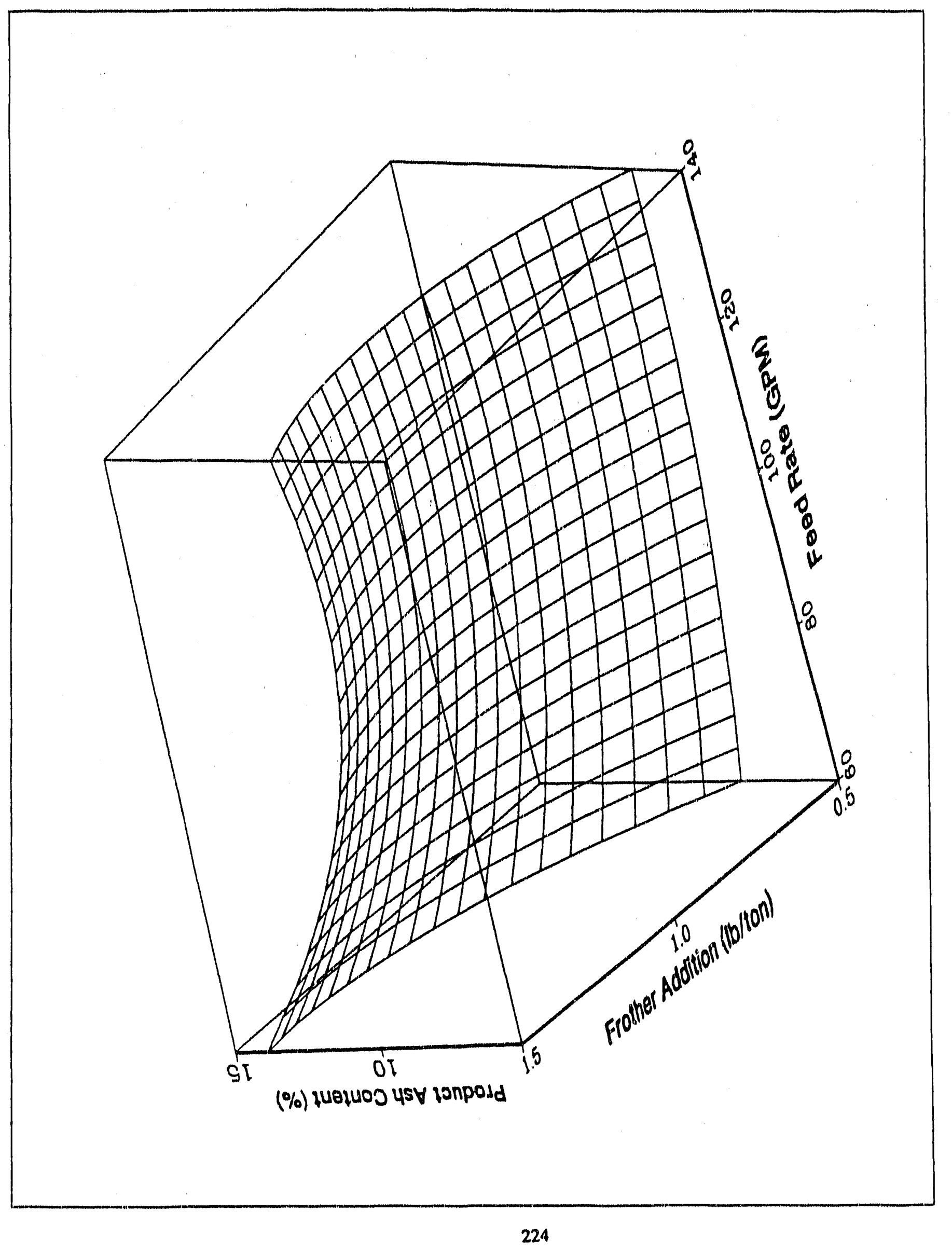




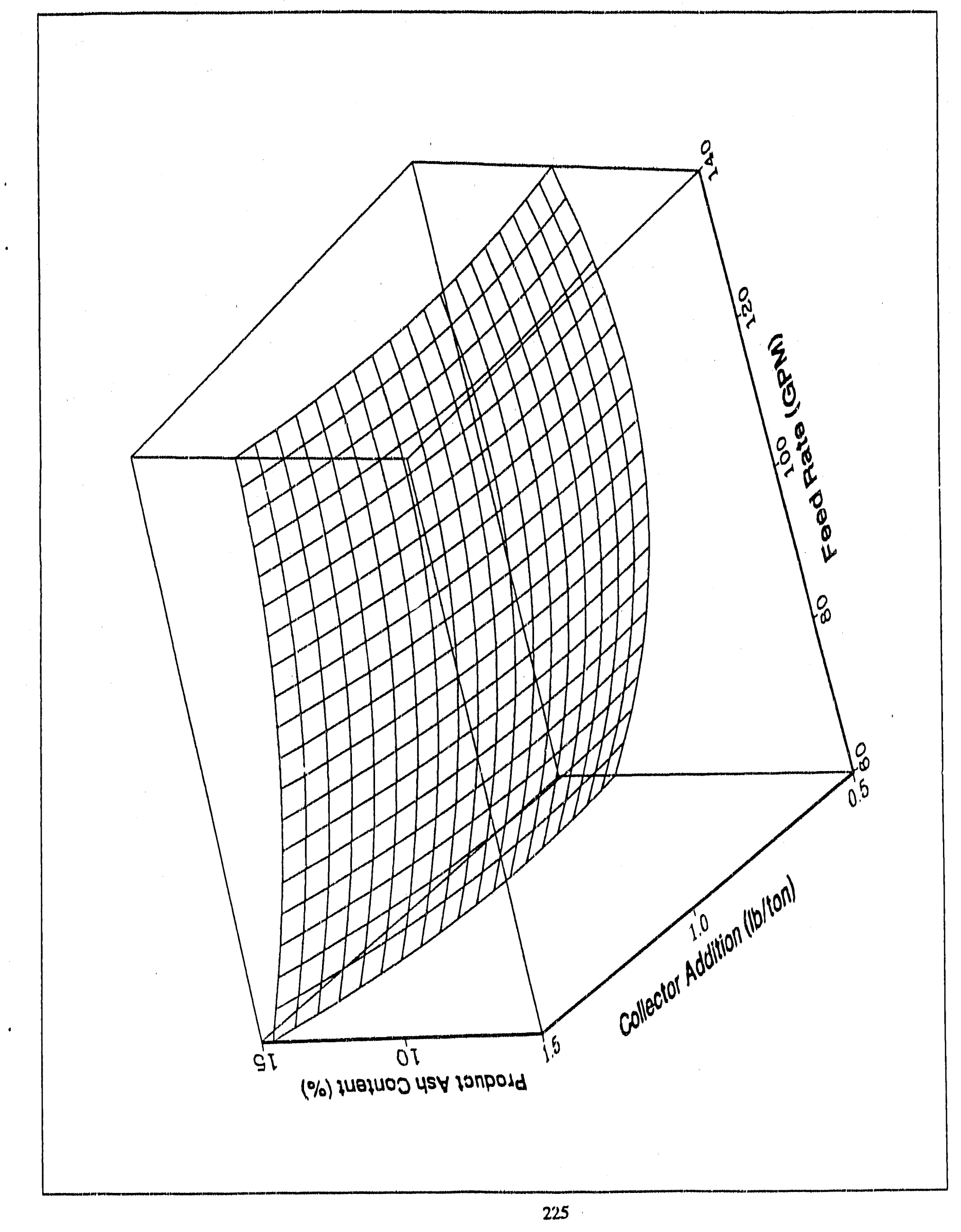




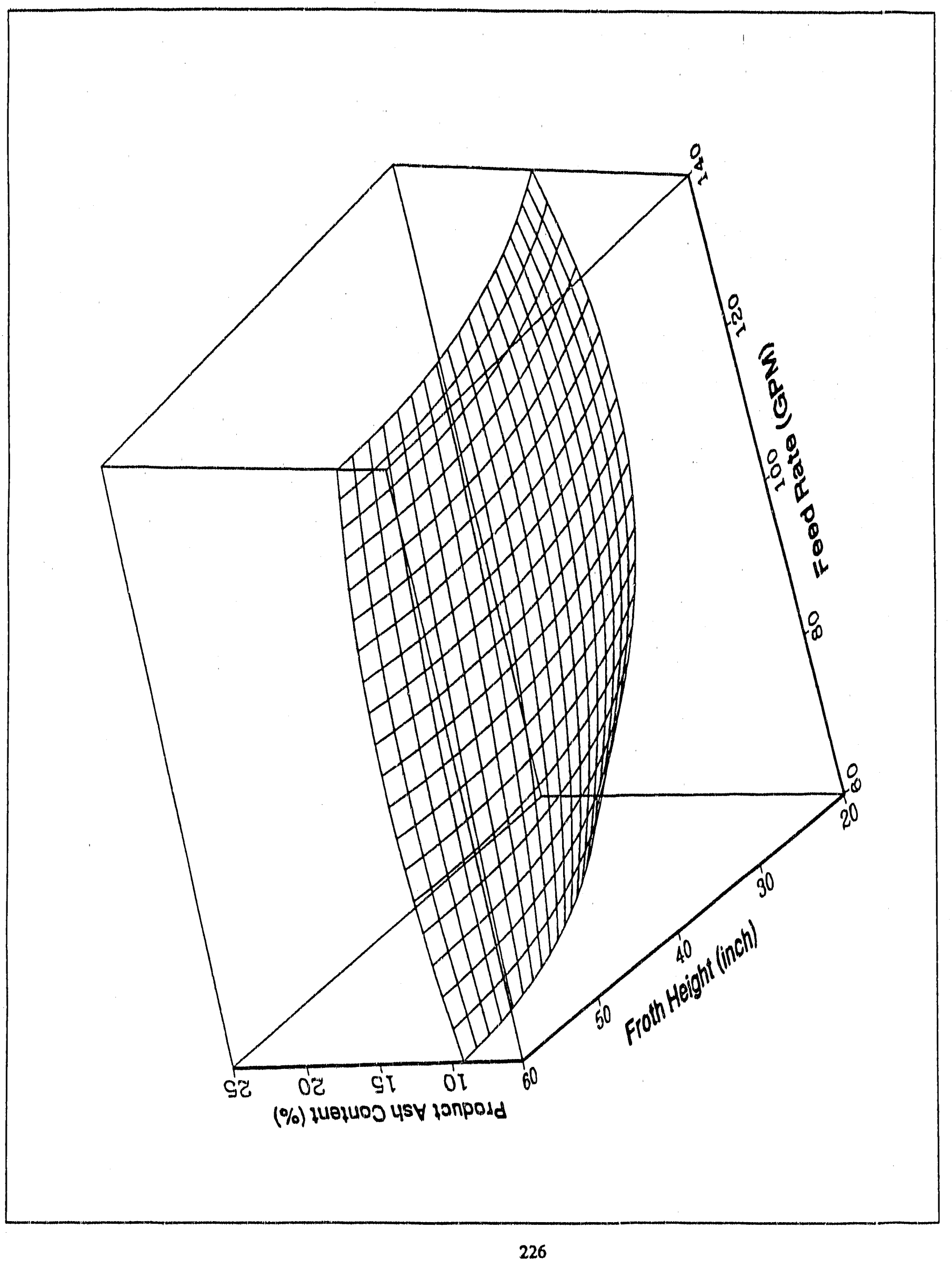




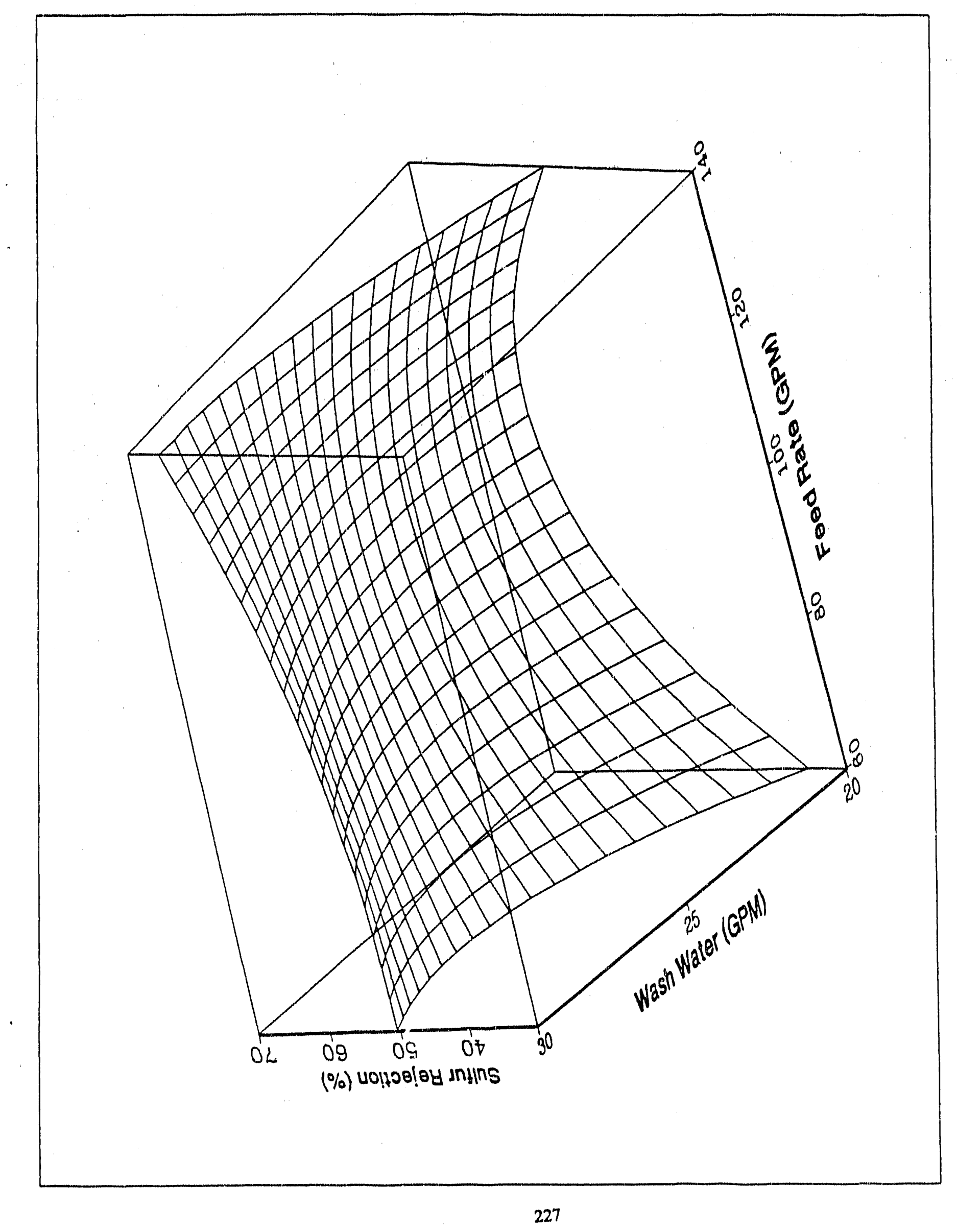




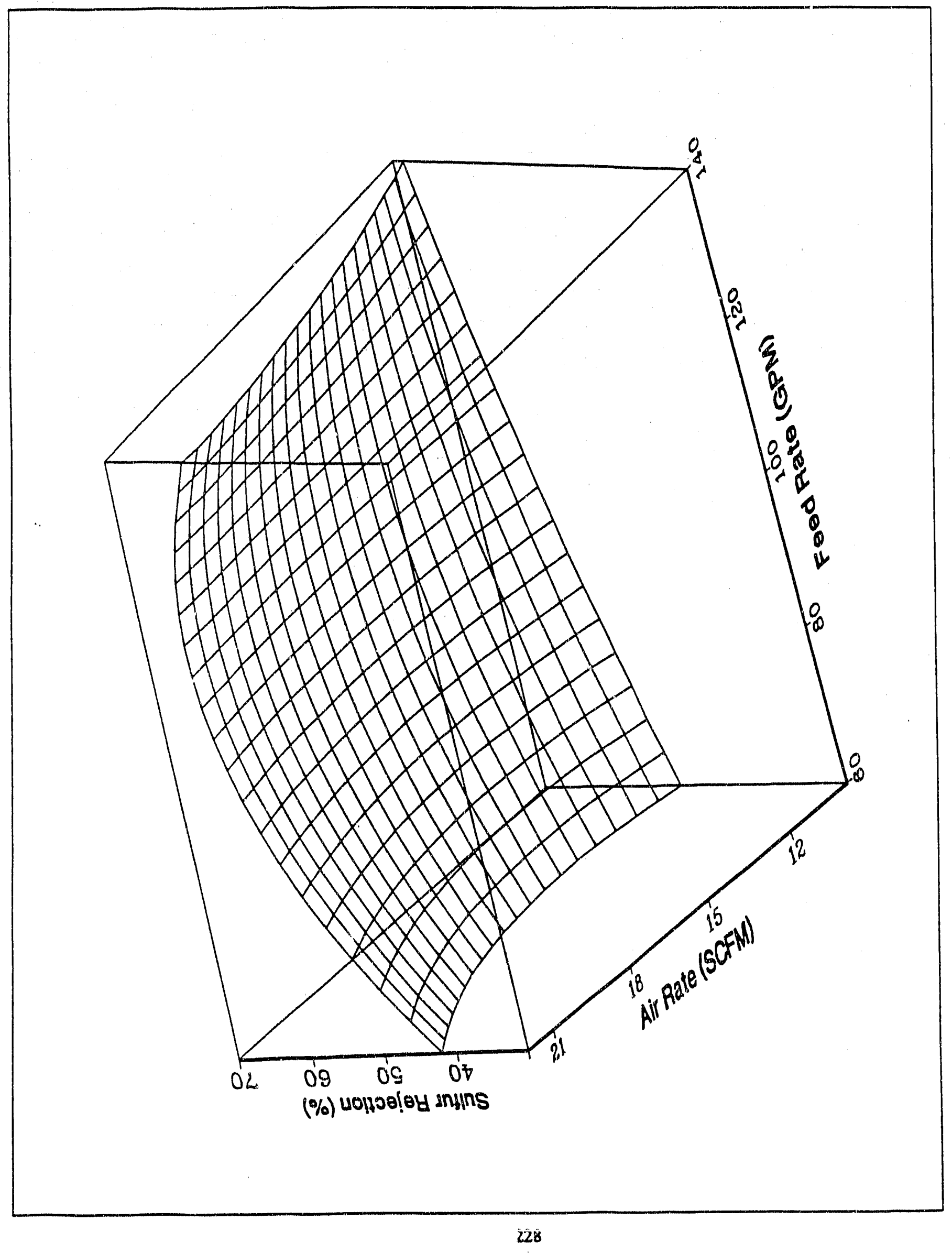




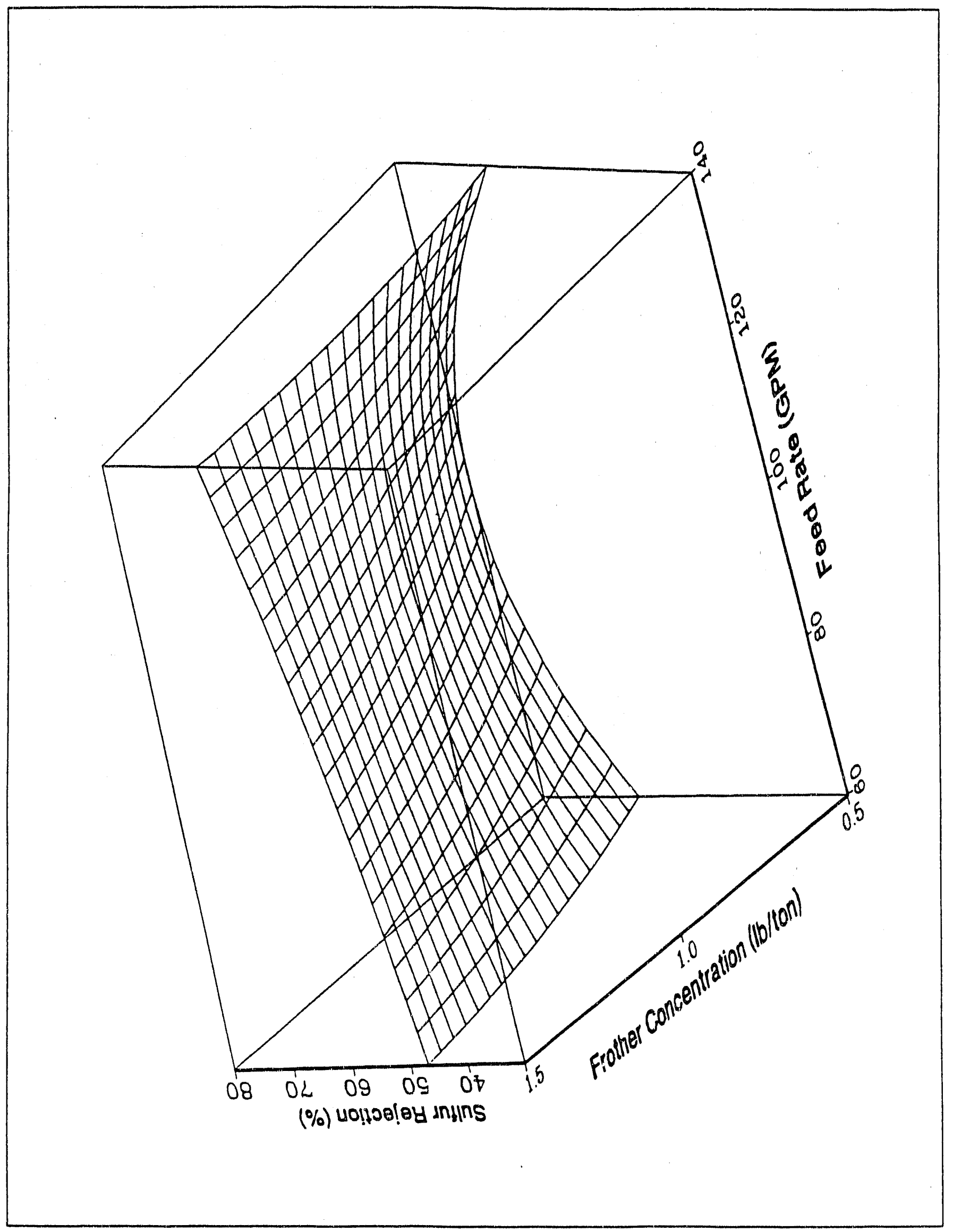




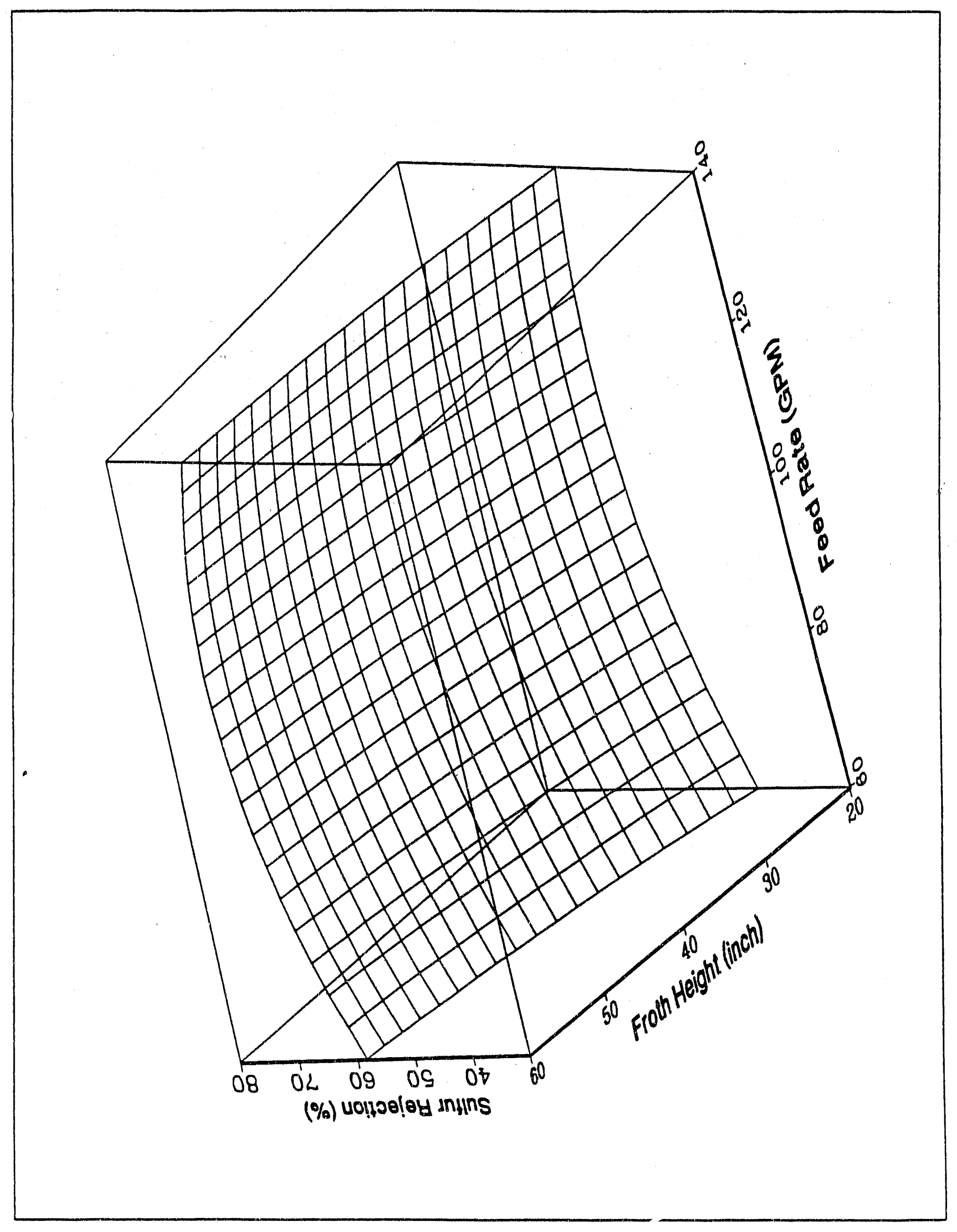




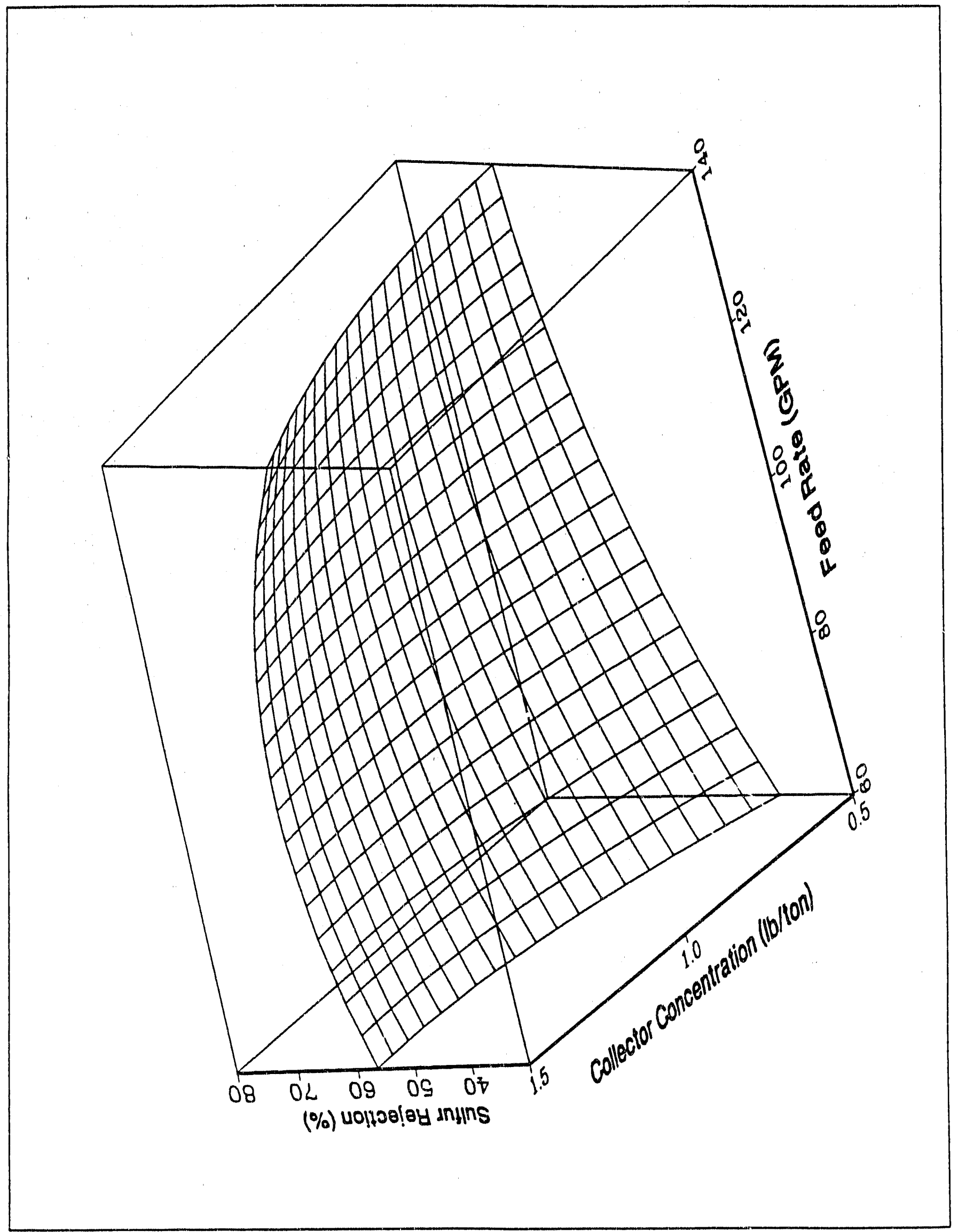




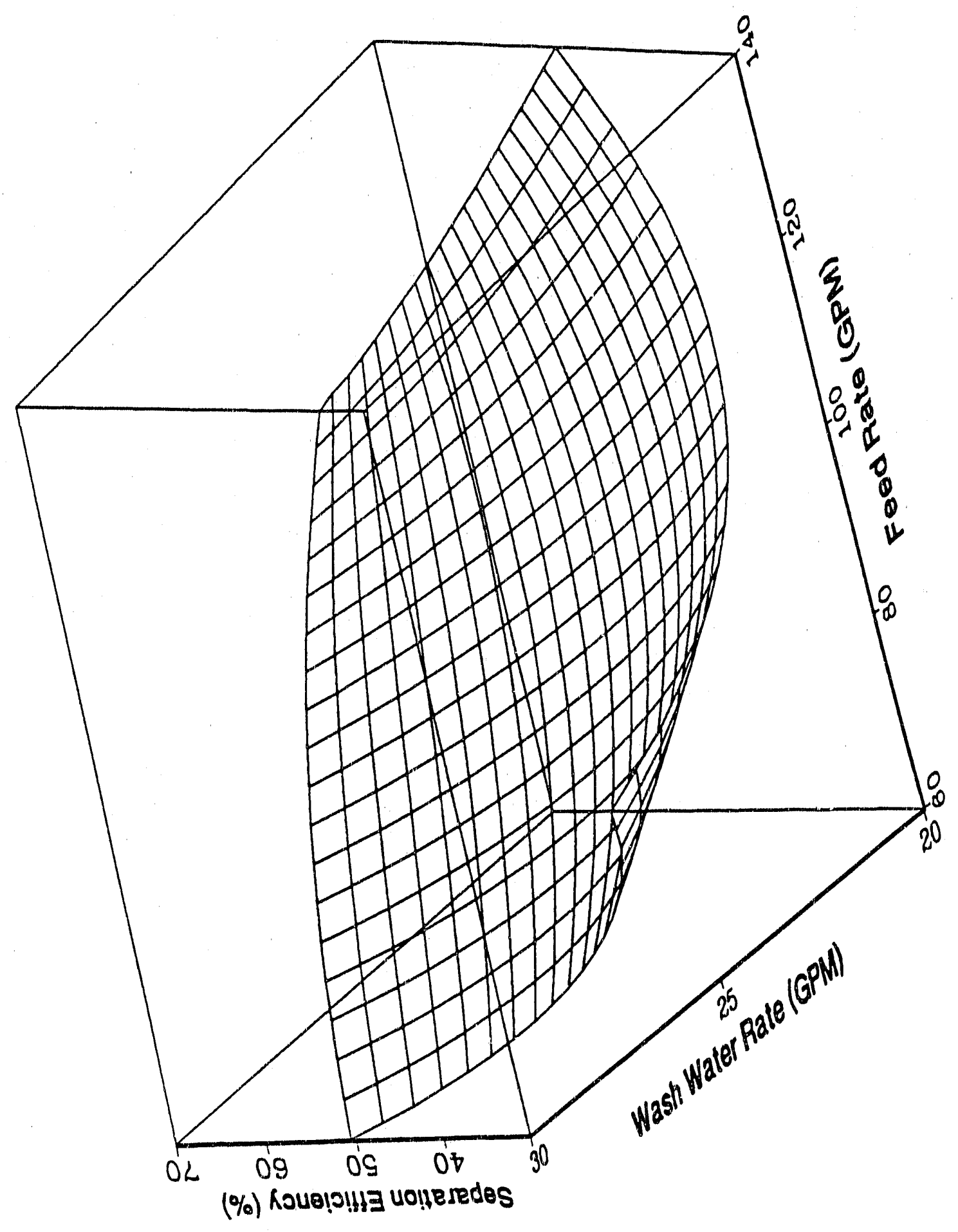




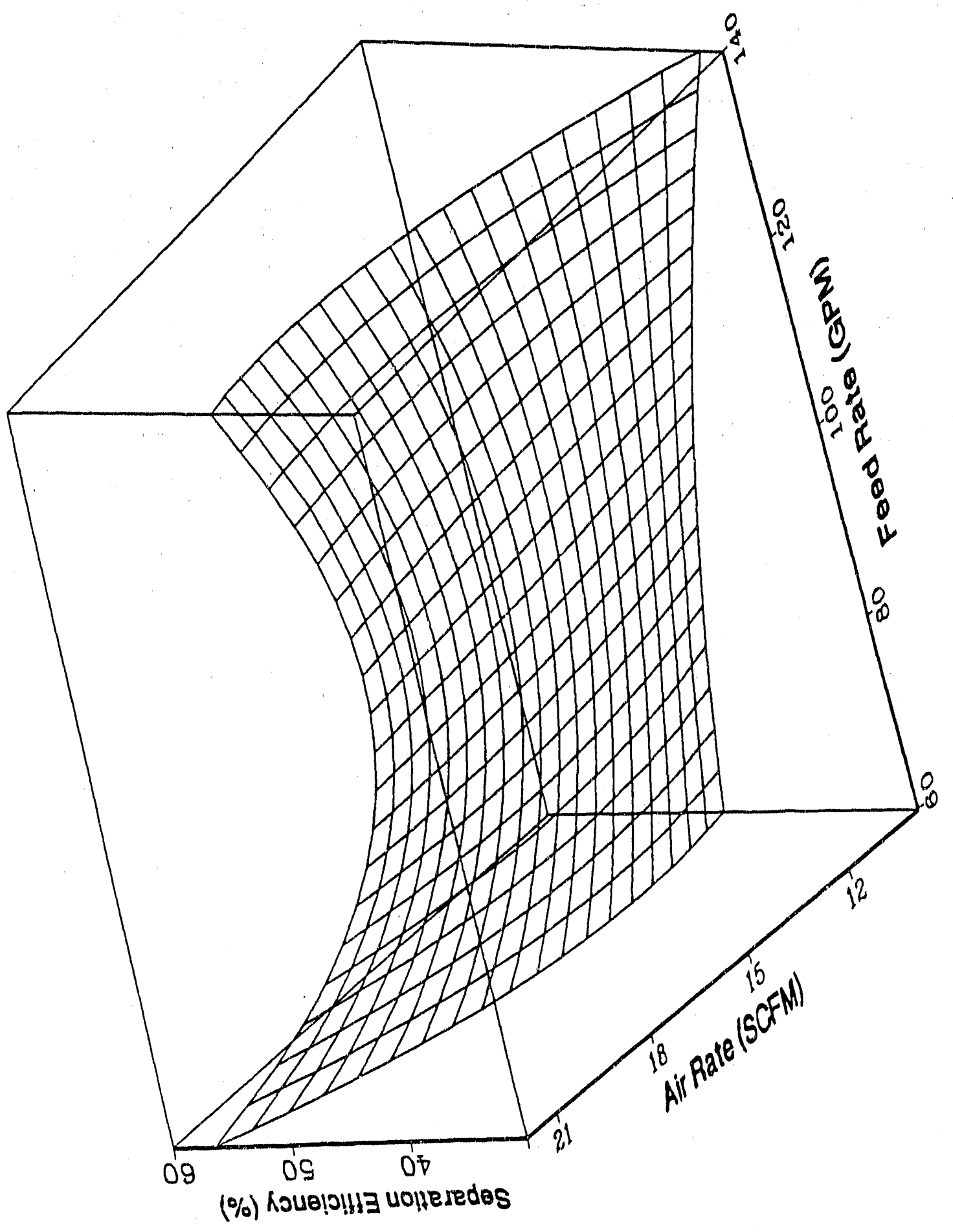




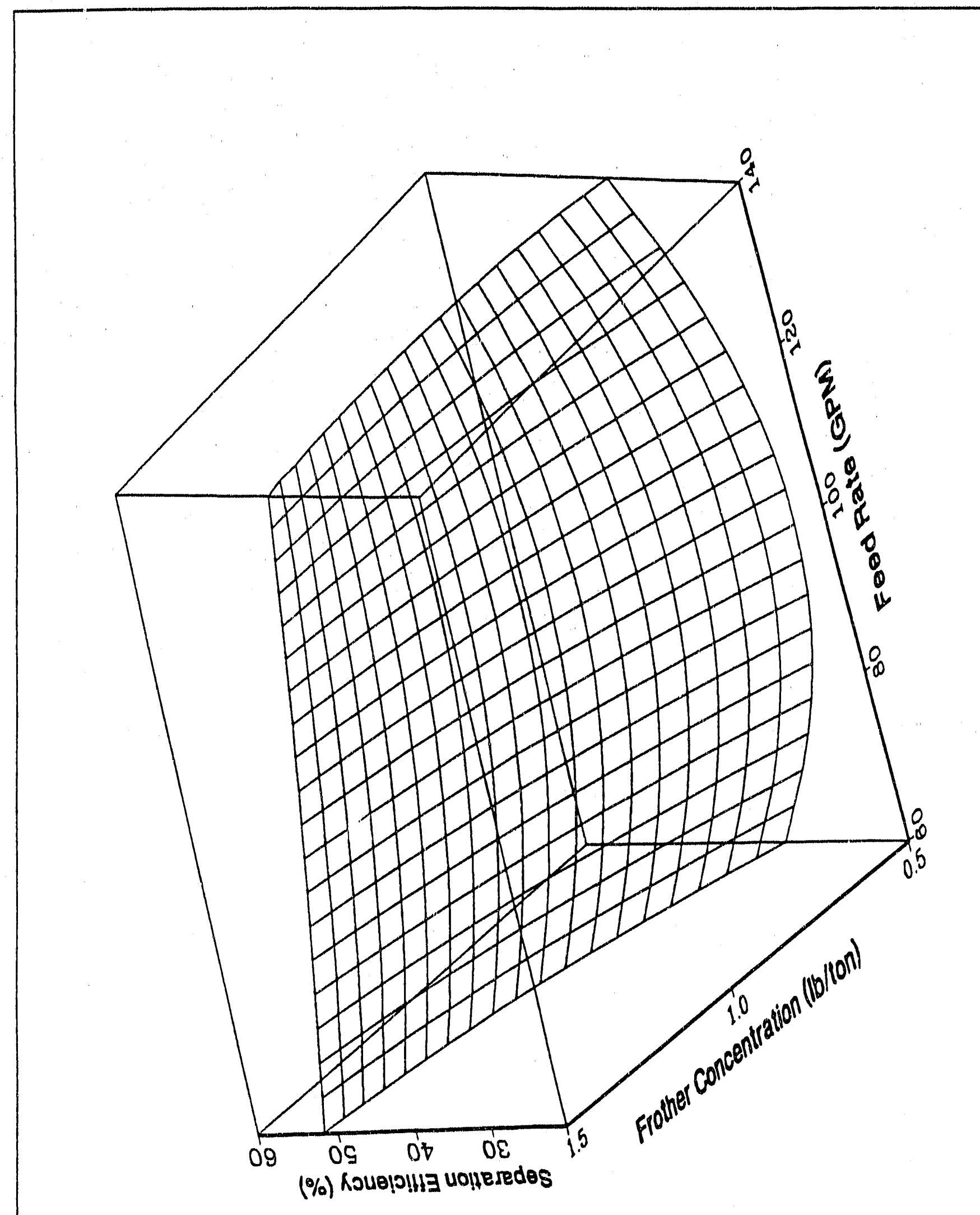




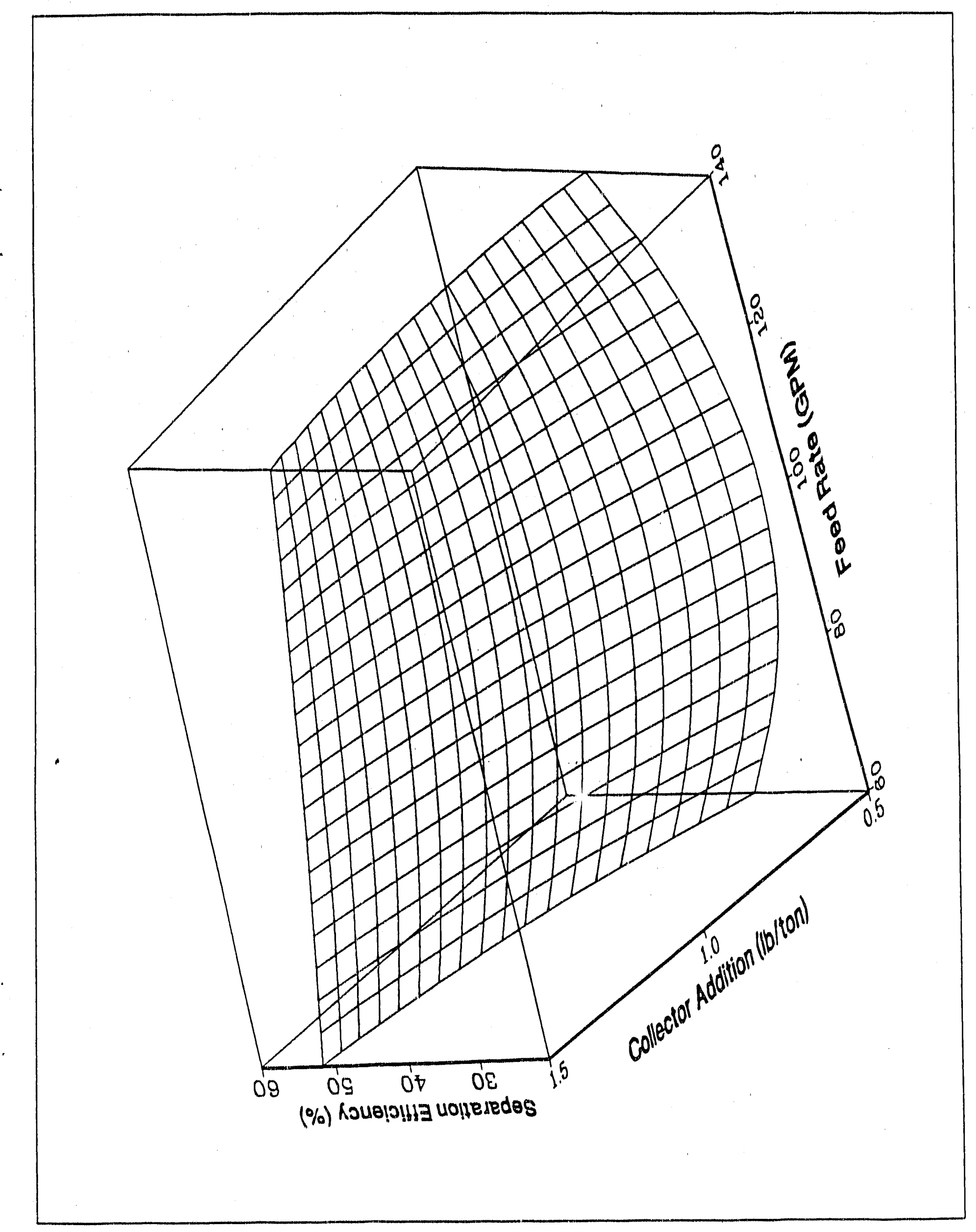




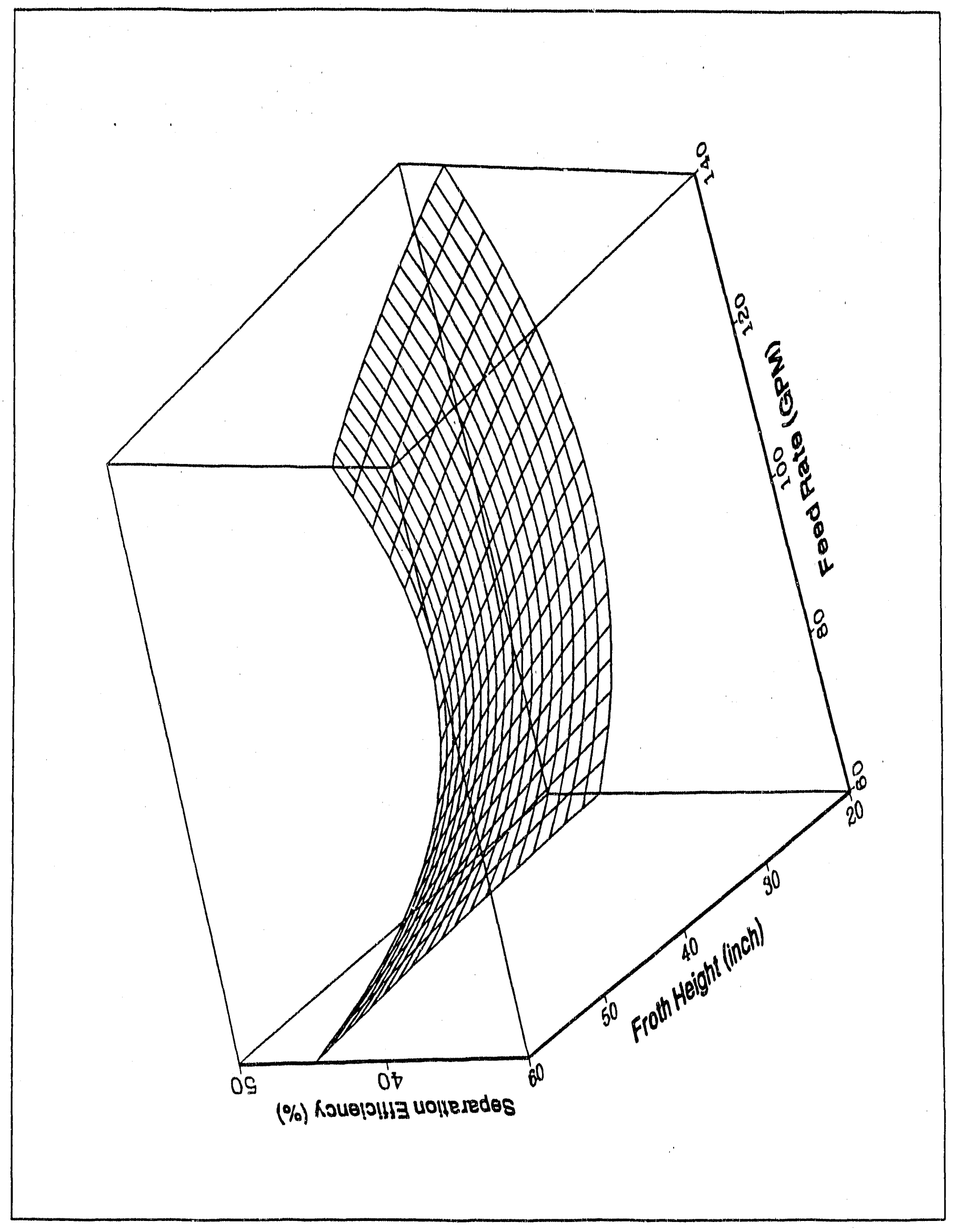


Appendix 7: Ladder logic program for column control 


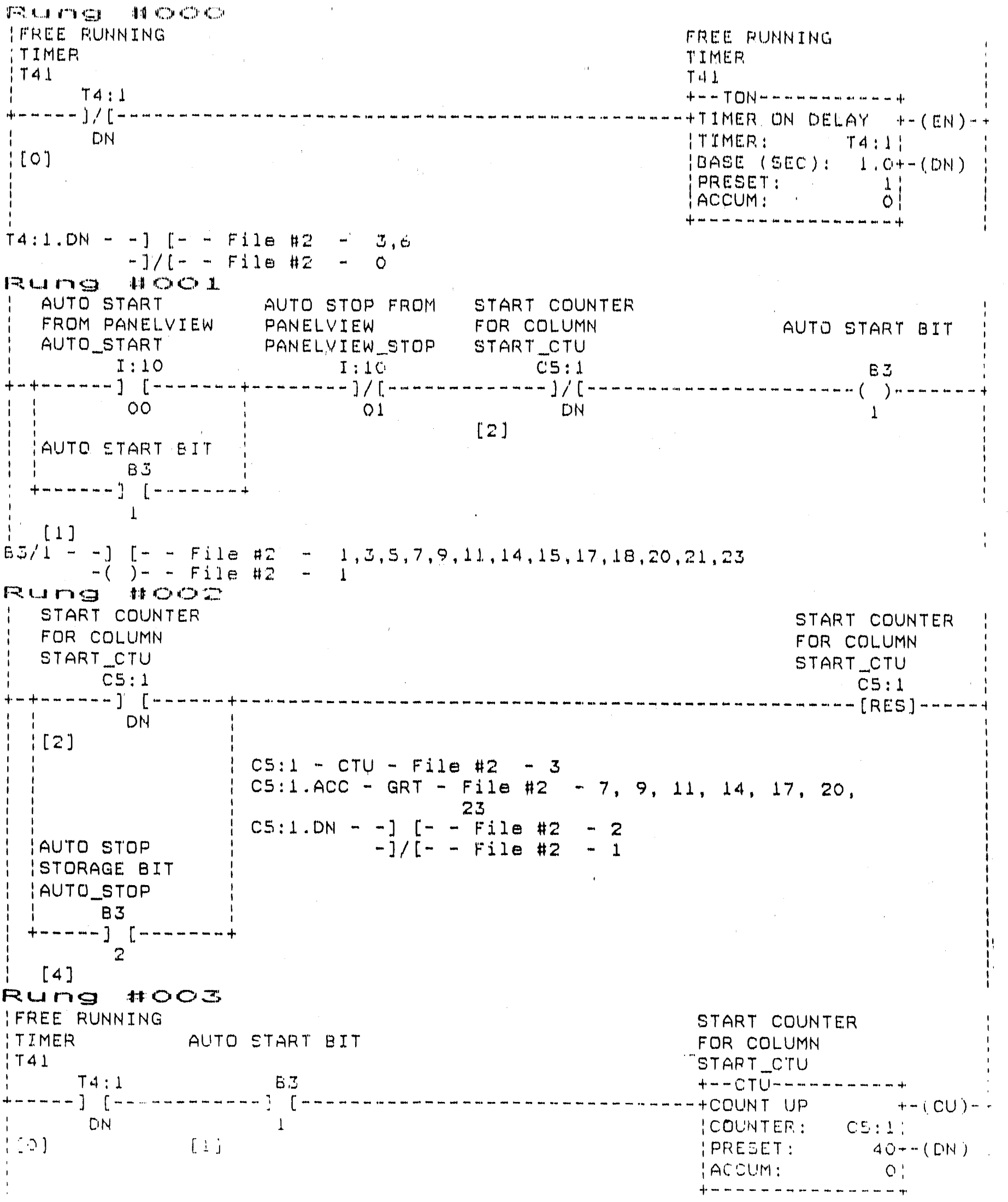




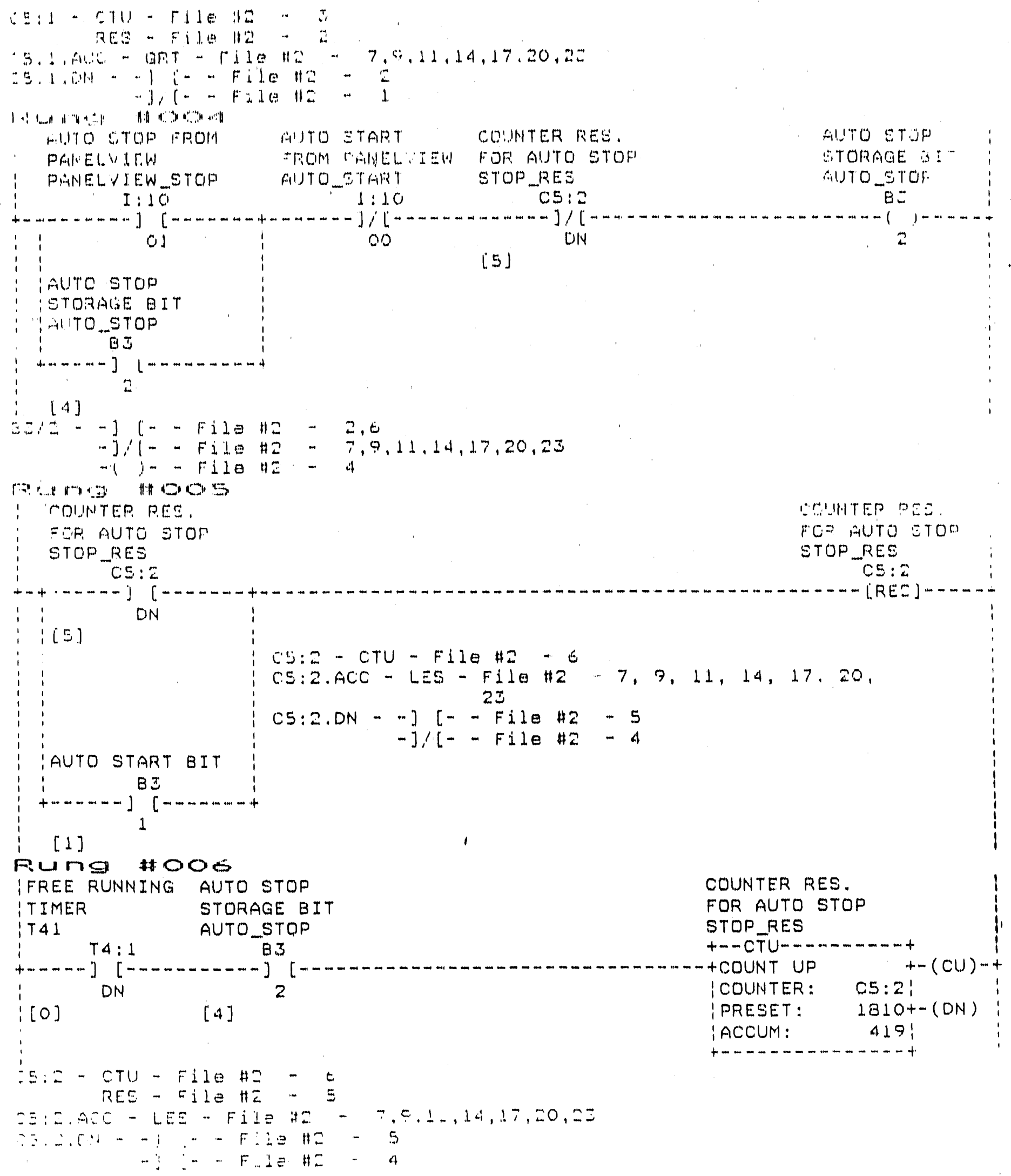




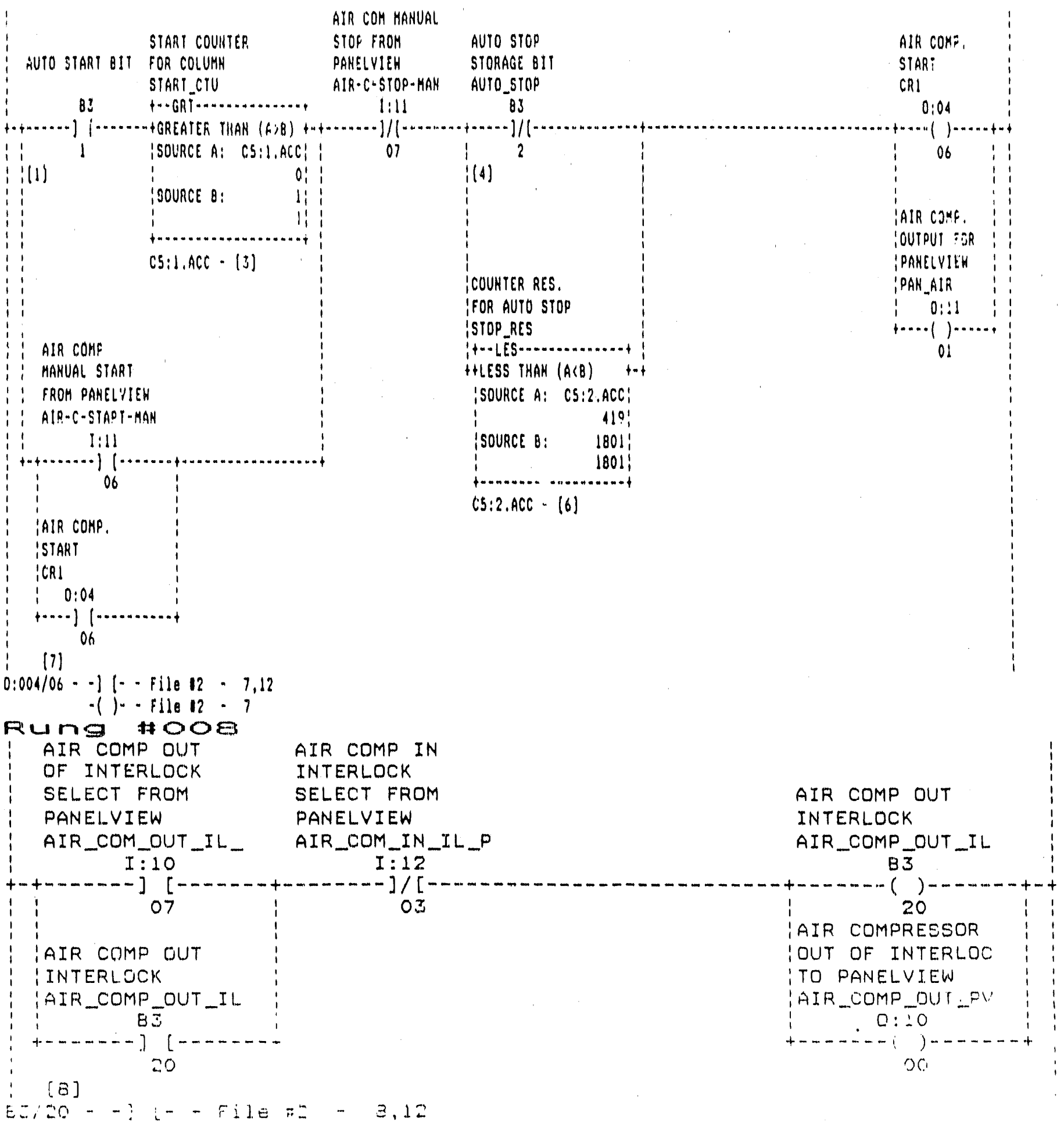




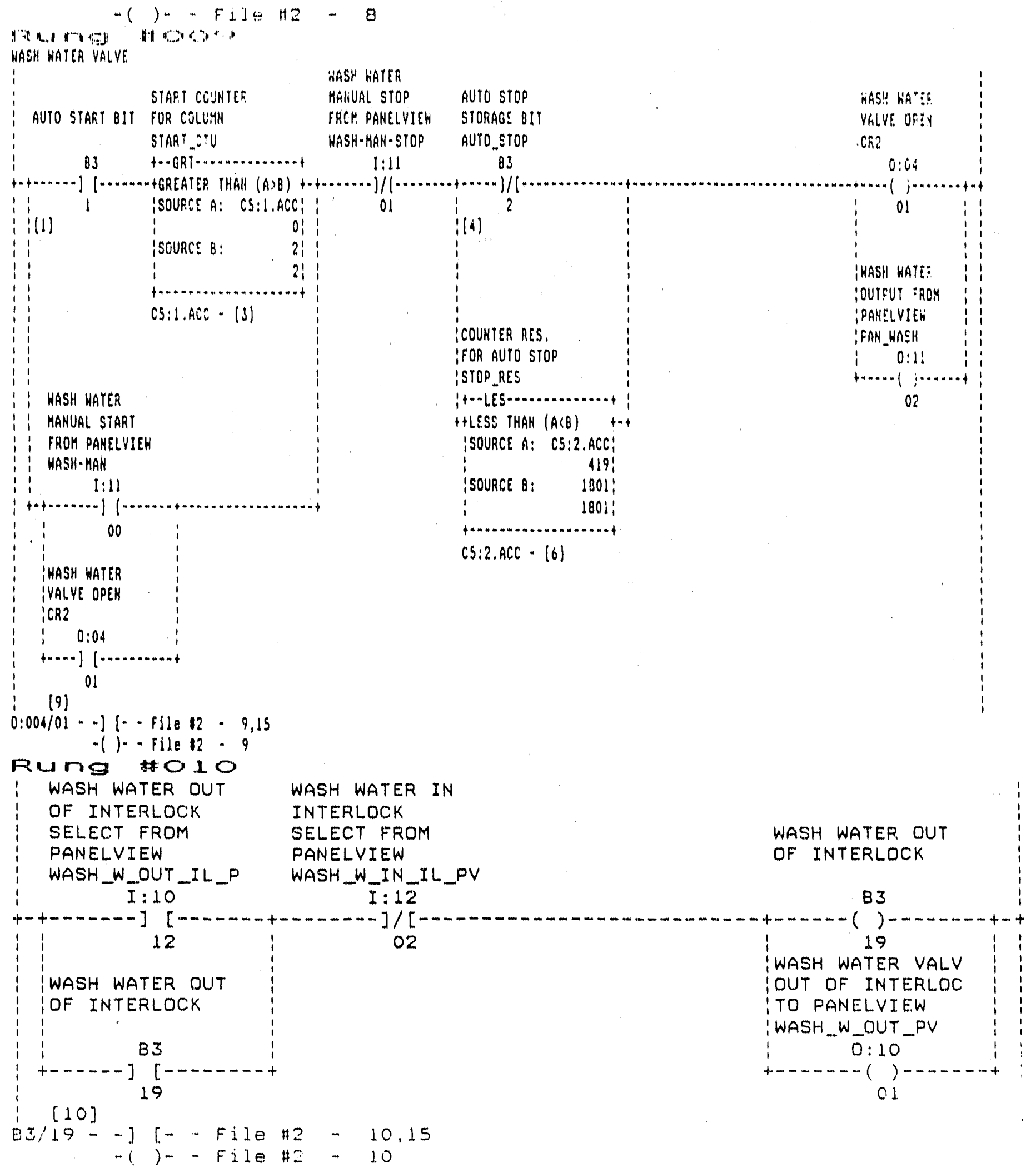




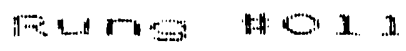

AIF VPLLVE

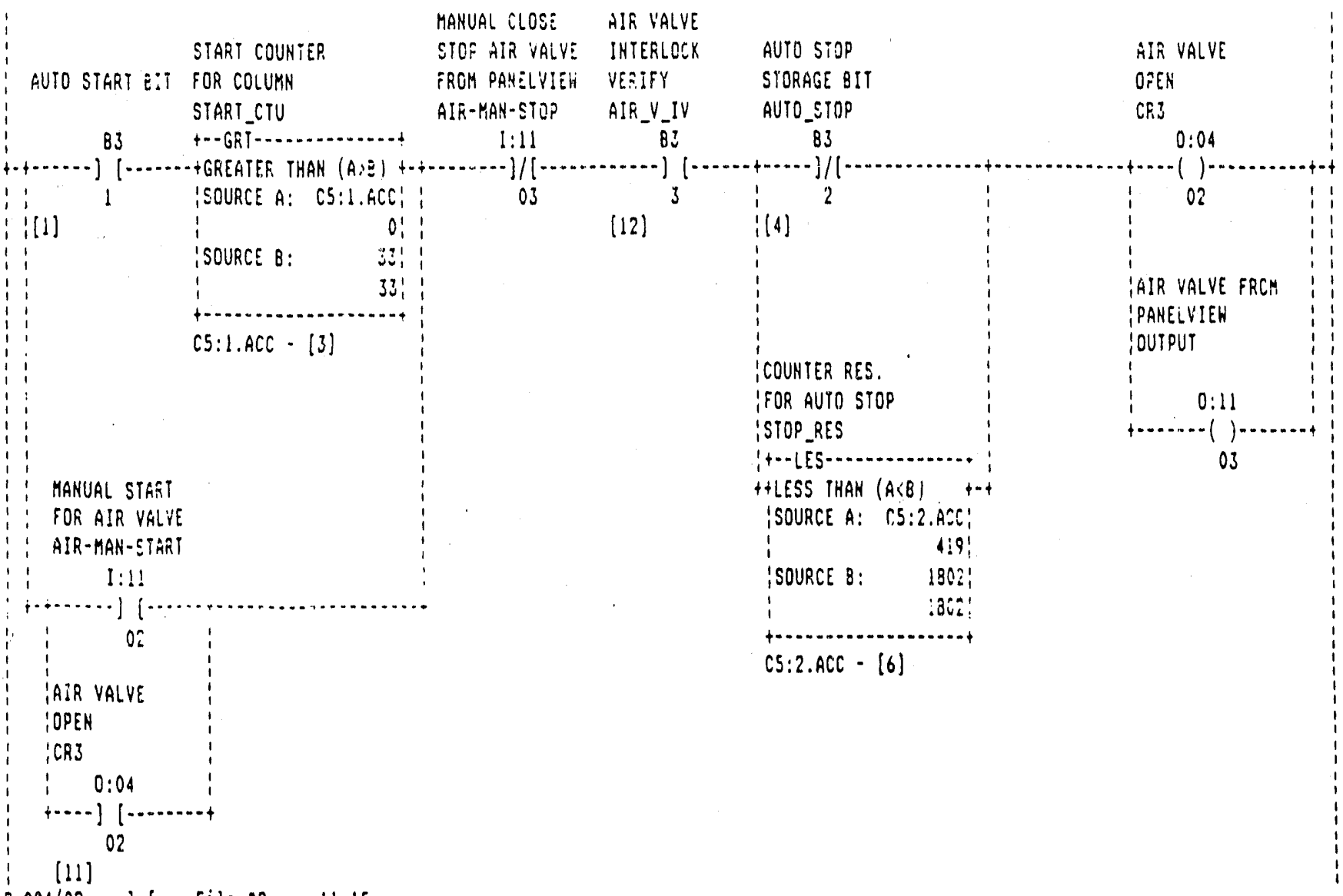

$0: 004 / 02 \cdots][-$ File $12-11,15$

$-(1) \cdot$ File 12 - 11

Rung \#012

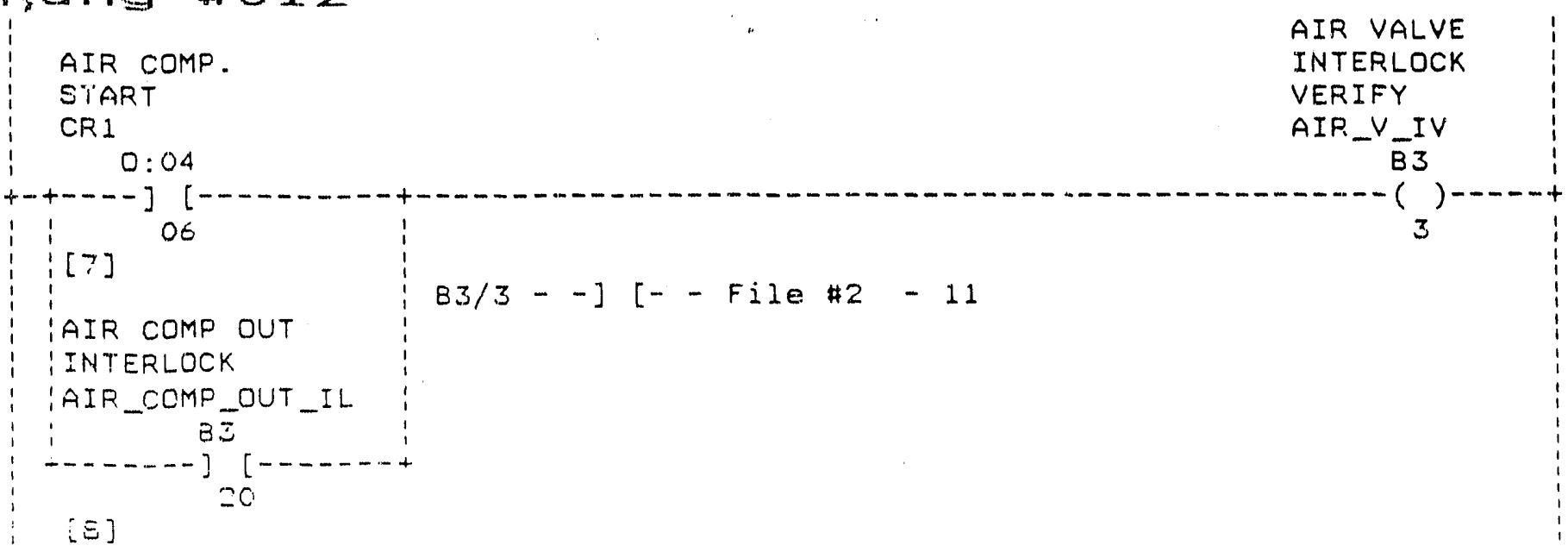




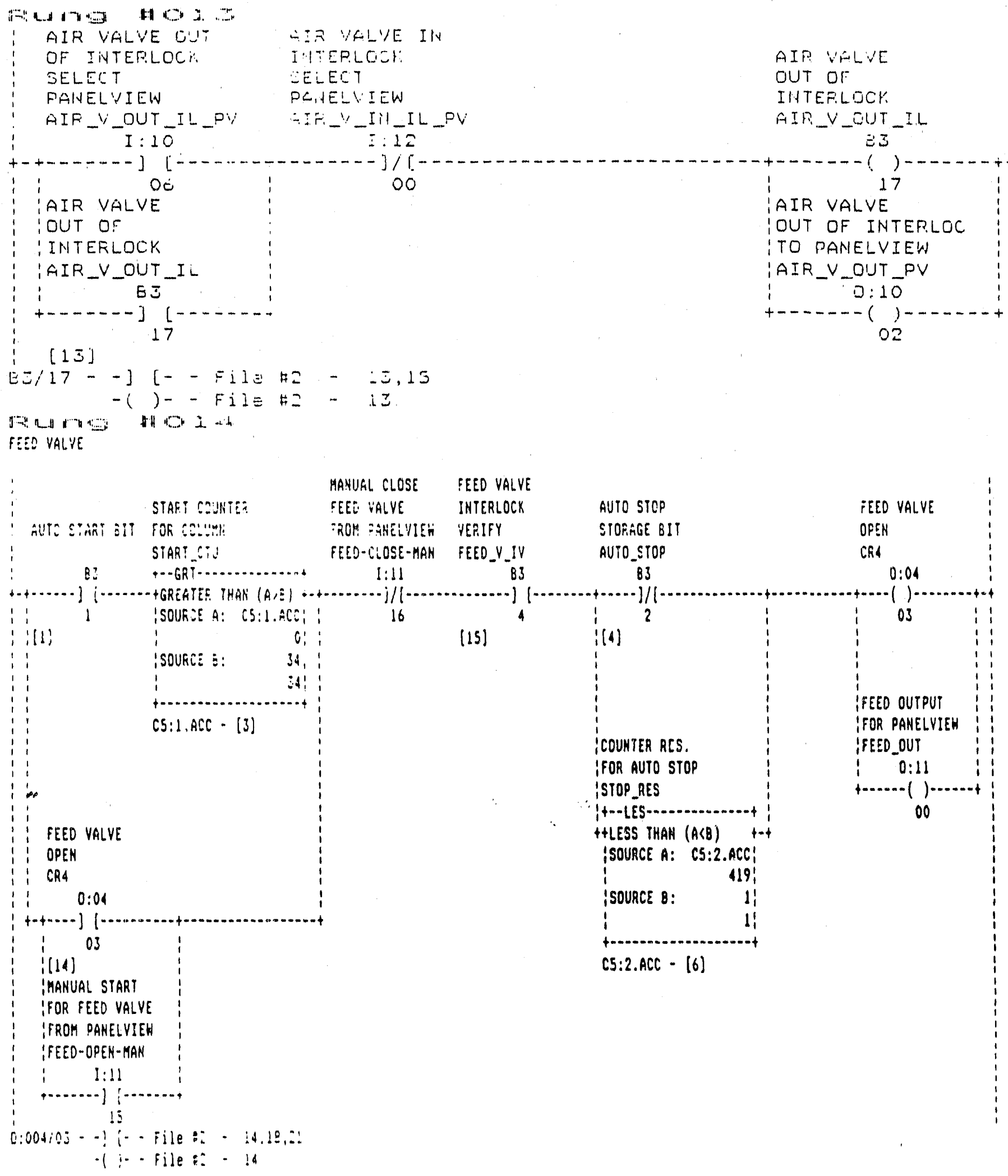




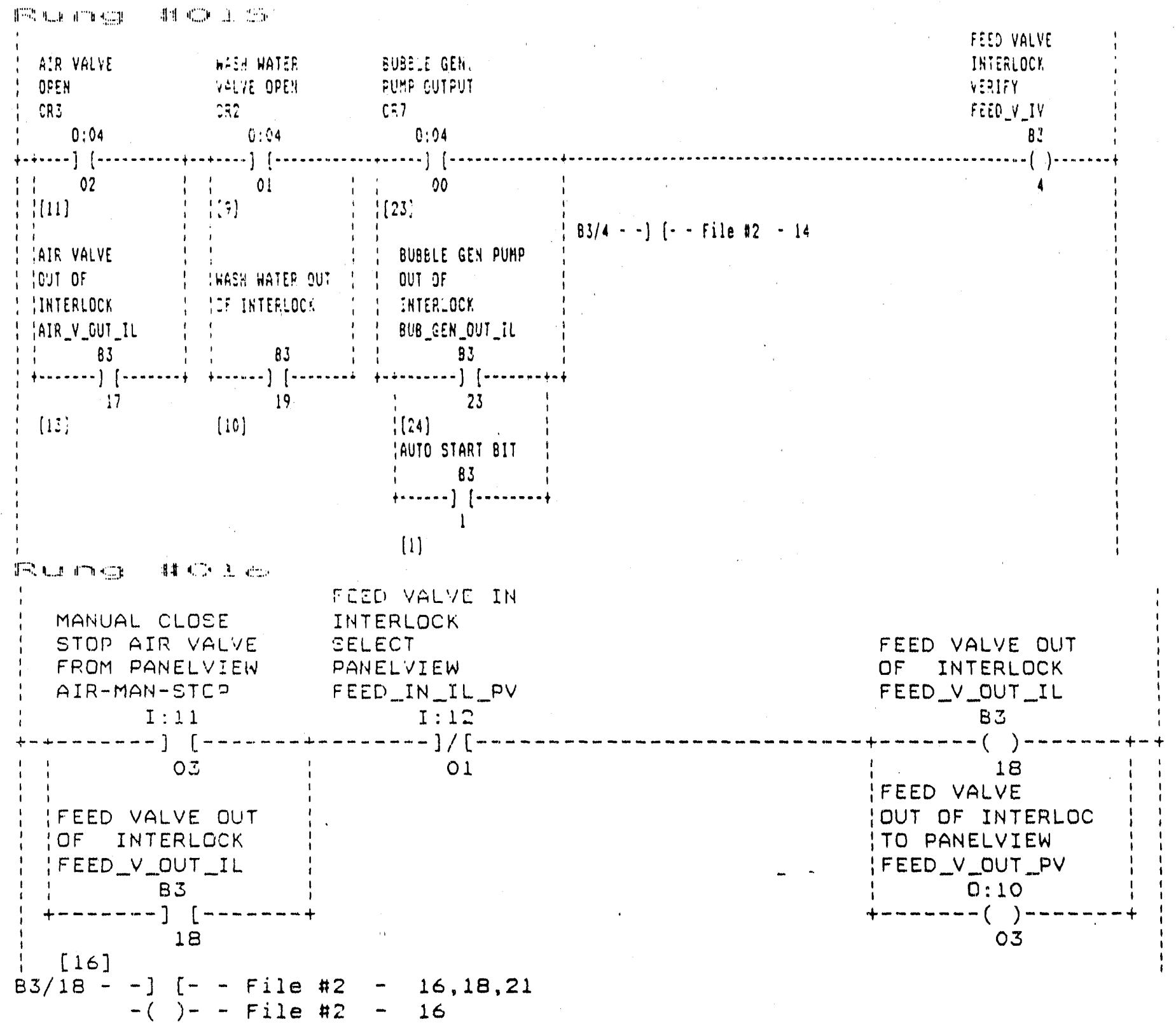




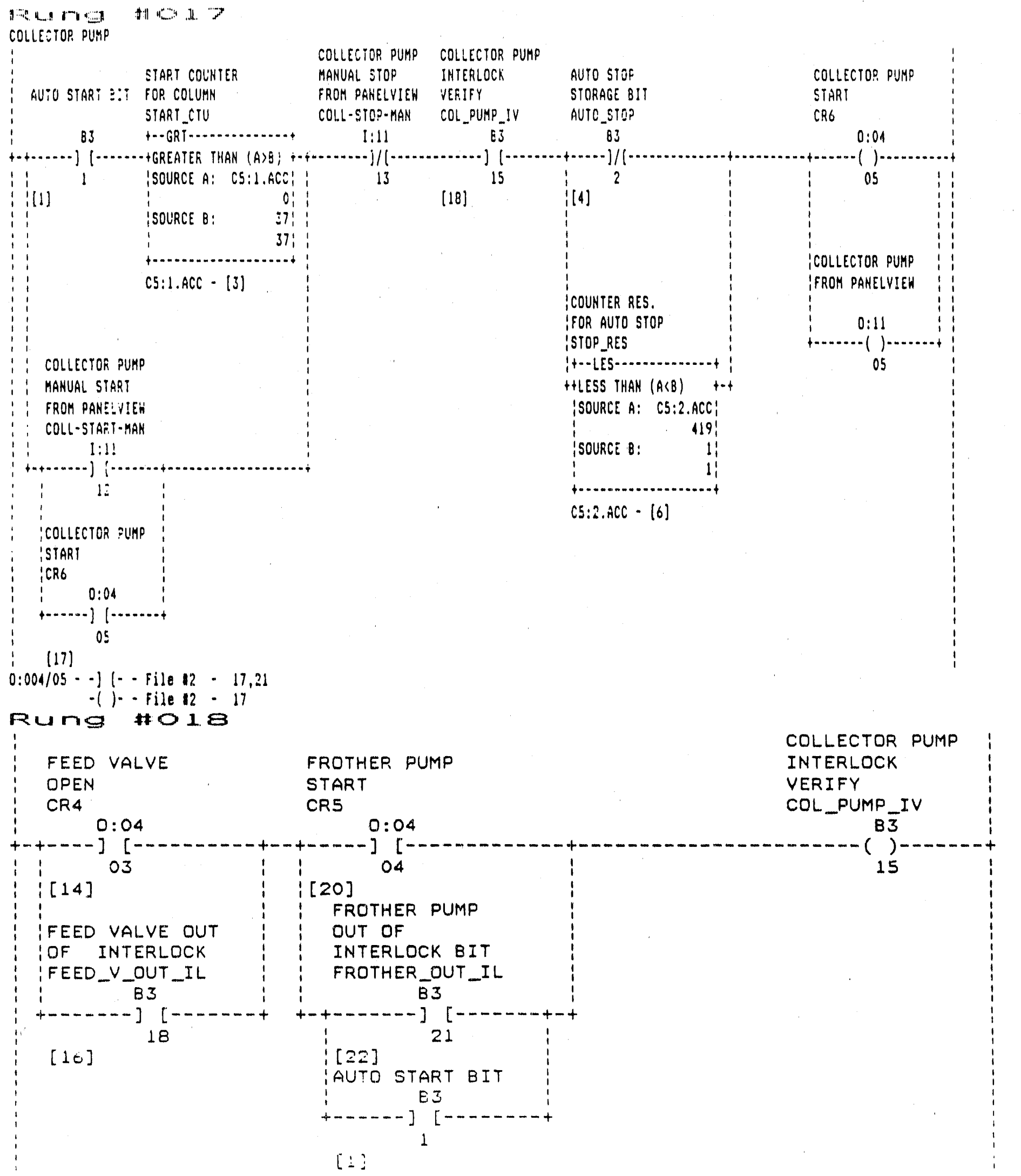




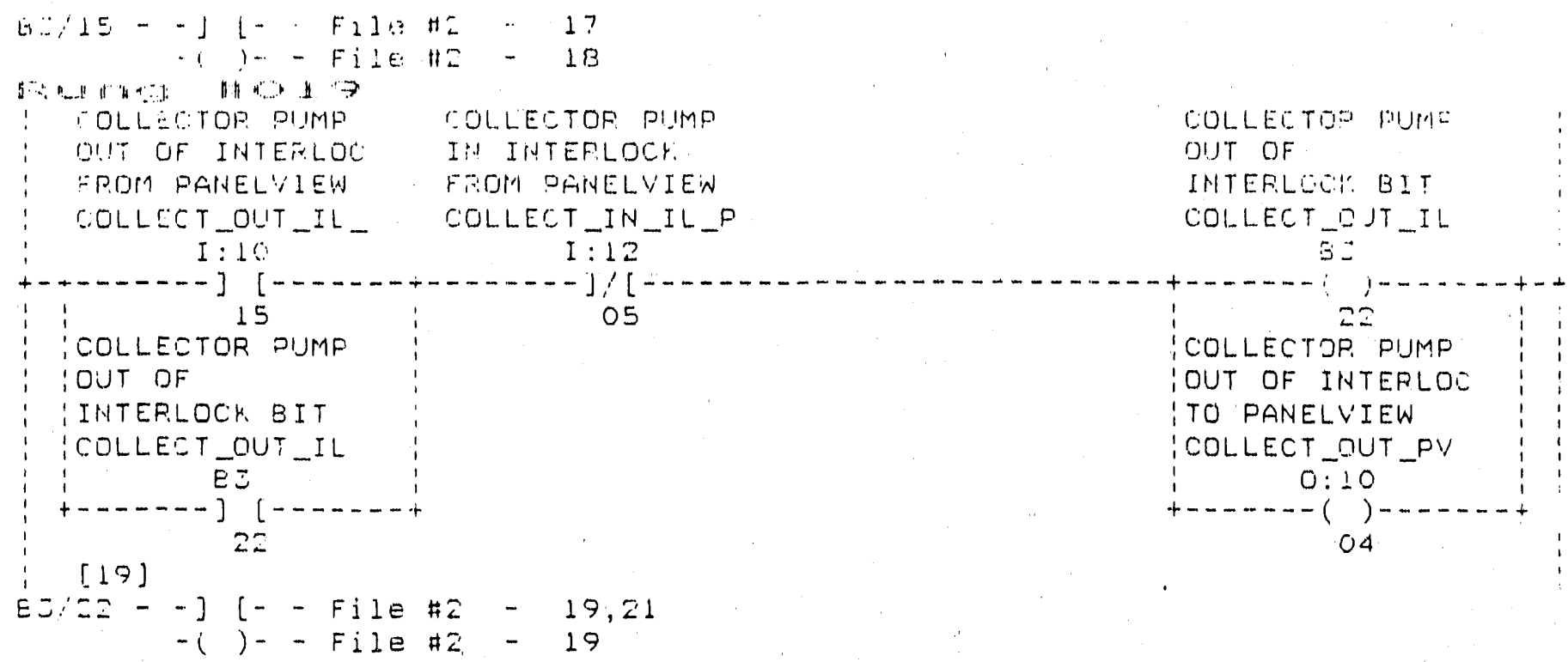

dan

FFoTHES PUM?

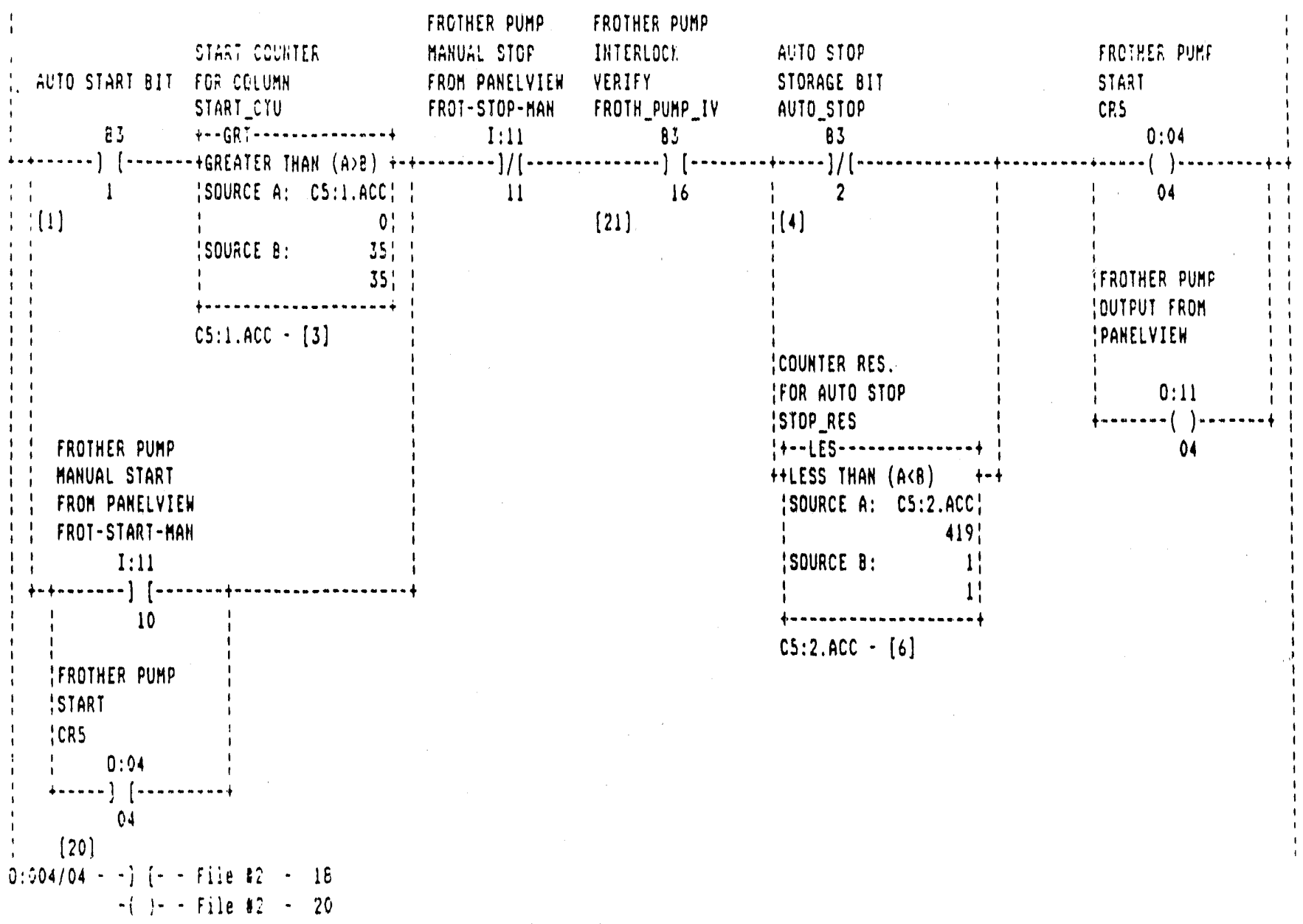




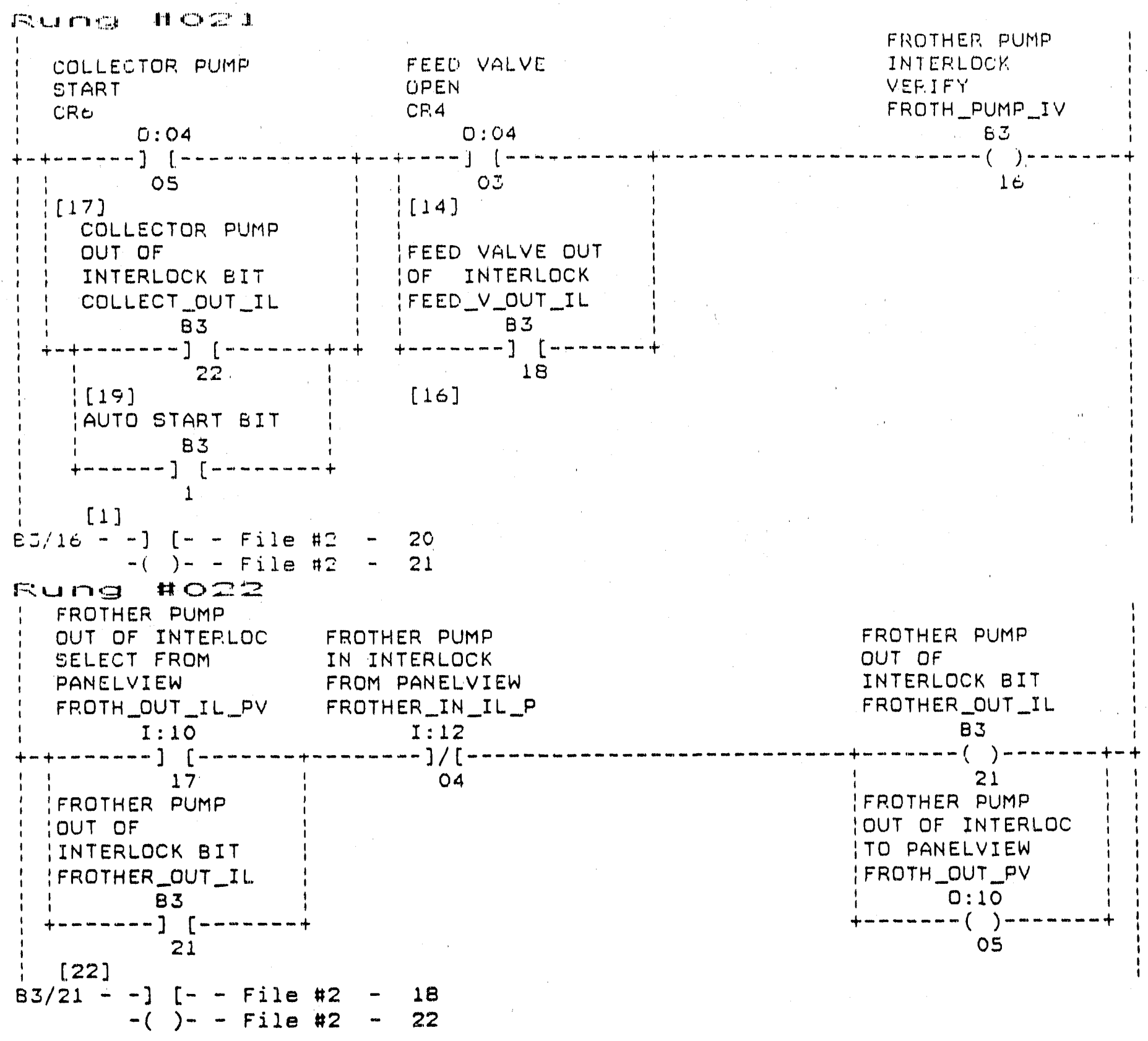




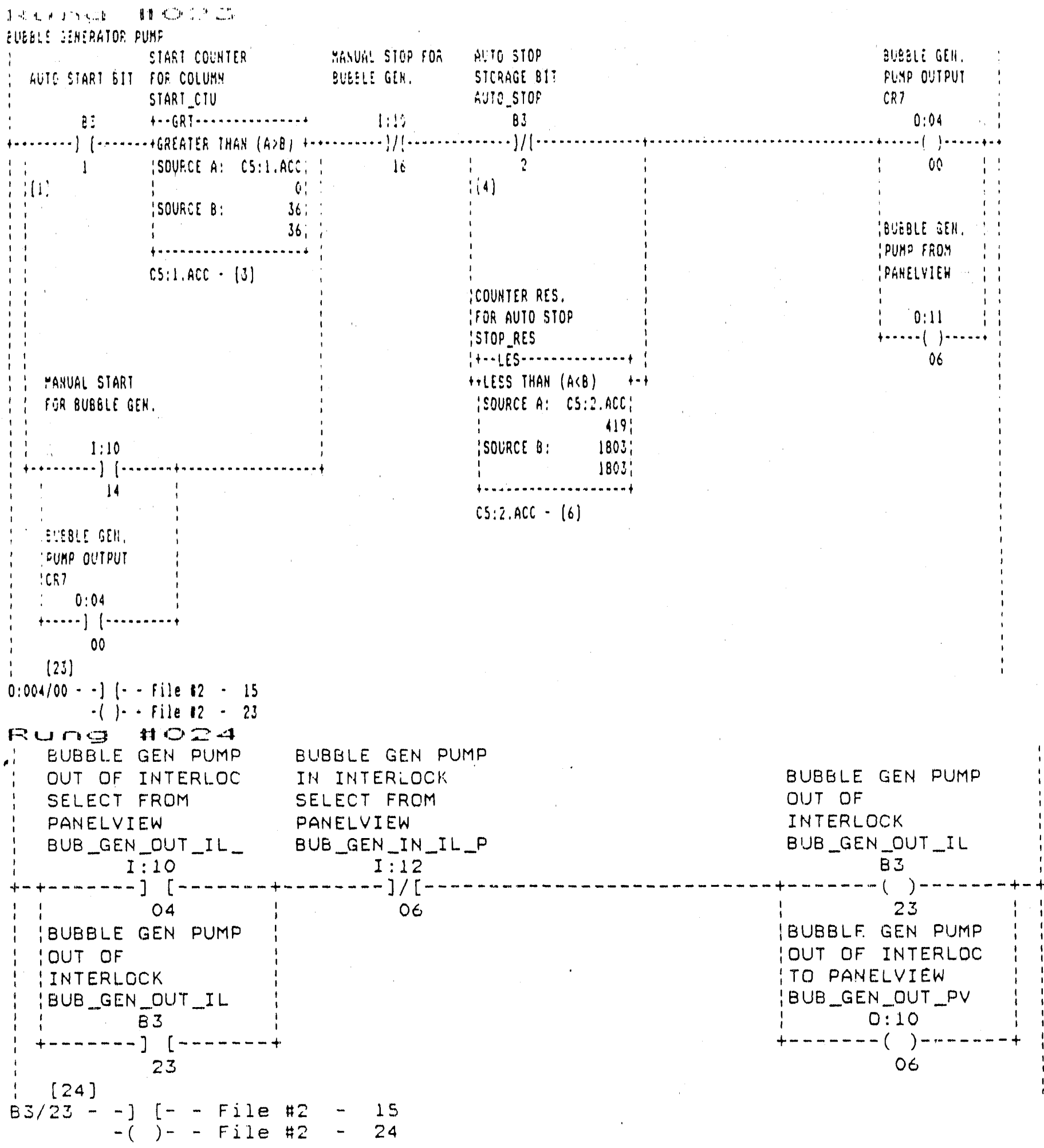




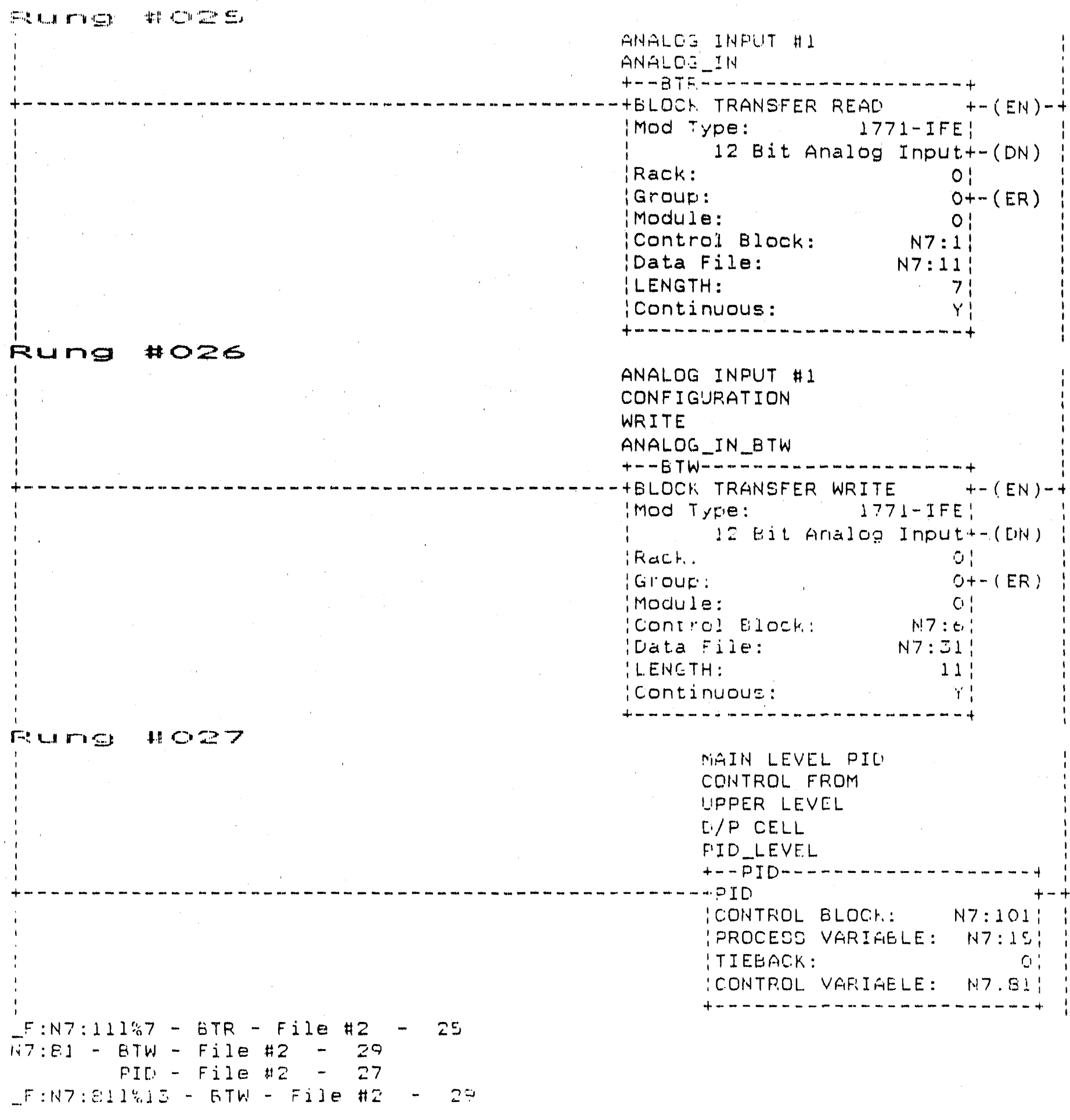




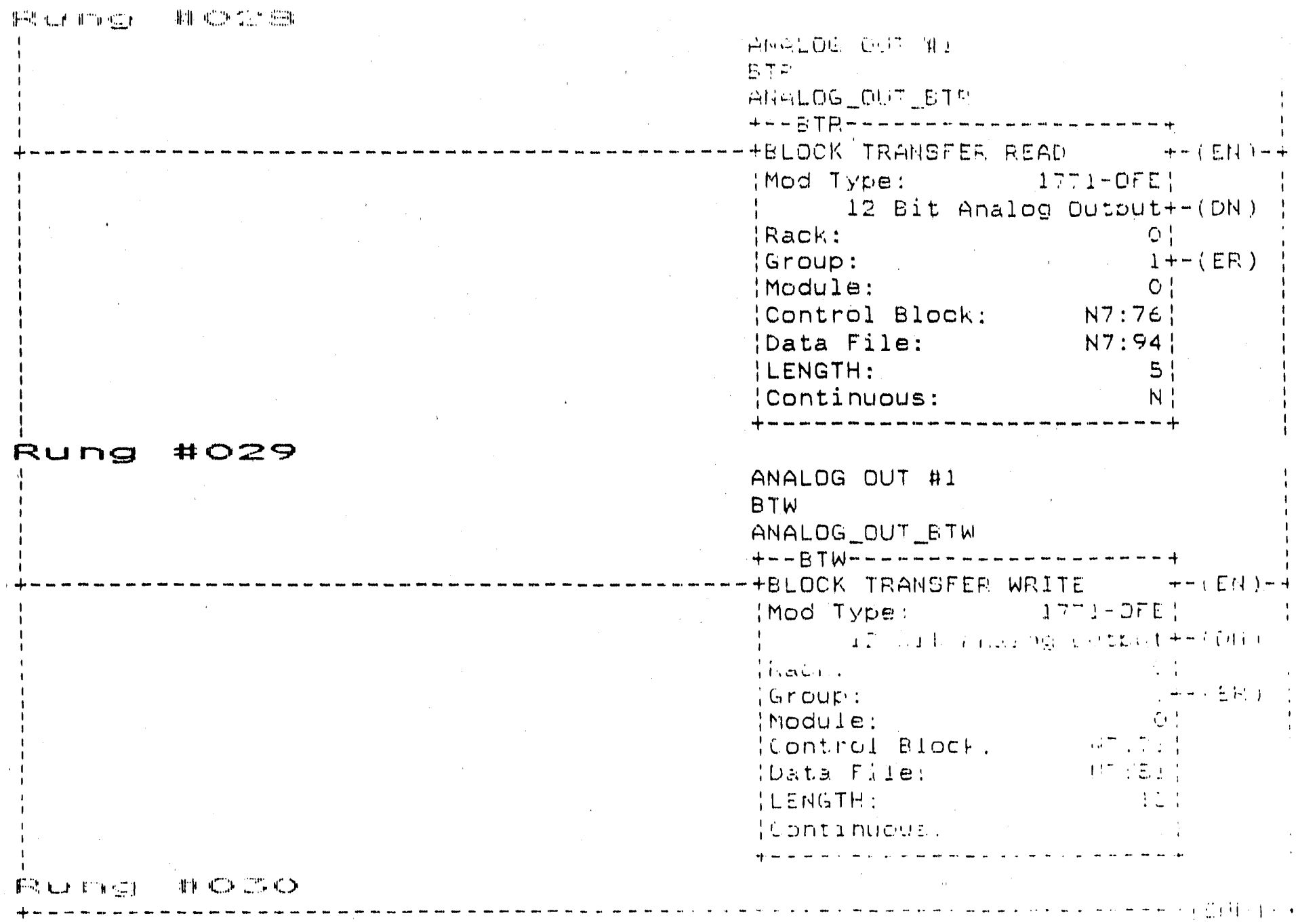


Rach Group slot comp Card type PlC.5 Addr Card Description

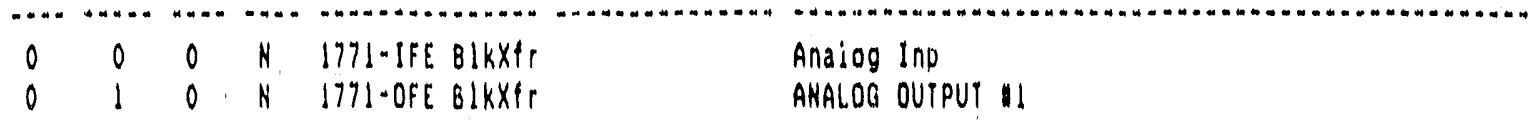

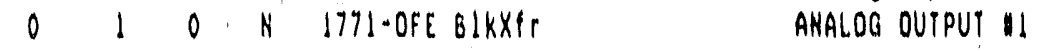


Quantily Card iype Card Description

$1 / 0$ points

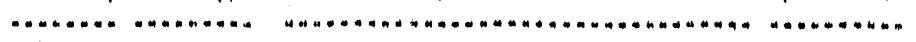

1 I971-1f8 12 Bit Analog Input

1 1771-0FE 12 Bit Analog Output 


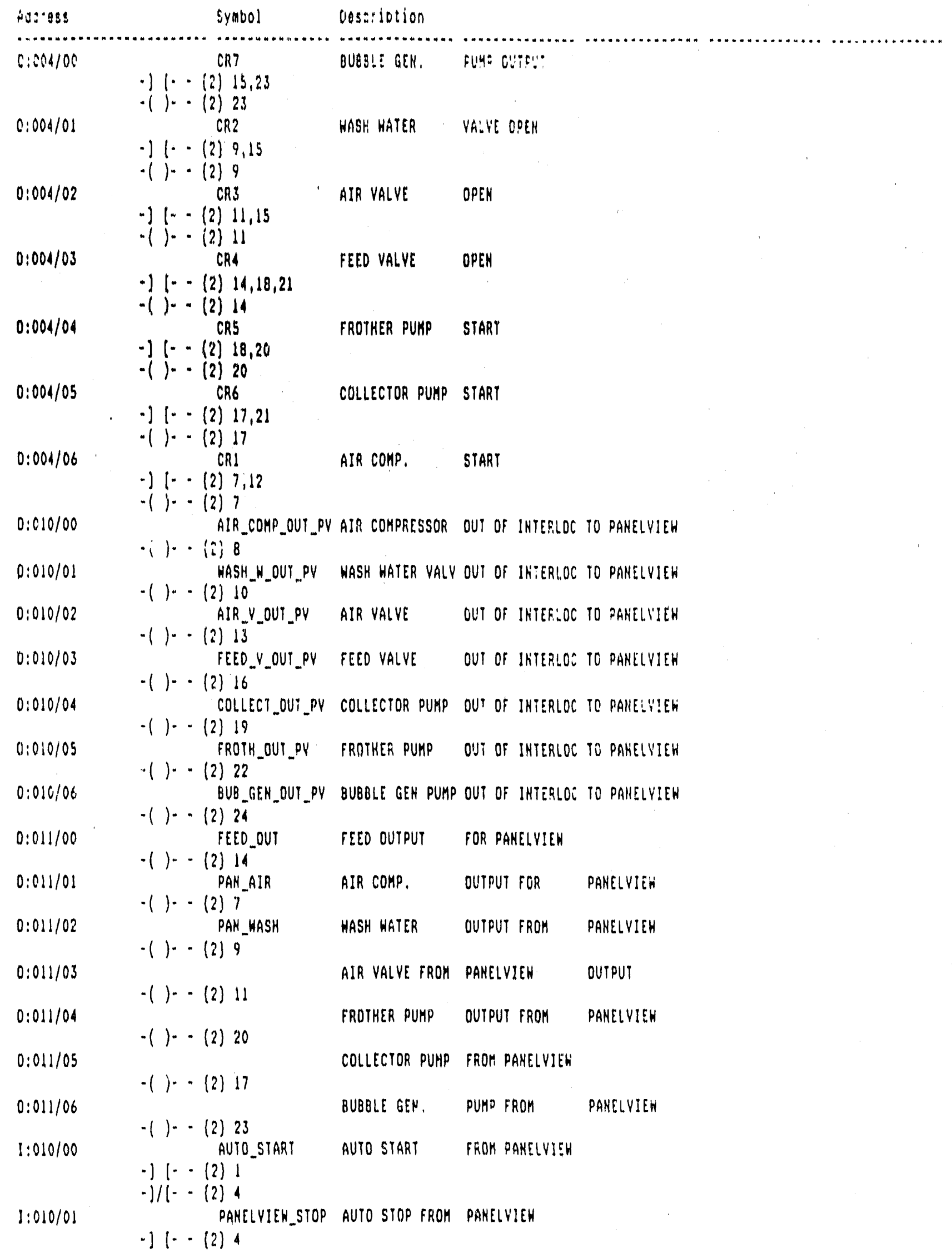




\begin{tabular}{|c|c|c|c|c|c|}
\hline Addiess & Symbol & Description & & & \\
\hline & & & & & \\
\hline $1: 010 / 04$ & $.11 \cdot .(2) 2 d^{B U B}$ GEN OUP $14^{-}$ & BUBBLE GEN PUHP & OUT OF INTERLOC & SELECT FROM & PAIIELYIEH \\
\hline $1: 010 / 06$ & $\cdot 11 \cdot$ (2) 13 & AIR VALVE OUT & OF INTERLOCK & SELECT & PAHELYIEK \\
\hline $1: 010 / 27$ & 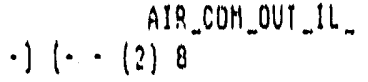 & AIR COMP OUT & OF IHTERLOCY. & SELECT PROM & PAIELLYIEH \\
\hline $1: 2: 0112$ & $\cdot: 1 \cdot(2) 10^{\text {HASH_H_OUT_IL_P }}$ & WASH WATER OUY & OF INTERLOCK & SELECT FROH & PANELVIEH \\
\hline $1: 010,14$ & $-11 \cdot(2) 23$ & MANUAL SIART & FOR BUBBLE GEN. & & \\
\hline $1: 010 / 15$ & $\begin{array}{c}\text { COLLECT_OUT_IL_ } \\
\cdot 11+\text { (2) } 19^{-}\end{array}$ & COLLECTOR PUAP & OUT OF INTERLOC & FROM PANELVIEH & \\
\hline $1: 010116$ & $\cdot 1 / 1 \cdot(2) 23$ & MANUAL STOP FOR & BUBBLE GEH. & & \\
\hline $1: 010 / 17$ & $-j 1-\cdot(2) 22$ & FROTHER, PUHP & OUT OF INTERLOC & SELECT FROH & PANE: VIEH \\
\hline $1: 011100$ & $-i\left(\cdot-(2)^{9} 9\right.$ & WASH WATER & MANUAL START & FROM PANELYIEH & \\
\hline $1: 011 ; 01$ & $\because I:-12: 9$ & WASH WATER & HANUAL STOP & FAOH PANELVIEH & \\
\hline $1:: 1::^{1: 2}$ & $\begin{array}{l}n \mid \hat{H} \cdot \text { MAN-START } \\
\because \vdots \cdot(a) \text { il }\end{array}$ & MANUAL SIARI & FOR AIR VALVE. & & \\
\hline [: $51: 0,03$ & 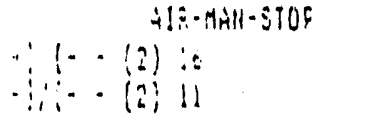 & MAIUHL CLOSE & STOP GIR VALVE & FROH PAIIELYIEH & \\
\hline :Pi. ot & $\therefore 1 \cdot(2) \quad \hat{A} i \hat{n}-i-$ SIART-MAH & AlR COYP & MANUAL START & FAOM PANELVIEH & \\
\hline$i: 011: 0 i$ & $\begin{array}{l}\text { Ali-C-STOP-MAH } \\
\because \because \cdot *(2) 7^{-}\end{array}$ & A!F. COH MANUAL & STOP FROH & PAHELVIEH & \\
\hline$:: 0 !: i 10$ & $\begin{array}{l}\text { GROT-START-HGH } \\
\because(--(2) ? 0\end{array}$ & FROTHER PUMP & MANUAL START & FROA PAKELLIEH & \\
\hline d:oil/l! & $-1 / 1-(2) 20$ & FROTHER PUMP & HANUAL STOP & FROM PANELVIEN & \\
\hline$\therefore: 01 ! 1: 2$ & $\begin{array}{l}\text { COLL-START-MAM } \\
-\because 1 \cdot-(2) 17\end{array}$ & COLLECTOR PUAP & MANUAL START & FROM PANELYIEH & \\
\hline $1: 011 / 113$ & $\begin{array}{c}\text { COLL-STOP-HAN } \\
-1 / 1-\cdot(2) 17\end{array}$ & COLLECTOR PUMP & HANUAL STOP & FROM PANELVIEH & \\
\hline $1: 011 / 15$ & $\begin{array}{l}\text { FEEO-OPEN-MAN } \\
-11-(2) 14\end{array}$ & MANUAL START & FOR FEFD VALVE & FROH PANELYIEH & \\
\hline $1: 011 / 16$ & $\begin{array}{l}\text { FEED-CLOSE-HAH } \\
-1 / 1-\cdots(2) 11\end{array}$ & KANUAL CLOSE & FEED VALVE & FROH PANEIVIEH & \\
\hline $1: 012 / 00$ & $-1 /(\cdots-(2) 13$ & AIR VALVE IN & IHTERLOCK & SELECT & PAHELVIEK \\
\hline $1: 012 / 01$ & $\begin{array}{l}\text { FEED_IH_IL_PV } \\
-1 / 1-\cdots(2) 16\end{array}$ & FEED VALVE IN & IHTERLOCK & SELECT & PANELLIEK \\
\hline $1: 012 / 02$ & $\begin{array}{l}\text { WASH_W_IH_IL_PY } \\
-: 11 \cdot-(2) 10\end{array}$ & HASH HATER IN & INTERLOCK & SELECT FROH & PAHELUIEH \\
\hline $1: 012 / 03$ & 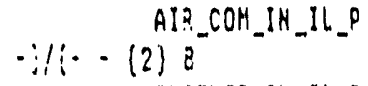 & AIR COHP IH & INTEFLOCK & SELECI FROH & PANELVIEH \\
\hline $1: 01: 104$ & 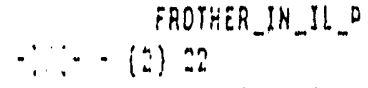 & FROTHER PUAP & IN INIEALLCK & FROM PANELYIEK & \\
\hline $2: 91: 285$ & 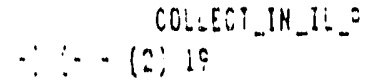 & COLLECTOR DUMP & IH INTERLOOCK & FROM PANELVIEH & \\
\hline
\end{tabular}




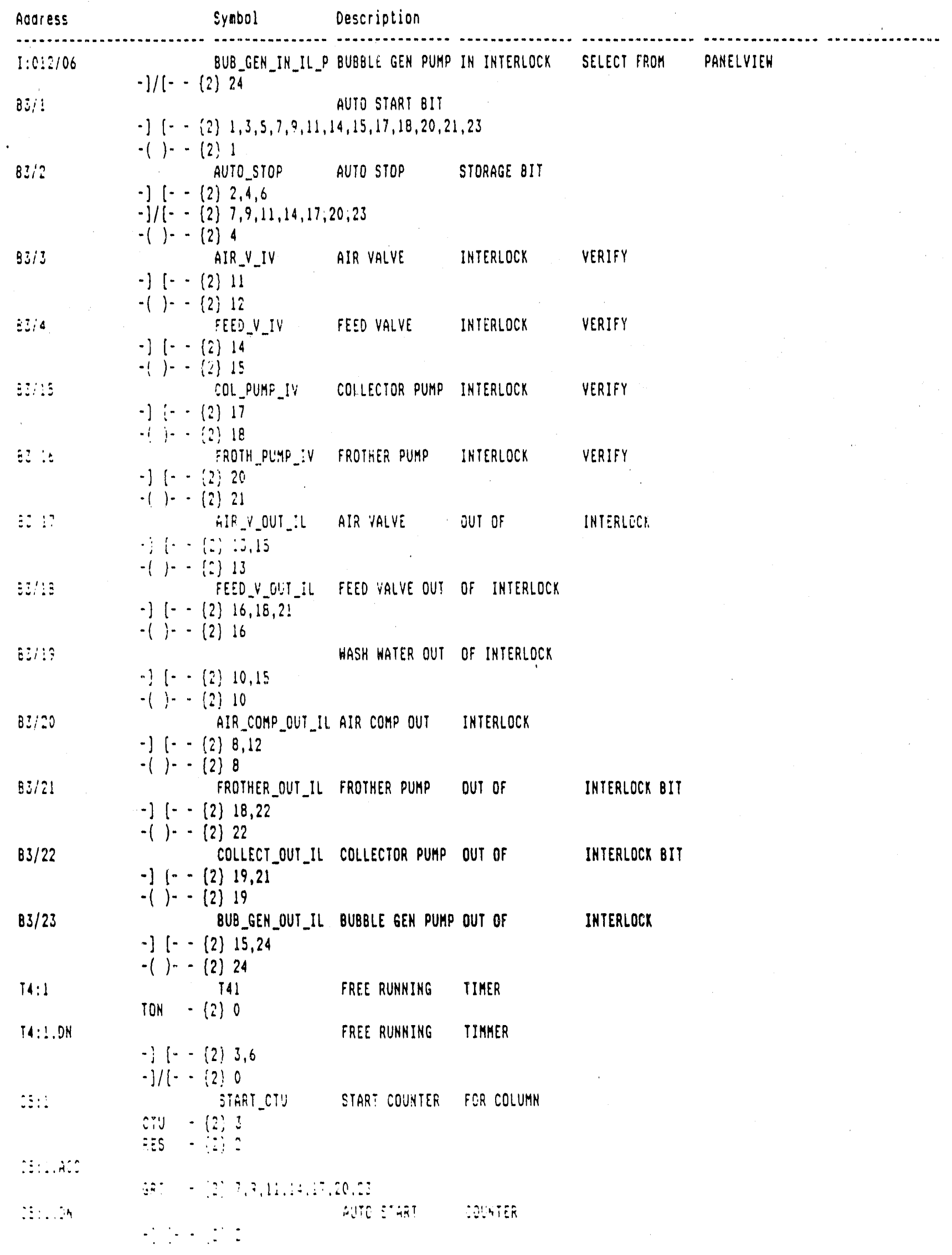




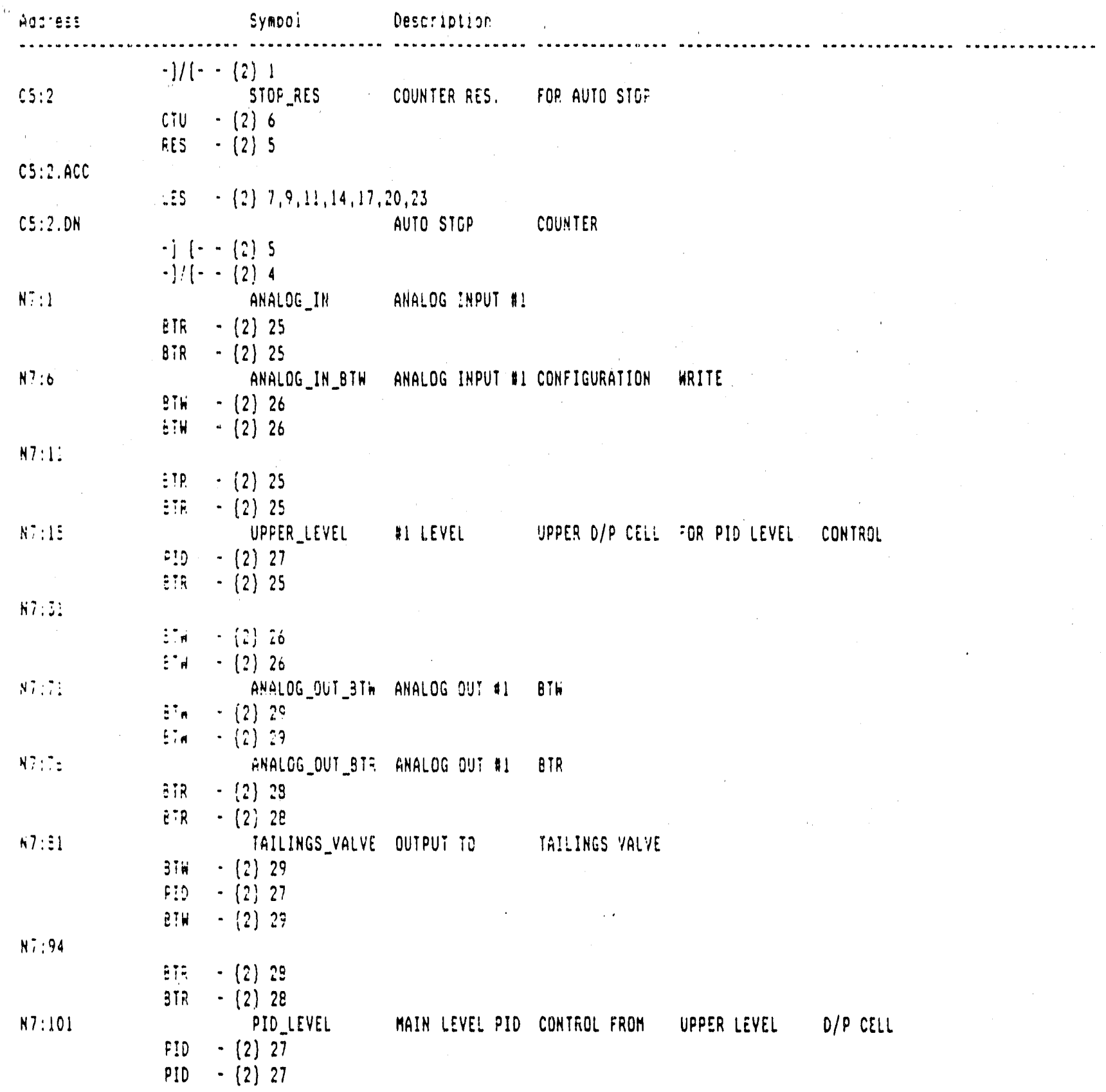


Huaber of Oata Fales:31!

Nave Description

$\begin{array}{rlrr}\text { iile Type } & \text { Mode Size:Elews Hords } \\ 0 & \text { O output Global } & 32 & 32 \\ 1 & \text { I input Global } & 32 & 32 \\ 2 & \text { S status Global } & 32 & 32 \\ 3 & \text { B binary Global } & 2 & 2 \\ 4 & \text { I tiaer Global } & 2 & 6 \\ 5 & \text { C counter Global } & 5 & 15 \\ 6 & \text { R control Global } & 1 & 3 \\ 7 & \text { H integer Global } & 124 & 124 \\ 8 & \text { f float Global } & 1 & 2 \\ 310 & \text { B binary Global } & 1 & 1\end{array}$


Duta File $\# 0$ Type : o output Elements: 32 words: 32

fiddre:s
$0: 0000$
$0: 0001$
$0: 0002$
$0: 0005$
$0: 0004$
$0: 0005$
$0: 0000$
$0: 0007$
$0: 0010$
$0: 0011$
$0: 0012$
$0: 0013$
$0: 0014$
$0: 0015$
$0: 0014$
$0: 0017$

Address

$0: 0020$

$0: 0021$

$0: 0022$

$0: 0023$

$0: 0024$

$0: 0025$

$0: 0026$

$0: 0027$

$0: 0030$

$0: 0031$

$0: 0032$

$0: 0033$

$0: 0034$

$0: 0035$

$0: 0030$

$0: 0037$

\begin{tabular}{|c|c|c|c|}
\hline & 0000 & 0000 & 000 \\
\hline & 0000 & 0000 & 000 \\
\hline & 000 & & \\
\hline & 0000 & 0000 & 0000 \\
\hline 100 & 0000 & 0000 & 0000 \\
\hline 800 & 0000 & 0000 & 0000 \\
\hline 10 & 0000 & 0000 & 0000 \\
\hline 000 & 0000 & 0000 & 0000 \\
\hline 200 & 0000 & 000 & 0000 \\
\hline 200 & 0000 & 0000 & 0000 \\
\hline 000 & 0000 & 0000 & 0000 \\
\hline 000 & 0000 & 0000 & 0000 \\
\hline & 0000 & 0000 & 0000 \\
\hline & 0000 & 0000 & 0000 \\
\hline & 0000 & 0000 & 0000 \\
\hline & 000 & 000 & \\
\hline
\end{tabular}

17 - D.- Data - - 0 0 $00000000 \quad 0000 \quad 0000$ 0000000000000000 0000000000000001 0000000000000000 $000000000000 \quad 0000$ $00000000 \quad 0000 \quad 0000$ $000000000000 \quad 0000$ 0000000000000000 0000000000000000 0000000000000000 0000000000000000 0000000000000000 0000 0r.00 0000000 0000000000000000

Lista file $\$ 1$ Type: I inout Elements: 32 words : 32

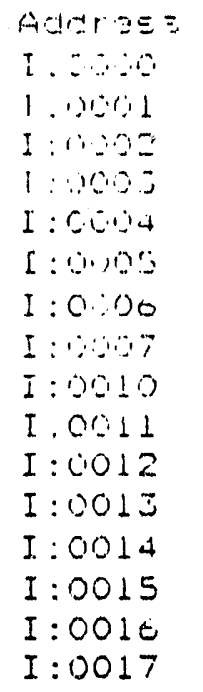

Adras

\begin{tabular}{|c|c|c|c|}
\hline & & 00 & 28 \\
\hline 600 & 1000 & 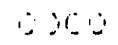 & $\therefore 8$ \\
\hline 0 & 0000 & 0000 & 000 \\
\hline $10 \%$ & 0000 & 0000 & 00.00 \\
\hline 0 & 2000 & 2000 & 000 \\
\hline 200 & 0000 & 0000 & 000 \\
\hline 0000 & 0000 & 0000 & Cu \\
\hline 000 & 0000 & 0000 & 5 \\
\hline 0000 & 0000 & 0000 & 000 \\
\hline 0000 & 0000 & 0000 & 000 \\
\hline 0000 & 0000 & 0000 & Con \\
\hline 200 & 0000 & 0000 & \\
\hline & 0000 & 000 & \\
\hline & & & \\
\hline 00 & 0000 & 000 & \\
\hline & & & \\
\hline
\end{tabular}

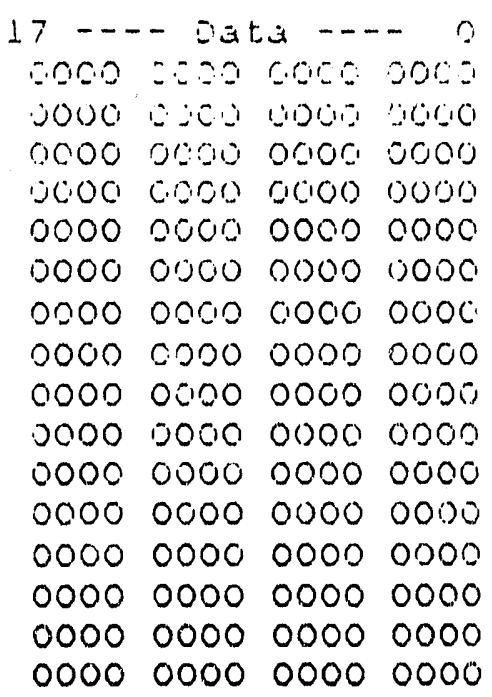

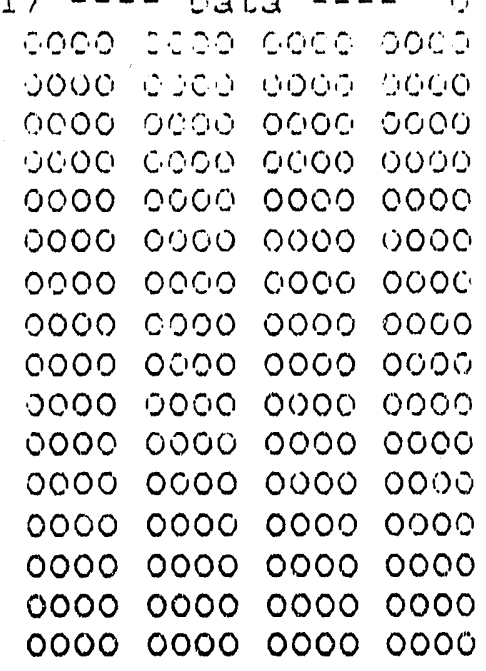

fiddres
I: 0020
I:0021
I.0022
I:00:3
$I: 00=4$
$I: 0025$
$I: 0020$
$I: 0027$
$I: 0030$
$I: 0031$
$I: 0032$
$I: 0033$
$I: 0034$
$I: 0035$
$I: 0036$
$I: 0037$

Data File \#3 Type : B binary Elements : 2 words : 2

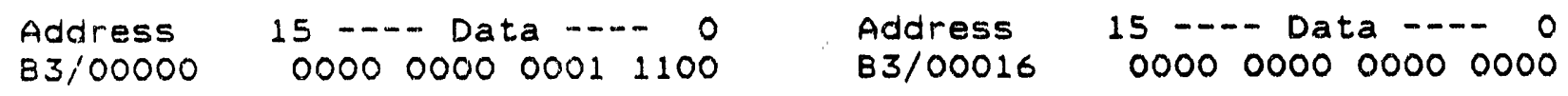

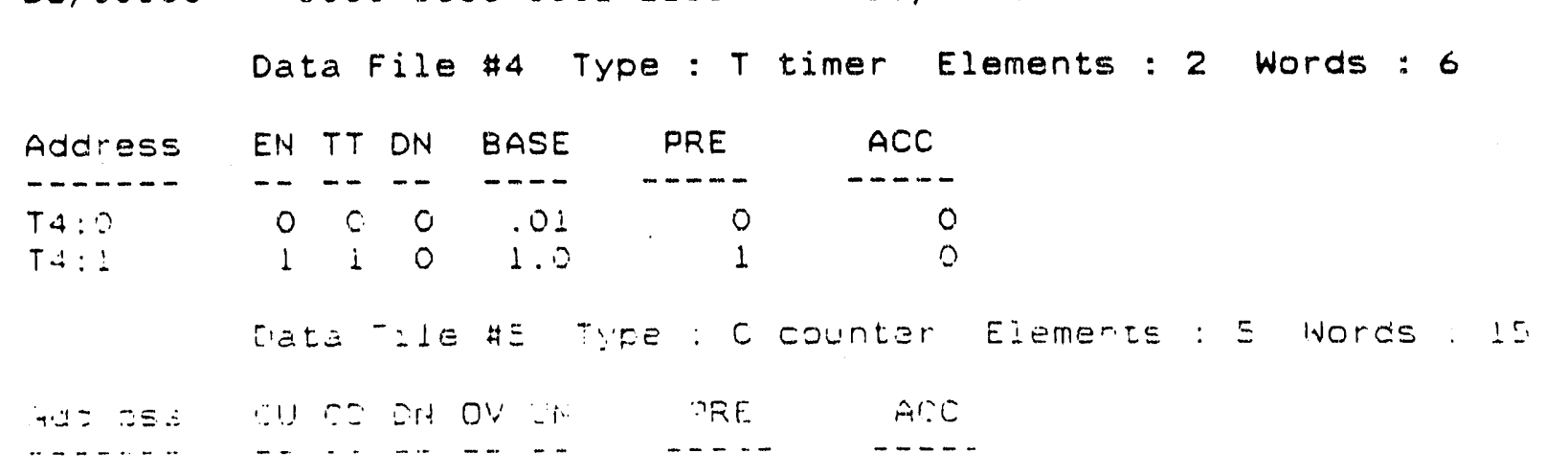




\begin{tabular}{|c|c|c|c|c|c|c|c|}
\hline fuddres & CU & $\mathrm{CO}$ & DN & OV & Un' & PP.E & $A C C$ \\
\hline$\ldots-\ldots$ & - & -- & -- & - & -- & $-\cdots-\cdots$ & $--\cdots$ \\
\hline C5:O & 0 & 0 & 0 & 0 & 0 & 0 & 0 \\
\hline$[5: 1$ & 0 & 0 & 0 & 0 & 0 & 40 & 0 \\
\hline C.5:2 & 0 & 0 & 0 & 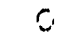 & 0 & 1810 & 419 \\
\hline$C 5:=$ & 0 & 3 & 0 & C & $\mathrm{C}$ & 60 & 0 \\
\hline $75: 4$ & 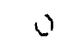 & 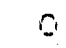 & 0 & 0 & 8 & 1 & 0 \\
\hline
\end{tabular}

Uata File \#t Type : R control Elements : 1 Words:

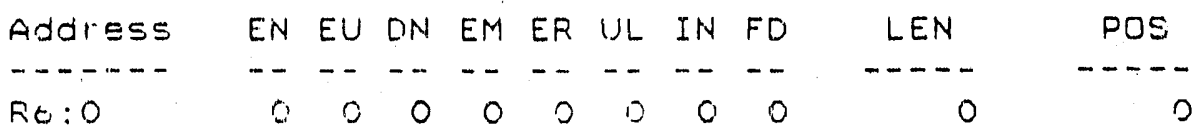

Oatj File\#- Type : N integer Elements: $1=4$ wol $25: 124$

\begin{tabular}{|c|c|c|c|c|c|c|c|c|c|c|}
\hline $\begin{array}{l}\text { ADJUEESS } \\
\cdots-\cdots-\cdots\end{array}$ & $\begin{array}{c}D \\
---.\end{array}$ & $\begin{array}{c}1 \\
-\cdots--\end{array}$ & $\begin{array}{c}2 \\
-\cdots\end{array}$ & $\begin{array}{c}3 \\
---\cdots\end{array}$ & $\begin{array}{c}4 \\
----\end{array}$ & 5 & $\begin{array}{c}\dot{ } \\
-----\end{array}$ & $\begin{array}{c}7 \\
----\cdots\end{array}$ & $\ddot{\theta}$ & $\begin{array}{c}7 \\
---- \\
-\end{array}$ \\
\hline $0^{-}: 0^{\prime}$ & $j$ & $-857 t$ & 7 & $a$ & 7 & 11 & -3704 & 11 & 0 & 7 \\
\hline$i=10$ & il & $c$ & 0 & 0 & 0 & 0 & C & 0 & 0 & 0 \\
\hline $117: \Xi$ & $?$ & $\because$ & $C$ & i & 3 & 0 & 0 & 0 & 9 & 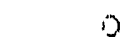 \\
\hline$\because-20$ & $\dot{0}$ & $\therefore$ & 2 & $1: 35$ & 0 & 0 & 0 & 0 & 0 & 0 \\
\hline$: 1: 4:$ & $\therefore$ & & 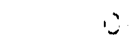 & $\therefore i$ & $\therefore$ & ij & $\because$ & $\therefore$ & $\because$ & 0 \\
\hline$-\quad \vdots$ & & $:$ & $\because$ & $\because$ & $=$ & $\because$ & $\because$ & . & $\because$ & r \\
\hline $1-\therefore$ & $\because$ & & j & 0 & 1) & 0 & 0 & u & 0 & C \\
\hline$\therefore \because 0$ & $\vdots$ & $-8 \div=$ & $\therefore=$ & $\because$ & 7 & $\Xi 1$ & $-100=2$ & 5 & 0 & \\
\hline A.1. . . & 74 & $\because$ & 2 & $\therefore$ & 0 & 0 & 0 & $16 \Xi=5$ & 0 & $\vdots 35 \Xi こ$ \\
\hline $1:$ : : Ju & 0 & IE口ここ & 0 & 1もミコこ & 0 & 0 & 0 & 0 & $\vdots$ & $c$ \\
\hline $11: 200$ & $\therefore$ & $\therefore=15=0$ & 0 & 0 & $1=00$ & 1000 & 0 & 0 & 9 & $c$ \\
\hline$\therefore \div: 21=$ & s & 2 & 100 & 0 & 16 & 0 & 0 & $c$ & 0 & \\
\hline$\omega=: 1:=$ & $\therefore$ & $\therefore$ & 0 & $\sigma$ & & & & & & \\
\hline
\end{tabular}

Gati: ZLe FE Tfee: F float Element: : I worde: 2

คコさレヒミล

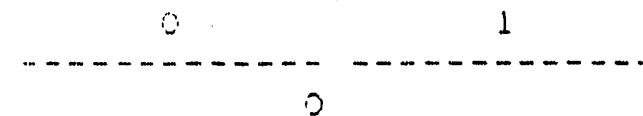

23

4

$F \equiv: 0$

Data File $\$ 10$ Type

Address

15 -.- Data -.. 0

B $310 / 000000000000000000000$

Address $15---$ Data -.. 0 
Catafile \#0 Type : 0 output Elements : 32 words : 32

iddress
$0: 0000$
$0: 0001$
$0: 0002$
$0: 000=$
$0: 0004$
$0: 0005$
$0: 0006$
$0: 0007$
$0: 0010$
$0: 0011$
$0: 0012$
0.0015
$0: 0014$
0.2015
0.0010
0.0017

$\dot{r}:=r s \Xi=$

I. .

j. $\therefore 1$

$\therefore \cdots$

an-

$\therefore+14$

$\therefore .1 \%$

1.30

. . .

$1: \therefore: 0$

I. . $: 1$

i.: 0.2

I : $: 010$

$1: 0014$

I:0015

I: $: 0016$

I: $: 0017$

\begin{tabular}{|c|c|c|c|}
\hline 0000 & 0000 & 0000 & 0000 \\
\hline 0000 & 0000 & 00 & \\
\hline & 0000 & 0000 & 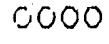 \\
\hline $00 \%$ & 0000 & 0000 & 0,00 \\
\hline 000 & 0000 & oxix & $\therefore<A_{A}$ \\
\hline 000 & 0006 & 0000 & יםod \\
\hline 000 & 00100 & 0000 & tcos \\
\hline 0000 & 0000 & 0000 & 0000 \\
\hline 0000 & 0,000 & $0 \times x\rangle:$ & $x \times x x$ \\
\hline 0000 & 0000 & OXXXX & $x, x+x$ \\
\hline 000 & 5000 & 0000 & 0000 \\
\hline 1000 & 0000 & 0000 & 6000 \\
\hline $000 \mathrm{C}$ & 2000 & 0000 & 0000 \\
\hline 0000 & 0000 & 0,00 & 0000 \\
\hline 0000 & 0000 & 0000 & 0000 \\
\hline & & & \\
\hline
\end{tabular}

$17 \ldots$... Uata -...

0000000000000000

0000 0n00 0000 0000

0000000000000000

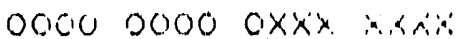

$000000000000 \quad 0000$

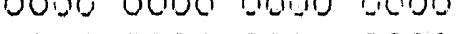

00000000 0xx: $x \times x x$

$00000000 \quad$ OXXXX X.XXXX

0000000000000000

00000000 onod

00C 0000 0000 0000

000000000000000

0000001000000000
Address
$0: 0020$
$0: 0021$
$0: 0022$
$0: 002=$
$0: 00: 24$
$0: 0025$
$0: 0026$
$0: 0027$
$0: 0030$
$0: 0031$
$0: 0032$
$0: 0053$
$0: 0024$
$0: 0055$
$0: 0030$
$0: 0057$

$\begin{array}{ccccc}17 & \cdots & 0 & 0 & 0 \\ 0000 & 0000 & 0000 & 0000 \\ 0000 & 0000 & 0000 & 0000 \\ 0000 & 0000 & 0000 & 0000 \\ 0000 & 0000 & 0000 & 0000 \\ 0000 & 0000 & 0000 & 0000 \\ 0000 & 0000 & 0000 & 0000 \\ 0000 & 0000 & 0000 & 0000 \\ 0000 & 0000 & 0000 & 0000 \\ 0000 & 0000 & 0000 & 0000 \\ 0000 & 0000 & 0000 & 0000 \\ 0000 & 0000 & 0000 & 0000 \\ 0000 & 0000 & 0000 & 0000 \\ 0000 & 0000 & 0000 & 0000 \\ 0000 & 0000 & 0000 & 0000 \\ 0000 & 0000 & 0000 & 0000 \\ 0000 & 0000 & 0000 & 0000\end{array}$

liata $=$ le \#: Type: I input elenents : 22 words : 22

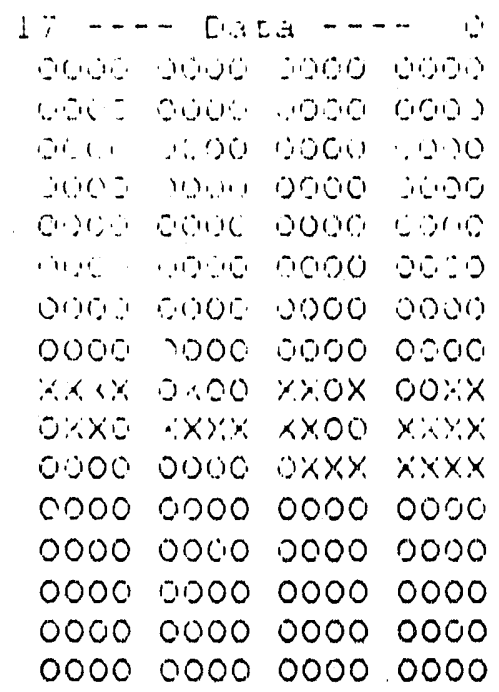

Addres

I : 000 ij

I : 0021

I:002

I.

i: $: 0024$

I: 0025

I:0020

I: 0027

I: :0030

I : 0031

I:00I2

I : 0035

I: $: 0034$

I: $: 0035$

I: 0036

I:0037

\begin{abstract}
1 7 -.. Data -.. O 0
ن 000000000

000020000000000

000000000000000

0000000000000000

0000000000000000

0000000000000000

10000200000000000

0000020000000000

0000000000000000

0000000000000000

0000000000000000

0000000000000000

0000000000000000

0000000000000000

0000000000000000

0000000000000000
\end{abstract}

Data File \#3 Type : B binary Elements: 2 words : 2

Address B3/00000

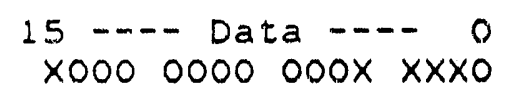

\section{Address} B3/00016
15 -..- Data -.. 0 00000000 XXXX XXXX

Data File 4 Type: T timer Elements: 2 words : 6

$\begin{array}{llllllllllllllllllll}1 & 1 & 1 & 1 & 1 & 1 & 1 & 1 & 1 & 1 & 2 & 2 & 2 & 2 & 2 & 2 & 2 & 2 & 2 & 2\end{array}$

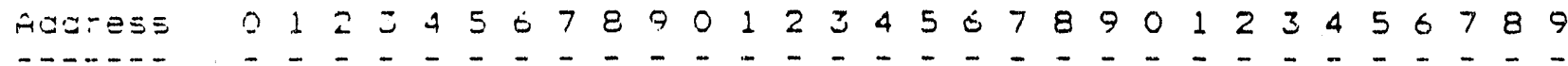

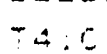

$\ddot{n}$ 
Data File $\$ 5$ Type : C counter Elements : 5 words : 15

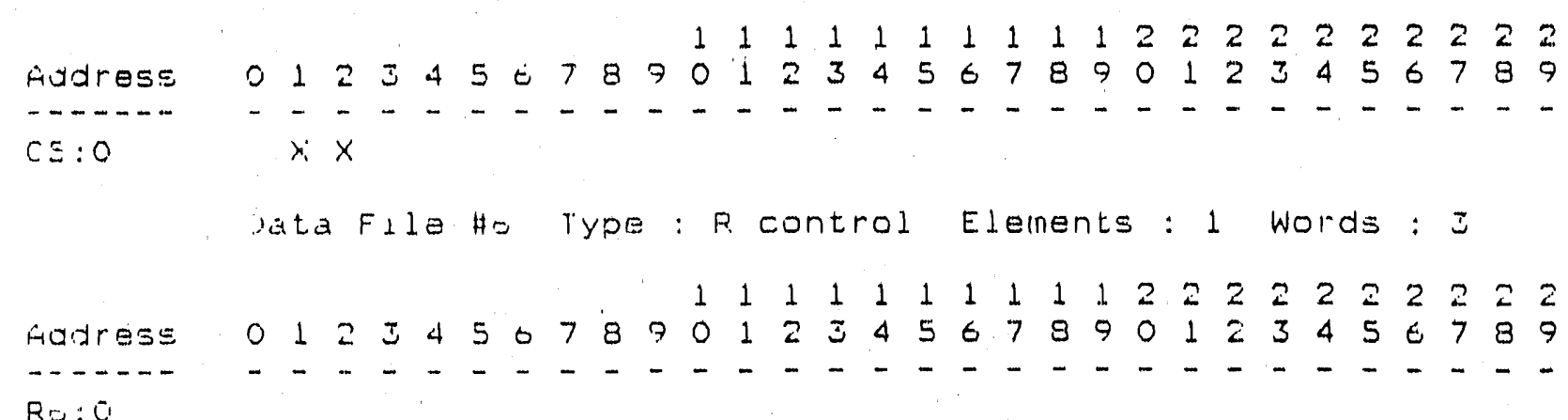

Clata file h7 Type : N integer Elements : 124 words : 124

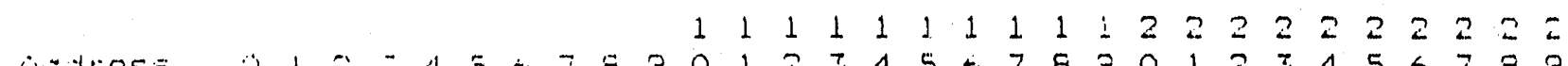

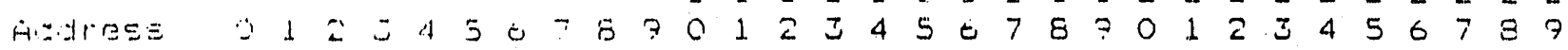
… - - - - - - - - - - - - - - - -

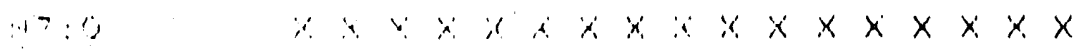

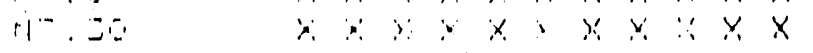

1.......

$\because$

$\because \times \times \times \times \times \times \times \times \times \times \times \times \times \times \times \times \times \times$

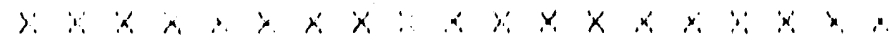

irat Flle ite Tyfe: F float Element: : 1 worde: :

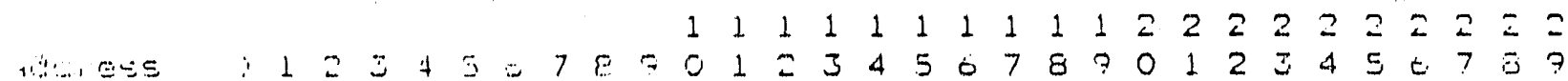
... $\because::$

Säta file Hilo Type : B binary Elements: 1 Words : 1

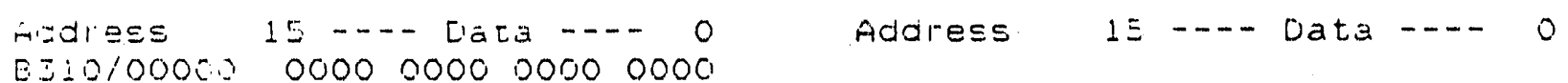




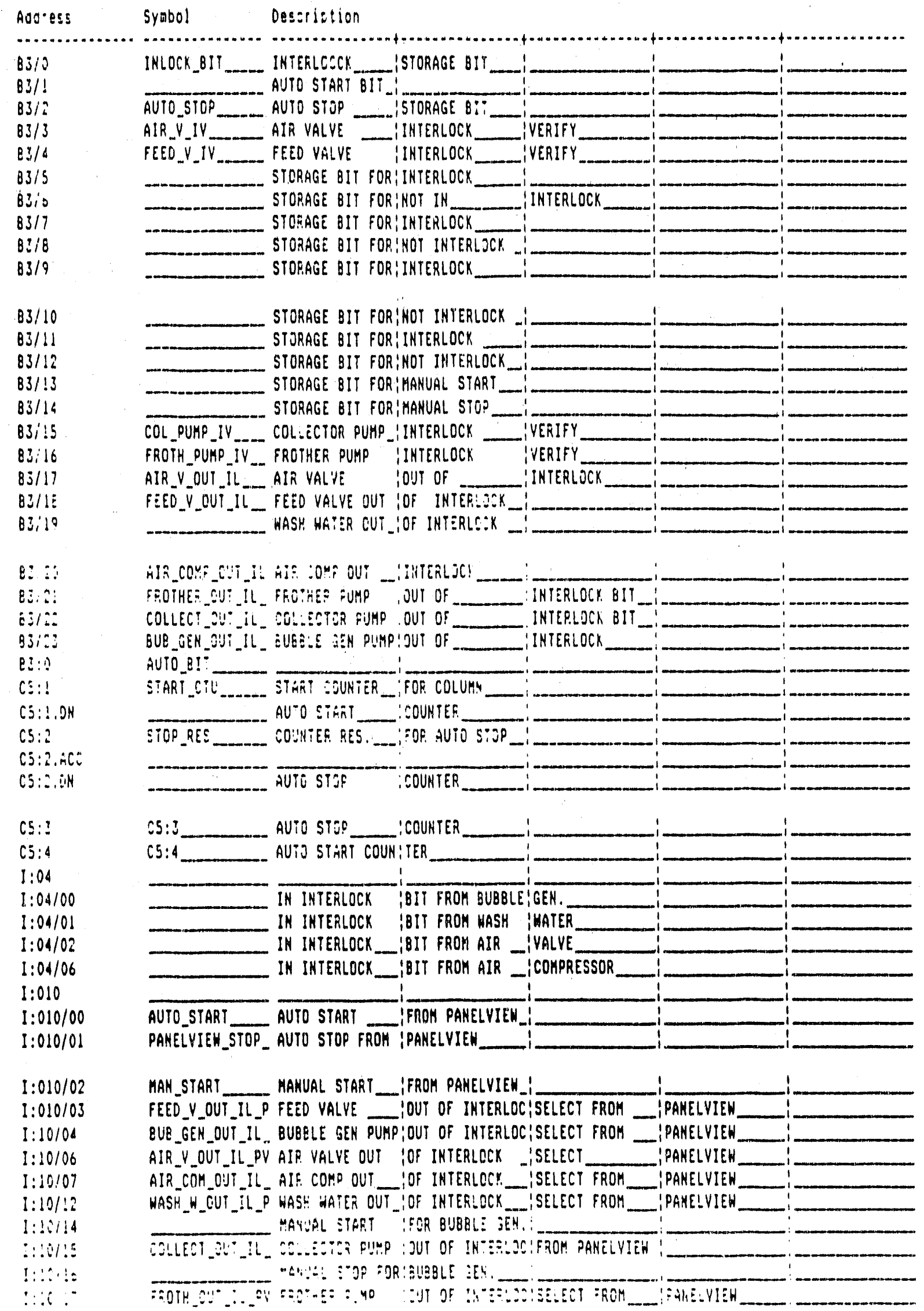




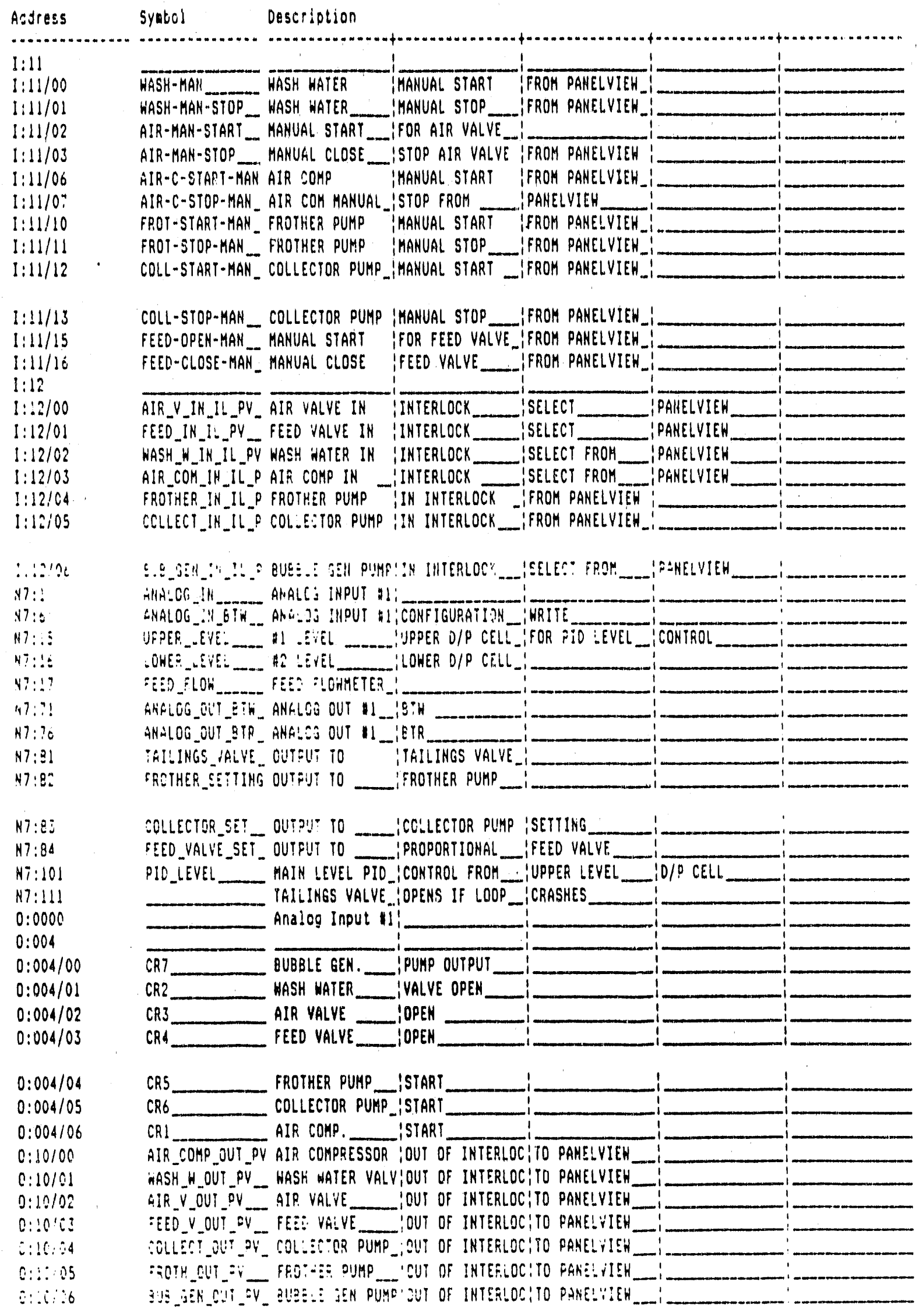




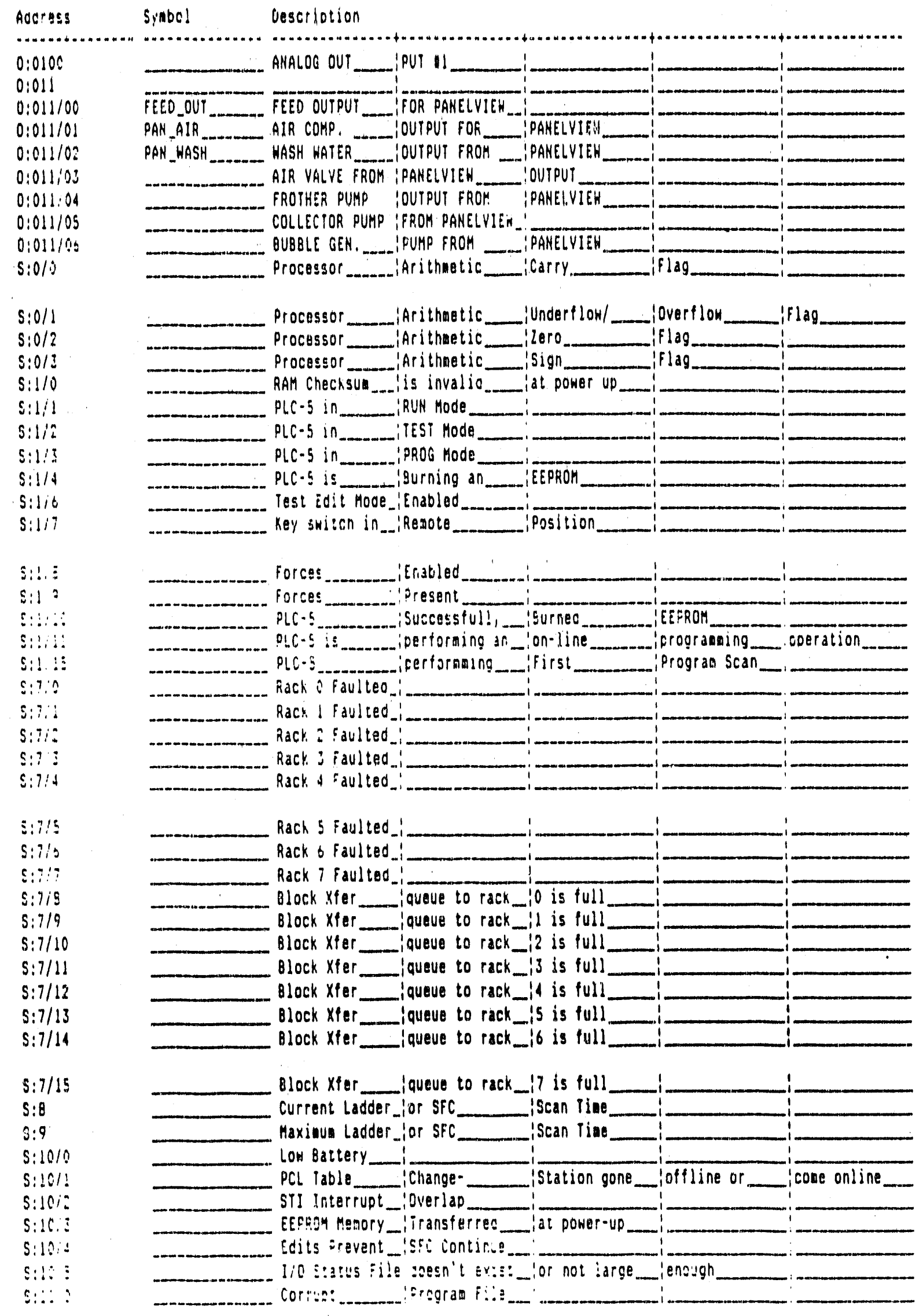




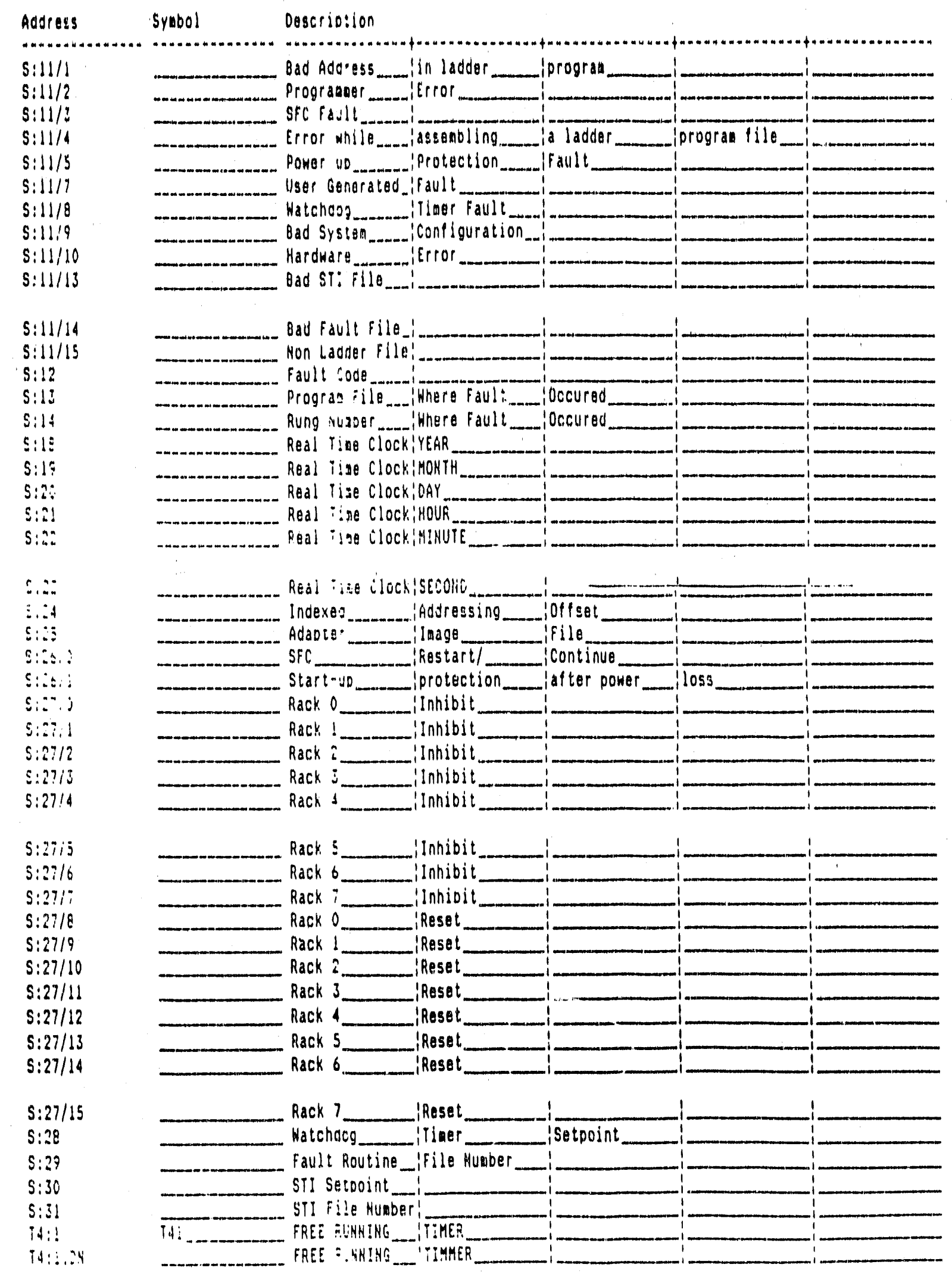




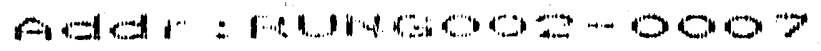
AUIC DESCRIPIION:

AIR COMPRESSOR

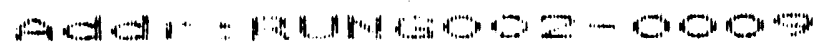
RUNG DESCRIPTION:

WASH WAYER VALVE

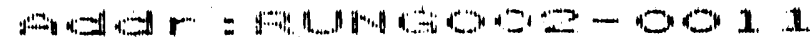
RUNG DESCRIPIIOH:

AIR VALVE

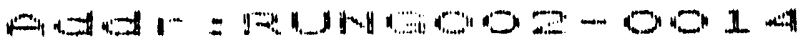
RUNG OESCRIPTION:

FEED VALUE

H RUNG OESCRIPTION:

COLLECTOR PUMP

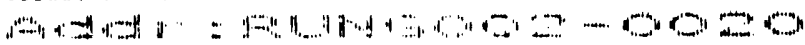
RUNG DESCRIFITCN:

FADTHEP FUMP

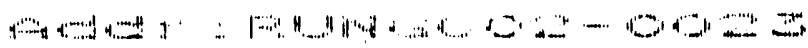
HING DESCSIPT:INA:

¿UQBLE GENERATGR OIMPP 


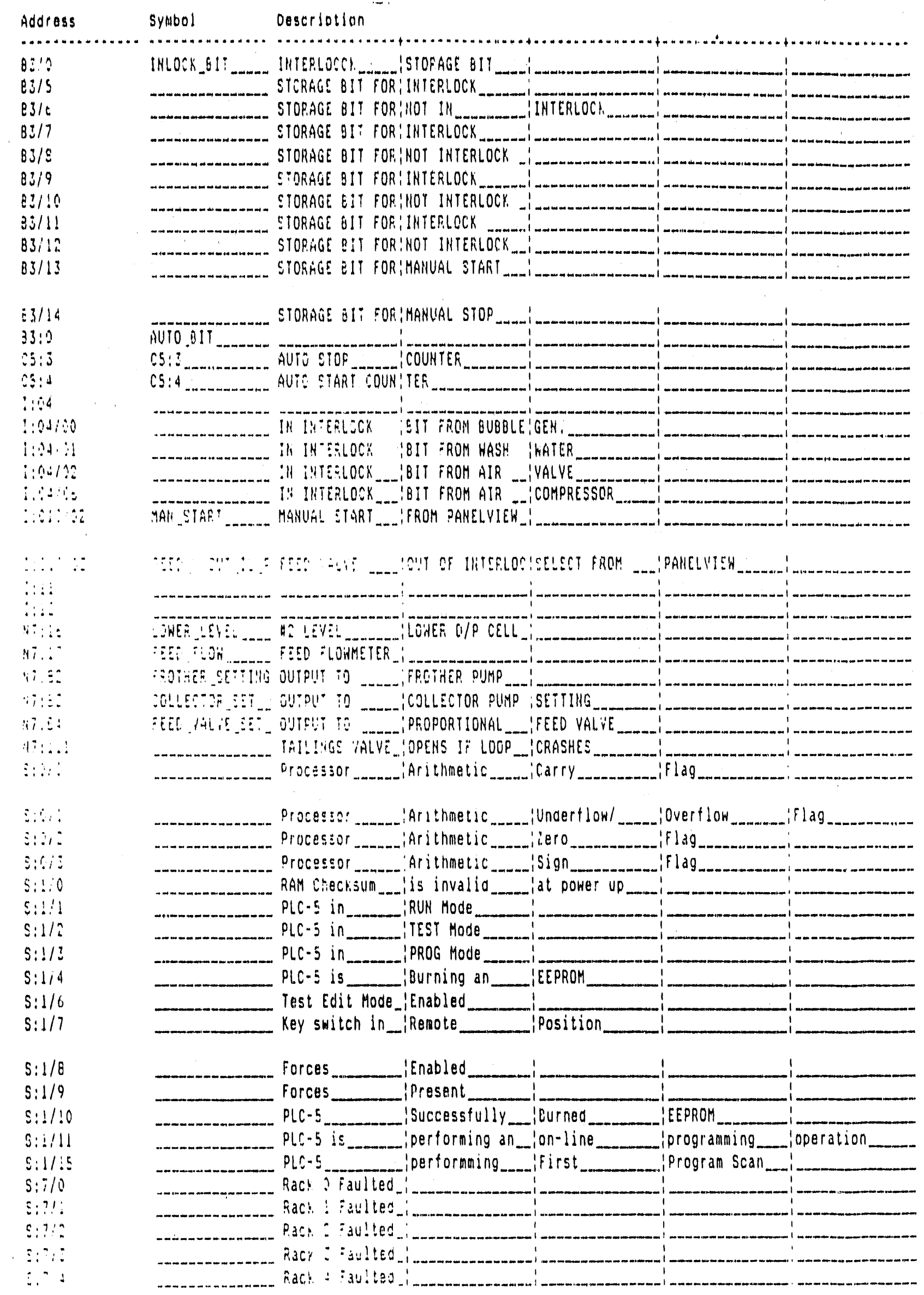




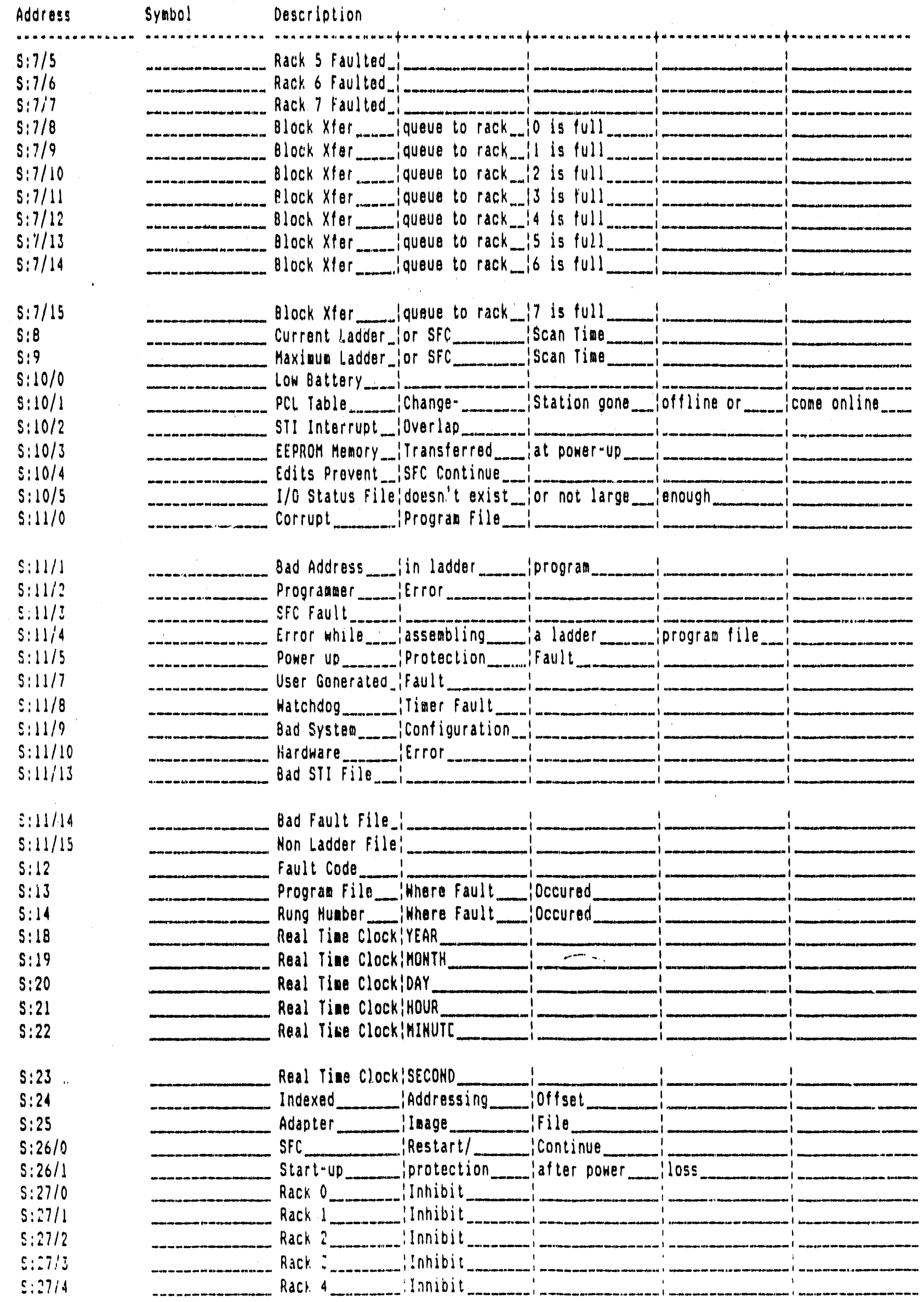




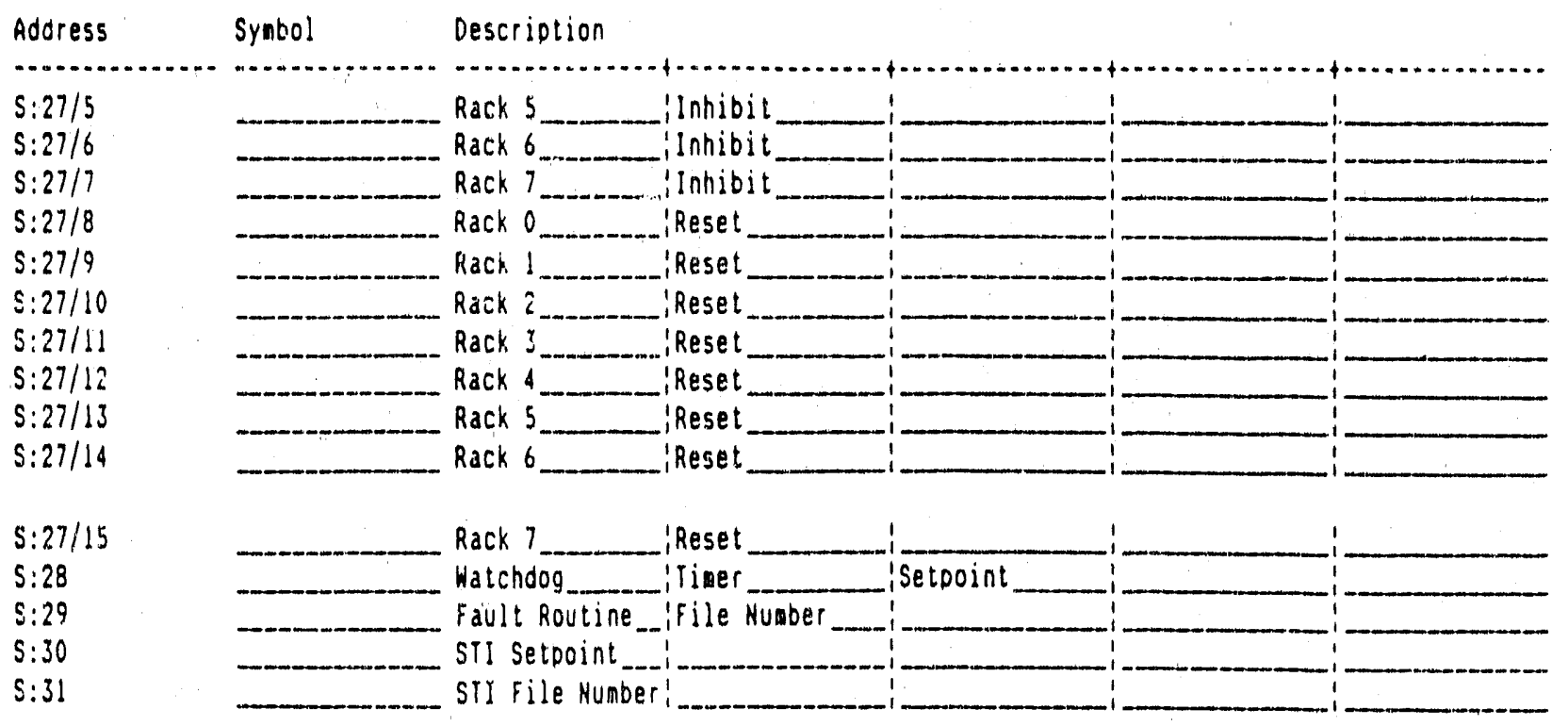


Gurrent proaram Fevision \#35

fl. - 5 Ladjer Logistics Revision last used:v5.04

\begin{tabular}{|c|c|c|c|}
\hline Rev日 55 & $04 / 05 / 91$ & $15: 50: 07$ & Des: \\
\hline$P \in \forall=4$ & $04 / 05 / 91$ & $15: 40: 04$ & Des: \\
\hline ReVH3Z & $04 / 05 / 31$ & $10: 30: 58$ & Cres: \\
\hline Rev $\geq 2$ & $04 / 05 / 01$ & $10: 09: 1 \mathrm{E}$ & Des. \\
\hline FEVHこ1 & $04 / 05 / 31$ & $08: 10: 45$ & Des: \\
\hline F.evH $=0$ & $04 / 05 / 91$ & OE:08:07 & Des: \\
\hline$P E=29$ & $04 / 05 / 91$ & $07: 02: 05$ & Des: \\
\hline Rev甘 $2 B$ & $04 / 04 / 91$ & $22: 44: 04$ & \\
\hline Rev\#27 & $04 / 04 / 91$ & $20: 51: 26$ & Des: \\
\hline Rev 26 & $04 / 04 / 91$ & $20: 43: 57$ & Des \\
\hline Rev\#25 & $04 / 04 / 91$ & $15: 58: 47$ & Des \\
\hline Rev 24 & $04 / 04 / 91$ & $14: 28: 31$ & Des \\
\hline Rev\#2Z & $04 / 02 / 91$ & $29: 06: 45$ & Des \\
\hline Re:A2: & $04 / 01 / 91$ & $12: 44: 07$ & \\
\hline REW $=1$ & $04 / 01,51$ & $12: 20: 02$ & cies: \\
\hline RevH20 & $5.4 / 01 / 71$ & $12: 23: 05$ & \\
\hline FiEvH19 & $03 / 15 / 31$ & $09: 00: 42$ & Des \\
\hline Re: IS & $0: 11 / 91$ & $09: 43: 13$ & \\
\hline RiEบ 17 & $2=111 ; 91$ & $08: 04: 42$ & [ies \\
\hline$F=1 \| 10$ & $C=! 1 ! / 0 !$ & $07: 55: 15$ & \\
\hline R.EYH15 & $0 \div ; 11 ; 91$ & $27: 44:: 3$ & De $\equiv$ \\
\hline$r=: 41.7$ & 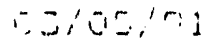 & $\partial \cdot z^{-} .15$ & \\
\hline$R-v+1=$ & $\therefore z:(i+b ;) 1$ & $07: 50.57$ & les \\
\hline F.ev1 & CU/Uこ: & $98:=7: 41$ & Des \\
\hline Fiニン\#! 1 & $\because 2: 01: 71$ & $1: 1: 17: \therefore 7$ & Des \\
\hline$P F \vee \# \perp 0$ & $\because 5 ; 01 / 71$ & $1 \pm: 04: 52$ & De $\equiv:$ \\
\hline 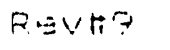 & $0: 01: 91$ & $00: 51: 50$ & DES \\
\hline R.EV\# & $C=128 / 91$ & $14: 1 \Xi: 15$ & Les: \\
\hline$P \in \cup \pitchfork 7$ & $22120 ; 01$ & $10:=1: 50$ & Cie \\
\hline Re⿻ $\because \$ 0$ & G-12B/OL & $05: 02:=0$ & Des: \\
\hline PEv 5 & $\theta=127 / 91$ & $15.50: 03$ & \\
\hline $\operatorname{Re:} \pitchfork 4$ & CEI:27/91 & $15: 1 \pm: 04$ & Des: \\
\hline$R \in V \# \bar{J}$ & $C=/ 27 / 71$ & $15: 0.5: \bar{\top}$ & Des: \\
\hline Rev\#z & $02 / 27 / 91$ & $1 \Xi: 30: 55$ & De \\
\hline Rev\#1 & $02 / 27 / 91$ & $10: 01: 15$ & \\
\hline
\end{tabular}




\begin{tabular}{|c|c|c|}
\hline$P$ sige & Fung & Description \\
\hline & $\cdots-\cdots$ & $-\cdots-\cdots-\cdots$ \\
\hline 1 & 0 & Program File List \\
\hline 2 & 0 & Ladder Diagram Dump \\
\hline 2 & 0 & File 2 Proj: COLUMN \\
\hline 15 & & I / O Part \\
\hline 18 & & Cross Reference Report \\
\hline 22 & & Dati Table Dump Report \\
\hline 25 & & Data Table Usage Report \\
\hline 27 & & [lata Base Uミage form \\
\hline 32 & & Unused fiddress Report \\
\hline 35 & & Reyision History Report \\
\hline
\end{tabular}


PLC.5 Program Information

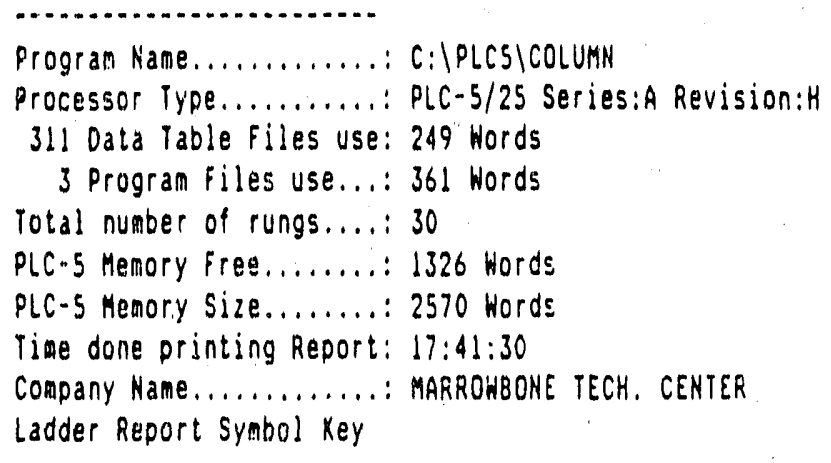

Rung $x x x \quad<$ Rung Nubber being Printed

Rung Description. Up to $64 k$ of text in either 80 columns or 132 coluans (Depends on Configuration) ...

5 Line by $15 \ldots$ instruction Descriotion iext character Description for.... each Instrue-..

tion...........

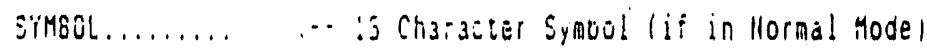

I:Is -.. Instruction's Adaress - NOTE: If Symbol REFLACE mode is enabled syobol will be here instead : 1 17

IAD $\quad \therefore$ The Type of $1 / 0$ card if address is a real $1 / 0$ point

(5:12j) (-. input Cross Reference (if enabled) ' $5:$ ' is the file and 123 is the rung that the contact, is used as an output

Output Cross Reference - Each address used in each output instruction is displayeo and cross refarenced here.

Right power rail can selectively be enabled/disabled 
Appendix 8: Material balances for the $\varnothing$-foot column long-term test 


\begin{tabular}{|c|l|}
\hline MICROBUBBLE COLUMN FLOTATION TESTWORK & Date: \\
\hline Sample: Marrowbone (Sholl Mining Co.) Naugatuck, WV, Long Term & Test No: 1 \\
\hline
\end{tabular}

\begin{tabular}{|l|l|}
\hline Sample Characteristics: \\
\hline Percent Solids (As Received) & 3.76 \\
\hline Particle Size & -150 mesh \\
\hline
\end{tabular}

\begin{tabular}{|l|l|}
\hline Column Geometry: & 24 feet \\
\hline Overall Height (bubble generators to cell lip) & 8 feet \\
\hline Diamoter & 5 feet \\
\hline Feed Entry Point & 40 inches \\
\hline Froth Height & \\
\hline
\end{tabular}

\begin{tabular}{|l|l|l|}
\hline Reagent Additions: & \multicolumn{1}{|c|}{ Dosage (lbs/ton) } & \multicolumn{1}{|c|}{ TYpe } \\
\hline Collector & 0.66 & Deisel \\
\hline Frother & 0.59 & DF1012 \\
\hline pH Modifier & & \\
\hline Dispersant & & \\
\hline
\end{tabular}

\begin{tabular}{|l|l|l|l|}
\hline Column Flows: & \multicolumn{1}{|c|}{ gpm } & gms/min & \%olids \\
\hline Gas Flowrate & 160 (cfm) & & \\
\hline Wash Water Flowrate & 225 & & \\
\hline Foed Flowrate & 1000 & & \\
\hline Product Flowrate & & & \\
\hline Roject (Tailings) Flowrate & & & \\
\hline
\end{tabular}

\begin{tabular}{|c|c|c|c|c|c|}
\hline Assays: & Ash $(\%)$ & Comb. $(\%)$ & Tot. S $(\%)$ & Pyr. S $(\%)$ & Btu/nb \\
\hline Product & 6.81 & 93.19 & & & \\
\hline Reject & 66.76 & 33.24 & & & \\
\hline Foed & 45.66 & 54.34 & & & \\
\hline
\end{tabular}

\begin{tabular}{|c|c|c|c|c|c|c|}
\hline Pecoveries $(\%)$ : & Yield & Ash & Comb. & Tot. $\mathbf{S}$ & Pyr. S & Btu \\
\hline Product & 35.20 & 5.25 & 60.36 & & & \\
\hline Reject & 64.80 & 94.75 & 39.64 & & & \\
\hline Feed & 100 & 100 & 100 & 100 & 100 & 100 \\
\hline
\end{tabular}




\begin{tabular}{|c|l|}
\hline MICROBUBBLE COLUMN FLOTATION TESTWORK & Date: \\
\hline Sample: Marrowbone (Sholl Mining Co.) Naugatuck, WV, Long Torm & Test No: 2 \\
\hline
\end{tabular}

\begin{tabular}{|l|l|}
\hline Sample Characteristics: \\
\hline Percent Solids (As Received) & 3.90 \\
\hline Particle Size & -150 mesh \\
\hline
\end{tabular}

\begin{tabular}{|l|l|}
\hline Column Geometry: & 24 feet \\
\hline Overall Hoight (bubble generators to cell lip) & 8 feet \\
\hline Diameter & 5 feet \\
\hline Feed Entry Point & 40 inches \\
\hline Froth Height & \\
\hline
\end{tabular}

\begin{tabular}{|l|l|l|}
\hline Reagent Additions: & \multicolumn{1}{|c|}{ Dosege llbs/ton) } & \multicolumn{1}{|c|}{ Type } \\
\hline Collector & 0.70 & Diesel \\
\hline Frother & 0.63 & DF1012 \\
\hline pH Modifier & & \\
\hline Dispersant & & \\
\hline
\end{tabular}

\begin{tabular}{|l|l|l|l|}
\hline Column Flows: & \multicolumn{1}{|c|}{ opm } & gms/min & \% solids \\
\hline Gas Flowrate & 160 (cfm) & & \\
\hline Wash Water Flowrate & 206 & & \\
\hline Foed Flowrate & 908 & & \\
\hline Product Flowrate & & & \\
\hline Reject (Tailings) Flowrate & & & \\
\hline
\end{tabular}

\begin{tabular}{|c|c|c|c|c|c|}
\hline Assays: & $\operatorname{Ash}(\%)$ & Comb. $(\%)$ & Tot. $\mathbf{S}(\%)$ & Pyr. S $(\%)$ & Btu/lb \\
\hline Product & 6.47 & 93.53 & & & \\
\hline Roject & 71.65 & 28.35 & & & \\
\hline Fened & 59.07 & 40.93 & & & \\
\hline
\end{tabular}

\begin{tabular}{|c|c|c|c|c|c|c|}
\hline Recoveries (\%): & Yiold & Ash & Comb. & Tot. $\mathbf{S}$ & Pyr. S & Btu \\
\hline Product & 19.30 & 2.11 & 44.10 & & & \\
\hline Reject & 80.70 & 97.89 & 55.90 & & & \\
\hline Foed & 100 & 100 & 100 & 100 & 100 & 100 \\
\hline
\end{tabular}




\begin{tabular}{|l|l|}
\hline MICROBUBBLE COLUMN FLOTATION TESTWORK & Date: \\
\hline Sample: Marrowbone (Sholl Mining Co.) Naugatuck, WV, Long Term & Test No: 3 \\
\hline
\end{tabular}

\begin{tabular}{|l|l|}
\hline Sample Characteristics: & \\
\hline Percent Solids (As Received) & 3.90 \\
\hline Particle Size & -150 mesh \\
\hline
\end{tabular}

\begin{tabular}{|l|l|}
\hline Column Geometry: & \\
\hline Overall Height (bubble generators to cell lip) & 24 feet \\
\hline Diameter & 8 feet \\
\hline Foed Entry Point & 5 feet \\
\hline Froth Height & 40 inches \\
\hline
\end{tabular}

\begin{tabular}{|l|l|l|}
\hline Reagent Additions: & \multicolumn{1}{|c|}{ Dosage (lbs/ton) } & \multicolumn{1}{|c|}{ Typo } \\
\hline Collector & 0.70 & Diesel \\
\hline Frother & 0.63 & DF10i 2 \\
\hline pH Modifier & & \\
\hline Dispersant & & \\
\hline
\end{tabular}

\begin{tabular}{|l|l|l|l|}
\hline Column Flows: & \multicolumn{1}{|c|}{ opm } & gms/min & \% solids \\
\hline Gas Flowrate & 160 (cfm) & & \\
\hline Wash Water Flowrate & 206 & & \\
\hline Food Flowrate & 908 & & \\
\hline Product Flowrate & & & \\
\hline Rojoct (Tailings) Flowrate & & & \\
\hline
\end{tabular}

\begin{tabular}{|c|c|c|c|c|c|}
\hline Assays: & Ash $(\%)$ & Comb. $(\%)$ & Tot. S $(\%)$ & Pyr. S $(\%)$ & Btu/lb \\
\hline Product & 8.83 & 91.17 & & & \\
\hline Reject & 73.01 & 26.99 & & & \\
\hline Feed & 55.18 & 44.82 & & & \\
\hline
\end{tabular}

\begin{tabular}{|c|c|c|c|c|c|c|}
\hline Recoveries $(\%)$ : & Yiold & Ash & Comb. & Tot. $\mathbf{s}$ & Pyr. S & Btu \\
\hline Product & 27.78 & 4.45 & 56.51 & & & \\
\hline Reject & 72.22 & 95.55 & 43.49 & & & \\
\hline Food & 100 & 100 & 100 & 100 & 100 & 100 \\
\hline
\end{tabular}




\begin{tabular}{|c|l|}
\hline MICROBUBBLE COLUMN FLOTATION TESTWORK & Date: \\
\hline Sample: Marrowbone (Sholl Mining Co.) Naugatuck, WV, Long Torm & Test No: 4 \\
\hline
\end{tabular}

\begin{tabular}{|l|l|}
\hline Sample Characteristics: & \\
\hline Percent Solids (As Received) & 3.90 \\
\hline Particle Size & -150 mesh \\
\hline
\end{tabular}

\begin{tabular}{|l|l|}
\hline Column Goometry: & 24 foet \\
\hline Overall Height (bubble generators to cell lip) & 8 feet \\
\hline Diameter & 5 feet \\
\hline Feed Entry Point & 40 inches \\
\hline Froth Height & \\
\hline
\end{tabular}

\begin{tabular}{|l|l|l|}
\hline Reagent Additions: & Dosage (lbs/ton) & Type \\
\hline Collector & 0.70 & \\
\hline Frothor & 0.63 & \\
\hline pH Modifier & & \\
\hline Dispersant & & \\
\hline
\end{tabular}

\begin{tabular}{|l|l|l|l|}
\hline Column Flows: & \multicolumn{1}{|c|}{ opm } & gms/min & $\%$ solids \\
\hline Gas Flowrate & 160 (cfm) & & \\
\hline Wash Water Flowrate & 206 & & \\
\hline Foed Flowrate & 908 & & \\
\hline Product Flowrate & & & \\
\hline Reject (Tailings) Flowrate & & & \\
\hline
\end{tabular}

\begin{tabular}{|c|c|c|c|c|c|}
\hline Assays: & $A \sin (\%)$ & Comb. $(\%)$ & Tot. $S(9)$ & Pyr. $\mathbf{s}(\%)$ & Btu/b \\
\hline Product & 7.46 & 92.54 & & & \\
\hline Reject & 73.96 & $\angle 0.04$ & & & \\
\hline Food & 55.14 & 44.86 & & & \\
\hline
\end{tabular}

\begin{tabular}{|l|c|c|c|c|c|c|}
\hline Recoveries $(\%):$ & Yield & Ash & Comb. & Tot. S & Pyr. S & Btu \\
\hline Product & 28.30 & 3.82 & 58.38 & & & \\
\hline Reject & 71.70 & 96.18 & 41.62 & & & \\
\hline Feed & 100 & 100 & 100 & 100 & 100 & 100 \\
\hline
\end{tabular}




\begin{tabular}{|c|l|}
\hline MICROBUBBLE COLUMN FLOTATION TESTWORK & Date: \\
\hline Samplo: Marrowbone (Shall Mining Co.) Naugatuck, WV, Long Torm & Test No: $\mathbf{5}$ \\
\hline
\end{tabular}

\begin{tabular}{||l|l||}
\hline Sample Characteristics: & \\
\hline Percent Solids (As Received) & 3.91 \\
\hline Particle Size & $-150 \mathrm{mesh}$ \\
\hline
\end{tabular}

\begin{tabular}{|l|l|}
\hline Column Geometry: & 24 feet \\
\hline Overall Height lbubble generators to cell lip) & 8 feet \\
\hline Diamoter & 5 foet \\
\hline Feed Entry Point & 40 inches \\
\hline Froth Hoight & \\
\hline
\end{tabular}

\begin{tabular}{|l|l|l|}
\hline Reagent Additions: & \multicolumn{1}{|c|}{ Dosage llbs/ton) } & \multicolumn{1}{|c|}{ Type } \\
\hline Collector & 0.66 & Diesel \\
\hline Frother & 0.60 & DF1012 \\
\hline pH Modifier & & \\
\hline Dispersant & & \\
\hline
\end{tabular}

\begin{tabular}{|l|l|l|l|}
\hline Co & gom & gms/min & \%olids \\
\hline Gas Flowrate & 160 (cfm) & & \\
\hline Wash Water Flowrate & 230 & & \\
\hline Foed Flowrate & 955 & & \\
\hline Product Flowrate & & & \\
\hline Reject (Tailings) Flowrate & & & \\
\hline
\end{tabular}

\begin{tabular}{|c|c|c|c|c|c|}
\hline Assal s: & Ash $(\%)$ & Comb. $(\%)$ & Tot. $S(\%)$ & Pyr. S $(\%)$ & Btu/b \\
\hline Product & 7.40 & 92.60 & & & \\
\hline Reject & 72.03 & 27,97 & & & \\
\hline Food & 52.29 & 47.71 & & & \\
\hline
\end{tabular}

\begin{tabular}{|c|c|c|c|c|c|c|}
\hline Recoveries (\%): & Yiold & Ash & Comb. & Tot. $\mathbf{S}$ & Pyr. S & Btu \\
\hline Product & 30.54 & 4.32 & 59.28 & & & \\
\hline Rejoct & 69.46 & 95.68 & 40.72 & & & \\
\hline Foed & 100 & 100 & 100 & 100 & 100 & 100 \\
\hline
\end{tabular}




\begin{tabular}{|c|l|}
\hline MICROBUBBLE COLUMN FLOTATION TESTWORK & Date: \\
\hline Sample: Marrowbone (Shell Mining Co.) Naugatuck, WV, Long Torm & Tost No: 6 \\
\hline
\end{tabular}

\begin{tabular}{|l|l|}
\hline Sample Characteristics: \\
\hline Percent Solids (As Recoived) & 3.90 \\
\hline Particle Size & -150 mesh \\
\hline
\end{tabular}

\begin{tabular}{|l|l|}
\hline Column Geomatry: & \\
\hline Overall Helght (bubble oenerators to cell lip) & 24 foot \\
\hline Diamoter & 8 foot \\
\hline Foed Entry Point & 5 foot \\
\hline Froth Height & 40 inches \\
\hline
\end{tabular}

\begin{tabular}{|l|l|l|}
\hline Resgent Additions: & \multicolumn{1}{|c|}{ Dosage llbs/tonl } & \multicolumn{1}{|c|}{ Type } \\
\hline Collector & 0.71 & Diesel \\
\hline Frother & 0.68 & DF 1012 \\
\hline pH Modifier & & \\
\hline Disparsant & & \\
\hline
\end{tabular}

\begin{tabular}{|l|l|l|l|}
\hline Column Flows: & \multicolumn{1}{|c|}{ gpm } & gms/min & \% solids \\
\hline Gas Flowrate & 1 iciofm) & & \\
\hline Wash Water Flowrate & 225 & & \\
\hline Foed Flowrate & 861 & & \\
\hline Product Flowrate & & & \\
\hline Rejoct (Tailings) Flowrate & & & \\
\hline
\end{tabular}

\begin{tabular}{|c|c|c|c|c|c|}
\hline Assays: & $\operatorname{Ash}(\%)$ & Comb. (\%) & Tot. $\mathbf{s}(\%)$ & Pyr. s $(\%)$ & Btu/b \\
\hline Product & 6.49 & 93.51 & & & \\
\hline Hoject & 79.84 & 28.16 & & & \\
\hline Feed & 49.28 & 50.72 & & & \\
\hline
\end{tabular}

\begin{tabular}{|c|c|c|c|c|c|c|}
\hline Recoverios $(\%)$ i & Yiold & Ash & Comb. & Tot, $\mathrm{S}$ & Pyr, s & Bru \\
\hline Product & 34.52 & 4.55 & 63.65 & & & \\
\hline Rejoct & 65.48 & 95.45 & 36.35 & & & \\
\hline Feed & 100 & 100 & 100 & 100 & 100 & 100 \\
\hline
\end{tabular}




\begin{tabular}{|l|l|}
\hline MICROBUBBLE COLUMN FLOTATION TESTWORK & Date: \\
\hline Sample: Marrowbone (Sholl Mining Co.) Naugatuok, WV, Long Toim & Test Noi 7 \\
\hline
\end{tabular}

\begin{tabular}{|l|l|}
\hline Sample Characteristics: & 3.90 \\
\hline Porcent Solids (As Recoived) & $-150 \mathrm{mesh}$ \\
\hline Particle Size & \\
\hline
\end{tabular}

\begin{tabular}{|l|l|}
\hline Column Geometry: & \\
\hline Overall Height (bubble generators to cell lip) & 24 feet \\
\hline Diameter & 8 feet \\
\hline Feed Entry Point & 5 feet \\
\hline Froth Height & 40 inches \\
\hline
\end{tabular}

\begin{tabular}{||l|l|l||}
\hline Reagent Additions: & \multicolumn{1}{|c|}{ Dosage (lbs/ton) } & Type \\
\hline Collector & 0.66 & Diesel \\
\hline Frother & 0.63 & DF1012 \\
\hline pH Modifior & & \\
\hline Dispersant & & \\
\hline
\end{tabular}

\begin{tabular}{|l|l|l|l|}
\hline Column Flows: & \multicolumn{1}{|c|}{ gpm } & gms/min & \%olids \\
\hline Gas Flowrate & 160 (c/m) & & \\
\hline Wash Water Flowrate & 225 & & \\
\hline Fead Flowrate & 908 & & \\
\hline Product Flowrate & & & \\
\hline Rejoct (Tailings) Flowrate & & & \\
\hline
\end{tabular}

\begin{tabular}{|c|c|c|c|c|c|}
\hline Assays: & $\operatorname{Ash}(\%)$ & Comb. (\%) & Tot. S $(\%)$ & Pyr. s (\%) & Btu/Ab \\
\hline Product & 6.89 & 93.11 & & & \\
\hline Reject & 73.03 & 26.97 & & & \\
\hline Foed & 46.65 & 53.35 & & & \\
\hline
\end{tabular}

\begin{tabular}{|c|c|c|c|c|c|c|}
\hline Recoverios $\left(X_{i}\right)$ : & Yiold & Ash & Comb. & Tot. $\mathrm{S}$ & Pyr. S & Btu \\
\hline Product & 39.88 & 5.89 & 69.61 & & & \\
\hline Reject & 60.12 & 94.10 & 30.39 & & & \\
\hline Feed & 100 & 100 & 100 & 100 & 100 & 100 \\
\hline
\end{tabular}




\begin{tabular}{|c|l|}
\hline MICROBUBBLE COLUMN FLOTATION TESTWORK & Date: \\
\hline Saniple: Marrowbane IShall Mining Co.I Naugatuck, WV, Long Torm & Tost No: 8 \\
\hline
\end{tabular}

\begin{tabular}{|l|l|}
\hline Sample Chargoteristios: & \\
\hline Percent Solids (As Recoived) & 3.92 \\
\hline Particle Size & $-150 \mathrm{rnesh}$ \\
\hline
\end{tabular}

\begin{tabular}{|l|l|}
\hline Column Geometry: & 24 feet \\
\hline Overall Holght (bubble genarators to coll lip) & 8 feet \\
\hline Dlametor & 5 feet \\
\hline Feed Entry Point & 40 inches \\
\hline Froth Height & \\
\hline
\end{tabular}

\begin{tabular}{|l|l|l|}
\hline Reagent Additions: & \multicolumn{1}{|c|}{ Dosage (lbs/ton) } & \multicolumn{1}{c|}{ Type } \\
\hline Collector & 0.37 & Diesel \\
\hline Frother & 0.39 & DF1012 \\
\hline pH Modifier & & \\
\hline Dispersant & & \\
\hline
\end{tabular}

\begin{tabular}{|l|c|c|c|}
\hline Column Flows: & opm & gms/min & \% solids \\
\hline Gas Flowrate & 160 (cfm) & & \\
\hline Wash Water Flowrate & 215 & & \\
\hline Foed Flowrate & $1347^{\circ}$ & & \\
\hline Product Flowrate & & & \\
\hline Rejoct Tailings) Flowrate & & & \\
\hline
\end{tabular}

\begin{tabular}{|c|c|c|c|c|c|}
\hline Assays: & $\operatorname{Ash}(\%)$ & Comb. $(\%)$ & Tot. $s(\%)$ & Pyr. S $(\%)$ & Btu/lb \\
\hline Product & 8.29 & 91.71 & & & \\
\hline Reject & 80.25 & 19.75 & & & \\
\hline Feed & 59.58 & 40.42 & & & \\
\hline
\end{tabular}

\begin{tabular}{|c|c|c|c|c|c|c|}
\hline Recoveries (\%): & Yiold & Ash & Comb. & Tot. $\mathbf{s}$ & Pyr. S & Btu \\
\hline Product & 28.72 & 3.99 & 65.17 & & & \\
\hline Hoject & 71.28 & 96.01 & 34.83 & & & \\
\hline Foed & 100 & 100 & 100 & 100 & 100 & 100 \\
\hline
\end{tabular}


Appendix 9: Summary of the statistical data analysis computations for the 8-foot column parametric test program 
Design Expert Data Analysis for Yield

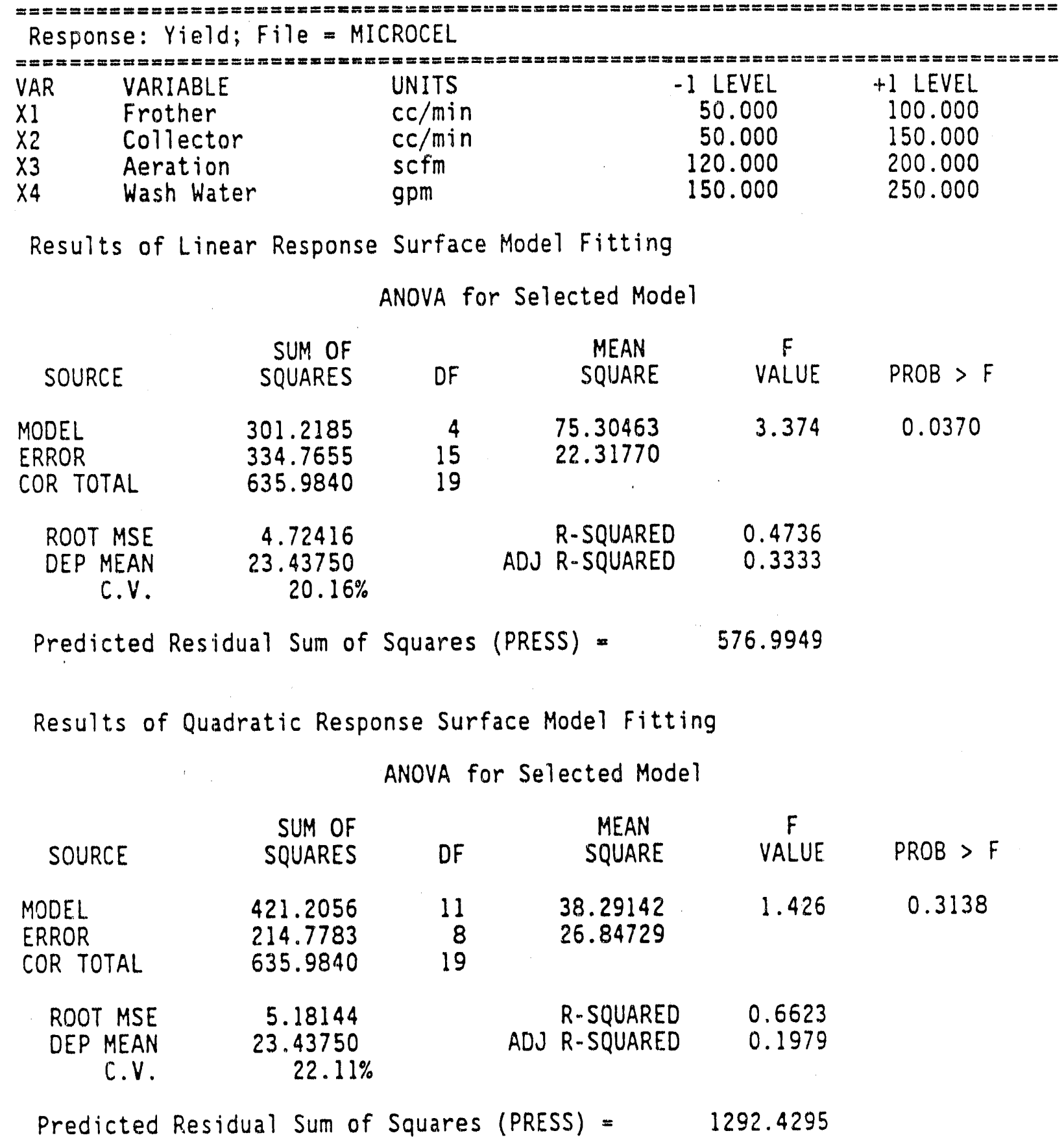


Results of Cubic Response Surface Model Fitting

ANOVA for Selected Model

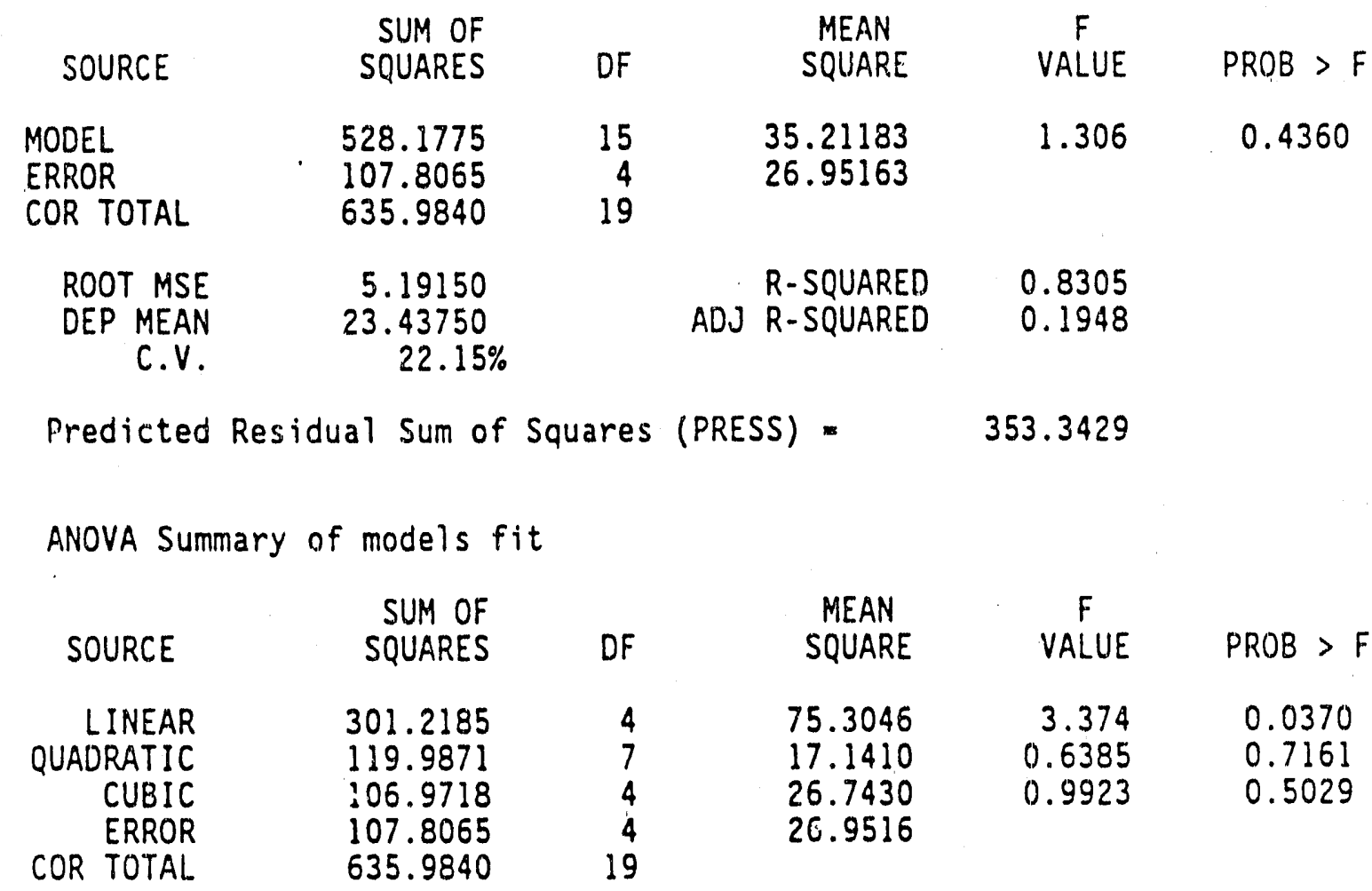

Lack of Fit tests

$\begin{array}{rrrrrr}\text { MODEL } & \text { SUM OF } & & \text { MEAN } & F & \text { V } \\ & \text { SQUARES } & \text { DF } & \text { SQUARE } & \text { VALUE } & \text { PROB > F } \\ \text { LINEAR } & 227.5950 & 12 & 18.9662 & 0.5309 & 0.8138 \\ \text { QUADRATIC } & 107.6078 & 5 & 21.5216 & 0.6024 & 0.7109 \\ \text { CUBIC } & 0.6360 & 1 & 0.6360 & 1.78 E-02 & 0.9023 \\ \text { PURE ERR } & 107.1705 & 3 & 35.7235 & & \end{array}$




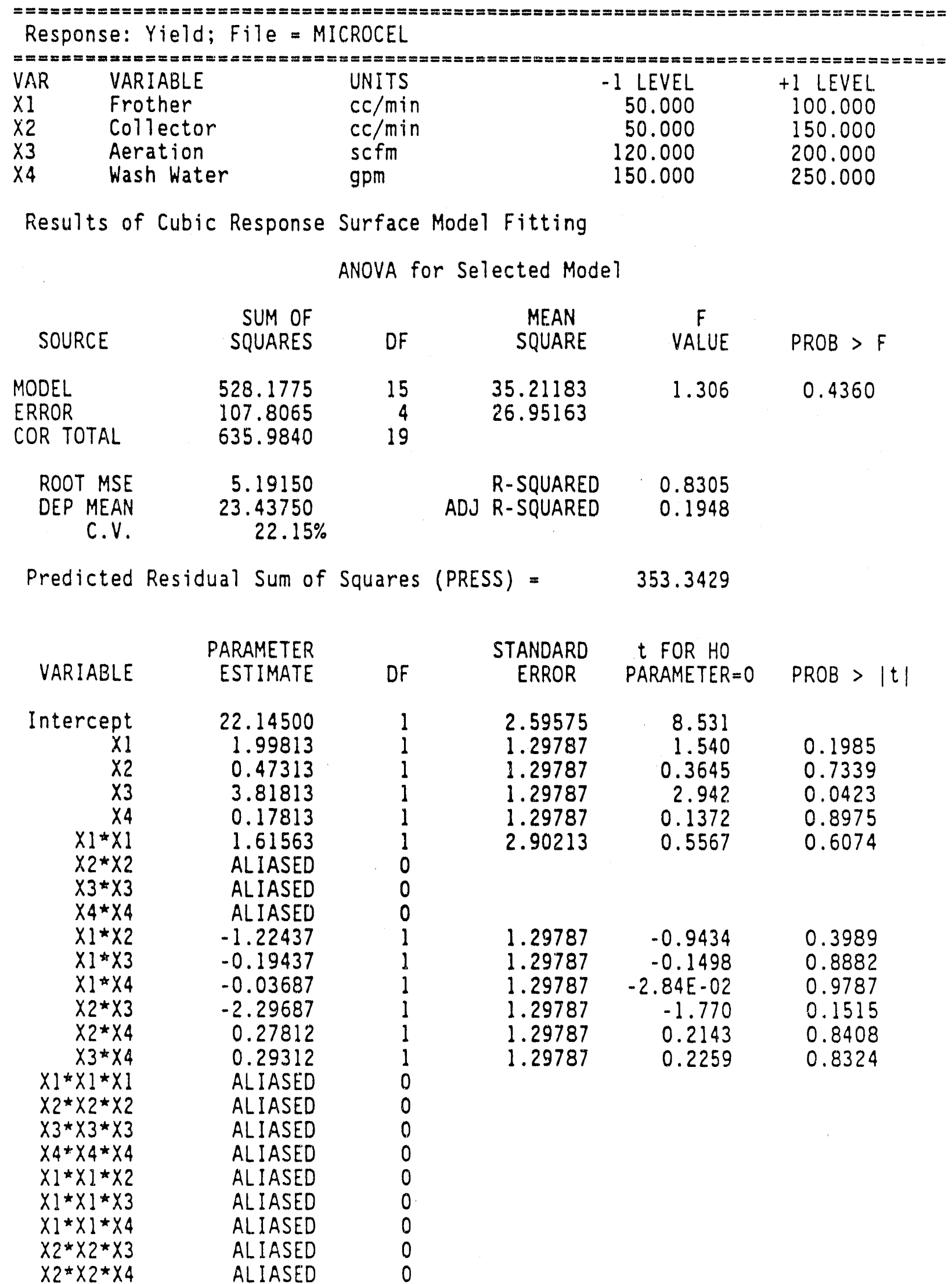




\begin{tabular}{|c|c|c|c|c|c|c|c|c|}
\hline & 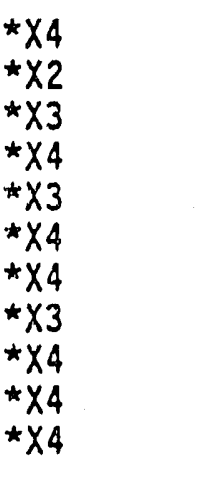 & $\begin{array}{l}\text { ALIASED } \\
\text { ALIASED } \\
\text { ALIASED } \\
\text { ALIASED } \\
\text { ALIASED } \\
\text { ALIASED } \\
\text { ALIASED } \\
-0.61938 \\
-1.01187 \\
-2.22187 \\
-0.58437\end{array}$ & $\begin{array}{l}0 \\
0 \\
0 \\
0 \\
0 \\
0 \\
0 \\
1 \\
1 \\
1 \\
1\end{array}$ & $\begin{array}{l}9787 \\
9787 \\
9787 \\
9787\end{array}$ & $\begin{array}{l}-0.477 \\
-0.775 \\
-1.71 \\
-0.450\end{array}$ & & $\begin{array}{l}0.6581 \\
0.4792 \\
0.1621 \\
0.6759\end{array}$ & \\
\hline ctd & ROR & 1.16085 & & & & & & \\
\hline & $\begin{array}{l}\text { ACTUAL } \\
\text { VALUE }\end{array}$ & $\begin{array}{l}\text { PREDICTED } \\
\text { VALUE }\end{array}$ & RESIDUAL & LEVER & $\begin{array}{l}\text { STUDENT } \\
\text { RESID }\end{array}$ & $\begin{array}{c}\text { COOK'S } \\
\text { DIST }\end{array}$ & VALUE & $\begin{array}{l}\text { Run } \\
\text { Ord }\end{array}$ \\
\hline $\begin{array}{l}1 \\
2 \\
3 \\
4 \\
5 \\
6 \\
7 \\
8 \\
9 \\
10 \\
11 \\
12 \\
13 \\
14 \\
15 \\
16 \\
17 \\
18 \\
19 \\
20\end{array}$ & $\begin{array}{l}18.35000 \\
17.95000 \\
21.75000 \\
22.18000 \\
23.93000 \\
33.32000 \\
22.16000 \\
29.02000 \\
10.40000 \\
21.99000 \\
20.50000 \\
26.42000 \\
27.58000 \\
32.78000 \\
29.43000 \\
22.41000 \\
16.83000 \\
25.80000 \\
17.31000 \\
28.64000\end{array}$ & $\begin{array}{l}18.54938 \\
17.75063 \\
21.55063 \\
22.37938 \\
23.73063 \\
33.51938 \\
22.35938 \\
28.82063 \\
10.20063 \\
22.18938 \\
20.69938 \\
26.22063 \\
27.77938 \\
32.58063 \\
29.23063 \\
22.60938 \\
22.14500 \\
22.14500 \\
22.14500 \\
22.14500\end{array}$ & $\begin{array}{r}-0.19938 \\
0.19937 \\
0.19937 \\
-0.19938 \\
0.19937 \\
-0.19938 \\
-0.19938 \\
0.19937 \\
0.19937 \\
-0.19938 \\
-0.19938 \\
0.19937 \\
-0.19938 \\
0.19937 \\
0.19937 \\
-0.19938 \\
-5.31500 \\
3.65500 \\
-4.83500 \\
6.49500\end{array}$ & $\begin{array}{l}0.937 \\
0.937 \\
0.937 \\
0.937 \\
0.937 \\
0.937 \\
0.937 \\
0.937 \\
0.937 \\
0.937 \\
0.937 \\
0.937 \\
0.937 \\
0.937 \\
0.937 \\
0.937 \\
0.250 \\
0.250 \\
0.250 \\
0.250\end{array}$ & $\begin{array}{r}-0.154 \\
0.154 \\
0.154 \\
-0.154 \\
0.154 \\
-0.154 \\
-0.154 \\
0.154 \\
0.154 \\
-0.154 \\
-0.154 \\
0.154 \\
-0.154 \\
0.154 \\
0.154 \\
-0.154 \\
-1.182 \\
0.813 \\
-1.075 \\
1.445\end{array}$ & $\begin{array}{l}0.022 \\
0.022 \\
0.022 \\
0.022 \\
0.022 \\
0.022 \\
0.022 \\
0.022 \\
0.022 \\
0.022 \\
0.022 \\
0.022 \\
0.022 \\
0.022 \\
0.022 \\
0.022 \\
0.029 \\
0.014 \\
0.024 \\
0.043\end{array}$ & $\begin{array}{r}-0.306 \\
0.306 \\
0.306 \\
-0.306 \\
0.306 \\
-0.306 \\
-0.306 \\
0.306 \\
0.306 \\
-0.306 \\
-0.306 \\
0.306 \\
-0.306 \\
0.306 \\
0.306 \\
-0.306 \\
-1.907 \\
1.486 \\
-1.813 \\
1.998\end{array}$ & $\begin{array}{r}20 \\
5 \\
18 \\
19 \\
9 \\
16 \\
6 \\
7 \\
1 \\
17 \\
14 \\
10 \\
8 \\
15 \\
12\end{array}$ \\
\hline
\end{tabular}




\section{Design Expert Data Analysis for Product Ash}

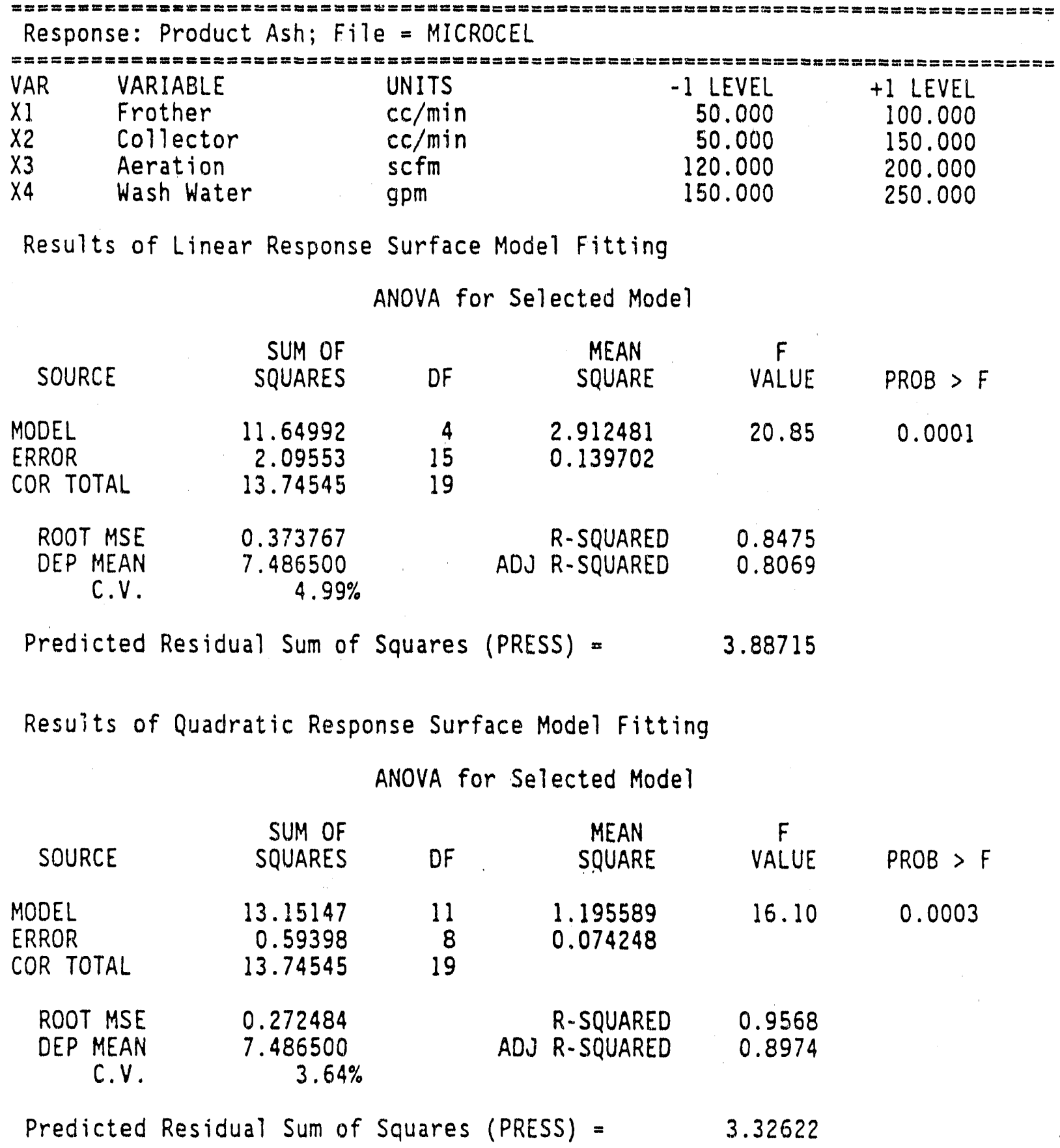


Results of Cubic Response Surface Model Fitting ANOVA for Selected Model

\begin{tabular}{lrrrrr}
\multicolumn{1}{c}{ SOURCE } & SUM OF & & MEAN & F & \\
& SQUARES & DF & SQUARE & VALUE & PROB > F \\
MODEL & 13.40350 & 15 & 0.893567 & 10.45 & 0.0177 \\
ERROR & 0.34196 & 4 & 0.085489 & & \\
COR TOTAL & 13.74545 & 19 & & &
\end{tabular}

$\begin{array}{cccc}\text { ROOT MSE } & 0.292385 & \text { R-SQUARED } & 0.9751 \\ \text { DEP MEAN } & 7.486500 & \text { ADJ R-SQUARED } & 0.8818 \\ \text { C.V. } & 3.91 \% & & \end{array}$

Predicted Residual Sum of Squares (PRESS) = 4.74062

ANOVA Summary of models fit

$\begin{array}{rrrrrr}\text { SOURCE } & \begin{array}{c}\text { SUM OF } \\ \text { SQUARES }\end{array} & \text { DF } & \begin{array}{c}\text { MEAN } \\ \text { SQUARE }\end{array} & \text { VALUE } & \text { PROB > F } \\ \text { LINEAR } & 11.64992 & 4 & 2.91248 & 20.85 & 0.0001 \\ \text { QUADRATIC } & 1.50155 & 7 & 0.21451 & 2.889 & 0.0802 \\ \text { CUBIC } & 0.25203 & 4 & 0.06301 & 0.7370 & 0.6127 \\ \text { ERROR } & 0.34196 & 4 & 0.08549 & & \\ \text { COR TOTAL } & 13.74545 & 19 & & & \end{array}$

Lack of Fit tests

$\begin{array}{rrrrrr}\text { SUDEL } & \text { SUM OF } & & \text { MEAN } & F & \\ \text { SQUARES } & \text { DF } & \text { SQUARE } & \text { VALUE } & \text { PROB > F } \\ \text { LINEAR } & 1.76983 & 12 & 0.14749 & 1.358 & 0.4496 \\ \text { QUADRATIC } & 0.26828 & 5 & 0.05366 & 0.4942 & 0.7707 \\ \text { CUBIC } & 0.01626 & 1 & 0.01626 & 0.1497 & 0.7246 \\ \text { PURE ERR } & 0.32570 & 3 & 0.10857 & & \end{array}$




\begin{tabular}{|c|c|c|c|c|}
\hline $\begin{array}{l}\text { VAR } \\
\times 1 \\
\times 2 \\
\times 3 \\
X 4\end{array}$ & $\begin{array}{l}\text { VARIABLE } \\
\text { Frother } \\
\text { Collector } \\
\text { Aeration } \\
\text { Wash Water }\end{array}$ & $\begin{array}{l}\text { UNITS } \\
\text { CC/min } \\
\text { cc/min } \\
\text { scfm } \\
\text { gpm }\end{array}$ & $\begin{array}{r}-1 \text { LEVEL } \\
50.000 \\
50.000 \\
120.000 \\
150.000\end{array}$ & $\begin{array}{r}+1 \text { LEVEL } \\
100.000 \\
150.000 \\
200.000 \\
250.000\end{array}$ \\
\hline
\end{tabular}

Results of Cubic Response Surface Model Fitting

ANOVA for Selected Model

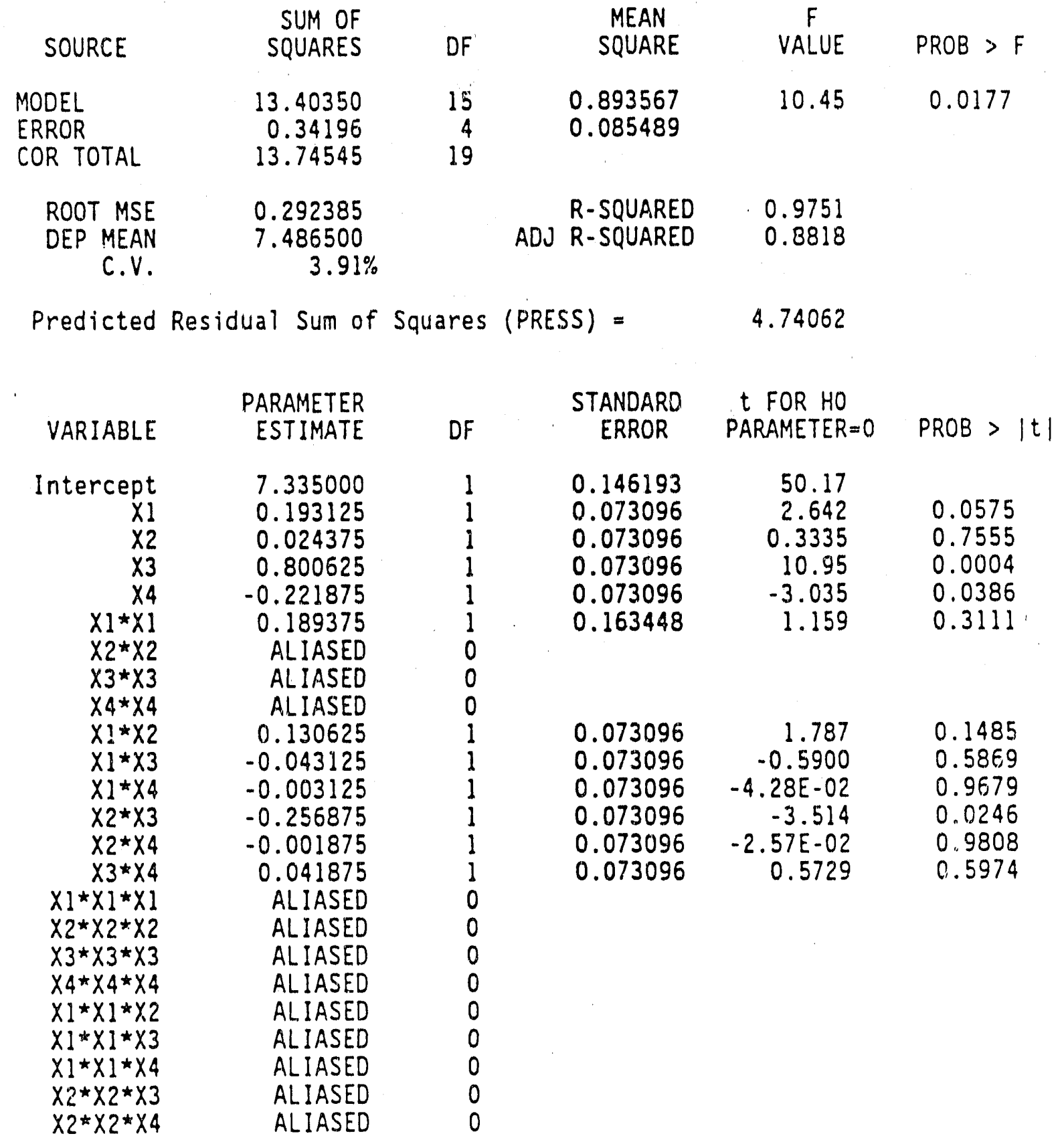




\begin{tabular}{|c|c|c|c|c|c|}
\hline $\begin{array}{l}x 3 * x 3 * x 4 \\
x 1 * x 2 * x 2 \\
x 1 * x 3 * x 3 \\
x 1 * x 4 * x 4 \\
x 2 * x 3 * x 3 \\
x 2 * x 4 * x 4 \\
x 3 * x 4 * x 4 \\
x 1 * x 2 * x 3 \\
x 1 * x 2 * x 4 \\
x 1 * x 3 * x 4 \\
x 2 * x 3 * x 4\end{array}$ & $\begin{array}{r}\text { ALIASED } \\
\text { ALIASED } \\
\text { ALIASED } \\
\text { ALIASED } \\
\text { ALIASED } \\
\text { ALIASED } \\
\text { ALIASED } \\
-0.038125 \\
-0.065625 \\
-0.091875 \\
0.039375\end{array}$ & $\begin{array}{l}0 \\
0 \\
0 \\
0 \\
0 \\
0 \\
0 \\
1 \\
1 \\
1 \\
1\end{array}$ & $\begin{array}{l}0.073096 \\
0.073096 \\
0.073096 \\
0.073096\end{array}$ & $\begin{array}{r}-0.5216 \\
-0.8978 \\
-1.257 \\
0.5387\end{array}$ & $\begin{array}{l}0.6295 \\
0.4201 \\
0.2772 \\
0.6187\end{array}$ \\
\hline
\end{tabular}

Std ERROR $\quad 0.065379$

\begin{tabular}{|c|c|c|c|c|c|c|c|}
\hline $\begin{array}{l}\text { ACTUAL } \\
\text { VALUE }\end{array}$ & $\begin{array}{l}\text { PREDICTED } \\
\text { VALUE }\end{array}$ & RESIDUAL & LEVER & $\begin{array}{c}\text { STUDENT } \\
\text { RESID }\end{array}$ & $\begin{array}{c}\text { COOK'S } \\
\text { DIST }\end{array}$ & $\stackrel{t}{t}$ & $\begin{array}{l}\text { Run } \\
\text { Ord }\end{array}$ \\
\hline $\begin{array}{l}6.720000 \\
6.610000 \\
6.960000 \\
7.660000 \\
8.720000 \\
8.830000 \\
7.800000 \\
8.670000 \\
6.030000 \\
6.410000 \\
6.240000 \\
7.160000 \\
8.280000 \\
8.400000 \\
7.900000 \\
8.000000 \\
7.700000 \\
7.350000 \\
6.900000 \\
7.390000\end{array}$ & $\begin{array}{l}6.751875 \\
6.578125 \\
6.928125 \\
7.691875 \\
8.688125 \\
8.861875 \\
7.831875 \\
8.638125 \\
5.998125 \\
6.441875 \\
6.271875 \\
7.128125 \\
8.311875 \\
8.368125 \\
7.868125 \\
8.031875 \\
7.335000 \\
7.335000 \\
7.335000 \\
7.335000\end{array}$ & $\begin{array}{r}-0.031875 \\
0.031875 \\
0.031875 \\
-0.031875 \\
0.031875 \\
-0.031875 \\
-0.031875 \\
0.031875 \\
0.031875 \\
-0.031875 \\
-0.031875 \\
0.031875 \\
-0.031875 \\
0.031875 \\
0.031875 \\
-0.031875 \\
0.365000 \\
0.015000 \\
-0.435000 \\
0.055000\end{array}$ & $\begin{array}{l}0.937 \\
0.937 \\
0.937 \\
0.937 \\
0.937 \\
0.937 \\
0.937 \\
0.937 \\
0.937 \\
0.937 \\
0.937 \\
0.937 \\
0.937 \\
0.937 \\
0.937 \\
0.937 \\
0.250 \\
0.250 \\
0.250 \\
0.250\end{array}$ & $\begin{array}{r}-0.436 \\
0.436 \\
0.436 \\
-0.436 \\
0.436 \\
-0.436 \\
-0.436 \\
0.436 \\
0.436 \\
-0.436 \\
-0.436 \\
0.436 \\
-0.436 \\
0.436 \\
0.436 \\
-0.436 \\
1.441 \\
0.059 \\
-1.718 \\
0.217\end{array}$ & $\begin{array}{l}0.178 \\
0.178 \\
0.178 \\
0.178 \\
0.178 \\
0.178 \\
0.178 \\
0.178 \\
0.178 \\
0.178 \\
0.178 \\
0.178 \\
0.178 \\
0.178 \\
0.178 \\
0.178 \\
0.043 \\
0.000 \\
0.061 \\
0.001\end{array}$ & $\begin{array}{r}-0.851 \\
0.851 \\
0.851 \\
-0.851 \\
0.851 \\
-0.851 \\
-0.851 \\
0.851 \\
0.851 \\
-0.851 \\
-0.851 \\
0.851 \\
-0.851 \\
0.851 \\
0.851 \\
-0.851 \\
1.998 \\
0.118 \\
-1.759 \\
0.431\end{array}$ & $\begin{array}{r}20 \\
5 \\
18 \\
19 \\
9 \\
16 \\
6 \\
7 \\
1 \\
17 \\
14 \\
10 \\
8 \\
15 \\
12 \\
3 \\
2 \\
13 \\
4 \\
11\end{array}$ \\
\hline
\end{tabular}


Design Expert Data Analysis for Separation Efficiency

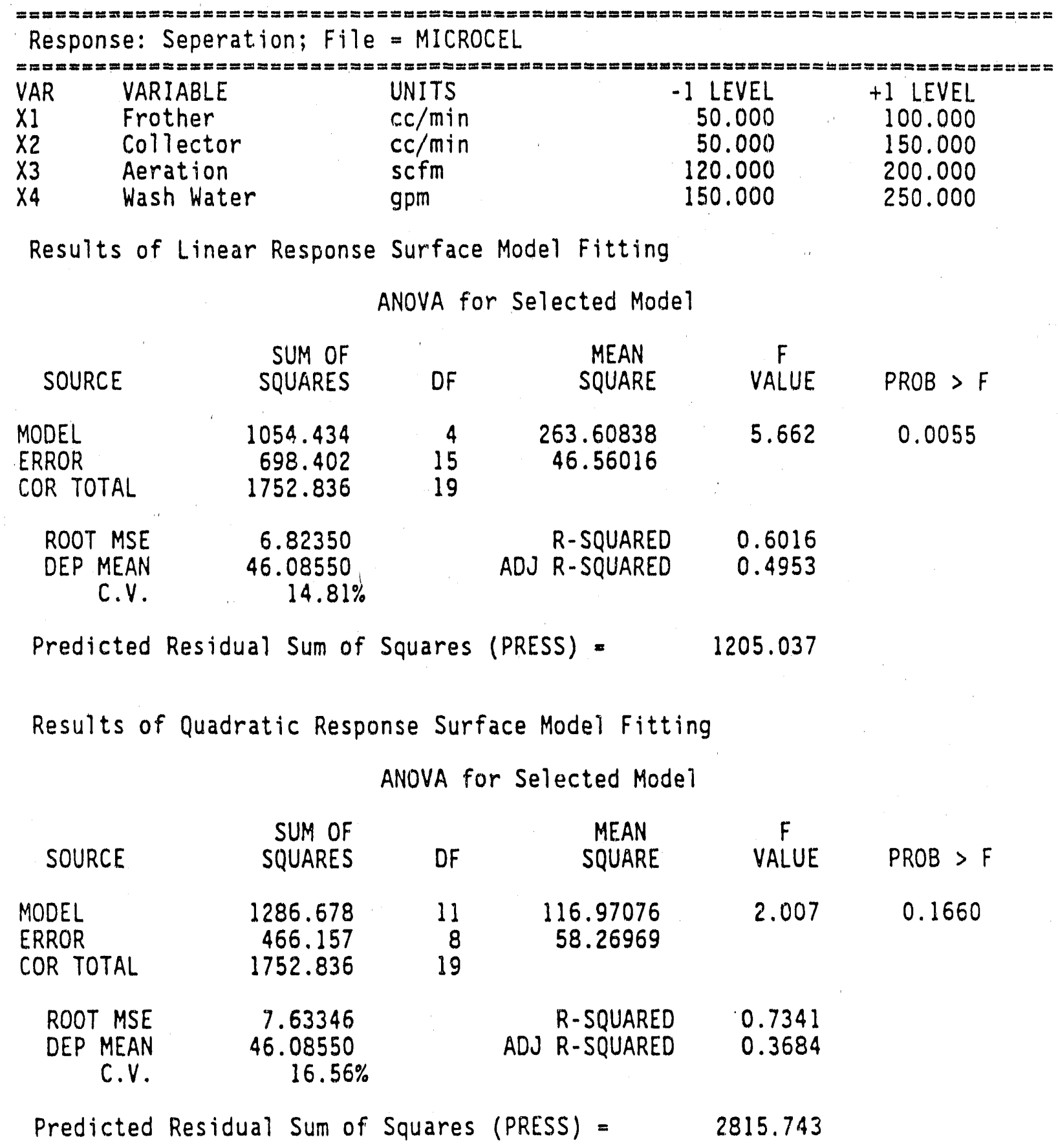


Results of Cubic Response Surface Model Fitting ANOVA for Selected Model

$\begin{array}{lrrrrr}\text { SOURCE } & \text { SUM OF } & & \text { MEAN } & F & \\ & \text { SQUARES } & \text { DF } & \text { SQUARE } & \text { VALUE } & \text { PROB }>F \\ \text { MODEL } & 1520.262 & 15 & 101.35082 & 1.743 & 0.3140 \\ \text { ERROR } & 232.574 & 4 & 58.14339 & & \\ \text { COR TOTAL } & 1752.836 & 19 & & & \end{array}$

$\begin{array}{cccc}\text { ROOT MSE } & 7.62518 & \text { R-SQUARED } & 0.8673 \\ \text { DEF MEAN } & 46.08550 & \text { ADJ R-SQUARED } & 0.3698 \\ \text { C.V. } & 16.55 \% & & \end{array}$

Predicted Residual Sum of Squares (PRESS) =

725.282

ANOVA Summary of models fit

\begin{tabular}{|c|c|c|c|c|c|}
\hline SOIJRCE & $\begin{array}{l}\text { SUM OF } \\
\text { SQUARES }\end{array}$ & DF & $\begin{array}{l}\text { MEAN } \\
\text { SQUARE }\end{array}$ & $\begin{array}{c}F \\
\text { VALUE }\end{array}$ & $\mathrm{PROB}>\mathrm{F}$ \\
\hline $\begin{array}{r}\text { LINEAR } \\
\text { QUADRATIC } \\
\text { CUBIC } \\
\text { ERROR } \\
\text { COR TOTAL }\end{array}$ & $\begin{array}{r}1054.434 \\
232.245 \\
233.584 \\
232.574 \\
1752.836\end{array}$ & $\begin{array}{r}4 \\
7 \\
4 \\
4 \\
19\end{array}$ & $\begin{array}{r}263.608 \\
33.178 \\
58.396 \\
58.143\end{array}$ & $\begin{array}{r}5.662 \\
0.5694 \\
1.004\end{array}$ & $\begin{array}{l}0.0055 \\
0.7638 \\
0.4984\end{array}$ \\
\hline \multicolumn{6}{|c|}{ Lack of Fit tests } \\
\hline MODEL & $\begin{array}{l}\text { SUM OF } \\
\text { SQUARES }\end{array}$ & DF & $\begin{array}{c}\text { MEAN } \\
\text { SQUARE }\end{array}$ & VALUE & $P R O B>F$ \\
\hline $\begin{array}{r}\text { LINEAR } \\
\text { QUADRATIC } \\
\text { CUBIC } \\
\text { PURE ERR }\end{array}$ & $\begin{array}{r}467.055 \\
234.810 \\
1.227 \\
231.347\end{array}$ & $\begin{array}{r}12 \\
5 \\
1 \\
3\end{array}$ & $\begin{array}{r}38.921 \\
46.962 \\
1.227 \\
77.116\end{array}$ & $\begin{array}{r}0.5047 \\
0.6090 \\
1.59 E-02\end{array}$ & $\begin{array}{l}0.8294 \\
0.7075 \\
0.9076\end{array}$ \\
\hline
\end{tabular}




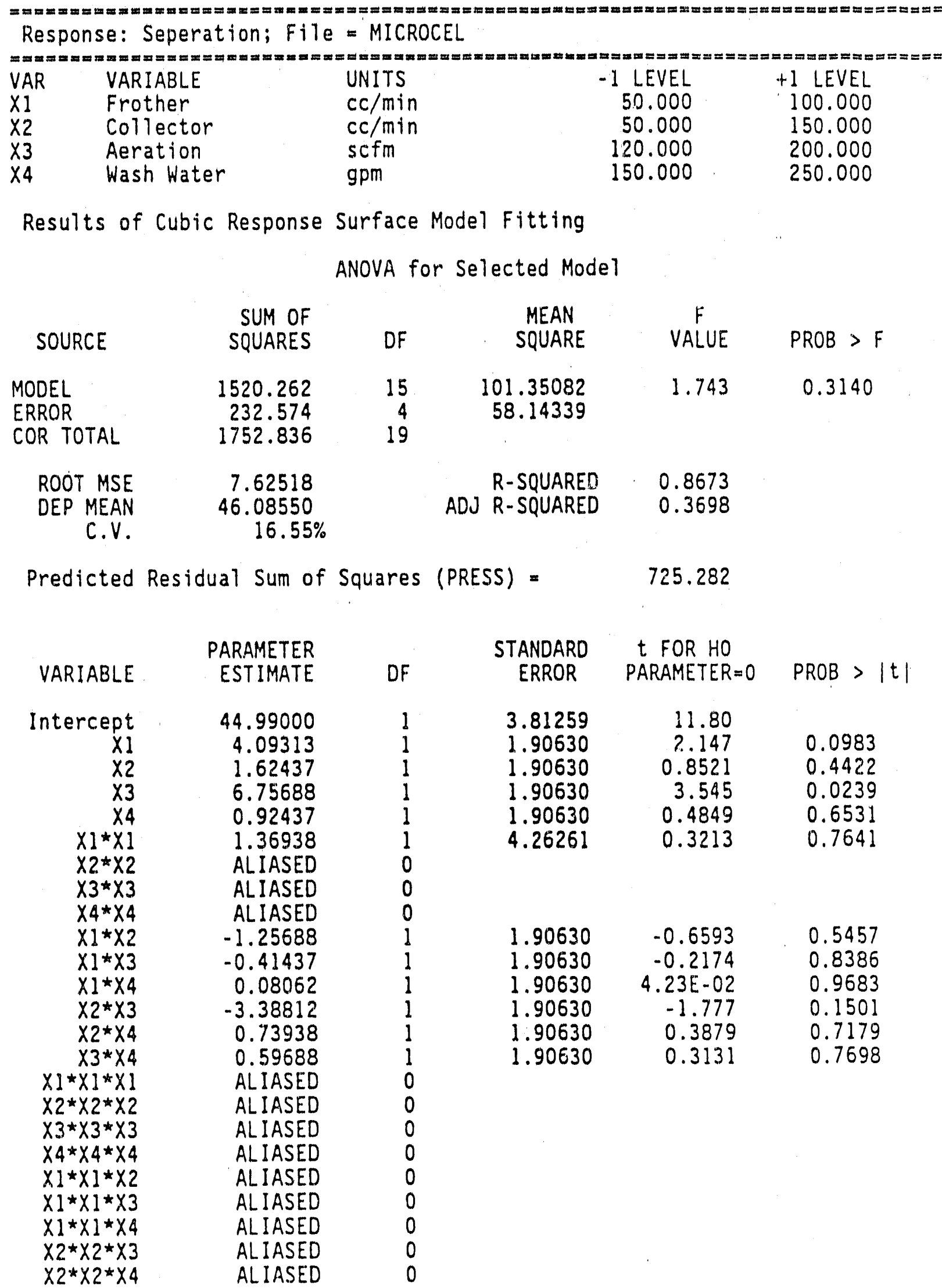




\begin{tabular}{|c|c|c|c|c|c|c|c|c|}
\hline \multicolumn{2}{|c|}{ 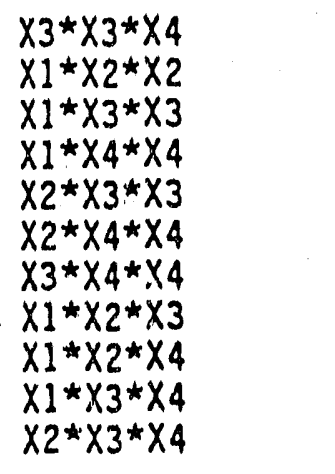 } & $\begin{array}{l}\text { ALIASED } \\
\text { ALIASED } \\
\text { ALIASED } \\
\text { ALIASED } \\
\text { ALIASED } \\
\text { ALIASED } \\
\text { ALIASED } \\
-0.59937 \\
-1.10937 \\
-3.50688 \\
-0.84312\end{array}$ & $\begin{array}{l}0 \\
0 \\
0 \\
0 \\
0 \\
0 \\
0 \\
1 \\
1 \\
1 \\
1\end{array}$ & $\begin{array}{l}90630 \\
90630 \\
90630 \\
90630\end{array}$ & \multicolumn{2}{|c|}{$\begin{array}{r}-0.3144 \\
-0.5820 \\
-1.840 \\
-0.4423\end{array}$} & $\begin{array}{l}0.7689 \\
0.5918 \\
0.1397 \\
0.6811\end{array}$ & \\
\hline Std & ROR & 1.70504 & & & & & & \\
\hline $\begin{array}{l}\text { Obs } \\
\text { Ord }\end{array}$ & $\begin{array}{l}\text { ACTUAL } \\
\text { VALUE }\end{array}$ & $\begin{array}{l}\text { PREDICTED } \\
\text { VALUE }\end{array}$ & RESIDUAL & LEVER & $\begin{array}{l}\text { STUDENT } \\
\text { RESID }\end{array}$ & $\begin{array}{l}\text { COOK'S } \\
\text { DIST' }\end{array}$ & $\stackrel{t}{t}$ & $\begin{array}{l}\text { Run } \\
\text { Ord }\end{array}$ \\
\hline $\begin{array}{r}1 \\
2 \\
3 \\
4 \\
5 \\
6 \\
7 \\
8 \\
9 \\
10 \\
11 \\
12 \\
13 \\
14 \\
15 \\
16 \\
17 \\
18 \\
19 \\
20\end{array}$ & $\begin{array}{l}35.10000 \\
36.59000 \\
41.61000 \\
43.80000 \\
45.68000 \\
60.83000 \\
43.30000 \\
56.57000 \\
23.75000 \\
42.92000 \\
39.92000 \\
53.13000 \\
53.01000 \\
60.00000 \\
55.76000 \\
49.78000 \\
36.76000 \\
49.85000 \\
38.48000 \\
54.87000\end{array}$ & $\begin{array}{l}35.37687 \\
36.31312 \\
41.33312 \\
44.07687 \\
45.40312 \\
61.10687 \\
43.57687 \\
56.29312 \\
23.47312 \\
43.19687 \\
40.19687 \\
52.85312 \\
53.28687 \\
59.72312 \\
55.48312 \\
50.05687 \\
44.99000 \\
44.99000 \\
44.99000 \\
44.99000\end{array}$ & $\begin{array}{r}-0.27687 \\
0.27688 \\
0.27688 \\
-0.27687 \\
0.27688 \\
-0.27687 \\
-0.27687 \\
0.27688 \\
0.27688 \\
-0.27687 \\
-0.27687 \\
0.27688 \\
-0.27687 \\
0.27688 \\
0.27688 \\
-0.27687 \\
-8.23000 \\
4.86000 \\
-6.51000 \\
9.88000\end{array}$ & $\begin{array}{l}0.937 \\
0.937 \\
0.937 \\
0.937 \\
0.937 \\
0.937 \\
0.937 \\
0.937 \\
0.937 \\
0.937 \\
0.937 \\
0.937 \\
0.937 \\
0.937 \\
0.937 \\
0.937 \\
0.250 \\
0.250 \\
0.250 \\
0.250\end{array}$ & $\begin{array}{r}-0.145 \\
0.145 \\
0.145 \\
-0.145 \\
0.145 \\
-0.145 \\
-0.145 \\
0.145 \\
0.145 \\
-0.145 \\
-0.145 \\
0.145 \\
-0.145 \\
0.145 \\
0.145 \\
-0.145 \\
-1.246 \\
0.736 \\
-0.986 \\
1.496\end{array}$ & $\begin{array}{l}0.020 \\
0.020 \\
0.020 \\
0.020 \\
0.020 \\
0.020 \\
0.020 \\
0.020 \\
0.020 \\
0.020 \\
0.020 \\
0.020 \\
0.020 \\
0.020 \\
0.020 \\
0.020 \\
0.032 \\
0.011 \\
0.020 \\
0.047\end{array}$ & $\begin{array}{r}-0.290 \\
0.290 \\
0.290 \\
-0.290 \\
0.290 \\
-0.290 \\
-0.290 \\
0.290 \\
0.290 \\
-0.290 \\
-0.290 \\
0.290 \\
-0.290 \\
0.290 \\
0.290 \\
-0.290 \\
-1.949 \\
1.369 \\
-1.715 \\
1.986\end{array}$ & $\begin{array}{r}20 \\
5 \\
18 \\
19 \\
9 \\
16 \\
6 \\
7 \\
1 \\
17 \\
14 \\
10 \\
8 \\
15 \\
12 \\
3 \\
2 \\
13 \\
4 \\
11\end{array}$ \\
\hline
\end{tabular}


Appendix 10: $\quad$ Predicted response surfaces for product ash percent (Figs. A), product yield (Figs. B), and separation efficiency (Figs. C) 
Model:

Cubic

Response:

Product Ash

Variables:

$X=$ Frother

$Y=$ Aeration

Constants:

Collector $=50.00$

Wash Water = 150.0
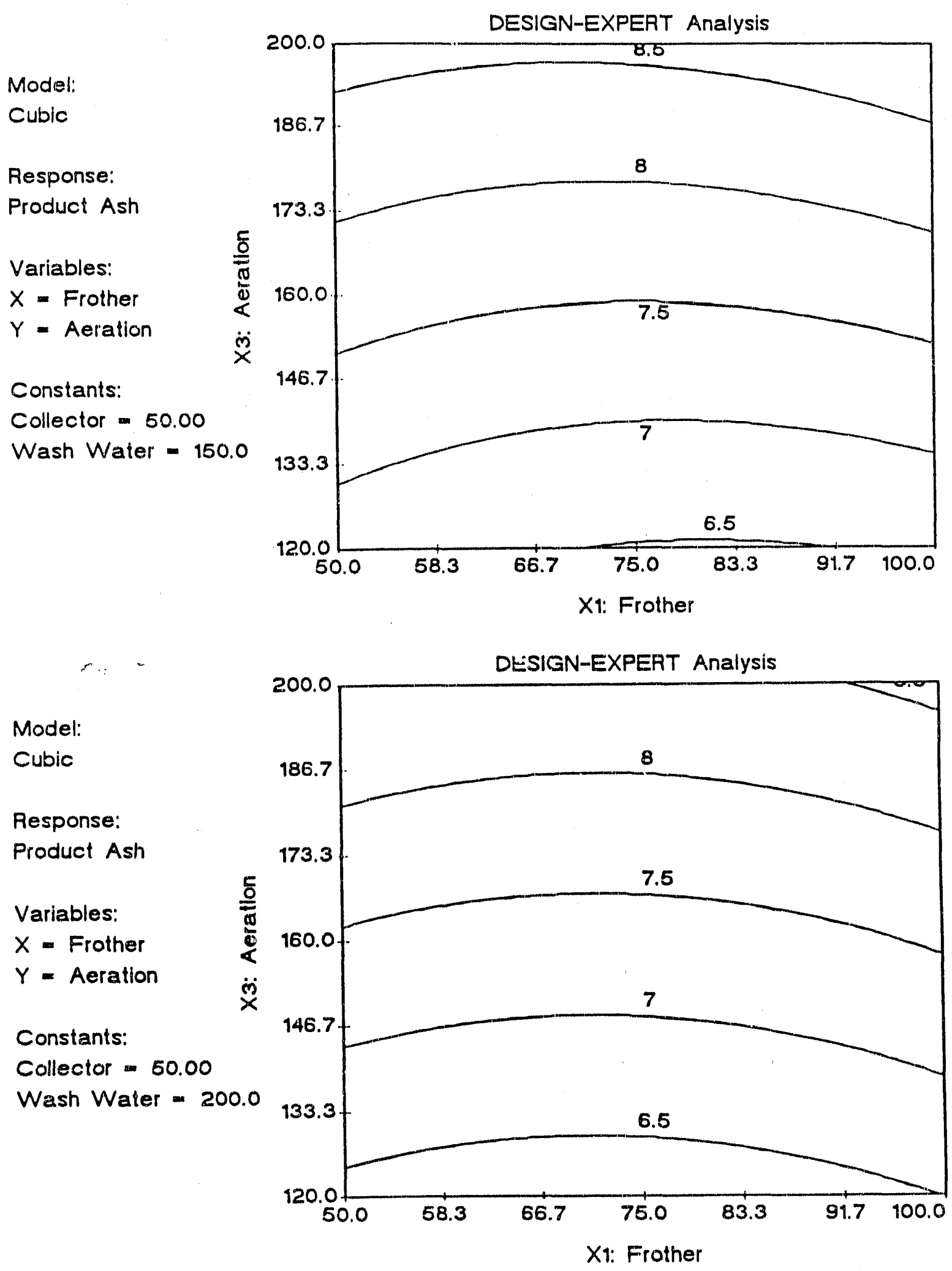

Figure A: Predicted response surfaces for product ash percent for various column operating conditions (continued). 
Model:

Cuble

Response:

Product Ash

Variables:

$X$ = Frother

$Y=$ Aeration

Coristants:

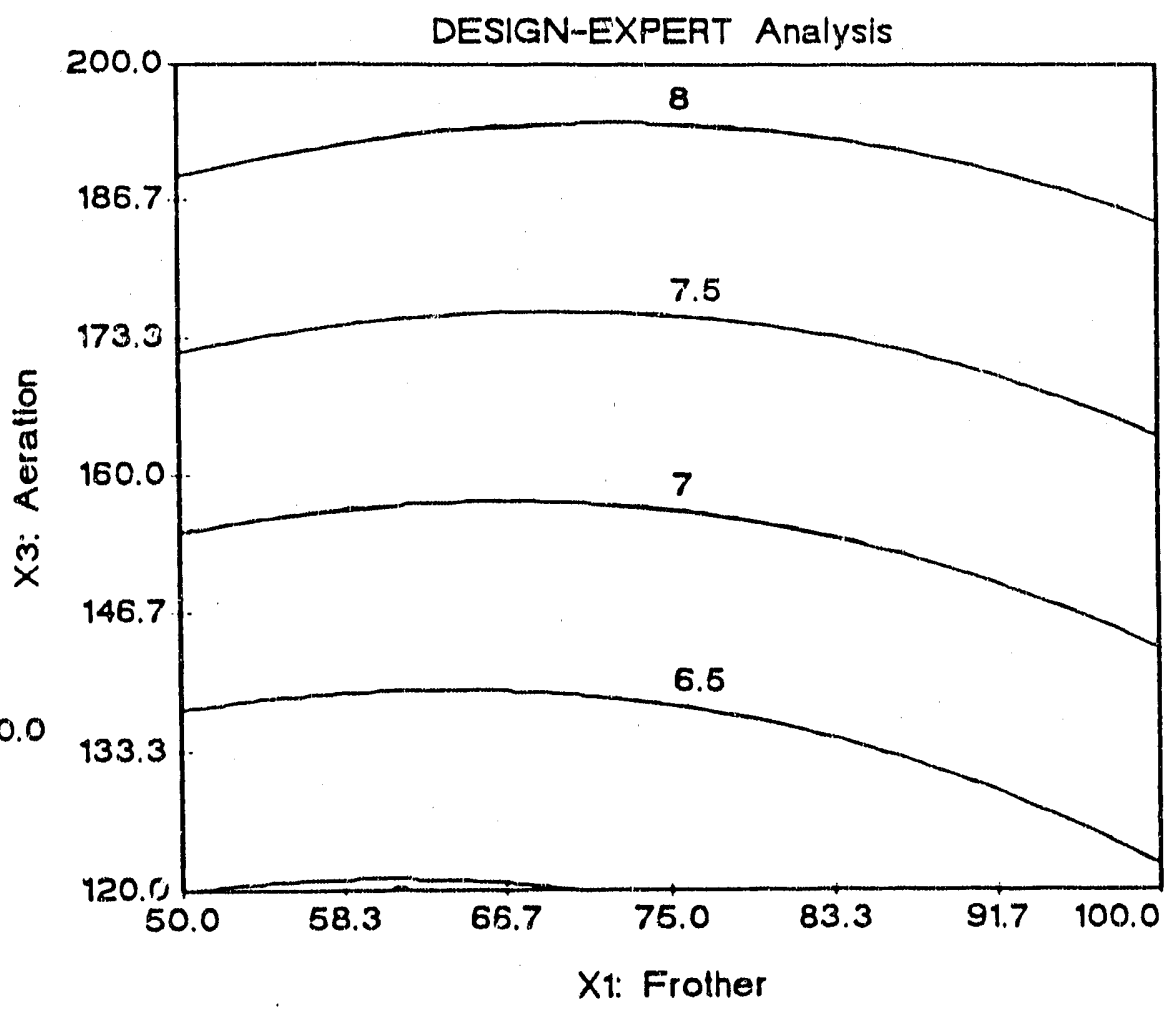

Model:

Cubic

Responise:

Product Ash

Variables:

$X$ - Frother

$Y=$ Aeration

Constants:

Collector - 100.0

Wash Water = 150.0

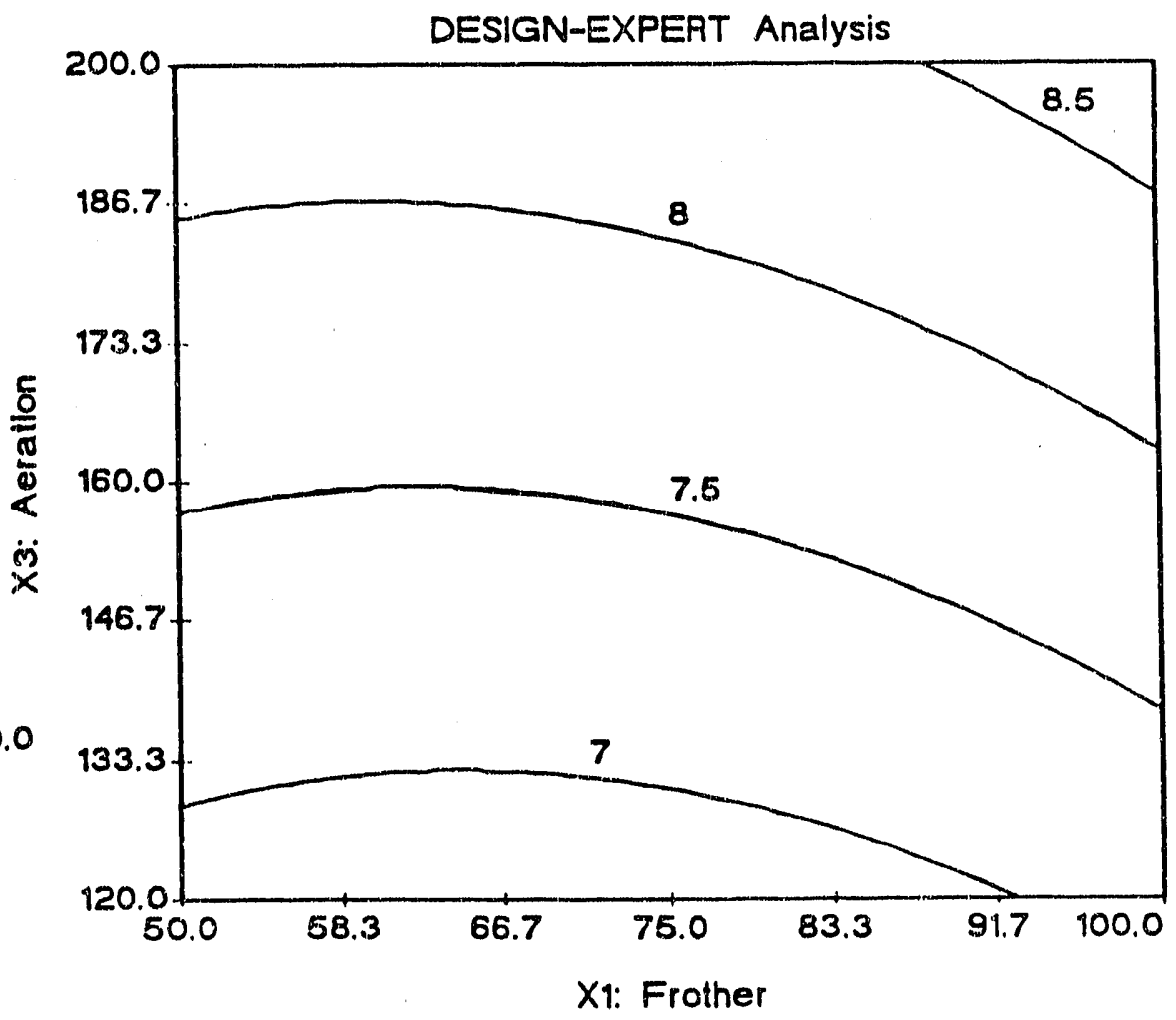

Figure A: Predicted response surfaces for product ash percent for various column operating conditions (continued). 

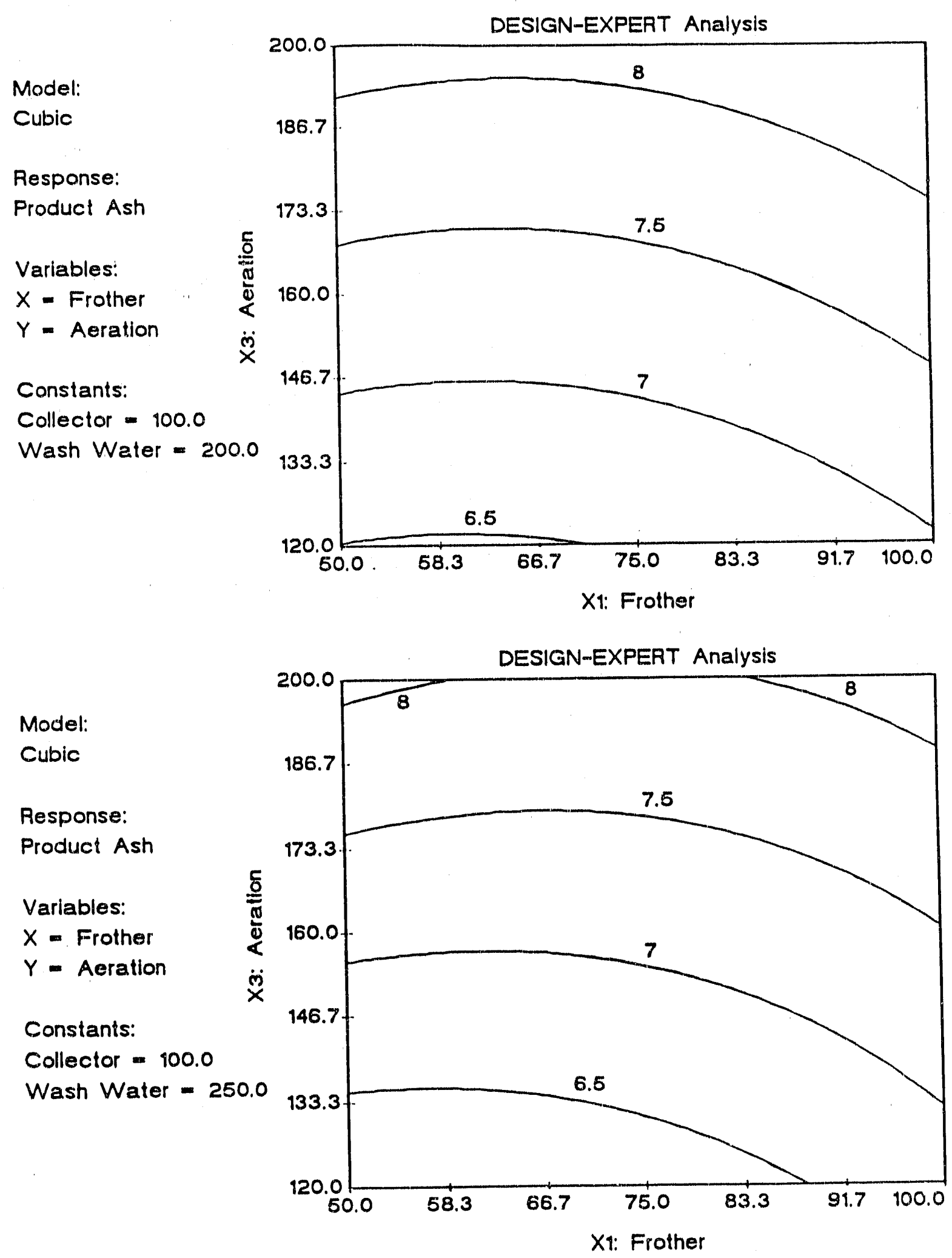

Figure A: Predicted response surfaces for product ash percent for various column operating conditions (continued). 

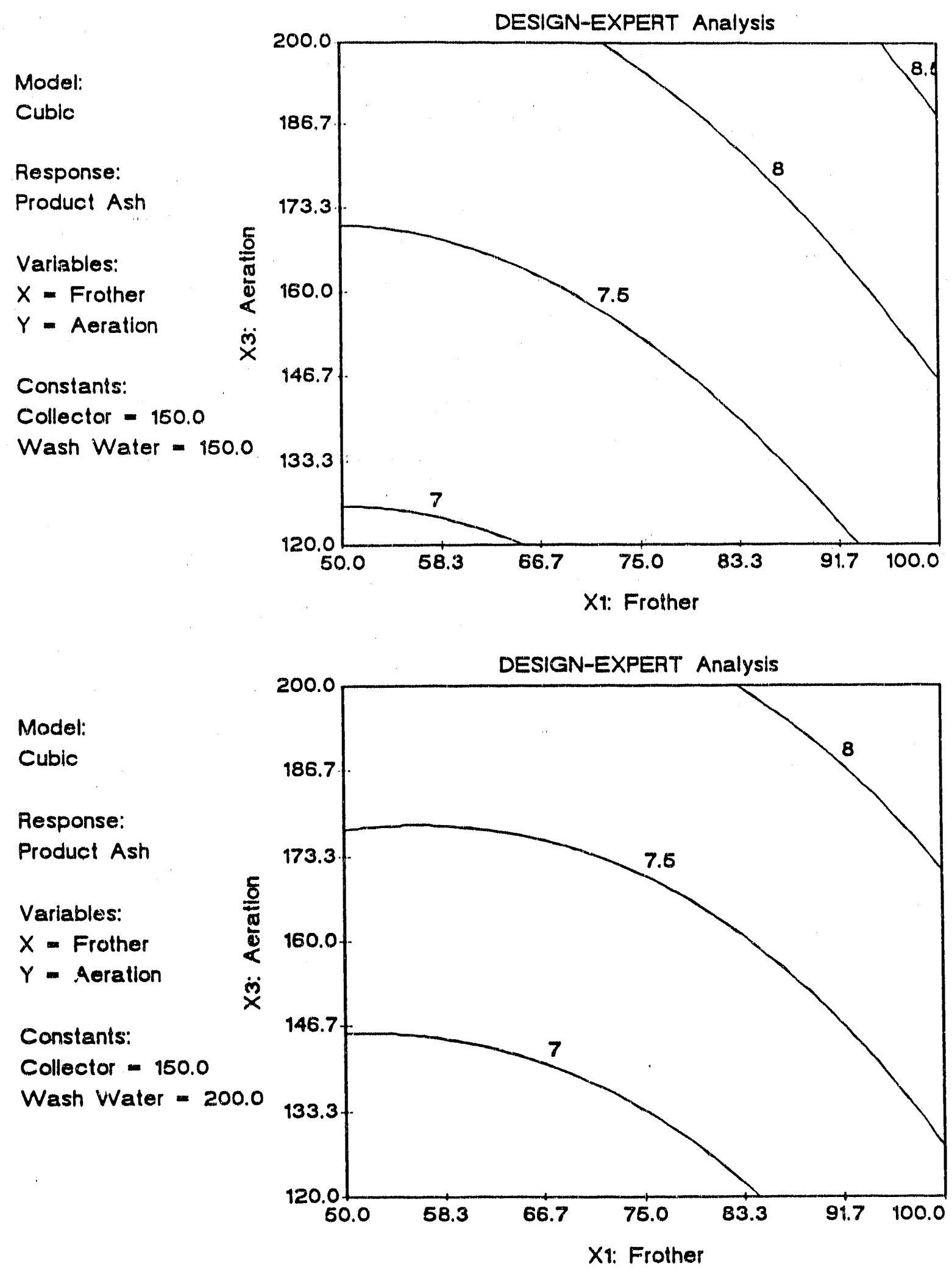

Figure A: Predicted response surfaces for product ash percent for various column operating conditions (continued). 


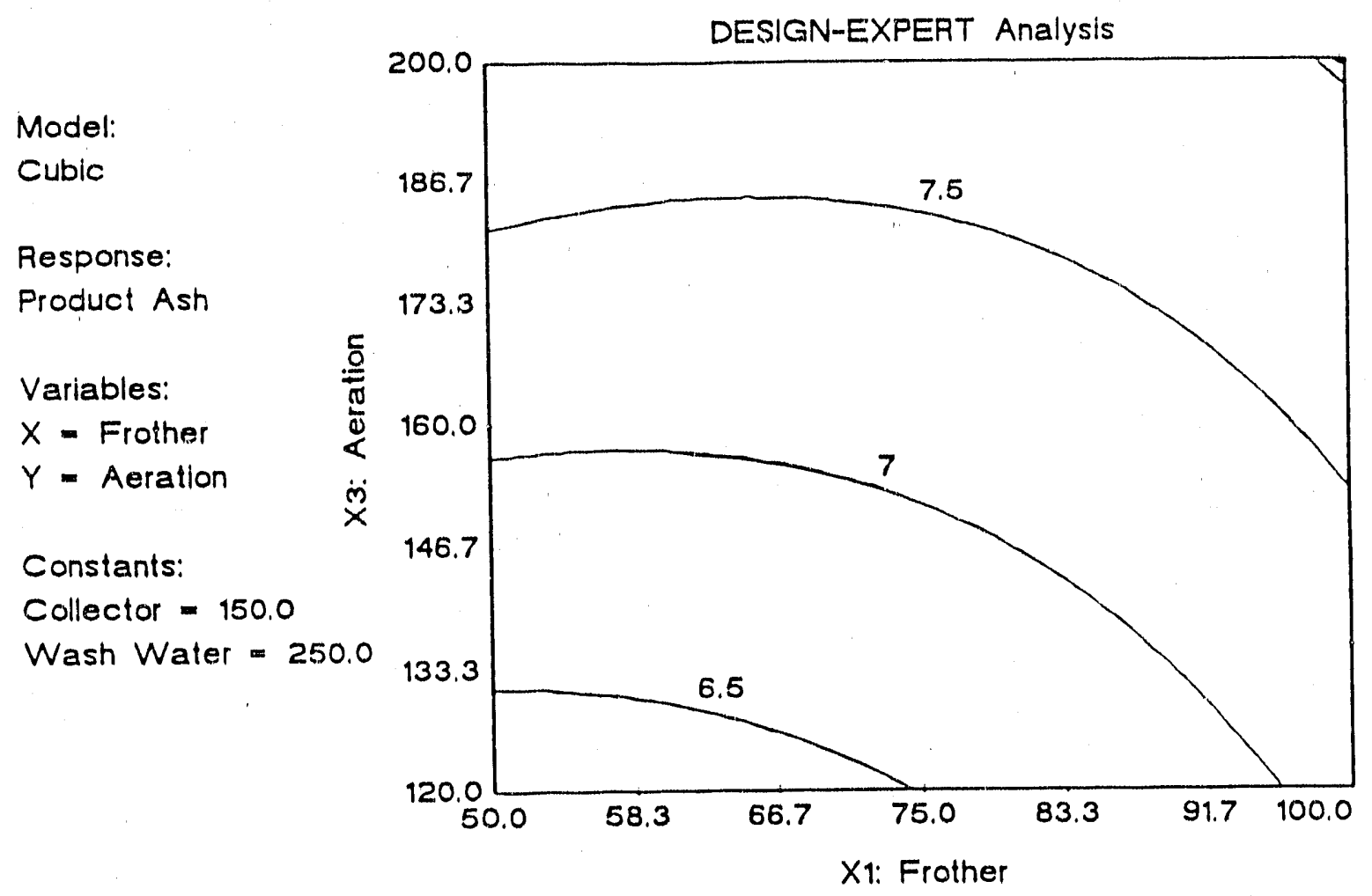

Figure A: $\quad$ Predicted response surfaces for product ash percent for various column operating conditions. 
Model:

Cuble

Response:

Yleld

Variables:

$X$ - Frother

$Y$ - Aeration

Constants:

Collector $=50.00$

Wash Water = 150.0

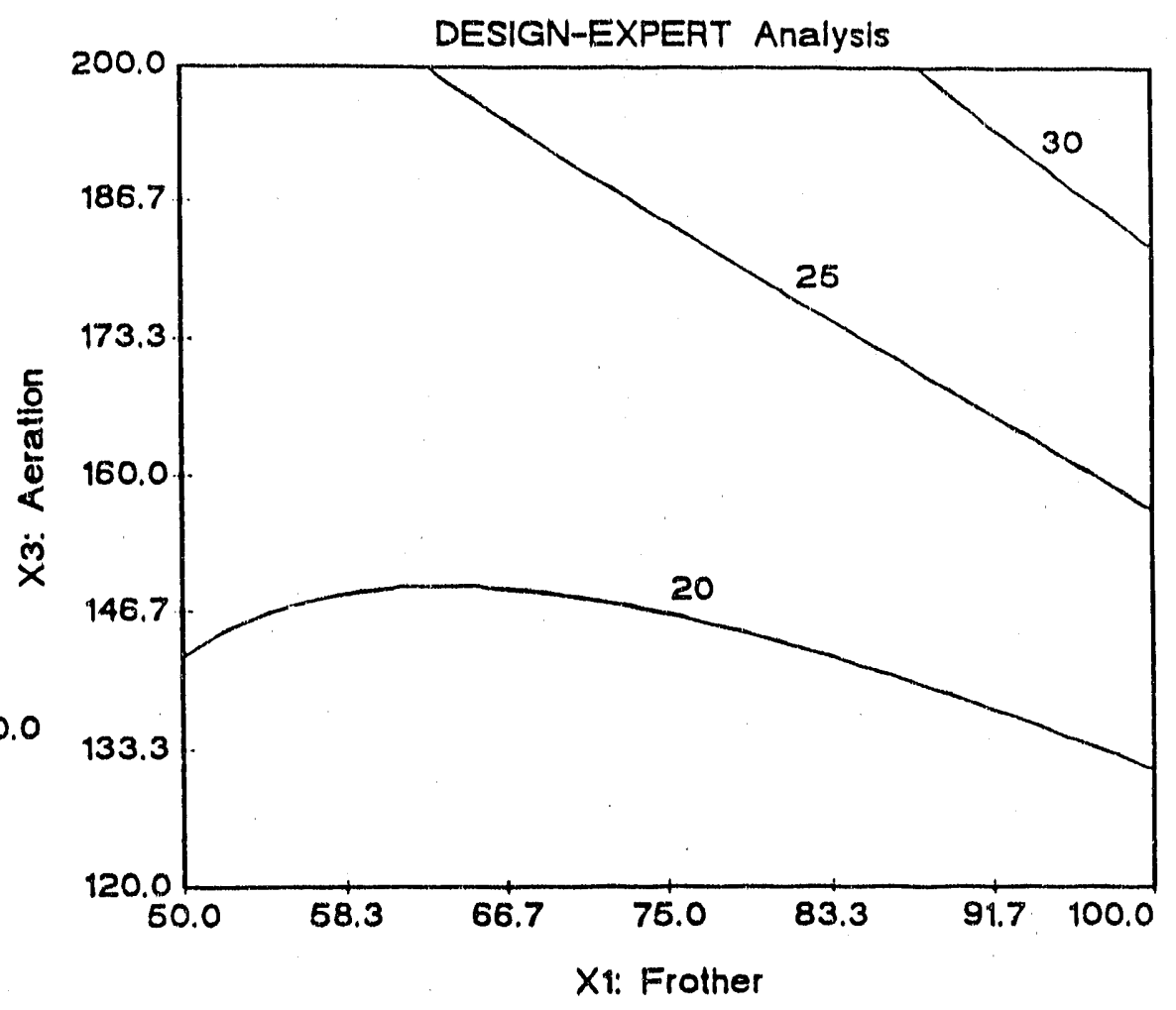

Model:

Cubic

Response:

Yield

Variables:

$X=$ Frother

$Y=$ Aeration

Constants:

Collector -50.00

Wash Water = 200.0

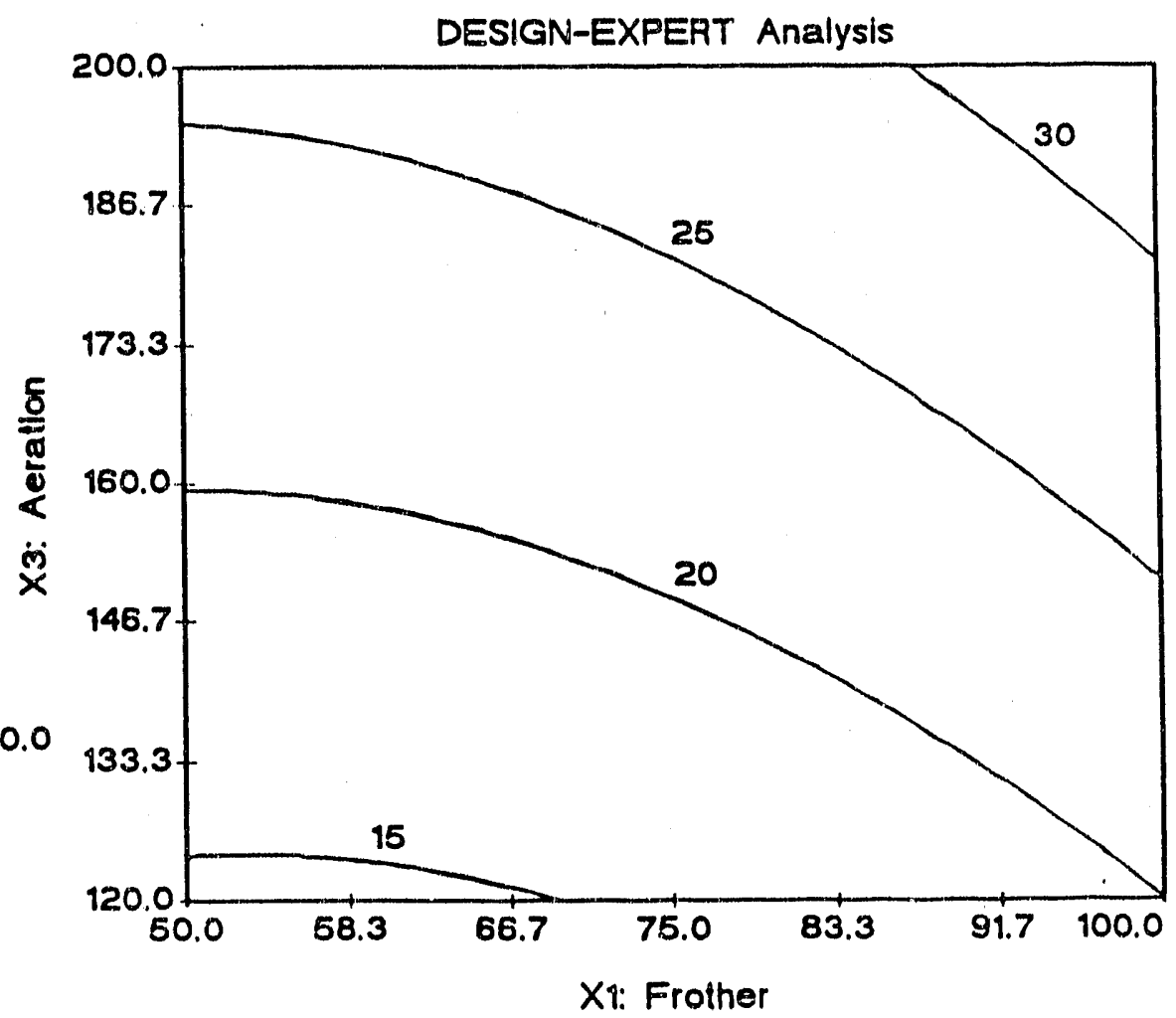

Figure B: Predicted response surfaces for product yield for various column operating conditions (continued). 
Model:

Cubic

Response:

Yleld

Variables:

$X$ - Frother

$Y=$ Aeration

Constants:

Collector $=50.00$

Wash Water $=250.0$
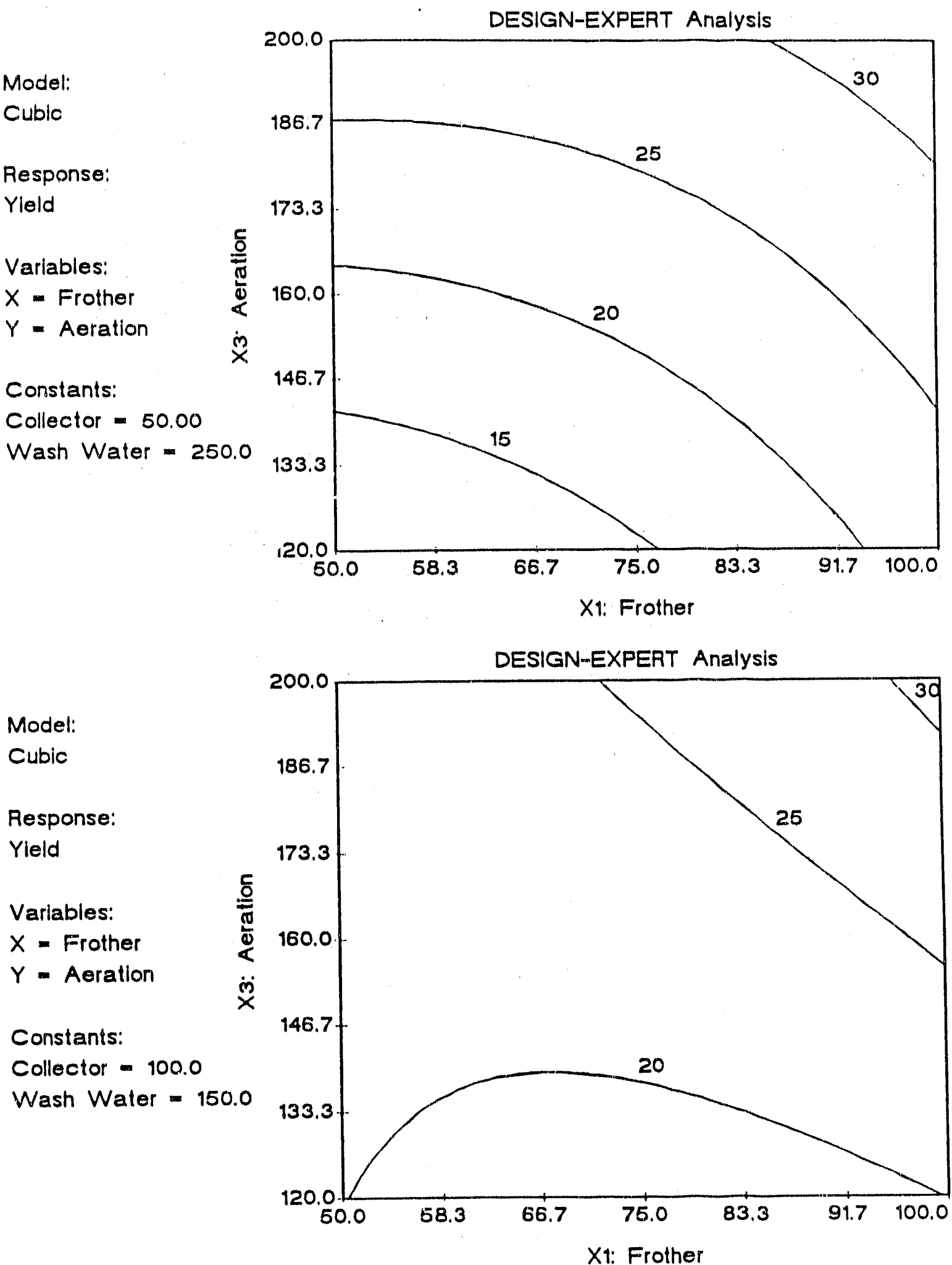

Figure B: Predicted response surfaces for product yield for various column operating conditions (continued). 

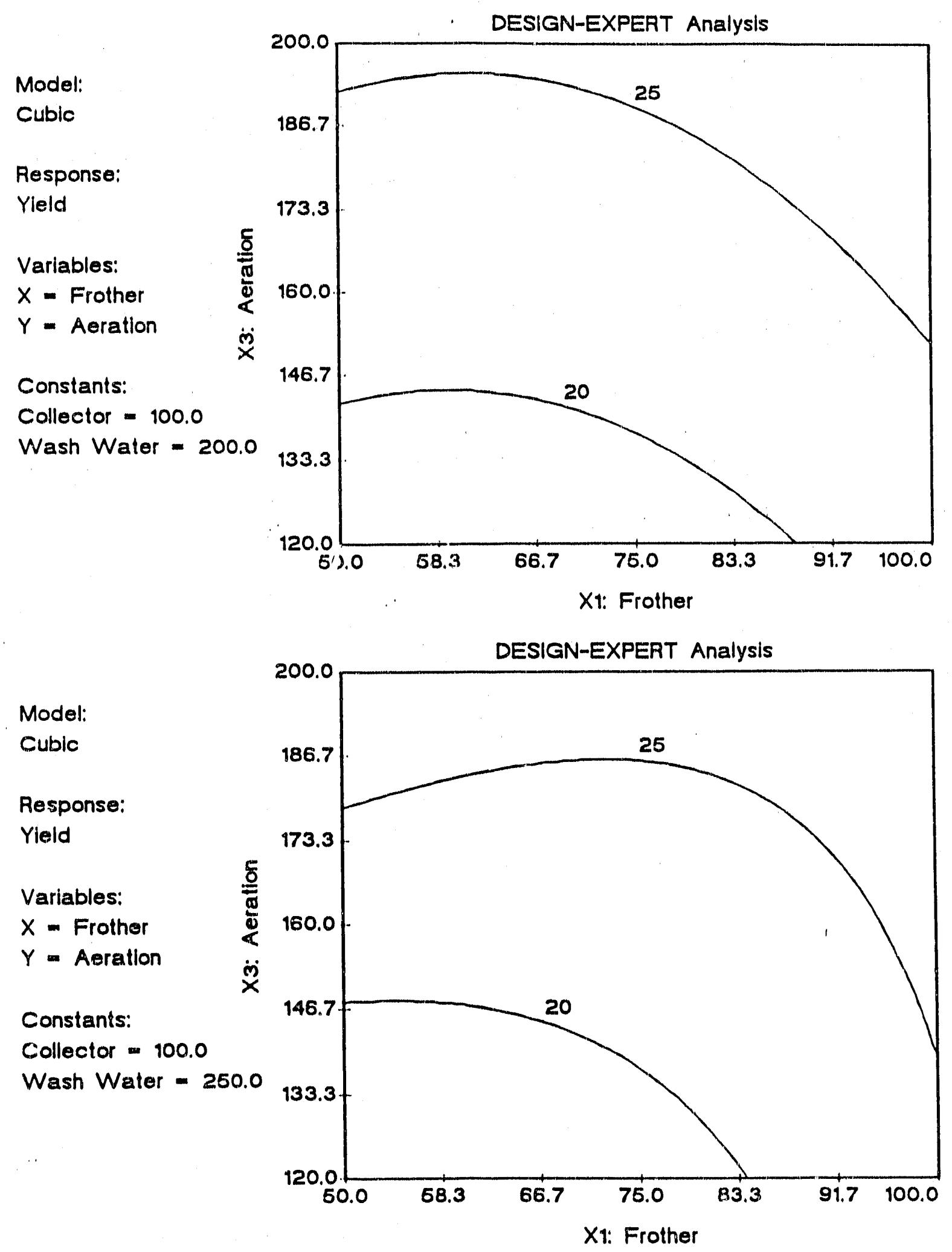

Figure B: Predicted response surfaces for product yield for various column operating conditions (continued). 

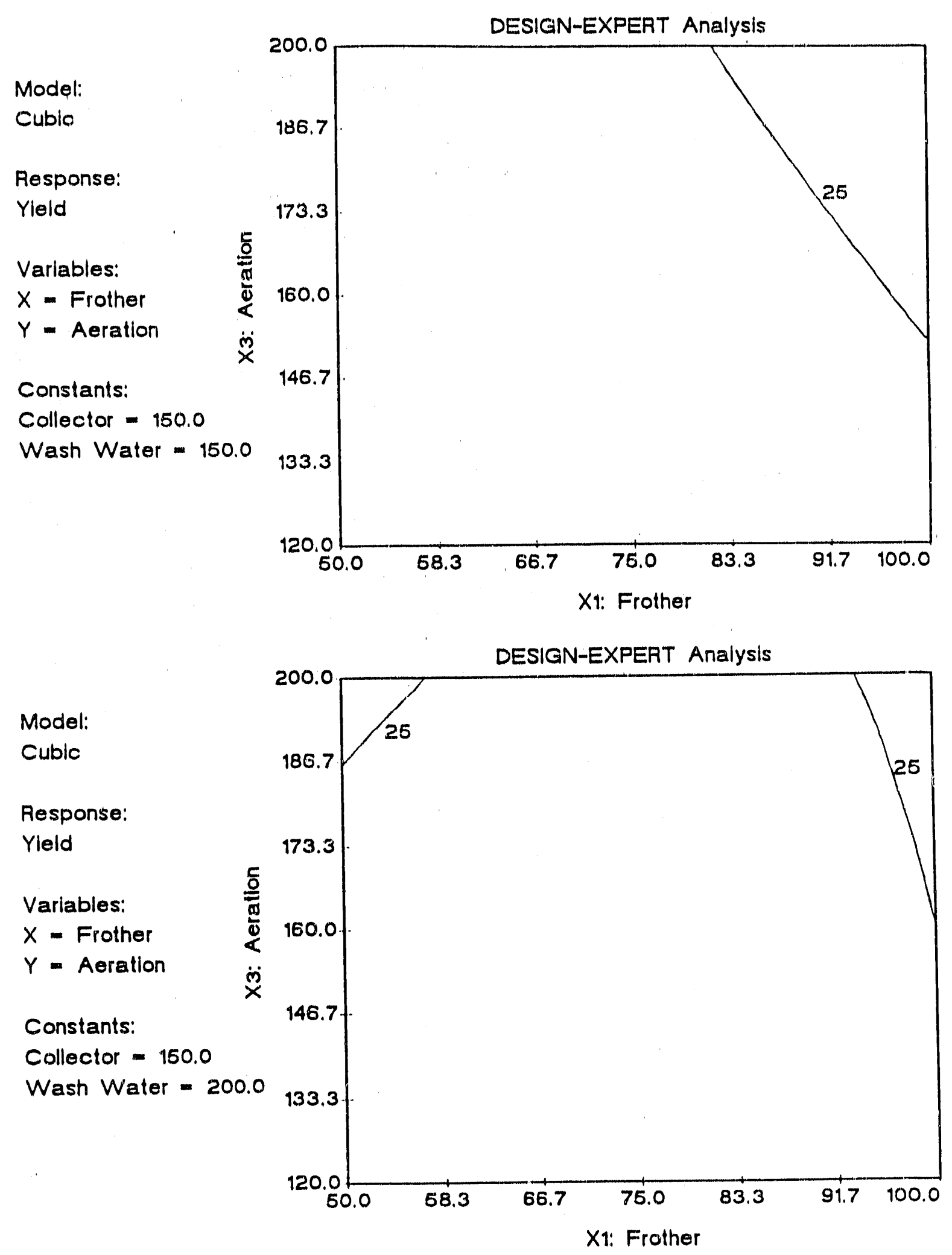

Figure B: $\quad$ Predicted response surfaces for product yield for various column operating conditions (continued). 


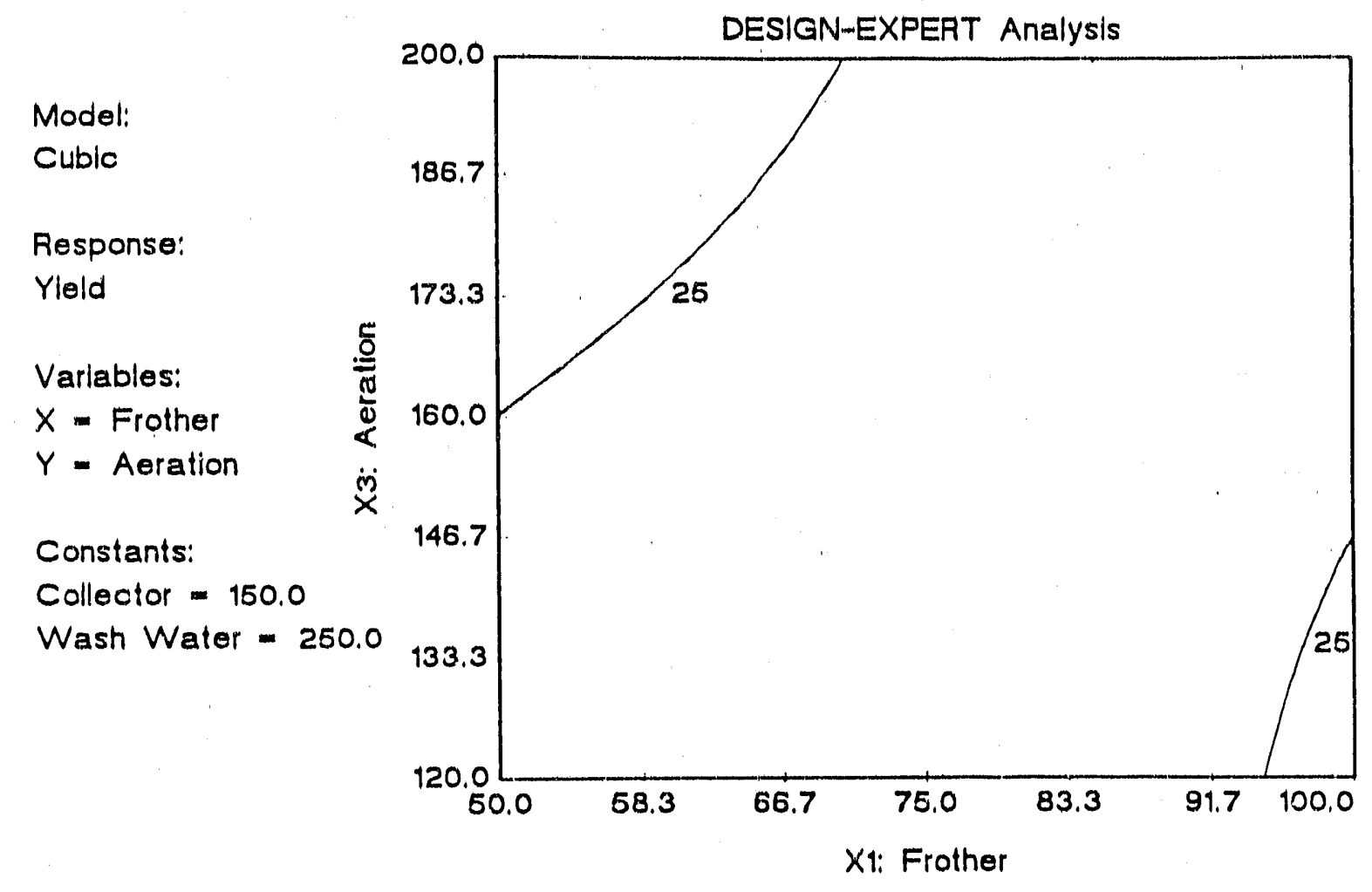

Figure B: Predicted response surfaces for product yield for various column operating conditions. 

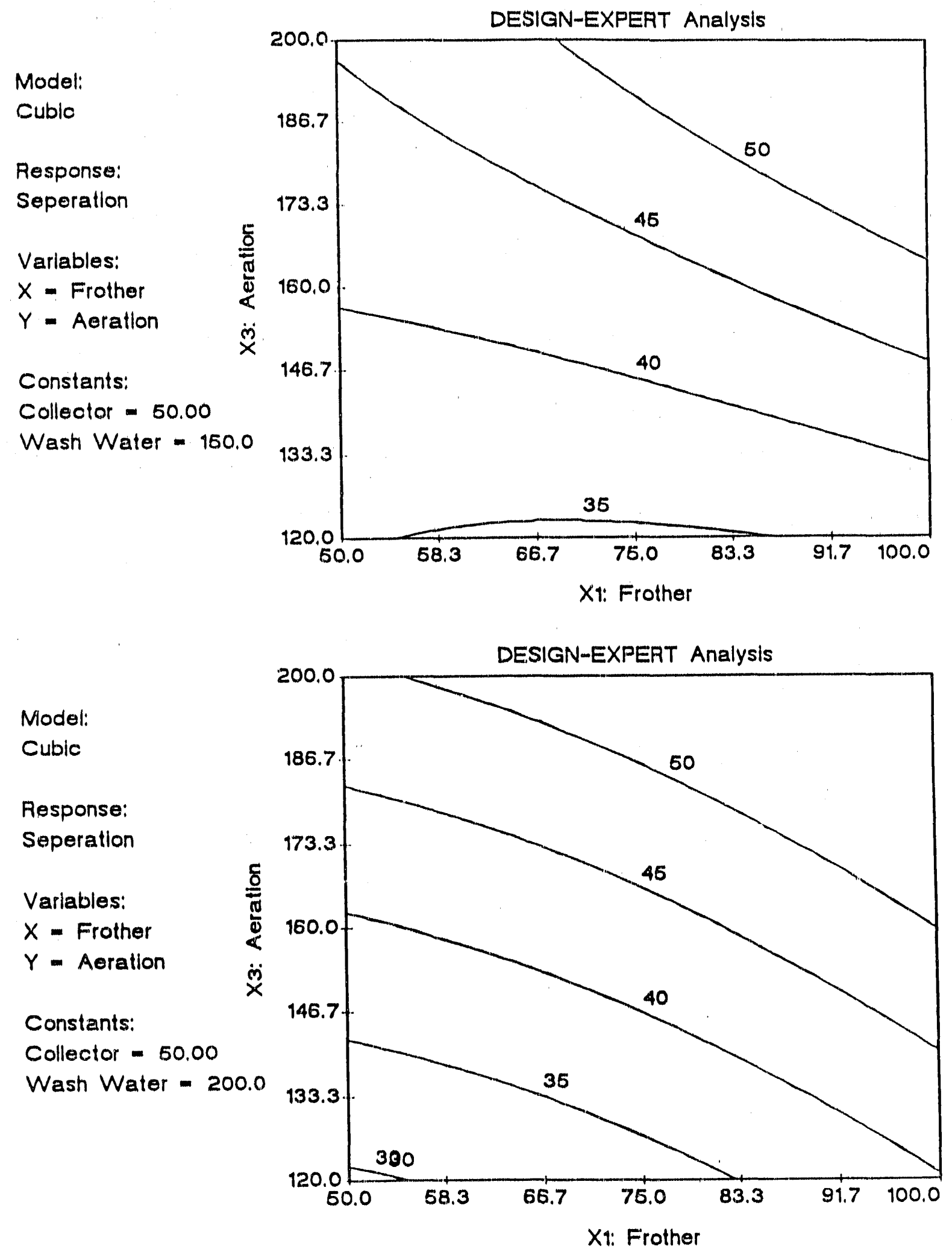

Figure C: $\quad$ Predicted response surfaces for separation efficiency for various column operating conditions (continued). 

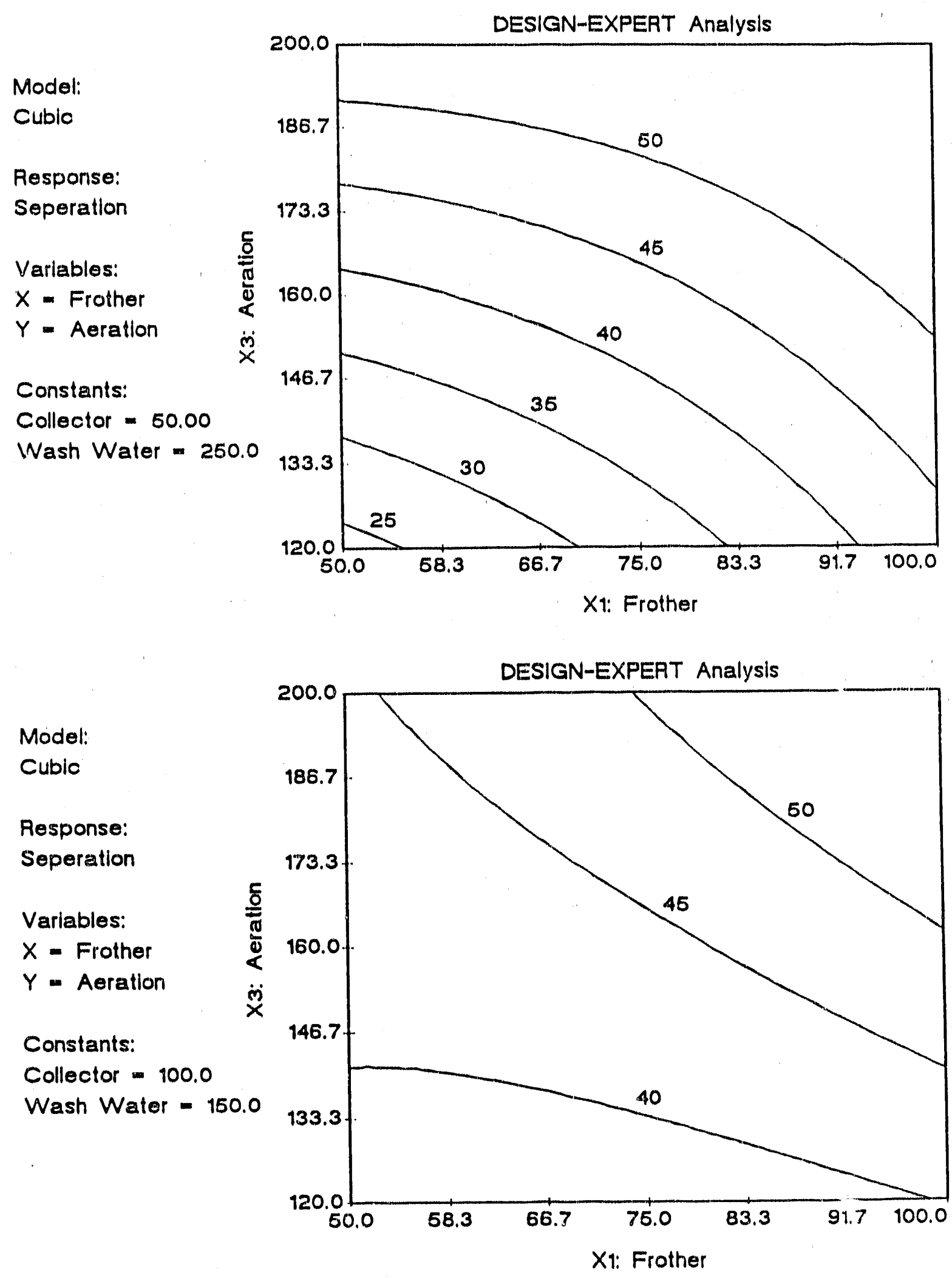

Figure C: Predicted response surfaces for separation efficiency for various column operating conditions (continued). 
Model:

Cuble

Fiesponse:

Seperation

Varlables:

$X$ - Frother

$Y=$ Aerallon

Constants:

Collector $=100.0$

Wash Water = 200.0

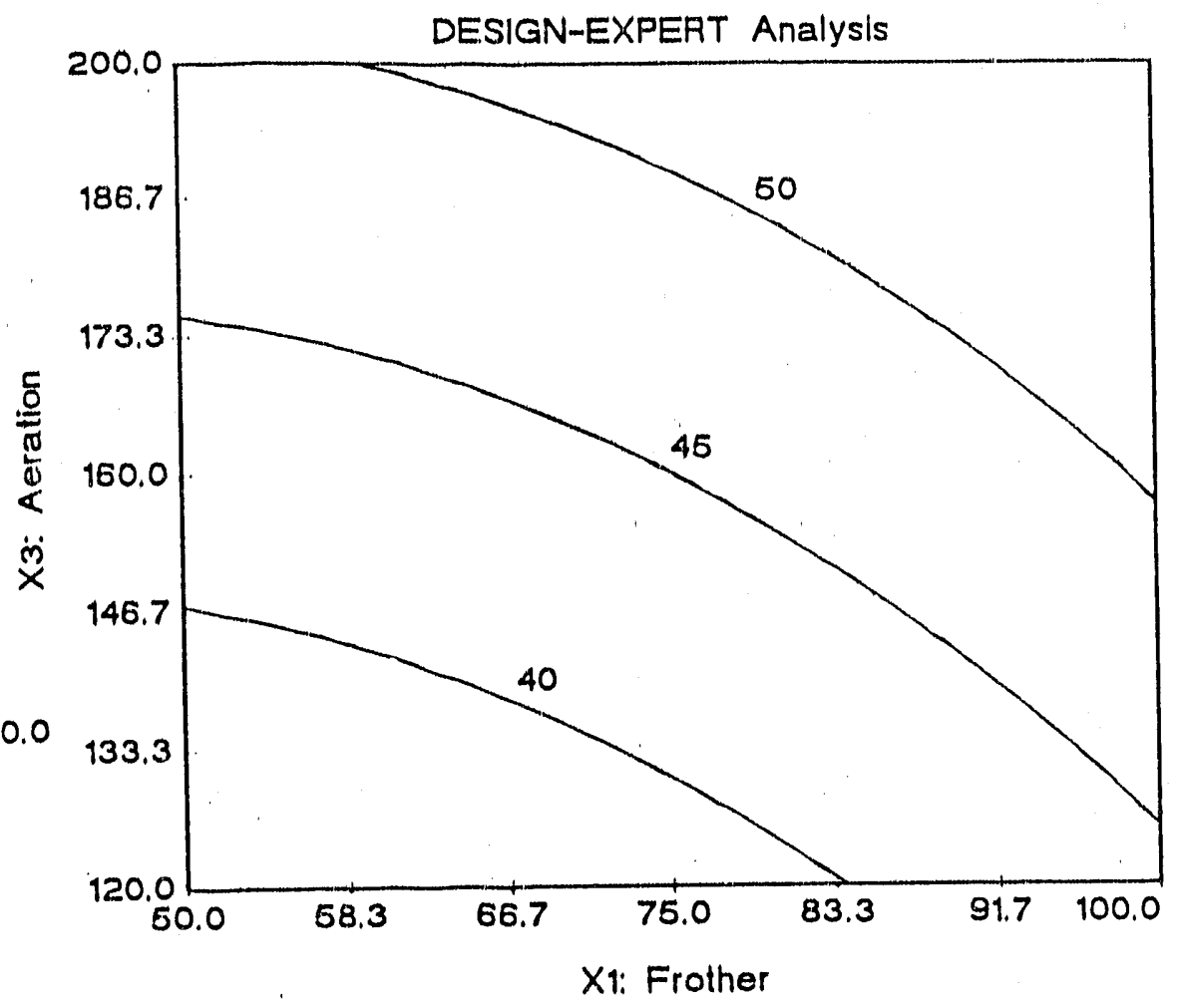

Model:

Cuble

Response:

Seperation

Variables:

$X$ - Frother

$Y=$ Aeration

Constants:

Collector - 100.0

Wash Waier 250.0

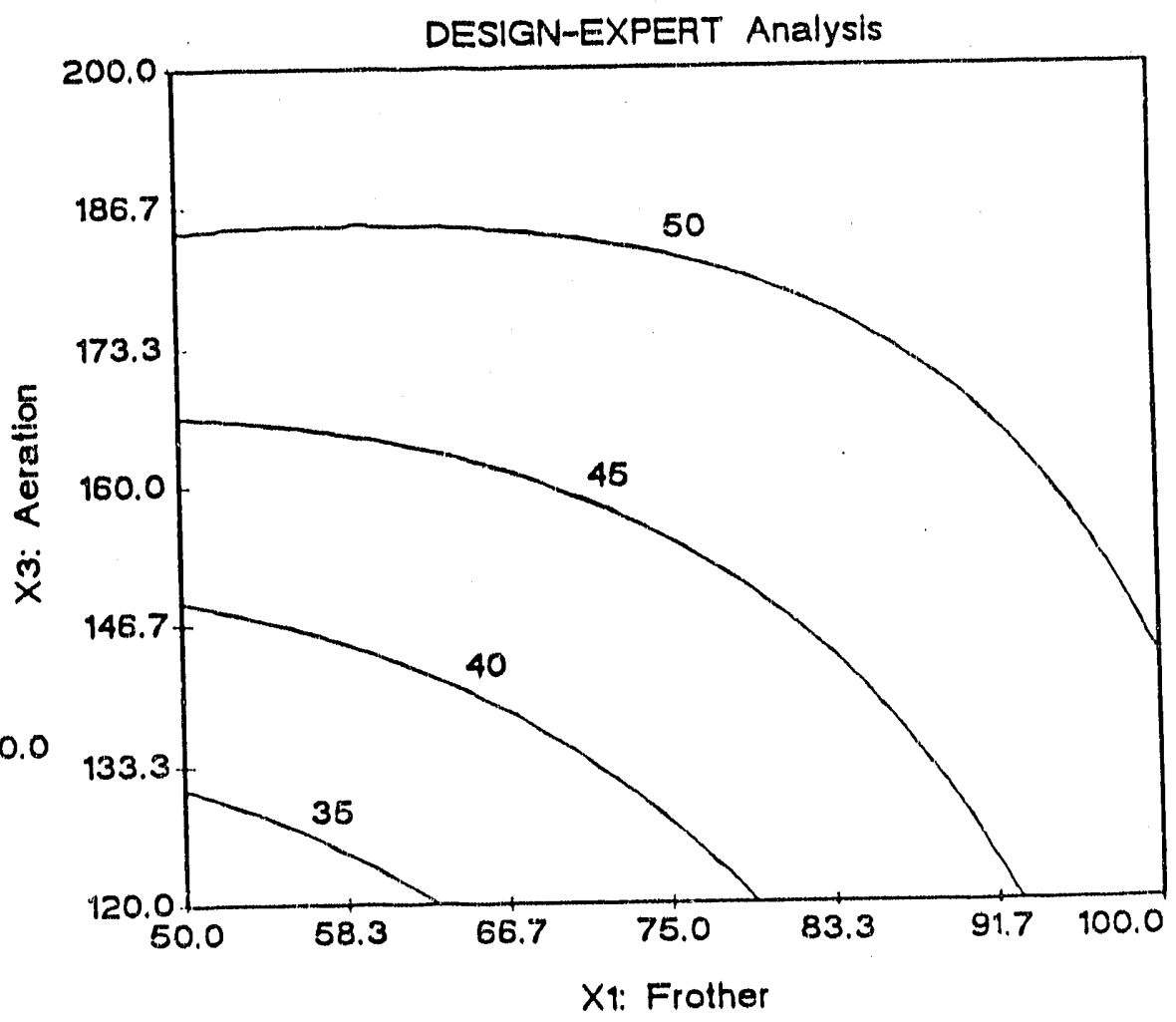

Figure $C_{\text {: }} \quad$ Predicted response surfaces for separation efficiency for various column operating conditions (continued). 
Model:

Cubic

Fesponse:

Seperation

Variables:

$X$ - Frother

$Y=$ Aeration

Constants:

Collector - 150.0

Wash Water = 150.0

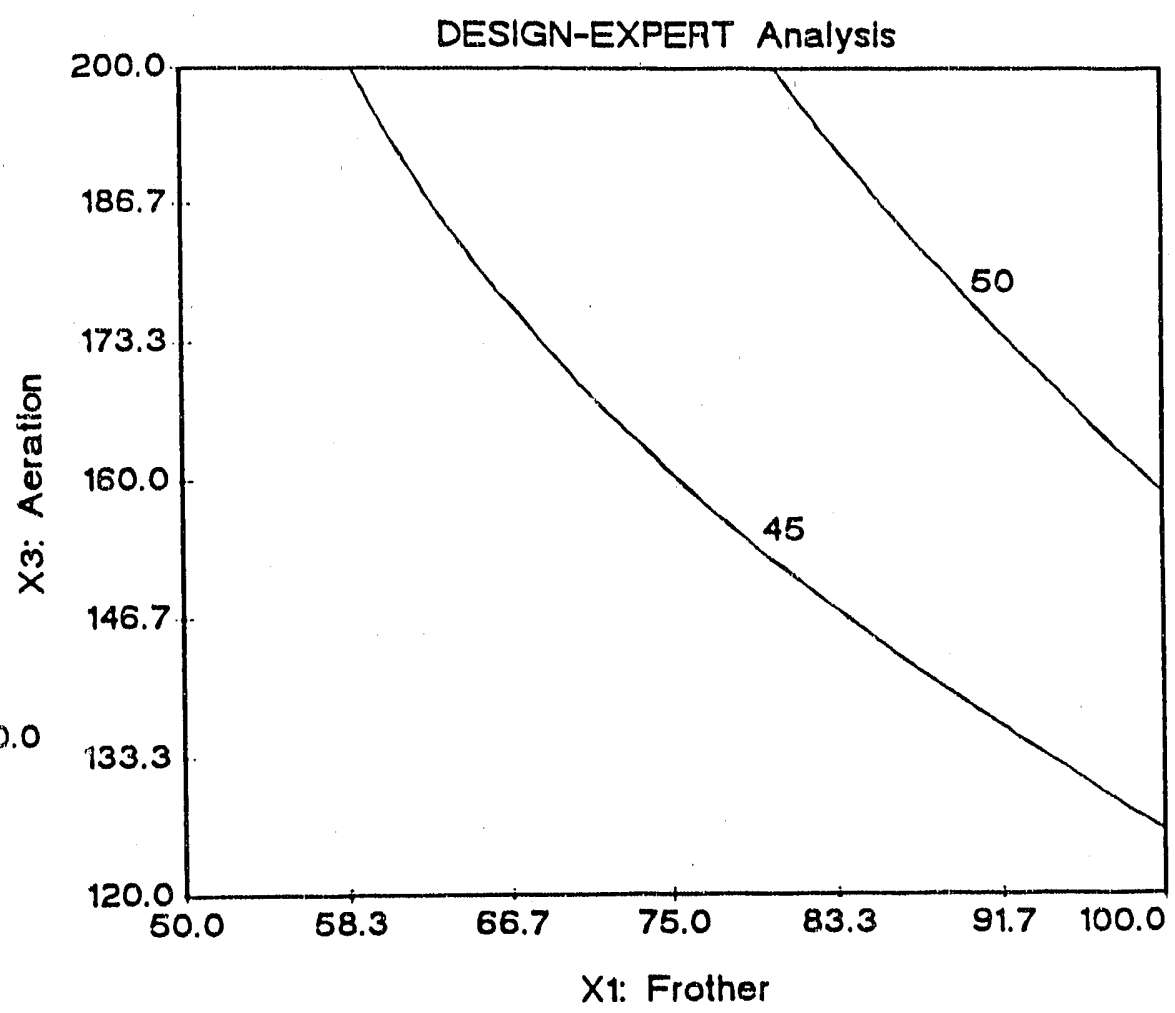

Model:

Cubic

Response:

Seperation

Variables:

$X$ = Frother

$Y=$ Aeration

Constanis:

Collector = 150.0

Wash Water - 200.0

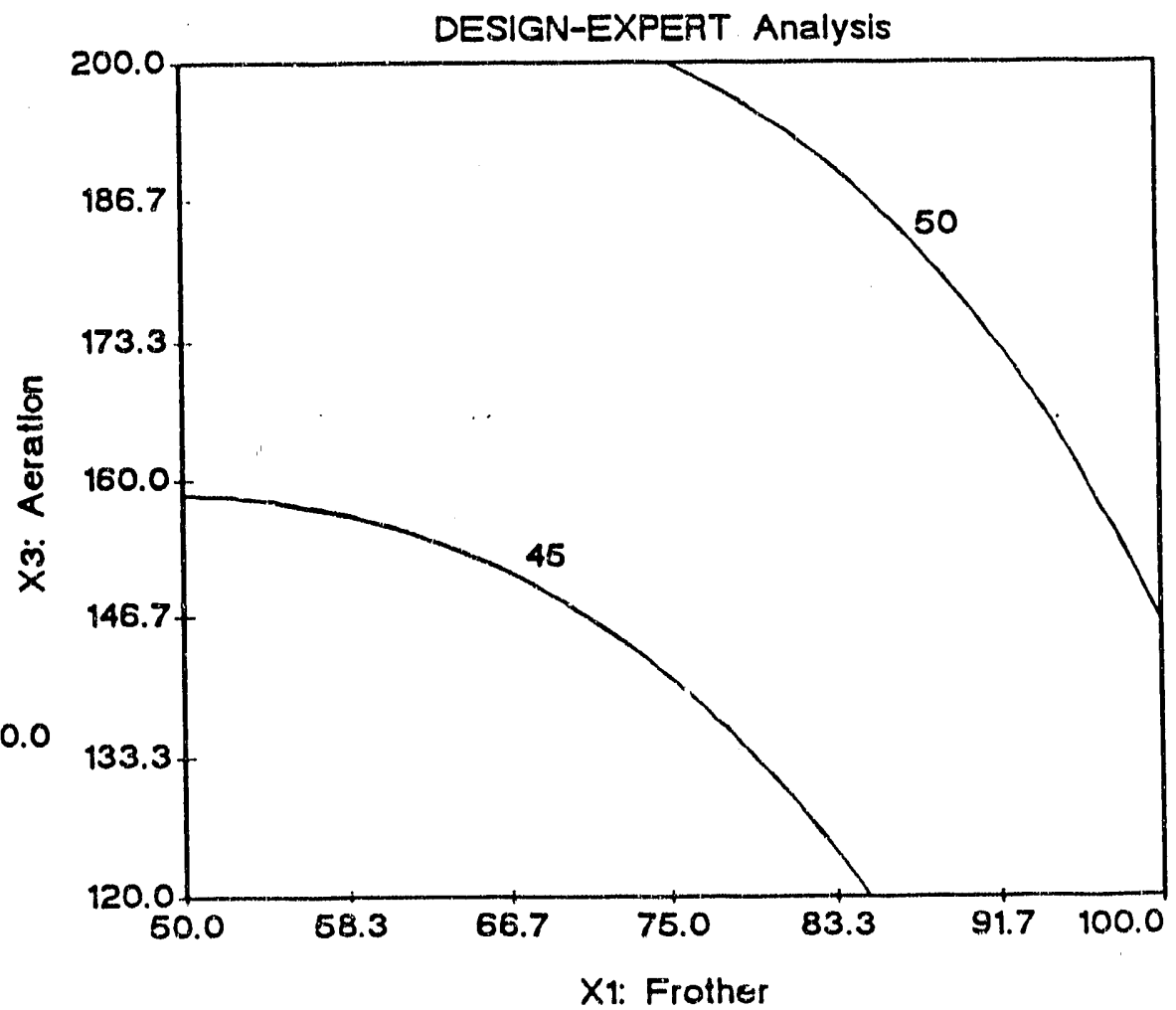

Figure C: Predicted response surfaces for separation efficiency for various column operating conditions (continued). 


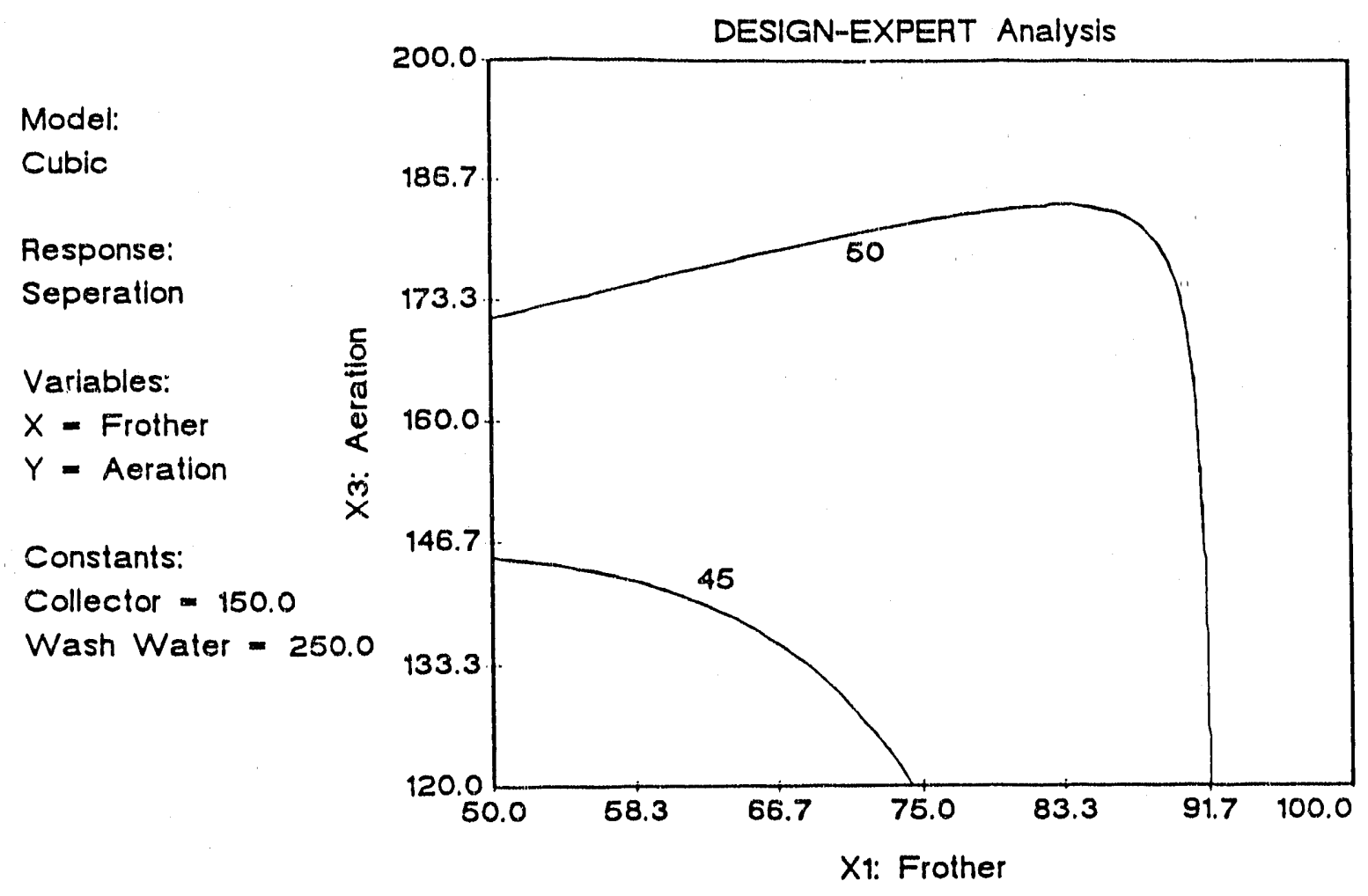

Figure C: Predicted response surfaces for separation efficiency for various column operating conditions. 
Appendix 11: Cash flow analyses 


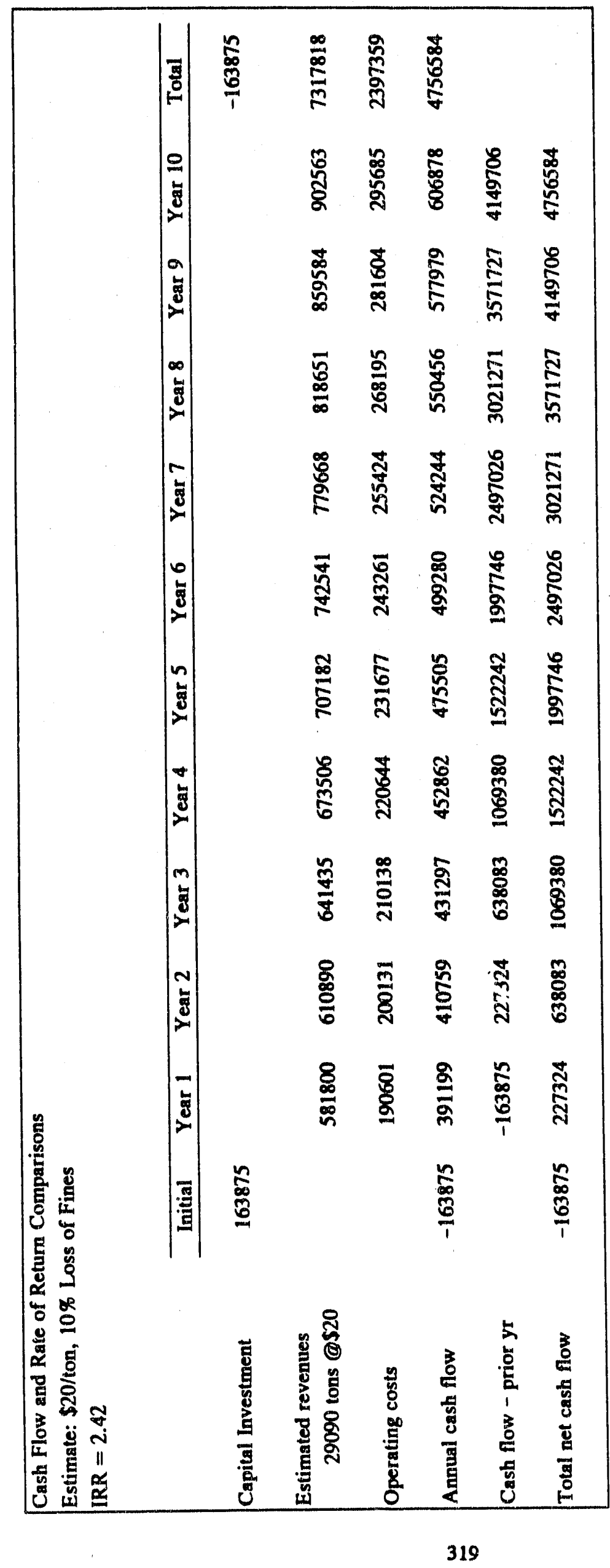




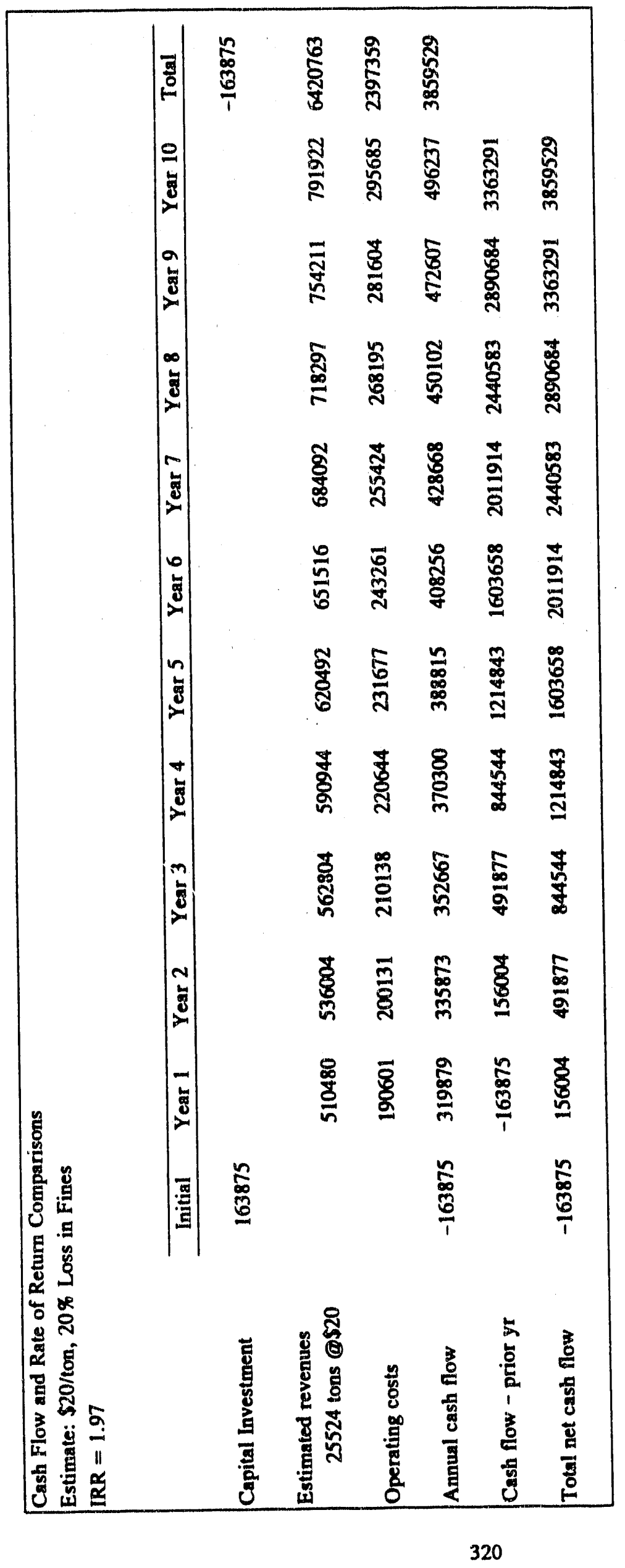




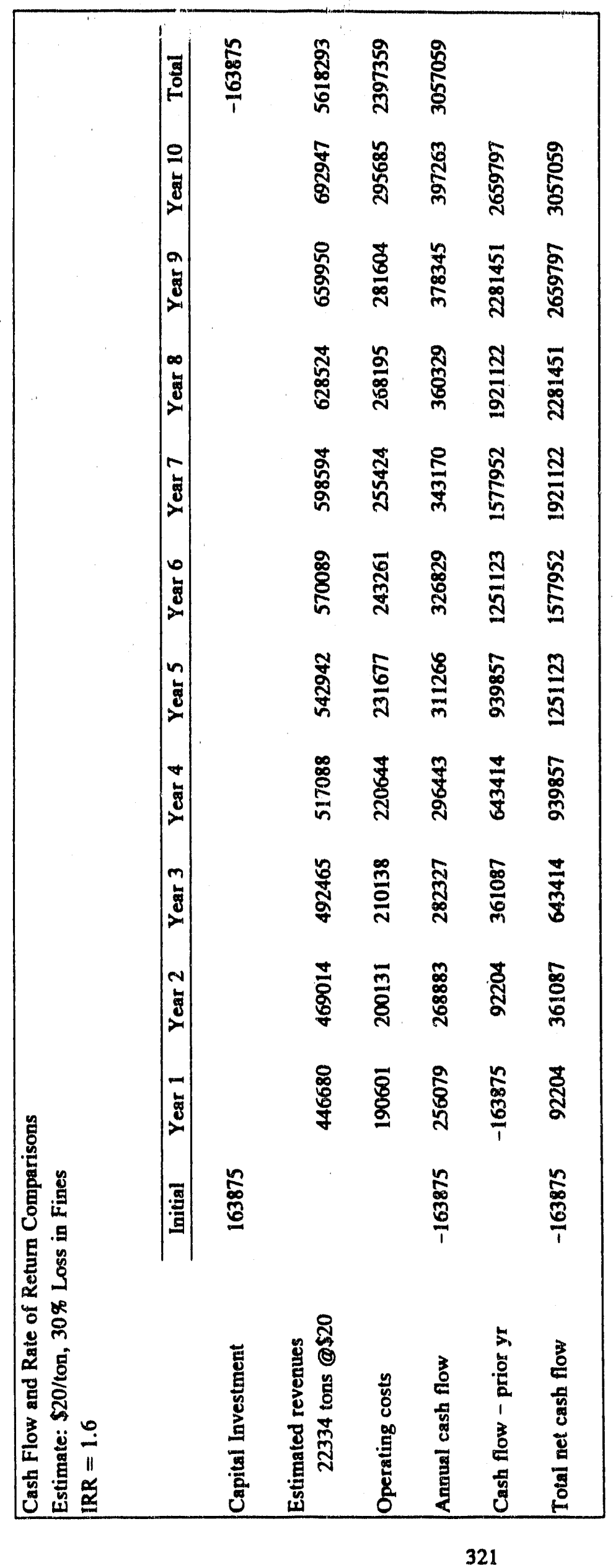




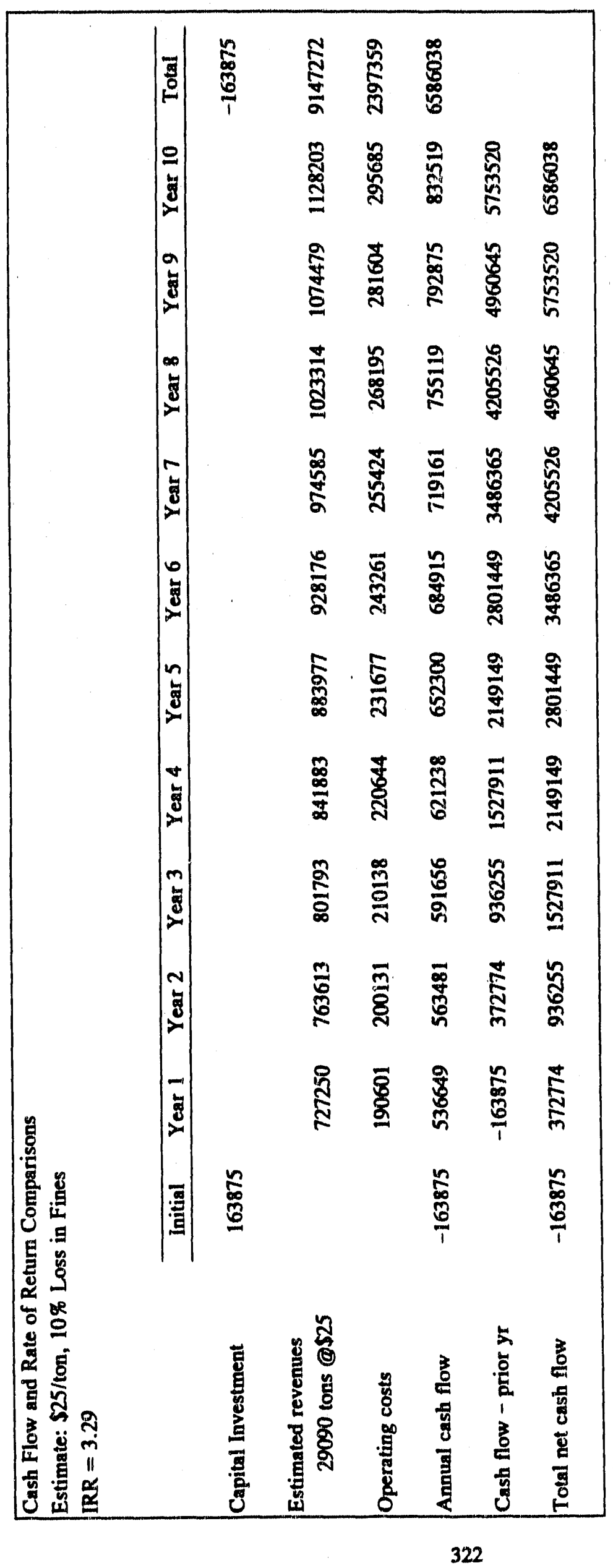




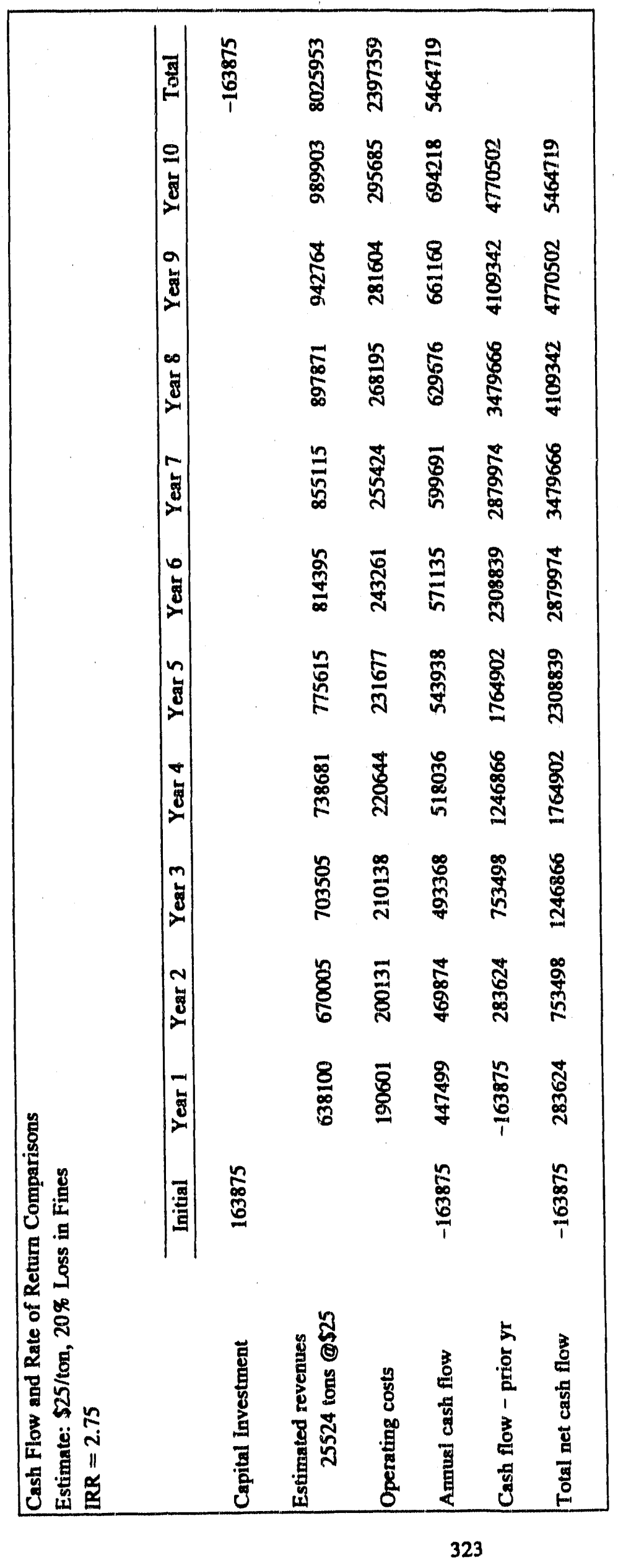




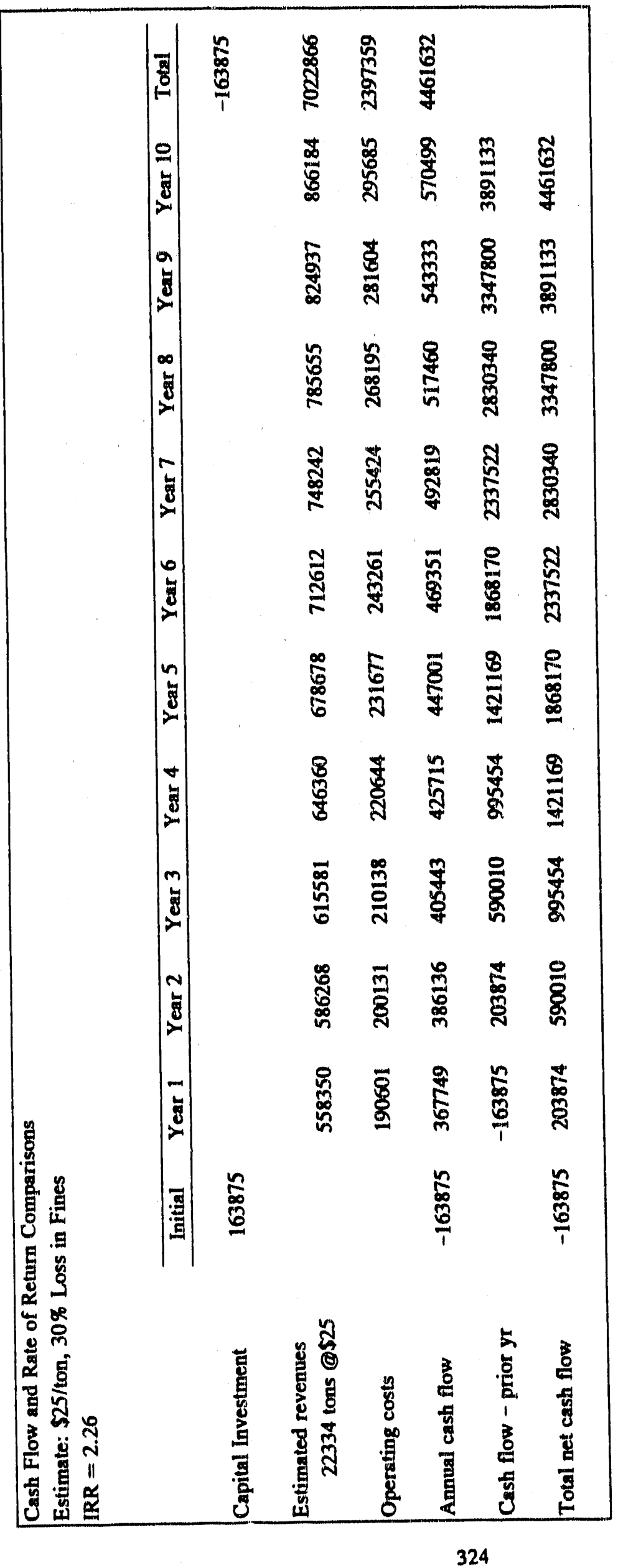




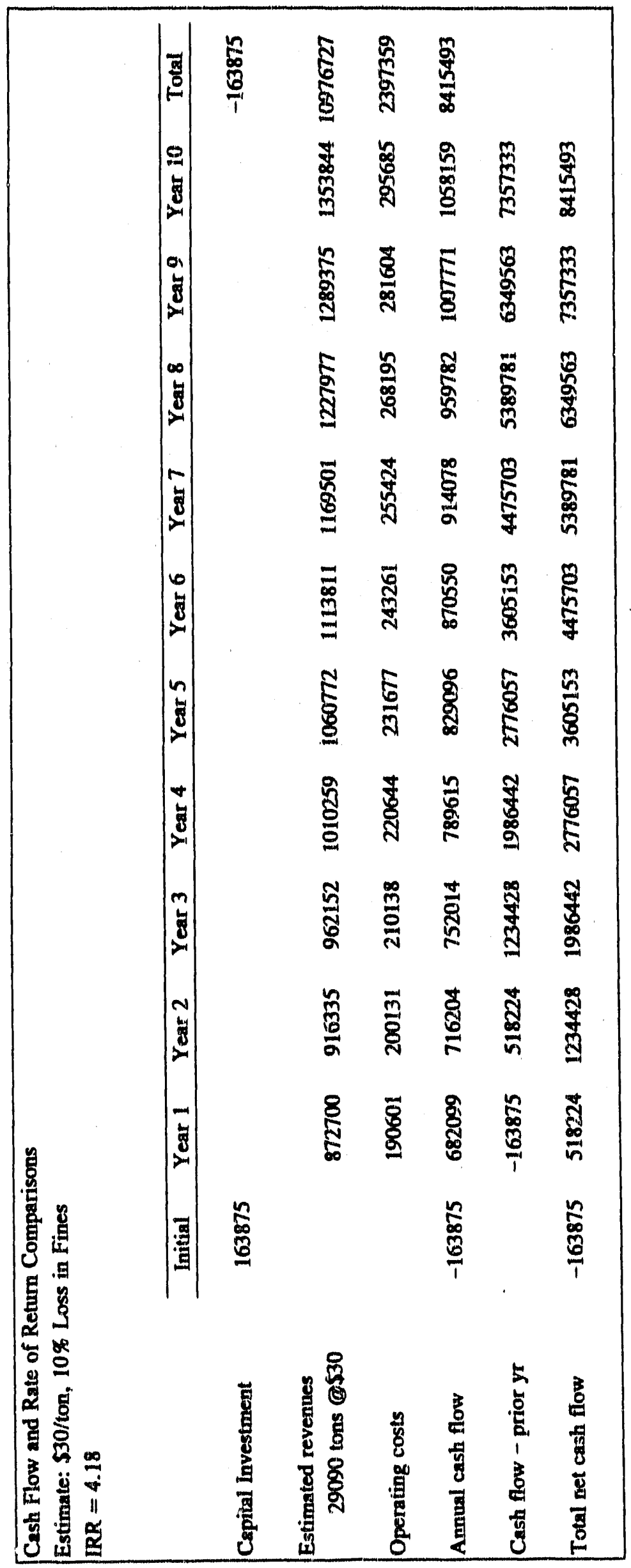




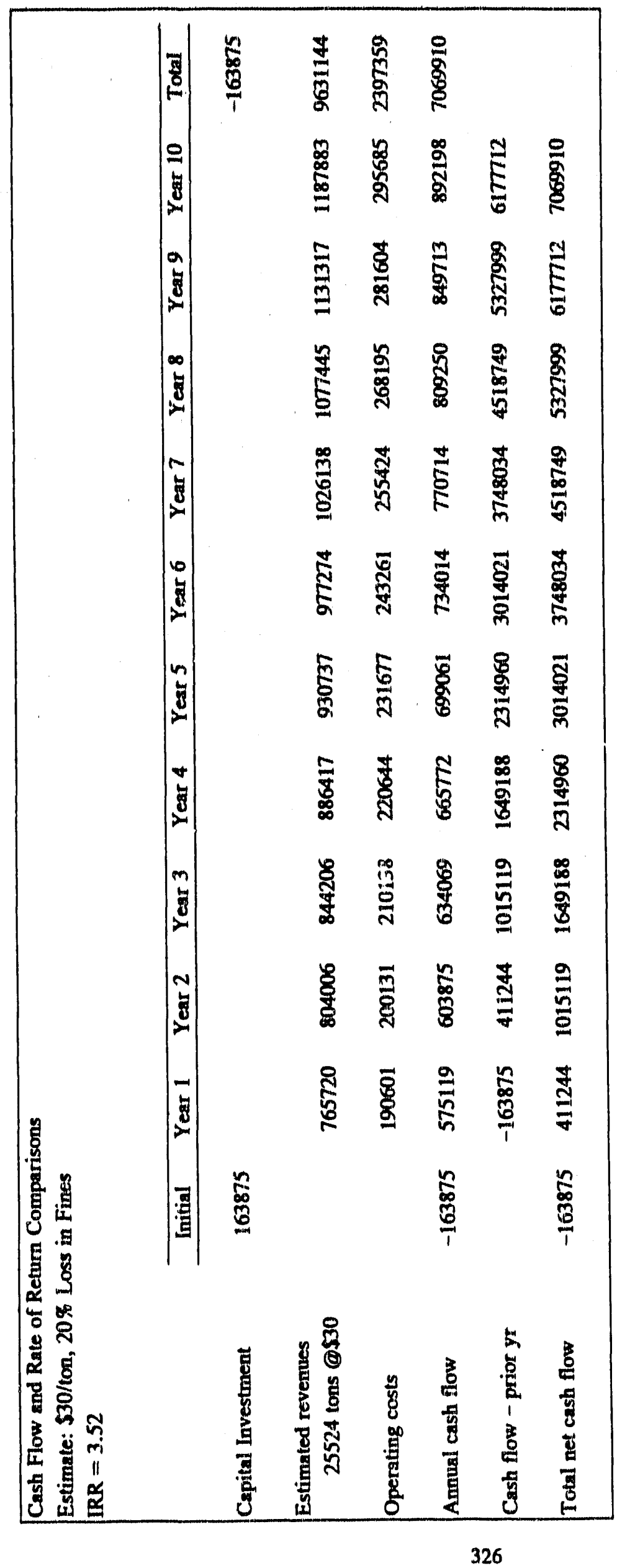




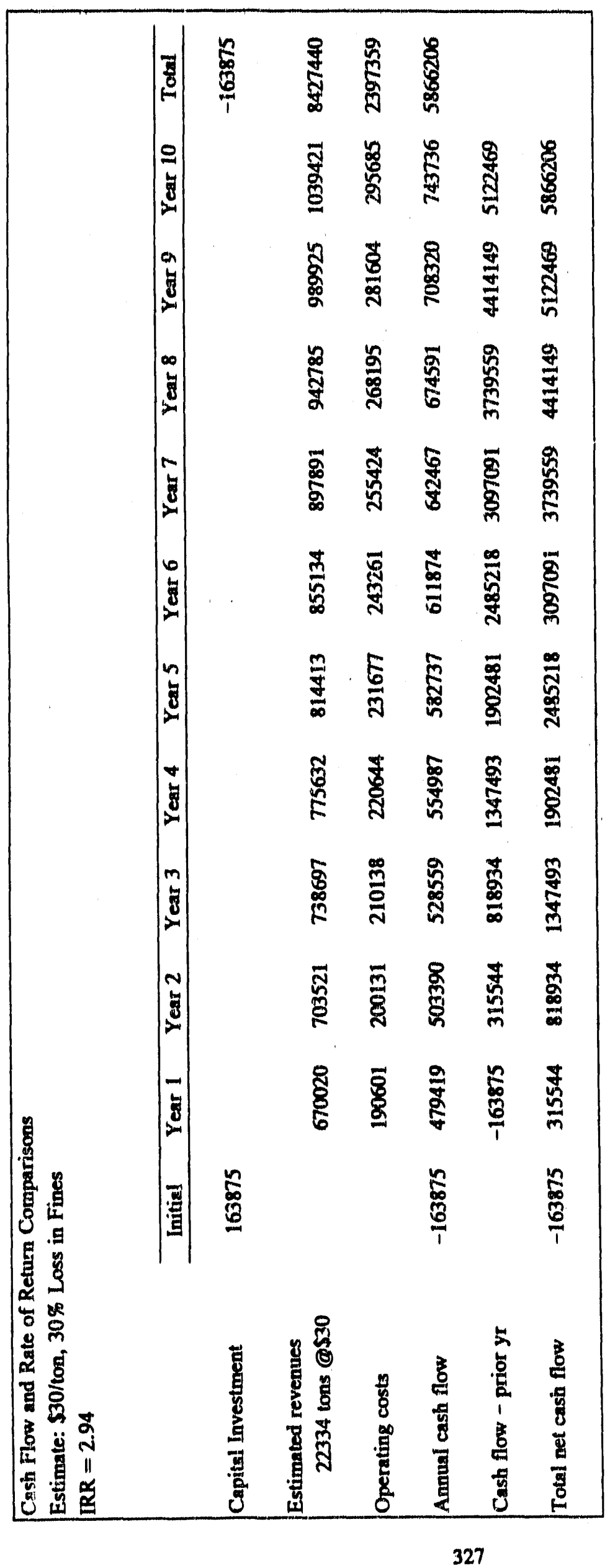



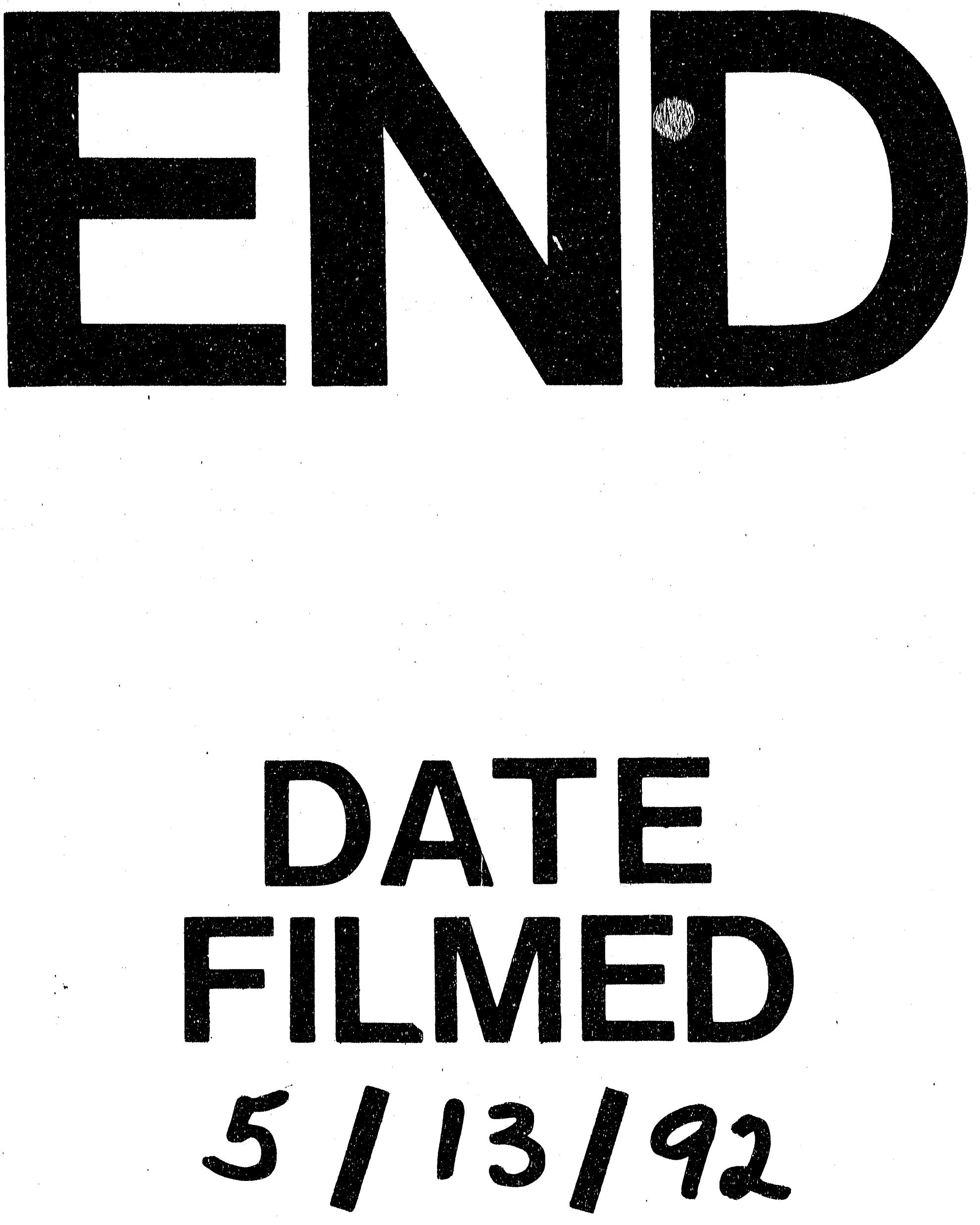

1 
